\title{
Das Schengener Informationssystem -
}

unter besonderer Berücksichtigung der Vereinbarkeit einer verdeckten Registrierung nach Art. 99 SDÜ mit Art. 8 der Charta der Grundrechte der Europäischen Union

Dissertation

zur Erlangung des Doktorgrades

der juristischen Fakultät

der Georg-August-Universität zu Göttingen

vorgelegt

von

Alexandra Schindehütte

aus Hofgeismar

Göttingen 2013 
Berichterstatter/in: Prof. Dr. Thomas Mann

Mitberichterstatter/in: Prof. Dr. Uwe Murmann

Tag der mündlichen Prüfung: 4. Juni 2013 


\section{Vorwort}

Die vorliegende Arbeit wurde von der Juristischen Fakultät der Georg-August-Universität Göttingen im Sommersemester 2013 als Dissertation angenommen. Gesetzeslage, Literatur und Rechtsprechung wurden bis zum März 2012 berücksichtigt.

In diesem Zusammenhang möchte ich darauf hinweisen, dass das Schengener Informationssystem der zweiten Generation - SIS II - am 9. April 2013 in Betrieb gegangen ist. ${ }^{1}$ Die Arbeit hat aufgrund ihres Entstehungszeitraumes ganz wesentlich das SIS der ersten Generation zum Gegenstand. Im 4. Teil finden sich jedoch auch einige Anmerkungen zum SIS II.

An erster Stelle gilt mein Dank meinem Doktorvater Herrn Prof. Dr. Thomas Mann für die hilfreiche Unterstützung bei der Eingrenzung des Themas sowie die freundliche und konstruktive weitere Betreuung während der Arbeit.

Herrn Prof. Dr. Uwe Murmann danke ich für die Erstellung des Zweitgutachtens.

Weiterhin danke ich den Mitarbeitern der das SIS in Deutschland betreuenden Sirene im Bundeskriminalamt und insbesondere dem langjährigen Leiter der Sirene, Herrn Dr. Martin Tuffner. Seine Auskünfte und Hinweise haben wesentlich dazu beigetragen, mir das Funktionieren des SIS und die damit verbundenen Probleme transparent zu machen. Zudem danke ich Herrn Matthias Taube im Bundesministerium des Inneren für das zur Verfügung Stellen einer konsolidierten Fassung des Schengener Durchführungsübereinkommens.

Sehr herzlich sage ich meinen Freunden Katja und Frank Brosch Dank. Mir halfen ihre immer vorhandene Diskussionsbereitschaft und in besonderer Weise das kritische Korrekturlesen der Arbeit durch Katja Brosch.

Ganz besonders herzlich danke ich meinen Eltern Heinz und Gerlinde Sperbaum, die mich während meiner gesamten Ausbildung und auch während der Erstellung dieser Dissertation stets vertrauensvoll und zuverlässig in vielfältigster Weise unterstützt haben. Nicht zuletzt im Hinblick auf ungezählte Stunden liebevoller Kinderbetreuung bin ich ihnen wie auch meiner Schwiegermutter Gudrun Schindehütte außerordentlich dankbar.

Schließlich danke ich meinem lieben Mann Jan Schindehütte für seine Geduld, sein Vertrauen und seine stetige Gesprächsbereitschaft.

Die Arbeit widme ich unseren Kindern. Vielleicht ermutigt sie der Abschluss dieser Dissertation dazu, sich später eigene wie auch immer geartete „Großprojekte“ zuzutrauen und sie mit Freude am Tun anzugehen.

Laatzen, im August 2013

Alexandra Schindehütte

\footnotetext{
${ }^{1}$ http://europa.eu/rapid/press-release IP-13-309 de.htm, Abruf vom 20. August 2013.
} 


\section{Inhaltsverzeichnis}

\section{Teil: Einführung.}

2. Teil: Vorstellung des SIS und der Sirene...........................................................................................3

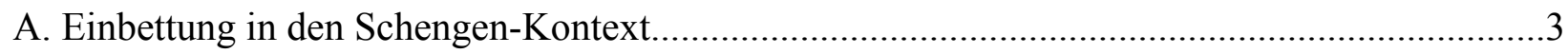

I. Von der Pariser Gipfelkonferenz 1974 bis zur Entschließung des Rates vom 7. Juli 1984....3

II. Deutsch-französisches (Saarbrücker) Abkommen vom 13. Juli 1984_................................4

III. Richtlinienvorschlag der Kommission vom 23. Januar 1985 ........................................6

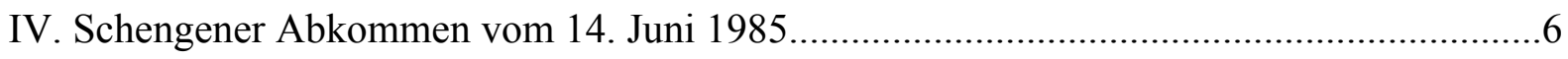

V. Einheitliche Europäische Akte vom 28. Februar 1986 .....................................................

VI. Schengener Durchführungsübereinkommen vom 19. Juni 1990.....................................8

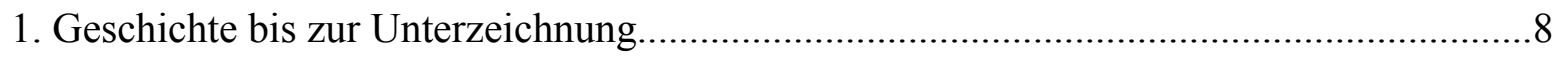

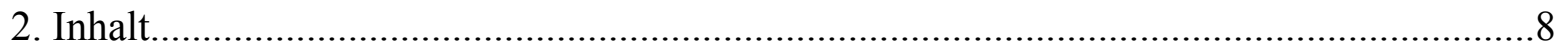

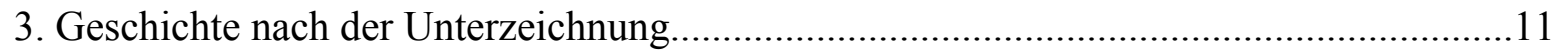

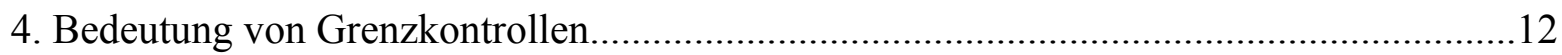

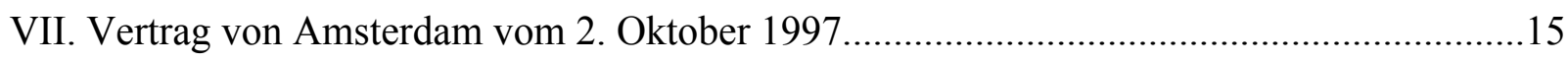

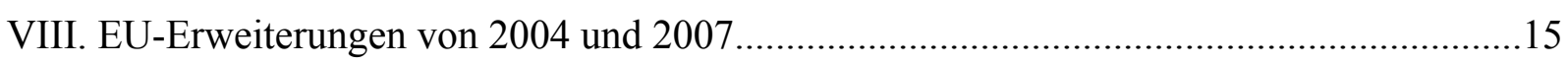

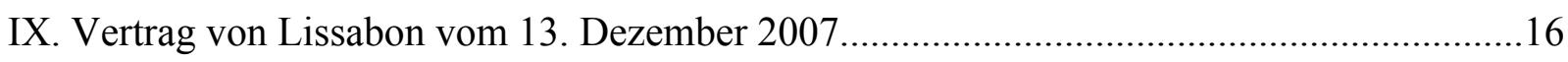

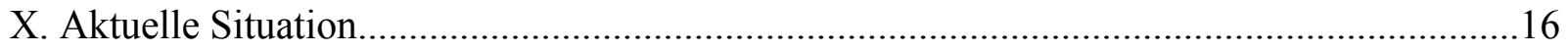

B. Fahndungssystem als Herzstück der Ausgleichsmaßnahmen............................................... 17

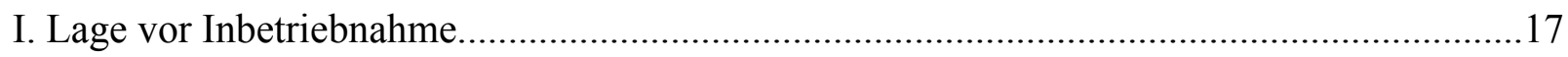

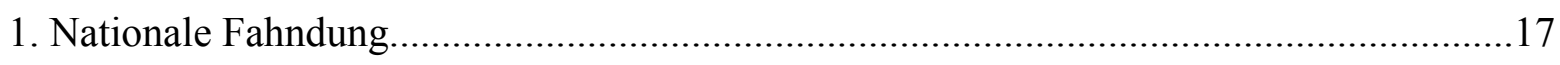

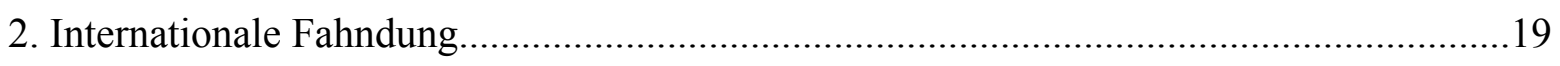

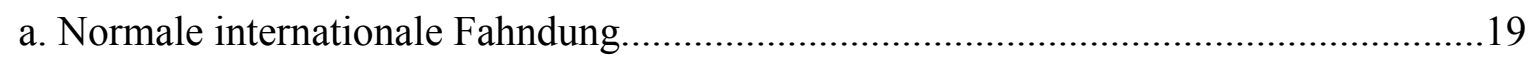

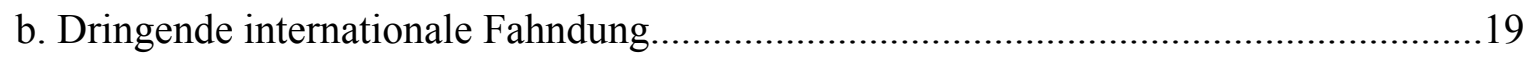

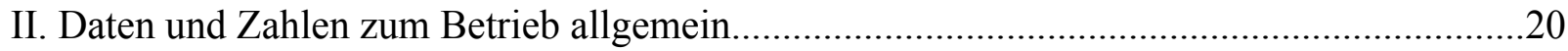

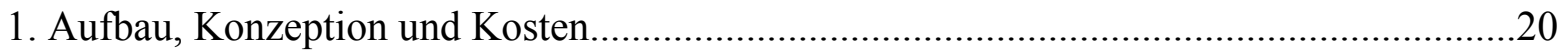

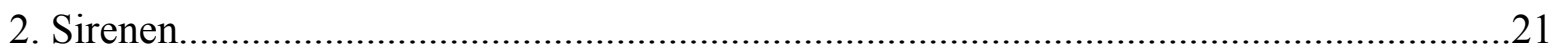

3. Schwierigkeiten bei der Entwicklung des SIS...........................................................22

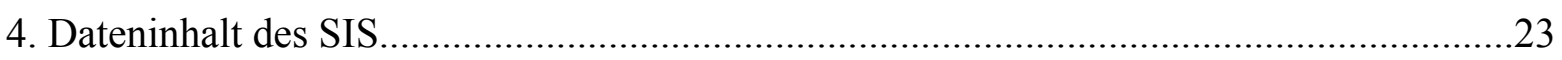

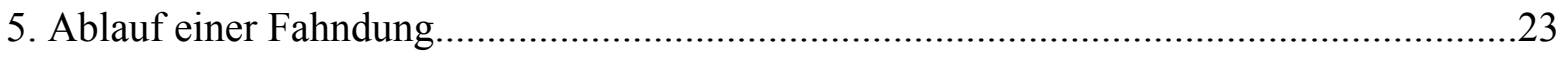


III. Die einzelnen Fahndungskategorien.

1. Fahndung nach Personen zur Festnahme zwecks Auslieferung gemäß Art. 95 SDÜ.......26

a. Verfahren vor bzw. ohne Geltung des Europäischen Haftbefehls. 26

aa. Voraussetzungen und Verfahren der Ausschreibung............................................26

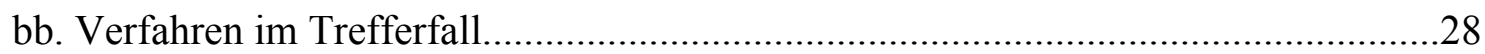

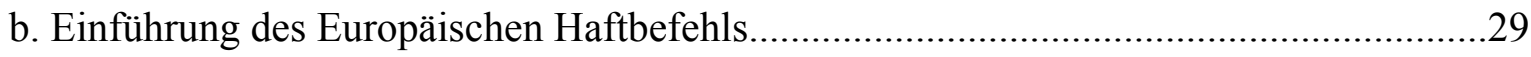

aa. Ziel und Inhalt des Rahmenbeschlusses zum Europäischen Haftbefehls.................29

bb. Urteil des BVerfG vom 18. Mai 2005 ......................................................................31

c. Verfahren unter Berücksichtigung des Europäischen Haftbefehls..................................35

aa. Voraussetzungen und Verfahren der Ausschreibung...............................................35

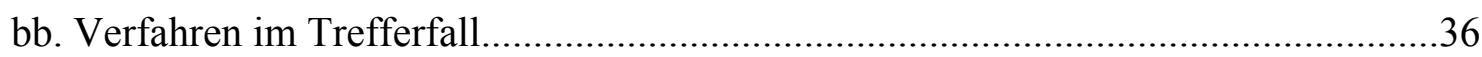

2. Fahndung nach Drittausländern, die zur Einreiseverweigerung bzw. Ausweisung/

Abschiebung bei Antreffen im Schengen-Raum ausgeschrieben sind gemäß Art. 96 SDÜ.

a. Voraussetzungen und Verfahren der Ausschreibung.....................................................

b. Verfahren im Trefferfall.

3. Fahndung nach Vermissten zur Aufenthaltsermittlung und/oder Ingewahrsamnahme

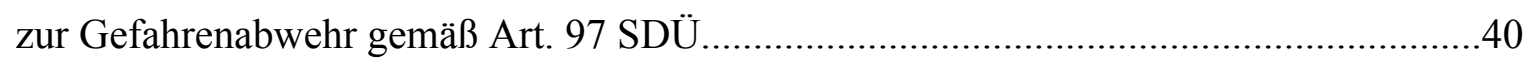

a. Voraussetzungen und Verfahren der Ausschreibung...................................................40

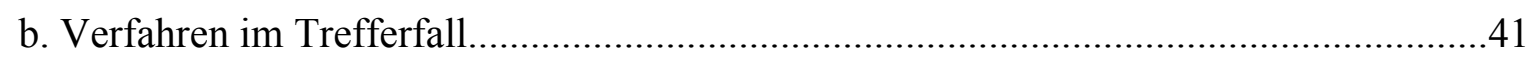

4. Fahndung zur Aufenthaltsermittlung für Justizbehörden gemäß Art. 98 SDÜ..................42

a. Voraussetzungen und Verfahren der Ausschreibung.....................................................42

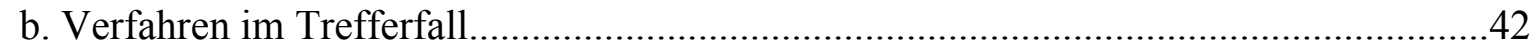

5. Fahndung zur verdeckten Registrierung und gezielten Kontrolle nach Personen

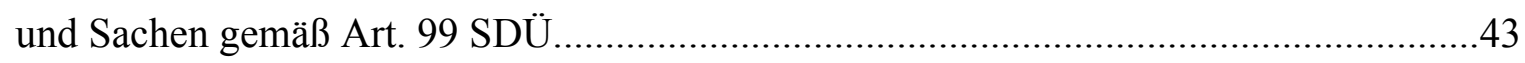

a. Voraussetzungen und Verfahren der Ausschreibung..................................................43

aa. Strafprozessuale Ausschreibungsvariante.............................................................4

(1) Kernvoraussetzungen des Tatbestandes...........................................................44

(a) Bestimmung des strafprozessualen Teils in Art. 99 SDÜ................................44

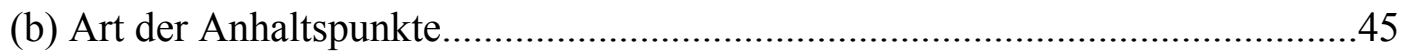

(c) Qualität und Quantität der Straftaten..........................................................46

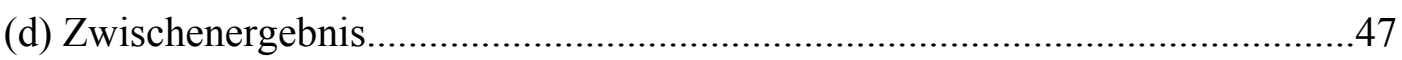

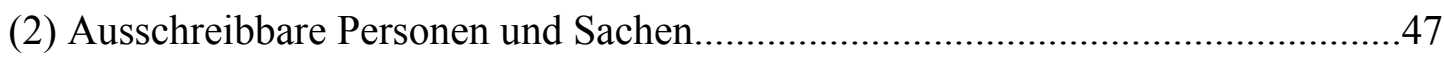

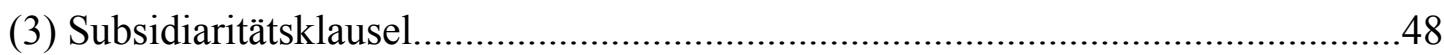




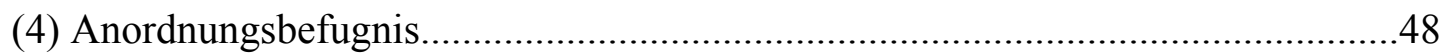

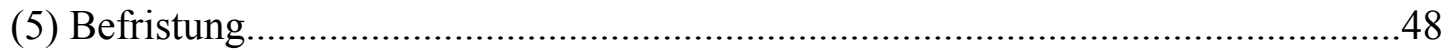

(6) Benachrichtigung des Betroffenen................................................................49

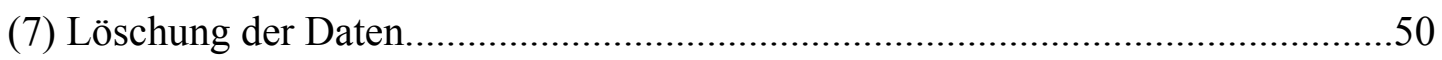

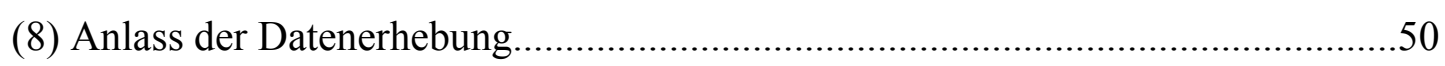

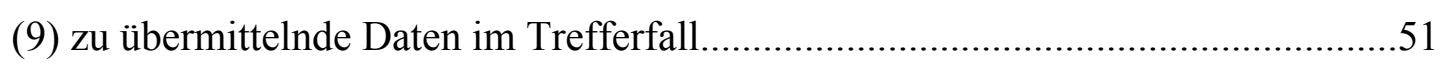

(10) Ergebnis des Vergleichs: Strafprozessuale Kombinationsnorm..........................51

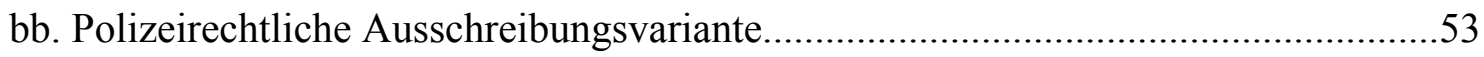

(1) Kernvoraussetzungen des Tatbestandes.......................................................53

(2) Ausschreibbare Personen und Sachen..............................................................54

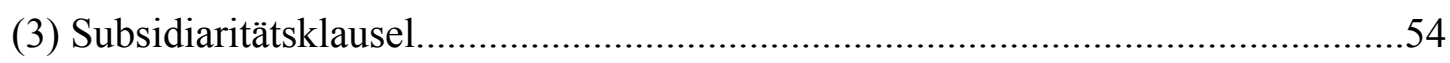

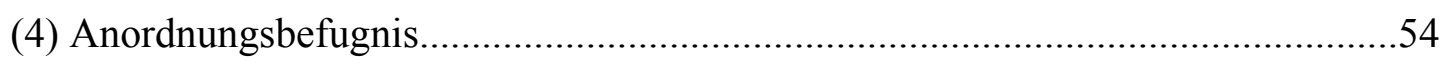

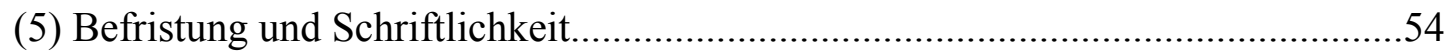

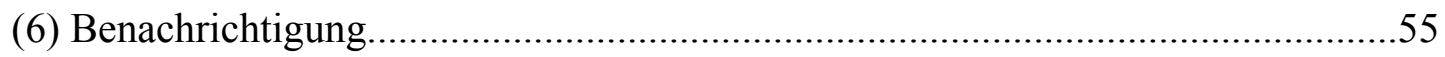

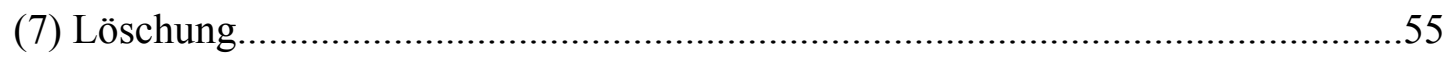

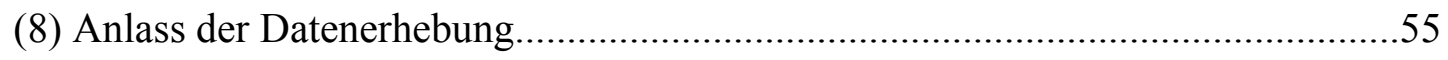

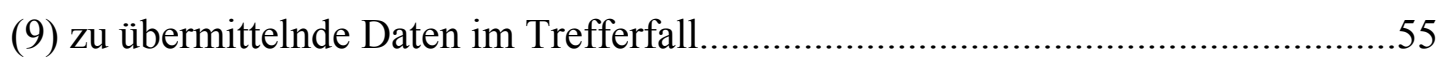

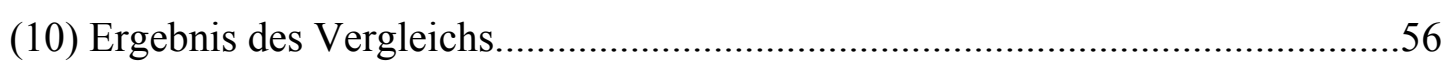

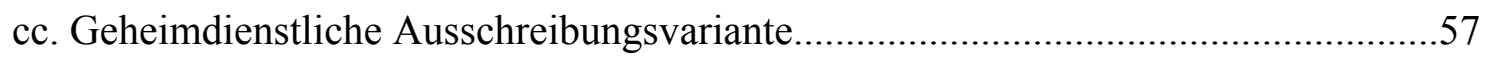

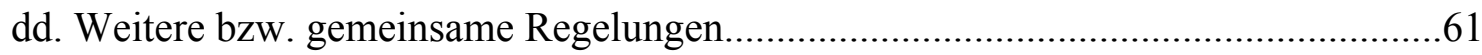

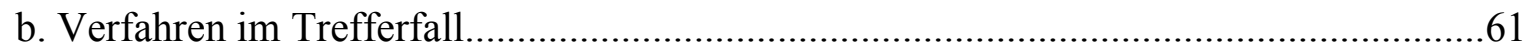

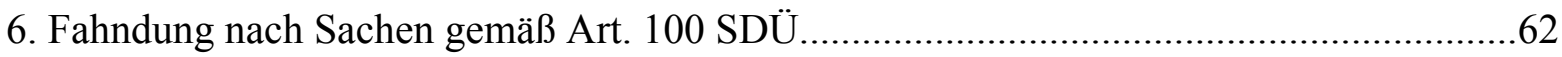

a. Verfahren und Voraussetzung der Ausschreibung......................................................62

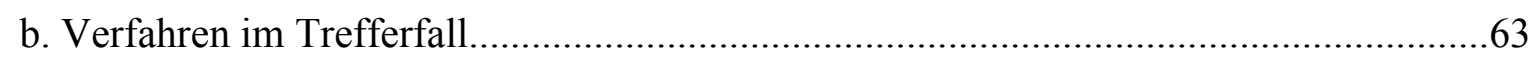

IV. Regelungen zum Datenschutz und zum hierauf gerichteten Rechtsschutz im

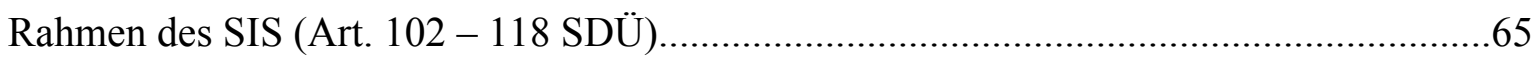

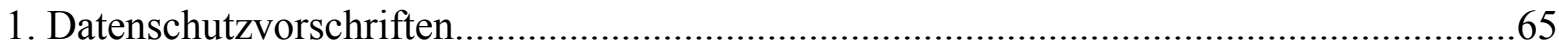

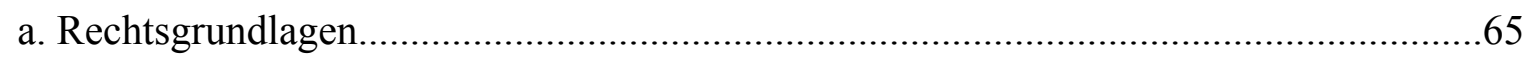

aa. Übereinkommen des Europarates über den Schutz des Menschen bei der automatischen Verarbeitung personenbezogener Daten vom 28. Januar 1981.........65

bb. Empfehlung des Ministerausschusses des Europarates über die Nutzung personenbezogener Daten im Polizeibereich vom 17. September 1987. 


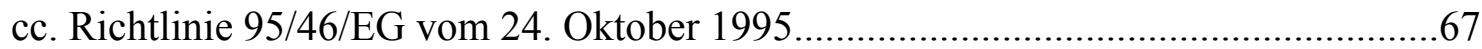

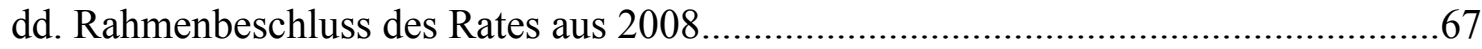

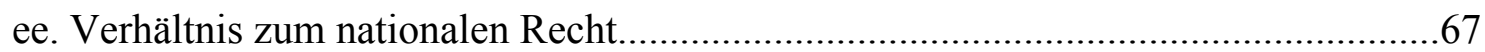

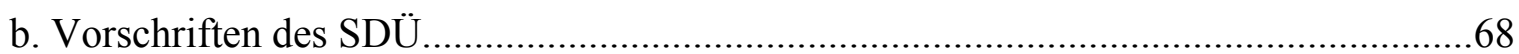

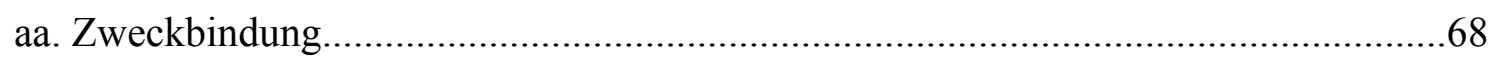

bb. Datenschutzrechtliche Verantwortlichkeit und Protokollierung.............................69

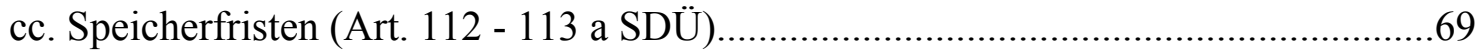

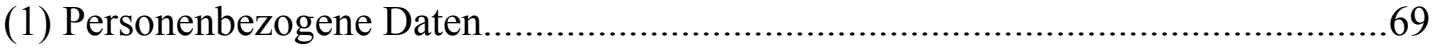

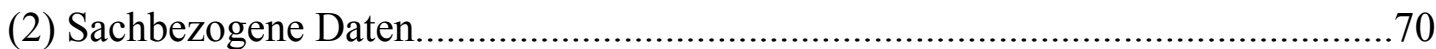

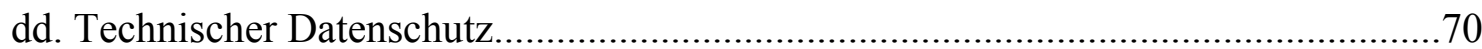

ee. Nationale Kontrollinstanz, Gemeinsame Kontrollinstanz und

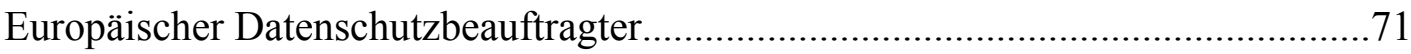

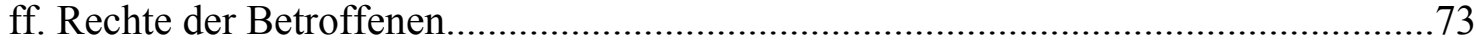

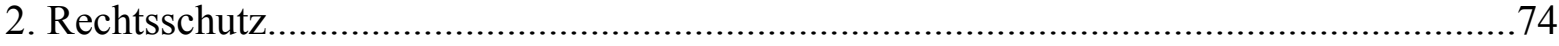

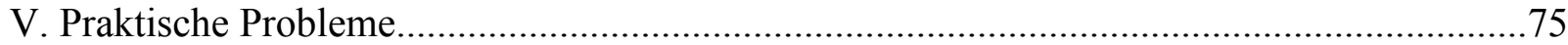

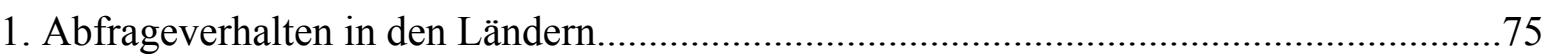

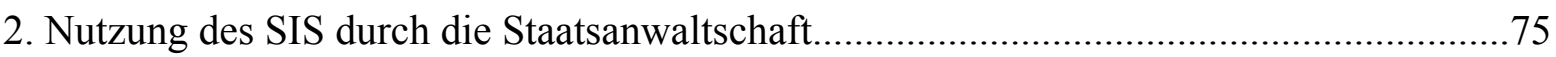

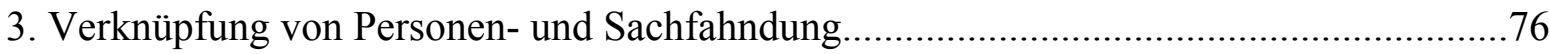

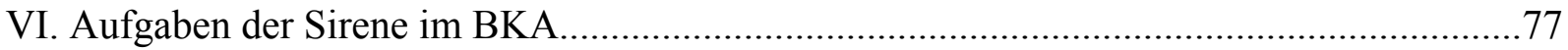

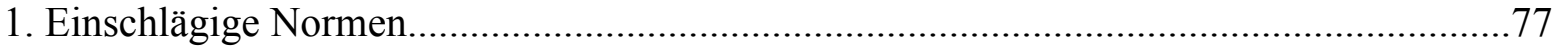

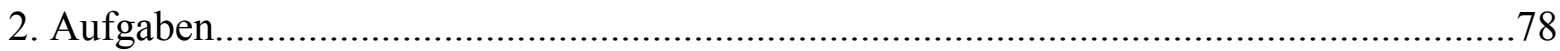

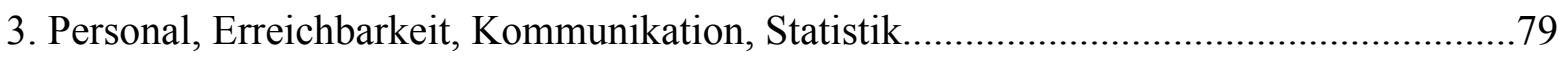

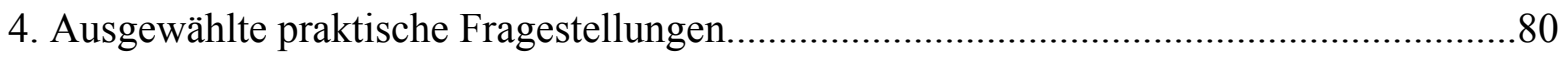

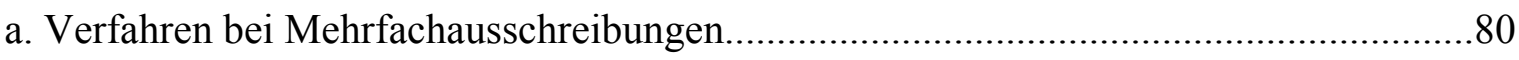

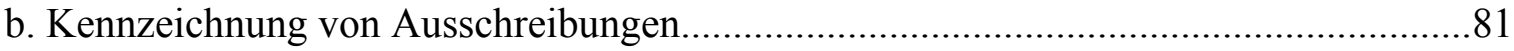

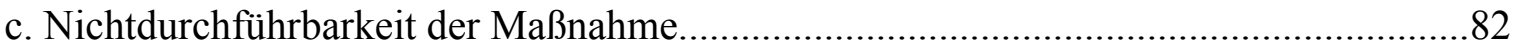

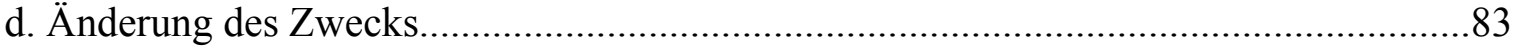

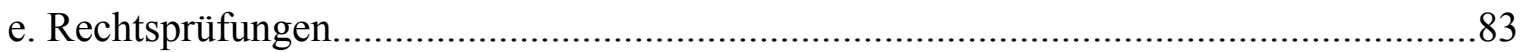

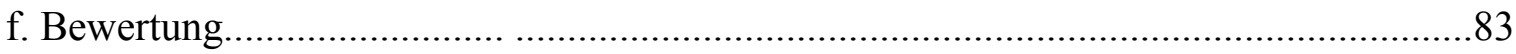

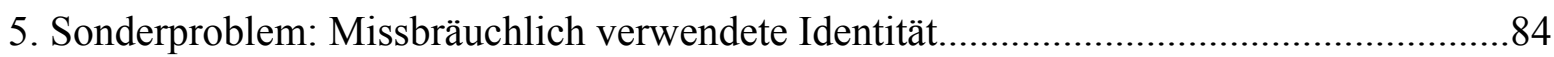


C. Abgrenzung des SIS zu anderen Systemen und Formen der Zusammenarbeit...........................86

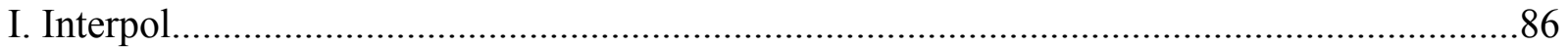

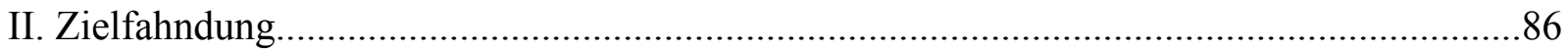

III. Europol-Informationssystem und Arbeitsdateien zu Analysezwecken.............................86

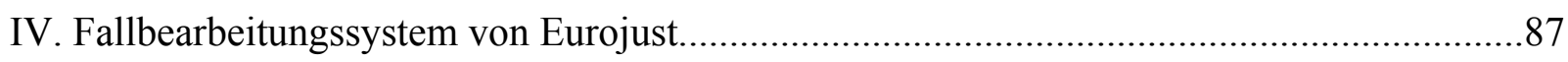

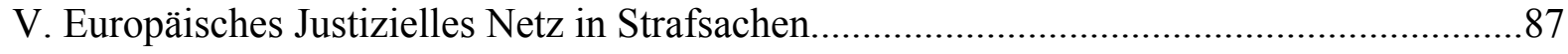

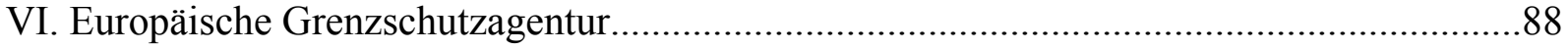

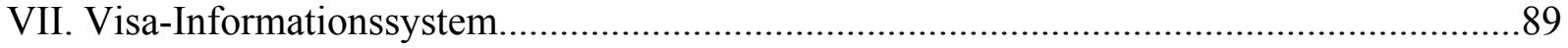

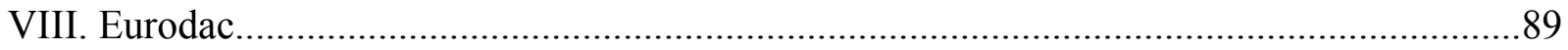

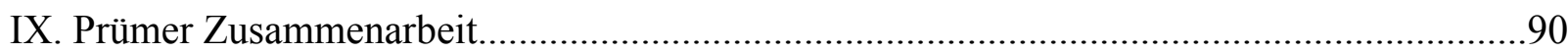

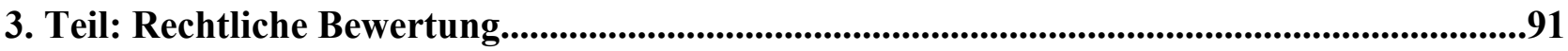

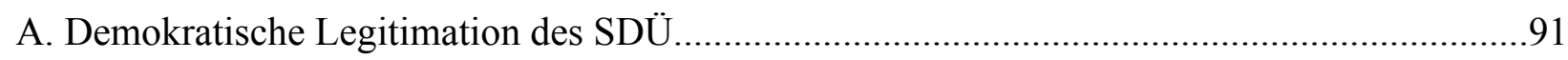

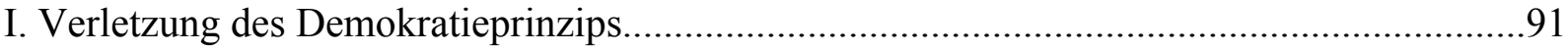

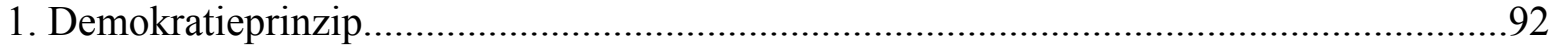

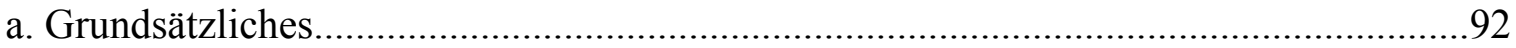

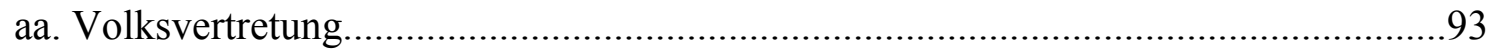

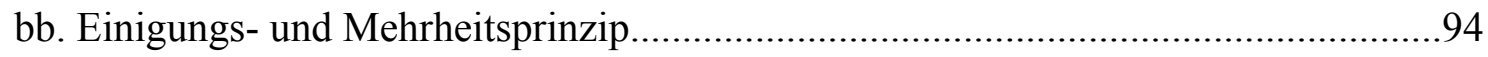

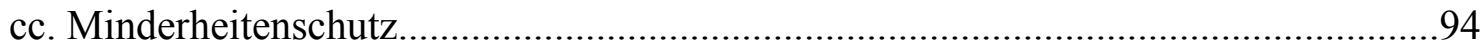

dd. Öffentlichkeit der Beratungs- und Entscheidungsprozesse...................................95

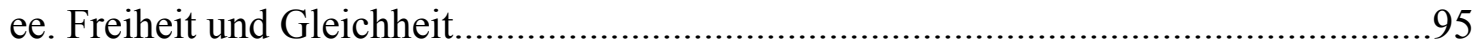

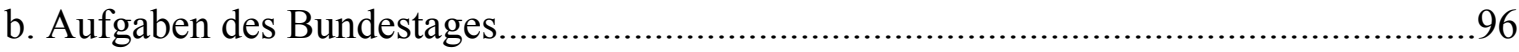

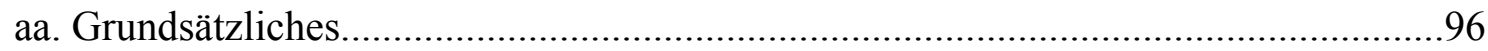

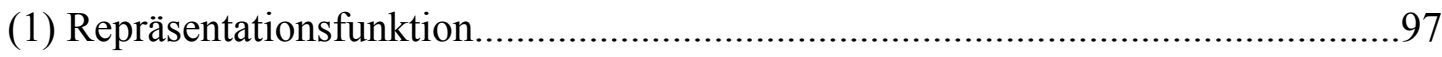

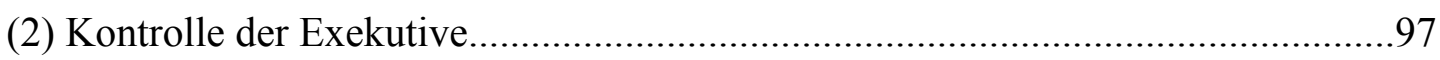

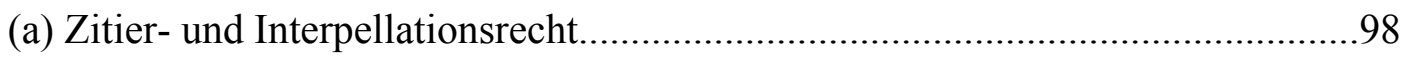

(b) Einsetzung von Untersuchungsausschüssen.................................................99

(c) Schlichte Parlamentsbeschlüsse ....................................................................100

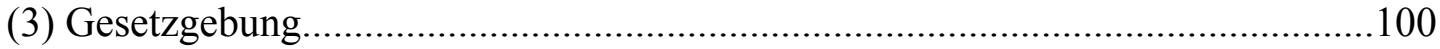

bb. Funktion des Bundestages bei der Gesetzgebung..................................................100

(1) Funktion des Bundestages bei Gesetzen mit maßgeblich innenpolitischem Bezug......

(2) Funktion des Bundestages bei Gesetzen mit maßgeblich außenpolitischem

Bezug. 
2. Konkrete Beteiligung des Bundestages beim SDÜ........................................................103

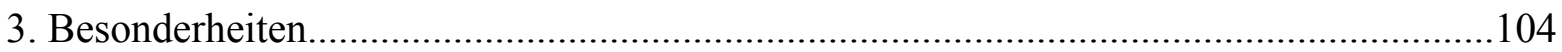

a. Unzureichende Information und Einbindung des Parlamentes im Vorfeld....................104

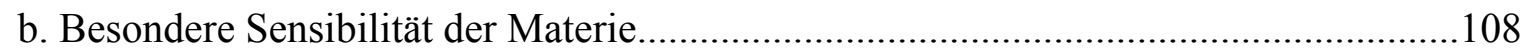

c. Strukturelles Defizit in Bezug auf Justiz- und Innenpolitik........................................109

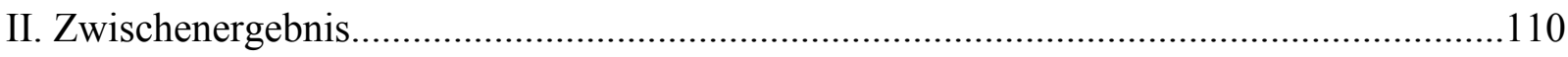

III. Notwendigkeit eines Gesetzes nach Art. 24 Abs. 1 GG................................................111

1. Übertragung von Hoheitsrechten...................................................................................111

a. Prüfung der Ausschreibungsvoraussetzungen durch einen anderen Staat....................111

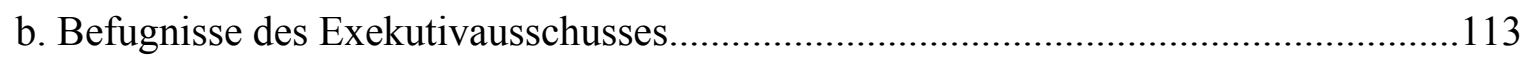

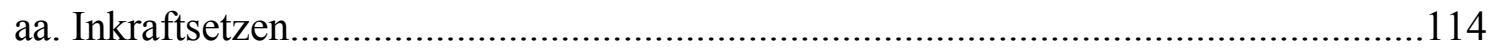

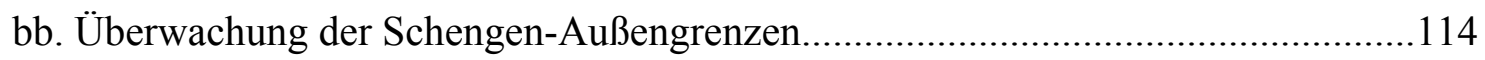

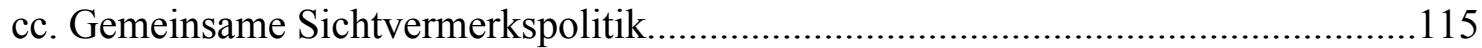

dd. Kosten der Abschiebung von Drittausländern.......................................................115

ee. Zuständigkeit für Asylbegehren.................................................................................116

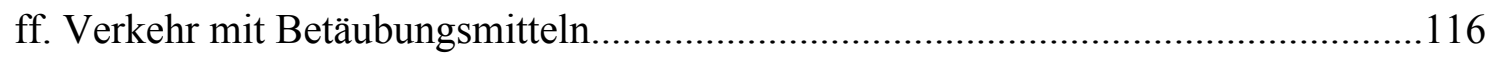

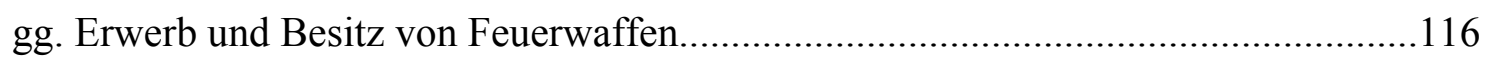

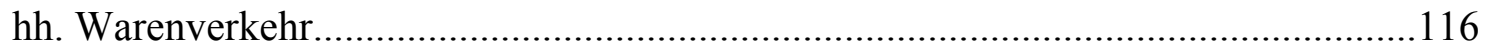

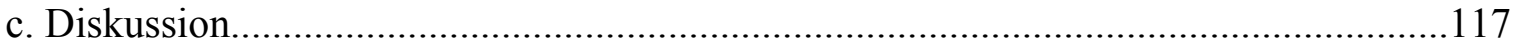

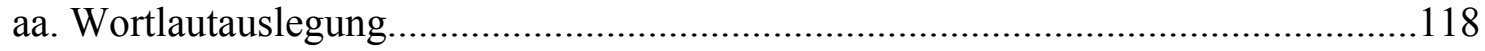

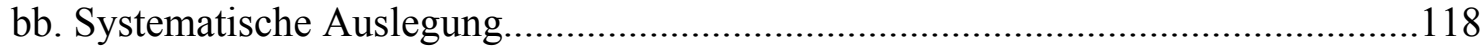

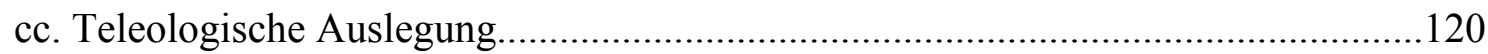

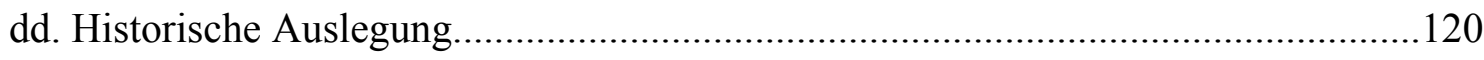

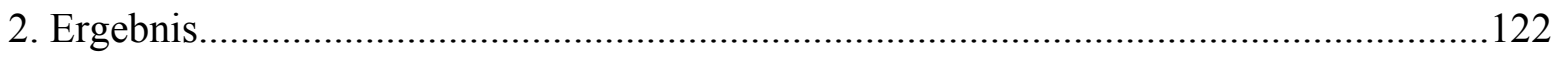

B. Vereinbarkeit der verdeckten Registrierung mit Art. 8 GR-Charta......................................123

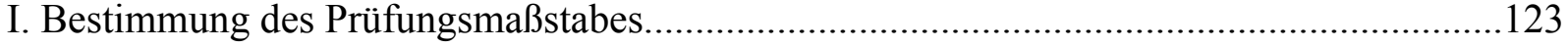

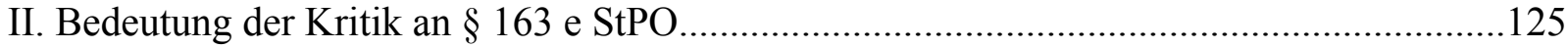

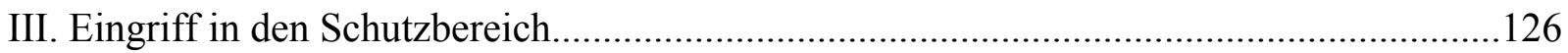

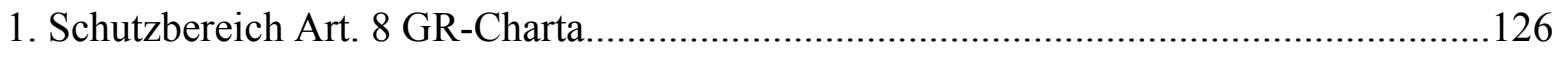

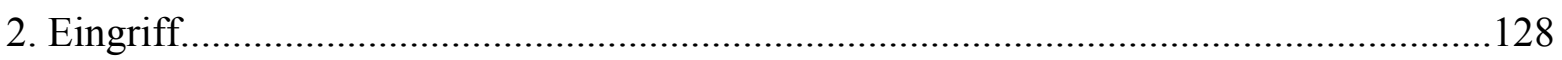

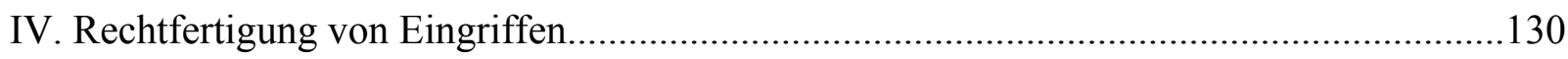

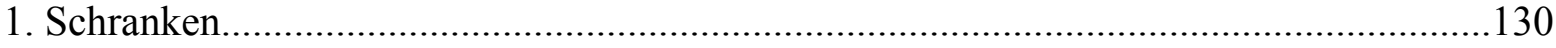


2. Anforderungen an das einschränkende Gesetz.......................................................133

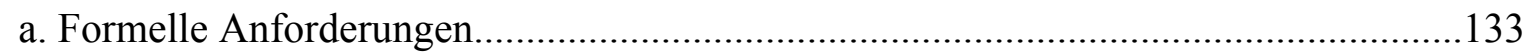

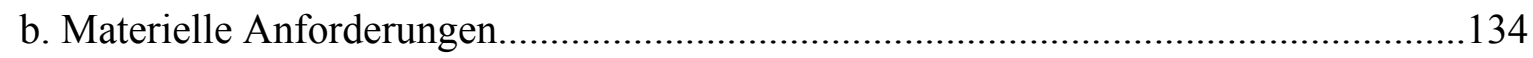

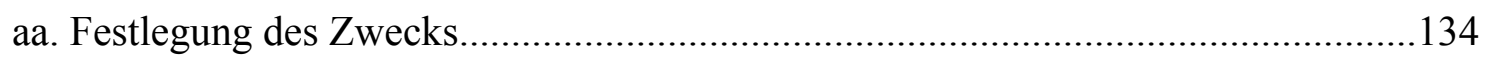

bb. Organisatorische und verfahrensrechtliche Vorkehrungen..................................136

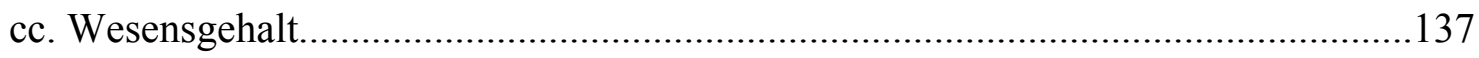

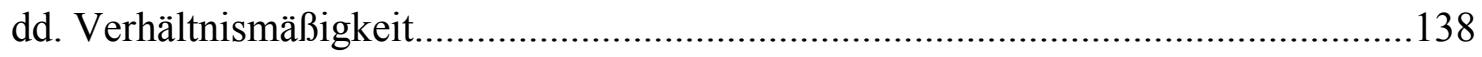

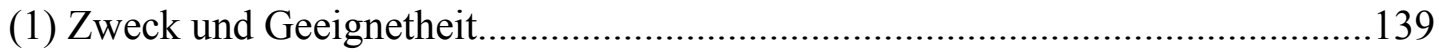

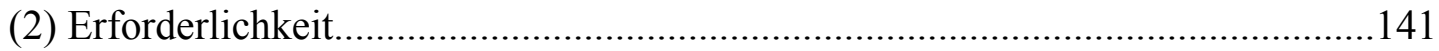

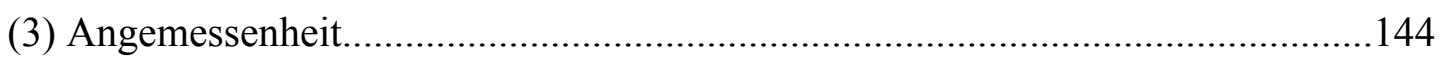

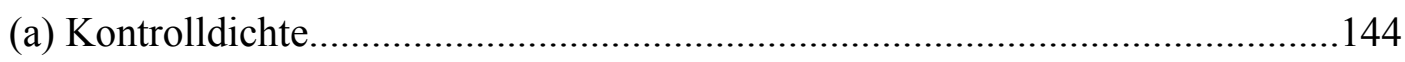

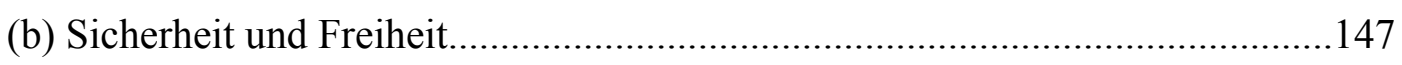

(aa) Staatstheoretische Erwägungen..........................................................147

(bb) Festlegungen im europäischen Primärrecht................................................148

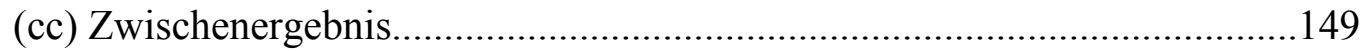

(c) Individual- und Gemeinschaftsrechtsgüter und konkrete Gefahren..................149

(aa) Gewicht und Rang der kollidierenden Rechtsgüter..................................149

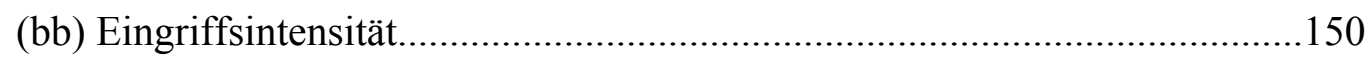

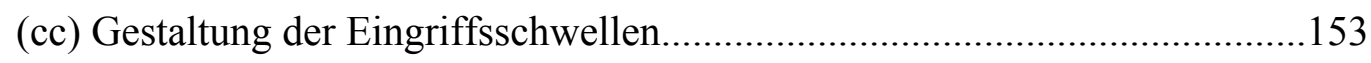

(dd) Grad der Geeignetheit bzw. Nutzen der Maßnahme................................154

(ee) Gegenüberstellung und Abwägung.......................................................155

(d) Kollektive Sicherheitsinteressen und objektiv-rechtlicher Gehalt des Grundrechts.

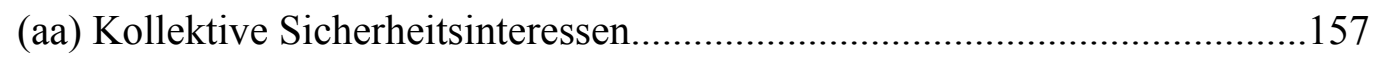

(bb) Objektiv-rechtlicher Gehalt des Grundrechts..........................................159

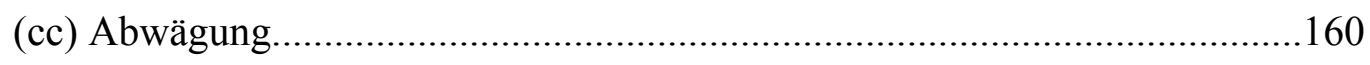

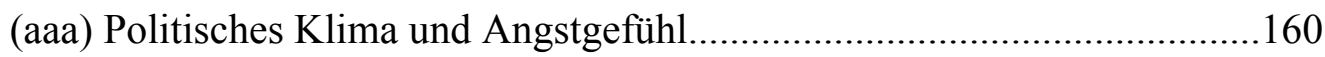

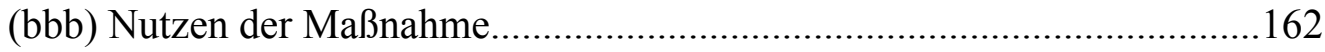

(i) Wünschenswerter bzw. realistischer Grad der Geeignetheit.................162

(ii) Wirkung staatlicher Eingriffsbefugnisse und Ursachen von Terrorismus.

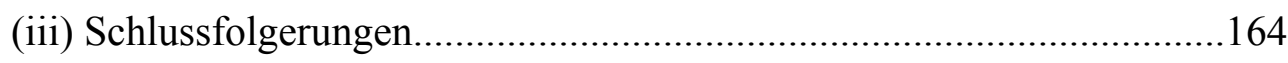

(iv) Übliche Blickrichtung und Konsequenzen......................................166

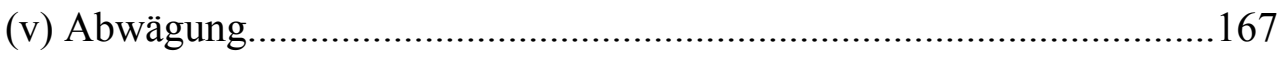


(vi) Zwischenergebnis 168

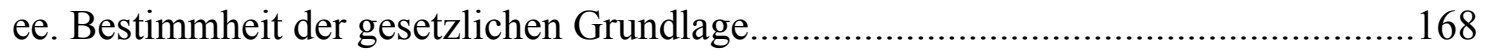

3. Zulässigkeit der Koppelung von Zwecken.............................................................170

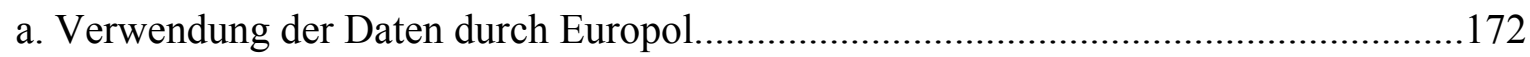

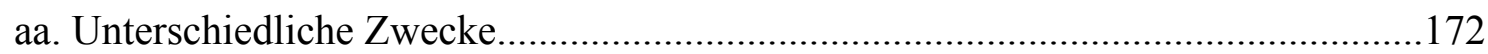

bb. Vereinbarkeit, Zweckbestimmung und -begrenzung.........................................173

cc. Organisations- und verfahrensrechtliche Vorschriften.........................................173

b. Weitergabe der Daten an Dritte und Einrichtungen der EU........................................175

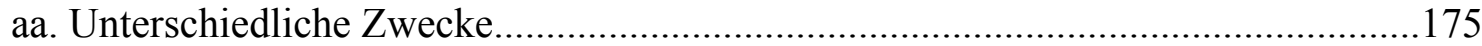

bb. Vereinbarkeit, Zweckbestimmung und -begrenzung.......................................177

cc. Organisations- und verfahrensrechtliche Vorschriften.........................................178

V. Ergebnis zur strafprozessualen Kombinationsnorm.................................................... 180

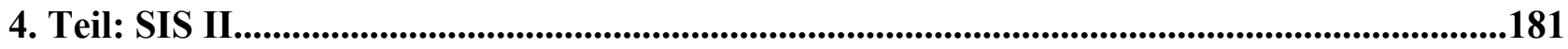

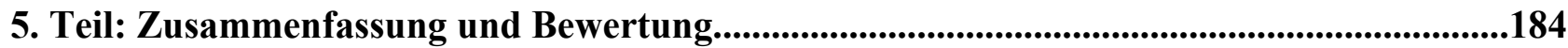

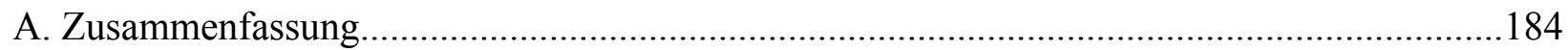

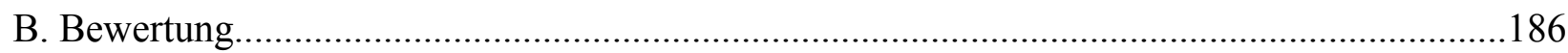

6. Teil: Anhang - Schengener Durchführungsübereinkommens - Konsolidierte Fassung.....189 


\section{Literaturverzeichnis}

Akmann, Torsten, Die Zusammenarbeit in den Bereichen Justiz und Inneres als „3. Säule“ des Maastrichter Unionsvertrages, JA 1994, 49 ff.

(zit.: Akmann, JA 1994)

Albers, Marion, Informationelle Selbstbestimmung, Baden-Baden 2005

(zit.: Albers, Informationelle Selbstbestimmung)

Bauer, Michael, Organisation und rechtlicher Rahmen des Politikfeldes Inneres und Justiz nach dem Vertrag von Lissabon, S. 99 ff., in: Weidenfeld, Werner (Hrsg.), Lissabon in der Analyse Baden-Baden, 2008

(zit.: Bauer, in: Weidenfeld, Lissabon)

Bieber, Roland, Die Abkommen von Schengen über den Abbau der Grenzkontrollen, NJW 1994, $294 \mathrm{ff}$.

(zit.: Bieber, NJW 1994)

Birzele, Frieder, Das „Schengener Abkommen“ und „Europol“ - Grundmodelle einer „Sicherheitsunion“?, S. 89 ff., in: Theobald, Volkmar (Hrsg.), Von der Europäischen Union zur „Europäischen Sicherheitsunion“?, Berlin 1997

(zit.: Birzele, in: Theobald, „Europäische Sicherheitsunion?“)

Böhrenz, Gunter/Siefken, Peter, Niedersächsisches Gesetz über die öffentliche Sicherheit und Ordnung (Nds. SOG), 9. A., Hannover 2008

(zit.: Böhrenz/Siefken, Nds. SOG)

Bölsche, Jochen, Der Weg in den Überwachungsstaat, Reinbek bei Hamburg 1983

(zit.: Bölsche, Überwachungsstaat)

Böhm, Michael, Das Europäische Haftbefehlsgesetz und seine rechtsstaatlichen Mängel, NJW 2005, 2588

(zit.: Böhm, NJW 2005)

Bosbach, Jens, Anmerkung zu BVerfG, Beschluss vom 18. Juli 2005 - 2 BvR 2236/04, NStZ 2006, 104

(zit.: Bosbach, NStZ 2006)

Brüner, Franz-Hermann/Hetzer, Wolfgang, Nationale Strafverfolgung und Europäische Beweisführung? NStZ 2003, $113 \mathrm{ff}$.

(zit.: Brüner/Hetzer, NStZ 2003)

Der Bundesbeauftragte für den Datenschutz, 19. Tätigkeitsbericht 2001 und 2002

(zit.: Der Bundesbeauftragte für den Datenschutz, 19. Tätigkeitsbericht)

Ders., 20. Tätigkeitsbericht 2003-2004, Bonn 2005

(zit.: Der Bundesbeauftragte für den Datenschutz, 20. Tätigkeitsbericht)

Bundeskriminalamt (Hrsg.), Fahndung, BKA-Arbeitstagung, Wiesbaden 1970

(zit.: Bearbeiter, in: Bundeskriminalamt, Arbeitstagung „Fahndung“) 
Dass. (Hrsg.), Neue Freiheiten, neue Risiken, neue Chancen, BKA-Arbeitstagung, Wiesbaden 1997 (zit.: Bearbeiter, in: Bundeskriminalamt, Arbeitstagung „Neue Freiheiten, neue Risiken, neue Chancen")

Dass. (Hrsg.), Kriminalitätsbekämpfung im zusammenwachsenden Europa, BKA-Arbeitstagung, Wiesbaden 1999

(zit.: Bearbeiter, in: Bundeskriminalamt, Arbeitstagung „Kriminalitätsbekämpfung im zusammenwachsenden Europa“")

Dass. (Hrsg.), Festschrift für Horst Herold zum 75. Geburtstag, Wiesbaden 1998

(zit.: Bearbeiter, in: Bundeskriminalamt, Festschrift für Herold)

Dass., (Hrsg.), Fakten und Zahlen, Wiesbaden 2005

(zit.: Bundeskriminalamt, Fakten und Zahlen, Stand 2005)

Dass., (Hrsg.), Fakten und Zahlen, Wiesbaden 2009

(zit.: Bundeskriminalamt, Fakten und Zahlen, Stand 2009)

Dass., Das Profil, Wiesbaden 2005

(zit.: Bundeskriminalamt, Das Profil, Stand 2005)

Bundesministerium des Innern (Hrsg.), Der Schengen-Raum (Poster), Stand: Mai 2009

(zit.: Bundesministerium des Innern, Der Schengen-Raum)

Dass., (Hrsg.), Mehr Freiheit - mit Sicherheit, - Die Bundespolizei informiert - (Faltblatt), Stand: 2007

(zit.: Bundesministerium des Innern, Mehr Freiheit mit Sicherheit)

Dass., (Hrsg.), Schengen-Erfahrungsberichte 2000, 2002, 2003, 2004, 2005 - 2007

(zit.: Bundesministerium des Innern, Schengen-Erfahrungsbericht)

Busch, Heiner, Europa - ein „Mekka der Kriminalität“?, KJ 1990, 1 ff.

(zit.: Busch, KJ 1990)

Ders., Kleine „Freiheit“" durch große „Sicherheit“, Vorgänge 1992, 53 ff.

(zit.: Busch, Vorgänge 1992)

Ders., Grenzenlose Polizei?, Münster 1995

(zit.: Busch, Grenzenlose Polizei?)

Callies, Christian/Ruffert, Matthias, (Hrsg.), EUV/AEUV - Das Verfassungsrecht der Europäischen Union mit Europäischer Grundrechtecharta, 4. A., München 2011

(zit.: Bearbeiter, in: Callies/Ruffert, EUV/AEUV)

Classen, Claus Dieter, Maastricht und die Verfassung: kritische Bemerkungen zum neuen „EuropaArtikel“ 23 GG, ZRP 1993, 57 ff.

(zit.: Classen, ZRP 1993)

Degenhart, Christoph, Staatsrecht I, 27. A., Heidelberg 2011

(zit.: Degenhart, Staatsrecht I) 
Denninger, Erhard, Prävention und Freiheit, Baden-Baden 2008

(zit.: Denninger, Prävention und Freiheit)

Dietl, Wilhelm, Die BKA-Story, München 2000

(zit.: Dietl, BKA-Story)

Di Fabio, Udo, Risikoentscheidungen im Rechtsstaat, Tübingen 1994

(zit.: Di Fabio, Risikoentscheidungen)

Dörr, Oliver, Das Schengener Durchführungsübereinkommen - ein Fall des Art. 24 Abs. 1 GG DÖV 1993, 696 ff.

(zit.: Dörr, DÖV 1993)

Dolzer, Rudolf/Waldhoff, Christian/Graßhof, Karin (Hrsg.), Bonner Kommentar zum Grundgesetz, Band 6, Art. 22-33, Loseblattsammlung, Heidelberg 2012 (Stand: Februar 2012)

(zit.: Bearbeiter, in: Dolzer u.a., BK, Band 6)

Dreier, Horst (Hrsg.), Grundgesetz, Band II (Art. 20 - 82 GG), 2. A., Tübingen 2006

(zit.: Bearbeiter, in: Dreier, GG, Band II)

Ehlers, Dirk (Hrsg.), Europäische Grundrechte und Grundfreiheiten, 3. A., Berlin 2009

(zit.: Bearbeiter, in: Ehlers, Europäische Grundrechte)

Epiney, Astrid, Das zweite Schengener Abkommen: Entstehung, Konzept und Einbettung in die Europäische Union, S. 21 ff., in: Achermann, Alberto/Bieber, Roland/Epiney, Astrid/Wehner, Ruth, Schengen und die Folgen, Bern 1995

(zit.: Epiney, in: Achermann u.a., Schengen)

Dies., Die Übernahme des „Schengen-Besitzstandes“ in die Europäische Union, S. 103 ff., in:

Hummer, Waldemar (Hrsg.); Die Europäische Union nach dem Vertrag von Amsterdam, Wien 1998

(zit.: Epiney, in: Hummer, Die Europäische Union nach Amsterdam)

Erb, Volker/Esser, Robert/Franke, Ulrich/Graalmann-Scheerer, Kirsten/Hilger, Hans/Ignor, Alexander (Hrsg.),

Löwe-Rosenberg - Die Strafprozessordnung und das Gerichtsverfassungsgesetz, Fünfter Band (§§ $151-212 b), 26$. A., Berlin 2008

(zit.: Bearbeiter, in: Erb u.a., Löwe-Rosenberg-StPO, Fünfter Band)

Fätkinhäuer, Hans Jürgen, OK-Bekämpfung und Rechtshilfe, KR 1994, 307 ff.

(zit.: Fätkinheuer, KR 1994)

Fastenrath, Ulrich, Kompetenzverteilung im Bereich der auswärtigen Gewalt, München 1986 (zit.: Fastenrath, Kompetenzverteilung)

Frowein, Jochen/Peukert, Wolfgang, Europäische Menschenrechtskonvention, 3. Auflage, Kehl am Rhein 2009

(zit.: Bearbeiter, in: Frowein/Peukert, EMRK)

Geiger, Rudolf, EUV/EGV, 4. A., München 2004

(zit.: Geiger, EUV/EGV, 4. A.) 
Gleß, Sabine , „...dass überall dem Gesetz ein Genüge geschehe“ - Justizielle Einbindung und Kontrolle des strafrechtlichen Ermittlungsverfahrens, DRiZ 2000, 365 ff.

(zit.: Gleß, DRiZ 2000)

Dies./Lüke, Monika, Rechtsschutz gegen grenzüberschreitende Strafverfolgung in Europa JURA 2000, $400 \mathrm{ff}$.

(zit.: Gleß/Lüke, JURA 2000)

Grote, Rainer/Marauhn, Thilo (Hrsg.), EMRK/GG , Tübingen 2006

(zit.: Bearbeiter, in: Grote/Marauhn, EMRK/GG)

Gusy, Christoph/Gimbal, Anke, Rechtliche Schranken der polizeilichen Zusammenarbeit im Rahmen des Schengener Informationssystems, S. 124 ff., in: Baldus, Manfred/Soiné, Michael (Hrsg.), Rechtsprobleme der internationalen polizeilichen Zusammenarbeit, Baden-Baden 1999 (zit.: Gusy/Gimbal, in: Baldus/Soiné, Internationale polizeiliche Zusammenarbeit)

Haft, Fritjof, Strafrecht Besonderer Teil I, 9. A., München 2009 (zit.: Haft, BT 1)

Hannich, Rolf (Hrsg.), Karlsruher Kommentar zu Strafprozessordnung, 6. A., München 2008 (zit.: Bearbeiter, in: Hannich, KK zur StPO)

Hailbronner, Kay, Asylrecht und Asylverfahren im Blick auf den europäischen Binnenmarkt, AnwBl 1989, 485 ff.

(zit.: Hailbronner, AnwB1 1989)

Harings, Lothar, Grenzüberschreitende Zusammenarbeit der Polizei- und Zollverwaltungen und Rechtsschutz in Deutschland, Berlin 1998

(zit.: Harings, Grenzüberschreitende Zusammenarbeit)

von Heintschel-Heinegg, Bernd (Hrsg.), KMR - Kommentar zur Strafprozessordnung, Band 3, $\S \S 151-225 a$, Loseblattsammlung, Köln 2011, Stand: Juli 2011

(zit.: Bearbeiter, in: von Heintschel-Heinegg, KMR-StPO, Band 3)

Hellenthal, Markus, Barrieren und Brücken, KR 1992, 247 ff.

(zit.: Hellenthal, KR 1992)

Hemesath, Wolfgang, Das Schengener Informationssystem - SIS -, KR 1995, 169 ff.

(zit.: Hemesath, KR 1995)

Hesse, Konrad, Grundzüge des Verfassungsrechts der Bundesrepublik Deutschland, 20. A., Heidelberg 1999

(zit.: Hesse)

Der Hessische Datenschutzbeauftragte (Hrsg.), 36. Tätigkeitsbericht 2007, Wiesbaden 2007 (zit.: Der Hessische Datenschutzbeauftragte, 36. Tätigkeitsbericht)

Hobbes, Thomas, Leviathan, Stuttgart 1970

(zit.: Hobbes, Leviathan) 
ders., Vom Menschen - Vom Bürger, Hamburg 1959

(zit.: Hobbes, Vom Bürger)

Hömig, Dieter (Hrsg.), Grundgesetz, 9. Auflage, Baden-Baden 2010

(zit.: Bearbeiter, in: Hömig, GG)

Hufeld, Ulrich, Der Europäische Haftbefehl vor dem BVerfG - NJW 2005, 2289, JuS 2005, 865

(zit.: Hufeld, JuS 2005)

van Iersel, Joost P., Free Movement of persons - democratic control, S. 369 ff., in: Schermers, Henry G. (Hrsg.), Free Movement of Persons in Europe, Dordrecht 1991

(zit.: van Iersel, in: Schermers, Free Movement)

Ingenerf, Peter, Das Schengener Abkommen, KR 1989, 341-362

(zit.: Ingenerf, KR 1989)

Ipsen, Jörn, Niedersächsisches Polizei- und Ordnungsrecht, 4. A., Stuttgart 2010

(zit.: Ipsen, Niedersächsisches POR)

Ders., Jörn, Staatsrecht I, 23. A., München 2011

(zit.: Ipsen, Staatsrecht I)

Ders., Staatsrecht I, 8. A., Neuwied u.a. 1996, (zit.: Ipsen, Staatsrecht I, 8. A.)

Isensee, Josef/Kirchof, Paul (Hrsg.), Handbuch des Staatsrechts, Band III, 3. A., Heidelberg 2005 (zit.: Bearbeiter, in: Isensee/Kirchof, HandbStR, Band III)

Dies., (Hrsg.), Handbuch des Staatsrechts, Band I, 2. A., Heidelberg 1995

(zit.: Bearbeiter, in: Isensee/Kirchhof, HandbStR, Band I)

Jarass, Hans D., EU-Grundrechte, München 2005

(zit.: Jarass, EU-Grundrechte)

Joecks, Wolfgang/Miebach, Klaus (Hrsg.), Münchener Kommentar zum Strafgesetzbuch, Band 3

(§§ 185 - 262 StGB), München 2003

(zit.: Bearbeiter, in: Joecks/Miebach, MüKo, Band 3)

Julius, Karl-Peter (Hrsg.)/Gercke, Björn (Hrsg.)/Kurth, Hans-Joachim/Lemke, Michael/Pollähne, Helmut/ Rautenberg, Erardo Cristoforo/Temming, Dieter (Hrsg.)/Woynar, Ines/Zöller, Mark Alexander (Hrsg.),

Strafprozessordnung, 4. A., Heidelberg 2009

(zit: Bearbeiter, in: Julius u.a., StPO)

Kämper, Gregor, Polizeiliche Zusammenarbeit in der Europäischen Union, Arnsberg 2001 (zit.: Polizeiliche Zusammenarbeit)

Kahlke, Svenja, Eurojust - Auf dem Weg zu einer Europäischen Staatsanwaltschaft?, Berlin 2004 (zit.: Kahlke, Eurojust - Auf dem Weg zur einer Europäischen Staatsanwaltschaft?) 
Karg, Michael Simon, Mehr Sicherheit oder Einschränkung von Bürgerrechten, München 2003 (zit.: Karg, Mehr Sicherheit)

Kattau, Thomas, Strafverfolgung nach Wegfall der europäischen Grenzkontrollen, Pfaffenweiler 1993

(zit.: Kattau, Strafverfolgung)

Krahl, Matthias, Der Anwendungsbereich der polizeilichen Beobachtung nach $§ 163$ e StPO als strafprozessuale Ermittlungsmaßnahme, NStZ 1998, 339-342

(zit.: Krahl, NStZ 1998)

Krekeler, Wilhelm, Informationssysteme der Polizei auf Bundes- und Landesebene, StraFo 1999, $82 \mathrm{ff}$.

(zit.: Krekeler, StraFo 1999)

Krüger, Ralf, Innere Sicherheit für Europa, KR 1994, 773 ff.

(zit.: Krüger, KR 1994)

Kühne, Hans-Heiner, Kriminalitätsbekämpfung durch innereuropäische Grenzkontrollen?, Berlin 1991

(zit.: Kühne, Kriminalitätsbekämpfung durch innereuropäische Grenzkontrollen?)

Ders., Die Bekämpfung von internationaler Kriminalität und von Drogenabhängigkeit als gemeinsames Interesse der Unionsstaaten, S. 85 ff., in: Müller-Graff, Peter-Christian (Hrsg.), Europäische Zusammenarbeit in den Bereichen Justiz und Inneres, Baden-Baden 1996

(zit.: Kühne, in: Müller-Graff, Europäische Zusammenarbeit)

Ders., Das Paradigma der inneren Sicherheit, Leipzig 1998

(zit.: Kühne, Das Paradigma)

Ders., Bürgerfreiheit und Verbrecherfreiheit. Der Staat zwischen Leviathan und Nachtwächter., Trier 2004

(zit.: Kühne, Bürgerfreiheit)

Kunig, Philip (Hrsg.), Grundgesetz-Kommentar, Band 1 (Präambel, Art. 1 - 69), 6. A., München 2012

(zit.: Bearbeiter, in: Kunig, GG, Band 1)

Lange, Hans-Jürgen, Innere Sicherheit im Politischen System der Bundesrepublik Deutschland Opladen 1999

(zit.: Lange, Innere Sicherheit)

ders. (Hrsg.), Staat, Demokratie und Innere Sicherheit in Deutschland, Opladen 2000

(zit.: Bearbeiter, in: Lange, Staat, Demokratie und Innere Sicherheit)

Lavranos, Nikolaos, Datenschutz in Europa, DuD 1996, $400 \mathrm{ff}$.

(zit.: Lavranos, DuD 1996)

Lenhard, Heinz, Probleme der Grenzöffnung aus der Sicht eines Landeskriminalamtes, Schriftenreihe der Polizei-Führungsakademie, Ausg. 3-4/1989, 34 ff.

(zit.: Lenhard, Schriftenreihe der PFA 3-4/1989) 


\section{XVIII}

Limbach, Jutta, Ist die kollektive Sicherheit Feind der individuellen Freiheit?, AnwBl. 2002, 454 ff. (zit.: Limbach, AnwB1. 2002)

Lisken, Hans/Denninger, Erhard (Hrsg.), Handbuch des Polizeirechts, 4. A. München 2007 (zit.: Bearbeiter, in: Lisken/Denninger, HandbPolR)

Dies., Handbuch des Polizeirechts, 3. A., München 2001

(zit.: Bearbeiter, in: Lisken/Denninger, HandbPolR, 3. A.)

Martínez Soria, José, Die polizeiliche Zusammenarbeit in Europa und der Rechtsschutz des Bürgers VA 1998, $400 \mathrm{ff}$.

(zit.: Martínez Soria, VA 1998)

Mathiesen, Thomas, Die Globalisierung der Überwachung, S. 21 ff., in: Schulzki-Haddouti, Christiane (Hrsg.), Vom Ende der Anonymität: die Globalisierung der Überwachung, 2. A., Hannover 2001

(zit.: Mathiesen, in: Schulzki-Haddouti, Globalisierung der Überwachung)

Meyer, Jürgen (Hrsg.), Charta der Grundrechte der Europäischen Union, 2. Auflage, Baden-Baden 2006

(zit.: Bearbeiter, in: Meyer, GR-Charta)

Meyer-Goßner, Lutz, Strafprozessordnung, 54. A., München 2011

(zit.: Meyer-Goßner, StPO)

Meyer-Ladewig, Jens, EMRK - Europäische Menschenrechtskonvention, 3. A., Baden-Baden 2011 (zit.: Meyer-Ladewig, EMRK)

Middel, Stefan, Innere Sicherheit und präventive Terrorismusbekämpfung, Baden-Baden 2007 (zit.: Middel, Innere Sicherheit)

Minkmar, Nils, Was hilft bei Terror?, Frankfurter Allgemeine Sonntagszeitung Nr. 25 vom 24. Juni 2007, S. 28

(zit.: Minkmar, Frankfurter Allgemeine Sonntagszeitung Nr. 25 vom 24. Juni 2007)

Müller, Michael H., Die innerstaatliche Umsetzung von einseitigen Maßnahmen der auswärtigen Gewalt, Berlin 1994

(zit.: Müller, Die innerstaatliche Umsetzung)

Pauly, Alexis (Hrsg.), Schengen en panne, Maastricht 1994

(zit.: Bearbeiter, in: Pauly, Schengen en panne)

Pfeiffer, Gerd (Hrsg.), Karlsruher Kommentar zur Strafprozessordnung, 3. Auflage, München 1993 (zit.: Bearbeiter, in: Pfeiffer, KK zur StPO, 3. A.)

Pieroth, Bodo/Schlink, Bernhard, Staatsrecht II, 25. A., Heidelberg 2009 (zit.: Pieroth/Schlink, Staatsrecht II)

Piosek, Astrid, Die Ausgleichsmaßnahmen des Schengener Durchführungsübereinkommens als Gegenstand einer übersetzungsbezogenen terminologischen Untersuchung, Trier 2005 (zit.: Piosek) 
Pitschas, Rainer, Europäisches Polizeirecht als Informationsrecht, ZRP 1993, 174 ff.

(zit.: Pitschas, ZRP 1993)

Radtke, Henning, Der Europäische Staatsanwalt, Ein Modell für Strafverfolgung in Europa mit Zukunft?, GA 2004, 1 ff. (zit.: Radtke, GA 2004)

Roxin, Claus, Strafrecht Allgemeiner Teil, Band I, 4. A., München 2006 (zit.: Roxin, Strafrecht AT, Band I)

Rudolphi, Hans-Joachim (Hrsg.)/Degener, Wilhelm/Frisch, Wolfgang/Frister, Helmut/Paeffgen, Hans-Ulrich/Rogall, Klaus/Schlüchter, Ellen/Velten, Petra/Weßlau, Edda/Wohlers, Wolfgang Systematischer Kommentar zur Strafprozessordnung und zum Gerichtsverfassungsgesetz Loseblattsammlung, Band 3, München/Unterschleißheim 2009, Stand: Oktober 2009 (zit.: Bearbeiter, in: Rudolphi u.a., SK StPO, Band 3)

Rupprecht, Reinhard, Wettlauf der Schnecken, KR 1989, 263 ff. (zit.: Rupprecht, KR 1989)

Ders./Hellenthal, Markus, Programm für eine Europäische Gemeinschaft der Inneren Sicherheit, S. 23 ff., in: dies., Innere Sicherheit im europäischen Binnenmarkt, Gütersloh 1992 (zit.: Bearbeiter, in: Rupprecht/Hellenthal, Innere Sicherheit)

Sachs, Michael (Hrsg.), Grundgesetz, 5. A., München 2009 (zit.: Bearbeiter, in: Sachs, GG)

Schaaf, Julia, Wir Angsthasen, Frankfurter Allgemeine Sonntagszeitung Nr. 49 vom 6. Dezember 2009, S. 57 (zit.: Schaaf, Frankfurter Allgemeine Sonntagszeitung Nr. 49 vom 6. Dezember 2009)

Schäuble, Wolfgang, Europa ohne Grenzen - eine sichere Gemeinschaft, Europa-Archiv 1990, $203 \mathrm{ff}$.

(zit.: Schäuble, Europa-Archiv 1990)

Schattenberg, Bernd, Das Schengener Informationssystem - technische und rechtliche Fragen bei der Verwirklichung, Schriftenreihe der Polizei-Führungsakademie, Ausg. 3-4/1989, 20 ff. (zit.: Schattenberg, Schriftenreihe der PFA 3-4/1989)

Scheller, Susanne, Das Schengener Informationssystem - Rechtshilfeersuchen ,per Computer“, JZ 1992, 904

(zit.: Scheller, JZ 1992)

Schewe, Christoph S., Das Sicherheitsgefühl und die Polizei, Berlin 2009 (zit.: Schewe, Sicherheitsgefühl)

Schoch, Friedrich, Das Asyl- und Ausländerrecht in der Europäischen Gemeinschaft, DVB1. 1992, $525 \mathrm{ff}$.

(zit.: Schoch, DVB1. 1992)

Ders., Das Recht auf informationelle Selbstbestimmung, JURA 2008, 352 ff.

(zit.: Schoch, JURA 2008) 
Schreckenberger, Waldemar, Von den Schengener Abkommen zu einer gemeinsamen Innen- und Justizpolitik (Die Dritte Säule), VA 1997, 389 ff.

(zit.: Schreckenberger, VA 1997)

Schreiber, Manfred, Abschaffung der Grenzkontrollen in Europa?, KR 1985, 93 ff.

(zit.: Schreiber, Manfred, KR 1985)

Schreiber, Wolfgang, Polizeiliche Zusammenarbeit in einem Europa ohne Grenzen, KR 1991, $369 \mathrm{ff}$.

(zit.: Schreiber, Wolfgang, KR 1991)

Schriever-Steinberg, Angelika, Das Schengener Informationssystem, DuD 2000, $209 \mathrm{ff}$.

(zit.: Schriever-Steinberg, DuD 2000)

Dies., Die datenschutzrechtliche Umsetzung und Praxis von Schengen in Deutschland, S. 159 ff., in: Breitenmoser, Stephan/Gleß, Sabine/Lagodny, Otto (Hrsg.), Schengen in der Praxis, Erfahrungen und Ausblicke, Zürich/St. Gallen 2009

(zit.: Schriever-Steinberg, in: Breitenmoser u.a., Schengen in der Praxis)

Schübel, Eva, Wie gut funktioniert die Strafverfolgung innerhalb Europas?, NStZ 1997, 105 ff. (zit.: Schübel, NStZ 1997)

Schütz, Raimund, Europaweite Freizügigkeit ohne demokratische Kontrolle?, AöR 1995, 509 ff. (zit.: Schütz, AöR 1995)

Schwarze, Jürgen (Hrsg.), EU-Kommentar, 2. A., Baden-Baden 2009

(zit.: Bearbeiter, in: Schwarze, EU-Kommentar)

Schwetzel, Wolfram, Freiheit, Sicherheit, Terror, München 2007

(zit.: Schwetzel, Freiheit, Sicherheit, Terror)

Sieber, Ulrich, Die Zukunft des europäischen Strafrechts, ZStW 121 (2009), $1 \mathrm{ff}$. (zit.: Sieber, ZStW 121 (2009))

Siemen, Birte, Grundrechtsschutz durch Richtlinien/Die Fälle Österreichischer Rundfunk u.a. und Lindqvist, EuR 2004, 306 ff.

(zit.: Siemen, EuR 2004)

Starck, Christian (Hrsg.), Kommentar zum Grundgesetz, Band 2, Art. 20 - 82, 5. Auflage, München 2005

(zit.: Bearbeiter, in: Starck, GG, Band 2)

Streinz, Rudolf(Hrsg.), EUV/AEUV, 2. Auflage, München 2012

(zit.: Bearbeiter, in: Streinz, EUV/AEUV)

Stubenrauch, Julia, Gemeinsame Verbunddateien von Polizei und Nachrichtendiensten, BadenBaden 2009

(zit.: Stubenrauch, Gemeinsame Verbunddateien)

Sturm, Joachim, Das Schengener Durchführungsübereinkommen - SDÜ -, KR 1995, 162 ff.

(zit.: Sturm, KR 1995) 
Taschner, Hans Claudius, Schengen, Baden-Baden 1997

(zit.: Taschner)

Tettinger, Peter/Stern, Klaus (Hrsg.), Kölner Gemeinschaftskommentar zur Europäischen Grundrechte-Charta, München 2006

(zit.: Bearbeiter, in: Tettinger/Stern, Kölner Gemeinschaftskommentar)

Tuffner, Martin, Das Schengener Informationssystem (SIS), KR 2000, $39 \mathrm{ff}$. (zit.: Tuffner, KR 2000)

Ders., Das Schengener Informationssystem, MEPA-Zeitung 2005, $21 \mathrm{ff.}$ (zit.: Tuffner, SIS, MEPA-Zeitung 2005)

Ders., Das SIS II und der Europäische Haftbefehl, MEPA-Zeitung 2005, 32 ff. (zit.: Tuffner, SIS II, MEPA-Zeitung 2005)

Ders., Auf dem Weg zur Europäischen Fahndungsunion, Polizei - heute 2007, S. 114 ff. (zit.: Tuffner, Polizei - heute 2007)

Ders., Der Europäische Haftbefehl und die Fahndung nach Personen im Schengener Informations system (SIS) - gegenwärtiger Stand und weitere Entwicklung bis 2007, Stand: 1. Juni 2007, unveröffentlichter Vortrag vor der deutschen Richterakademie in Trier im Rahmen des European Judicial Training Network Seminar 19a/05 vom 20. bis 25. Juni 2005 (zit.: Tuffner, unveröffentlichter Vortrag vor der deutschen Richterakademie in Trier im Juni 2005)

Umbach, Dieter/Clemens, Thomas (Hrsg.), Grundgesetz, Band I, Heidelberg 2002 (zit.: Bearbeiter, in: Umbach/Clemens, GG, Band I)

Waechter, Kay, Polizei- und Ordnungsrecht, Baden-Baden 2000

(zit.: Waechter, Polizei- und Ordnungsrecht)

Wehner, Ruth, Europäische Zusammenarbeit bei der polizeilichen Terrorismus-Bekämpfung aus rechtlicher Sicht, Baden-Baden 1993

(zit.: Wehner, Europäische Zusammenarbeit)

Weichert, Thilo, Das geplante Schengen-Informationssystem, CR 1990, 62 ff.

(zit.: Weichert, CR 1990)

Werner, Ulrich, Schengen und Europol, CR 1997, 34 ff.

(zit.: Werner, CR 1997)

Wessels, Johannes/Beulke, Werner, Strafrecht Allgemeiner Teil, 41. A. Heidelberg 2011 (zit.: Wessels/Beulke, Strafrecht AT)

Wilkesmann, Peter, Plädoyer für das Schengener Informationssystem (SIS), NStZ 1999, 68 ff. (zit.: Wilkesmann, NStZ 1999)

Wolter, Jürgen/Schenke, Wolf-Rüdiger/Hilger, Hans/Ruthig, Josef/Zöller, Mark Alexander (Hrsg.), Alternativentwurf Europol und europäischer Datenschutz, Heidelberg 2008 (zit.: Bearbeiter, in: Wolter u.a., Alternativentwurf Europol) 
Wolters, Jörg, Verbrechensbekämpfung - Eine europäische Sache?, KR 1997, 86 ff. (zit.: Wolters, KR 1997)

Würz, Karl, Das Schengener Durchführungsübereinkommen, Stuttgart u.a. 1997 (zit.: Würz)

Ziercke, Jörg, Neue Sicherheitsarchitektur für Deutschland, KR 2002, 346 ff. (zit.: Ziercke, KR 2002)

Ders., Internationale Erscheinungsformen von Kriminalität und Gewalt, Internationale Kooperationsformen und die Rolle des BKA, KR 2005, 700 ff.

(zit.: Ziercke, KR 2005)

Zieschang, Frank, Chancen und Risiken der Europäisierung des Strafrechts, ZStW 113 (2001), $255 \mathrm{ff}$.

(zit.: Zieschang, ZStW 113 (2001))

Zöberlein, Renate, Eurojust als Keimzelle einer europäischen Staatsanwaltschaft?, Berlin 2004 (zit.: Zöberlein, Eurojust)

Zöller, Mark Alexander, Informationssysteme und Vorfeldmaßnahmen von Polizei, Staatsanwaltschaft und Nachrichtendiensten, Heidelberg 2002

(zit.: Zöller, Informationssysteme und Vorfeldmaßnahmen)

Ders., Heimlichkeit als System, StraFo 2008, S. 15 ff.

(zit.: Zöller, StraFo 2008) 


\section{Abkürzungsverzeichnis}

A.

ABl.

Abs.

AEUV

AnwBl.

AöR

Art.

Ausg.

BDSG

BGBl.

BKA

BKAG

BMI

BPolG

BT

BR-Drs.

BT-Drs.

BVerfG

BVerfGE

BVerfSchG

bzw.

CR

C.SIS

dass.

DDR

ders.

dies.

DNA

DÖV

DRiZ

DuD

DVBl.

EGMR

EGV

EJN

EJN-Beschluss

EMRK

EU

EuAlÜbk

EuDSK
Auflage

Amtsblatt

Absatz

Vertrag über die Arbeitsweise der Europäischen Union

Anwaltsblatt

Archiv des öffentlichen Rechts

Artikel

Ausgabe

Bundesdatenschutzgesetz

Bundesgesetzblatt

Bundeskriminalamt

Gesetz über das Bundeskriminalamt und die Zusammenarbeit des Bundes und der Länder in kriminalpolizeilichen Angelegenheiten

Bundesministerium des Innern

Bundespolizeigesetz

Besonderer Teil

Bundesratsdrucksache

Bundestagsdrucksache

Bundesverfassungsgericht

Entscheidungen des Bundesverfassungsgerichts

Gesetz über die Zusammenarbeit des Bundes und der Länder in Angelegenheiten des Verfassungsschutzes und über das Bundesamt für Verfassungsschutz

beziehungsweise

Computer und Recht

zentraler Teil des Schengener Informationssystems

dasselbe

Deutsche Demokratische Republik

derselbe

dieselbe $/ \mathrm{n}$

Desoxyribonucleic acid

Die Öffentliche Verwaltung

Deutsche Richterzeitung

Datenschutz und Datensicherheit

Deutsches Verwaltungsblatt

Europäischer Gerichtshof für Menschenrechte

Vertrag zur Gründung der Europäischen Gemeinschaft

Europäisches Justizielles Netz

Beschluss des Rates vom 16. Dezember 2008 über das Europäische Justizielle Netz

Europäische Konvention zum Schutze der Menschenrechte und Grundfreiheiten

Europäische Union

Europäisches Auslieferungsübereinkommen

Übereinkommen des Europarates über den Schutz des Menschen bei der automatischen Verarbeitung personenbezogener Daten vom 28. Januar 1981 
Eurodac

EuropolB

EUV

f.

FAZ

ff.

Fn.

Frontex

GA

gem.

GG

ggf.

GMB1.

GOBT

GR-Charta

HandbPolR

HandbStR

Hrsg.

Interpol

IRG

i.S.v.

i.V.m.

JA

JURA

$\mathrm{JuS}$

$\mathrm{JZ}$

$\mathrm{KJ}$

KK

KMR

KR

lit.

Ls.

MEPA

MI

MJ

MüKo

NATO

Nds.

Nds. SOG

NJW

N.SIS

NStZ

$\mathrm{Nr}$.

o.g.

OK

PFA

RAF
Zusammensetzung aus den Wörtern „Europa“ und „Daktyloskopie“; Bezeichnung für eine europäische Datenbank zur Speicherung von Fingerabdrücken

Europol-Beschluss 2009/371/JI vom 6. April 2009

Vertrag über die Europäische Union

folgende

Frankfurter Allgemeine Zeitung

folgende, folgende

Fußnote

Europäische Agentur für die operative Zusammenarbeit an den Außengrenzen der Mitgliedstaaten der Europäischen Union

Goltdammer's Archiv für Strafrecht

gemeinsamer

Grundgesetz

gegebenenfalls

Gemeinsames Ministerialblatt

Geschäftsordnung des Bundestages

Charta der Grundrechte der Europäischen Union

Handbuch des Polizeirechts

Handbuch des Staatsrechts

Herausgeber

Internationale Kriminalpolizeiliche Organisation

Gesetz über die internationale Rechtshilfe in Strafsachen

im Sinne von

in Verbindung mit

Juristische Arbeitsblätter

Juristische Ausbildung

Juristische Schulung

JuristenZeitung

Kritische Justiz

Karlsruher Kommentar

Kleinknecht, Müller, Reitberger

Kriminalistik

Buchstabe

Leitsatz

Mitteleuropäische Polizeiakademie

Innenministerien

Justizministerien

Münchener Kommentar

North Atlantic Treaty Organization

Niedersächsisches

Niedersächsisches Gesetz über die öffentliche Sicherheit und Ordnung

Neue Juristische Wochenschrift

nationaler Teil des Schengener Informationssystems

Neue Zeitschrift für Strafrecht

Nummer

oben genannte/oben genannten

Organisierte Kriminalität

Polizei-Führungsakademie

Rote Armee Fraktion 
$\mathrm{RbEuHb} \quad$ Rahmenbeschluss 2002/584/JI über den Europäischen Haftbefehl vom 13. Juni 2002

RiStBV

RL

$\mathrm{S}$

SDÜ

SIS

SIS II

Sirene

Slg.

Spstr.

StGB

StPO

StraFo

StVG

u.a.

Unterabs.

Urt.

U.S.A.

VA

vgl.

VIS

VO

z.B.

ZRP

ZStW

z.T.
Richtlinien für das Strafverfahren und das Bußgeldverfahren

Richtlinie

Satz/Seite

Übereinkommen zur Durchführung des Schengener Übereinkommens vom 19. Juni 1990

Schengener Informationssystem

Schengener Informationssystem der zweiten Generation

Supplementary Information Request at the National Entry

Sammlung

Spiegelstrich

Strafgesetzbuch

Strafprozessordnung

Strafverteidiger Forum

Straßenverkehrsgesetz

unter anderem/unter anderen/und andere

Unterabsatz

Urteil

United States of America

Verwaltungs-Archiv

vergleiche

Visa-Informationssystem

Verordnung

zum Beispiel

Zeitschrift für Rechtspolitik

Zeitschrift für die gesamte Strafrechtswissenschaft

zum Teil 


\section{Teil: Einführung}

Die vorliegende Arbeit beschäftigt sich mit dem Schengener Informationssystem, kurz SIS. Es hat seine Rechtsgrundlage in den Schengener Abkommen aus den Jahren 1985 ${ }^{1}$ bzw. $1990^{2}$ und ist seit 1995 in Betrieb. Mit Hilfe des Systems konnte innerhalb Europas erstmals elektronisch nach Personen und Sachen gefahndet werden. ${ }^{3}$ In dem Willen und der Fähigkeit, sich zwischen den Staaten Europas zu einigen, offenbaren sich in Kombination mit der technischen Entwicklung faszinierende neue Möglichkeiten der polizeilichen und justiziellen Zusammenarbeit. Den praktischen Nutzen dieser Zusammenarbeit erfährt auch der „einfache“ Bürger auf vielfältige Weise. Wenn er beispielsweise Opfer eines Autodiebstahls wird, kann das SIS dazu führen, dass das Fahrzeug tausende von Kilometern entfernt an einer EU-Außengrenze sichergestellt und zum rechtmäßigen Eigentümer zurückgeführt wird. Zur Steigerung des Sicherheitsgefühls jedes einzelnen $^{4}$ trägt es auch bei, wenn spektakuläre Straftaten wie beispielsweise der so genannte Hubschrauberüberfall, bei dem die Täter nach einem Banküberfall mit einem gekaperten Hubschrauber flüchteten, mit Hilfe des SIS nach kurzer Zeit aufgeklärt und die Tatverdächtigen gefasst werden können. ${ }^{5}$ Von der Politik untrennbar verbunden mit dem Funktionieren des Fahndungssystems war und ist zudem der Wegfall der Grenzkontrollen zwischen den teilnehmenden Staaten. Offene Grenzen bedeuten für die Menschen in den Mitgliedstaaten der Zusammenarbeit ein freies und ungehindertes Reisen von Land zu Land und sind ein Sinnbild für ein Europa der Bürger.

Man könnte nach diesen Ausführungen davon ausgehen, dass mit dem SIS und der es ermöglichenden Kooperation zwischen den Staaten sowie auf europäischer Ebene ausschließlich positive Wirkungen für Bürger und Gesellschaft verbunden sind. Allerdings gibt es auch zahlreiche kritische Stimmen, die auf mögliche Gefahren einer solchen Zusammenarbeit hinweisen. Eine immer wieder geäußerte Sorge betrifft die demokratische Legitimation der Schengener Abkommen. Zudem sollen anhand der Fahndungskategorie der verdeckten Registrierung grundlegende Fragen des europäischen Persönlichkeits- und Datenschutzes, wie er in der Grundrechte-Charta niedergelegt ist, diskutiert werden. Dabei muss auch die Reaktion der Politik auf die Herausforderungen des internationalen Terrorismus eine Rolle spielen.

\footnotetext{
${ }^{1}$ GMB1. 1986, 79.

${ }^{2}$ BGBl. II 1993, 1013, vgl. die konsolidierte Fassung, als Anhang zu dieser Arbeit.

${ }^{3}$ Sturm, KR 1995, 162 (167).

${ }^{4}$ Zur Bedeutung des Sicherheitsgefühls siehe auch die Arbeit von Schewe: „Das Sicherheitsgefühl und die Polizei“.

${ }^{5}$ FAZ Nr. 13 vom 16. Januar 1997, S. 9, und FAZ Nr. 18 vom 22. Januar 1997, S. 9; der Banküberfall fand in Offenburg in Baden-Württemberg statt, und der dritte der Täter wurde eine Woche nach der Tat im südspanischen Algeciras festgenommen.
} 
Die Arbeit befasst sich in ihrem 2. Teil zunächst mit der Einbettung des SIS in den Kontext der Schengen-Zusammenarbeit und der entsprechenden Vereinbarungen auf Ebene der Europäischen Gemeinschaft bzw. der Europäischen Union. Es folgt eine Darstellung der Funktionsweise des Systems, seines Inhaltes, der Aufgaben der so genannten Sirene ${ }^{6}$ sowie der Datenschutz- und Rechtsschutzmöglichkeiten. Anschließend werden zur Abgrenzung andere Systeme und Formen der grenzüberschreitenden Zusammenarbeit im Bereich Polizei und Justiz dargestellt.

Der 3. Teil der Arbeit befasst sich mit der Bedeutung des Demokratieprinzips für das Verfahren, das in Deutschland zur Implementierung des Schengener Abkommens von 1990 gewählt wurde sowie mit der Frage, ob die Fahndungskategorie der Verdeckten Registrierung mit Art. 8 der seit dem 1. Dezember 2009 geltenden europäischen Grundrechte-Charta vereinbar ist.

Abschließend ist die bisherige Entwicklung des seit vielen Jahren geplanten, aber bisher nicht realisierten SIS der zweiten Generation zu skizzieren.

Insgesamt bewegt sich die Arbeit in einem Schnittfeld zwischen Strafrecht, Strafprozessrecht, Polizeirecht, Öffentlichem Recht, Völkerrecht und Europarecht.

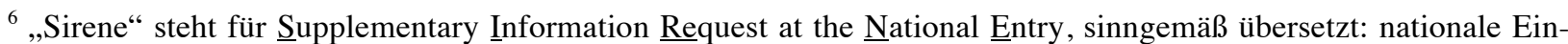
gangsstelle, von der Zusatzinformationen angefordert werden können, Tuffner, in: Bundeskriminalamt, Festschrift für Herold, S. 239 (243).
} 


\section{Teil: Vorstellung des SIS und der Sirene}

\section{A. Einbettung in den Schengen-Kontext}

Wenn in den Medien von den „Schengen-Staaten“ oder der „Schengen-Zusammenarbeit“ die Rede ist, wird damit Bezug genommen auf die beiden Schengener Abkommen aus den Jahren 1985 und 1990. Während ersteres, das „Übereinkommen zwischen den Regierungen der Benelux-Wirtschaftsunion, der Bundesrepublik Deutschland und der Republik Frankreich betreffend den schrittweisen Abbau der Kontrollen an den gemeinsamen Grenzen vom 14. Juni 1985“, zunächst politische Absichtserklärungen enthielt, regelt letzteres, das „Übereinkommen zur Durchführung des Schengener Übereinkommens vom 19. Juni 1990“8 - kurz SDÜ - , die konkreten Maßnahmen zur Umsetzung dieser Absichtserklärungen.

Die Schengen-Zusammenarbeit begann als selbständiger völkerrechtlicher Zusammenschluss von fünf Mitgliedstaaten der damaligen Europäischen Gemeinschaft. Dennoch ist diese Zusammenarbeit - auch schon im Vorfeld der Vertragsabschlüsse - eng mit der inhaltlich entsprechenden Entwicklung auf der Ebene der Europäischen Gemeinschaft bzw. der Europäischen Union verknüpft. Diese Verknüpfung und der Inhalt der Schengen-Zusammenarbeit sollen im Folgenden chronologisch skizziert werden.

\section{Von der Pariser Gipfelkonferenz 1974 bis zur Entschließung des Rates vom 7. Juli 1984}

Die Schengener Vereinbarungen haben ihren Ausgangspunkt in der europäischen Idee eines Raumes, in dem sich Personen frei bewegen und Waren, Dienstleistungen und Kapital frei bewegt werden können. Erste konkrete Schritte zur Erreichung dieses Ziels ergriffen die Staatsund Regierungschefs auf ihrer Pariser Gipfelkonferenz von 1974. ${ }^{9}$ Hauptbeweggrund war dabei, ein über Industrie, Handel, Landwirtschaft und Verkehr hinausgehendes „Europa der Bürger“ zu schaffen, das diese im kontrollfreien Überschreiten der Binnengrenzen erfahren können sollten. ${ }^{10}$ Die Staats- und Regierungschefs setzten eine Arbeitsgruppe ein, die die Möglichkeit der Schaffung einer Passunion mit vorheriger Einführung eines einheitlichen Passes prüfen sollte. ${ }^{11}$ Unverzichtbares Merkmal einer Passunion ist die Aufhebung der Kontrollen an den gemeinsamen Binnengrenzen. Eine Unterscheidung zwischen (Pass-) Unionsbürgern und Drittstaatsangehörigen wird damit unmöglich, so dass diese Reiseerleichterung notwendig sämtlichen Personen,

\footnotetext{
${ }^{7}$ GMB1. 1986, 79.

${ }^{8}$ BGB1. II 1993, 1013.

${ }^{9}$ Akmann, JA 1994, 49 (50); Schreckenberger, VA 1997, 389 (396); Epiney, in: Achermann u.a., Schengen, S. 21 (22 f.).

${ }^{10}$ Taschner, Rn. 8 .

${ }^{11}$ Akmann, JA 1994, 49 (50); Epiney, in: Achermann u.a, Schengen, S. 21 (23).
} 
die sich im Gebiet der Union aufhalten, zugute kommt. Aus diesem Grund wird man als weiteres typisches Merkmal einer Passunion die Verstärkung der Kontrollen an den Außengrenzen ansehen können. Auf diese Weise möchte man erreichen, dass Drittstaatsangehörige nur dann einund anschließend kontrollfrei weiterreisen können, wenn alle Voraussetzungen für einen rechtmäßigen Aufenthalt gegeben sind. ${ }^{12}$

Die von der beim Pariser Gipfel eingesetzten Arbeitsgruppe im Jahr 1975 vorgelegten Ergebnisse führten zunächst nur dazu, dass im Jahr 1981 ein Europapass vereinbart wurde. Weitere nennenswerte Maßnahmen im Hinblick auf die Kernfragen einer Passunion gab es nicht. ${ }^{13}$

Die Kommission nahm sich der Problematik im Jahr 1982 wieder an und schlug dem Rat in dem Entwurf zu einer Entschließung zwar keine Aufhebung, aber doch die Erleichterungen der Binnengrenzkontrollen vor. Systematische Kontrollen sollten dabei für EG-Bürger, erkennbar am Vorzeigen des geschlossenen Europapasses, durch vereinzelte Stichproben ersetzt werden. Bei Verdachtsmomenten sollten die Grenzbeamten jederzeit eine eingehende Kontrolle der EGAngehörigen durchführen können. Längerfristiges Ziel des Kommissionsvorschlages war die Prüfung, ob die Personenkontrollen einmal ganz aufgehoben werden könnten.

Während das Europäische Parlament die Initiative der Kommission unterstützte, zogen sich die Verhandlungen im Rat zwei Jahre hin. Eine große Zahl von Mitgliedstaaten befürchtete eine zu hohe Einbuße an nationaler Sicherheit. ${ }^{14}$ Zudem hielten einige Staaten die EG auch für nicht zuständig, da der Personenverkehr im Sinne des EWG-Vertrages die Regelung von Grenzkontrollen ihrer Ansicht nach nicht umfasste. Aus diesem Grund verfassten sowohl der Rat als auch die Mitgliedstaaten am 7. Juni 1984 eine Entschließung, ${ }^{15}$ die eine Erleichterung der Grenzkontrollen für EG-Bürger nach Belieben eines jeden Mitgliedstaates vorsah. Innerhalb von vier Jahren wollten die Mitgliedstaaten auf der Grundlage eines Berichtes der Kommission eine erneute Bewertung vornehmen.

\section{Deutsch-französisches (Saarbrücker) Abkommen vom 13. Juli 1984}

Zeitgleich vereinbarten der deutsche Bundeskanzler Kohl und der französische Staatspräsident Mitterand im Juni 1984 - wohl mit Blick auf die im Juli 1984 stattfindenden Wahlen zum Europäischen Parlament - den schrittweisen Abbau der Kontrollen an der deutsch-französischen Grenze. ${ }^{16}$ Diese Übereinkunft führte ihrerseits zu erneuten Aktivitäten auf Ebene des Europäi-

\footnotetext{
${ }^{12}$ Taschner, Rn. 2.

${ }^{13}$ Taschner, Rn. 10, 17.

${ }^{14}$ Epiney, in: Achermann u.a., Schengen, S. 21 (23).

${ }^{15}$ ABl. C 159, 1.

${ }^{16}$ Schreckenberger, VA 1997, 389 (396), Taschner, Rn. 13.
} 
schen Rates von Fontainebleau, der ebenfalls im Juni 1984 stattfand, blieb aber im Ergebnis von der Europäischen Gemeinschaft und den meisten Mitgliedstaaten unbeachtet. ${ }^{17}$

Zwischen Deutschland und Frankreich kam es hingegen am 13. Juli 1984 zum „Regierungsabkommen über den schrittweisen Abbau der Kontrollen an den Grenzen Frankreichs und der Bundesrepublik Deutschland“. ${ }^{18}$ Die Präambel nimmt Bezug auf die Staaten der Europäischen Gemeinschaft sowie darauf, dass die Solidarität zwischen den Völkern Deutschlands und Frankreichs durch die Aufhebung der Hindernisse für den freien Verkehr gestärkt werden soll. Das Abkommen, das noch am gleichen Tag in Kraft trat, ${ }^{19}$ legt in drei Titeln „Unverzüglich anwendbare Maßnahmen“, einen „Zweiten Schritt“ und „Bis zum 31.12.1986 zu ergreifende Maßnahmen“ fest.

Als unverzüglich anwendbare Maßnahme wird bestimmt, dass die Polizei- und Zollbehörden die die Grenze mit verminderter Geschwindigkeit überquerenden Fahrzeuge im Regelfall nur einer einfachen Sichtkontrolle unterziehen. Eingehendere Stichproben sollten zur Aufrechterhaltung des Verkehrsflusses auf einer gesonderten Spur erfolgen.$^{20}$ Begünstigte des Abkommens sind nicht nur Angehörige der beiden Staaten, sondern alle EG-Bürger. Da hier noch keine Passunion, sondern lediglich eine Kontrollerleichterung vereinbart wurde, mag diese Entscheidung überraschen. Sie zeugt jedoch von dem Geist, dass der Raum ohne Binnengrenzkontrollen einmal alle Staaten der EG umfassen soll und zwei dieser Staaten lediglich die Initiative ergreifen.

Zur schnellen Unterscheidung zwischen EG- und Nicht-EG-Bürgern soll der Fahrzeugführer eine grüne Scheibe an der Windschutzscheibe, das „Europa-E“ , anbringen. ${ }^{21}$

Als unverzüglich anwendbare Maßnahmen werden außerdem die Einrichtung gemeinsamer Kontrollstellen sowie die „entschiedene Fortführung des Kampfes gegen Drogen, Kriminalität und illegale Einreise“ genannt. ${ }^{22}$

Im Titel „Zweiter Schritt“, der bis Oktober 1984 vorbereitet werden sollte, werden u.a. die Verstärkung der Zusammenarbeit zwischen Zoll- und Polizeiverwaltungen, eine gemeinsame Sichtvermerkspolitik sowie die Verlagerung der Kontrollen von der deutsch-französischen Grenze an die Außengrenzen genannt. ${ }^{23}$ Gerade letztere Vereinbarung bedeutet einen deutlichen Schritt in Richtung einer Passunion.

\footnotetext{
${ }^{17}$ Epiney, in: Achermann u.a., Schengen, 21 (23 f.); Taschner, Rn. 13 f.

${ }^{18}$ BGB1. II 1984, $767 \mathrm{f}$.

${ }^{19}$ Art. 18.

${ }^{20}$ Sog. ,(Kontroll-)Verfahren ohne Wartezeiten“, vgl. Würz, Rn. 11.

${ }^{21}$ Art. 3; der 1981 vereinbarte Europapass war zum Zeitpunkt des Abschlusses des Abkommens von beiden Vertragsstaaten noch nicht allgemein einführt worden, so dass eine Ersatzregelung erforderlich schien, vgl. Taschner, Rn. 17.

${ }^{22}$ Art. 4 und 5.

${ }^{23}$ Art. 7 bis 10 .
} 
Bis zum 31. Dezember1986 schließlich, Titel III des Abkommens, sollten die Voraussetzungen für die Abschaffung jeglicher Kontrolle im Personenverkehr geschaffen werden, ${ }^{24}$ womit die Angleichung der entsprechenden Rechts- und Verwaltungsvorschriften insbesondere im Ausländerrecht, im Betäubungsmittelrecht und im Recht des Waffenverkehrs gemeint war.

\section{Richtlinienvorschlag der Kommission vom 23. Januar 1985}

Ermutigt durch die Initiative Frankreichs und Deutschlands, legte die Kommission dem Rat im Januar 1985 einen Richtlinienentwurf vor, der die Erleichterung der Grenzkontrollen zwischen den Mitgliedstaaten für EG-Bürger vorsah. ${ }^{25}$ Die Mitgliedstaaten begrüßten zwar mittlerweile die Idee einer durchlässigeren Grenze, legten den Fokus ihrer Diskussion aber auf die Maßnahmen, die als Ausgleich für den befürchteten Verlust an nationaler Sicherheit - nicht im Rahmen der Gemeinschaft, sondern rein zwischenstaatlich - durchzuführen seien. ${ }^{26}$

\section{Schengener Abkommen vom 14. Juni $1985^{27}$}

Nach Abschluss des deutsch-französischen Abkommens vom Juli 1984 und angesichts der weiterhin ergebnislosen Diskussionen auf europäischer Ebene kam es zu Verhandlungen mit den BENELUX-Staaten, ${ }^{28}$ die untereinander bereits im Jahr 1960 eine Passunion vereinbart hatten. ${ }^{29}$ Diese Verhandlungen mündeten am 14. Juni 1985 in das Schengener Abkommen. Es handelt sich hierbei um ein rein intergouvernementales Verwaltungsabkommen. ${ }^{30}$ Die Wahl für die Unterzeichnung des Vertrages fiel auf den kleinen luxemburgischen Moselort, weil er als geographischer Mittelpunkt zwischen den Unterzeichnerstaaten angenommen wurde. ${ }^{31}$

Das Schengener Abkommen umfasst 33 Artikel und legt in zwei Titeln zum einen kurzfristig und zum anderen langfristig durchzuführende Maßnahmen fest.

$\mathrm{Zu}$ den kurzfristig durchzuführenden Maßnahmen zählt, wie bereits im Saarbrücker Übereinkommen zwischen Frankreich und Deutschland geregelt, eine sofortige Lockerung der Grenzkontrollen durch einfache Sichtkontrolle der die Grenze überquerenden Fahrzeuge sowie die eingehendere Stichprobenkontrolle auf einer gesonderten Fahrspur. ${ }^{32}$ Bezug genommen wird auch auf die grüne Europa-Scheibe, die EG-Bürger an der Windschutzscheibe ihres Fahrzeuges

\footnotetext{
${ }^{24}$ Art. 15 Abs. 2.

${ }^{25}$ AB1. C 47, 5; Epiney, in: Achermann u.a., Schengen, S. 21 (24).

${ }^{26}$ Ihren Richtlinien-Vorschlag zog die Kommission Ende 1992 zurück, vgl. Taschner, Rn. 23.

${ }^{27}$ Siehe Fn. 1 sowie Anhang.

${ }^{28}$ Epiney, in: Achermann u.a., Schengen, S. 21 (24).

${ }^{29}$ Übereinkommen vom 11. April 1960, vgl. Taschner, Rn. 3.

${ }^{30}$ Lange, Innere Sicherheit, S. 158.

${ }^{31}$ Taschner, Rn. 1.

${ }^{32}$ Art. 2.
} 
befestigen konnten. Mit dem Zeigen der Scheibe waren die Erklärung verbunden, dass man die grenzpolizeilichen und die Devisenvorschriften einhielt sowie lediglich erlaubte Waren im Rahmen der Freigrenzen mit sich zu führte. ${ }^{33}$ Die Parteien verpflichteten sich zur weiteren Einrichtung gemeinsamer Grenzkontrollstellen, zum Bemühen um Annäherung in der Visapolitik sowie zur verstärkten Zusammenarbeit zwischen Zoll- und Polizeibehörden vor allem in den Bereichen Betäubungsmittel- und Waffenkriminalität, unerlaubte Einreise und Aufenthalt, Schmuggel, Steuer- und Zollhinterziehung. ${ }^{34}$

$\mathrm{Zu}$ den langfristig durchzuführenden Maßnahmen, deren Verwirklichung damals bereits bis zum 1. Januar 1990 angestrebt war, ${ }^{35}$ zählt der Abbau der Personenkontrollen an den gemeinsamen Grenzen und deren Verlegung an die Außengrenzen. Zuvor sollen Rechtsvorschriften, insbesondere in den Bereichen Betäubungsmittel-, Waffen- und Sprengstoff- sowie Hotelmelderecht harmonisiert und ergänzende Maßnahmen zum Schutz der inneren Sicherheit sowie zur Verhinderung der unerlaubten Einreise von Drittstaatsangehörigen ergriffen werden. ${ }^{36}$

\section{Einheitliche Europäische Akte vom 28. Februar 1986}

Zeitgleich zum Abschluss des Schengener Abkommens, im Juni 1985, legte die Kommission sämtlichen damaligen EG-Mitgliedstaaten das Weißbuch zur Vollendung des Binnenmarktes ${ }^{37}$ vor. Es bereitet über die Bestimmungen der Einheitlichen Europäischen Akte vom 28. Februar $1986^{38}$ die Einführung des späteren Artikels $14 \mathrm{EGV}^{39}$ vor, nach dem der Binnenmarkt gemäß den Bestimmungen des Vertrages einen Raum ohne Binnengrenzen umfasst und bis zum 31 . Dezember 1992 schrittweise verwirklicht werden soll. Allerdings findet sich keine Vorschrift, die besagt, dass diese Freizügigkeit ebenfalls für Drittstaatsangehörige gelten soll, was zum damaligen Zeitpunkt auch nicht dem Willen aller europäischen Staaten entsprach. ${ }^{40}$ Demnach

\footnotetext{
${ }^{33}$ Art. 3.

${ }^{34}$ Art. 5, 7 bis 9, die weiteren Artikel 10 bis 16 beschäftigen sich insbesondere mit Regelungen zum Straßengüterund Eisenbahnverkehr.

${ }^{35}$ Art. 30 .

${ }^{36}$ Art. $17,19$.

${ }^{37}$ KOM (85) 310 endg.

${ }^{38}$ AB1. L 169, 1, vom 29. Juni 1987.

${ }^{39}$ In der Fassung des Vertrags von Amsterdam vom 2. Oktober 1997, AB1. C 340, 173; Art. 8 a EGV durch Einheitliche Europäische Akte vom 28. Februar 1986, ABl. L 169, 1, vom 29. Juni 1987; Art. 7 a EGV mit Abschluss des Vertrages von Maastricht vom 7. Februar 1992, AB1. C 191, 109; Epiney, in: Achermann u.a., Schengen, S. 21 (21).

${ }^{40}$ Vgl. auch die Allgemeine Erklärung zu Art. 13 bis 19 der Einheitlichen Europäischen Akte, wo es u.a. in Bezug auf Art. 8 a EWGV heisst: „Diese Bestimmungen berühren in keiner Weise das Recht der Mitgliedstaaten, diejenigen Maßnahmen zu treffen, die sie zur Kontrolle der Einwanderung aus dritten Ländern...für erforderlich halten“, vgl. BGB1. II 1986, 1114; mit Art. 8 a EGV, eingefügt durch den Vertrag von Maastricht vom 7. Februar 1992, AB1. C 191, 109, kam es zu einer Klarstellung innerhalb der Verträge, indem er festlegte, dass die Freizügigkeit nur für Unionsbürger gelten sollte, Art. 18 EGV mit dem Vertrag von Amsterdam, AB1. C 340, 173, jetzt Art. 21 AEUV; zu den damaligen Rechtssetzungskompetenzen siehe ausführlicher auch Schoch, DVB1. 1992, 525 (529 f.).
} 
musste an den Binnengrenzen weiterhin zwischen beiden Gruppen unterschieden werden. ${ }^{41}$ Ein Wegfall der Kontrollen war damit bereits aus diesem Grund nicht auf der Grundlage des EGV möglich. ${ }^{42}$

\section{Schengener Durchführungsübereinkommen vom 19. Juni $1990^{43}$}

\section{Geschichte bis zur Unterzeichnung}

Wie bereits erwähnt, bedurfte das Schengener Abkommen noch der Umsetzung mit Hilfe besonderer Durchführungsbestimmungen. Der Schwerpunkt lag hierbei auf der Vereinbarung der „Ersatzmaßnahmen“, die die Mitgliedstaaten als Ausgleich für den Wegfall der Binnengrenzkontrollen und den damit angenommenen Sicherheitsverlust ergreifen wollten. Wegen der hiermit verbundenen Eingriffe in die Rechte der Bürger mussten die Parlamente - anders als beim Abkommen von 1985 - dem SDÜ zustimmen. Der unterschriftsreife Text lag schließlich im Spätherbst 1989 vor. Zur Unterzeichnung kam es jedoch erst am 19. Juni 1990, weil sich Deutschland durch die Grenzöffnung zur damaligen DDR und die hiermit verbundenen Unsicherheiten bezüglich der weiteren Entwicklung, beispielsweise hinsichtlich der Kontrollen an der deutsch-polnischen Grenze, zunächst außerstande sah, den Vertrag abzuschließen. ${ }^{44}$

\section{Inhalt}

In den mehr als zwanzig Jahren seit seiner Unterzeichnung sind weite Teile des SDÜ geändert und ergänzt worden bzw. weggefallen und durch andere Rechtsakte ersetzt worden. Um die Geschlossenheit der Vorschriften darzustellen, wird nachfolgend jedoch der ursprüngliche Inhalt des SDÜ ${ }^{45}$ wiedergegeben und lediglich in den Fußnoten auf die aktuelle Rechtslage hingewiesen.

Das SDÜ regelt in acht Titeln und 142 Artikeln umfassend die Umsetzung der Vereinbarungen aus dem Ausgangsabkommen. Titel I befasst sich mit Begriffsbestimmungen, Titel II mit dem Überschreiten der Binnen- und der Außengrenzen. Grundsätzlich dürfen die Binnengrenzen an jeder Stelle ohne Personenkontrolle überschritten werden. Ausnahmsweise kann eine Vertragspartei die Kontrollen vorübergehend wieder einführen, wenn die öffentliche Ordnung oder die nationale Sicherheit es erfordern. ${ }^{46}$

\footnotetext{
${ }^{41}$ Würz, Rn. 10; Epiney, in: Achermann u.a., Schengen, S. 21 (33); Bieber, NJW 1994, 294 (294); Piosek, S. 18.

${ }^{42} \mathrm{Vgl}$. zu weiteren Erwägungen zur Wirkung von Art. 7 a EGV (in der Fassung des Vertrags von Maastricht vom 7. Februar 1992, AB1. C 191, 109): Epiney, in: Achermann u.a, Schengen, S. 21 (33 ff.).

${ }^{43}$ Siehe Fn. 2 sowie Anhang.

${ }^{44}$ Lange, Innere Sicherheit, S. 160; Taschner, Rn. 32; Piosek, S. 19.

${ }^{45}$ Als „SDÜ-1990“ bezeichnet.

46 Art. 2 Abs. 2 SDÜ-1990, gedacht war hier z.B. an Großereignisse wie Fußballmeisterschaften, bei denen man bereits die Einreise polizeibekannter gewaltbereiter „Fans“ verhindern will.
} 
Die Außengrenzen dürfen nur nach entsprechender Kontrolle überschritten werden, wobei alle Mitgliedstaaten einheitliche Grundsätze anwenden und möglichst eng zusammenarbeiten. ${ }^{47} 48$ Drittausländer, also Personen aus anderen als Mitgliedstaaten der Europäischen Gemeinschaften, unterliegen vor allem bei der Einreise einer besonders eingehenden Kontrolle. Korrespondierend hierzu nehmen die Regeln zu den Sichtvermerken einen breiten Raum ein, ${ }^{49}$ wobei sich die Vertragsparteien auf die Einführung eines im ganzen Vertragsgebiet gültigen einheitlichen Sichtvermerks für kurzfristige Aufenthalte für bei zu drei Monaten einigen. ${ }^{50}$ Mit in diesen Zusammenhang gehören die Vereinbarungen, die die Zuständigkeit für die Behandlung von Asylbegehren betreffen. ${ }^{51}$

Titel III ${ }^{52}$ befasst sich mit der polizeilichen Zusammenarbeit und weiteren Aspekten der Sicherheitspolitik. Der Abschnitt polizeiliche Zusammenarbeit enthält Regelungen zur gegenseitigen Hilfeleistung der Polizeidienste untereinander, ${ }^{53}$ zur Abkürzung des Dienstweges im Eilfall, ${ }^{54}$ zur verbesserten technischen Erreichbarkeit, ${ }^{55}$ zum Meldewesen für Ausländer, ${ }^{56}$ zum präventivpolizeilichen Informationsaustausch ohne Ersuchen, ${ }^{57}$ zur Entsendung von Verbindungsbeamten ${ }^{58}$ sowie sehr detaillierte Vorschriften zu Observation und Nacheile durch die Beamten des einen Vertragsstaates auf dem Hoheitsgebiet eines anderen Vertragsstaates. ${ }^{59}$ Ergänzt wird die Nacheile-Regelung durch eine gesonderte Erklärung, in der die Vertragsparteien detaillierte Festlegungen zu den Nacheilemodalitäten treffen. ${ }^{60}$ Unter der Überschrift Sicherheit haben die Parteien

\footnotetext{
${ }^{47}$ Art. 3 bis 8 SDÜ-1990.

${ }^{48}$ Art. 2 bis 8 sind seit 13. Oktober 2006 ersetzt durch den Schengener Grenzkodex, VO (EG) Nr. 562/2006 vom 15. März 2006, ABl. L 105, 1; die Möglichkeit, Kontrollen vorübergehend wieder einzuführen, besteht auch nach diesen Vorschriften, vgl. Art. 23 ff. Schengener Grenzkodex.

${ }^{49}$ Art. 9 bis 27 SDÜ-1990.

${ }^{50}$ Art. 9 bis 17 SDÜ-1990, die sich mit Sichtvermerken für einen kurzfristigen Aufenthalt befassen, sind ab dem 4. April 2010 ersetzt durch den Visa-Kodex, VO (EG) Nr. 810/2009 vom 13. Juli 2009, AB1. L 243, 1.

${ }^{51}$ Art. 28 bis 38 SDÜ-1990, mittlerweile ersetzt durch VO (EG) Nr. 343/2003 zur Bestimmung des für einen Asylantrag zuständigen Mitgliedstaat (Dublin II) vom 18. Februar 2003, AB1. L 50, 1.

${ }^{52}$ Art. 39 bis 91 .

${ }^{53}$ Art. 39.

${ }^{54}$ Art. 39 Abs. 3 S. 2 SDÜ-1990.

${ }^{55}$ Art. 44 SDÜ-1990.

${ }^{56}$ Art. 45 SDÜ-1990.

${ }^{57}$ Art. 46 SDÜ-1990.

${ }^{58}$ Art. 47 SDÜ-1990.

${ }^{59}$ Art. 40 bis 44 SDÜ-1990, die observierenden bzw. nacheilenden Beamten dürfen hierbei z.B. keine Wohnungen und keine öffentlich nicht zugängliche Grundstücke betreten, der Gebrauch der Dienstwaffe ist nur zur Notwehr zulässig, und die Maßnahmen sind sofort einzustellen, wenn die Vertragspartei, auf deren Hoheitsgebiet die Beamten tätig werden, dies verlangt, vgl. Art. 40 Abs. 3 Buchst. d, e, Art. 41 Abs. 1 S. 4 SDÜ-1990.

${ }^{60}$ Art. 41 Abs. 9, S. 1 SDÜ-1990, so gestattet z.B. die Bundesrepublik Deutschland den Beamten aller Vertragsstaaten die Nacheile für alle auslieferungsfähigen Straftaten ohne zeitliche und räumliche Begrenzung unter Anwendung des Festhalterechtes, während Frankreich den luxemburgischen Beamten die Nacheile lediglich für eine Katalogstraftat des Art. 41 Abs. 4 a) SDÜ-1990 innerhalb eines Gebietes von zehn Kilometern jenseits der Grenze und ohne Ausübung des Festhaltesrechtes einräumt, die Erklärungen sind abgedruckt bei Taschner, S. 127 ff.
} 
innerhalb des Titels III Vereinbarungen zum Umgang mit Betäubungsmitteln,${ }^{61}$ Feuerwaffen und Munition $^{62}$ sowie zur Rechtshilfe in Strafsachen, ${ }^{63}$ zur Auslieferung ${ }^{64}$ und zur Übertragung der Vollstreckung von Strafurteilen ${ }^{65}$ getroffen. Zu einem großen Teil ergänzen diese Regeln bereits vorhandene europäische Übereinkommen. ${ }^{66}$ Hervorzuheben ist in diesem Bereich noch die Vereinbarung des Verbots der Doppelbestrafung, wonach eine durch eine Vertragspartei rechtskräftig abgeurteilte Person wegen derselben Tat durch eine andere Vertragspartei im Grundsatz nicht verfolgt werden darf. ${ }^{67}$

Titel IV des Übereinkommens beschäftigt sich mit dem Schengener Informationssystem. ${ }^{68}$ Es geht um Einrichtung, ${ }^{69}$ Betrieb und der Nutzung, ${ }^{70}$ Datenschutz und Datensicherung ${ }^{71}$ sowie um die Kostenverteilung zwischen den Vertragsparteien. ${ }^{72}$

Titel V trifft Regelungen zu Transport und Warenverkehr, ${ }^{73}$ Titel VI enthält Vorschriften zum Datenschutz ${ }^{74}$ die allerdings nicht für die Datenübermittlung im SIS gelten.$^{75}$

Titel VII ${ }^{76}$ stellt Regeln für den sogenannten Exekutivausschuss auf, in dem jede Vertragspartei einen Sitz hat und durch einen Minister vertreten wird. Die Beschlüsse werden einstimmig gefasst. Der Ausschuss hat als allgemeine Aufgabe die Überwachung der richtigen Anwendung des Übereinkommens. Zusätzlich sind ihm in den jeweiligen Vorschriften des Abkommens spezielle Befugnisse übertragen. ${ }^{77} 78$

\footnotetext{
${ }^{61}$ Art. 70 bis 75 SDÜ-1990, Art. 73 ist aufgehoben durch das Übereinkommen gemäß Art. 34 des Vertrags über die Europäische Union - vom Rat erstellt - über die Rechtshilfe in Strafsachen zwischen den Mitgliedstaaten der Europäischen Union, AB1. 197 vom 12. Juli 2000, 3.

${ }^{62}$ Art. 77 bis 91 SDÜ-1990.

${ }^{63}$ Art. 48 bis 53 SDÜ-1990, Art. 49 Buchst. a, Art. 52 und 53 sind aufgehoben durch das Übereinkommen gemäß Art. 34 des Vertrags über die Europäische Union - vom Rat erstellt - über die Rechtshilfe in Strafsachen zwischen den Mitgliedstaaten der Europäischen Union, AB1. 197 vom 12. Juli 2000, 3; Art. 50 ist aufgehoben durch das Protokoll zum Übereinkommen über die Rechtshilfe, AB1. 326 vom 21. November 2001, 2.

${ }^{64}$ Art. 59 bis 66 SDÜ-1990, ersetzt durch den Rahmenbeschluss 2002/584/JI des Rates vom 13. Juni 2002 über den europäischen Haftbefehl und die Übergabeverfahren zwischen den Mitgliedstaaten, AB1. L 190, 2.

${ }^{65}$ Art. 67 bis 69 SDÜ-1990.

${ }^{66}$ Europäisches Übereinkommen über die Rechtshilfe in Strafsachen vom 20. April 1959, BGB1. II 1964, 1386, mittlerweile ergänzt durch das Übereinkommen gemäß Art. 34 des Vertrags über die Europäische Union - vom Rat erstellt - über die Rechtshilfe in Strafsachen zwischen den Mitgliedstaaten der Europäischen Union, AB1. 197 vom 12. Juli 2000, 3; Europäisches Auslieferungsübereinkommen vom 13. Dezember 1957, BGB1. II 1964, 1370; Übereinkommen des Europarates vom 21. März 1983 über die Überstellung verurteilter Personen, BGB1. II 1991, 1006 und BGB1. II 1992, 98.

${ }^{67}$ Art. 54 bis 58 SDÜ-1990.

${ }^{68} \mathrm{Vgl}$. im einzelnen Abschnitt B. dieses Teils der Arbeit.

${ }^{69}$ Art. 92 SDÜ-1990.

${ }^{70}$ Art. 93 bis 101 SDÜ-1990.

${ }^{71}$ Art. 102 bis 118 SDÜ-1990.

${ }^{72}$ Art. 119 SDÜ-1990.

${ }^{73}$ Art. 120 bis 125 SDÜ-1990.

${ }^{74}$ Art. 126 bis 130 SDÜ-1990.

${ }^{75}$ Art. 126 Abs. 4 S. 1, Art. 127 Abs. 3 SDÜ-1990.

${ }^{76}$ Art. 131 bis Art. 133 SDÜ-1990.

${ }^{77}$ So trifft er z.B. die erforderlichen Entscheidungen über die praktischen Einzelheiten der Durchführung der Kontrollen und der Überwachung der Außengrenzen und legt die Grenzübertrittspapiere fest, in deren Besitz ein Drittausländer bei der Einreise in das Schengen-Gebiet sein muss, Art. 8, Art. 5 Abs. 1 a), weiter bestimmt er gemeinsa-
} 
Titel VIII enthält verschiedene Schlussbestimmungen. ${ }^{79}$ Beitreten kann dem Übereinkommen jeder Mitgliedstaat der Europäischen Gemeinschaften. ${ }^{80}$ Klar festgelegt wird ein Anwendungsvorrang von anders lautendem Gemeinschaftsrecht, was auch für künftiges Gemeinschaftsrecht hinsichtlich der Verwirklichung eines Raumes ohne Binnengrenzkontrollen gilt. Die Parteien verpflichten sich zudem gegenseitig, zwei- oder mehrseitige Vereinbarungen über die Erleichterung oder den Abbau der Grenzkontrollen mit Drittstaaten nur mit vorheriger Zustimmung der anderen Vertragsparteien zu schließen. ${ }^{81}$ Ergänzt wird das Abkommen durch eine Schlussakte, ein Protokoll, eine gemeinsame Erklärung der Minister und Staatssekretäre sowie durch die Erklärungen der Regierungen gemäß Art. 41 Abs. 9 zur Nacheileregelung. ${ }^{82}$

\section{Geschichte nach der Unterzeichnung}

Zur praktischen Anwendung des SDÜ bedurfte es weiterhin des Inkrafttretens und zusätzlich als Besonderheit - des Inkraftsetzens. Nach der Ratifikation in allen fünf „Gründungsstaaten“833 trat das Übereinkommen gemäß der Bestimmung des Art. 139 Abs. 2 SDÜ am 1. September 1993 in Kraft. ${ }^{84}$

In einer gemeinsamen Erklärung zu Artikel 139, die in die Schlussakte aufgenommen wurde, vereinbarten die Vertragsparteien zudem, dass „,das Übereinkommen erst in Kraft gesetzt wird, wenn die Voraussetzungen der Anwendung des Übereinkommens bei den Unterzeichnerstaaten gegeben sind und die Kontrollen an den Außengrenzen tatsächlich durchgeführt werden." Gemeint war hiermit insbesondere das Funktionieren des SIS $^{85}$. Nachdem die hiermit verbundenen Probleme im Laufe des Jahres 1994 gelöst werden konnten, wurde das Inkraftsetzen zum 26. März $1995^{86}$ beschlossen. $^{87}$

me Regelungen für die Prüfung der Sichtvermerksanträge, achtet auf deren richtige Anwendung und passt sie an neue Situationen und Umstände an, Art. 17 Abs. 1; die Qualität der Rechte des Exekutivausschusses wird im 3. Teil der Arbeit näher untersucht.

${ }^{78}$ An die Stelle des Exekutivausschusses ist mit in Inkrafttreten des Vertrags von Amsterdam der Rat der Europäischen Union getreten, Art. 2 Abs. 1 S. 2 Protokoll zum Vertrag von Amsterdam zur Einbeziehung des SchengenBesitzstandes in den Rahmen der Europäischen Union, AB1. 1997 C 340, 173.

${ }^{79}$ Art. 134 bis 142 SDÜ-1990.

${ }^{80}$ Art. 140 Abs. 1 SDÜ-1990.

${ }^{81}$ Art. 134, 136 und 142 SDÜ-1990.

${ }^{82}$ Abgedruckt bei Taschner, S. 123 ff.

${ }^{83}$ Der deutsche Bundestag stimmte dem Gesetz am 17. Juni 1993 zu, vgl. BGBl. II 1993, 1010; die Diskussion wurde vor allem von der Frage bestimmt, ob die Zustimmung von einer Änderung des Asylgrundrechtes, Art. 16 GG, abhängig sein sollte, vgl. hierzu Taschner, Rn. 37 sowie Lange, Innere Sicherheit, S. 164; zur Rolle des Parlamentes siehe auch 3. Teil, Abschnitt A. dieser Arbeit.

${ }^{84}$ BGB1. II 1994, $631 \mathrm{ff}$.

${ }^{85}$ Lange, Innere Sicherheit, S. 163, 164; Bieber, NJW 1994, 294 (295); Würz, Rn. 12.

${ }^{86}$ An diesem Tag trat der Sommerflugplan der Luftverkehrsgesellschaften in Kraft, was für die an den Flughäfen durchzuführenden bzw. bei Binnenflügen gerade nicht mehr durchzuführenden Personenkontrollen von Bedeutung war, vgl. Taschner, Rn. 39.

${ }^{87}$ Epiney, in: Achermann u.a., Schengen, S. 21 (22), Taschner, Rn. 39. 
Die Schengen-Zusammenarbeit erwies sich schließlich auch für die anderen Mitgliedstaaten der Europäischen Gemeinschaft als reizvoll, so dass den Abkommen mit Ausnahme von Großbritannien und Irland bis zum Jahr 1996 sämtliche damalige EU-Staaten beitraten. ${ }^{88}$

Zudem kam es zu einer Teilnahme der Nicht-EU-Staaten Norwegen und Island. Gemeinsam mit den nordischen EU-Staaten Finnland, Schweden und Dänemark bilden sie die Nordische Passunion, und obwohl Art. 140 SDÜ nur Mitgliedstaaten der Europäischen Gemeinschaften den Beitritt zum SDÜ ermöglichen will, war der politische Wille groß, für diese beiden Staaten eine Ausnahmeregelung zu finden. Letztlich wurde daran angeknüpft, dass Norwegen und Island dem Europäischen Wirtschaftsraum angehören, der die Personenfreizügigkeit gewährleistet. Beide Staaten unterzeichneten am 19. Dezember 1996 in Luxemburg ein entsprechendes Übereinkommen..$^{89} 90$

\section{Bedeutung von Grenzkontrollen}

Die Politik hat den Wegfall der Binnengrenzkontrollen - gestützt auf Innen- und Sicherheitsexperten - grundsätzlich unter die Voraussetzung gestellt hat, dass Ausgleichsmaßnahmen vereinbart werden. Als Herzstück wird immer wieder das SIS genannt ${ }^{91}$ und sein tatsächliches Funktionieren galt und gilt vielen als unverzichtbare Bedingung für den Wegfall der Kontrollen. Unter der Überschrift des SDÜ, das die Ausgleichsmaßnahmen festlegt, soll an dieser Stelle zur Abrundung der Thematik diskutiert werden, welche Wirkung Grenzkontrollen haben und ob mit ihrem Wegfall tatsächlich ein spürbarer und deshalb auszugleichender Sicherheitsverlust verbunden ist.

Die einen, allen voran die Polizeipraktiker, bejahen die wichtige Sicherheitsfunktion der Grenze. ${ }^{92}$ Sie bilde als Ende des Territoriums des einen Staates und als Anfang des Gebietes des anderen Staates eine natürliche strategische Linie. Wie man an den Aufgriffszahlen ablesen könne, habe die Grenze eine tatsächliche Filterfunktion und zudem für Rechtsbrecher eine subjektive

\footnotetext{
${ }^{88} \mathrm{Vgl}$. hierzu Anlage 3.

${ }^{89}$ Abgedruckt bei Taschner, Anhang IV, vgl. hierzu auch das spätere Übereinkommen vom 18. Mai 1999 zwischen dem Rat der Europäischen Union und der Republik Island sowie dem Königreich Norwegen über deren Assoziierung bei der Umsetzung, Anwendung und Entwicklung des Schengen-Besitzstandes, ABl. EG L 176, 36.

${ }^{90}$ Die Zusammenarbeit mit den fünf nordischen Staaten wird in Bezug auf das SIS auch häufig als „SIS I plus“ bezeichnet, Mokros, in: Lisken/Denninger, HandbPolR, 3. A. 2001, Teil O, Rn. 144; Schengen-Erfahrungsbericht 2000, S. 41.

${ }^{91}$ Hellenthal, KR 1992, 247 (250); Schreiber, Wolfgang, KR 1991, 369 (370).

${ }^{92}$ Wehner, Europäische Zusammenarbeit, S. 203 ff.; Ingenerf, KR 1989, 341 (342 ff., 361 f.); Krüger, KR 1994, 773 (775); Hellenthal, KR 1992, 247 (248 f.); Lenhard, Schriftenreihe der PFA 3-4/1989, S. 34 (34); Rupprecht, KR 1989, 263 (263, 264); Schattenberg, Schriftenreihe der PFA 3-4/1989, S. 20 (22); Schreiber, Manfred, KR 1985,93 (95); Schäuble, Europa-Archiv 1990, 203 (206); Schreiber, Wolfgang, KR 1991, 369 (371); Rupprecht/Hellenthal, in: Rupprecht/Hellenthal, Innere Sicherheit, S. 23 (42 ff., 89 ff., 129 ff.); Blessmann, in: Pauly, Schengen en panne, S. 55 (65 f.).
} 
Abschreckungswirkung. Damit könne verhindert werden, dass Verbrecherbanden ihre Fluchtund Ruheräume jenseits der Grenze aufsuchten. Eine in genauen Zahlen messbare Wirkung sei nicht zu benennen, da man zum Beispiel nicht wisse, wie viele Kriminelle sich wegen des Bestehens der Grenzkontrollen vom Überschreiten der Grenze abhielten ließen. Zwar sei „der Schlagbaum kein besonders intelligentes Fahndungsinstrument““93 jedoch seien die genannten abstrakten Überlegungen letztlich ausreichend, um die wichtige Funktion der Grenze zu belegen. ${ }^{94} 95$

Die andere Seite misst den Grenzkontrollen wenig Bedeutung bei ${ }^{96}$ und legt bei ihrer Argumentation einen Fokus auf konkrete Zahlen. So hat Kühne ${ }^{97}$ die Statistiken der Grenzschutzdirektion Koblenz aus den Jahren 1980 bis 1989 ausgewertet. Er unterscheidet zunächst zwischen allgemeiner und grenzgemachter Kriminalität. ${ }^{98}$ Letztere meint solche Delikte, die nur begangen werden können, weil Grenzen bestehen, z.B. Verstöße gegen das Ausländer- und Passgesetz und praktisch alle aufgegriffenen Fälle von Urkundenstrafrecht, also Passfälschungen. Geschützt würden durch diese Vorschriften nicht unmittelbar Grundrechte der einheimischen Bürger, sondern ordnungspolitische Konzepte des Staates. Wenn der Staat sich aber für eine Erweiterung der Binnengrenzen entschieden habe, habe er damit auch das frühere Ordnungskonzept korrigiert. Wolle er sich nicht widersprüchlich verhalten, müsse er diese Art von Kriminalität bei den Zahlen unberücksichtigt lassen, weil sie ja im neuen Binnengrenzraum keine Rolle mehr spielten. Dagegen beeinträchtige die allgemeine Kriminalität, unterteilt in Delikte wider das Leben, wider

\footnotetext{
${ }^{93}$ So der damalige Bundesinnenminister Schäuble am 26. Juni 1989, vgl. Schreiber, Wolfgang, KR 1991, 369 (371) sowie Rupprecht/Hellenthal, in: Rupprecht/Hellenthal, Innere Sicherheit, S. 23 (43 f. und Fn. 11.)

${ }^{94}$ Schreiber, Manfred, KR 1985, 93 (95); Rupprecht/Hellenthal, in: Rupprecht/Hellenthal, Innere Sicherheit, S. 23 (44).

${ }^{95}$ Immer wieder wird auch die Frage gestellt, ob der befürchtete Sicherheitsverlust nicht durch Kontrollen ,im Hinterland“ aufgefangen werden sollte. Dieser Gedanke wird allerdings sofort wieder verworfen, insbesondere mit der Begründung, dass eine solche Verlagerung mit dem Sinn des Abbaus der Grenzkontrollen unvereinbar und daher politisch nicht durchsetzbar sei, vgl. Hellenthal, KR 1992, 247 (249); Rupprecht, KR 1989, 263 (264); Schreiber, Manfred, KR 1985, 93 (95). Gleichwohl finden sich in den vom Bundesministerium des Innern herausgegebenen Schengen-Erfahrungsberichten Hinweise, dass die Binnengrenzen für Personenkontrollen durch die Polizei noch immer eine wichtige Bedeutung haben, so ist z.B. von „Straftaten entlang der Binnengrenze zu Österreich“ bzw. „entlang der Schengen-Binnengrenzen zu Luxemburg und Belgien“ sowie von „Feststellungen, die den Binnengrenzen zuzuordnen waren“ die Rede, vgl. Schengen-Erfahrungsbericht 2003, S. 1 und Schengen-Erfahrungsbericht 2004, S. 1, 3; ebenso versichert das Bundesinnenministerium mit Blick auf den Wegfall der Grenzkontrollen zwischen Deutschland und Polen bzw. Tschechien am 21. Dezember 2007, dass die Bundespolizei ,weiterhin mit erheblichen Kräften im Grenzraum bis zu einer Tiefe von $30 \mathrm{~km}$ präsent bleiben und die grenzpolizeiliche Überwachung sowie die Bekämpfung der illegalen Migration und grenzüberschreitenden Kriminalität in bewährter Art und Weise fortsetzen“" wird, vgl. Bundesministerium des Innern, Mehr Freiheit - mit Sicherheit.

${ }^{96}$ Bieber, NJW 1994, 294 (295); Kühne, Kriminalitätsbekämpfung durch innereuropäische Grenzkontrollen?, S. 1 ff.; ders., in: Pauly, Schengen en panne, S. 89 (93) ff., ders., in: Müller-Graff, Europäische Zusammenarbeit, S. 85 (89 ff.); Busch, KJ 1990, S. 1 (1 f.); Lange, Innere Sicherheit, S. 159; Birzele, in: Theobald, „Europäische Sicherheitsunion?“", S. 89 (94 ff.); Kattau, Strafverfolgung, S. 160 ff.; Lavranos, DuD 1996, 400 (403), der die Sicherheitsfunktion der Grenzkontrollen zumindest für zweifelhaft hält.

${ }^{97}$ Kühne, Kriminalitätsbekämpfung durch innereuropäische Grenzkontrollen?, S. 1 ff.

${ }^{98}$ Kühne, Kriminalitätsbekämpfung durch innereuropäische Grenzkontrollen?, S. 43 ff.
} 
das Eigentum und Vermögen, Waffen und Sprengstoff sowie Betäubungsmittelsachen potentiell die innere Sicherheit.

Zudem unterscheidet der Autor zwischen Fahndungs- und Initiativaufgriffen. ${ }^{99}$ Fahndungsaufgriffe sind durch Vorinformation vorbereitet. Gemeint ist damit z.B., dass ein Verdächtiger observiert wird und der Grenzübertritt lediglich eine von mehreren Gelegenheiten für einen Aufgriff bietet. Der Initiativaufgriff hat dagegen seine Ursache in eigenständiger, unvorbereiteter Verdachtschöpfung durch den kontrollierenden Beamten an der Grenze. So betrachtet spricht vieles dafür, lediglich Initiativaufgriffe zu den durch die Grenzkontrollen originär verursachten Aufgriffen zu zählen. ${ }^{100}$

Nachdem der Autor die Aufgriffszahlen derart interpretiert hat, erhält er auf 100.000 registrierte Grenzübertritte an den Westgrenzen im Jahr 1988 knapp 2 Aufgriffe. Insgesamt wurden an den Westgrenzen im Jahr 1988 etwa 260 Aufgriffe im Bereich Betäubungsmittel und rund 700 Aufgriffe bei der Eigentums- und Vermögenskriminalität, meist ging es um gestohlene Autos, registriert. ${ }^{101}$ Der Autor schlussfolgert aus diesen Zahlen, dass die Bedeutung der Grenzkontrollen als relativ gering einzustufen ist.

Zwar erscheint der abstrakte Ansatz der Befürworter der Wirkung von Grenzkontrollen plausibel. Andererseits spricht vieles dafür, konkrete Zahlen zu betrachten und differenziert zu interpretieren. Das Ergebnis liefert einen wichtigen Anhaltspunkt für eine rationale Kosten/Nutzenabwägung, die bei aller Symbolkraft, die von einer staatlich kontrollierten Grenze ausgeht, in der Argumentation eine wichtige Rolle spielen sein sollte.

Im Ergebnis wird man sagen können, dass eine verbesserte polizeiliche und justizielle Zusammenarbeit, insbesondere durch den Betrieb eines gemeinsamen Fahndungssystems, unabhängig vom Wegfall der Grenzkontrollen sinnvoll ist. ${ }^{102}$ Denn es ist kein Grund ersichtlich, warum sich z.B. ein mit Haftbefehl in Deutschland gesuchter Straftäter darauf verlassen können sollte, dass er nach einem trotz Binnengrenzkontrolle unerkannten Grenzübertritt bei einer Routinekontrolle in Frankreich nicht als verfolgter Straftäter erkannt wird. Dass in den Abkommen gleichwohl immer ein untrennbarer Zusammenhang zwischen der Aufhebung der Kontrollen und dem Funktionieren des Fahndungssystems hergestellt wurde, hat vermutlich einen anderen Grund. Sicher-

\footnotetext{
${ }^{99}$ Kühne, Kriminalitätsbekämpfung durch innereuropäische Grenzkontrollen?, S. 45 ff.

${ }^{100}$ Innerhalb der Fahndungsaufgriffe differenziert Kühne noch einmal nach denjenigen, die lediglich zufällig gerade an der Grenze erfolgen und solchen, bei denen die Abfrage in einem Fahndungssystem bei Gelegenheit der Grenzkontrolle zum Aufgriff führt. Letztere seien zwar durch Vorinformation vorbereitet, der Aufgriff hätte ohne die Grenzkontrolle aber nicht stattgefunden. Insofern zählt er sie zu den Initiativaufgriffen hinzu, vgl. Kühne, in: Pauly, Schengen en panne, S. 89 (98).

${ }^{101}$ Kühne, in: Müller-Graff, Europäische Zusammenarbeit, S. 85 (90 f.).

${ }^{102}$ Epiney, in: Achermann u.a., Schengen, S. 21 (26, Fn. 21).
} 
heitspolitisch ist eine solche Sichtweise hilfreich: Der ausgeprägte Wille, die Grenzen zu öffnen ${ }^{103}$ und der jedenfalls zunächst plausible Zusammenhang schafft den notwendigen politischen und zeitlichen Druck, um nationale Widerstände und technische Probleme bei der Entwicklung des Fahndungssystems zu überwinden. ${ }^{104}$

\section{Vertrag von Amsterdam vom 2. Oktober $1997^{105}$}

Mit dem Vertrag von Amsterdam kam es zur Überführung des sogenannten SchengenBesitzstandes in den Rahmen der Europäischen Union. ${ }^{106}$ Mit dem Schengen-Besitzstand bezeichnet das Schengen-Protokoll in seinem Anhang das Schengener Abkommen, das SDÜ, sämtliche Beitrittsprotokolle und -übereinkommen mit den dazugehörigen Schlussakten und Erklärungen sowie die Beschlüsse und Erklärungen des Exekutivausschusses und Rechtsakte zur Durchführung des SDÜ. Mit dem Zeitpunkt des Inkrafttretens des Vertrags von Amsterdam tritt der Rat an die Stelle des Exekutivausschusses und sämtliche Vorschläge und Initiativen auf der Grundlage des Schengen-Besitzstandes unterliegen den einschlägigen Bestimmungen der Verträge. Es ist vorgesehen, dass der Rat zur Klarstellung die Rechtsgrundlage für jede Bestimmung und jeden Beschluss festlegt, ob also die Zuständigkeiten und Rechtsinstrumente der ersten oder der dritten Säule gelten sollen. Trifft er keine Festlegung, gelten die Bestimmungen und Beschlüsse des Schengen-Besitzstandes als solche der dritten Säule. ${ }^{107}$

Insgesamt ist „Schengen“ damit Teil der EU-Materie geworden, bleibt innerhalb derer jedoch grundsätzlich der zwischenstaatlichen Zusammenarbeit zugeordnet.

\section{EU-Erweiterungen von 2004 und 2007}

Mit Wirkung vom 1. Mai 2004 traten der EU die Staaten Estland, Lettland, Litauen, Polen, Tschechien, die Slowakei, Slowenien, Ungarn, Malta und Zypern bei. Art. 8 Schengen-Protokoll bestimmt, dass neue Mitgliedstaaten den Schengen-Besitzstand und die Maßnahmen seiner Weiterentwicklung vollständig zu übernehmen haben. Aus diesem Grund sind die Neu-Mitglieder der EU auch Teilnehmer der Schengen-Zusammenarbeit. Gleichwohl ist damit nicht automatisch ein Wegfall der Grenzkontrollen verbunden. Bedingung war auch hier, dass das SIS in den neuen Staaten funktionierte. Nachdem sich die Arbeiten an einem SIS der zweiten Generation aufgrund technischer Probleme unerwartet lange hinzogen, ermöglichte eine Initiative Portugals den Ein-

\footnotetext{
${ }^{103}$ Vgl. auch Schreiber, Wolfgang, KR 1991, 369 (371).

${ }^{104}$ In diese Richtung argumentierend auch Taschner, Rn. 61, der die Erforderlichkeit von Ausgleichsmaßnahmen in Frage stellt und vermutet, dass die Politik eher eine günstige Gelegenheit zur Vereinbarung derselben nutzte.

105 AB1. C 340, 173.

106 Vgl. Protokoll zum Vertrag von Amsterdam zur Einbeziehung des Schengen-Besitzstandes in den Rahmen der Europäischen Union, im Folgenden: Schengen-Protokoll.

${ }^{107}$ Art. 2 Abs. 1 UA 1, UA 2 S. 2 , Art. 5 Abs. 1 UA 1, Art. 2 Abs. 1 UA 4 Schengen-Protokoll.
} 
satz einer besonderen Form des SIS der ersten Generation, des sogenannten SISone4ALL. ${ }^{108}$ Bis auf die Insel Zypern ${ }^{109}$ fielen damit die Grenzkontrollen bei allen oben genannten Mitgliedstaaten am 21. Dezember 2007 weg.

Für die der EU in 2007 beigetretenen neuen EU-Staaten Rumänien und Bulgarien war der kontrollfreie Grenzübertritt zunächst für 2011 geplant. Aktuell fordern die Niederlande jedoch vor einer möglichen positiven Entscheidung zugunsten von Bulgarien und Rumänien im September 2012 einen Bericht, der die Lage zur Korruption einschätzt. ${ }^{110}$

\section{Vertrag von Lissabon vom 13. Dezember $2007^{111} 112$}

Der Vertrag von Lissabon, der nach der Überwindung zahlreicher Hürden am 1. Dezember 2009 in Kraft trat, gibt das 3-Säulen-Modell auf und überführt die Dritte-Säule-Materie der Bereiche Justiz und Inneres in der Weise in den Rechtsrahmen der Europäischen Union, dass die Entscheidungsmodi des - ehemaligen - Gemeinschaftspfeilers zum Standard wurden. Das Mitentscheidungsverfahren, nach dem Rat und Europäisches Parlament gleichberechtigt über Rechtsakte entscheiden, ist nunmehr das Regelverfahren. ${ }^{113}$ Für den Schengen-Besitzstand bedeutet dies, dass die Mitgliedstaaten bei der Anwendung seiner Regelungen EU-Recht ausführen und seine Weiterentwicklung nunmehr nach Art. 294 AEUV zu betreiben ist.

\section{Aktuelle Situation}

Aktuell gibt es 25 ,vollwertige“ Schengenmitglieder. Damit sind die Staaten gemeint, die kraft eines ausdrücklichen völkerrechtlichen Beitritts zum SDÜ oder ihres Beitritts zur EU die Regelungen des Schengen-Besitzstandes anerkennen und keine Grenzkontrollen mehr durchführen. Ausgenommen Großbritannien, Irland, Zypern, Bulgarien und Rumänien handelt es sich dabei um alle EU-Staaten sowie um Norwegen, Island und die Schweiz. ${ }^{114}$

\footnotetext{
${ }^{108}$ Schriever-Steinberg, in: Breitenmoser u.a., Schengen in der Praxis, S. 159 (161); Tuffner, Polizei-heute 2007, 114 (118); beim SISone4ALL handelt es sich um einen neunfachen Klon des portugiesischen SIS, der die mit dem Zentralbestand identischen Daten zum Inhalt hat, vgl. Tuffner, Polizei-heute 2007, 114 (118).

${ }^{109}$ Zypern beteiligt sich nicht am SIS, weil der Wegfall der Grenzkontrollen zu den übrigen EU-Staaten die Umwandlung der provisorischen Grenze zwischen dem griechisch-zypriotischen und dem türkisch-zypriotischen Teil in eine EU-Außengrenze zur Türkei zur Folge hätte; das würde zu erheblichen Schwierigkeiten bei der Verfolgung des Ziels einer Wiedervereinigung Zyperns führen, Tuffner, Polizei-heute 2007, 114 (118).

${ }^{110} \mathrm{http}: / /$ euobserver.com/1016/115459, Abruf vom 2. April 2012.

${ }_{111} \mathrm{ABl}$. C 306, 1.

${ }^{112}$ Mit dem Vertrag von Nizza vom 26. Februar 2001, AB1. C 80, 1, wurden keine Änderungen vorgenommen, die für die vorliegende Fragestellung von Interesse wären; einzige materielle Neuerung im Bereich Justiz und Inneres war die Festlegung der Aufgaben von Eurojust, vgl. Art. 31 Abs. 2 EUV.

${ }^{113}$ Für den Bereich der polizeilichen Zusammenarbeit vgl. Art. 87 Abs. 2 mit Verweis auf Art. 294 AEUV; Bauer, in: Weidenfeld, Lissabon, S. 99 (102).

${ }^{114} \mathrm{Vgl}$. Bundesministerium des Innern, Der Schengen-Raum.
} 


\section{B. Fahndungssystem als Herzstück der Ausgleichsmaßnahmen des SDÜ}

\section{Lage vor Inbetriebnahme}

\section{Nationale Fahndung}

Eine unverzichtbare Voraussetzung für die Existenz des SIS sind die technischen Fortschritte, die in der Datenverarbeitung Ende der sechziger bzw. Anfang der siebziger Jahre gemacht wurden. Vor diesem Zeitpunkt verliefen viele Fahndungen nach Personen und Sachen erfolglos, weil der Umgang mit den vorhandenen Daten nicht nur aus heutiger Sicht ineffizient war.

So bezeichnet ein Mitarbeiter des Polizeipräsidiums München im Jahr 1970 die Sachfahndung als Stiefkind der Kriminalpolizei, die mit dem Personalstand von vorgestern und den Mitteln von gestern betrieben würde. ${ }^{115}$ Er beklagt u.a., dass die den Schaden aufnehmenden Beamten mit einer „bunten Vielfalt von Formblättern“ arbeiteten, was das Einordnen in Karteien nach gemeinsamen Kriterien erschwerte bzw. unmöglich machte. Zudem wurden die Sachfahndungsmeldungen ganz überwiegend dezentral bei den verschiedenen örtlichen Polizeibehörden erfasst. ${ }^{116}$ Das Anlegen und Auswerten der Karteien geschah bis auf wenige Ausnahmen manuell. ${ }^{117}$ Die Erfahrung, dass die Sachfahndungskartei aufgrund der genannten Widrigkeiten wenige Erkenntnisse brachte, führte dazu, dass sie immer weniger in Anspruch genommen wurde, was wiederum die Pflege der Karteien weiter verschlechterte. Im Hinblick auf die eigentlich zu leistende Arbeit werden die Sachfahndungsdienststellen als personell unterbesetzt und zudem als beliebter Abstellbahnhof für dienstmüde oder sonst nicht mehr voll einsatzfähige Beamten beschrieben, was die personellen Defizite noch erhöhte. ${ }^{118}$

Mit ähnlichen Problemen hatten die Beamten in der Personenfahndung zu kämpfen. Zwar sammelte das BKA die Personenfahndungen zentral im „Deutschen Fahndungsbuch“, Teil A - Aufenthaltsermittlung - sowie Teil F - Festnahme - und veröffentlichte Suchmeldungen z.T. mit Lichtbildern im täglich erscheinenden Bundeskriminalblatt. ${ }^{119}$ Allerdings bedeutete das für den jeweiligen Beamten vor Ort, dass er bei der Personenkontrolle die rund 100000 Einträge umfassenden schriftlichen Unterlagen mit den vorgelegten Personalausweisen oder Reisepässen abzu-

\footnotetext{
${ }^{115}$ Häring, in: Bundeskriminalamt, Arbeitstagung „Fahndung“, S. 131 (132).

${ }^{116}$ Ausgenommen abhanden gekommene Kraftfahrzeuge, Mopeds, Fahrräder und Waffen, für die es eine zentrale Erfassung beim BKA gab; zudem führten auch die Landeskriminalämter einzelne Karteien, vgl. Häring, in: Bundeskriminalamt, Arbeitstagung „Fahndung“, S. 131 (133 f., 145); Lach, in: Bundeskriminalamt, Arbeitstagung „Fahndung“, S. 55 (63 f.).

${ }^{117}$ Häring, in: Bundeskriminalamt, Arbeitstagung „Fahndung“, S. 131 (133 f.).

${ }^{118}$ Häring, in: Bundeskriminalamt, Arbeitstagung „Fahndung“, S. 131 (134).

${ }^{119}$ Lach, in: Bundeskriminalamt, Arbeitstagung „Fahndung“, S. 55 (56, 58, 63).
} 
gleichen hatte. ${ }^{120}$ Wie bei der Sachfahndung drohten wichtige Fahndungen in der Masse der Daten übersehen zu werden. Es kam hinzu, dass das Fahndungsbuch nur in gewissen zeitlichen Abständen ${ }^{121}$ neu aufgelegt wurde. Damit war es bereits bei seinem Erscheinen nicht mehr auf dem aktuellen Stand.

In den Veröffentlichungen aus dieser Zeit wird immer wieder deutlich, dass die Polizeipraktiker große Hoffnungen in die Möglichkeiten moderner Datenverarbeitung setzten. ${ }^{122}$ Diese Hoffnung wird u.a. aus den Erfahrungen gespeist, die bei der Auswertung von damals bereits vereinzelt auf Magnetband gespeicherten Daten gemacht wurden. ${ }^{123}$

Der entscheidende Schritt hin zu INPOL, dem von Bund und Ländern genutzten elektronischen Informationsverbund „Informationssystem Polizei“, geschah im Jahr 1972 mit BKA-Präsident Horst Herold, ${ }^{124}$ der sich von einer effizienten Datenauswertung auch eine erfolgreichere Bekämpfung des aufkommenden Links-Terrorismus versprach. ${ }^{125}$

INPOL ermöglichte erstmals die bundesweite zentrale elektronische Sammlung und Abfrage von Informationen. Der Verbund besteht aus mehreren polizeilichen Anwendungen auf Bundes- und Landesebene, die für die gemeinsame Nutzung verfügbar gehalten werden und über eine einheitliche Kommunikationsschnittstelle miteinander verbunden sind. ${ }^{126}$ Das seit dem Jahr 2003 in einer neuen technischen Version betriebene System ${ }^{127}$ enthielt $\mathrm{zu}$ Beginn des Jahres 2009 etwa 1,2 Millionen Personenfahndungen sowie mehr als 26 Millionen Fahndungen nach Sachen. ${ }^{128}$ Die Beamten der Polizei-, Grenzschutz und Zollbehörden haben von entsprechenden Terminals sekundenschnellen Zugriff auf diesen Datenbestand. ${ }^{129}$

\footnotetext{
${ }^{120}$ Busch, Grenzenlose Polizei?, S. 37; Lach, in: Bundeskriminalamt, Arbeitstagung „Fahndung“, S. 55 (55).

${ }^{121}$ So erschien z.B. das Fahndungsbuch - A - am 15. März und 15. September eines Jahres, vgl. Lach, in: Bundeskriminalamt, Arbeitstagung „Fahndung“, S. 55 (59).

${ }^{122}$ Lach, in: Bundeskriminalamt, Arbeitstagung „Fahndung“, S. 55 (58 ff.); Häring, in: Bundeskriminalamt, Arbeitstagung „Fahndung“, S. 131 (142, 145 f.); Bux, in: Bundeskriminalamt, Arbeitstagung „Fahndung“, S. 191 (193, 195); Gemmer, in: Bundeskriminalamt, Arbeitstagung „Fahndung“, S. 217 (217) bereits mit dem Vorschlag, wichtige Fahndungsdaten europäischer Nachbarländer in einen Datenverbund auf Bundesebene mit aufzunehmen.

${ }^{123}$ Eine teilweise Datenspeicherung auf Magnetband gab es beim BKA seit 1968, Lach, in: Bundeskriminalamt, Arbeitstagung „Fahndung“, S. 55 (61); Bux, in: Bundeskriminalamt, Arbeitstagung „Fahndung“, S. 191 (193, 198).

${ }^{124}$ Tuffner, in: Bundeskriminalamt, Festschrift für Herold, S. 239 (239).

${ }^{125}$ Krekeler, StraFo 1999, 82 (82); Busch, Grenzenlose Polizei?, S. 37, Dietl, BKA-Story, S. 83 ff.

${ }^{126}$ Neben der Personen- und Sachfahndung gehören zu INPOL die IT-Anwendungen Kriminalaktennachweis (KAN), Haftdatei, Erkennungsdienst/Daktyloskopie (AFIS), Arbeitsdateien für besondere Kriminalitätsbereiche (PIOS-Dateien), Falldateien von Straftaten mit länderübergreifender Bedeutung, Hinweis- und Spurendokumentation im Ermittlungsverfahren mit länderübergreifender Bedeutung (SPUDOK), Beweismitteldokumentation, Leuchtendatei für Unfallflucht-Nachforschungen (LUNA), Fahrzeugidentifizierungs- und Auswertungssystem (FINAS), Unbekannte Tote und Vermisste (VERMI/UTOT), Literaturdokumentation (COD) und Polizeiliche Kriminalstatistik, vgl. Krekeler, StraFo 1999, 82 (82), siehe auch $\S 9$ Verordnung über die Art der Daten, die nach den $\S \S 8$ und 9 des Bundeskriminalamtsgesetzes gespeichert werden dürfen, BGB1. 2010, 716.

${ }^{127}$ Gegenüber INPOL „alt“ bietet das neue INPOL eine leicht zu bedienende Benutzeroberfläche, die Möglichkeit, Lichtbilder zu speichern sowie Beziehungsgeflechte zwischen Personen und Sachen abzubilden, vgl. Bundeskriminalamt, Das Profil, Stand 2005, S. 26.

${ }^{128}$ Bundeskriminalamt, Fakten und Zahlen, Stand 2009, S. 10.

${ }^{129}$ Bundeskriminalamt, Fakten und Zahlen, Stand 2005, S. 10.
} 


\section{Internationale Fahndung}

Internationale Personen- und Sachfahndung war bis zur Inbetriebnahme des SIS im Jahr 1995 ausschließlich über die 1923 gegründete Internationale Kriminalpolizeiliche Organisation IKPO - möglich, besser bekannt unter der Bezeichnung „Interpol““. ${ }^{130}$ Jedes der angeschlossenen Länder unterhielt eine als nationales Zentralbüro bezeichnete Stelle, die Ansprechpartner für das Generalsekretariat der Organisation, die Behörden des eigenen Landes sowie die nationalen Zentralbüros der anderen Länder war. ${ }^{131}$ Man hatte die Möglichkeit der normalen internationalen und der dringenden internationalen Fahndung.

\section{a. Normale internationale Fahndung}

Fahndete eine nationale Behörde beispielsweise nach einer Person zwecks Festnahme und Auslieferung, beantragte der zuständige Justizbeamte die internationale Durchgabe des Haftbefehls beim nationalen Zentralbüro seines Landes. Dieses leitete das Ersuchen nach Prüfung an das Generalsekretariat weiter, welches den Haftbefehl nach eigener Prüfung an die nationalen Zentralbüros der anderen Staaten in Form der ,,roten internationalen Ausschreibung“ ${ }^{\text { } 132}$ übermittelte. Die nationalen Zentralbüros, an die die Suchmeldung gerichtet war, veranlassten die Fahndung nach der betreffenden Person. ${ }^{133}$

Dieses grundsätzlich in Papierform durchgeführte Verfahren dauerte relativ lange. So vergingen allein vom Zeitpunkt des Ersuchens eines nationalen Zentralbüros bis zur Weiterleitung durch das Generalsekretariat mehrere Tage bis Wochen. ${ }^{134}$

\section{b. Dringende internationale Fahndung}

Erachtete ein Land eine Fahndung als eilbedürftig, stand ihm die Möglichkeit der Funktelegraphie zur Verfügung. Der betreffende Funkspruch wurde der nationalen Funkstation durchgegeben und von dieser an die Zentralstation des Generalsekretariates übermittelt. Diese gab ihn gleichzeitig an alle Empfänger durch.

In dringenden Fällen konnte ein nationales Zentralbüro eine Suchmeldung als InterpolDurchgabe beantragen. Hierbei war eine Beteiligung des Generalsekretariates nicht notwendig.

\footnotetext{
${ }^{130}$ Piosek, S. 95; vgl. Schattenberg, Schriftenreihe der PFA 3-4/1989, S. 20 (27); Girerd, in: Bundeskriminalamt, Arbeitstagung „Fahndung“, S. 17 (17).

${ }^{131}$ Girerd, in: Bundeskriminalamt, Arbeitstagung „Fahndung“, S. 17 (35 f.).

${ }^{132}$ Sog. „Rotecken“; die Fahndung zur Aufenthaltsermittlung, Personalienüberprüfung, Vernehmung im Interesse laufender Ermittlungen etc. erfolgte in Form der blauen Ausschreibung, sog. „Blauecken“, und jene zur Identifizierung unbekannter Toter in Form der schwarzen Ausschreibung, sog. „Schwarzecken“, vgl. Girerd, in: Bundeskriminalamt, Arbeitstagung „Fahndung“, S. 17 (21 ff.); vgl. Schattenberg, Schriftenreihe der PFA 3-4/1989, S. 20 (27); siehe auch Scheller, JZ 1992, 904 (905) sowie Fn. 13 und 16.

${ }^{133}$ Girerd, in: Bundeskriminalamt, Arbeitstagung „Fahndung“, S. 17 (20 f.).

${ }^{134}$ Girerd, in: Bundeskriminalamt, Arbeitstagung „Fahndung“, S. 17 (23, 28).
} 
Schließlich bestand die Möglichkeit, dass jedes nationale Zentralbüro über Funk mit jedem anderen nationalen Zentralbüro in Kontakt trat. ${ }^{135}$

Mit Hilfe der dringenden internationalen Fahndung gelang es, Suchmeldungen innerhalb eines Tages zu verbreiten und entsprechend schnelle Fahndungserfolge zu erzielen. ${ }^{136}$

Trotz dieser Möglichkeit gab es im Hinblick auf eine schnelle Datenübermittlung mehrere Lücken: Nicht alle Interpol angeschlossenen Länder verfügten über Funkstationen. Funksprüche konnten nur nacheinander übermittelt werden, so dass diese noch einmal vier unterschiedlichen Dringlichkeitsstufen zugeordnet werden mussten. Alle beteiligten Länder hatten einen eigens für diesen Zweck geschaffenen Abkürzungsschlüssel für das Abfassen der Meldungen zu benutzen, um das Funknetz nicht zu überlasten. ${ }^{137}$ Schließlich mussten die Beamten des ersuchenden Landes jeweils ex ante entscheiden, ob eine Fahndung als dringend anzusehen war. Taten sie es nicht, verpassten sie unter Umständen die Möglichkeit, eine gesuchte Person z.B. bei einer zeitnahen Grenzkontrolle festnehmen zu lassen.

\section{Daten und Zahlen zum Betrieb allgemein}

Innerhalb der Schengen-Staaten hat die SIS-Fahndung die Interpol-Fahndung seit dem 26. März 1995 abgelöst. ${ }^{138}$

Die Vorschriften zum SIS finden sich in Titel IV Art. 92 bis 119 SDÜ. Nach Art. 93 SDÜ soll der Betrieb des SIS die öffentliche Sicherheit und Ordnung sowie die Sicherheit des Staates und die Anwendung der Bestimmungen des SDÜ im Bereich des Personenverkehrs gewährleisten.

\section{Aufbau, Konzeption und Kosten}

Das als Rechner-Verbundsystem konzipierte SIS besteht aus einem nationalen Teil bei jeder Vertragspartei, dem sogenannten N.SIS, ${ }^{139}$ und einer zentralen technischen Unterstützungseinheit, dem sogenannten C.SIS. ${ }^{140}{ }^{141}$ Die N.SIS kommunizieren auf der einen Seite mit dem jeweiligen nationalen polizeilichen Informationssystem, in Deutschland also mit INPOL, und auf der anderen Seite mit dem C.SIS, das seinen Sitz in Straßburg ${ }^{142}$ hat. Ziel ist es, dass der Datenbe-

\footnotetext{
${ }^{135}$ Girerd, in: Bundeskriminalamt, Arbeitstagung „Fahndung“, S. 17 (28 ff.).

${ }^{136}$ Girerd, in: Bundeskriminalamt, Arbeitstagung „Fahndung“, S. 17 (32 f.).

${ }^{137}$ Girerd, in: Bundeskriminalamt, Arbeitstagung „Fahndung“", S. 17 (29, 31 f.).

${ }_{138}$ Sirene-Handbuch, 2.12.1., ABl. L 186, 1, vom 15. Juli 2011; Hemesath, KR 1995, 169 (171); Tuffner, SIS, MEPA-Zeitung 2005, 21 (21); RiStBV, Anlage F. , I. 2 .

${ }^{139}$ National Schengen Information System, vgl. Tuffner, in: Bundeskriminalamt, Festschrift für Herold, S. 239 (243).

${ }^{140}$ Central Schengen Information System, vgl. Tuffner, in: Bundeskriminalamt, Festschrift für Herold, S. 239 (243).

${ }^{141}$ Art. 92 Abs. 1 S. 1 SDÜ.

${ }^{142}$ Art. 92 Abs. 3 S. 2 SDÜ; um den Betrieb des C.SIS hatten sich auch Den Haag und Wiesbaden beworben, vgl. Interview mit dem damaligen BKA-Präsidenten Zachert, KR 1990, 498 (498) sowie Busch, KJ 1990, 1 (8).
} 
stand in allen N.SIS zu jedem Zeitpunkt identisch ist. ${ }^{143} \mathrm{Zu}$ diesem Zweck werden die in einem Vertragsstaat eingegebenen Daten an das C.SIS übermittelt und dort einer großen Kopiermaschine gleich innerhalb von Minuten an alle N.SIS verteilt. Das C.SIS muss mehrere Funktionen erfüllen: Es prüft das Datenformat eingehender und ausgehender Fahndungsdaten, garantiert die gleichzeitige und inhaltlich identische Verteilung an die N.SIS, gibt dem sendenden N.SIS eine Kontrollrückmeldung, vergibt und prüft automatisch Ausschreibungsfristen für jeden Fahndungsdatensatz und löscht Fahndungsdaten nach Fristablauf automatisch im Gesamtsystem aller N.SIS. ${ }^{144}$

Die N.SIS nehmen demgegenüber vor der elektronischen Weiterleitung der Daten einer Ausschreibung an das C.SIS eine Plausibilitätsprüfung vor, sie gleichen den bestehenden Datenbestand im SIS durch Kontrollläufe mit dem nationalen Fahndungsbestand ab und verschicken Warnmeldungen bei bevorstehendem Fristablauf. ${ }^{145}$

Eine Fahndung ist grundsätzlich immer nur für das gesamte Schengen-Gebiet möglich. Es ist technisch nicht vorgesehen, dass die ausschreibende Partei die Suche auf wenige Schengenstaaten beschränkt. ${ }^{146}$ Das SIS wird auch häufig als ein Fahndungssystem mit einem Online-Zugriff „in Echtzeit“ bezeichnet. Gemeint ist damit, dass in jedem Vertragsstaat das sofortige Erscheinen der Fahndung nach Dateneingabe und die sekundenschnelle Abfragemöglichkeit sichergestellt sind. ${ }^{147}$

Nach Art. 119 SDÜ tragen die Mitgliedstaaten die Kosten für die Einrichtung und den Betrieb des C.SIS gemeinsam, während die im Hinblick auf das jeweilige N.SIS anfallenden Kosten von jedem Mitgliedstaat selbst zu zahlen sind.

\section{Sirenen}

Nach Art. 108 Abs. 1 SDÜ bestimmt jede Vertragspartei eine Stelle, die als Zentrale für den nationalen Teil des N.SIS zuständig ist. Gemeint ist damit die für Deutschland im Bundeskriminalamt in Wiesbaden angesiedelte Sirene. ${ }^{148} 149$ Grob skizziert wacht sie über die Einhaltung der Bestimmungen des SDÜ und sorgt für das reibungslose Funktionieren des N.SIS. ${ }^{150}$ Sie ist dabei Ansprechpartner für in- und ausländische Stellen u.a. im Falle nicht kompatibler Daten, hält bei einer erfolgreichen Ausschreibung, einem sogenannten „Trefferfall“, bezüglich bestimmter Aus-

\footnotetext{
${ }^{143}$ Art. 92 Abs. 2 S. 1 SDÜ.

${ }^{144}$ Tuffner, in: Bundeskriminalamt, Festschrift für Herold, S. 239 (244).

${ }^{145}$ Würz, Rn. 162.

${ }^{146}$ Hemesath, KR 1995, 169 (170).

${ }^{147}$ Tuffner, KR 2000, 39 (39); Mokros, in: Lisken/Denninger, HandbPolR, Teil O, Rn. 143.

${ }^{148}$ Art. 92 Abs. 4 S. 1 SDÜ; vgl. zur Bezeichnung Fn. 6 der Arbeit.

${ }^{149} \S 3$ Abs. 1a BKAG.

${ }^{150}$ Art. 108 Abs. 3 SDÜ.
} 
schreibungskategorien zusätzliche Informationen bereit und übersetzt diese bei Bedarf. ${ }^{151}$ Die Sirenen kommunizieren untereinander und mit dem C.SIS über ein gesondertes elektronisches Nachrichtennetz, das sogenannte SISNET. ${ }^{152}$

Der elektronische Austausch von Lichtbildern und Fingerabdrücken zu Identifizierungszwecken ist zwischen den Sirenen über den Sirene-Bild-Transfer, kurz SIRPIT, ${ }^{153}$ möglich. ${ }^{154} 155$

\section{Schwierigkeiten bei der Entwicklung des SIS}

Ursprünglich wurde die Inbetriebnahme des SIS für den 1. Juli 1992 angestrebt; es waren also nach Unterzeichnung des SDÜ zwei Jahre für die Entwicklung des SIS eingeplant. ${ }^{156}$ Sie verzögerte sich jedoch aufgrund technischer und organisatorischer Schwierigkeiten fast um drei weitere Jahre. So waren beispielsweise an der Entwicklung des C.SIS drei große Computerfirmen beteiligt. Zudem erwiesen sich die Ausgangsbedingungen in den Teilnehmerstaaten als sehr unterschiedlich. Während es für die luxemburgische Polizei noch gar kein elektronisches Datenverarbeitungssystem gab, besaßen Frankreich, Belgien, Spanien, Portugal und Italien der Polizeistruktur ihrer Länder entsprechend mehrere polizeiliche Datenverarbeitungssysteme, die mit dem jeweiligen N.SIS zu koppeln waren. ${ }^{157}$

Eine besondere Herausforderung stellte sich auch durch die verschiedenen Nationalsprachen der Teilnehmerstaaten. Zum einen galt es, die Verständigung hinsichtlich der Ausschreibungskategorien und der Handlungsanweisungen für den Endbenutzer sicherzustellen. Das geschah so weit wie möglich durch eine Standardisierung und Formatisierung von Informationen und die Reduzierung von Informationen auf numerische Daten. Soweit eine individuelle Kommunikation von Nöten ist, können die mehrsprachigen Mitarbeiter in den Sirenen behilflich sein. ${ }^{158}$

Zum anderen mussten Lösungen für die Darstellung von Lauten wie $\beta$, ä, ö, ü im Deutschen oder é, è, ê im Französischen gefunden werden, da ansonsten eine Suche beispielsweise nach dem Kfz-Kennzeichen „Gö“ - für Göttingen - häufig erfolglos verläuft. Ein elektronisches Fahndungssystem recherchiert bei auch nur geringen Differenzen zwischen Eingabe- und Abfrage-

\footnotetext{
${ }^{151}$ Vgl. Art. 92 Abs. 4 SDÜ; Gusy/Gimbal, in: Baldus/Soiné, Internationale polizeiliche Zusammenarbeit, S. 124 (125).

${ }^{152}$ Bis zum Juni 2002 benutzten die Sirenen untereinander das X-400-Netz, vgl. Bundesinnenministerium, Schengen-Erfahrungsbericht 2002, S. 10; Tuffner, in: Bundeskriminalamt, Festschrift für Herold, S. 239 (249); Tuffner, SIS, MEPA-Zeitung 2005, 21 (22).

${ }^{153}$ Abkürzung für „SIRene Picture Transfer“.

${ }^{154}$ Sirene-Handbuch, 2.10.6., AB1. L 186, 1, vom 15. Juli 2011

${ }^{155} \mathrm{Vgl}$. hierzu auch die Regeln der das SDÜ ergänzenden Zusammenarbeit von Prüm, 2. Teil, C. IX.

${ }^{156}$ Interview mit dem damaligen BKA-Präsidenten Zachert, KR 1990, 498 (498).

${ }^{157}$ Sturm, KR 1995, 162 (167); Tuffner, in: Bundeskriminalamt, Festschrift für Herold, S. 239 (241).

${ }^{158}$ Tuffner, in: Bundeskriminalamt, Festschrift für Herold, S. 239 (242 f.).
} 
modalität am Zielobjekt oder der Zielperson vorbei. Aus diesem Grund vereinbarte man Transliterationsregeln für die alphanumerische Wiedergabe von Namen und Daten. ${ }^{159}$

\section{Dateninhalt des SIS}

Art. 104 Abs. 1 SDÜ legt für die Ausschreibung fest, dass grundsätzlich das nationale Recht Anwendung findet, wenn nicht das Übereinkommen engere Voraussetzungen für die Ausschreibung enthält.

Hinsichtlich der Durchführung der mit der Ausschreibung erbetenen Maßnahme regelt Art. 104 Abs. 3 SDÜ, dass das nationale Recht gilt, wenn nicht das Übereinkommen eine besondere Regelung enthält. Die sich aus dieser besonderen Regelung ergebenden Befugnisse werden allerdings wiederum durch das nationale Recht begrenzt.

Mit Blick auf die Grundsätze der Erforderlichkeit und der Zweckbindung legt Art. 94 SDÜ fest, dass nur bestimmte Daten im SIS gespeichert werden und benennt diese. Aufgenommen werden dürfen grundsätzlich Personen und die in den Artikeln 99 und 100 SDÜ festgelegten Sachen. Zu den Personen werden maximal Name, Vornamen, ggf. Aliasnamen, besondere unveränderliche physische Merkmale, Geburtsort und -datum, Geschlecht, Staatsangehörigkeit, der Hinweis auf Bewaffnung oder Gewalttätigkeit, der Ausschreibungsgrund sowie die zu ergreifende Maßnahme gespeichert.

\section{Ablauf einer Fahndung ${ }^{160}$}

Bevor innerhalb der einzelnen Fahndungskategorien die Eingabe- und Abfragemodalitäten sowie das Verfahren im Trefferfall detailliert darzustellen sind, soll der Ablauf einer Fahndung zunächst möglichst allgemein erläutert werden.

Die Einleitung einer Fahndung wird in Deutschland von der jeweils zuständigen Stelle, also je nach Datenkategorie von Gerichten, Staatsanwaltschaften, Verwaltungsbehörden, Polizeibehörden, oder den Geheimdiensten ${ }^{161}$ betrieben. Die Eingabe der Daten sämtlicher Kategorien erfolgt durch die technisch mit so genannten Datenstationen ausgerüsteten örtlichen Polizeidienststellen direkt in das deutsche INPOL. INPOL-Fahndungen werden, wenn es auf dem entsprechenden Vordruck nicht ausdrücklich ausgestrichen wird, in das deutsche N.SIS übernommen, dort automatisch auf Plausibilität geprüft und bei korrekter Eingabe nach Umwandlung von N.SIS in

\footnotetext{
${ }^{159}$ Piosek, S. 91 f., Tuffner, in: Bundeskriminalamt, Festschrift für Herold, S. 239 (242 f.).

${ }^{160}$ Zur Einbindung der Landeskriminalämter vgl. Würz, Rn. 218, 220.

${ }^{161}$ Vgl. $§ 17$ Abs. 3 BVerfSchG.
} 
C.SIS-Format beim BKA an das C.SIS zur Weiterleitung an die übrigen N.SIS übermittelt. ${ }^{162}$ Eine Besonderheit gilt bei Ausschreibungen nach Art. 95 SDÜ, der Ausschreibung von Personen zur Festnahme. Zusätzlich zu den im SIS notierten Informationen sind hier weitere Angaben erforderlich. Diese werden von der Sirene formell, inhaltlich und rechtlich überprüft und erst nach dem positiven Abschluss dieser Prüfung wird die Fahndung zur Weiterleitung an das C.SIS freigegeben, während die Sirene des ausschreibenden Staates die zusätzlichen Informationen direkt an alle anderen Sirenen versendet. ${ }^{163}$

Die ersuchten Staaten haben nach Art. 94 Abs. 4 SDÜ die Möglichkeit, Ausschreibungen gemäß Art. 95, 97 oder 99 SDÜ aus bestimmten Gründen wie z.B. einer Unvereinbarkeit mit nationalem Recht kennzeichnen zu lassen. In der Folge wird die erbetene Maßnahme in ihrem Hoheitsgebiet nicht vollzogen.

Zur Abfrage im SIS standen im Jahr 2007 in den 15 teilnehmenden Staaten über 200.000 Datenterminals zur Verfügung. ${ }^{164}$ Grundsätzlich abfrageberechtigt sind die Polizeidienststellen des Bundes und der Länder, der Polizei- und Sicherungsdienst des Deutschen Bundestages, das Zollkriminalamt, die Zollfahndungsdienststellen, das Bundesverwaltungsamt, die deutschen Auslandsvertretungen sowie die Ausländerbehörden. ${ }^{165}$ Außerdem erlaubt das SDÜ den Abruf der für den jeweiligen Aufgabenbereich erforderlichen Daten für nationale Justizbehörden ${ }^{166}$ sowie Kraftfahrzeug-Zulassungsstellen. ${ }^{167}$

Zusätzlich kann die Europäische Polizeibehörde Europol auf Daten nach Art. 95, 99 und 100 SDÜ zugreifen und die europäische „Staatsanwaltschaft““ Eurojust auf Daten nach Art. 95 und 98 SDÜ. ${ }^{168}$

Im Trefferfall erhält der abfragende Endbenutzer innerhalb von Sekunden Kenntnis. Er kann anschließend weitere Informationen aufrufen, insbesondere zum Grund der Ausschreibung und zu den für ihn relevanten Handlungsanweisungen. ${ }^{169}$ Er kann auch Kontakt zur Sirene seines

\footnotetext{
${ }^{162}$ Würz, Rn. 162; Gusy/Gimbal, in: Baldus/Soiné, Internationale polizeiliche Zusammenarbeit, S. 124 (129 f.); Wilkesmann, NStZ 1999, 68 (68); Hemesath, KR 1995, 169 (169 f.); Piosek, S. 70; vgl. auch § 11 Abs. 2 BKAG.

${ }^{163}$ Tuffner, KR 2000, 39 (40).

${ }^{164}$ Tuffner, Polizei-heute 2007, 114 (116); durch die Teilnahme von mittlerweile 10 weiteren Staaten zum 21. Dezember 2007 bzw. 12. Dezember 2008 dürfte sich diese Zahl signifikant erhöht haben.

${ }^{165}$ Art. 101 Abs. 1 SDÜ; Art. 6 Nr. 2 Zustimmungsgesetz zum SDÜ, BGBl. II 1993, 1010; Würz, Rn. 164; vgl. Hemesath, KR 1995, 169 (170).

${ }^{166}$ Art. 101 Abs. 1 S. 3 SDÜ; für die Staatsanwaltschaften innerstaatlich in $\S 11$ Abs. 4 S. 2 Nr. 1 BKAG umgesetzt.

167 Art. 102 a SDÜ; der Zugriff ist in Deutschland über die bestehende technische Infrastruktur, das so genannte Zentrale Verkehrsinformationssystem, kurz ZEVIS, zwischen Kraftfahrtbundesamt und Zulassungsbehörden realisiert; das ergab ein telefonische Auskunft durch das Kraftfahrtbundesamt am 8. Juni 2010, Frau Junge-Grützmacher, Sachgebietsleiterin 212.

${ }^{168}$ Art. 101 a und $101 \mathrm{~b}$ SDÜ.

${ }^{169}$ Tuffner, KR 2000, 39 (40).
} 
Staates aufnehmen, die dann wiederum ggf. mit der Sirene des ausschreibenden Staates Verbindung aufnimmt und zusätzliche Informationen anfordert.

Im Jahr 2009 umfasste das SIS rund 28 Millionen Fahndungen. Als einer der 24 SISTeilnehmerstaaten in 2009 stellte Deutschland dabei mehr als ein Sechstel des gesamten Fahndungsbestandes. ${ }^{170}$

\section{Die einzelnen Fahndungskategorien}

In diesem Abschnitt sollen die Voraussetzungen und das Verfahren sowie das Verhalten im sogenannten „Trefferfall“ bei einer jeden Fahndungskategorie vorgestellt werden. Durch die schengenweite Anbindung des SIS sind aus deutscher Sicht für die Personenfahndung grundsätzlich acht verschiedene Konstellationen denkbar, nämlich:

1. Ausschreibung eines (Dritt-) Ausländers ${ }^{171}$ im Ausland und Treffer im Ausland,

2. Ausschreibung eines Inländers im Ausland und Treffer im Ausland,

3. Ausschreibung eines (Dritt-) Ausländers in Deutschland und Treffer in Deutschland,

4. Ausschreibung eines Inländers in Deutschland und Treffer in Deutschland,

5. Ausschreibung eines (Dritt-) Ausländers in Deutschland und Treffer im Ausland,

6. Ausschreibung eines Inländers in Deutschland und Treffer im Ausland,

7. Ausschreibung eines (Dritt-) Ausländers im Ausland und Treffer in Deutschland,

8. Ausschreibung eines Inländers im Ausland und Treffer in Deutschland.

Je nach Konstellation können andere, ggf. ausländische, Rechtsvorschriften und völkerrechtliche Übereinkommen gelten. Aus Gründen der Übersichtlichkeit und zum besseren Verständnis des Funktionierens des Systems aus deutscher Sicht haben die nachfolgenden Erläuterungen grundsätzlich einerseits eine deutsche Ausschreibung eines Inländers oder (Dritt-) Ausländers zum Gegenstand. Beim Trefferfall kommt es zum Perspektivwechsel. Es wird eine ausländische Ausschreibung unterstellt, die zum Antreffen eines Inländers oder (Dritt-) Ausländers in Deutschland

\footnotetext{
${ }^{170}$ Bundeskriminalamt, Fakten und Zahlen, Stand 2009, S. 10.

${ }^{171}$ Drittausländer im hier gemeinten Sinne ist eine Person, die nicht die Angehörigkeit eines Staates besitzt, der das Schengener Abkommen anwendet. Ausländer in diesem Sinne ist eine Person, deren Heimatstaat das Schengener Abkommen anwendet, aber nicht die deutsche Staatsangehörigkeit hat; wenig hilfreich erscheint in diesem Zusammenhang die Defintion des Art. 1 SDÜ, wonach Drittausländer ist, wer nicht die Staatsangehörigkeit eines der Mitgliedstaaten der Europäischen Gemeinschaften besitzt: Zum einen gibt es keine Europäischen Gemeinschaften mehr sondern nur noch eine Europäische Union; zum anderen sind die Staatsangehörigen der assoziierten Staaten Norwegen, Island und der Schweiz keine EU-Bürger, aber dennoch keine Drittausländer, da sie beispielsweise nicht nach Art. 96 SDÜ zur Einreiseverweigerung ausgeschrieben werden können.
} 
führt. Das gleiche gilt für die Sachfahndung mit dem Unterschied, dass an die Stelle der Staatsangehörigkeit der Person, die gesucht wird, die Staatsangehörigkeit des Eigentümers tritt.

Für das Verhältnis von nationalem Recht zum Recht des Schengener Durchführungsabkommens stellt Art. 104 SDÜ Regeln auf. Dieser Artikel unterscheidet zwischen den Voraussetzungen für eine Ausschreibung, den Umgang mit im nationalen Teil des SIS gespeicherten Daten sowie den Regeln über die Durchführung der mit der Ausschreibung erbetenen Maßnahme. Relevanz hat diese Vorschrift insbesondere bei den Ausschreibungen nach Art. 96 und 99 SDÜ, ${ }^{172}$ so dass dort auch näher auf sie eingegangen werden wird.

\section{Fahndung nach Personen zur Festnahme zwecks Auslieferung gemäß Art. 95 SDÜ}

Das Verfahren nach dieser Kategorie hat durch den Rahmenbeschluss der EU zum Europäischen Haftbefehl vom 13. Juni $2002^{173}$ und das deutsche Umsetzungsgesetz vom 20. Juli $2006^{174}$ eine wesentliche Änderung erfahren.

Zunächst soll jedoch das Verfahren dargestellt werden, wie es vor der Geltung des Europäischen Haftbefehls zwischen allen SIS-Teilnehmerstaaten ablief und noch heute im Verhältnis zu den Nicht-EU-Staaten Norwegen, Island und der Schweiz Gültigkeit hat. ${ }^{175}$

\section{a. Verfahren vor bzw. ohne Geltung des Europäischen Haftbefehls}

Die Ausschreibung nach Art. 95 SDÜ soll gewährleisten, dass eine Person vorläufig festgenommen wird, damit wegen einer Straftat im ausschreibenden Staat ein Auslieferungsverfahren betrieben werden kann.

\section{aa. Voraussetzungen und Verfahren der Ausschreibung}

Zuständig sind die Justizbehörden, in Deutschland die Staatsanwaltschaften. Liegen keine Anhaltspunkte dafür vor, dass sich die gesuchte Person nur im Inland aufhält, ist eine Ausschreibung im SIS angezeigt. ${ }^{176}$ Weiterhin prüft die Staatsanwaltschaft nach Art. 95 Abs. 2 S. 1 SDÜ, ob eine Festnahme nach dem Recht der ersuchten Vertragsparteien, also aller SchengenMitgliedstaaten, zulässig ist. Das ist der Fall, wenn bei einer Ausschreibung zur Festnahme zwecks Strafverfolgung die Strafandrohung mindestens ein Jahr Freiheitsstrafe im Höchstmaß

\footnotetext{
${ }^{172}$ Würz, Rn. 157.

${ }^{173}$ AB1. L 190, 1

${ }^{174}$ BGB1. 2006, 1721.

${ }^{175}$ Vgl. Tuffner, SIS II, MEPA-Zeitung 2005, 32 (36).

${ }^{176}$ Art. 95 Abs. 1 SDÜ; Nr. 43 III RiStBV.
} 
beträgt und bei einer Auslieferung zur Strafvollstreckung mindestens noch vier Monate Freiheitsstrafe $\mathrm{zu}$ vollstrecken sind. ${ }^{177}$

Zusätzlich zu den im SIS vermerkten Informationen nach Art. 94 Abs. 3 SDÜ zur Person des Täters sowie zu Ausschreibungsgrund und zur zu ergreifenden Maßnahme fasst die Behörde weitere Informationen in einem Begleitpapier zusammen. Aufzuführen sind die um Festnahme ersuchende Behörde, das Bestehen eines Haftbefehls oder einer Urkunde mit gleicher Rechtswirkung oder eines rechtskräftigen Urteils, die Art und die Würdigung der strafbaren Handlung, die Beschreibung der Umstände, unter denen die Straftat begangen wurde einschließlich der Zeit, des Orts und der Art der Täterschaft sowie, soweit möglich, die Folgen der Straftat. ${ }^{178}$ Die Daten nach Art. 94 Abs. 3 SDÜ werden von der örtlichen Polizeidienststelle in INPOL eingegeben, während das Begleitpapier in der Regel per Fax an die Sirene übermittelt wird. Die Mitarbeiter der Sirene prüfen die Fahndung auf Einhaltung der Form, des Inhaltes sowie kursorisch rechtlich. Zudem werden Teile ins Englische übersetzt. Erst nach Abschluss dieser Arbeiten wird die Fahndung an das C.SIS zur weiteren Verteilung an die N.SIS freigegeben, während die Sirene Deutschland das Begleitpapier an die anderen Sirenen elektronisch über das gesonderte SISNET weiterleitet. ${ }^{179}$

Aufgrund der ihm vorliegenden Informationen hat der ersuchte Staat nunmehr die Möglichkeit, selbst die Zulässigkeit der Ausschreibung nach seinem Recht zu prüfen. Zu diesem Zweck kann er die Ausschreibung in seinem N.SIS für 24 Stunden so kennzeichnen lassen, ${ }^{180}$ dass bis zur Löschung der Kennzeichnung keine Festnahme aufgrund der Ausschreibung erfolgen darf. Sofern die Komplexität des Sachverhaltes es in besonderen Ausnahmefällen erfordert, kann die Prüffrist auf eine Woche verlängert werden. ${ }^{181}$ Während der Zeit der Kennzeichnung und sofern eine Vertragspartei die Zulässigkeit der erbetenen Festnahme nach Abschluss der Prüfung aus Rechtsgründen oder besonderen Opportunitätserwägungen verneint, wird die Ausschreibung in ihrem N.SIS in eine Ausschreibung zur Aufenthaltsermittlung ${ }^{182}$ umgewandelt. $^{183}$

Wie bereits erwähnt, ist auch nachträglich eine Kennzeichnung möglich. Art. 94 Abs. 4 SDÜ fordert hierfür, dass der betreffende Mitgliedstaat die Ausschreibung nach Art. 95 SDÜ für nicht vereinbar hält mit seinem nationalen Recht, mit internationalen Verpflichtungen oder wesentli-

\footnotetext{
${ }^{177}$ Art. 2 Nr. 1 EuAlübk.

${ }^{178}$ Art. 95 Abs. 2 S. 3 SDÜ.

${ }^{179}$ Würz, Rn. 175; Tuffner, unveröffentlichter Vortrag vor der deutschen Richterakademie in Trier im Juni 2005 , S. 15, Text liegt der Verfasserin vor; vgl. Gusy/Gimbal, in: Baldus/Soiné, Internationale polizeiliche Zusammenarbeit, S. 124 (131).

${ }^{180}$ Auch als „Flag setzen“ bezeichnet, vgl. Gusy/Gimbal, in: Baldus/Soiné, Internationale polizeiliche Zusammenarbeit, S. 124 (132).

${ }^{181}$ Art. 95 Abs. 3 SDÜ.

${ }^{182}$ Wegen der Sachnähe wohl nach Art. 98 SDÜ.

${ }^{183}$ Art. 95 Abs. 3 S. 2, Abs. 5 SDÜ.
} 
chen nationalen Interessen. Mit den anderen Vertragsparteien sind hierüber Konsultationen zu führen. Für die anderen Staaten, die keine Flag setzen lassen, bleibt die Ausschreibung zur Festnahme gültig. ${ }^{184}$ In Fällen besonderer Eilbedürftigkeit kann der ersuchende Staat um eine Sofortfahndung mit der Folge bitten, dass der ersuchte Staat prüft, ob er auf die Kennzeichnung verzichten kann. Gleichzeitig soll der ersuchte Staat alle Vorkehrungen treffen, damit die erbetene Maßnahme im Fall der Zulässigkeit sofort vollzogen werden kann. ${ }^{185}$

Abfrageberechtigt sind alle Polizeidienststellen des Bundes und der Länder, das Zollkriminalamt und die Zollfahndungsdienststellen sowie die Staatsanwaltschaften. ${ }^{186}$ Zudem haben, soweit es ihre Aufgaben erfordern, sowohl das Europäische Polizeiamt, Europol, als auch die Europäische „Staatsanwaltschaft“, Eurojust, seit 1. Oktober $2006^{187}$ Zugriff auf die Daten nach Art. 95 SDÜ. ${ }^{188}$

\section{bb. Verfahren im Trefferfall}

Im Trefferfall sollen die erbetenen Maßnahmen auf der Grundlage der geltenden Auslieferungsübereinkommen und nach Maßgabe des nationalen Rechts ausgeführt werden. ${ }^{189}$ Das sich anschließende Verfahren richtet sich damit nach den Übereinkommen des Europarates über Auslieferung, EuAlÜbk, vom 13. Dezember $1957^{190}$ und über die Rechtshilfe in Strafsachen, EuRHÜbk, vom 20. April 1959, ${ }^{191}$ nach dem Gesetz über die internationale Rechtshilfe in Strafsachen, IRG ${ }^{192}$ und nach den Richtlinien für den Verkehr mit dem Ausland in strafrechtlichen Angelegenheiten, RiVASt. ${ }^{193}$ Die von der Staatsanwaltschaft beantragte Ausschreibung im SIS gemäß Art. 95 SDÜ ist nach Art. 64 SDÜ ${ }^{194}$ einem Ersuchen um vorläufige Festnahme nach Art. 16 EuAlÜbk gleichgestellt. Nimmt der zuständige Beamte die im SIS ausgeschriebene Person auf Grundlage von Art. 64 SDÜ i.V.m. § 19 IRG fest, meldet er der Sirene im BKA die Festnahme und fordert die dort vorliegenden und auszugsweise übersetzten Begleitpapiere an. ${ }^{195}$ Un-

\footnotetext{
${ }^{184}$ Art. 94 Abs. 4 S. 3, Art. 95 Abs. 3 S. 4 SDÜ.

${ }^{185}$ Art. 95 Abs. 4 SDÜ.

${ }^{186}$ Art. 101 Abs. 1 S. 1 und 2 sowie S. 3 SDÜ i.V.m. § 11 Abs. 4 S. 2 Nr. 1 BKAG; Würz, Rn. 164.

187 Beschluss 2006/631/JI des Rates vom 24. Juli 2006, ABl. L 256, 18 unter Bezugnahme auf den Beschluss 2005/211/JI des Rates vom 24. Februar 2005, AB1. L 68, 44.

${ }^{188}$ Art. 101 a und 101 b SDÜ.

${ }^{189}$ Art. 95 Abs. 6 S. 1 SDÜ.

${ }^{190}$ Europäisches Auslieferungsübereinkommen, BGB1. II 1964, 1371 ff.; dieses Übereinkommen gilt nach Art. 60 SDÜ auch für die Staaten, die es nicht unterzeichnet haben.

${ }^{191}$ Europäisches Übereinkommen über die Rechtshilfe in Strafsachen, BGB1. II 1964, 1386 ff.

${ }^{192}$ BGBl. 1994, $1537 \mathrm{ff}$.

${ }^{193}$ Gusy/Gimbal, in: Baldus/Soiné, Internationale polizeiliche Zusammenarbeit, S. 124 (131).

${ }^{194}$ Im Verhältnis zu den assoziierten Staaten wird dessen Gültigkeit durch Art. 31 Abs. 1 e Rahmenbeschluss zum Europäischen Haftbefehl nicht berührt, AB1. L 190, 1, vom 18. Juli 2002

${ }^{195}$ Würz, Rn. 212.
} 
ter Vorlage der Begleitpapiere ist der Festgenommene nach $\S 22$ IRG unverzüglich, spätestens jedoch am nächsten Tag dem Richter des nächsten Amtsgerichtes vorzuführen, der gemäß $\S 23$ IRG über die Fortdauer der vorläufigen Auslieferungshaft bis zur Entscheidung des zuständigen Oberlandesgerichts befindet.

\section{b. Einführung des Europäischen Haftbefehls}

Mit dem Rahmenbeschluss vom 13. Juni $2002^{196}$ gab der Rat der Europäischen Union den Mitgliedstaaten auf, innerstaatlich die Voraussetzungen für die Anwendung eines Europäischen Haftbefehls zu schaffen.

\section{aa. Ziel und Inhalt des Rahmenbeschlusses zum Europäischen Haftbefehl}

Ziel war es, das Auslieferungsverfahren von seiner politischen Komponente zu befreien und stattdessen zu verrechtlichen. Diese Absicht schlägt sich in der Definition des Begriffes „Europäischer Haftbefehl“" nieder, in der dieser als justizielle Entscheidung bezeichnet wird, die in einem Mitgliedstaat ergangen ist und die Festnahme und Übergabe einer gesuchten Person durch einen anderen Mitgliedstaat zur Strafverfolgung oder zur Vollstreckung einer Freiheitsstrafe oder einer freiheitsentziehenden Maßregel der Sicherung bezweckt. ${ }^{197}$ Der Beschluss legt fest, dass die Mitgliedstaaten, freilich unter besonderer Berücksichtigung von Art. 6 EUV, ${ }^{198}$ grundsätzlich jeden Europäischen Haftbefehl zu vollstrecken haben. ${ }^{199}$ Voraussetzung für die Ausstellung des Europäischen Haftbefehls ist es, dass die Handlung im Ausstellungsmitgliedstaat mit einer Freiheitsstrafe oder einer freiheitsentziehenden Maßregel der Sicherung im Höchstmaß von mindestens zwölf Monaten bedroht ist oder dass es eine Verurteilung zu einer Strafe oder eine Anordnung einer Maßregel der Sicherung gibt, deren Maß mindestens vier Monate beträgt. ${ }^{200}$

Im Gegensatz zur bisherigen Rechtslage verzichten die Staaten auf das Vorliegen der beiderseitigen Strafbarkeit, wenn die fragliche Handlung im Ausstellungsmitgliedstaat mit einer Freiheitsstrafe oder einer freiheitsentziehenden Maßregel der Sicherung im Höchtsmaß von mindestens drei Jahren bedroht ist und dem umfangreichen Straftaten-Katalog des Art. 2 Abs. 2 RbEuHb unterfällt. $^{201}$

\footnotetext{
${ }^{196}$ Rahmenbeschluss 2002/584/JI des Rates vom 13. Juni 2002 über den Europäischen Haftbefehl und die Übergabeverfahren zwischen den Mitgliedstaaten, ABl. L 190, 1; im folgenden als RbEuHb bezeichnet.

${ }^{197}$ Art. 1 Abs. 1 RbEuHb; der Terminologie des Rahmenbeschlusses folgend ist nunmehr von „Ausstellungsmitgliedstaat“ für den die Auslieferung begehrenden Mitgliedstaat und von „Vollstreckungsmitgliedstaat" für den um Auslieferung ersuchten Mitgliedstaat die Rede.

${ }^{198} \mathrm{Vgl}$. hierzu nunmehr die europäische Grundrechte-Charta.

${ }^{199}$ Art. 1 Abs. 2 und 3 RbEuHb.

${ }^{200}$ Art. 2 Abs. 1 RbEuHb.

${ }^{201}$ Beteiligung an einer kriminellen Vereinigung, Terrorismus, Menschenhandel, sexuelle Ausbeutung von Kindern und Kinderpornografie, illegaler Handel mit Drogen und psychotropen Stoffen, illegaler Handel mit Waffen, Muni-
} 
Art. $3 \mathrm{RbEuHb}$ nennt Gründe, aus denen die Vollstreckung des Europäischen Haftbefehls abzulehnen ist. Aufgeführt wird hier der Fall einer Amnestie im Vollstreckungsstaat, wenn dieser Staat nach seinem eigenen Recht für die Verfolgung der Straftat zuständig war; der Fall, dass die gesuchte Person wegen derselben Handlung von einem Mitgliedstaat rechtskräftig verurteilt worden ist und die Sanktion bereits vollstreckt wurde, gerade vollstreckt wird oder nach dem Rechts des Urteilsmitgliedstaates nicht mehr vollstreckt werden kann sowie der Fall der fehlenden Strafmündigkeit aufgrund des Alters.

Weiterhin stellt es der Rahmenbeschluss den Mitgliedstaaten nach den Art. 4, 4a RbEuHb frei, die Vollstreckung des Europäischen Haftbefehls in bestimmten Fällen abzulehnen. Genannt wird hier u.a. die Konstellation, dass die betroffene Person im Vollstreckungsmitgliedstaat wegen derselben Handlung bereits strafrechtlich verfolgt wird; der Fall, dass die Strafverfolgung oder Strafvollstreckung nach den Vorschriften des Vollstreckungsmitgliedstaates bereits verjährt ist und dass dieser Staat nach seinen Vorschriften zuständig gewesen wäre sowie schließlich der Fall, dass sich der Europäische Haftbefehl auf Straftaten erstreckt, die nach den Rechtsvorschriften des Vollstreckungsmitgliedstaates ganz oder zum Teil in dessen Hoheitsgebiet oder an einem diesem gleichgestellten Ort begangen worden sind oder außerhalb des Hoheitsgebiets des Ausstellungsmitgliedsstaats begangen wurden, und die Rechtsvorschriften des Vollstreckungsmitgliedsstaats die Verfolgung von außerhalb seines Hoheitsgebiets begangenen Straftaten gleicher Art nicht zulassen. ${ }^{202}$

Nach Art. 5 RbEuHb kann der Vollstreckungsstaat für die Übergabe der gesuchten Person Bedingungen stellen, z.B. dass der Betroffene, der Staatsangehöriger des Vollstreckungsmitgliedstaates ist oder in diesem wohnt, nach Abschluss der Verfahrens zur Strafverbüßung in den Vollstreckungsmitgliedstaat rücküberstellt wird..$^{203}$

\footnotetext{
tion und Sprengstoffen, Korruption, Betrugsdelikte, Wäsche von Erträgen aus Straftaten, Geldfälschung, Cyberkriminalität, Umweltkriminalität, Beihilfe zur illegalen Einreise und zum illegalen Aufenthalt, vorsätzliche Tötung, schwere Körperverletzung, illegaler Handel mit Organen und menschlichem Gewebe, Entführung, Freiheitsberaubung und Geiselnahme, Rassismus und Fremdenfeindlichkeit, Diebstahl in organisierter Form oder mit Waffen, illegaler Handel mit Kulturgütern, Erpressung und Schutzgelderpressung, Nachahmung und Produktpiraterie, Fälschung von amtlichen Dokumenten und Handel damit, Fälschung von Zahlungsmitteln, illegaler Handel mit Hormonen und anderen Wachstumsförderern, illegaler Handel mit nuklearen und radioaktiven Substanzen, Handel mit gestohlenen Kraftfahrzeugen, Vergewaltigung, Brandstiftung, Verbrechen, die in die Zuständigkeit des Internationalen Gerichtshofs fallen, Flugzeug- und Schiffsentführung, Sabotage.

${ }^{202}$ Art. 4 Nr. 2, 4 und 7 RbEuHb.

${ }^{203}$ Art. 5 Nr. 3 RbEuHb.
} 
Der Rahmenbeschluss sah die Umsetzung in innerstaatliches Recht bis zum 31. Dezember 2003 vor.

\section{bb. Urteil des BVerfG vom 18. Mai 2005}

Das zunächst gültige deutsche Umsetzungsgesetz vom 21. Juli $2004^{204}$ wurde vom Bundesverfassungsgericht am 18. Mai 2005 für verfassungswidrig erklärt. Das Gericht stellte Verstöße gegen Art. 16 Abs. 2 S. 2 GG und gegen Art. 19 Abs. 4 GG fest. ${ }^{205}$

Der Entscheidung lag der Fall eines Deutsch-Syrers zugrunde, der nach entsprechender Entscheidung des Hanseatischen Oberlandesgerichts Hamburg und der Bewilligung der Justizbehörde der Freien und Hansestadt Hamburg aufgrund eines spanischen Europäischen Haftbefehls im November 2004 an Spanien ausgeliefert werden sollte. Dem Beschwerdeführer wurde zur Last gelegt, in Spanien, Deutschland und Großbritannien als eine der Schlüsselfiguren des terroristischen Netzwerkes Al-Qaida im Bereich der logistischen und finanziellen Unterstützung dieser Organisation aktiv gewesen zu sein. ${ }^{206}$

Das Bundesverfassungsgericht erläutert zunächst den Schutzbereich des Art. 16 GG $^{207}$ mit Blick auf seine Einbettung in den historisch-internationalen bzw. europäischen Kontext. So ist es Teil der konstituierenden Grundlage des Gemeinwesens, dass die Bürger nicht gegen ihren Willen aus der ihnen vertrauten Rechtsordnung entfernt werden sollen. ${ }^{208}$ Nur in einer statusrechtlich gesicherten Weise können die Bürger ihre politische und zivilrechtliche Rechtsstellung genießen. Dieses Grundrecht hat auch mit Blick auf die Zeit des Nationalsozialismus einen hohen Rang, da in dieser Zeit die Staatsangehörigkeit als Institution entwertet wurde und Deutsche jüdischen Glaubens am neuen „,völkischen Status“ nicht teil hatten. ${ }^{209}$ Strafbare Handlungen Deutscher im Ausland waren bisher, also vor der Entscheidung für einen Europäischen Haftbefehl, über die Strafgewalt der Bundesrepublik nach den $\S \S 5$ ff. StGB zu verfolgen.

$\mathrm{Zu}$ berücksichtigen sind aber allgemeine überstaatliche und völkerrechtliche neuere Entwicklungen, die darauf abzielen, die Auslieferung eigener Staatsangehöriger zu ermöglichen. ${ }^{210}$ Das Verfassungsgericht nennt als Beispiele die Errichtung der internationalen Strafgerichtshöfe für das

\footnotetext{
${ }^{204}$ BGB1. 2004, S. 1748 .

${ }^{205}$ BVerfGE 113, 273, siehe hierzu auch differenzierend: Böhm, NJW 2005, 2588; sehr kritisch: Hufeld, JuS 2005, 865 sowie die grundsätzlich zustimmende Anmerkung von Bosbach, NStZ 2006, 104.

${ }^{206}$ BVerfGE 113, 273 (275 ff.).

${ }^{207}$ Diese grundgesetzliche Norm als Ausgangspunkt der Prüfung ablehnend: Hufeld, JuS 2005, 865 (867).

${ }^{208}$ B VerfGE 113, 273 (292 ff.).

${ }^{209}$ BVerfGE 113, 273 (294 f.)

${ }^{210}$ BVerfGE 113, 273 (295 ff.)
} 
ehemalige Jugoslawien und Ruanda in Den Haag/Niederlande und Arusha/Tansania sowie den ständigen Internationalen Strafgerichtshof in Den Haag. Deutschland unterstützt diesen Prozess der Herausbildung einer internationalen Strafjustiz für Verbrechen gegen die Menschlichkeit, der mit den Kriegsverbrechertribunalen von Nürnberg und Tokio nach dem Zweiten Weltkrieg begann.

Als Mitglied der Europäischen Union ist Deutschland darüber hinaus dazu verpflichtet, den Aufund Ausbau eines Raums der Freiheit, der Sicherheit und des Rechts voranzutreiben. Art. 31 Abs. 1 b EUV ${ }^{211}$ sieht hierzu vor, im Rahmen der justiziellen Zusammenarbeit in Strafsachen die Auslieferung zwischen den Mitgliedstaaten zu erleichtern.

Nach einer Grundgesetzänderung im Jahr $2000^{212}$ gibt es eine Möglichkeit, Eingriffe in das Grundrecht aus Art. 16 GG, also die Auslieferung Deutscher an das Ausland, zu rechtfertigen. Art. 16 Abs. 2 S. 2 GG nennt eine qualifizierte Schranke, nach der die Auslieferung Deutscher an einen Mitgliedstaat der Europäischen Union oder einen internationalen Gerichtshof erlaubt ist, soweit rechtsstaatliche Grundsätze gewahrt sind. ${ }^{213}$ Bei dieser Bezugnahme handelt es sich um eine Erwartung im Sinne einer Strukturentsprechung. Der die Auslieferung erlaubende deutsche Gesetzgeber muss insoweit prüfen, ob diese rechtsstaatlichen Voraussetzungen von den ersuchenden Stellen erfüllt werden. Grundsätzlich wird hiervon mit Blick auf Art. 6 Abs. 1 EUV $^{214}$ auszugehen sein. Gleichwohl muss der Gesetzgeber bei nachhaltiger Erschütterung des Vertrauens in die Rechtsstaatlichkeit der allgemeinen Verfahrensbedingungen in einem Mitgliedstaat reagieren. ${ }^{215}$

Als weitere Schranken-Schranke nennt das Gericht die grundsätzliche Pflicht des Gesetzgebers, den Eingriff unter Beachtung des Verhältnismäßigkeitsgrundsatzes schonend auszugestalten. Hierzu führt es aus, dass das Vertrauen des Verfolgten in die eigene Rechtsordnung von Art. 16 Abs. 2 GG in Verbindung mit dem Rechtsstaatsprinzip dann in besonderer Weise geschützt ist, wenn die dem Auslieferungsersuchen zu Grunde liegende Handlung ganz oder teilweise auf deutschem Staatsgebiet, auf deutschen Schiffen und Luftfahrzeugen oder an Orten unter deutscher Hoheitsgewalt begangen wurde. Solche Taten mit maßgeblichem Inlandsbezug sind bei deutschen Tatverdächtigen prinzipiell im Inland durch deutsche Strafermittlungsbehörden aufzuklären. Ein maßgeblicher Inlandsbezug liegt jedenfalls dann vor, wenn wesentliche Teile des Handlungs- und Erfolgsortes auf deutschem Staatsgebiet liegen. Die Verantwortung des Staates für die Unversehrtheit seiner Rechtsordnung und die grundrechtlichen Ansprüche des Verfolgten

\footnotetext{
${ }^{211}$ In der Fassung des Vertrags von Nizza, AB1. C 80, 1, vom 10. März 2001.

${ }^{212}$ Gesetz vom 29. November 2000, BGB1. 2000, 1633.

${ }^{213}$ BVerfGE 113, 273 (299).

${ }^{214}$ In der Fassung des Vertrags von Nizza, AB1. C 80, 1, vom 10. März 2001.

${ }^{215}$ Kritisch zum grundsätzlichen gegenseitigen Vertrauen: Bosbach, NStZ 2006, 104 (105).
} 
führen in dieser Konstellation zu einem Auslieferungshindernis. Wer als Deutscher im eigenen Rechtsraum eine Tat begeht, muss grundsätzlich nicht mit der Auslieferung an eine andere Staatsgewalt rechnen, ansonsten würde unter Umständen der Wesensgehalt des Grundrechts berührt. Durch die Überstellung in einen anderen Mitgliedstaat der Europäischen Union ist ein Tatverdächtiger grundsätzlich schlechter gestellt. Zum einen kennt er Sprache, Kultur und Prozessrecht nicht in der Tiefe; zum anderen konnte er materielles Strafrecht demokratisch nicht mitgestalten und muss es auch nicht kennen. Eine Auslieferung ist dagegen zulässig bei Taten mit maßgeblichem Auslandsbezug, also wenn die Tathandlung vollständig oder in wesentlichen Teilen im europäischen Ausland begangen wurde und dort auch der Erfolg eingetreten ist. Dies gilt auch dann, wenn die Tat von vornherein eine typische grenzüberschreitende Dimension hat und eine entsprechende Schwere aufweist, z.B. beim internationalen Terrorismus. ${ }^{216}$

Das Gericht kommt zu dem Ergebnis, dass der Gesetzgeber die ihm von Art. 16 Abs. 2 GG in Verbindung mit dem Rechtsstaatsprinzip aufgegebene Abwägung zwischen dem grenzüberschreitenden europäischen Strafverfolgungsinteresse und den aus dem Statusrecht als Deutscher folgenden Schutzanspruch verfehlt hat. Er hat die Möglichkeiten, die der Rahmenbeschluss zur Grundrechtsschonung bietet, nicht ausgenutzt. Art. 4 Nr. 7 RbEuHb erlaubt es den vollstreckenden Justizbehörden der Mitgliedstaaten, die Vollstreckung des Haftbefehls zu verweigern, wenn er sich zum einen auf Straftaten erstreckt, die nach den Rechtsvorschriften des Vollstreckungsmitgliedstaates ganz oder zum Teil in dessen Hoheitsgebiet oder an einem gleichgestellten Ort begangen worden sind oder wenn der Haftbefehl sich zum anderen auf Straftaten erstreckt, die außerhalb des Ausstellungsmitgliedstaates begangen wurden und die Rechtsvorschriften des Vollstreckungsmitgliedstaates die Verfolgung von außerhalb seines Hoheitsgebietes begangenen Straftaten gleicher Art nicht zulassen. Bei Taten mit Inlandsbezug in diesem Sinn muss der Gesetzgeber die tatbestandliche Möglichkeit und die Rechtspflicht schaffen, die Auslieferung Deutscher zu verweigern. ${ }^{217}$

Nicht ausreichend ist es, dass bei bis dahin erfolgter Umsetzung des Rahmenbeschlusses in deutsches Recht die Auslieferung eines Deutschen unter die Bedingung gestellt wird, dass der ersuchende Mitgliedstaat nach Verhängung einer rechtskräftigen Freiheitsstrafe oder sonstigen Sanktion anbieten wird, den Verfolgten auf seinen Wunsch zur Vollstreckung nach Deutschland zurückzuüberstellen. ${ }^{218}$ Dieser Schutzaspekt betrifft nur einen Teil des Strafverfahrens, nämlich den der Vollstreckung aber nicht den der Verfolgung. ${ }^{219}$

\footnotetext{
${ }^{216}$ Dieser Grenzziehung des Gerichts zustimmend: Böhm, NJW 2005, 2588 (2589).

${ }^{217}$ B VerfGE 113, 273 (300, 302 ff.).

${ }^{218}$ Diesen Aspekt hervorhebend: Bosbach, NStZ 2006, 104 (105).

${ }^{219}$ B VerfGE 113, 273 (309).
} 
Das deutsche Umsetzungsgesetz genügte damit nach Auffassung des Gerichts nicht den Anforderungen des qualifizierten Gesetzesvorbehaltes des Art. 16 Abs. 2 S. 2 GG.

Zudem stellt das Gericht einen Verstoß gegen Art. 19 Abs. 4 GG fest. Art. 19 Abs. 4 GG enthält ein Grundrecht auf effektiven und möglichst lückenlosen richterlichen Rechtsschutz gegen Akte der öffentlichen Gewalt, soweit diese in die Rechte des Betroffenen eingreifen. ${ }^{220}$

Der Verstoß ergibt sich daraus, dass die behördliche Bewilligungsentscheidung zur Auslieferung eines Deutschen nach den damaligen Vorschriften des IRG, $\S \S 78$ ff. IRG, nicht anfechtbar war. Zunächst war das Auslieferungsverfahren zweigeteilt in Zulässigkeits- und Bewilligungsverfahren. Das Zulässigkeitsverfahren diente und dient in der hergebrachten Zweiteilung dem präventiven Rechtsschutz des Verfolgten, während das Bewilligungsverfahren die Berücksichtigung außen- und allgemeinpolitischer Aspekte des jeweiligen Falles ermöglichen soll. Durch die Änderung von Art. 16 Abs. 2 GG und das deutsche Umsetzungsgesetz zum Europäischen Haftbefehl haben sich die rechtlichen Rahmenbedingungen für Auslieferungen in Mitgliedstaaten der Europäischen Union grundlegend verändert. Im Grundsatz gilt nunmehr, dass zulässige Ersuchen von Mitgliedstaaten der Europäischen Union auf Auslieferung oder Durchlieferung nur abgelehnt werden können, soweit dies im achten Teil des Gesetzes über die Internationale Rechtshilfe in Strafsachen vorgesehen ist. Das Verfahren wird damit im Sinne des Rahmenbeschlusses zum Europäischen Haftbefehl verrechtlicht. Die Bewilligungsentscheidung der Behörde ist Verwaltungsakt und muss als solcher überprüfbar sein.

Aufgrund der genannten Verstöße stellt das Gericht die Nichtigkeit des deutschen Umsetzungsgesetzes fest, § 95 Abs. 3 S. 2 BVerfGG, und erklärt die Auslieferung eines Deutschen an einen Mitgliedstaat der Europäischen Union solange für unzulässig, bis ein neues Ausführungsgesetz gilt. $^{221222}$

Das neue deutsche Umsetzungsgesetz vom 20. Juli $2006^{223}$ greift die Vorgaben durch das Bundesverfassungsgericht insbesondere im achten Teil des IRG $^{224}$ auf und wirkt sich auf die Ausschreibung zwecks Festnahme im SIS aus.

\footnotetext{
${ }^{220}$ BVerfGE 113, 273 (309 ff.).

${ }^{221}$ BVerfGE 113, 273 (315), kritisch zur Nichtigkeitsfolge: Böhm, NJW 2005, 2588 (2588, 2590).

${ }^{222}$ Drei der acht Richter des Zweiten Senats verfassten eine abweichende Meinung. Das Ansichtenspektrum reicht von der Zustimmung zur Nichtigkeitsfolge bei jedoch deutlich restriktiverem Verständnis der Auslieferungspflicht, vgl. abweichende Meinung des Richters Broß, BVerfGE 113, 273 (319), bis zur Ablehnung der Nichtigkeitsfolge unter Bezugnahme auf die Verpflichtungen der Bundesrepublik Deutschland gegenüber der Europäischen Union, vgl. abweichende Meinungen der Richterin Lübbe-Wolff und des Richters Gerhardt, BVerfGE 113, 273 (327/339).

${ }^{223}$ BGB1. 2006, 1721.
} 


\section{c. Verfahren unter Berücksichtigung der Geltung des Europäischen Haftbefehls aa. Voraussetzungen und Verfahren der Ausschreibung}

Die Anwendung des Europäischen Haftbefehls vereinfacht und beschleunigt damit die Ausschreibung und Auslieferung von gesuchten Personen. Zunächst entfällt für die Staatsanwaltschaften bei der Ausschreibung die Pflicht, die Strafbarkeit nach dem Recht sämtlicher SISTeilnehmerstaaten zu prüfen. Für den Erlass genügt es, wenn feststeht, dass die Handlung nach den Vorschriften des Ausstellungsstaates mit einer Freiheitsstrafe oder einer freiheitsentziehenden Maßregel der Sicherung im Höchstmaß von mindestens zwölf Monaten bedroht ist oder dass im Falle einer Verurteilung zu einer Strafe oder der Anordnung einer Maßregel der Sicherung deren Maß mindestens vier Monate beträgt.

Ist die Straftat im Ausstellungsmitgliedstaat nach dessen Recht zudem mit einer Freiheitsstrafe oder einer freiheitsentziehenden Maßregel der Sicherung im Höchstmaß von mindestens drei Jahren bedroht und handelt es sich um eine Katalogstraftat nach Art. 2 Abs. 2 RbEuHb, kann der Vollstreckungsstaat die Übergabe nicht mit dem Argument verweigern, dass die Handlung nach seinem Recht nicht strafbar sei.

Der Rahmenbeschluss verweist in Art. 9 Abs. 2 auf die Möglichkeit, eine mit Europäischem Haftbefehl gesuchte Person im SIS auszuschreiben. Das Formular zur Ausstellung eines Europäischen Haftbefehls enthält nach Art. 8 RbEuHb zusammengefasst in einem Dokument die Informationen, die bisher zu einem Teil dem SIS und zum anderen Teil dem Begleitpapier zu entnehmen sind. Da das SIS I technisch noch nicht in der Lage ist, den Haftbefehl selbst abzubilden, sind bis zur Fertigstellung des SIS II wie bisher die Ausschreibungsmerkmale des Art. 94 Abs. 3 SDÜ, die um die Informationen im Begleitpapier ergänzt werden, zu nutzen. Diese Ausschreibung in der alten Form steht einem Europäischen Haftbefehl gleich. Sie wird erst ersetzt, wenn bei der Vollstreckungsbehörde das Original in der gebührenden Form eingegangen ist. ${ }^{25}$

Den um Auslieferung ersuchten Staaten bleibt grundsätzlich der Möglichkeit der Kennzeichnung nach Art. 94 Abs. 4 und Art. 95 Abs. 3 SDÜ. So kann die Ausschreibung zur Festnahme z.B. in den Fällen in eine Ausschreibung zur Aufenthaltsermittlung umgewandelt werden, in denen die fragliche Handlung nicht dem Straftatenkatalog des Art. 2 Abs. 2 RbEuHb unterfällt und der ersuchte Staat eine Strafbarkeit nach seinen Vorschriften ausschließt.

Abfrageberechtigt sind alle Polizeidienststellen des Bundes und der Länder, das Zollkriminalamt und die Zollfahndungsdienststellen sowie die Staatsanwaltschaften. ${ }^{226}$ Zudem haben, soweit es ihre Aufgaben erfordern, sowohl das Europäische Polizeiamt, Europol, als auch die Europäische

\footnotetext{
${ }^{224} \mathrm{Vgl}$. $\S 79$ Abs. 2, 80 Abs. 1 und 2 sowie 83 a und 83 b IRG; ablehnend hierzu: Hufeld, JuS 2005, 865 (870). ${ }^{225}$ Art. 9 Abs. 3 RbEuHb.

${ }^{226}$ Art. 101 Abs. 1 S. 1 und 2 sowie S. 3 SDÜ i.V.m. § 11 Abs. 4 S. 2 Nr. 1 BKAG; Würz, Rn. 164.
} 
„Staatsanwaltschaft“, Eurojust, seit 1. Oktober $2006^{227}$ Zugriff auf die Daten nach Art. 95 SDÜ. ${ }^{228}$

\section{bb. Verfahren im Trefferfall}

Nach Art. 31 Abs. 1 Buchstabe a) RbEuHb ersetzt der Rahmenbeschluss zum Europäischen Haftbefehl im Verhältnis zu den Mitgliedstaaten die entsprechenden Vorschriften des EuAlÜbk, vom 13. Dezember 1957. Es entfällt die Grundlage dafür, die Ausschreibung im SIS einem Ersuchen um vorläufige Festnahme nach Art. 16 EuAlÜbk gleichzustellen. Vielmehr legt der Rahmenbeschluss fest, dass die Mitgliedstaaten grundsätzlich jeden Europäischen Haftbefehl nach dem Grundsatz der gegenseitigen Anerkennung vollstrecken. ${ }^{229}$ Entsprechend heisst es im Achten Teil der IRG, der unter der Überschrift „Auslieferungs- und Durchlieferungsverkehr mit Mitgliedstaaten der Europäischen Union“ steht, nunmehr, dass zulässige Ersuchen nur abgelehnt werden dürfen, soweit es im achten Teil IRG vorgesehen ist. Bis zur endgültigen Entscheidung über die Auslieferung durch das OLG nach § 23 IRG entspricht das Verfahren jedoch dem vor der Geltung des Europäischen Haftbefehls. Relevant für die Festnahme und unmittelbar sich anschließenden Rechte für den Betroffenen sind ist $§ 78$ Abs. 1 i.V.m. §§ 19 und 22 IRG.

\section{Fahndung nach Drittausländern, die zur Einreiseverweigerung bzw. Auswei-} sung/Abschiebung bei Antreffen im Schengen-Raum ausgeschrieben sind gemäß Art. 96 SDÜ

In dieser Kategorie werden Drittausländer ${ }^{230}$ erfasst, die aufgrund einer nationalen Entscheidung zur Einreiseverweigerung, Ausweisung oder Abschiebung ausgeschrieben sind. Die Existenz von Art. 96 SDÜ ist eine konsequente Folge der Hauptmerkmale einer Passunion, wie sie die Schengener Zusammenarbeit geschaffen hat. ${ }^{231}$ Die in nach Art. 96 SDÜ gespeicherten Informationen

\footnotetext{
${ }^{227}$ Beschluss 2006/631/JI des Rates vom 24. Juli 2006, AB1. L 256, 18 unter Bezugnahme auf den Beschluss 2005/211/JI des Rates vom 24. Februar 2005, AB1. L 68, 44.

${ }^{228}$ Art. 101 a und 101 b SDÜ.

${ }^{229}$ Art. 1 Abs. 2 RbEuHb.

${ }^{230}$ Nach der Definition des Art. 1 SDÜ ist Drittausländer „eine Person, die nicht Staatsangehöriger eines der Mitgliedstaaten der Europäischen Gemeinschaften ist“; diese Defintion erscheint in doppelter Hinsicht nicht mehr zeitgemäß: Da es die eine Europäische Gemeinschaft bzw. Gemeinschaften nicht mehr gibt, vgl. Art. 1 Abs. 2 S. 1 AEUV, kann nur die Mitgliedschaft in der Europäischen Union gemeint sein; zudem dürfen dem Sinn und Zweck der Assoziierungsabkommen mit Norwegen, Island und der Schweiz entsprechend auch deren Staatsangehörige nicht nach Art. 96 SDÜ ausgeschrieben werden, obwohl ihre Staaten nicht zur EU gehören, vgl. in diesem Sinne auch den 36. Tätigkeitsbericht des Hessischen Datenschutzbeauftragten, S. 38.

${ }^{231}$ Vgl. 2. Teil A.
} 
dienen dazu, von vorneherein nur rechtmäßig sich aufhaltenden Drittausländern die Einreise zu ermöglichen, Art. 13 i.v.m. Art. 5 Abs. 1 a) - e) „Schengener Grenzkodex“. 232

In Bezug auf die Personenfahndung handelt es sich zahlenmäßig um die größte Kategorie. So umfasste der gesamte Personenfahndungsbestand des SIS am 1. Januar 2000 eine Zahl von 855765 Ausschreibungen, von denen 764747 auf die Ausschreibungen nach Art. 96 SDÜ entfielen. Dieses Verhältnis besteht konstant. Am 1. Januar 2007 waren es insgesamt 894776 Personenfahndungen, darunter 752338 Art. 96-Ausschreibungen. ${ }^{233}$

\section{a. Voraussetzungen und Verfahren der Ausschreibung}

In Art. 96 Abs. 3 SDÜ wird als Grundlage für die Ausschreibung zur Einreiseverweigerung auf eine Ausweisung, Zurückweisung oder Abschiebung des Ausländers Bezug genommen, wobei die fragliche Maßnahme nicht aufgeschoben oder aufgehoben worden sein darf, ein Verbot der Einreise oder des Aufenthalts enthalten oder davon begleitet sein muss und auf der Nichtbeachtung des nationalen Rechts über die Einreise oder den Aufenthalt von Ausländern beruhen muss. $^{234}$

Eine Ausschreibung nach Art. 96 Abs. 2 SDÜ kommt nur in Betracht, wenn die Ausweisung geplant war, aber wegen fehlender Bekanntgabe unterblieben ist, z.B. weil der Ausländer ausgereist oder untergetaucht ist. ${ }^{235}$ Art. 96 Abs. 2 SDÜ setzt voraus, dass die Anwesenheit eines Drittausländers im Hoheitsgebiet der jeweiligen Vertragspartei eine Gefahr für die öffentliche Sicherheit und Ordnung oder die nationale Sicherheit bedeuten würde. Beispielhaft werden hier aufgeführt, dass die betreffende Person wegen einer Straftat verurteilt wurde, die mit Freiheitsstrafe von mindestens einem Jahr bedroht ist oder dass ein begründeter Verdacht besteht, dass der Drittausländer schwere Straftaten, ggf. auch im Zusammenhang mit unerlaubtem Handel mit Betäubungsmitteln, begangen hat oder konkrete Hinweise dafür vorliegen, dass er eine solche im Hoheitsgebiet einer Vertragspartei plant.

Veranlasst werden die Ausschreibungen gem. Art. 96 Abs. 1 SDÜ durch die zuständigen Verwaltungsbehörden, also die Ausländerbehörden, sowie die befassten Gerichte, demnach die

\footnotetext{
${ }^{232}$ VO (EG) Nr. 562/2006 über einen Gemeinschaftskodex für das Überschreiten der Grenzen durch Personen, AB1. L 105, 1, vom 13. April 2006.

233 Bundesministerium der Innern, Schengen-Erfahrungsbericht 2000, S. 43 f. und Schengen-Erfahrungsbericht 2005-2007, S. 35 f.; zu den Gründen vgl. den nachfolgenden Abschnitt in diesem Teil, B. III. 2. a.

234 Tauchen Drittausländer nach zeitlichem Ablauf ihres Aufenthaltstitels unter oder wird ihnen gegenüber in einer ausländerrechtlichen Verfügung lediglich die Pflicht ausgesprochen, Deutschland zu verlassen, können sie nicht nach Art. 96 Abs. 3 SDÜ ausgeschrieben werden, da es an einer förmlichen Ausweisungs- oder Abschiebungsverfügung fehlt. Zwar ist eine Ausschreibung im nationalen INPOL möglich, aber über Art. 104 Abs. 1 SDÜ gelten die engeren Regeln des SDÜ für die Ausschreibung im SIS; vgl. hierzu und zu den Ergebnissen einer entsprechenden Überprüfung: Schriever-Steinberg, in: Breitenmoser u.a., Schengen in der Praxis, S. 159 (163).

${ }^{235}$ Würz, Rn. 180 f.
} 
Verwaltungs- und Strafgerichte. ${ }^{236}$ Die Eingabe erfolgt über die zuständige Polizeidienststelle in das deutsche Fahndungssystem INPOL. Diese INPOL-Fahndungen werden in das deutsche N.SIS übernommen, dort automatisch auf Plausibilität geprüft und bei korrekter Eingabe nach Umwandlung von N.SIS in C.SIS-Format beim BKA an das C.SIS zur Weiterleitung an die übrigen N.SIS übermittelt. ${ }^{237}$

Begleitpapiere sind bei dieser Fahndungskategorie nicht vorhanden, und es gibt keine Möglichkeit der Kennzeichnung. Grundsätzlich besteht nach Art. 23 Abs. 1 SDÜ eine Bindungswirkung. Gleichwohl war Art. 96 SDÜ in Deutschland zunächst nicht voll umgesetzt. Längere Zeit gab es keine ausländerrechtliche Grundlage, auf der ein von einem anderen Schengen-Staat ausgeschriebener und in Deutschland angetroffener Ausländer in sein Herkunftsland abgeschoben werden konnte, wenn er nicht auch gegen deutsches Ausländerrecht verstoßen hatte. ${ }^{238}$ Nunmehr kann $\S 58$ Abs. 2 Nr. 3 des deutschen Aufenthaltsgesetz herangezogen werden.

Abfrageberechtigt hinsichtlich der Daten von Art. 96 SDÜ sind neben den Polizeidienststellen des Bundes und der Länder sowie den Ausländerbehörden auch die deutschen Auslandsvertretungen und das Bundesverwaltungsamt. ${ }^{239}$ Die Ausländerbehörden haben die Aufgabe, Aufenthaltstitel zu erteilen. Deutsche Auslandsvertretungen und das Bundesverwaltungsamt müssen die Voraussetzungen für die Vergabe von Visa für den Aufenthalt im Schengenraum prüfen. Diese sogenannten Schengen-Visa werden anstelle der früheren nationalen Visa erteilt und gelten für alle Schengen-Staaten. ${ }^{240}$ Die Tatsache, dass andere Behörden als Polizeibehörden Zugriff auf Daten des SIS haben und die zahlenmäßig große Bedeutung von Art. 96 SDÜ bei der Personenfahndung machen deutlich, dass das SIS in nicht unerheblichem Umfang auch einem anderen Zweck als der polizeilichen Fahndung dient. Kritiker sind deshalb der Auffassung, dass das SIS in erster Linie dazu bestimmt ist, eine „Festung Europa“ aufzubauen und damit unliebsame Drittausländer effektiv fernzuhalten. ${ }^{241}$ Wie bereits hinsichtlich der Diskussion zur Bedeutung von Grenzkontrollen ${ }^{242}$ trennen sich die Argumentationslinien bei der Bewertung der sogenannten grenzgemachten Kriminalität. Diese meint solche Delikte, die nur begangen werden können, weil Grenzen bestehen, z.B. Verstöße gegen das Ausländer- und Passgesetz und praktisch alle

\footnotetext{
${ }^{236}$ Würz, Rn. 183.

${ }^{237}$ Würz, Rn. 162, 184; Gusy/Gimbal, in: Baldus/Soiné, Internationale polizeiliche Zusammenarbeit, S. 124 (129 f.); Wilkesmann, NStZ 1999, 68 (68); Hemesath, KR 1995, 169 (169 f.).

${ }^{238} \mathrm{Vgl}$. Schuster, in: Bundeskriminalamt, Arbeitstagung „Kriminalitätsbekämpfung im zusammenwachsenden Europa“, S. 117 (127); Gusy/Gimbal, in: Baldus/Soiné, Internationale polizeiliche Zusammenarbeit, S. 124 (133).

${ }^{239}$ Art. 101 Abs. 1 S. 1, 2 SDÜ; Art. 101 Abs. 2 SDÜ i.V.m. Art. 6 Nr. 2 SchÜbkDÜbkG, BGB1 II 1993, 1010 (1010) i.V.m. Art. 25 Abs. 1 S. 1 SDÜ; Würz, Rn. 164.

${ }^{240}$ Tuffner, in: Bundeskriminalamt, Festschrift für Herold, S. 239 (247).

${ }^{241}$ Mathiesen, in: Schulzki-Haddouti, Globalisierung der Überwachung, S. 21 (26).

${ }^{242} 2$. Teil, A. der Arbeit
} 
aufgegriffenen Fälle von Urkundenstrafrecht, also Passfälschungen. ${ }^{243}$ Während die einen dieser Art von Kriminalität keine besondere Bedeutung zumessen, sehen die anderen in jeder illegal einreisenden Person ein potentielles Sicherheitsrisiko für die Schengen-Staaten. ${ }^{244}$ Folgt man der zuerst genannten Argumentationslinie, dient das SIS zu einem bedeutenden Teil der Abschottung des Schengen-Landes gegenüber Personen, die man aus (volks-)wirtschaftlichen, gesellschaftlichen oder politischen Gründen schlicht nicht einreisen lassen möchte. Folgt man der anderen Linie, bedeutet Art. 96 SDÜ einen Sicherheitsgewinn und verhindert in bedeutsamem Ausmaß die Begehung von Straftaten.

Bei genauerer Betrachtung setzt die Kritik am SIS an der falschen Stelle an. Die Fahndungskategorie des Art. 96 SDÜ dient lediglich der konsequenten Umsetzung eines Charakteristikums einer Pass-Union. Die Verstärkung der Kontrolle an den Außengrenzen muss danach auch einen Informationsaustausch über Drittausländer umfassen, die sich nicht im Schengen-Gebiet aufhalten sollen. Richtiger Ansatzpunkt der Kritik wäre vielmehr das Ausländer- und Asylrecht, das sich mit den Gründen für die Ablehnung eines Aufenthaltsrechts befasst und hierfür Verfahren festlegt.

\section{b. Verfahren im Trefferfall}

Im Trefferfall ist danach zu differenzieren, wo sich die ausgeschriebene Person aufhält. Befindet sie sich im „Drittausland“ und stellt von dort aus einen Antrag auf Erteilung eines Visums, wird ihr Antrag abgelehnt. ${ }^{245}$

Möchte sie an einer Schengen-Außengrenze einreisen, ist ihr die Einreise grundsätzlich zu verweigern. ${ }^{246}$

Befindet sie sich bereits im Schengen-Gebiet, ist zunächst die Identität und der ausländerrechtliche Status der Person festzustellen. Dabei wird sich ergeben, dass der Aufenthalt entweder legal oder illegal ist oder dass der Ausländer um Asyl nachsucht. ${ }^{247}$

Im ersten Fall des legalen Aufenthaltes trotz SIS-Ausschreibung, denkbar ist z.B. ein Sichtvermerk im Reisepass, muss die betroffene Person an die örtlich zuständige Ausländerbehörde verwiesen werden. Diese hat dann die Möglichkeit, den Sachverhalt weiter aufzuklären und die Ausschreibung ggf. zu löschen.

\footnotetext{
${ }^{243}$ Kühne, Kriminalitätsbekämpfung durch innereuropäische Grenzkontrollen, S. 43 ff.

${ }^{244}$ Tuffner, in: Bundeskriminalamt, Festschrift für Herold, S. 239 (247).

${ }^{245}$ Tuffner, in: Bundeskriminalamt, Festschrift für Herold, S. 239 (247).

${ }^{246}$ Art. 13 Abs. 1 S. 1 VO (EG) Nr. 562/2006 über einen Gemeinschaftskodex für das Überschreiten der Grenzen durch Personen, AB1. L 105, 1, vom 13. April 2006; unberührt von diesem Grundsatz bleibt die Anwendung besonderer Bestimmungen zum Asylrecht und zum internationalen Schutz oder zur Ausstellung von Visa für längerfristige Aufenthalte, Art. 13 Abs. 1 S. 2 dieser VO.

${ }^{247}$ Würz, Rn. 213 f.; Piosek, S. 74 f.
} 
Im zweiten Fall des illegalen Aufenthaltes besteht der Verdacht eines Vergehens nach § 95 Abs. 1 Nr. 2 Aufenthaltsgesetz, so dass strafprozessuale Maßnahmen nach $\S 163$ b, 127 Abs. 2 StPO $\mathrm{zu}$ ergreifen sind. Soweit die Identität bereits festgestellt wurde, ist die betroffene Person also festzuhalten und sofort Kontakt mit der zuständigen Ausländerbehörde aufzunehmen. Diese wird dann über Maßnahmen wie Ausweisung und Abschiebung entscheiden. Zudem muss die Polizeidienststelle der Sirene den Trefferfall melden. Die Sirene Deutschland informiert ggf. die Sirene des ausschreibenden Staates und kann dann Erkenntnisse der Ausländerbehörde übermitteln, die die betreffende Person ausgeschrieben hat.

Im dritten Fall, in dem der angetroffene Ausländer um Asyl nachsucht, sind naturgemäß vor allem asylrechtliche Bestimmungen einschlägig. Erforderlich ist im Wesentlichen die Durchsuchung der Person und der mitgeführten Sachen, ${ }^{248}$ die Inverwahrungnahme der Unterlagen ${ }^{249}$ sowie die erkennungsdienstliche Behandlung. ${ }^{250}$ Weiterhin ist dem Ausländer eine Bescheinigung über die Meldung als Asylsuchender auszustellen und er ist an die zuständige zentrale Aufnahmestelle weiterzuverweisen. ${ }^{251}$

\section{Fahndung nach Vermissten zur Aufenthaltsermittlung und/oder Ingewahrsamnahme zur Gefahrenabwehr gemäß Art. 97 SDÜ}

\section{a. Voraussetzungen und Verfahren der Ausschreibung}

Die Ausschreibung nach Art. 97 SDÜ dient der Gefahrenabwehr. Gemeint ist hier zum einen der Fall, dass für die ausgeschriebene Person selbst eine Gefahr droht, z.B. bei Hinweisen auf eine Suizidabsicht. Zum anderen fallen hierunter Personen, von denen eine Gefahr ausgeht, beispielsweise Patienten einer geschlossenen Anstalt oder Überträger ansteckender Krankheiten. ${ }^{252}$ Schließlich nennt Art. 97 SDÜ ganz allgemein Vermisste. Handelt es sich um Minderjährige, genügt die Tatsache des Vermisstwerdens für die Annahme einer Gefahr aus, da die Eltern nicht in der Lage sind, das ihnen zustehende Aufenthaltsbestimmungsrecht nach $\S 1626$ Abs. 1, 1631 Abs. 1 BGB auszuüben. Handelt es sich um volljährige Personen, müssen zusätzliche Fakten vorliegen, die eine Gefahr begründen. ${ }^{253}$

Zuständig für die Veranlassung der Ausschreibung ist die Behörde oder ggf. das Gericht, die bzw. das auch für den der Ausschreibung zugrunde liegenden Sachverhalt zuständig ist. Gemeint

\footnotetext{
${ }^{248} \S 15$ Abs. 4 AsylVfG, unter den dort genannten Voraussetzungen.

${ }^{249} \S 21$ Abs. 1 AsylVfG.

$250 \S 19$ Abs. 2 i.V.m. § 16 Abs. 1 AsylVfG.

${ }^{251}$ Vgl. Würz, Rn. 216; Piosek, S. 75.

${ }^{252}$ Piosek, S. 76; Würz, Rn. 218.

${ }^{253}$ Mokros, in: Lisken/Denninger, HandbPolR, O, Rn. 197 f.
} 
sind Polizeivollzugsdienst, Polizeibehörden, also z.B. Jugendamt oder Gesundheitsamt, sowie befasste Gerichte. ${ }^{254}$

Die Eingabe der Daten erfolgt über die zuständige Polizeidienststelle in das deutsche Fahndungssystem INPOL. Diese INPOL-Fahndungen werden in das deutsche N.SIS übernommen, dort automatisch auf Plausibilität geprüft und bei korrekter Eingabe nach Umwandlung von N.SIS in C.SIS-Format beim BKA an das C.SIS zur Weiterleitung an die übrigen N.SIS übermittelt. $^{255}$

Begleitpapiere gibt es hier nicht. Jedoch besteht nach Art. 94 Abs. 4 SDÜ die Möglichkeit der nachträglichen Kennzeichnung im jeweiligen nationalen Bestand. Gemeint ist damit, dass die Ausschreibung zunächst automatisch in den N.SIS aller Vertragsstaaten erscheint und nicht vorab auf ihren Inhalt geprüft wird. Erforderlich für die Kennzeichnung ist, dass der betreffende Mitgliedstaat die Ausschreibung nach Art. 97 SDÜ für nicht vereinbar hält mit seinem nationalen Recht, mit internationalen Verpflichtungen oder wesentlichen nationalen Interessen. Entscheidet sich der ersuchte Staat für eine Kennzeichnung, darf die Maßnahme in seinem Hoheitsgebiet nicht aufgrund der Ausschreibung vollzogen werden. Mit den anderen Vertragsparteien sind hierüber Konsultationen zu führen. Will der ausschreibende Staat die Ausschreibung dennoch bestehen lassen, haben alle anderen Staaten weiterhin die Pflicht, diese zu vollziehen.

Abfrageberechtigt sind alle Polizeidienststellen des Bundes und der Länder. ${ }^{256}$

\section{b. Verfahren im Trefferfall}

Im Hinblick auf die unterschiedlichen Konstellationen, die Art. 97 SDÜ unterfallen, sind die zu ergreifenden Maßnahmen nach eigener Lagebeurteilung unter Berücksichtigung der Grundsätze der Erforderlichkeit und der Verhältnismäßigkeit zu ergreifen. Grundsätzlich sind jedoch zuerst die Identität, § 13 Nds. SOG, und der Aufenthaltsort festzustellen. ${ }^{257}$ Das Festhalten, das erforderlich ist, um den aktuellen Aufenthaltsort zu ermitteln, soll seine Rechtsgrundlage unmittelbar in Art. 97 SDÜ haben. Ist es darüber hinaus erforderlich, die ausgeschriebene Person an der Weiterreise zu hindern, müssen die Voraussetzungen für eine Ingewahrsamnahme nach $\S 18$ Nds. SOG bzw. nach Unterbringungsrecht vorliegen. ${ }^{258}$

Die Übermittlung des Aufenthaltes eines volljährigen Vermissten bedarf nach Art. 97 S. 3 SDÜ seiner Einwilligung.

\footnotetext{
${ }^{254}$ Würz, Rn. 188, 218.

${ }^{255}$ Würz, Rn. 162, 189; Gusy/Gimbal, in: Baldus/Soiné, Internationale polizeiliche Zusammenarbeit, S. 124 (129 f.); Wilkesmann, NStZ 1999, 68 (68); Hemesath, KR 1995, 169 (169 f.).

${ }^{256}$ Art. 101 Abs. 1 S. 1, 2 SDÜ; Würz, Rn. 164.

${ }^{257}$ Vgl. Würz, Rn. 218.

${ }^{258}$ Vgl. Mokros, in: Lisken/Denninger, HandbPolR, Teil O, Rn. 199.
} 
Dazu, wie eine angetroffene Person in den ausschreibenden Staat zurückgebracht werden soll, macht das SDÜ keine Aussagen. Zur Klärung der Rückführungsmodalitäten muss deshalb die Sirene eingeschaltet werden, die auch häufig Informationen zu den Kostenträgern einer Rückführung hat. ${ }^{259}$

\section{Fahndung zur Aufenthaltsermittlung gemäß Art. 98 SDÜ}

\section{a. Voraussetzungen und Verfahren der Ausschreibung}

Nach Art. 98 SDÜ werden vier Fallgruppen unterschieden: Zeugen, sonstige Personen, die im Rahmen eines gegen sie gerichteten Strafverfahrens vor Gericht erscheinen müssen, Personen, denen ein Strafurteil zugestellt werden soll sowie Personen, denen die Ladung zum Antritt einer Freiheitsentziehung zugestellt werden muss.

Die Ausschreibung wird durch die jeweilige Justizbehörde, also die Staatsanwaltschaft oder das Gericht, veranlasst. ${ }^{260}$ Die Eingabe der Daten erfolgt über die zuständige Polizeidienststelle in das deutsche Fahndungssystem INPOL. Diese INPOL-Fahndungen werden in das deutsche N.SIS übernommen, dort automatisch auf Plausibilität geprüft und bei korrekter Eingabe nach Umwandlung von N.SIS in C.SIS-Format beim BKA an das C.SIS zur Weiterleitung an die übrigen N.SIS übermittelt. ${ }^{261}$

Die Berechtigung zur Abfrage haben die Polizeidienststellen des Bundes und der Länder, das Zollkriminalamt, die Zollfahndungsdienstellen, die Staatsanwaltschaften ${ }^{262}$ sowie Eurojust. $^{263}$

\section{b. Verfahren im Trefferfall}

Grundlage für die Feststellung der Identität und des Aufenthaltsortes sind die Regeln nach polizeirechtlichen Vorschriften und der StPO, also insbesondere $\S \S 12,13$ Nds. SOG sowie $\S 163$ b StPO. Ein Treffer ist der Sirene mitzuteilen, die dann Kontakt mit der ausländischen Sirene des ausschreibenden Staates aufnimmt. ${ }^{264}$ Die Übermittlung der Daten an den ersuchenden Staat richtet sich gemäß Art. 98 Abs. 2 SDÜ nach dem nationalen Recht und den Übereinkommen über Rechtshilfe in Strafsachen.

\footnotetext{
${ }^{259}$ Mokros, in: Lisken/Denninger, HandbPolR, Teil O, Rn. 199; Würz, Rn. 218.

${ }^{260}$ Würz, Rn. 193.

${ }^{261}$ Würz, Rn. 162, 194; Gusy/Gimbal, in: Baldus/Soiné, Internationale polizeiliche Zusammenarbeit, S. 124 (129 f.); Wilkesmann, NStZ 1999, 68 (68); Hemesath, KR 1995, 169 (169 f.).

${ }^{262}$ Art. 101 Abs. 1 S. 1 und 2 sowie S. 3 SDÜ i.V.m. § 11 Abs. 4 S. 2 Nr. 1 BKAG; Würz, Rn. 164.

${ }^{263}$ Art. 101 b SDÜ.

${ }^{264} \mathrm{Vgl}$. Würz, Rn. 219.
} 


\section{Fahndung zur verdeckten Registrierung und gezielten Kontrolle nach Personen und Sa- chen gemäß Art. 99 SDÜ}

\section{a. Voraussetzungen und Verfahren der Ausschreibung}

Art. 99 SDÜ sieht zwei Ausschreibungsalternativen vor, nämlich einmal die Ausschreibung zur verdeckten Registrierung, Art. 99 Abs. 2 bis 4 SDÜ, und zum anderen die Ausschreibung zur gezielten Kontrolle, Art. 99 Abs. 5 SDÜ. In beiden Fällen sollen zur betroffenen Person oder zum betroffenen Fahrzeug Daten erhoben werden, jedoch bei der verdeckten Registrierung heimlich und bei der gezielten Kontrolle mit Hilfe einer Durchsuchung. Im deutschen Recht finden sich in manchen Landespolizeigesetzen Ermächtigungsgrundlagen für eine gezielte Kontrolle, ${ }^{265}$ eine entsprechende Vorschrift fehlt jedoch in der StPO und auch im hier in Bezug genommenen Niedersächsischen Polizeigesetz. In allen diesen Fällen greift Art. 99 Abs. 5 S. 2 SDÜ, wonach die Ausschreibung eines anderen Staates zur gezielten Kontrolle automatisch in eine verdeckte Registrierung umgewandelt wird.

Bei der hier somit ausschließlich näher zu untersuchenden verdeckten Registrierung kommt der Verweis auf nationale Vorschriften in besonderem Maße zum Tragen. Nach Art. 99 Abs. 1 bzw. Art. 104 Abs. 1 1. Halbsatz SDÜ werden Daten in Bezug auf Personen oder Fahrzeuge nach Maßgabe des nationalen Rechts in das SIS aufgenommen. Art. 104 Abs. 12 . Halbsatz SDÜ bestimmt jedoch, dass die Regelungen des SDÜ dem nationalen Recht vorgehen, wenn das SDÜ engere Voraussetzungen, für die Ausschreibung enthält, also höhere Anforderungen stellt. ${ }^{266}$ Während Art. 104 Abs. 1 SDÜ Fragen der Voraussetzungen der Ausschreibung betrifft, beschäftigt sich Art. 104 Abs. 3 SDÜ mit der Rechtsfolgenseite, also mit der Durchführung der mit der Ausschreibung erbetenen Maßnahme. Hier geht das SDÜ-Recht dem nationalen Recht der ersuchten Vertragspartei vor, wenn das SDÜ besondere Regelungen trifft. Gleichzeitig werden die Befugnisse aber durch das nationale Recht der ersuchten Vertragspartei begrenzt. Schließlich enthält auch Art. 104 Abs. 2 SDÜ eine Regelung für das Verhältnis zwischen SDÜ-Recht und nationalem Recht. Danach findet das nationale Recht der jeweiligen Vertragspartei auf die in ihrem nationalen Teil des Schengener Informationssystems gespeicherten Daten Anwendung, soweit das SDÜ keine besondere Regelung enthält. Um Voraussetzungen und Rechtsfolgen einer verdeckten Registrierung zu ermitteln, reicht es nicht aus, die Vorschriften des SDÜ heranzuziehen. Vielmehr sind stets die einschlägigen nationalen Normen zu berücksichtigen. Unter An-

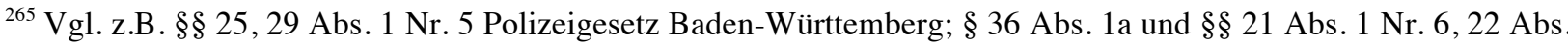
1 Nr. 1 Brandenburgisches Polizeigesetz.

${ }^{266}$ Würz, Rn. 196 ff., 273.
} 
wendung von Art. 104 SDÜ ist dann zu ermitteln, welche Bestimmung, und gemeint sind hier auch die übrigen Verfahrensvorschriften, gilt. $^{267}$

Die verdeckte Registrierung enthält drei Ausschreibungsvarianten, nämlich eine strafprozessuale, eine polizeirechtliche und eine geheimdienstliche. Die Entsprechung der verdeckten Registrierung findet sich im nationalen Recht für die strafprozessuale Variante als ,polizeiliche Beobachtung“ in $\S 163$ e StPO sowie im jeweiligen Landespolizeirecht; für Niedersachsen als „Kontrollmeldung“ in $§ 37$ Nds. SOG. Die geheimdienstlichen Vorschriften erwähnen die verdeckte Registrierung als eine „Mitteilung über das Antreffen“ nach $§ 17$ Abs. 3 BVerfSchG.

Bei allen Varianten soll durch den oben genannten Vergleich die jeweils relevante Norm ermittelt werden.

\section{aa. Strafprozessuale Ausschreibungsvariante, Art. 99 SDÜ und $§ 163$ e StPO}

\section{(1) Kernvoraussetzungen des Tatbestandes}

\section{(a) Bestimmung des strafprozessualen Teils in Art. 99 SDÜ}

$\S 163$ e StPO verlangt, dass zureichende tatsächliche Anhaltspunkte dafür vorliegen, dass eine Straftat von erheblicher Bedeutung begangen wurde.

Art. 99 Abs. 2 SDÜ erlaubt die Ausschreibung zur Strafverfolgung und zur Gefahrenabwehr und zwar, wenn nach Art. 99 Abs. 2 a) SDÜ entweder konkrete Anhaltspunkte dafür vorliegen, dass der Betroffene in erheblichem Umfang außergewöhnlich schwere Straftaten plant oder begeht oder nach Art. 99 Abs. 2 b) SDÜ, wenn die Gesamtbeurteilung des Betroffenen, insbesondere aufgrund der bisher von ihm begangenen Straftaten, erwarten lässt, dass er auch künftig außergewöhnlich schwere Straftaten begehen wird. Zunächst gilt es, zum Zwecke des Vergleichs mit $\S$ 163 e StPO klar zu bestimmen, welche der Alternativen die Voraussetzungen für die Strafverfolgung beschreibt. Diese Unterscheidung ist insofern nicht eindeutig als beide Alternativen vom Wortlaut her eher in die Zukunft gerichtet scheinen. Dies gilt eindeutig für Alternative b), aber auch das „Planen von Straftaten“ in Alternative a) berührt eher den Bereich der Gefahrenabwehr als den der Strafverfolgung. Andererseits erwähnt der Absatz 2 „Strafverfolgung“ einerseits und „Gefahrenabwehr“ andererseits und führt dann zwei eindeutig voneinander getrennte Alternativen auf. Dieser Aufbau legt nahe, dass die eine Alternative die Voraussetzungen für den zuerst genannten Zweck und die andere Alternative die Voraussetzungen für den an zweiter Stelle genannten Zweck benennen soll. Danach wären für die strafprozessuale Ausschreibungsvariante die Voraussetzungen des Art. 99 Abs. 2 a) SDÜ relevant, wobei man hinsichtlich des Begriffs

\footnotetext{
${ }^{267}$ Mokros, in: Lisken/Denninger, HandbPolR, O, Rn. 203 f.; einen anderen, im Hinblick auf Art. 99 Abs. 1 und Art. 104 SDÜ nicht überzeugenden Weg wählt Kämper, der die Verfassungsmäßigkeit von Art. 99 SDÜ ohne Bezugnahme auf die nationalen Normen überprüft, vgl. Kämper, Polizeiliche Zusammenarbeit, S. 164 ff.
} 
der „Planung“ die Delikte ausdrücklich einbezogen hätte, bei denen bereits die Planung im Sinnes eines Vorbereitungsstadiums strafbar ist, z.B. $\S 30$ Abs. 2, 80, 83, 98, 149 StGB. Andererseits würde das bedeuten, dass nach Art. 99 Abs. 2 b) SDÜ für die gefahrenabwehrrechtliche Alternative nur die Fälle blieben, in denen der Täter bereits strafrechtlich auffällig geworden ist, da ja davon auszugehen sein muss, dass er ,auch künftig außergewöhnlich schwere Straftaten begehen wird“. Die Ausschreibung eines bisher unauffälligen möglichen Ersttäters, seien die Anhaltspunkte für die Vorbereitung einer Straftat auch noch so konkret, ließe sich danach schwer rechtfertigen. Dafür, dass der Vertragsgesetzgeber die Möglichkeiten für die gefahrenabwehrrechtliche Variante auf diese Weise einschränken wollte, gibt es keine Anhaltspunkte. Vielmehr ist davon auszugehen, dass der Einsatz des Instrumentes ,,verdeckte Registrierung“ im Bereich der Gefahrenabwehr nicht an außerordentlich hohe Voraussetzungen geknüpft werden sollte. ${ }^{268}$

Versteht man den Vertragstext auf diese Weise, müssen nach Art. 99 SDÜ für eine Ausschreibung zum Zweck der Strafverfolgung konkrete Anhaltspunkte dafür vorliegen, dass der Betroffene in erheblichem Umfang außergewöhnlich schwere Straftaten begeht bzw. begangen hat. ${ }^{269}$ Vergleicht man nun die beiden Normbereiche miteinander, finden sich zwei Unterschiede.

\section{(b) Art der Anhaltspunkte}

Einerseits fordert $\S 163$ e StPO zureichende tatsächliche Anhaltspunkte, während Art. 99 SDÜ konkrete Anhaltspunkte verlangt. Nach dem oben zu Art. 104 Abs. 1 2. Halbsatz SDÜ Gesagten würde die Bestimmung mit den höheren Voraussetzungen gelten. Beide Formulierungen betreffen den Grad der Wahrscheinlichkeit, mit der zum Zeitpunkt der Ausschreibung vom Vorliegen einer Straftat ausgegangen werden kann. Im deutschen Recht sind zureichende tatsächliche Anhaltspunkte dann gegeben, wenn es aufgrund konkreter Tatsachen nach der kriminalistischen Erfahrung möglich erscheint, dass eine verfolgbare Straftat vorliegt. ${ }^{270}$ Aufgrund der vergleichbaren Wortbedeutung von „konkret“ und „zureichend tatsächlich“ sowie mangels entgegenstehender Gründe ist davon auszugehen, dass die von Art. 99 SDÜ genannten Anhaltspunkte ebenso zu definieren sind.

\footnotetext{
${ }^{268}$ So offenbar auch Mokros, in: Lisken/Denninger, HandbPolR, O, Rn 200; eher im Sinne der zuerst aufgezeigten Auslegungsmöglichkeit: Würz, Rn. 196.

${ }^{269}$ Worunter dann selbstverständlich ggf. auch die o.g. Delikte fallen würden, bei denen bereits das Vorbereitungsstadium strafbar ist.

${ }^{270}$ Meyer-Goßner, StPO, § 152, Rn. 4.
} 


\section{(c) Qualität und Quantität der Straftaten}

Der andere Unterschied betrifft die Qualität und Quantität der Straftaten. § 163 e StPO fordert eine Straftat von erheblicher Bedeutung, während Art. 99 SDÜ von der Begehung außergewöhnlich schwerer Straftaten in erheblichem Umfang spricht. Bei beiden Tatbestandsmerkmalen handelt es sich um unbestimmte Rechtsbegriffe, die, anders als z.B. in $\$ \S 98$ a I und 110 a I StPO nicht durch einen Straftatenkatalog eingeschränkt werden. Zunächst soll versucht werden, die nach Art. 104 Abs. 1 2. Halbsatz SDÜ relevanten engeren Tatbestandsvoraussetzungen mit Hilfe der gängigen Definitionen zu bestimmen. Danach sind Straftaten von erheblicher Bedeutung mindestens der mittleren Kriminalität zuzuordnen, müssen den Rechtsfrieden empfindlich stören und sind geeignet, das Gefühl der Rechtssicherheit erheblich zu beeinträchtigen. ${ }^{271}$ Demgegenüber müssen außergewöhnlich schwere Straftaten Verbrechen sein, die im Einzelfall geeignet sind, den Rechtsfrieden besonders zu stören. ${ }^{272}$ Nach diesen Definitionen müssen die Straftaten nach Art. 99 SDÜ stets Verbrechen sein, während das für Art. 163 e StPO nicht unbedingt erforderlich ist. Weiterhin kann die Straftat in dem einen Fall den Rechtsfrieden empfindlich stören und im anderen Fall hat sie hierzu eine besondere Eignung. Dieser auf den Rechtsfrieden bezogene Teil der Definitionen führt zu keiner greifbaren Unterscheidbarkeit. Schließlich fehlt in der Definition für die außergewöhnlich schweren Straftaten die Bezugnahme auf das Rechtssicherheitsgefühl, was wiederum dafür sprechen würde, die höheren Anforderungen beim Begriff „Straftat von erheblicher Bedeutung“ zu verorten. Zusammenfassend lässt sich festhalten, dass ein Vergleich der Definitionen an dieser Stelle nicht weiterführt.

Dass mit den unterschiedlichen Formulierungen jedoch auch in der Sache unterschiedliche Sachverhalte gemeint sind, legt ein Blick auf Art. 102 Abs. 3 S. 1 SDÜ nahe, in dem im Gegensatz zu Art. 99 SDÜ von einer „Straftat mit erheblicher Bedeutung“ die Rede ist. Klärung kann letztlich das einfache Wortverständnis bringen. Während man den Begriff der schweren Straftat mit der Straftat von erheblicher Bedeutung noch gleichsetzen könnte, so wird durch die Beifügung des Attributes ,außergewöhnlich“ deutlich, dass damit nicht nur hohe, sondern besonders hohe Anforderungen gestellt werden.

Es ist also davon auszugehen, dass Art. 99 SDÜ mit der Forderung außergewöhnlich schwerer Straftaten die höheren Hürden für eine Ausschreibung formuliert. ${ }^{273}$

Die Straftaten dieser Qualität müssen dazu nach Art. 99 SDÜ noch in erheblichem Umfang begangen werden.

\footnotetext{
${ }^{271}$ Erb, in: Löwe-Rosenberg, StPO, § 163 e, Rn. 13; Meyer-Goßner, StPO, § 163 e, Rn. 5 , § 98 a, Rn. 5. ${ }^{272}$ Würz, Rn. 197.

${ }^{273}$ So im Ergebnis auch Würz, Rn. 197 und Schriever-Steinberg, in: Breitenmoser u.a., Schengen in der Praxis, S. $159(163)$.
} 


\section{(d) Zwischenergebnis}

Kernvoraussetzungen des durch Vergleich ermittelten Tatbestandes sind, dass zureichende tatsächliche Anhaltspunkte dafür vorliegen, dass außergewöhnlich schwere Straftaten in erheblichem Umfang begangen wurden.

\section{(2) Ausschreibbare Personen und Sachen}

Nach $\S 163$ e Abs. 1 S. 2 und 3 StPO dürfen der Beschuldigte oder auch andere Personen ausgeschrieben werden, wenn auf Grund bestimmter Tatsachen anzunehmen ist, dass sie mit dem Täter in Verbindung stehen oder eine solche Verbindung hergestellt wird, dass die Maßnahme zur Erforschung des Sachverhaltes oder zur Ermittlung des Aufenthaltsortes des Täters führen wird und dies auf andere Weise erheblich weniger erfolgversprechend oder wesentlich erschwert wäre.

Nach dem SDÜ ist nur die Ausschreibung des Betroffenen zulässig, Art. 99 Abs. 2 SDÜ. Insofern stellt in diesem Punkt das SDÜ die höheren Hürden auf und gilt nach Art. 104 Abs. 12 . Halbsatz SDÜ. Zudem benennt Art. 94 Abs. 3 SDÜ präzise, welche Angaben zur Identifizierung von Personen in das System eingespeist werden dürfen. Es ist damit normenklarer und i.S.v. Art. 104 Abs. 1 2. Halbsatz SDÜ enger.

$\S 163$ e Abs. 2 StPO erlaubt die Ausschreibung des Kennzeichens eines Kraftfahrzeugs, die Identifizierungsnummer oder äußere Kennzeichnung eines Wasserfahrzeuges, Luftfahrzeuges oder eines Containers, wenn das Fahrzeug auf eine nach Abs. 1 ausgeschriebene Person zugelassen ist oder das Fahrzeug oder der Container von ihr oder einer bisher namentlich nicht bekannten Person genutzt wird, die einer Straftat von erheblicher Bedeutung verdächtig ist.

Art. 99 Abs. 1 und 4 SDÜ spricht schlicht von Fahrzeugen. Darunter sind jedenfalls nicht Container zu fassen. Fraglich ist jedoch, ob damit neben Kraftfahrzeugen auch Wasser- und Luftfahrzeuge gemeint sind. Dafür spricht der Umkehrschluss aus Art. 100 Abs. 3 a) SDÜ, in dem ausdrücklich von Kraftfahrzeugen die Rede ist. Die Vertragsparteien waren sich der Differenzierungsmöglichkeit bewusst. Haben sie davon keinen Gebrauch gemacht, sind unter dem Begriff demnach Fahrzeuge allgemein in einem umfassenden Sinn zu verstehen.

Diese Fahrzeuge müssen zudem einen relevanten Bezug zum möglichen Täter oder zur Tat aufweisen. 
Damit ist diese Bestimmung hinsichtlich der Ausschreibungsobjekte in Art. 99 SDÜ enger gefasst ist, weil Container danach nicht ausgeschrieben werden können. Art. 104 Abs. 1 2. Halbsatz SDÜ ist anzuwenden. Art. 163 e StPO ist dagegen hinsichtlich der Art der Fahrzeuge, der Ausschreibungsmodalitäten und des notwendigen Bezugs des Fahrzeugs zur Tat oder zum Täter präziser gefasst. Im Hinblick auf diesen Teil gilt nach Art. 99 Abs. 1 i.V.m. Art. 104 Abs. 1 1. Halbsatz SDÜ das nationale Recht.

\section{(3) Subsidiaritätsklausel}

Nach $\S 163$ e StPO darf die Anordnung nur dann getroffen werden, wenn die Erforschung des Sachverhaltes oder die Ermittlung des Aufenthaltsortes des Täters auf andere Weise erheblich weniger erfolgversprechend oder wesentlich erschwert wäre.

Art. 99 SDÜ enthält zu dieser Frage keine Regelung, so dass Art. 99 Abs. 1 i.V.m. Art. 104 Abs. 1 1. Halbsatz SDÜ zum Tragen kommt, wonach die Ausschreibung nach Maßgabe des nationalen Rechts zu erfolgen hat.

\section{(4) Anordnungsbefugnis}

$\S 163$ e Abs. 4 StPO enthält Vorschriften über die Anordnungsbefugnis. Die Ausschreibung zur polizeilichen Beobachtung darf grundsätzlich nur durch ein Gericht angeordnet werden.

Da Art. 99 SDÜ hierzu keine Aussage trifft, gilt nach Art. 99 Abs. 1 i.V.m. Art. 104 Abs. 11. Halbsatz SDÜ wiederum das nationale Recht.

\section{(5) Befristung}

Voraussetzung für die erstmalige Ausschreibung bzw. das Beibehalten einer Ausschreibung ist sowohl nach SDÜ- als auch nach StPO-Recht eine Befristung. Nach $§ 163$ e Abs. 4 S. 5 StPO ist die Anordnung auf höchstens ein Jahr zu befristen und kann gegebenenfalls um jeweils maximal drei Monate verlängert werden. Art. 112 Abs. 1 S. 3 SDÜ benennt eine entsprechende Frist, verlangt eine erneute Prüfung jedoch erst spätestens nach einem weiteren Jahr.

Auch hier gilt mit Blick auf Art. 99 Abs. 1 i.V.m. Art. 104 Abs. 1 1. Halbsatz SDÜ das nationale Recht. 


\section{(6) Benachrichtigung des Betroffenen}

$\S 101$ StPO enthält seit dem Jahr $2007^{274}$ eine sehr differenzierte Benachrichtigungsregelung in Fällen von polizeilichen Beobachtungen. Nach $\S 101$ Abs. 1, Abs. 4 S. 1 Nr. 11, Abs. 5 S. 1 StPO sind der Betroffene und Begleitpersonen zu benachrichtigen, sobald dies ohne Gefährdung des Untersuchungszwecks möglich ist. Eine Zurückstellung ist aktenkundig zu machen und bedarf bei längerer Dauer als 12 Monate der gerichtlichen Zustimmung. ${ }^{275}$ In der Benachrichtigung ist der nach $\S 163$ e StPO Beobachtete auf eine gerichtliche Überprüfungsmöglichkeit der Rechtmäßigkeit der Maßnahme sowie der Art und Weise ihres Vollzugs hinzuweisen. Gegen die Entscheidung des Gerichtes ist sofortige Beschwerde statthaft. ${ }^{276}$

Im SDÜ selbst findet sich keine Regelung zu einer Benachrichtigung nach Beendigung der Maßnahme. Art. 109 Abs. 2 S. 2 SDÜ bestimmt lediglich, dass eine Auskunftserteilung immer während der Ausschreibung zu einer verdeckten Registrierung unterbleibt. Während die Vertragsparteien bei Art. 109 SDÜ die Fälle vor Augen hatten, in denen der Betroffene ausdrücklich Auskunft erbittet, unterbleibt eine Information darüber hinaus denklogisch bei einer heimlichen Maßnahme ebenfalls, wenn der Betroffene nicht nachfragt.

Unter Bezugnahme auf die Formulierungen in neueren Polizeigesetzen wurde in das deutsche Zustimmungsgesetz zum SDÜ jedoch Art. 5 aufgenommen. ${ }^{277}$ Er unterscheidet zwischen von deutschen und von ausländischen Stellen veranlassten Ausschreibungen. Das Bundeskriminalamt hat bei Ausschreibungen zur verdeckten Registrierung durch ausländische Stellen den Betroffenen dann zu informieren, wenn zuvor eine Auskunft nach Art. 109 Abs. 2 SDÜ unterblieben ist und nunmehr die der Auskunftserteilung entgegenstehenden Umstände entfallen sind. Es tut dies im Zusammenwirken mit der Stelle, die die Ausschreibung veranlasst hat, spätestens zum vorgesehenen Zeitpunkt der Löschung im nationalen Teil des Schengener Informationssystems.

Für von deutschen Stellen veranlasste Ausschreibungen postuliert Art. 5 SDÜ-Gesetz eine Benachrichtigungspflicht nach Beendigung der Maßnahme, soweit die Benachrichtigung nicht aufgrund anderer besonderer gesetzlicher Bestimmungen vorgesehen ist. Die Stelle, die die Ausschreibung veranlasst hat, unterrichtet das Bundeskriminalamt über die Löschung und darüber, ob der Betroffene benachrichtigt werden kann.

Anders als bei den bisher erläuterten Tatbestandsmerkmalen sind bezüglich der Benachrichtigungspflicht nicht die Regelungen des SDÜ mit den nationalen Regeln zu vergleichen. Vielmehr stehen sich zwei nationale Regelungen gegenüber. Art. 104 SDÜ gilt nicht. Es ist stattdessen zu

\footnotetext{
${ }^{274}$ Vgl. Gesetz zur Neuregelung der Telekommunikationsüberwachung und anderer verdeckter Ermittlungsmaßnahmen sowie zur Umsetzung der Richtlinie 2006/24/EG vom 21. Dezember 2007, BGB1. 2007, 3198.

${ }^{275} \S 101$ Abs. 5 S. 2, Abs. 6 S. 1 StPO.

${ }^{276} \S 101$ Abs. 4 S. 2, Abs. 7 S. 2 und 3 StPO.

${ }^{277}$ BT-Drs. 12/2453, S. 10; der spätere Art. 5 ist hier noch Art. 6 Gesetz zum SDÜ.
} 
klären, ob die Regelung in $\S 101$ StPO hinsichtlich der durch deutsche Stellen veranlassten Ausschreibung als ,andere besondere gesetzliche Bestimmung“ im Sinne von Art. 5 Abs. 1 S. 1 SDÜ-Gesetz angesehen werden kann und insofern vorgeht. Für das Merkmal „Besonderheit“ spricht, dass $\S 101$ StPO sehr detaillierte Regelungen gerade für den Fall heimlicher Ermittlungsmethoden aufstellt. Die Norm versucht, einen gerechten Ausgleich zwischen dem Geheimhaltungsinteresse der Strafverfolgungsbehörden und dem Informationsinteresse des Bürgers zu schaffen. Allerdings gilt $\S 101$ StPO nicht für eine SIS-Ausschreibung, sondern für die Ausschreibung auf nationaler Ebene. Insofern gibt es keine besondere gesetzliche Bestimmung, die Art. 5 Abs. 1 SDÜ-Gesetz vorgeht.

\section{(7) Löschung der Daten}

$\S 101$ Abs. 8 StPO enthält eine Regelung, wonach die personenbezogenen Daten unverzüglich zu löschen sind, sobald sie zur Strafverfolgung und für eine etwaige gerichtliche Überprüfung nicht mehr benötigt werden. Die Löschung ist aktenkundig zu machen.

Nach Art. 112 Abs. 1 S. 1 SDÜ dürfen die Daten ebenfalls nicht länger als für den verfolgten Zweck erforderlich gespeichert werden. Das C.SIS weist die ausschreibende Vertragspartei einen Monat vorher auf den Ablauf der Jahres-Frist hin. Innerhalb dieses Monats kann nach Prüfung der Erforderlichkeit eine Verlängerung eingegeben werden. Geschieht das nicht, werden die Daten automatisch gelöscht. ${ }^{278}$ Gelöschte Daten werden ein weiteres Jahr in der technischen Unterstützungseinheit gespeichert. Der Zweck dieser Regelung ist ausschließlich die Überprüfbarkeit der Richtigkeit der Daten sowie der Rechtmäßigkeit ihrer Speicherung. ${ }^{279}$

Hinsichtlich der Löschungsregeln lässt sich feststellen, dass sich die Bestimmungen inhaltlich im Wesentlichen entsprechen. Unter Anwendung des hier geltenden Art. 104 Abs. 2 SDÜ ist maßgeblich, dass das SDÜ die besonderen technischen Möglichkeiten des SIS und die Vernetzung mit den anderen Vertragsparteien einbezieht. Insofern geht es der nationalen Regelung vor.

\section{(8) Anlass der Datenerhebung}

$\S 163$ e StPO erlaubt eine Datenerhebung zur Beobachtung anlässlich von polizeilichen Kontrollen, die die Feststellung der Personalien zulassen, wie z.B. Grenzkontrollen oder Kontrollen nach $\S \S 111$ oder 163 b StPO. Die Kontrollstellen werden für die polizeiliche Beobachtung also nicht errichtet, sondern bereits bestehende Kontrollstellen werden hierfür genutzt. ${ }^{280}$

\footnotetext{
${ }^{278}$ Art. 112 SDÜ.

${ }^{279}$ Art. 113 Abs. 2 SDÜ.

${ }^{280}$ Meyer-Goßner, StPO, § 163 e, Rn. 4.
} 
Art. 99 Abs. 4 S. 1 SDÜ trifft eine entsprechende Regelung.

Für diesen Bereich ist nunmehr Art. 104 Abs. 3 SDÜ einschlägig, da er die Modalitäten der Durchführung der erbetenen Maßnahme betrifft. Da das SDÜ hier keine besondere Regelung formuliert, gilt Art. 104 Abs. 3 S. 1 SDÜ und das nationale Recht ist anzuwenden.

\section{(9) zu übermittelnde Daten im Trefferfall}

Nach $\S 163$ e Abs. 3 StPO können im Falle eines Antreffens ,auch“ personenbezogene Daten eines Begleiters der ausgeschriebenen Person, des Führers eines ausgeschriebenen Fahrzeugs oder des Nutzers eines ausgeschriebenen Containers gemeldet werden.

Art. 99 Abs. 4 SDÜ bestimmt, dass nachstehende Informationen unter Berücksichtung des verdeckten Charakters ganz oder teilweise eingeholt und der ausschreibenden Stelle übermittelt werden können: Antreffen der ausgeschriebenen Person oder des ausgeschriebenen Fahrzeugs; Ort, Zeit oder Anlass der Überprüfung; Reiseweg und Reiseziel; Begleitpersonen oder Insassen; benutztes Fahrzeug; mitgeführte Sachen sowie Umstände des Antreffens der Person oder des Fahrzeugs.

Art. 99 SDÜ formuliert präziser, auf welche Art und Weise welche Informationen erhoben und an welche Stelle weitergegeben werden dürfen. Er enthält damit eine besondere Regelung i.S.v. Art. 104 Abs. 3 S. 1 SDÜ. Diese besondere Regelung wird nicht durch das offen formulierte ${ }^{281}$ nationale Recht des $§ 163$ e Abs. 3 StPO begrenzt. Es gilt die Regelung des SDÜ.

\section{(10) Ergebnis des Vergleichs: Strafprozessuale Kombinationsnorm}

Zusammenfassend hat der nach Art. 99 Abs. 1 SDÜ und Art. 104 SDÜ durchzuführende Vergleich von $§ 163$ e StPO und Art. 99 SDÜ folgende strafprozessuale Variante ergeben:

\section{Absatz 1}

Die Ausschreibung zur Beobachtung anlässlich von polizeilichen Kontrollen, die die Feststellung des Personalien zulassen, kann angeordnet werden, wenn zureichende tatsächliche Anhaltspunkte dafür vorliegen, dass in erheblichem Umfang außergewöhnlich schwere Straftaten begangen werden bzw. wurden.

\footnotetext{
${ }^{281}$ Formulierung ,auch“.
} 
Absatz 2

Die Anordnung darf sich nur gegen den Beschuldigten richten und nur dann getroffen werden, wenn die Erforschung des Sachverhaltes oder die Ermittlung des Aufenthaltsortes des Täters auf andere Weise erheblich weniger erfolgversprechend oder wesentlich erschwert wäre.

Absatz 3

Möglich ist die Ausschreibung von Personen, wenn konkrete Anhaltspunkte dafür bestehen, dass der Betroffene Straftaten nach Absatz 1 begangen hat. Bei der Ausschreibung von Personen werden höchstens angegeben: Name und Vorname, gegebenenfalls Aliasname in einem neuen Datensatz; besondere unveränderliche und physische Merkmale; erster Buchstabe des zweiten Vornamens; Geburtsort und Datum; Geschlecht; Staatsangehörigkeit; der personenbezogene Hinweis „,bewaffnet“; der personenbezogene Hinweis „gewalttätig“; Ausschreibungsgrund und zu ergreifende Maßnahme. Das Kennzeichen eines Kraftfahrzeuges, die Identifizierungsnummer oder äußere Kennzeichnung eines Wasser- oder Luftfahrzeuges kann ausgeschrieben werden, wenn es auf eine nach Absatz 1 ausgeschriebene Person zugelassen ist oder das Fahrzeug von ihr oder einer bisher namentlich nicht bekannten Person genutzt wird, die einer Straftat im Sinne von Absatz 1 verdächtig ist.

Absatz 4

Die Ausschreibung zur polizeilichen Beobachtung darf nur durch ein Gericht angeordnet werden. Bei Gefahr im Verzug kann die Anordnung auch durch die Staatsanwaltschaft getroffen werden. Hat die Staatsanwaltschaft die Anordnung getroffen, so beantragt sie unverzüglich die gerichtliche Bestätigung der Anordnung. Soweit die Anordnung der Staatsanwaltschaft nicht binnen drei Werktagen von dem Gericht bestätigt wird, tritt sie außer Kraft.

Absatz 5

Die Anordnung ist auf höchstens ein Jahr zu befristen. Eine Verlängerung um jeweils nicht mehr als drei Monate ist zulässig, soweit die Voraussetzungen der Anordnung fortbestehen.

Absatz 6

Bei der Ausschreibung durch eine Stelle der Bundesrepublik Deutschland hat das Bundeskriminalamt im Einvernehmen mit der Stelle, die die Ausschreibung veranlasst hat, den Betroffenen nach Beendigung der Ausschreibung zu benachrichtigen. Die Benachrichtigung unterbleibt, wenn dadurch die Durchführung einer rechtmäßigen Aufgabe im Zusammenhang mit der Ausschreibung gefährdet würde. Die Stelle, die die Ausschreibung veranlasst hat, unterrichtet das Bundeskriminalamt über die Löschung und darüber, ob der Betroffene benachrichtigt werden kann. 


\section{Absatz 7}

Die Daten nach dieser Vorschrift werden nicht länger als für den verfolgten Zweck erforderlich gespeichert. Das C.SIS weist die ausschreibende Vertragspartei einen Monat vorher auf den Ablauf der Frist nach Absatz 5 hin. Innerhalb dieses Monats kann nach Prüfung der Erforderlichkeit eine Verlängerung eingegeben werden. Geschieht das nicht, werden die Daten automatisch gelöscht. Gelöschte Daten werden ein weiteres Jahr in der technischen Unterstützungseinheit gespeichert. Der Zweck dieser Regelung ist ausschließlich die Überprüfbarkeit der Richtigkeit der Daten sowie der Rechtmäßigkeit ihrer Speicherung.

\section{Absatz 8}

Im Falle eines Antreffens können die nachstehenden Informationen ganz oder teilweise eingeholt und der ausschreibenden Stelle übermittelt werden:

a) Antreffen der ausgeschriebenen Person oder des ausgeschriebenen Fahrzeugs,

b) Ort, Zeit oder Anlass der Überprüfung,

c) Reiseweg und Reiseziel,

d) Begleitpersonen oder Insassen,

e) benutztes Fahrzeug,

f) mitgeführte Sachen,

g) Umstände des Antreffens der Person oder des Fahrzeugs.

Bei der Erhebung dieser Daten ist darauf zu achten, dass der verdeckte Charakter der Maßnahme nicht gefährdet wird.

\section{bb. Polizeirechtliche Ausschreibungsvariante}

Auch für die in Art. 99 SDÜ vorgesehene polizeirechtliche Ausschreibungsvariante ist ein Vergleich mit der nationalen Norm, hier des $§ 37$ Nds. SOG, durchzuführen.

\section{(1) Kernvoraussetzungen des Tatbestandes}

Anlass der Ausschreibung muss nach $\S 37$ Abs. 1 Nds. SOG sein, dass Tatsachen die Annahme rechtfertigen, dass eine Person eine Straftat von erheblicher Bedeutung begehen wird.

Art. 99 Abs. 2 SDÜ verlangt, dass entweder konkrete Anhaltspunkte dafür vorliegen, dass der Betroffene in erheblichem Umfang außergewöhnlich schwere Straftaten plant oder dass die Gesamtbeurteilung des Betroffenen, insbesondere aufgrund der bisher von ihm begangenen Straftaten, erwarten lässt, dass er auch künftig außergewöhnlich schwere Straftaten begehen wird. Trotz unterschiedlicher Formulierungen muss es hinsichtlich der Anhaltspunkte für eine Ausschreibung nach beiden Normen einen Bezug zu einem konkreten Sachverhalt geben; eine bloße 
Vermutung oder die allgemeine kriminalistische Erfahrung reichen nicht aus. ${ }^{282}$ Insofern sind die Voraussetzungen inhaltsgleich.

Unter Heranziehung des oben zur strafprozessualen Variante Ausgeführten ${ }^{283}$ stellt Art. 99 Abs. 2 SDÜ die strengeren Anforderungen und gilt insofern.

\section{(2) Ausschreibbare Personen und Sachen}

$\S 37$ Abs. 1 Nds. SOG erlaubt das Ausschreiben der Personalien einer verdächtigen Person sowie des amtlichen Kennzeichens des von ihr benutzten oder eingesetzten Kraftfahrzeuges.

Art. 99 SDÜ erlaubt die Ausschreibung des Betroffenen mit den Angaben nach Art. 94 Abs. 3 S. 1 SDÜ sowie die Ausschreibung von Fahrzeugen.

Nach Art. 99 Abs. 1 i.V.m. Art. 104 Abs. 1 1. Halbsatz SDÜ kommt hier hinsichtlich der Fahrzeuge das nationale Recht zum Tragen, da es konkreter gefasst ist. Bezüglich der Personenausschreibung gilt Art. 104 Abs. 1 2. Halbsatz SDÜ, weil in diesem Punkt das SDÜ normenklarer formuliert.

\section{(3) Subsidiaritätsklausel}

$\S 37$ Abs. 1 Nds. SOG erlaubt die Ausschreibung nur, wenn dies zur Verhütung der Straftat erforderlich ist. Da Art. 99 SDÜ keine Erforderlichkeitsklausel enthält, gilt nach Art. 99 Abs. 1 i.V.m. Art. 104 Abs. 1 1. Halbsatz SDÜ das nationale Recht.

\section{(4) Anordnungsbefugnis}

Nach $\S 37$ Abs. 3 S. 1 und 2 Nds. SOG darf die Behördenleitung die Ausschreibung anordnen.

Die Leitung kann ihre Anordnungsbefugnis auf Dienststellenleiterinnen oder Dienststellenleiter sowie Bedienstete des höheren Dienstes übertragen. Art. 99 SDÜ trifft hierzu keine Regelung, so dass nach Art. 99 Abs. 1 i.V.m. 104 Abs. 1 1. Halbsatz SDÜ wiederum das nationale Recht einschlägig ist.

\section{(5) Befristung und Schriftlichkeit}

Die Anordnung ist schriftlich zu begründen und auf höchstens ein Jahr zu befristen. Sie kann wiederholt werden, $\S 37$ Abs. 3 S. 3 und 4 Nds. SOG.

Nach Art. 112 Abs. 1 S. 3 SDÜ beträgt die maximale Speicherfrist, nach der eine erneute Prüfung notwendig ist, ebenfalls ein Jahr. Da das nationale Recht zusätzlich die Schriftlichkeit für

\footnotetext{
${ }^{282}$ Für $§ 37$ Nds. SOG: Böhrenz/Siefken, Nds. SOG, § 37, 2.

${ }^{283}$ 2. Teil B. III. 5. a. aa. (1) (b), (c).
} 
die Begründung erfordert, gilt auch hier wegen Art. 99 Abs. 1 i.V.m. Art. 104 Abs. 1 1. Halbsatz SDÜ das nationale Recht.

\section{(6) Benachrichtigung}

$\S 30$ Abs. 4 Nds. SOG enthält eine Benachrichtigungsregel. Danach ist die betroffene Person einer Kontrollmeldung zu unterrichten, sobald dies möglich ist, ohne den Untersuchungszweck zu gefährden. Gleichzeitig ist sie auf die Rechtsgrundlage der Datenverarbeitung und ihr Auskunftsrecht hinzuweisen. ${ }^{284}$ Das Gesetz enthält ferner Regelungen zur Rückstellung und ihrer Überprüfung. ${ }^{285}$

Im Hinblick auf Art. 5 Abs. 1 des deutschen Zustimmungsgesetzes zum SDÜ gilt das zur strafprozessualen Variante Ermittelte. Auch $\S 30$ Nds. SOG enthält keine Regelung über eine Ausschreibung im SIS. Insofern ist Art. 5 Abs. 1 deutsches Zustimmungsgesetz heranzuziehen.

\section{(7) Löschung}

Nach $\S 39$ a Nds. SOG sind die Daten zu löschen, sofern sie zur Zweckerreichung nicht mehr erforderlich sind. Er nennt ferner Gründe, aus denen die Löschung unterbleibt und die Daten stattdessen gesperrt werden.

Hinsichtlich der Regelung im SDÜ und dem nach § 104 Abs. 2 SDÜ durchzuführenden Vergleich gilt das zur strafprozessualen Variante Erarbeitete. Maßgeblich sind damit die Bestimmungen des SDÜ.

\section{(8) Anlass der Datenerhebung}

$\S 37$ Abs. 2 Nds. SOG nimmt Bezug auf den Fall eines Antreffens. Dieses wird regelmäßig zufällig erfolgen, etwa bei Grenzübertritten oder an polizeilichen Kontrollstellen. ${ }^{286}$ Insofern ist von einer dem Art. 99 Abs. 4 SDÜ entsprechenden Regelung auszugehen. Nach Art. 104 Abs. 3 S. 1 SDÜ gilt das nationale Recht.

\section{(9) zu übermittelnde Daten im Trefferfall}

Nach $§ 37$ Abs. 2 Nds. SOG darf die Polizei die für die Ausschreibung bedeutsamen Umstände des Antreffens an die ausschreibende und die sachbearbeitende Dienststelle übermitteln.

Art. 99 Abs. 4 SDÜ bestimmt, dass nachstehende Informationen unter Berücksichtigung des verdeckten Charakters ganz oder teilweise eingeholt und der ausschreibenden Stelle übermittelt

\footnotetext{
${ }^{284}$ Vgl. $\$ 30$ Abs. 4 S. 1 bis 3 Nds. SOG.

${ }^{285} \S 30$ Abs. 5 S. 1 , Abs. 6 Nds. SOG.

${ }^{286}$ Waechter, Polizei- und Ordnungsrecht, Rn. 645; Böhrenz/Siefken, Nds. SOG, § 37, 4.
} 
werden können: Antreffen der ausgeschriebenen Person oder des ausgeschriebenen Fahrzeugs; Ort, Zeit oder Anlass der Überprüfung; Reiseweg und Reiseziel; Begleitpersonen oder Insassen; benutztes Fahrzeug; mitgeführte Sachen sowie Umstände des Antreffens der Person oder des Fahrzeugs.

Art. 99 SDÜ formuliert im Vergleich zu $§ 37$ Nds. SOG eine präzisere und damit besondere Regelung hinsichtlich der Art der zu übermittelnden Daten. Auch der Adressat der Datenübermittlung wird präzise benannt. Die Bestimmungen werden durch das nationale Recht inhaltlich nicht begrenzt. Insofern gilt nach Art. 104 Abs. 3 S. 2 SDÜ die Regelung des SDÜ.

\title{
(10) Ergebnis des Vergleichs
}

Abschließend hat der Vergleich zwischen der Norm des SDÜ und der nationalen Norm folgende polizeirechtliche Variante ergeben:

\begin{abstract}
Absatz 1
Die Polizei kann die Personalien einer Person sowie das amtliche Kennzeichen des von ihr benutzten oder eingesetzten Kraftfahrzeuges zum Zweck der Ausschreibung in einer Datei speichern, wenn Tatsachen die Annahme rechtfertigen, dass die Person entweder in erheblichem Umfang außergewöhnlich schwere Straftaten plant oder dass die Gesamtbeurteilung der Person, insbesondere aufgrund der bisher von ihr begangenen Straftaten erwarten lässt, dass sie auch künftig außergewöhnlich schwere Straftaten begehen wird. Bei der Ausschreibung von Personen werden höchstens angegeben: Name und Vorname, gegebenenfalls Aliasname in einem neuen Datensatz; besondere unveränderliche und physische Merkmale; erster Buchstabe des zweiten Vornamens; Geburtsort und Datum; Geschlecht; Staatsangehörigkeit; der personenbezogene Hinweis „,bewaffnet“; der personenbezogene Hinweis „gewalttätig“; Ausschreibungsgrund und zu ergreifende Maßnahme.
\end{abstract}

Absatz 2

Die Ausschreibung muss zur Verhütung einer Straftat erforderlich sein.

Absatz 3

Die Ausschreibung bedarf der Anordnung durch die Behördenleitung. Diese kann ihre Anordnungsbefugnis auf Dienststellenleiterinnen oder Dienststellenleiter sowie Bedienstete des höheren Dienstes übertragen. Die Anordnung ist schriftlich zu begründen und auf höchstens ein Jahr zu befristen. Sie kann wiederholt werden. 
Absatz 4

Bei der Ausschreibung durch eine Stelle der Bundesrepublik Deutschland hat das Bundeskriminalamt im Einvernehmen mit der Stelle, die die Ausschreibung veranlasst hat, den Betroffenen nach Beendigung der Ausschreibung zu benachrichtigen. Die Benachrichtigung unterbleibt, wenn dadurch die Durchführung einer rechtmäßigen Aufgabe im Zusammenhang mit der Ausschreibung gefährdet würde. Die Stelle, die die Ausschreibung veranlasst hat, unterrichtet das Bundeskriminalamt über die Löschung und darüber, ob der Betroffene benachrichtigt werden kann.

\section{Absatz 5}

Die Daten nach dieser Vorschrift werden nicht länger als für den verfolgten Zweck erforderlich gespeichert. Das C.SIS weist die ausschreibende Vertragspartei einen Monat vorher auf den Ablauf der Frist nach Absatz 3 hin. Innerhalb dieses Monats kann nach Prüfung der Erforderlichkeit eine Verlängerung eingegeben werden. Geschieht das nicht, werden die Daten automatisch gelöscht. Gelöschte Daten werden ein weiteres Jahr in der technischen Unterstützungseinheit gespeichert. Der Zweck dieser Regelung ist ausschließlich die Überprüfbarkeit der Richtigkeit der Daten sowie der Rechtmäßigkeit ihrer Speicherung.

Absatz 6

Im Falle eines Antreffens können die nachstehenden Informationen ganz oder teilweise eingeholt und der ausschreibenden Stelle übermittelt werden:

a) Antreffen der ausgeschriebenen Person oder des ausgeschriebenen Fahrzeugs,

b) Ort, Zeit oder Anlass der Überprüfung,

c) Reiseweg und Reiseziel,

d) Begleitpersonen oder Insassen,

e) benutztes Fahrzeug,

f) mitgeführte Sachen,

g) Umstände des Antreffens der Person oder des Fahrzeugs.

Bei der Erhebung dieser Daten ist darauf zu achten, dass der verdeckte Charakter der Maßnahme nicht gefährdet wird.

\section{cc. Geheimdienstliche Ausschreibungsvariante}

Nach Art. 99 Abs. 3 SDÜ gibt es auch eine geheimdienstliche Ausschreibungsvariante, wenn es das nationale Recht erlaubt. Mit Art. 1 Nr. 4 des Terrorismusbekämpfungsergänzungsgesetzes vom 5. Januar 2007 hat der deutsche Gesetzgeber eine entsprechende Rechtsgrundlage geschaf- 
fen, indem er $\S 17$ BVerfschG einen entsprechenden Absatz 3 hinzufügte. ${ }^{287}$ Im Gegensatz zu den bereits erläuterten Varianten ist die geheimdienstliche Entsprechung also in Kenntnis des Art. 99 SDÜ geschaffen worden und sie hat auch nur die schengenweite Ausschreibung zum Gegenstand. Grundsätzlich ist also davon auszugehen, dass sich die Normen inhaltlich nicht widersprechen, sondern sinnvoll ineinander greifen. Die Konstellation, die der Vertragsgesetzgeber bei Art. 104 SDÜ eigentlich vor Augen hatte, ist damit nicht gegeben. Gleichwohl ist kein Grund ersichtlich, warum die von Art. 104 SDÜ vorgenommenen Wertungen ihre Berechtigung in dieser anders gelagerten Variante verlieren sollten. Die Norm bleibt daher anwendbar.

Unter Berücksichtigung dessen ergibt sich folgende geheimdienstliche Ausschreibungsvariante:

\section{Absatz 1}

Das Bundesamt für Verfassungsschutz, der Militärische Abschirmdienst und der Bundesnachrichtendienst können eine Person oder ein Fahrzeug im polizeilichen Informationssystem zur Mitteilung über das Antreffen ausschreiben, wenn tatsächliche Anhaltspunkte dafür vorliegen, dass die nach Absatz 6 bezeichneten Informationen zur Abwehr einer von dem Betroffenen ausgehenden erheblichen Gefährdung oder anderer erheblicher Gefahren für die innere oder äußere Sicherheit des Staates erforderlich sind. Zudem müssen tatsächliche Anhaltspunkte für einen grenzüberschreitenden Verkehr vorliegen. ${ }^{288}$

\section{Absatz 2}

Bei der Ausschreibung von Personen werden höchstens angegeben: Name und Vorname, gegebenenfalls Aliasname in einem neuen Datensatz; besondere unveränderliche und physische Merkmale; erster Buchstabe des zweiten Vornamens; Geburtsort und Datum; Geschlecht; Staatsangehörigkeit; der personenbezogene Hinweis „,bewaffnet“; der personenbezogene Hinweis „gewalttätig“; Ausschreibungsgrund und zu ergreifende Maßnahme.

\section{Absatz 3}

Die Ausschreibung muss für die Erfüllung der Aufgaben der in Absatz 1 genannten Behörden erforderlich sein. ${ }^{289}$

\footnotetext{
${ }^{287}$ BGB1. 2007, 2.

${ }^{288} \S 17$ Abs. 3 S. 1 BVerfSchG i.V.m. Art. 99 Abs. 3 S. 1 SDÜ; unter Anwendung von Art. 99 Abs. 1 i.V.m. Art. 104 Abs. 1 1. Halbsatz SDÜ.

${ }^{289} \S 17$ Abs. 3 S. 1 BVerfSchG; unter Anwendung von Art. 99 Abs. 1 i.V.m. Art. 104 Abs. 1 1. Halbsatz SDÜ.
} 


\begin{abstract}
Absatz 4
Zuständig für die Ausschreibungen ist das vom Bundeskanzler beauftragte Bundesministerium, wobei für Ausschreibungen durch den Militärischen Abschirmdienst das Bundesministerium der Verteidigung und für Ausschreibungen durch den Bundesnachrichtendienst das Bundeskanzleramt zuständig ist. ${ }^{290}$
\end{abstract}

\begin{abstract}
Absatz 5
Ausschreibungen ordnet der Behördenleiter, sein Vertreter oder ein dazu besonders beauftragter Bediensteter, der die Befähigung zum Richteramt hat, an. ${ }^{291}$
\end{abstract}

\begin{abstract}
Absatz 6
Die Ausschreibung ist auf höchstens sechs Monate zu befristen und kann wiederholt angeordnet werden. ${ }^{292}$
\end{abstract}

\begin{abstract}
Absatz 7
Das Bundeskriminalamt hat den Betroffenen nach Beendigung der Maßnahme im Einvernehmen mit der Stelle, die die Ausschreibung veranlasst hat, zu benachrichtigen. Die Benachrichtigung unterbleibt, wenn dadurch die Durchführung einer rechtmäßigen Aufgabe im Zusammenhang mit der Ausschreibung gefährdet würde. Die Stelle, die die Ausschreibung veranlasst hat, unterrichtet das Bundeskriminalamt über die Löschung und darüber, ob der Betroffene benachrichtigt werden kann. ${ }^{293}$
\end{abstract}

\begin{abstract}
Absatz 8
Die Daten werden nicht länger als für den verfolgten Zweck erforderlich gespeichert.

Das C.SIS weist die ausschreibende Vertragspartei einen Monat vorher auf den Ablauf der Frist nach Absatz 6 hin. Innerhalb dieses Monats kann nach Prüfung der Erforderlichkeit eine Verlängerung eingegeben werden. Geschieht das nicht, werden die Daten automatisch gelöscht. Ge-
\end{abstract}

\footnotetext{
${ }^{290} \S 17$ Abs. 3 S. 6 i.V.m. $\S 8$ a Abs. 6 S. 1 und Abs. 4 S. 4 BVerfSchG; unter Anwendung von Art. 99 Abs. 1 i.V.m. Art. 104 Abs. 1 1. Halbsatz SDÜ.

${ }^{291} \S 17$ Abs. 3 S. 3 BVerfSchG; unter Anwendung von Art. 99 Abs. 1 i.V.m. Art. 104 Abs. 1 1. Halbsatz SDÜ.

$292 \S 17$ Abs. 3 S. 4 SDÜ; Art. 112 Abs. 1 S. 3 SDÜ bestimmt die Jahresfrist. Nach § 112 Abs. 2 SDÜ kann das nationale Recht für SIS-Ausschreibungen jedoch kürzere Fristen vorsehen, was hier geschehen ist.

${ }^{293}$ Da das BVerfSchG zu dieser Frage keine besondere gesetzliche Bestimmung enthält, gilt Art. 5 Abs. 1 des Zustimmungsgesetzes zum SDÜ. Eine differenzierte Benachrichtigungsregel findet sich SIS-II-Gesetz vom 6. Juni 2009, BGBl. 2009, 1226. Dieses Gesetz sieht in seinem Art. 2 Nr. 5 eine Änderung des Bundeskriminalamtsgesetzes zur nachträglichen Benachrichtigung bei verdeckten Registrierungen im allgemeinen wie speziell zu Ausschreibungen nach $\S 17$ Abs. 3 BVerfSchG vor. Das Gesetz ist in diesem Punkt jedoch noch nicht in Kraft, vgl. Art. 7 Abs. 1 S. 2 SIS-II-Gesetz.
} 
löschte Daten werden ein weiteres Jahr in der technischen Unterstützungseinheit gespeichert. Der Zweck dieser Regelung ist ausschließlich die Überprüfbarkeit der Richtigkeit der Daten sowie der Rechtmäßigkeit ihrer Speicherung. ${ }^{294}$

Absatz 9

Im Falle des Antreffens kann die um Mitteilung ersuchte Stelle der ausschreibenden Behörde folgende Informationen übermitteln:

a) Antreffen der ausgeschriebenen Person oder des ausgeschriebenen Fahrzeugs,

b) Ort, Zeit oder Anlass der Überprüfung,

c) Reiseweg und Reiseziel,

d) Begleitpersonen oder Insassen,

e) benutztes Fahrzeug,

f) mitgeführte Sachen,

g) Umstände des Antreffens der Person oder des Fahrzeugs.

Bei der Erhebung der Daten ist darauf zu achten, dass der verdeckte Charakter der Maßnahme nicht gefährdet wird. ${ }^{295}$

\section{Absatz 10}

Das jeweils zuständige Bundesministerium unterrichtet im Abstand von höchstens sechs Monaten das Parlamentarische Kontrollgremium über Ausschreibungen nach Art. 99 SDÜ; dabei ist insbesondere ein Überblick über Anlass, Umfang, Dauer, Ergebnis und Kosten der im Berichtszeitraum durchgeführten Maßnahmen zu geben. Das Gremium erstattet dem Deutschen Bundestag jährlich einen Bericht über die Durchführung sowie Art, Umfang und Anordnungsgründe der Maßnahmen; dabei sind die Grundsätze die Grundsätze des $\S 10$ Abs. 1 des Kontrollgremiumsgesetzes zu beachten. ${ }^{296}$

\section{Absatz 11}

Der ausschreibende Mitgliedstaat ist verpflichtet, die anderen Mitgliedstaaten zu unterrichten. ${ }^{297}$

\footnotetext{
${ }^{294}$ Art. 112 Abs. 1 S. 1, Abs. 3 SDÜ unter Anwendung von Art. 104 Abs. 2 SDÜ.

${ }^{295} \S 17$ Abs. 3 S. 2 BVerfSchG i.V.m. Art. 99 Abs. 4 SDÜ.

${ }^{296} \S 17$ Abs. 3 S. 6 i.V.m. $\S 8$ a Abs. 6 BVerfSchG.

${ }^{297}$ Art. 99 Abs. 3 S. 2 SDÜ.
} 


\section{dd. Weitere bzw. gemeinsame Regelungen}

Für alle drei genannten Varianten sind die Kennzeichnungsmöglichkeiten der Mitgliedstaaten von Art. 94 Abs. 4 sowie Art. 99 Abs. 6 SDÜ zu beachten. Anders als bei Art. 95 SDÜ gibt es zur Durchführung der Prüfung keine Begleitpapiere. Die Regelung des Art. 99 Abs. 6 SDÜ entspricht im wesentlichen der Vorschrift des Art. 95 Abs. 3 SDÜ, allerdings mit dem Unterschied, dass es keine Möglichkeit gibt, die Vierundzwanzig-Stunden-Prüffrist aufgrund eines komplexen Sachverhaltes zu verlängern. Auch nachträglich ist eine Kennzeichnung wie bei Art. 95 und 97 SDÜ nach Art. 94 Abs. 4 SDÜ möglich. Wegen der im Rahmen von Art. 99 Abs. 3 SDÜ erwünschten besonderen Vertraulichkeit sind die Kontakte zwischen den Sirene-Büros zwischen den für die Sicherheit des Staates zuständigen Stellen zu trennen. ${ }^{298}$

Nur bei Art. 99 SDÜ besteht die Möglichkeit einer Verknüpfung der Fahndung nach Personen und Fahrzeugen. ${ }^{299}$

Die Fahndung wird durch die zuständige Behörde, also Justiz- oder Polizeibehörde, sowie die in $\S 17$ Abs. 3 BVerfSchG genannten Dienste eingeleitet. Über die zuständige Polizeidienststelle werden die Daten in INPOL eingegeben. Anschließend findet der Datensatz automatisch seinen Weg über das C.SIS in die N.SIS der anderen Staaten. ${ }^{300}$

Abfrageberechtigt sind alle Polizeidienststellen des Bundes und der Länder, das Zollkriminalamt und die Zollfahndungsdienststellen. ${ }^{301}$ Zudem hat nach Art. 101 a SDÜ das Europäische Polizeiamt - Europol - Zugriff auf die Daten nach Art. 99 SDÜ, soweit es die Erfüllung seiner Aufgabe erfordert.

\section{b. Verfahren im Trefferfall}

Die bei einer verdeckten Registrierung nach Art. 99 Abs. 4 SDÜ erhobenen Daten werden auf konventionellem Weg an die Sirene übermittelt, in deren Land die Kontrolle stattfindet. Diese kontaktiert die Sirene des ausschreibenden Staates, die die Informationen wiederum an die ausschreibende Stelle weitergibt. ${ }^{302}$

\footnotetext{
${ }^{298}$ Sirene-Handbuch, 7.2., AB1. L 186, 1, vom 15. Juli 2011.

${ }^{299}$ Würz, Rn. 200.

${ }^{300}$ Würz, Rn. 199.

${ }^{301}$ Art. 101 Abs. 1 S. 1 SDÜ; Würz, Rn. 164.

${ }^{302}$ Vgl. Mokros, in: Lisken/Denninger, HandbPolR, O, Rn. 202.
} 


\section{Fahndung nach Sachen gemäß Art. 100 SDÜ}

\section{a. Voraussetzungen und Verfahren der Ausschreibung}

Nach Art. 100 SDÜ können Sachen ausgeschrieben werden, die im Strafverfahren zur Beweissicherung oder Sicherstellung gesucht werden. Eine präventivpolizeiliche Ausschreibung, z.B. eines nicht versicherten Kraftfahrzeuges ist nicht zulässig. ${ }^{303}$

Abschließend nennt Art. 100 Abs. 3 SDÜ Kategorien leicht identifizierbarer Sachen. Es sind dies:

- gestohlene, unterschlagene oder sonst abhanden gekommene Kraftfahrzeuge mit einem Hubraum von mehr als $50 \mathrm{ccm}$,

- gestohlene, unterschlagene oder sonst abhanden gekommene Anhänger und Wohnwagen mit einem Leergewicht von mehr als $750 \mathrm{~kg}$,

- gestohlene, unterschlagene oder sonst abhanden gekommene Feuerwaffen

- gestohlene, unterschlagene oder sonst abhanden gekommene Blankodokumente

- gestohlene, unterschlagene oder sonst abhanden gekommene oder für ungültig erklärte ausgestellte Identitätsdokumente

- gestohlene, unterschlagene, sonst abhanden gekommene oder für ungültlig erklärte Fahrzeugscheine und Kfz-Kennzeichen sowie

- Banknoten

Eine Ausschreibung nach Art. 100 SDÜ darf außer einer Justizbehörde auch eine Polizeidienststelle veranlassen. ${ }^{304}$ Diese Regelung liegt nahe, da die Polizei regelmäßig erster Ansprechpartner für Diebstahlsopfer ist und auf diese Weise eine gestohlene Sache mit der gebotenen Geschwindigkeit zur Fahndung ausschreiben kann. ${ }^{305}$ In jedem Fall erfolgt die Eingabe der Daten über die zuständige Polizeidienststelle in das deutsche Fahndungssystem INPOL. Diese INPOLFahndungen werden in das deutsche N.SIS übernommen, dort automatisch auf Plausibilität geprüft und bei korrekter Eingabe nach Umwandlung von N.SIS in C.SIS-Format beim BKA an das C.SIS zur Weiterleitung an die übrigen N.SIS übermittelt. ${ }^{306}$

\footnotetext{
${ }^{303}$ Vgl. Würz, Rn. 202.

${ }^{304}$ Würz, Rn. 203.

305 Als Beispiel kann hier folgender Fall dienen: Einem deutschen Touristen wurde in Toulouse/Südfrankreich um 0.15 Uhr der PKW gestohlen. Der Diebstahl wurde der französischen Polizei am nächsten Tag gegen 15 Uhr gemeldet. Um 15.40 Uhr erschien die Fahndungsnotierung im den N.SIS, so auch im deutschen N.SIS. Als der Wagen um 22.30 Uhr in Berlin auf der Fahrt Richtung polnische Grenze routinemäßig kontrolliert wurde, konnten die Täter festgenommen und Wagen dem Eigentümer zurückgeben werden, vgl. Piosek, S. 83.

306 Würz, Rn. 204; Gusy/Gimbal, in: Baldus/Soiné, Internationale polizeiliche Zusammenarbeit, S. 124 (129 f.); Wilkesmann, NStZ 1999, 68 (68); Hemesath, KR 1995, 169 (169 f.).
} 
Abfrageberechtigt sind neben den Polizeidienststellen des Bundes und der Länder, dem Zollkriminalamt, den Zollfahndungsdienststellen ${ }^{307}$ und Europol ${ }^{308}$ auch die Stellen, die in den Mitgliedstaaten für die Ausstellung von Zulassungsbescheinigungen für Fahrzeuge zuständig sind. Sie sollen nach Maßgabe des innerstaatlichen Rechts im Rahmen ihrer Aufgabe Zugriff haben auf die Kraftfahrzeuge, Anhänger, Wohnwagen, Zulassungsbescheinigungen und KfzKennzeichenschilder, die nach Art. 100 SDÜ im SIS ausgeschrieben sind. ${ }^{309}$ Der Zugriff ist in Deutschland über die bestehende technische Infrastruktur, das so genannte Zentrale Verkehrsinformationssystem, kurz ZEVIS, zwischen Kraftfahrtbundesamt und Zulassungsbehörden realisiert. ${ }^{310}$ Eine Abfrageberechtigung in Bezug auf Daten nach Art. 100 Abs. 3 d) und e) SDÜ ist nach Art. 101 Abs. 2 S. 2 SDÜ nach Maßgabe des nationalen Rechts zudem vorgesehen für die mit der Sichtvermerkserteilung befassten Stellen, für die für die Sichtvermerkserteilung zentral zuständigen Stellen sowie die Behörden, die für die Erteilung von Aufenthaltstiteln und für die Handhabung der ausländerrechtlichen Bestimmungen des SDÜ im Bereich des Personenverkehrs zuständig sind.

\section{b. Verfahren im Trefferfall}

Für die Maßnahmen im Trefferfall verweist Art. 100 Abs. 2 S. 3 SDÜ auf nationale Eingriffsnormen. Grundsätzlich können sowohl strafprozessuale als auch polizeigesetzliche Vorschriften zur Anwendung kommen. Zwar handelt es sich in der hier angenommenen Konstellation um ein ausländisches Strafverfahren und einen Trefferfall im Inland. Gleichwohl ist stets zu prüfen, ob nicht auch im Inland Anlass für die Einleitung eines Ermittlungsverfahrens besteht. Zur Klärung, ob die entsprechenden Voraussetzungen dafür vorliegen, ist der Rückgriff auf strafprozessuale Eingriffsnormen gerechtfertigt. Gleichzeitig dient das Handeln der Polizei hier präventivpolizeilichen Zwecken, da sie mit ihrem Tun das private Eigentumsrecht schützt.

Der fragliche Gegenstand ist zur Eigentumssicherung zunächst sicherzustellen bzw. zu beschlagnahmen und anschließend ist die Identität der Person festzustellen, die die Sache in Besitz hat, §§ 26, 13 Nds. PolG. Alternativ kommen als Eingriffsnormen für Beschlagnahme, Durchsuchung und Identitätsfeststellung die $§ 99$ ff., 102 sowie 163 b StPO in Betracht.

Die befasste Polizeidienststelle nimmt zur weiteren Klärung Kontakt mit der Sirene auf, die sich wiederum mit der Sirene des ausschreibenden Staates in Verbindung setzt. Dort liegen häufig

\footnotetext{
${ }^{307}$ Würz, Rn. 164.

${ }^{308}$ Art. 101 a SDÜ.

${ }^{309}$ Art. 102 a SDÜ.

${ }^{310}$ Telefonische Auskunft durch das Kraftfahrtbundesamt am 8. Juni 2010, Frau Junge-Grützmacher, Sachgebietsleiterin 212 .
} 
zusätzliche Informationen zum rechtmäßigen Eigentümer vor, so dass die Rückführung des Gegenstandes in die Wege geleitet werden kann. ${ }^{311}$

Soweit sich ein Treffer ergibt, weil beispielsweise ein im SIS ausgeschriebenes Fahrzeug der Kfz-Zulassungsbehörde mit der Bitte um Zulassung vorgestellt wird, haben die Zulassungsstellen bei Verdacht auf das Vorliegen einer strafbaren Handlung unverzüglich Kontakt zur Polizei oder Staatsanwaltschaft aufzunehmen. ${ }^{312}$

${ }^{311}$ Art. 100 Abs. 2 SDÜ, Piosek, S. 83.

${ }^{312} \mathrm{Vgl}$. Art. 102 a Abs. 3 SDÜ. 


\section{Regelungen zum Datenschutz und zum hierauf gerichteten Rechtsschutz im Rahmen des SIS}

\section{Datenschutzvorschriften}

Das SDÜ enthält allgemeine Datenschutzvorschriften, Art. 126 bis 130 SDÜ. Gemäß Art. 126 Abs. 4 und Art. 127 Abs. 3 SDÜ gelten diese jedoch nicht für Datenübermittlungen innerhalb des SIS. Für den Umgang mit diesen Daten sind stattdessen Art. 102 bis 118 SDÜ heranzuziehen.

Art. 117 Abs. 1 SDÜ nimmt Bezug auf das Übereinkommen des Europarates über den Schutz des Menschen bei der automatischen Verarbeitung personenbezogener Daten vom 28. Januar $1981^{313}$ sowie auf die Empfehlung des Ministerausschusses des Europarates über die Nutzung personenbezogener Daten im Polizeibereich vom 17. September $1987^{314}$.

Die in diesen Vereinbarungen festgelegten Grundsätze bilden den gemeinsamen Datenschutzstandard, der den betroffenen Personen jedoch unmittelbar keine subjektiven Rechte gewährt und den die Vertragsstaaten deshalb in nationales Recht umsetzen müssen. Deutschland hat dies mit dem Bundesdatenschutzgesetz, den Landesdatenschutzgesetzen sowie den Landespolizeigesetzen getan. ${ }^{315}$

Nach Art. 117 Abs. 2 SDÜ durfte die Datenübermittlung nur beginnen, nachdem die dem EuDSK und der Empfehlung R (87) 15 entsprechenden nationalen Regeln im Hoheitsgebiet aller teilnehmenden Staaten in Kraft getreten waren.

\section{a. Rechtsgrundlagen}

aa. Übereinkommen des Europarates über den Schutz des Menschen bei der automatischen Verarbeitung personenbezogener Daten vom 28. Januar $1981^{316}$

Grob skizziert verlangt das Übereinkommen des Europarates eine Bindung der Datensammlung an rechtmäßige Zwecke und unterstreicht die Bedeutung des Erforderlichkeitsgrundsatzes. ${ }^{317}$ Art. 6 EuDSK stellt personenbezogene Daten, die die rassische Herkunft, politische oder religiöse oder andere Überzeugung, Gesundheit, das Sexualleben oder Strafurteile betreffen, unter besonderen Schutz. Die Vertragsstaaten haben zudem einen technischen Datenschutz zu gewährleisten, indem Sicherungsmaßnahmen gegen Zerstörung, Verlust, unbefugten Zugang und Ähnli-

\footnotetext{
${ }^{313}$ BGB1. II 1985, 538 (539 ff.).

${ }^{314}$ Abgedruckt bei Würz, Anhang 2, S. 225.

${ }^{315}$ Gusy/Gimbal, in: Baldus/Soiné, Internationale polizeiliche Zusammenarbeit, S. 124 (137); vgl. Würz, Rn. 246.

${ }^{316}$ Im Folgenden: EuDSK.

${ }^{317}$ Art. 5 EuDSK.
} 
ches zu ergreifen sind. ${ }^{318}$ Jedermann ist ein Auskunfts-, Berichtigungs-, Löschungs- und Klagerecht einzuräumen. ${ }^{319}$ Alle diese Regeln des Übereinkommens beziehen sich auf das Verhältnis eines jeden Bürgers zu seinen Staat.

Für den grenzüberschreitenden Datenverkehr heisst es, dass eine Vertragspartei die Datenübermittlung nicht allein zum Zweck des Schutzes des Persönlichkeitsbereiches verbieten oder von einer besonderen Genehmigung abhängig machen darf. ${ }^{320}$ Für den einzelnen ist in diesem Kapitel festgelegt, dass jede Vertragspartei Personen, die im Ausland wohnen bei der Ausübung der Rechte, deren Umsetzung Art. 8 des Übereinkommens verlangt, unterstützt. ${ }^{321}$

\section{bb. Empfehlung des Ministerausschusses des Europarates über die Nutzung personenbezo- gener Daten im Polizeibereich vom 17. September $1987^{322}$}

In einigen Punkten stärkt die Empfehlung R (87) 15 den Datenschutz gegenüber dem EuDSK bzw. präzisiert dessen Forderungen. So verlangt Grundsatz 1 die Einrichtung einer unabhängigen Datenschutzkontrollbehörde, der ständige automatisierte Dateien gemeldet werden. Diese Kontrollbehörde soll auch darauf achten, dass die Öffentlichkeit von der Existenz meldepflichtiger Dateien Kenntnis hat und über ihre Rechte in Bezug auf diese Dateien informiert wird. ${ }^{323}$ Grundsatz 2.1 verlangt, dass die Sammlung personenbezogener Daten für den Polizeibereich für die Abwehr einer konkreten Gefahr oder die Verfolgung einer speziellen Straftat erforderlich ist. Sie verbietet grundsätzlich die Sammlung von Daten über Personen allein aufgrund ihrer Zugehörigkeit zu einer Rasse, einer bestimmten religiösen Anschauung, politischen Meinung, ihres Sexualverhaltens sowie ihrer Zugehörigkeit zu bestimmten Bewegungen und Organisationen, die gesetzlich nicht verboten sind. ${ }^{324}$ Für die Weitergabe von Daten an ausländische Polizeibehörden verlangt Grundsatz 5.4 eine eindeutige Rechtsgrundlage, die Notwendigkeit, eine ernste und unmittelbar bevorstehende Gefahr abzuwehren oder die Verfolgung einer schweren Straftat.

\footnotetext{
${ }^{318}$ Art. 7 EuDSK.

${ }^{319}$ Art. 8 EuDSK.

${ }^{320}$ Art. 12 Abs. 2 EuDSK.

${ }^{321}$ Art. 14 EuDSK.

${ }^{322}$ Im Folgenden: Empfehlung R (87) 15.

${ }^{323}$ Grundsatz 6.1.

${ }^{324}$ Grundsatz 2.4.
} 


\section{cc. Richtlinie 95/46/EG vom 24 . Oktober $1995^{325}$}

Die sogenannte EU-Datenschutzrichtlinie nimmt von ihrem Anwendungsbereich die Verarbeitung personenbezogener Daten aus, die sich auf die öffentliche Sicherheit, die Sicherheit des Staates und den strafrechtlichen Bereich beziehen. ${ }^{326}$ Damit hat diese Richtlinie für die Daten nach dem SDÜ keine Bedeutung. ${ }^{327}$

\section{dd. Rahmenbeschluss des Rates aus $2008^{328}$}

Die Vorschriften dieses Rahmenbeschlusses beziehen sich ausdrücklich auf personenbezogene Daten, die im Rahmen der polizeilichen und justiziellen Zusammenarbeit in Strafsachen verarbeitet werden. Insofern gelten sie nach entsprechender nationaler Umsetzung ${ }^{329}$ eigentlich auch für das SIS. Allerdings geht der Rat im Erwägungsgrund Nr. 39 davon aus, dass die Datenschutzregeln für die Arbeitsweise des SIS ausführlicher sind und ein in sich geschlossenes Regelwerk bilden. Aus diesem Grund, so die Schlussfolgerung des Rates, bleiben die einschlägigen Datenschutzvorschriften zum SIS vom Rahmenbeschluss unberührt. ${ }^{330}$

\section{ee. Verhältnis zum nationalen Recht}

Nach Art. 104 Abs. 2 SDÜ ${ }^{331}$ gilt das nationale Recht für die im nationalen Teil des Schengener Informationssystems gespeicherten Daten, wenn nicht das Übereinkommen eine besondere Re-

\footnotetext{
${ }^{325}$ AB1. EG L 281, 31.

${ }^{326}$ Art. 3 Abs. 2 1. Spstr.

${ }^{327}$ Nach dem aktuellen Sirene-Handbuch soll diese Richtlinie gleichwohl auf den Austausch von Zusatzinformationen über Ausschreibungen zur Einreiseverweigerung Anwendung finden, vgl. Erwägungsgrund (3) Durchführungsbeschluss der Kommission zur Änderung des Sirene-Handbuchs, AB1. L 186, 1, vom 15. Juli 2011 sowie die Ausführungen zum Sirene-Handbuch in diesem Teil der Arbeit, IV.1. Die Verfasserin sieht eine solche Anwendung als problematisch an, da der Durchführungsbeschluss der Kommission zur Änderung des Sirene-Handbuches normenhierarchisch unterhalb der Regelungen der Richtlinie des Europäischen Parlamentes und des Rates steht und eine Anwendung angesichts des klaren Wortlauts der Richtlinie im Widerspruch zum Gebot der Rechtsklarheit stünde.

${ }^{328}$ Rahmenbeschluss 2008/977/JI des Rates vom 27. November 2008 über den Schutz personenbezogener Daten, die im Rahmen der polizeilichen und justiziellen Zusammenarbeit in Strafsachen verarbeitet werden, AB1. L 350, 60.

${ }^{329}$ Die Umsetzung in Deutschland erfolgte nicht durch einen Rechtsakt sondern in Form administrativer Rundschreiben, vgl. Bericht der Kommission vom 25. Januar 2012, KOM(2012) 12 endgültig, Ziffer 2.1.1.

${ }^{330}$ Nach dem aktuellen Sirene-Handbuch soll der Rahmenbeschluss Anwendung auf den Austausch von Zusatzinformationen bei allen anderen Ausschreibungen als der zur Einreiseverweigerung finden, vgl. Erwägungsgrund (3) Durchführungsbeschluss der Kommission zur Änderung des Sirene-Handbuchs, AB1. L 186, 1, vom 15. Juli 2011. Einer solchen Anwendbarkeit steht die Verfasserin wie schon mit Blick auf die Richtlinie 95/46/EG dargelegt kritisch gegenüber. Bedenken bestehen hier wegen der normenhierarchischen Untergeordnetheit des Durchführungsbeschlusses der Kommission gegenüber dem Rahmenbeschluss des Rates sowie wegen des ganz klaren Wortlautes des Rahmenbeschlusses bezüglich der Rechtsklarheit. Gleichwohl dürfte eine Anwendung des Rahmenbeschlusses im vom Sirene-Handbuch vorgesehenen Umfang auf das Ergebnis der im 3. Teil B. vorgenommenen Prüfung bereits deshalb keinen Einfluss haben, weil für den Bereich, den der Rahmenbeschluss regelt, in Bezug auf die Vorschriften zum SIS keine Mängel festgestellt wurden. Allein hinsichtlich der bei der Koppelung von Zwecken festgestellten Mängel, vgl. 3. Teil der Arbeit, B. IV. 3., könnte die Anwendung des Rahmenbeschlusses im Abhilfe schaffen; hierzu trifft der Durchführungsbeschluss der Kommission zum Sirene-Handbuch jedoch keine Regelung.

${ }^{331}$ Der bei der Ermittlung der einschlägigen Norm nach Art. 99 SDÜ bereits Anwendung fand, vgl. diesen Teil der Arbeit, III. 5.
} 
gelung enthält. Die nachfolgend erläuterten Bestimmungen, die sich ausdrücklich mit dem Dateninhalt des SIS beschäftigen, gehen damit dem allgemeineren nationalen Regeln vor.

\section{b. Vorschriften des SDÜ}

\section{aa. Zweckbindung}

Art. 102 SDÜ bestimmt, dass die innerhalb der einzelnen Fahndungskategorien gespeicherten Daten nach den Art. 95 bis 100 SDÜ nur für die der jeweiligen Ausschreibung entsprechenden Zwecke genutzt werden dürfen.

Hiervon gibt es jedoch Ausnahmen. So darf die eine Ausschreibungskategorie durch eine andere ersetzt werden, soweit dies zur Abwehr einer schwerwiegenden und unmittelbar bevorstehenden Gefahr für die öffentliche Sicherheit und Ordnung oder aus schwerwiegenden Gründen der Sicherheit des Staates oder zur Verhütung einer Straftat mit erheblicher Bedeutung erforderlich ist. Erforderlich ist zudem die Zustimmung des ausschreibenden Staates. ${ }^{332}$

Vorgesehen ist die Möglichkeit zur Zweckänderung auch, sofern Europol oder Eurojust im Rahmen ihrer Aufgaben auf eine Ausschreibung im SIS stoßen. Eine Nutzung der Daten durch diese beiden Stellen setzt ebenfalls die Zustimmung des ausschreibenden Mitgliedsstaates voraus. ${ }^{333}$

Eine Nutzung der im SIS gespeicherten Daten zu Verwaltungszwecken ist nach Art. 102 Abs. 4 S. 1 SDÜ ausdrücklich grundsätzlich ausgeschlossen. Allerdings werden zwei Ausnahmen aufgeführt, die mit dem zu den Abfragemöglichkeiten nach Art. 96 und 100 SDÜ Ausgeführten korrespondieren. ${ }^{334}$

Zum einen ist die Nutzung der Daten nach Art. 96 und Art. 100 Abs. 3 d) und e) SDÜ für die Ausländerbehörden, die deutschen Auslandsvertretungen sowie das Bundesverwaltungsamt insofern erlaubt, als sie diese zur Bearbeitung von Sichtvermerksanträgen, die Erteilung von Aufenthaltstiteln und die Anwendung von ausländerrechtlichen Bestimmungen nach dem SDÜ benötigen. ${ }^{335}$

Zum anderen erlaubt Art. 102 a SDÜ den Stellen, die für die Ausstellung von Zulassungsbescheinigungen für Fahrzeuge zuständig sind, den Zugriff auf die Daten von Kraftfahrzeugen, Anhängern, Wohnwagen, Zulassungsbescheinigungen sowie Kfz-Kennzeichenschildern, die nach Art. 100 SDÜ im SIS ausgeschrieben sind.

\footnotetext{
${ }^{332}$ Art. 102 Abs. 3 SDÜ.

${ }^{333}$ Art. 101 a Abs. 3 und Abs. 4 S. 1 sowie Art. 101 b Abs. 3 SDÜ.

${ }^{334} \mathrm{Vgl}$. B. III. 2. und 6.

${ }^{335}$ Art. 102 Abs. 4 S. 2 i.V.m. Art. 101 Abs. 2 SDÜ i.V.m. Art. 6 Nr. 2 Zustimmungsgesetz zum SDÜ, BGB1. II 1993, 1010 (1010); Würz, Rn. 164.
} 
Eine Vervielfältigung der gespeicherten Daten ist nach Art. 102 Abs. 2 SDÜ nur zu technischen Zwecken und nur dann erlaubt, soweit dies zum unmittelbaren Abruf der berechtigten Stellen erforderlich ist. Weiterhin ist der Bestand des N.SIS streng von anderen nationalen Datenbanken $\mathrm{zu}$ trennen.

\section{bb. Datenschutzrechtliche Verantwortlichkeit und Protokollierung}

Art. 105 und 106 SDÜ legen fest, dass für die Richtigkeit und Aktualität der im SIS vorhandenen Daten sowie die Rechtmäßigkeit der Speicherung die ausschreibende Vertragspartei verantwortlich ist. Konsequenterweise darf auch nur sie die Daten ändern, ergänzen, berichtigen oder löschen. Dieser Grundsatz der datenschutzrechtlichen Verantwortlichkeit meint nicht nur eine allgemeine Zuständigkeit der Vertragspartei, sondern die alleinige Zuständigkeit der die Fahndung ursprünglich veranlassenden Stelle, etwa nach Art. 95 SDÜ des Staatsanwaltes. ${ }^{336}$

Von wem Eingaben gemacht oder verändert wurden, lässt sich in Deutschland über INPOL feststellen, das diesen Vorgang festhält. ${ }^{337} \mathrm{Zu}$ Nachverfolgungszwecken wird gemäß Art. 103 SDÜ auch jede Abfrage aus dem SIS protokolliert. ${ }^{338}$

\section{cc. Speicherfristen}

Für die Dauer der Speicherung postulieren Art. 112 Abs. 1 S. 1, 112 a Abs. 1 S. 1 SDÜ noch einmal ausdrücklich das Erforderlichkeitsprinzip.

\section{(1) Personenbezogene Daten}

Bei den personenbezogenen Daten ist zu differenzieren zwischen jenen, die unmittelbar im SIS gespeichert sind, und jenen, die bei den Sirenen als zusätzliche Informationen beispielsweise durch die Begleitpapiere nach Art. 95 SDÜ vorliegen.

Für die zuerst genannten Daten gibt es keine absolute Speicherfrist, sondern lediglich die Verpflichtung, spätestens drei Jahre nach der Einspeicherung die Erforderlichkeit einer weiteren Speicherung zu prüfen. Für eine Ausschreibung nach Art. 99 SDÜ beträgt diese Frist ein Jahr.

Das C.SIS weist die ausschreibende Vertragspartei einen Monat vorher auf den Ablauf der jeweiligen Frist hin. Innerhalb dieses Monats kann nach Prüfung der Erforderlichkeit eine Verlängerung um bis zu ein bzw. drei Jahre eingegeben werden. Geschieht das nicht, werden die Daten automatisch gelöscht. ${ }^{339}$

\footnotetext{
${ }^{336}$ Vgl. Werner, CR 1997, 34 (35).

${ }^{337}$ Martínez Soria, VA 1998, 400 (414).

${ }^{338}$ Art. 103 SDÜ.

${ }^{339}$ Vgl. Art. 112 Abs. 3.
} 
Gelöschte Daten werden ein weiteres Jahr in der technischen Unterstützungseinheit gespeichert. Der Zweck dieser Regelung ist ausschließlich die Überprüfbarkeit der Richtigkeit der Daten sowie der Rechtmäßigkeit ihrer Speicherung. ${ }^{340}$ Hintergrund dürften die Rechtschutzmöglichkeiten des Betroffenen nach Art. 111 SDÜ sein. ${ }^{341}$ Insbesondere bei der Geltendmachung eines Schadensersatzanspruchs muss zur Prüfung seiner Berechtigung für eine gewisse Zeit nach der Löschung die Rechtmäßig- oder Rechtswidrigkeit der Speicherung nachvollziehbar bleiben.

Die Speicherfrist für die von den Sirenen gespeicherten zusätzlichen Daten beträgt nach Art. 112 a SDÜ ein Jahr nach Löschung der jeweiligen Ausschreibung.

\section{(2) Sachbezogene Daten}

Auch bei den sachbezogenen Daten ist zwischen den direkt im SIS gespeicherten und den bei den Sirenen ergänzend vorliegenden Daten zu unterscheiden.

Erstere unterliegen der absoluten Speicherfrist des Art. 113 Abs. 1 SDÜ. Danach werden alle nach Art. 100 SDÜ gespeicherten Daten nach maximal 10 Jahren und Daten über Gegenstände nach Art. 99 SDÜ nach spätestens fünf Jahren gelöscht.

Auch gelöschte sachbezogene Daten sind ein weiteres Jahr in der technischen Unterstützungseinheit gespeichert. Zweck dieser Regelung ist hier ebenfalls, dass die Richtigkeit der Daten sowie die Rechtmäßigkeit ihrer Speicherung überprüft werden kann. ${ }^{342}$

Für die bei den Sirenen zusätzlich vorliegenden sachbezogenen Daten ist Bezugspunkt wie bei den personenbezogenen Daten die jeweilige Ausschreibung, zu der die Daten gespeichert wurden. Spätestens ein Jahr nach ihrer Löschung werden diese Daten ebenfalls gelöscht. ${ }^{343}$

\section{dd. Technischer Datenschutz}

Art. 118 SDÜ fordert von den Vertragsparteien detaillierte organisatorische, bauliche und personelle Maßnahmen, um die Voraussetzungen für einen effektiven Datenschutz zu schaffen. So ist u.a.

- Unbefugten der Zugang zu Datenverarbeitungsanlagen, mit denen personenbezogene Daten verarbeitet werden, zu verwehren,

\footnotetext{
${ }^{340}$ Art. 113 Abs. 2 SDÜ.

${ }^{341}$ Vgl. hierzu in diesem Teil der Arbeit: B. IV.2.

${ }^{342}$ Art. 113 Abs. 2 SDÜ.

${ }^{343}$ Art. 113 a SDÜ.
} 
- zu verhindern, dass Datenträger unbefugt gelesen, kopiert, verändert oder entfernt werden können,

- sicherzustellen, dass nachträglich überprüft und festgestellt werden kann, welche personenbezogenen Daten zu welcher Zeit und von wem in automatisierte Datenverarbeitungssysteme eingegeben wurden und

- zu gewährleisten, dass lediglich Personen für die Datenverarbeitung eingesetzt werden, die besonders geschult und einer Sicherheitsüberprüfung unterzogen sind.

\section{ee. Nationale Kontrollinstanz, Gemeinsame Kontrollinstanz und Europäischer Daten- schutzbeauftragter}

Art. 114 SDÜ erläutert die Aufgaben der Nationalen Kontrollinstanzen. Sie sollen nach Maßgabe des jeweiligen nationalen Rechts das N.SIS ihres Staates unabhängig überwachen und prüfen, ob durch Verarbeitung und Nutzung der im SIS gespeicherten Daten die Rechte des Betroffenen verletzt werden. Zu diesem Zweck hat die Kontrollinstanz Zugriff auf das jeweilige N.SIS.

In Deutschland ist Nationale Kontrollinstanz der Bundesdatenschutzbeauftragte, § 24 BDSG. Er hat grundsätzlich Zutritt zu allen Diensträumen und kann spontan, aber auch im Rahmen längerfristiger Strategien Kontrollen vornehmen. Auch die Sirene im BKA ist seit ihrem Bestehen mehrfach kontrolliert worden. ${ }^{344}$ Anlass zur Beanstandung gab beispielsweise bei der Kontrolle in 2003/2004 die Tatsache, dass die Prüfung der Erforderlichkeit der weiteren Speicherung einer Ausschreibung vielfach nicht dokumentiert worden war. Mehrfach war aus den Akten keine eigenständige Entscheidung des zuständigen Sachbearbeiters nachzuvollziehen. Stattdessen bestand die Dokumentation in der Meldung des BKA über die Verlängerung der Ausschreibung. ${ }^{345}$ Seine Tätigkeitsberichte gemäß Art. 115 Abs. 4 SDÜ, die auch die Ergebnisse der N.SISKontrollen enthalten, legt der Bundesbeauftragte für den Datenschutz dem Deutschen Bundestag vor. ${ }^{346}$ Zwar haben seine Prüfergebnisse keine unmittelbare Rechtswirkung, schaffen aber Öffentlichkeit und tragen damit häufig zur Behebung der festgestellten Missstände bei.

Art. 115 SDÜ legt die Einrichtung einer Gemeinsamen Kontrollinstanz fest. Sie hat Zugriff auf die Daten des C.SIS und soll in Bezug auf diese Daten die richtige Anwendung der Bestimmungen des SDÜ sowie die Beachtung des EuDSK und der Empfehlung R (87) 15 überprüfen. Zugleich soll sie Anwendungs- und Auslegungsfragen im Zusammenhang mit dem Funktionieren des Schengener Informationssystems prüfen, die Nationalen Kontrollinstanzen bei aufkommen-

\footnotetext{
${ }^{344}$ Gusy/Gimbal, in: Baldus/Soiné, Internationale polizeiliche Zusammenarbeit, S. 124 (139).

${ }^{345}$ Der Bundesbeauftragte für den Datenschutz, 20. Tätigkeitsbericht, S. 36, 3.3.2.2, 4 Spstr.

${ }^{346} \mathrm{Vgl}$. 26 Abs. 1 BDSG
} 
den Unklarheiten in ihrer Arbeit unterstützen sowie allgemein Vorschläge für die gemeinsame Lösung bestehender Fragen entwickeln. Zur Erledigung dieser Aufgaben stehen der Gemeinsamen Kontrollinstanz je zwei Vertreter der jeweiligen Nationalen Kontrollinstanzen zur Verfügung, wobei in Abstimmungen jede Vertragspartei eine Stimme hat. Für die Bundesrepublik Deutschland nehmen der Bundesbeauftragte für den Datenschutz und der Hessische Datenschutzbeauftragte als Vertreter der Landesdatenschutzbeauftragten an den Sitzungen teil. ${ }^{347}$

Auch die Gemeinsame Kontrollinstanz erstellt regelmäßig Tätigkeitsberichte, die ebenfalls dem Deutschen Bundestag übermittelt werden, Art. 115 Abs. 4 SDÜ i.V.m. § 26 Abs. 1 BDSG. ${ }^{348}$

Die Unabhängigkeit der Gemeinsamen Kontrollinstanz wird im Text des SDÜ nicht ausdrücklich erwähnt. Allerdings fordern die Empfehlungen R (87) 15 die Unabhängigkeit solcher Datenschutzkontrollstellen. ${ }^{349}$ Zudem sind Mitglieder der Gemeinsamen Kontrollinstanz die Vertreter der unabhängigen Nationalen Kontrollinstanzen, so dass letztlich auch die Unabhängigkeit der Gemeinsamen Kontrollinstanz nicht in Frage steht. ${ }^{350}$

Im Jahr 2000 entschied sich die EU zudem, einen Europäischen Datenschutzbeauftragten zu bestellen, der seit dem Jahr 2004 im Amt ist. ${ }^{351}$ Er soll sicherstellen, dass die Organe und Einrichtungen der EU das Recht der Bürger auf Privatsphäre achten. ${ }^{352} \mathrm{Im}$ Vergleich zur nationalen und gemeinsamen Kontrollinstanz ist er mit weitreichenden Befugnissen ausgestattet. So kann er neben der Erstellung eines Parlament, Rat und Kommission vorzulegenden und veröffentlichungsbedürftigen Tätigkeitsberichtes ${ }^{353}$ z.B. den für die Verarbeitung von Daten Verantwortlichen ermahnen oder verwarnen sowie die Berichtigung, Sperrung, Löschung oder Vernichtung von unrechtmäßig verarbeiteten personenbezogenen Daten anordnen. ${ }^{354}$ Im Hinblick auf das SIS hat der Europäische Datenschutzbeauftragte zwei Aufgaben. Soweit Organe und Einrichtungen

\footnotetext{
${ }^{347}$ Der Hessische Datenschutzbeauftragte, 36. Tätigkeitsbericht, S. 34, 3., wonach ihm die Konferenz der Datenschutzbeauftragten des Bundes und der Länder die Wahrnehmung der Interessen der Länderdatenschutzbeauftragten u.a. in der europäischen Kontrollinstanz für Schengen übertragen hat.

348 Nachzulesen auf der Website der gemeinsamen Kontrollinstanz unter http://www.schengenjsa.dataprotection.org., Abruf vom 31. Juli 2010.

${ }^{349}$ Grundsatz 1.1, abgedruckt bei Würz, Anhang 2, S. 225.

${ }^{350}$ Vgl. Mokros, in: Lisken/Denninger, HandbPolR, O, Rn. 215.

${ }^{351}$ VO EG Nr. 45/2001, ABl. L 8 vom 12. Januar 2001, 1; http://www.edps.europa.eu/EDPSWEB/edps/cache/off/lang/de/EDPS/Membersmission/Members, Abruf vom 28. April 2012.

${ }^{352}$ Art. 41 Abs. 2 VO EG Nr. 45/2001, ABl. L 8 vom 12. Januar 2001, 1.

${ }^{353}$ Art. 48 Abs. 1 VO EG Nr. 45/2001, ABl. L 8 vom 12. Januar 2001, 1.

${ }^{354}$ Art. 47 Abs. 1 d, e VO EG Nr. 45/2001, ABl. L 8 vom 12. Januar 2001, 1.
} 
der EU in Bezug auf das SIS handeln, hat er diese zu kontrollieren. Zum anderen soll er mit der nationalen und gemeinsamen Kontrollinstanz kooperieren. ${ }^{355}$

\section{ff. Rechte der Betroffenen}

Jede Person hat grundsätzlich das Recht, Auskunft zu den über sie im SIS gespeicherten Daten zu erlangen. Umfang und Ausübung des Rechtes richten sich nach dem nationalen Recht der Vertragspartei, in deren Gebiet es beansprucht wird. ${ }^{356}$ In Deutschland ergibt sich der Auskunftsanspruch insbesondere aus dem allgemeinen Datenschutzrecht. ${ }^{357}$

Ist die um Auskunft ersuchte Vertragspartei nicht die ausschreibende, darf sie Auskunft nur erteilen, nachdem sie der ausschreibenden Partei Gelegenheit zur Stellungnahme gegeben hat. ${ }^{358}$

Die Auskunft unterbleibt nach Art. 109 Abs. 2 SDÜ, wenn dies zur Durchführung einer rechtmäßigen Aufgabe im Zusammenhang mit der Ausschreibung oder zum Schutz der Rechte und Freiheiten Dritter unerlässlich ist. Eine Auskunft wird nie während der Ausschreibung zur verdeckten Registrierung erteilt.

Als einen gewissen Ausgleich hierzu verankert Art. 5 des deutschen Zustimmungsgesetz zum SDÜ ${ }^{359}$ die grundsätzliche Pflicht des Bundeskriminalamtes, den Betroffenen nach Beendigung einer deutschen Ausschreibung zur verdeckten Registrierung über die Maßnahme zu benachrichtigen. Handelte es sich um eine ausländische Ausschreibung, soll die Benachrichtigung in Absprache mit der ausländischen Stelle nachgeholt werden, wenn die der Auskunftserteilung entgegenstehenden Umstände entfallen sind.

Ergänzend zum Anspruch auf Auskunftserteilung hat jedermann gemäß Art. 110 SDÜ das Recht, auf seine Person bezogene unrichtige Daten berichtigen oder gänzlich unrechtmäßig gespeicherte Daten löschen zu lassen.

Art. 116 SDÜ enthält eine Schadensersatznorm für den Fall, dass eine Person beim Betrieb eines N.SIS geschädigt wird. Zur Geltendmachung ihres Anspruchs kann sie sich an jede Vertragspartei wenden, die nach Maßgabe ihres nationalen Rechts haftet. Hat die in Anspruch genommene Vertragspartei den Schaden nicht verursacht, kann sie von der verantwortlichen Partei Erstattung verlangen.

\footnotetext{
${ }^{355}$ Art. 3 Abs. 1 sowie 46 c, f ii VO EG Nr. 45/2001, ABl. L 8 vom 12. Januar 2001, 1; in der Praxis ist der Europäische Datenbeauftragte noch nicht involviert; Schriever-Steinberg, in: Breitenmoser u.a., Schengen in der Praxis, S. 159 (168).

${ }^{356}$ Art. 109 Abs. 1 S. 1 SDÜ.

${ }^{357}$ Gusy/Gimbal, in: Baldus/Soiné, Internationale polizeiliche Zusammenarbeit, S. 124 (141).

${ }^{358}$ Art. 109 Abs. 1 S. 3 SDÜ.

${ }^{359}$ BGB1 II 1993, 1010.
} 
Betroffene oder potentiell betroffene Personen können sich zur Ausübung ihrer Rechte in Deutschland unmittelbar an die Sirene im Bundeskriminalamt wenden ${ }^{360}$ oder nach Art. 114 Abs. 2 SDÜ die nationale Kontrollinstanz um Überprüfung ihrer Daten bitten.

\section{Rechtsschutz}

Dem Bürger wird in Art. 111 SDÜ ein Klagerecht zur Durchsetzung eines Auskunfts-, Berichtigungs-, Löschungs- oder Schadensersatzanspruchs eingeräumt. Mit der Überführung des Schengen-Besitzstandes in den institutionellen Rahmen der Europäischen Union durch den Vertrag von Amsterdam wäre es grundsätzlich möglich gewesen, eine Zuständigkeit des EuGH zu begründen. Allerdings wurde eine solche Zuständigkeit im Schengen-Protokoll kategorisch für die Bereiche Aufrechterhaltung der öffentlichen Ordnung sowie Schutz der inneren Sicherheit ausgeschlossen. ${ }^{361}$ Somit blieb die Regelung bestehen, dass die Klage vor dem zuständigen Gericht eines jeden Vertragsstaates nach dem jeweiligen nationalen Recht gegen diesen Staat ${ }^{362}$ eingereicht werden kann. ${ }^{363}$ Auch mit dem Inkrafttreten des Vertrags von Lissabon kann nicht von einer Zuständigkeit des EuGH für mit dem SIS zusammenhängende Maßnahmen ausgegangen werden. Zum einen schließt Art. 10 Abs. 1, Abs. 3 des Protokolls über die Übergangsbestimmungen $^{364}$ eine Zuständigkeit des EuGH in diesem Bereich für fünf Jahre ab Inkrafttreten des Vertrags von Lissabon aus. Zum anderen bestimmt Art. 276 AEUV eine dauerhafte Unzuständigkeit des EuGH für mitgliedstaatliche Polizeimaßnahmen.

Nach Art. 111 Abs. 2 SDÜ verpflichten sich die Vertragsparteien, die so ergangenen unanfechtbaren Entscheidungen der Gerichte oder Behörden zu vollziehen. Klagt also jemand in Deutschland erfolgreich gegen die Bundesrepublik Deutschland auf Löschung einer Fahndung, wurde diese Fahndung aber von Frankreich veranlasst, so darf nach Art. 106 Abs. 1 SDÜ nur Frankreich diese Löschung vornehmen. Über Art. 111 Abs. 2 SDÜ ist es jedoch an die unanfechtbare Entscheidung des deutschen Gerichtes gebunden. Lautete die Klage auf Schadensersatz, so hat

\footnotetext{
${ }^{360} \mathrm{Vgl}$. Harings, Grenzüberschreitende Zusammenarbeit, S. 266.

${ }^{361}$ Art. 2 Abs. 1 Unterabs. 3 S. 2 Schengen-Protokoll; Epiney, in: Hummer, Die Europäische Union nach Amsterdam, S. 103 (122)

${ }^{362} \mathrm{Zu}$ diesem Ergebnis kommt auch Harings, der problematisiert, ob der Gerichtsstaat oder der ausschreibende Staat der richtige Klagegegner ist, Harings, Grenzüberschreitende Zusammenarbeit, S. 265 ff.; vgl. auch Gleß/Lüke, JURA 2000, Fn. 49, die dieses Ergebnis ebenfalls unter Bezugnahme auf die erwünschte Rechtssicherheit für den Bürger, die Auslegung des SDÜ sowie die allgemeinen Grundsätze des internationalen Rechts stützen; $G u$ sy/Gimbal, in: Baldus/Soiné, Internationale polizeiliche Zusammenarbeit, S. 124 (142).

${ }^{363} \mathrm{Vgl}$. zur Zuständigkeit der Gerichte, zu Klagegegner, Prüfungsumfang sowie einstweiligem Rechtsschutz ausführlich Harings, Grenzüberschreitende Zusammenarbeit, S. 304 ff.

${ }^{364}$ Protokoll vom 13. Dezember 2007, AB1. C 306,157.
} 
den Schaden zunächst die Bundesrepublik Deutschland zu begleichen. Allerdings kann sie über Art. 116 Abs. 2 SDÜ Erstattung von Frankreich verlangen.

Die Regeln des Art. 111 SDÜ eröffnen theoretisch die Möglichkeit, das für das Klagebegehren günstigste nationale Recht auszusuchen und dann in diesem Staat Klage zu erheben. Praktisch wird ein solches Vorgehen jedoch in aller Regel an Sprachbarrieren und fehlenden finanziellen Möglichkeiten scheitern. ${ }^{365}$ Für den Bürger mag es auf den ersten Blick zudem unübersichtlich erscheinen, dass er aufgrund einer Eintragung im SIS nicht ohne weiteres erkennen kann, welcher Staat diese Ausschreibung veranlasst hat. Allerdings kommt ihm hier zu Hilfe, dass eine Klagemöglichkeit in jedem Vertragsstaat besteht und in Ergänzung hierzu der verantwortliche Staat die Entscheidung nach Art. 111 Abs. 2 SDÜ umsetzen muss. Insofern wird man den nach diesem System gewährleisteten Rechtsschutz insgesamt als zufrieden stellend ansehen können. ${ }^{366}$

\section{Praktische Probleme}

Wie bei allen technischen Neuerungen wurden einige Probleme erst mit Aufnahme des praktischen Betriebes offenbar. Drei dieser Bereiche sollen in diesem Abschnitt erläutert werden.

\section{Abfrageverhalten in den Ländern}

Zunächst erwies sich das Abfrageverhalten in den einzelnen Bundesländern als sehr unterschiedlich. ${ }^{367}$ Hierbei spielte eine Rolle, dass der kontrollierende Polizeibeamte zusätzlich zur nationalen INPOL-Abfrage eine SIS-Abfrage durchführen musste. ${ }^{368}$ Mittlerweile erfolgt in allen Bundesländern mit der INPOL-Abfrage automatisch auch eine N.SIS-Abfrage. Im Trefferfall leuchtet auf dem Bildschirm des Beamten ein besonderes Signal auf, und der Fahndungssatz kann aufgerufen werden. Gleichzeitig wird der Beamte darauf hingewiesen, dass er sofort die Sirene benachrichtigen soll. ${ }^{369}$ Das Problem ist auf diese Weise behoben worden.

\section{Nutzung des SIS durch die Staatsanwaltschaft}

Nach Aufnahme des SIS-Betriebes stellte sich heraus, dass die Zahl der deutschen Ausschreibungen nach Art. 95 SDÜ im Vergleich zu den entsprechenden Ausschreibungen in INPOL rela-

\footnotetext{
${ }^{365}$ Gusy/Gimbal, in: Baldus/Soiné, Internationale polizeiliche Zusammenarbeit, S. 124 (142 f.), Weichert, CR 1990, $62(65)$.

${ }^{366}$ Vgl. Gleß/Lüke, JURA 2000, 400 (406); Harings, Grenzüberschreitende Zusammenarbeit, S. 316 f.

${ }^{367}$ Schuster, in: Bundeskriminalamt, Arbeitstagung „Kriminalitätsbekämpfung im zusammenwachsenden Europa“, S. 117 (127).

${ }^{368}$ Tuffner, KR 2000, 39 (43, Fn. 19).

${ }^{369}$ Tuffner, SIS, MEPA-Zeitung 2005, 21 (22).
} 
tiv gering war. ${ }^{370}$ Man führte das darauf zurück, dass sich die die Fahndung veranlassenden Staatsanwaltschaften im täglichen Dienstbetrieb nicht in der Lage sahen, die Rechtmäßigkeitsprüfung für alle anderen SIS-Teilnehmer-Staaten durchzuführen. Zum Teil wurde gefordert, die Prüfung der Auslieferungsfähigkeit wie in anderen Schengen-Staaten zur Sirene abgeordneten und spezialisierten Juristen zu überlassen. Diese Forderung fand jedoch keine Mehrheit. ${ }^{371}$ Das Bundeskriminalamt behalf sich damit, entsprechende Rechtsübersichten bei den Staatsanwaltschaften zu verteilen. ${ }^{372}$ Eine spürbare Änderung könnte sich nunmehr durch die Geltung des Europäischen Haftbefehls im Verhältnis zu den meisten SIS-Teilnehmerstaaten ergeben. ${ }^{373}$ Eine Prüfung der gegenseitigen Strafbarkeit entfällt hier bei Vorliegen einer Katalogstraftat. Da sich eine SIS-Fahndung aber nicht auf bestimmte Teilnehmerstaaten reduzieren lässt, bleibt weiterhin die Auslieferungsfähigkeit nach norwegischem, isländischem und schweizerischem Recht zu prüfen.

\section{Verknüpfung von Personen- und Sachfahndung}

Bisher ist es nicht möglich, im SIS eine Personenfahndung nach den Art. 95 bis 98 SDÜ mit einer Sachfahndung nach Art. 100 SDÜ zu verknüpfen und umgekehrt. ${ }^{374}$ Zwar können die zuständigen Stellen sowohl einen des Mordes Verdächtigen als auch sein Fluchtfahrzeug ausschreiben. Allerdings ist eine Ausschreibung nach Art. 100 SDÜ davon abhängig, dass das Fahrzeug gestohlen, unterschlagen oder sonst abhanden gekommen ist; zudem können die das Fahrzeug kontrollierenden Beamten nicht sofort durch eine Verknüpfung erkennen, dass der Fahrer einer schwereren Straftat als des Autodiebstahls verdächtig ist und nach Art. 95 SDÜ gesucht wird. Abhilfe würde hier das SIS II bringen. ${ }^{375}$ Danach können einerseits Fahrzeuge ausgeschrieben werden, die lediglich als Fluchtfahrzeug dienen und nicht abhanden gekommen sind, sondern vom Täter als Fahrzeug rechtmäßig genutzt werden. ${ }^{376}$ Zudem wird ein Hinweis auf andere Fahndungskategorien ermöglicht, ${ }^{377}$ wird also die komplexe Wirklichkeit im SIS komplexer als bisher darstellbar sein.

\footnotetext{
${ }^{370}$ Im Jahr 1999 standen etwa 18.000 INPOL-Ausschreibungen ca. 3.300 deutsche Ausschreibungen im SIS gegenüber; vgl. Schuster, in: Bundeskriminalamt, Arbeitstagung „Kriminalitätsbekämpfung im zusammenwachsenden Europa“, S. 117 (126).

${ }^{371}$ Wilkesmann, NStZ 1999, 68 (70).

372 Schuster, in: Bundeskriminalamt, Arbeitstagung „Kriminalitätsbekämpfung im zusammenwachsenden Europa“, S. 117 (126 f.).

${ }^{373}$ Vgl. zur Fahndung mit und ohne Geltung des Europäischen Haftbefehls diesen Teil der Arbeit, III. 1.

${ }^{374}$ Vgl. Würz, Rn. 177, 190, Piosek, S. 72, 77.

${ }^{375} \mathrm{Vgl}$. zum SIS II den 4. Teil der Arbeit.

${ }^{376}$ Art. 38 Abs. 2 a) SIS II-Ratsbeschluss vom 12. Juni 2007, AB1. L 205, 63.

377 Art. 52 SIS II-Ratsbeschluss vom 12. Juni 2007, AB1. L 205, 63; SIS II- Ratsverordnung vom 20. Dezember 2006, AB1. L 381, 4.
} 


\section{Aufgaben der Sirene im BKA}

Der Verantwortungsbereich der Sirene war im Verlauf der Arbeit bereits Gegenstand der Erläuterungen. In diesem Abschnitt sollen die Aufgaben dieser wichtigen Schnittstellen-Einheit noch einmal zusammenfassend dargestellt und an einigen Punkten vertiefend behandelt werden.

\section{Einschlägige Normen}

Im Gegensatz zu ihrer umständlichen Langform ${ }^{378}$ erscheint die Abkürzung „Sirene“ sehr eingängig und vermittelt jedenfalls in der deutschen Sprache die zutreffende Assoziation, dass es hier um die zügige Erledigung dringender Anfragen geht.

Zunächst enthielten die veröffentlichten Rechtsgrundlagen nur wenige Normen zu Aufgaben und Arbeitsweise der Sirenen. So legt Art. 108 SDÜ fest, dass jede Vertragspartei eine Stelle zu bestimmen habe, die als Zentrale für den nationalen Teil des SIS zuständig ist. Die Ausschreibungen sollen zudem über diese Stelle vorgenommen werden. Sie wird als verantwortlich bezeichnet für das reibungslose Funktionieren des nationalen Teils des SIS; die nationale zentrale Stelle soll die erforderlichen Maßnahmen für die Einhaltung der Bestimmungen des SDÜ treffen. Art. 6 Nr. 1. a) des deutschen Zustimmungsgesetzes zum Schengener Übereinkommen ${ }^{379}$ bestimmte das Bundeskriminalamt als diese nationale Stelle und weist ihm als Aufgabe die technische Überwachung als auch den erforderlichen zusätzlichen Informationsaustausch zu.

Eine Entwicklung hin zu mehr Transparenz begann, wenn auch zögerlich, mit der Überführung des Schengen-Besitzstandes in den Rahmen der Europäischen Union im Jahr 1999. ${ }^{380}$

Der Rat der EU entschloss sich im Jahr 2002 zur Veröffentlichung weiter Teile des sogenannten Sirene-Handbuches, das vom Schengener Exekutiv-Ausschuss angenommen und zunächst unter Verschluss gehalten worden war. ${ }^{381}$ Das Handbuch enthält Weisungen für die Bediensteten in den Sirenen und gibt eine detaillierte Beschreibung der Vorschriften und Verfahren für den bioder multilateralen Austausch der Zusatzinformationen. Der Rechtscharakter der Vorschriften ist nicht eindeutig bestimmt. Einerseits wurde das Handbuch ursprünglich vom Exekutivausschuss, an dessen Stelle später der Rat trat, ${ }^{382}$ angenommen, so dass von einer Art Empfehlung des Rates

\footnotetext{
${ }^{378}$ Siehe Fn. 6.

${ }^{379}$ BGB1. II 1993, 1010; aufgehoben durch Art. 5, Art. 7 Abs. 1 S. 1 SIS II-Gesetz vom 06. Juni 2009; nunmehr ist das BKA nach $\S 3$ Abs. 1 a BKAG zentrale nationale Stelle mit den entsprechenden Aufgaben.

${ }^{380}$ Dazu oben in diesem Teil A. VII.

${ }^{381}$ AB1. EG L 8, 34, vom 14. Januar 2003; AB1. C 38, 1, vom 17. Februar 2003 (altes Sirene-Handbuch); AB1. L 317, 1, vom 16. November 2006 (überarbeitetes Sirene-Handbuch), als Grund für die Überarbeitung wird in Erwägungsgrund (2) die Einrichtung neuer Funktionen angeführt, insbesondere die Regelung des Zugriffs auf bestimmte SIS-Daten, vgl. z.B. Art. 101a SDÜ, sowie die lückenlose Protokollierung der Übermittlung personenbezogener Daten; ABl. L 186, 1, vom 15. Juli 2011 (erneut überarbeitetes Sirene-Handbuch; Grund für die Überarbeitung ist die Weiterentwicklung der Normen für die Arbeitsverfahren der SIRENE-Büros und des EU-Rechts, vgl. Erwägungsgrund (2) des Durchführungsbeschlusses), Zöller, Informationssysteme und Vorfeldmaßnahmen, S. 396.

${ }^{382}$ Art. 2 Unterabs. 1 S. 2 Schengen-Protokoll.
} 
gesprochen werden könnte. Andererseits erfolgt die Überarbeitung des Handbuchs regelmäßig durch die Kommission und der Ausdruck „Weisung für die Bediensteten“ lässt eher an Innenrecht für die Verwaltung denken. Unter diesem Gesichtspunkt ließen sich die Vorschriften auch als Verwaltungsvorschriften qualifizieren. Unabhängig von dieser Einstufung ermöglicht die Veröffentlichung dem Bürger einen detaillierten Einblick in die Arbeitsweise der Sirenen.

Erst im Jahr 2005 wurde im SDÜ selbst Art. 92 Abs. 4 eingefügt, ${ }^{383}$ der den Begriff „Sirene“ benennt und die Hauptaufgabe der Sirenen, nämlich den Austausch zusätzlicher Informationen, konkret formuliert. In Ergänzung wurden auch die Normen beschlossen, die sich mit der Löschung dieser zusätzlichen Informationen befassen, Art. 112 a und 113 a SDÜ. ${ }^{384}$

Ein umfassender Schritt in Richtung Transparenz und Nachvollziehbarkeit wäre mit der Inbetriebnahme des SIS II verbunden. Die hierzu verabschiedeten Rechtsinstrumente enthalten präzise Begriffsfestlegungen, ${ }^{385}$ Bestimmungen zu den Sirene-Büros, ${ }^{386} \mathrm{zu}$ Ausschreibungszielen, bedingungen und $\mathrm{zu}$ ergreifenden $\mathrm{Maßnahmen}^{387}$ und stellen einen Bezug zum SireneHandbuch $^{388}$ her.

Der Grund für die zunächst lückenhafte Normierung der Aufgaben der Sirenen hat vermutlich zwei Aspekte. Zum einen meidet die Polizei bisweilen die Öffentlichkeit, wenn sie fürchtet, dadurch den Erfolg ihrer Arbeit zu gefährden. ${ }^{389}$ Zum anderen werden viele Fragestellungen ${ }^{390}$ erst mit dem tatsächlichen Betrieb des SIS ins Bewusstsein gerückt sein.

\section{Aufgaben}

Die Hauptaufgaben der Sirene sind:

- allgemeine Zuständigkeit für das N.SIS ${ }^{391}$

- Vornahme der Ausschreibungen über diese Stelle 392

- Verantwortlichkeit für das reibungslose Funktionieren des N.SIS 393

\footnotetext{
${ }^{383}$ Beschluss 2005/211/JI des Rates vom 24. Februar 2005, AB1. L 68, 44, vom 15. März 2005.

${ }^{384}$ Vgl. Abschnitt IV .; Beschluss 2005/211/JI des Rates vom 24. Februar 2005, AB1. L 68, 44 vom 15. März 2005.

385 Z.B. zu „Zusatzinformationen“, „,ergänzende Daten“, „personenbezogene Daten“, vgl. Art. 3 SIS IIRatsbeschluss, AB1. C 205, 63, vom 7. August 2007.

${ }^{386}$ Art. 7 SIS II-Ratsbeschluss, AB1. C 205, 63, vom 7. August 2007.

${ }^{387}$ Z.B. Art. 26 und 31 SIS II-Ratsbeschluss, AB1. C 205, 63, vom 7. August 2007.

${ }^{388}$ Art. 7 Abs. 2, Art. 8 und Art. 67 SIS II-Ratsbeschluss, AB1. C 205, 63, vom 7. August 2007.

389 Zum Teil hat auch der Gesetzgeber diesem Bedürfnis nach Geheimhaltung Rechnung getragen, vgl. etwa Art. 109 Abs. 2 SDÜ

${ }^{390}$ Z.B. wie lange die zusätzlichen Informationen aus datenschutzrechtlicher Sicht aufbewahrt werden dürfen.

${ }^{391}$ Art. 108 Abs. 1 SDÜ.

${ }^{392}$ Art. 108 Abs. 2 SDÜ.

${ }^{393}$ Art. 108 Abs. 3 SDÜ.
} 
- Ergreifen von Maßnahmen für die Einhaltung der Bestimmungen des SDÜ ${ }^{394}$

- Ansprechpartner für die Sirenen der anderen Mitgliedstaaten ${ }^{395}$

- Ansprechpartner für Länderpolizeien, Bundespolizei, Polizei- und Sicherungsdienst des Deutschen Bundestages, Bundesinnenministerium, Bundesjustizministerium, Staatsanwaltschaften, Amtsgerichte, Ausländerbehörden, Bundesverwaltungsamt/Auswärtiges Amt, Zollkriminalamt, den Bundesbeauftragten für den Datenschutz, Europol, ${ }^{396}$ Eurojust, ${ }^{397}$ Dienste $^{398}$ sowie KfzZulassungsstellen 399400

- Prüfung und Übermittlung der Begleitpapiere zur Fahndung nach Art. 95 SDÜ̈01

- Weitergabe von Zusatzinformationen im Trefferfall ${ }^{402}$

- Herstellen des Kontaktes zwischen ausschreibender Stelle und antreffender Stelle 403

- Übersetzung im Bedarfsfall ${ }^{404}$

- Zuständigkeit für die Kennzeichnung von Ausschreibungen ${ }^{405}$

- Identifizierung von im SIS ausgeschriebenen Personen im In- und Ausland bei Zweifeln an der Identität eines Festgenommenen oder eines Visumsantragstellers ${ }^{406}$

- Beteiligung an Konsultationen nach Art. 25 SDÜ und Art. 5 Schengener Grenzkodex 407408

\section{Personal, Erreichbarkeit, Kommunikation, Statistik}

Die Sirene Deutschland im Bundeskriminalamt in Wiesbaden hat etwa 60 Mitarbeiter und ist 24 Stunden erreichbar. ${ }^{409} 410$ Um die Erledigung der Aufgaben möglichst reibungslos zu gewährleisten und aufeinander abzustimmen, treffen sich die Leiter der Sirenen mindestens zwei Mal jährlich. ${ }^{411}$ Ein gegenseitiges Kennenlernen auf persönlicher und fachlicher Ebene soll auch für die

\footnotetext{
${ }^{394}$ Art. 108 Abs. 3 SDÜ.

${ }^{395}$ Art. 92 Abs. 4 SDÜ; Hemesath, KR 1995, 169 (170).

${ }^{396}$ Art. 101 a SDÜ.

${ }^{397}$ Art. 101 b SDÜ.

${ }^{398}$ Art. 99 Abs. 3 SDÜ i.V.m. $§ 17$ Abs. 3 BVerfSchG.

${ }^{399}$ Art. 102 a SDÜ.

${ }^{400}$ Vgl. Würz, Rn. 164; vgl. Hemesath, KR 1995, 169 (170).

${ }^{401}$ Tuffner, in: Bundeskriminalamt, Festschrift für Herold, S. 239 (250); Tuffner, MEPA-Zeitung 2005, SIS, 21 (23).

${ }^{402}$ Tuffner, MEPA-Zeitung 2005, SIS, 21 (23).

${ }^{403}$ Tuffner, MEPA-Zeitung 2005, SIS, 21 (23).

${ }^{404}$ Gusy/Gimbal, in: Baldus/Soiné, Internationale polizeiliche Zusammenarbeit, S. 124 (125).

${ }^{405}$ Tuffner, in: Bundeskriminalamt, Festschrift für Herold, S. 239 (249).

${ }^{406}$ Tuffner, in: Bundeskriminalamt, Festschrift für Herold, S. 239 (249).

${ }^{407}$ ABl. L 105, 1, vom 13. April 2006.

${ }^{408}$ Vgl. Tuffner, in: Bundeskriminalamt, Festschrift für Herold, S. 239 (249).

${ }^{409}$ Von 6.00 bis 20.00 Uhr, davor und danach werden die Aufgaben vom Kriminaldauerdienst des BKA wahrgenommen; Zöller, Informationssysteme und Vorfeldmaßnahmen, S. 396, Fn. 24.

${ }^{410}$ Sirene-Handbuch, 1.3.1, ABl. L 186, 1, vom 15. Juli 2011; vgl. Zöller, Informationssysteme und Vorfeldmaßnahmen, S. 396; Tuffner, in: Bundeskriminalamt, Festschrift für Herold, S. 239 (249).

${ }^{411}$ Sirene-Handbuch, 1.3.2., Abs. 2, AB1. L 186, 1, vom 15. Juli 2011.
} 
anderen Mitarbeiter der Sirene möglich sein. Aus diesem Grund werden neben den nationalen Schulungen mindestens einmal jährlich gemeinsame internationale Schulungen organisiert. ${ }^{412}$ Eine einheitliche Arbeitssprache auf Sirene-Ebene wurde nicht festgelegt. Die Sirenen verständigen sich untereinander in den jeweiligen Nationalsprachen. Die am häufigsten verwendeten Sprachen sind jedoch Englisch, Französisch und Spanisch. ${ }^{413}$ Für die Übermittlung der Hauptinformationen im SIS wählte man so weit wie möglich eine nationalsprachenunabhängige Standardisierung und Formatierung von Informationen und die Reduzierung von Informationen auf numerische Daten. Für die Darstellung von Lauten wie $\beta$, ä, ö, ü im Deutschen oder é, è, ê im Französischen vereinbarte man sogenannte Transliterationsregeln für die alphanumerische Wiedergabe von Namen und Daten. ${ }^{414}$

Die Sirenen kommunizieren untereinander und mit dem C.SIS über ein gesondertes elektronisches Nachrichtennetz, das sogenannte SISNET. ${ }^{415}$

Der elektronische Austausch von Lichtbildern und Fingerabdrücken zu Identifizierungszwecken ist zwischen den Sirenen über den Sirene-Bild-Transfer, kurz SIRPIT, ${ }^{416}$ möglich. ${ }^{417}$

Alljährlich erstellen die Sirene-Büros Statistiken und leiten sie dem Generalsekretariat des Rates der EU zu. ${ }^{418}$ Angaben zu Ausschreibungszahlen und Trefferfällen finden sich auch in den vom Bundesministerium des Innern herausgegeben Schengen-Erfahrungsberichten. ${ }^{419}$

\section{Ausgewählte praktische Fragestellungen}

Da nicht jeder Arbeitsablauf im einzelnen dargestellt werden kann, sollen einige typische Arbeitsabläufe, die auch im Sirene-Handbuch beschrieben sind, exemplarisch vorgestellt werden.

\section{a. Verfahren bei Mehrfachausschreibungen}

Art. 107 SDÜ enthält eine Regelung für den Fall, dass eine Person durch eine Vertragspartei bereits ausgeschrieben wurde und eine andere Vertragspartei die Person ebenfalls ausschreiben möchte. Die Vorschrift fordert allgemein eine Abstimmung zwischen den Parteien und eröffnet die Möglichkeit, generelle Regelungen zu treffen. ${ }^{420}$ Diese generellen Regelungen finden sich im

\footnotetext{
${ }^{412}$ Sirene-Handbuch, 1.4.2., AB1. L 186, 1, vom 15. Juli 2011.

${ }^{413}$ Allein Frankreich arbeitet ausschließlich mit Französisch, Piosek, S. 91.

${ }^{414}$ Piosek, S. 91 f., Tuffner, in: Bundeskriminalamt, Festschrift für Herold, S. 239 (242 f.).

${ }^{415}$ Bis zum Juni 2002 benutzten die Sirenen untereinander das X-400-Netz, vgl. Bundesministerium des Innern, Schengen-Erfahrungsbericht 2002, S. 10; Tuffner, in: Bundeskriminalamt, Festschrift für Herold, S. 239 (249).

${ }^{416}$ Abkürzung für „SIRene Picture Transfer“.

${ }^{417}$ Sirene-Handbuch, 2.10.1., AB1. L 186, 1, vom 15. Juli 2011.

${ }^{418}$ Sirene-Handbuch, 9., AB1. L 186, 1, vom 15. Juli 2011.

${ }^{419} \mathrm{Vgl}$. zuletzt Bundesministerium des Innern, Schengen-Erfahrungsbericht 2005-2007.

${ }^{420}$ Art. 107 S. 2 SDÜ.
} 
Sirene-Handbuch. Hier wird klargestellt, dass mehrere Ausschreibungen zur selben Person den Endbenutzer verwirren können, ${ }^{421}$ worunter die Funktionsfähigkeit des SIS leiden würde.

Zunächst wird festgelegt, dass für jede Person pro Mitgliedstaat nur eine Ausschreibung in das SIS eingegeben werden darf. Die nationalen Sirenen haben auf die Einhaltung dieser Regel zu achten. $^{422}$

Will ein weiterer Staat das SIS zur Fahndung nutzen, gilt es zweifelsfrei festzustellen, ob es sich bei der auszuschreibenden Person tatsächlich um dieselbe handelt. Stimmen Name, Vorname und Geburtsdatum mit einer schon ausgeschriebenen Person überein, setzt sich die Sirene der fraglichen Vertragspartei mit dem Sirene-Büro des Landes in Verbindung, das bereits nach der Person fahndet. Stellt sich bei der Überprüfung heraus, dass es sich um verschiedene Personen handelt, kann die Ausschreibung gleichwohl erfolgen. Handelt es sich um dieselbe Person, ist das Verfahren für die Eingabe einer Mehrfachausschreibung anzuwenden, das bestimmte Vereinbarkeitsregeln aufstellt. ${ }^{423}$

Ergibt sich aufgrund der genannten Regeln eine Unvereinbarkeit oder Unklarheit, sind Konsultationen zwischen den Sirenen erforderlich, um letztlich einer der Ausschreibungen den Vorrang einzuräumen. Kann keine Einigung erzielt werden, bleibt die zuerst bestehende Ausschreibung im System. Wird einer neuen Ausschreibung der Vorrang gegeben, ist die bestehende Ausschreibung zu löschen. Wird die neue Ausschreibung später gelöscht, erhalten die Staaten, die ihre Ausschreibung nicht eingeben konnten, über das C.SIS und die Sirene des betreffenden Staates wiederum über das N.SIS Nachricht. Ein neues Verfahren zur Eingabe der zurückgestellten Ausschreibung kann durchgeführt werden. ${ }^{424}$

\section{b. Kennzeichnung von Ausschreibungen}

Art. 94 Abs. 4 SDÜ, jeweils in Verbindung mit Art. 95, 97 und 99 SDÜ, sowie Art. 95 Abs. 3 und Art. 99 Abs. 6 SDÜ sehen die Möglichkeit einer Kennzeichnung vor, wenn eine Vertragspartei eine Ausschreibung in ihrem Hoheitsgebiet nicht vollziehen möchte. ${ }^{425}$ Art. 95 Abs. 3 und Art. 99 Abs. 6 SDÜ erläutern die Voraussetzungen für eine sofortige Kennzeichnung der Ausschreibung, während Art. 94 Abs. 4 i.V.m. dem jeweiligen o.g. Artikel die nachträgliche Kennzeichnung meint. Wünscht ein Mitgliedstaat eine Kennzeichnung, ersucht er den ausschreiben-

\footnotetext{
${ }^{421}$ Sirene-Handbuch, 2.1., AB1. L 186, 1, vom 15. Juli 2011.

${ }^{422}$ Sirene-Handbuch, 2.1.1. Abs. 1 ABl. L 186, 1, vom 15. Juli 2011.

${ }^{423}$ Sirene-Handbuch, 2.1.1. und 2.1.2., AB1. L 186, 1, vom 15. Juli 2011.

${ }^{424}$ Sirene-Handbuch, 2.1.3., AB1. L 186, 1, vom 15. Juli 2011.

${ }^{425} \mathrm{Vgl}$. hierzu diesen Teil der Arbeit, B. II. 5. sowie B. III. 1. a. aa., 3. a. und 5. a. dd.
} 
den Staat unter Angabe der Gründe darum. ${ }^{426}$ Nach einem Informationsaustausch gibt es mehrere Möglichkeiten: Der ersuchende Mitgliedstaat bleibt bei seinem Begehren und überzeugt mit seinen Gründen auch den ausschreibenden Staat. In diesem - vermutlich seltenen - Fall, wird die Ausschreibung insgesamt aus dem SIS gelöscht. ${ }^{427}$

Häufiger wird die Konstellation vorkommen, dass der ersuchende Mitgliedstaat bei seinem Begehren bleibt, der ausschreibende Staat jedoch die Ausschreibung beibehalten will. Dann ist die Kennzeichnung umgehend anzubringen. ${ }^{428}$

Es besteht weiterhin die Möglichkeit, dass der ersuchende Mitgliedstaat im Rahmen des Informationsaustausches vom ausschreibenden Staat von der Entbehrlichkeit einer Kennzeichnung überzeugt wird. Folglich unterbleibt diese; die Ausschreibung ist auch im N.SIS des ersuchenden Staates sichtbar. ${ }^{429}$

Schließlich können die Staaten bei einer Ausschreibung nach Art. 95 SDÜ auch zu dem Ergebnis kommen, dass eine Änderung in eine Ausschreibung zur Aufenthaltsermittlung den Interessen der Staaten am ehesten gerecht würde. In diesem Fall wird die Ausschreibung zur Festnahme im N.SIS der ersuchenden Vertragspartei in eine solche zur Aufenthaltsermittlung umgewandelt. ${ }^{430}$ 431

Das Sirene-Handbuch sieht weiterhin die Möglichkeit vor, dass ein Mitgliedstaat die Sirene eines anderen Mitgliedstaates um systematische Kennzeichnung der Ausschreibungen nach Art. 95 SDÜ bittet, wenn die gesuchte Person ein eigener Staatsangehöriger ist. Diese Bestimmung gilt nur für die Fälle, in denen der Rahmenbeschluss über den Europäischen Haftbefehl ${ }^{432}$ keine Anwendung findet. ${ }^{433}$

\section{c. Nichtdurchführbarkeit der Maßnahme}

Soweit eine eigentlich durchzuführende Maßnahme nicht ergriffen werden kann, soll der betreffende Mitgliedstaat die ausschreibende Partei unverzüglich über das Sirene-Büro benachrichtigen und seine Gründe erläutern. Die Staaten sollen sich unter Beachtung der Vorschriften des SDÜ und ihrer nationalen Rechtsvorschriften auf gegebenenfalls alternativ zu ergreifende Maßnahmen einigen. ${ }^{434}$

\footnotetext{
${ }^{426}$ Sirene-Handbuch, 2.15.1. a), AB1. L 186, 1, vom 15. Juli 2011.

${ }^{427}$ Sirene-Handbuch, 2.15.1. c), AB1. L 186, 1, vom 15. Juli 2011.

${ }^{428}$ Sirene-Handbuch, 2.15. 1. b), AB1. L 186, 1, vom 15. Juli 2011.

${ }^{429}$ Sirene-Handbuch, 2.15.1. c), AB1. L 186, 1, vom 15. Juli 2011.

${ }^{430}$ Vgl. Art. 95 Abs. 5 SDÜ, Sirene-Handbuch, 3.5. Abs. 2, ABl. L 186, 1, vom 15. Juli 2011.

${ }^{431}$ In aller Regel nach Art. 98 SDÜ.

${ }^{432}$ Rahmenbeschluss 2002/584/JI des Rates, AB1. L 190, 1, vom 18. Juli 2002.

${ }^{433}$ Sirene-Handbuch, 3.5.1., AB1. L 186, 1, vom 15. Juli 2011.

${ }^{434}$ Art. 104 Abs. 3 S. 2 SDÜ; Sirene-Handbuch, 2.3., AB1. L 186, 1, vom 15. Juli 2011.
} 


\section{d. Änderung des Zwecks}

Art. 102 SDÜ bestimmt, dass die innerhalb der einzelnen Fahndungskategorien gespeicherten Daten nach den Art. 95 bis 100 SDÜ grundsätzlich nur für die der jeweiligen Ausschreibung entsprechenden Zwecke genutzt werden dürfen.

Hiervon gibt es jedoch eine allgemein formulierte Ausnahme. So darf die eine Ausschreibungskategorie durch eine andere ersetzt werden, soweit dies zur Abwehr einer schwerwiegenden und unmittelbar bevorstehenden Gefahr für die öffentliche Sicherheit und Ordnung oder aus schwerwiegenden Gründen der Sicherheit des Staates oder zur Verhütung einer Straftat mit erheblicher Bedeutung erforderlich ist. Erforderlich ist zudem die Zustimmung des ausschreibenden Staates. $^{435}$

Das Sirene-Handbuch hält ein Verfahren zur Zweckänderung nach der o.g. Vorschrift nur in Trefferfällen für angezeigt. Danach teilt der entdeckende Mitgliedstaat dem ausschreibenden Mitgliedstaat über seine Sirene mit, aus welchen Gründen er um Änderung des ursprünglichen Zwecks ersucht. Der ausschreibende Mitgliedstaat prüft diese Anfrage so schnell wie möglich und teilt seine Entscheidung gegebenenfalls vorbehaltlich gewisser Auflagen für die Nutzung der Daten mit. Der entdeckende Mitgliedstaat handelt gemäß dieser Antwort. ${ }^{436}$

\section{e. Rechtsprüfungen ${ }^{437}$}

In den Sirenen vieler Vertragsstaaten führen dort eingesetzte Richter und Staatsanwälte Rechtsprüfungen u.a. zur Frage der Auslieferungsfähigkeit durch. Bei der Sirene Deutschland findet eine Rechtsprüfung durch Polizeivollzugsbeamte statt. Da das Ergebnis ihrer Prüfung für die ausschreibende Stelle nicht bindend ist und vielmehr beratenden Charakter hat, ${ }^{438}$ bestehen diesbezüglich keine rechtlichen Bedenken. Zwar werden die meisten ausschreibenden Stellen wie Staatsanwälte im Rahmen einer Ausschreibung nach Art. 95 SDÜ dieser Beratungsempfehlung folgen; gleichwohl entlässt sie diese Empfehlung nicht aus der Pflicht, unter Einbeziehung der Fachkenntnisse und Erfahrung der Sirene-Mitarbeiter eine eigenverantwortliche Entscheidung zu treffen.

\section{f. Bewertung}

Diese insgesamt sehr detaillierten Regeln machen deutlich, dass es mit Hilfe der Sirenen feste Kommunikationsstrukturen geben soll. Sie sind Ansprechpartner sowohl für die standardmäßige

\footnotetext{
${ }^{435}$ Art. 102 Abs. 3 SDÜ.

${ }^{436}$ Sirene-Handbuch, 2.4., ABl. L 186, 1, vom 15. Juli 2011.

${ }^{437} \mathrm{Vgl}$. hierzu auch diesen Teil der Arbeit, B. V. 2.

${ }^{438}$ Vgl. Wilkesmann, NStZ 1999, 68 (69); Tuffner, SIS, MEPA-Zeitung 2005, 21 (23); vgl. Sirene-Handbuch, 1.4.1., AB1. L 186, 1, vom 15. Juli 2011.
} 
Übermittlung von Informationen als auch dann, wenn es Meinungsverschiedenheiten gibt und ein Vorgang individuell bearbeitet werden muss. Dieser immer wiederkehrende konkrete Verweis auf die Sirene dient dazu, das System so effizient wie möglich zu nutzen und zwischenstaatlichen Befindlichkeiten von vornherein wenig Raum zu geben. Es soll verhindert werden, dass ein Staat aufgrund bestehender Verstimmungen seine Ausschreibungen trotz Unvereinbarkeit eingibt oder etwa das System vorübergehend gar nicht mehr in Anspruch nimmt.

Immer wieder findet sich im Sirene-Handbuch auch die Aufforderung, Probleme sofort zur Sprache zu bringen oder beim Wegfall von Bedenken unverzüglich das normale Verfahren in Gang zu setzen. ${ }^{439}$ Damit soll unter stetiger Einbindung der Sirenen gewährleistet werden, dass das SIS tatsächlich ein schnelles und aktuelles System ist.

\section{Sonderproblem: Missbräuchlich verwendete Identität}

Abschließend soll in diesem Abschnitt zu den Aufgaben der Sirene ein Problem geschildert werden, dessen Brisanz unter maßgeblicher Beteiligung der Sirenen entschärft werden konnte.

Die Problematik der sogenannten „Misused identity“ hat potentielle Auswirkung für jeden Bürger. Ihr liegt folgende Konstellation zugrunde: Im SIS ausgeschriebene Personen benutzen häufiger die Personalien eines unbescholtenen Dritten und legen bei Kontrollen beispielsweise dessen abhanden gekommenen Personalausweis vor. Das SIS bietet in Art. 94 Abs. 3 S. 1 lit. a SDÜ die Möglichkeit, zu den gesuchten Personen diese bekanntermaßen benutzten Aliasnamen zu speichern. Allerdings gab es zunächst keine Möglichkeit, im System einen Hinweis darauf einzufügen, dass es auch eine reale Person mit dem Aliasnamen gibt, gegen die aber nicht ermittelt wird. Für den Betroffenen bedeutete diese Situation nicht unerhebliche Unannehmlichkeiten. Eine Ausschreibung nach Art. 96 SDÜ führte beispielsweise zur Verweigerung der Einreise aus dem Nicht-Schengen-Gebiet; bei einer Ausschreibung nach Art. 95 SDÜ wurde der Betroffene ohne weiteres bis zur Klärung seiner tatsächlichen Identität in Gewahrsam genommen und musste Befragungen und erkennungsdienstliche Maßnahmen dulden. Die Möglichkeit, bekanntermaßen missbräuchlich verwendete Personalien nicht zu speichern, wurde zwar erwogen, aber eine solche Vorgehensweise wurde nicht beschlossen. Zunächst behalf man sich in Deutschland damit, dem Dritten nach seiner erkennungsdienstlichen Behandlung eine Bescheinigung auszustellen, dass er nicht mit der gesuchten Person identisch ist. $^{440}$

\footnotetext{
${ }^{439}$ Sirene-Handbuch, z.B. 1.3.5., Abs. 4 und 2.15., Abs. 2, S. 4, AB1. L 186, 1, vom 15. Juli 2011.

${ }^{440}$ Zöller, Informationssysteme und Vorfeldmaßnahmen, S. 416; Schriever-Steinberg, DuD 2000, 209 (211).
} 
Mittlerweile ist es technisch möglich, im SIS einen Hinweis darauf anzubringen, dass die angegebenen Personalien vermutlich missbräuchlich verwendet werden und dass Zusatzinformationen im BKA bei der Sirene vorliegen. ${ }^{441}$ Voraussetzung ist aber, dass zuvor die Nichtidentität zwischen dem berechtigten Inhaber und der im SIS gesuchten Person zweifelsfrei festgestellt wird. Dazu muss grundsätzlich erkennungsdienstliches Material, also insbesondere Fingerabdrücke und Lichtbilder, der tatsächlich gesuchten Person vorhanden sein. Zusätzlich muss sich der Dritte zu einem Zeitpunkt seiner Wahl und mit anderer Zielrichtung als beim eben beschriebenen Szenario geschildert bei einer Polizeidienststelle erkennungsdienstlich untersuchen lassen. Im BKA wird anschließend festgestellt, ob der vermeintliche Dritte tatsächlich eine andere Person als die gesuchte ist. Ist dies der Fall, werden alle erhobenen Daten mit Zustimmung des Betroffenen bei der Sirene als Zusatzinformation hinterlegt. Wird der Dritte nun kontrolliert, kann über das beim BKA vorhandene Material die wahre Identität schneller als zuvor ermittelt werden. Nach Löschung der Fahndung sind auch die Daten der Person zu löschen, deren Identität missbräuchlich verwendet wurde. ${ }^{42}$ Die hier gefundene Lösung ist das Ergebnis einer Abwägung zwischen den berechtigten Interessen des unbescholtenen Dritten, nicht ohne materiellen Grund in seiner Freiheit und seiner Freizügigkeit eingeschränkt zu werden und dem Strafverfolgungsinteresse bzw. dem Sicherheitsinteresse des Staates. Da der Dritte weiterhin erkennungsdienstliche Maßnahmen und die Speicherung seiner persönlichen Daten dulden sowie von einer Sonderbehandlung bei einer polizeilichen Kontrolle ausgehen muss, ${ }^{443}$ ist diese Abwägung im Ergebnis zugunsten der staatlichen Interessen ausgegangen.

An dieser Stelle ist, je nachdem, ob die Polizei im Zusammenhang mit der Klärung der Identität präventive oder repressive Zwecke verfolgt, an Entschädigungsansprüche des Betroffenen nach Polizeirecht ${ }^{444}$ oder aus dem allgemeinen Aufopferungsanspruch ${ }^{445} \mathrm{zu}$ denken. Vieles spricht dafür, die Inanspruchnahme als ein Sonderopfer für die Allgemeinheit anzusehen, das so vom Gesetzgeber nicht voraus gesehen wurde und mit dessen Auferlegung ein Betroffener grundsätzlich nicht zu rechnen braucht.

\footnotetext{
${ }^{441}$ Sog. „Code 3“, Sirene-Handbuch, 2.8. Abs. 2 bis 4, AB1. L 186, 1, vom 15. Juli 2011; Der Bundesbeauftragte für den Datenschutz, 19. Tätigkeitsbericht, S. 108.

${ }^{442}$ Sirene-Handbuch, 2.8. Abs. 10 S. 2, ABl. L 186, 1, vom 15. Juli 2011.

${ }^{443}$ Zwar schreibt das Sirene-Handbuch eine ausdrückliche Prüfung der Erforderlichkeit der weiteren Ausschreibung im Falle einer „Misused Identity“ vor, vgl. Sirene-Handbuch, 2.8. Abs. 9, ABl. L 186, 1, vom 15. Juli 2011, gleichwohl wird die Ausschreibung um des Fahndungserfolges willen in den meisten Fällen bestehen bleiben.

${ }^{444}$ In Niedersachsen gemäß § 80 NSOG bzw. § 80 NSOG analog, vgl. hierzu Ipsen, Niedersächsisches POR, Rn. $142 \mathrm{ff}$. sowie $661 \mathrm{ff}$.

${ }^{445} \mathrm{Vgl}$. hierzu grundlegend Ossenbühl, StaatshaftungsR, S. $124 \mathrm{ff..}$
} 


\section{Abgrenzung des SIS zu anderen Systemen und Formen der Zusammenarbeit}

Zum besseren Überblick soll im Folgenden dargestellt werden, welche anderen Informationssysteme und Formen der Zusammenarbeit es im Umfeld des SIS gibt und worin sie sich von diesem unterscheiden.

\section{Interpol}

Wie bereits erörtert, gab es die Interpol-Fahndung schon vor der Schengen-Fahndung. Im Schengen-Raum hat eine SIS-Fahndung jedoch nunmehr Vorrang. Außerhalb des SchengenGebietes steht weiterhin eine Interpol-Fahndung zur Verfügung. ${ }^{446}$

\section{Zielfahndung}

Im Fall von Zielfahndungen hat das ersuchende Land konkrete Anhaltspunkte über den Aufenthaltsort einer gesuchten Person oder den Verbleib einer Sache. Diese Kenntnis ermöglicht gezielte, örtlich begrenzte Fahndungsmaßnahmen. Rechtsgrundlage hierfür ist eine entsprechende Ausschreibung im SIS. ${ }^{447}$

\section{Europol-Informationssystem und Arbeitsdateien zu Analysezwecken}

Zur Erreichung seiner Ziele unterhält das Europäische Polizeiamt - Europol - sowohl ein Informationssystem sowie Arbeitsdateien zu Analysezwecken. Ziel von Europol ist es, die Tätigkeit der zuständigen Behörden der Mitgliedstaaten sowie deren Zusammenarbeit bei der Prävention und Bekämpfung von organisierter Kriminalität, Terrorismus und anderen Formen schwerer Kriminalität zu unterstützen und zu verstärken, wenn zwei oder mehr Mitgliedstaaten betroffen sind. ${ }^{448}$ Eine Beschreibung der Aufgaben von Europol, deren Erfüllung sowohl das Informationssystem wie auch die Arbeitsdateien zu Analysezwecken dienen sollen, ${ }^{449}$ findet sich in Art. 5 EuropolB. Darin wird deutlich, dass es um die Bereiche Ermittlung und Auswertung geht. Zwar werden die in den Dateien von Europol enthaltenen Daten häufig mit den SIS-Daten identisch sein, jedoch ist die unmittelbare Fahndung, der das SIS dient, nicht Aufgabe von Europol.

\footnotetext{
${ }^{446}$ Sirene-Handbuch, 2.12., 2.12.1. AB1. L 186, 1, vom 15. Juli 2011; Hemesath, KR 1995, 169 (171).

${ }^{447}$ Sirene-Handbuch, 2.14.1., 2.14.2., ABl. L 186, 1, vom 15. Juli 2011.

${ }^{448}$ Art. 3 UA 1 sowie Art. 10 Abs. 1 S. 1 und 2 des Beschlusses des Rates 2009/371/JI vom 6. April 2009 zur Errichtung des Europäischen Polizeiamts (Europol), AB1. L 121, 37, im Folgenden EuropolB; in Kraft seit dem 1. Januar 2010, vgl. Art. 64 Abs. 2 S. 1 1. Alt. EuropolB; Rechtsvorgänger ist Europol, wie es durch das entsprechende Übereinkommen von 1995 ins Leben gerufen wurde, vgl. Art. 1 Abs. 2 EuropolB sowie Europol-Übereinkommen vom 26. Juli 1995, AB1. C 316, 2.

${ }^{449}$ Art. 12 Abs. 1 S. 1 und Art. 14 Abs. 1 S. 1 EuropolB, AB1. L 121, 37, vom 15. Mai 2009.
} 


\section{Fallbearbeitungssystem von Eurojust ${ }^{450}$}

Mit Beschluss vom 28. Februar $2002^{451}$ hat der Rat der Europäischen Union entschieden, eine Stelle einzurichten, bei der Staatsanwälte, Richter oder Polizeibeamte, die nach dem Recht des jeweiligen Mitgliedsstaates gleichwertige Befugnisse haben, zusammengeschlossen sind. Sie sollen bei schweren Straftaten mit grenzüberschreitendem Bezug die Koordinierung der laufenden Ermittlungen und Strafverfolgungsmaßnahmen zwischen den Mitgliedstaaten fördern sowie insgesamt die Zusammenarbeit der zuständigen Behörden der Mitgliedstaaten auf diesem Gebiet verbessern. ${ }^{452}$ Eurojust unterhält zur Erreichung dieser Ziele ein Fallbearbeitungssystem, das aus einem Index mit personenbezogenen Daten, einem Index ohne personenbezogene Daten sowie aus befristet geführten Arbeitsdateien besteht. ${ }^{453}$ Die in diesem Fallbearbeitungssystem enthaltenen Daten sind z.T. identisch mit den im SIS enthaltenen Daten. Sie dienen jedoch dem Zweck der Koordinierung von Ermittlungen und Strafverfolgungsmaßnahmen, nicht der Fahndung nach einer konkreten Person oder Sache.

\section{Europäisches Justizielles Netz in Strafsachen}

Wichtiger Ansprechpartner der bei Eurojust tätigen Staatsanwälte, Richter und Polizisten sind die Kontaktstellen des Europäischen Justiziellen Netzes, kurz EJN, das im Jahr 1998 durch die EU ins Leben gerufen ${ }^{454}$ und 2008 auf eine neue Rechtsgrundlage ${ }^{455}$ gestellt wurde. Im Gegensatz zu Eurojust gibt es keine zentrale Organisation, vielmehr kommen die verantwortlichen Ansprechpartner der nationalen Kontaktstellen aus den Mitgliedstaaten regelmäßig zu gemeinsamen Treffen zusammen. ${ }^{456}$ Aufgabe des Netzes ist es, die justizielle Zusammenarbeit zwischen den Mitgliedstaaten durch Herstellung sachdienlicher Kontakte sowie rechtlicher und praktischer Informationen im Einzelfall zu verbessern. Zudem stellt das Netz Angaben zur einschlägigen aktuellen Rechtslage im jeweiligen Mitgliedstaat zur Verfügung. ${ }^{457}$ Das EJN bringt mit anderen Worten in Bezug auf konkrete Verfahren in Strafsachen die richtigen Personen zueinander und

\footnotetext{
${ }^{450} \mathrm{Vgl}$. zur Bedeutung von Eurojust insgesamt die Arbeit von Kahlke, „Eurojust - Auf dem Weg zu einer Europäischen Staatsanwaltschaft?".

${ }^{451}$ Beschluss des Rates vom 28. Februar 2002 über die Errichtung von Eurojust zur Verstärkung der Bekämpfung der schweren Kriminalität (2002/187/JI), AB1. L 63, 1; geändert durch Beschluss 2003/659/JI des Rates vom 18. Juni 2003, AB1. L 245, 44, sowie Beschluss 2009/426/JI des Rates vom 16. Dezember 2008 zur Stärkung von Eurojust und zur Änderung des Beschlusses 2002/187/JI über die Errichung von Eurojust zur Verstärkung der Bekämpfung der schweren Kriminalität, ABl. L 138, 14, vom 4. Juni 2009; die konsolidierte Fassung, die sich aus den o.g. Beschlüssen der Jahre 2002, 2003 und 2008 ergibt, wird im Folgenden als Eurojust-Beschluss bezeichnet.

${ }^{452}$ Art. 2 Abs. 1, Art. 3 Abs. 1 Eurojust-Beschluss.

${ }^{453}$ Art. 16 Abs. 1 und 2 Eurojust-Beschluss.

${ }^{454}$ Gemeinsame Maßnahme vom 29. Juni 1998 zur Einrichtung eines Europäischen Justiziellen Netzes, AB1. L 191, 4.

${ }^{455}$ Beschluss 2008/976/JI des Rates vom 16. Dezember 2008 über das Europäische Justizielle Netz, ABl. L 348, 130 , im Folgenden EJN-Beschluss.

${ }^{456}$ Art. 3 Buchst. b EJN-Beschluss.

${ }^{457}$ Art. 3 Buchst. a, Art. 4 Abs. 1 und 2, Art. 7 Buchst. c und d EJN-Beschluss.
} 
versorgt sie mit den notwendigen abstrakten rechtlichen Informationen. Es betreibt kein System, das der Fahndung nach Personen oder Sachen im konkreten Fall dient.

\section{Europäische Grenzschutzagentur}

Die europäische Agentur für die operative Zusammenarbeit an den Außengrenzen der Mitgliedstaaten der EU, ${ }^{458}$ kurz Frontex, nahm ihre Arbeit am 1. Mai $2005^{459}$ auf und hat die folgenden Aufgaben:

a) Koordinierung der operativen Zusammenarbeit der Mitgliedstaaten im Bereich des Schutzes der Außengrenzen

b) Unterstützung der Mitgliedstaaten bei der Ausbildung der Grenzschutzbeamten

c) Durchführung von Risikoanalysen

d) Verfolgung der Entwicklung im Bereich der einschlägigen Forschung

e) Unterstützung der Mitgliedstaaten in Situationen, die eine verstärkte technische und operative Unterstützung an den Außengrenzen erfordern

f) Unterstützung der Mitgliedstaaten bei der Organisation gemeinsamer Rückführungsaktionen

g) rasche operative und zeitlich befristete Unterstützung eines darum ersuchenden Mitgliedstaates, der einem plötzlichen und außergewöhnlichen Druck ausgesetzt ist, insbesondere durch den Zustrom einer großen Anzahl von Drittstaatsangehörigen an bestimmten Stellen der Außengrenzen, die versuchen, illegal in sein Hoheitsgebiet einzureisen. ${ }^{460}$

Unter der Überschrift „Systeme für den Informationsaustausch“ wird der Agentur die Befugnis an die Hand gegeben, alle erforderlichen Maßnahmen zu ergreifen, um den Austausch von Informationen, die für ihre Tätigkeit von Bedeutung sind, mit der Kommission und den Mitgliedstaaten zu erleichtern. ${ }^{461}$ Gemeint sind damit im Hinblick auf die oben aufgeführten Aufgaben jedoch keine personenbezogenen Daten wie sie das SIS enthält. Dennoch lässt sich eine unmittelbare Verbindung zwischen Frontex und SIS herstellen. Die Ausschreibungskategorie des Art. 96 SDÜ dient der Einreiseverweigerung von Drittstaatsangehörigen. Die kontrollierenden Beamten, zu denen in bestimmten Situationen auch die Beamten der Agentur zählen, ${ }^{462}$ müssen das

\footnotetext{
${ }^{458}$ VO (EG) Nr. 2007/2004 des Rates vom 26. Oktober 2004 zur Errichtung einer Europäischen Agentur für die operative Zusammenarbeit an den Außengrenzen der Mitgliedstaaten der Europäischen Union, ABl. L 349, 1, VO (EG) 863/2007 des Europäischen Parlaments und des Rates vom 11. Juni 2007 über einen Mechanismus zur Bildung von Soforteinsatzteams für Grenzsicherungszwecke und zur Änderung der VO (EG) Nr. 2007/2004 des Rates hinsichtlich dieses Mechanismus und der Regelung der Aufgaben und Befugnisse von abgestellten Beamten, ABl. L 199, 30, sowie VO (EU) Nr. 1168/2011 des Europäischen Parlamentes und des Rates vom 25. Oktober 2011 zur Änderung der VO (EG) Nr. 2007/2004, AB1. L 304, 1; im Folgenden wird die konsolidierte Fassung als „VO Frontex" bezeichnet.

${ }^{459}$ Art. 34 Unterabs. 2 VO Frontex.

${ }^{460}$ Art. 2 Abs. 1, lit. a bis g sowie Art. 8 a VO Frontex.

461 Art. 11 VO Frontex.

${ }^{462}$ Bei Erfüllung der Aufgaben nach Art. 2 Abs. 1 lit. e bis g VO Frontex.
} 
SIS auf eine Ausschreibung nach Art. 96 SDÜ hin abfragen und die Einreise verweigern, wenn es einen entsprechenden Eintrag gibt. ${ }^{463}$

\section{Visa-Informationssystem}

Das geplante Visa-Informationssystem, kurz VIS, ${ }^{464}$ soll folgende Aufgaben erfüllen:

a) die Visumantragsverfahren erleichtern,

b) die Umgehung der Kriterien zur Bestimmung eines Mitgliedstaates, der für die Antragsprüfung zuständig ist, verhindern,

c) die Betrugsbekämpfung erleichtern,

d) die Kontrollen an den Außengrenzübergangsstellen und im Hoheitsgebiet der Mitgliedstaaten erleichtern,

e) zur Identifizierung von Personen beitragen, die die Voraussetzungen für die Einreise in das Hoheitsgebiet der Mitgliedstaaten oder den dortigen Aufenthalt nicht oder nicht mehr erfüllen,

f) die Anwendung der Regelungen, die sich mit der Bestimmung des für die Prüfung eines Asylbegehrens zuständigen Mitgliedstaates beschäftigen, erleichtern und

g) einen Beitrag zur Verhinderung von Gefahren für die innere Sicherheit der einzelnen Mitgliedstaaten leisten. ${ }^{465}$

Mit Hilfe des VIS tauschen die Mitgliedstaaten die notwendigen personenbezogenen Daten über die Antragsteller und sämtliche mit ihnen in Zusammenhang stehenden Visa aus. ${ }^{466}$

Eine inhaltliche Verbindung zum SIS besteht wiederum über Art. 96 SDÜ. Es erhält kein Visum, wer zur Einreiseverweigerung ausgeschrieben ist. ${ }^{467}$

\section{Eurodac}

Der Begriff „Eurodac“ ist zusammengesetzt aus den Wörtern „Europa“ und „Daktyloskopie“ und bezeichnet eine europäische Datenbank zur Speicherung von Fingerabdrücken. Der Inhalt dieser

\footnotetext{
${ }^{463}$ Art. 5 Abs. 1 lit. d), Art. 7 Abs. 3 lit. a), Art. 13 Abs. 1 S. 1 Schengener Grenzkodex, ABl. L 105, 1, vom 13. April 2006.

${ }^{464}$ Entscheidung 2004/512/EG des Rates vom 8. Juni 2004 zur Einrichtung des Visa-Informationssystems (VIS), ABl. L 213, 5; VO (EG) Nr. 767/2008 des Europäischen Parlaments und des Rates vom 9. Juli 2008 über das VisaInformationssystem (VIS) und den Datenaustausch zwischen den Mitgliedsstaaten über Visa für einen kurzfristigen Aufenthalt (VIS-VO), ABl. L 218, 60, geändert durch die VO (EG) Nr. 810/2009 des Europäischen Parlamentes und des Rates vom 13. Juli 2009 über einen Visakodex der Gemeinschaft, ABl. L 243, 1; im Folgenden wird die konsolidierte Fassung als VIS-VO bezeichnet.

${ }^{465}$ Art. 2 lit. a bis g VIS-VO.

${ }^{466} \mathrm{Zu}$ den ausgetauschten Daten gehören auch Fotos und Fingerabdrücke der Antragsteller, Art. 5 Abs. 1 lit. b und c VIS-VO.

${ }^{467}$ Art. 12 Abs. 2 lit. a) v) VIS-VO.
} 
Datenbank soll bei der Bestimmung des für die Prüfung eines Asylantrages zuständigen Mitgliedstaates herangezogen werden. ${ }^{468}$

Eine inhaltliche Verknüpfung mit dem SIS gibt es nicht, da es ausschließlich um die Bestimmung der Zuständigkeit eines Mitgliedstaates geht.

\section{Prümer Zusammenarbeit}

Ziel des Vertrags von Prüm ${ }^{469}$ bzw. des diesen Vertrag ergänzenden Ratsbeschlusses ${ }^{470}$ ist die Vertiefung der grenzüberschreitenden Zusammenarbeit insbesondere zur Bekämpfung des Terrorismus und der grenzüberschreitenden Kriminalität. Zur Erreichung dieses Ziels haben die Mitgliedstaaten kein gemeinsames zentrales System errichtet, sondern erlauben sich den gegenseitigen Zugriff auf national elektronisch gespeicherte DNA-Profile, ${ }^{471}$ daktyloskopische Daten ${ }^{472}$ sowie Daten aus Fahrzeugregistern. ${ }^{473}$ Daneben stellt der Ratsbeschluss Prüm Regeln für die Übermittlung von Daten im Einzelfall auf, sei es im Zusammenhang mit Großveranstaltungen oder zur Verhinderung terroristischer Straftaten. ${ }^{474}$ Zudem enthält der Beschluss Vorschriften über weitere Formen der Zusammenarbeit. ${ }^{475}$

Der Ratsbeschluss Prüm setzt im Verhältnis zum SIS an dem Punkt an, ab dem der Beamte vor Ort Zusatzinformationen zur Identifizierung der kontrollierten Person oder Sache benötigt. Über die beschleunigten Zugriffsmöglichkeiten wird es der jeweiligen Sirene schneller als zuvor gelingen, die notwendigen Informationen wie DNA-Profile, Fingerabdrücke oder mit Fahrzeugen in Zusammenhang stehende Daten beizubringen. Die hierauf bezogenen Regeln des Ratsbeschlusses Prüm ergänzen damit die Zusammenarbeit, die das SIS ermöglicht.

\footnotetext{
${ }^{468}$ Art. 1 Abs. 1, Art. 4 Abs. 5, Art. 15 Abs. 1 UA 2 VO (EG) Nr. 2725/2000 des Rates vom 11. Dezember 2000 über die Einrichtung von „Eurodac“ für den Vergleich von Fingerabdrücken zum Zwecke der effektiven Anwendung des Dubliner Übereinkommens, ABl. L 316, 1; vgl. Lexikon unter http://www.bmi.bund.de/DE/Service/Glossar/Functions/glossar.html?nn=105094\&lv2=296422\&lv3=152174, Abruf vom 14. April 2012.

${ }^{469}$ Vertrag vom 27. Mai 2005 zwischen Belgien, Deutschland, Frankreich, Luxemburg, Niederlande, Österreich und Spanien, BGB1. II 2006, 628, Zustimmung der Bundesrepublik Deutschland durch Ausführungsgesetz vom 10. Juli 2006, BGB1. 2006, 1458.

${ }^{470}$ Beschluss 2008/615/JI des Rates vom 23. Juni 2008, AB1. L 210, 1, im Folgenden: Ratsbeschluss Prüm.

${ }^{471}$ Art. 2 ff. Ratsbeschluss Prüm.

${ }^{472}$ Art. 8 ff. Ratsbeschluss Prüm.

${ }^{473}$ Art. 12 ff. Ratsbeschluss Prüm.

${ }^{474}$ Art. 13 ff. und Art. 16 Ratsbeschluss Prüm.

${ }^{475}$ Art. 17 ff. Ratsbeschluss Prüm.
} 


\section{Teil: Rechtliche Bewertung}

\section{A. Demokratische Legitimation des SDÜ}

\section{Verletzung des Demokratieprinzips}

Am 17. Juni 1993 hat der deutsche Bundestag dem SDÜ nach Art. 59 Abs. 2 GG zugestimmt. ${ }^{476}$ In diesem Zusammenhang wird von zahlreichen Autoren die Art der Beteiligung des deutschen Parlamentes kritisiert. ${ }^{477}$ So sei der Einfluss des Bundestages wegen der besonders zurückhaltenden Information durch die Exekutive auf ein bloßes „Ja“ oder „Nein“ zum Gesetz im Ganzen reduziert und eine differenzierte inhaltliche Einflussnahme nicht möglich gewesen. Stattdessen hätten die Vorarbeiten zum Gesetz quasi unter Ausschluss der Öffentlichkeit stattgefunden. Nur „Insider“ hätten über eine umfassende Kenntnis der Aufgaben, Zusammensetzung und Ergebnisse der zahlreichen intergouvernementalen Arbeitsgruppen verfügt. ${ }^{478}$ Die Exekutive habe in Gestalt der Innenministerkonferenz bereits 1986 ihre Forderungen vorgelegt und mit dem Bundesministerium des Innern abgestimmt. Der Bundestagsinnenausschuss habe die Verhandlungen dagegen allenfalls im Ergebnis nachvollziehen können, während es eine Plenardebatte zu einem Entwurf des Schengener Abkommens nicht gegeben habe. ${ }^{479}$

Diese Kritik lässt sich unter dem Stichwort „Demokratiedefizit“ zusammenfassen. Möglicherweise hat die erwähnte Kritik so viel Gewicht, dass von einer Verletzung des Demokratieprinzips gesprochen werden kann, was sich möglicherweise auch auf die Rechtmäßigkeit des Betriebs des SIS auswirken würde. Ob eine solche Verletzung vorliegt, soll im Folgenden geprüft werden. Dazu wird zunächst dargestellt, was Inhalt des Demokratieprinzips ist und inwieweit hier dem Parlament Bedeutung zukommt. Insbesondere wird geprüft, wie das Parlament bei Angelegenheiten mit außenpolitischem Bezug verfahrensmäßig typischerweise eingebunden wird und ob diese Vorgaben beim Schengener Vertragsgesetz erfüllt wurden. Soweit dies der Fall war, bleibt zu prüfen, ob im konkreten Fall Besonderheiten vorlagen, die eine andere, umfassendere Beteiligung des Parlamentes verlangt hätten. Käme man zu diesem Ergebnis, wäre zu prüfen, inwiefern hierin eine Verletzung des Demokratieprinzips zu sehen ist.

\footnotetext{
${ }^{476}$ Plenarprotokoll 12/163 vom 17. Juni 1993, S. 14029B; da ausschließliche Kompetenzen der Bundesländer ebenfalls betroffen waren, bedurfte das SDÜ nach der Lindauer Vereinbarung auch der Zustimmung des Bundesrates; vgl. BT-Drs. 12/2453, Anlage 2, Nr. 8; diese Zustimmung hat er am 9. Juli 1993 erteilt, BR-Drs. 426/93 (Beschluss). Die Rolle des Bundesrates soll im hiesigen Zusammenhang nicht Gegenstand der Erläuterung sein.

${ }^{477}$ Schoch, DVB1. 1992, 525 (530 f.); Akmann, JA 1994, 49 (55); Maurer/Monar, in: Lange, Staat, Demokratie und Innere Sicherheit, S. 311 (320 ff.); Busch, KJ 1990, 1 (6 f.); ders., Vorgänge 1992, 53 (62).

${ }^{478}$ Schoch, DVBl. 1992, 525 (530 f.).

${ }^{479}$ Busch, KJ 1990, 1 (7).
} 


\section{Demokratieprinzip}

\section{a. Grundsätzliches}

Nach Art. 20 Abs. 1 GG ist die Bundesrepublik Deutschland ein demokratischer und sozialer Bundesstaat. Das in dieser Vorschrift niedergelegte Demokratieprinzip bildet eine der fundamentalen Bestimmungen des Grundgesetzes. Art. 20 Abs. 1 GG meint nicht irgendein Regierungssystem demokratischen Zuschnitts, sondern den demokratischen Rechtsstaat im Sinne des Grundgesetzes. Er bringt die im Grundgesetz verstreuten Bestimmungen über die Willensbildung des Volkes und das parlamentarische Regierungssystem auf eine Kurzformel, ohne selbst Detailregelungen zu enthalten. Demokratie im Sinne des Art. 20 Abs. 1 GG ist deshalb die durch das Grundgesetz in seinen einzelnen Vorschriften verfasste parlamentarische Demokratie. ${ }^{480}$ Dabei enthält das Grundgesetz kein vollständiges und vollkommenes Modell. Stattdessen sichert es Grundlagen und Grundstrukturen verfassungsmäßig und schafft damit einen Rahmen, innerhalb dessen die freie politische Auseinandersetzung stattfinden kann. ${ }^{481}$ Dieses „entwicklungsoffene Prinzip“ ist auch im Zusammenhang mit Art. 79 Abs. 3 GG zu sehen. Gestaltete das Grundgesetz das Demokratieprinzip allzu detailliert aus, würde dem Verfassungsgesetzgeber zu viel entzogen, was wegen der stetigen Entwicklung, in der sich die politischen Verhältnisse befinden, zu seiner Verfügung bleiben muss. ${ }^{482}$

Eine Konkretisierung des Art. 20 Abs. 1 GG folgt in Art. 20 Abs. 2 S. 1 GG, wonach alle Staatsgewalt vom Volke ausgeht. Der Begriff der Staatsgewalt wird im Grundgesetz selbst nicht definiert, sondern vorausgesetzt als die originäre, gegenständlich nicht beschränkte, im Verfassungsstaat aber durch die Verfassung rechtlich gebundene Herrschaftsmacht des Staates, als wichtigste und entscheidende Voraussetzung für die Existenz eines Staates, neben Staatsgebiet und Staatsvolk im Sinn der „3-Elemente-Lehre“. Im Bundesstaat des Grundgesetzes ist dabei die Ausübung der Staatsgewalt aufgeteilt zwischen Bund und Ländern. Die staatlichen Befugnisse ergänzen sich zur einheitlichen, umfassenden Staatsgewalt, deren Träger das Volk ist, nämlich das Volk in den Ländern, soweit es um deren staatliche Befugnisse geht und das Bundesvolk für die Staatsgewalt der Bundesrepublik. ${ }^{483} 484$

\footnotetext{
${ }^{480}$ Sommermann, in: Starck, GG, Band 2, Art. 20 Abs. 1, Rn. 87; Hesse, Rn. 127; Ipsen, Staatsrecht I, Rn. 62.

${ }^{481}$ Hesse, Rn. 129.

482 Streinz, in: Sachs, GG, Art. 20, Rn. 12; Antoni, in: Hömig, GG, Art. 20, Rn. 3; vgl. Sommermann, in: Starck, GG, Band 2, Art. 20 Abs. 1, Rn. 90.

483 Sommermann, in: Starck, GG, Band 2, Art. 20 Abs. 2, Rn. 145 ff.; Degenhart, Staatsrecht I, Rn. 7.

${ }^{484}$ Zum Begriff der Staatsgewalt im Sinne eines von vornherein bestehenden einheitlichen Volkswillens, vgl. Hesse, Rn. $130 \mathrm{ff}$.
} 
Die Bestimmung des Art. 20 Abs. 2 S. 1 GG verdeutlicht, dass die Staatsgewalt der Bundesrepublik Deutschland nicht in der Hand eines Einzelnen, einer Gruppe, einer oder mehrerer Parteien oder sonstiger Verbände, eines Standes, Berufs, einer Klasse, Religionsgemeinschaft, Nationalität oder Rasse, sondern beim Gesamtvolk liegen soll. ${ }^{485}$ Da ein Staat von der Größe der Bundesrepublik Deutschland in unmittelbarer Demokratie nicht regierbar ist, legt Art. 20 Abs. 2 S. 2 GG fest, dass das Volk diese Gewalt durch Wahlen und Abstimmungen ausübt. Während sich Abstimmungen auf Sachfragen beziehen, ${ }^{486}$ geht es bei der Wahl um die Entscheidung, einer bestimmten Person oder Personengruppe Aufgaben zu übertragen. Damit bekennt sich das Grundgesetz zur mittelbaren Demokratie und verpflichtet zur Schaffung eines Organs, das stellvertretend für das Gesamtvolk Träger der Staatsgewalt ist.

Wenn also unmittelbar durch das Volk nur das Parlament über Wahlen demokratisch legitimiert ist, bedürfen alle anderen staatlichen Organe ihrerseits der Legitimation durch das Parlament und damit durch den Volkswillen. Konkret bedeutet dies, dass die Ausübung jeglicher staatlicher Gewalt in einer ununterbrochenen demokratischen Legitimationskette ${ }^{487}$ auf das Volk zurückführbar sein muss. In diesem Sinn ist Demokratie in der griechischen Wortbedeutung „Herrschaft des Volkes.“488

\section{aa. Volksvertretung}

Eine Volksvertretung muss, um ihrer Stellvertreterrolle gerecht werden zu können, wirksame Instrumente zur Kontrolle der Regierung haben und über umfassende Gesetzgebungsrechte verfügen. Zudem muss sie in periodischen Abständen unter Bedingungen zustande kommen, die es ermöglichen, dass der tatsächliche Volkswille zum Ausdruck kommt. Angesprochen sind hier die Wahlrechtsgrundsätze der allgemeinen, geheimen, unmittelbaren, freien und gleichen Wahl, auf die Art. 38 Abs. 1 S. 1 und Art. 28 Ab. 1 S. 2 GG Bezug nehmen. ${ }^{489}$ Allgemeinheit der Wahl bedeutet, dass das Wahlrecht grundsätzlich allen Bürgern zusteht. Geheimheit der Wahl meint, dass die Umstände der Stimmabgabe so sein müssen, dass die Wahlentscheidung niemandem bekannt wird. Öffentlich ist dagegen die Auszählung. Der Grund hierfür dürfte auch im Demokratieprinzip wurzeln, denn nur der transparente Wahlvorgang kann Legitimation verschaffen. Während Unmittelbarkeit darauf zielt, dass es keine zwischengeschalteten Instanzen zwischen Wähler und zu Wählendem gibt, schließen freie Wahlen jeden auch nur mittelbaren Zwang oder

\footnotetext{
${ }^{485}$ Sommermann, in: Starck, GG, Band 2, Art. 20 Abs. 2, Rn. 148; Antoni, in: Hömig, GG, Art. 20, Rn. 3.

${ }^{486}$ Hesse, Rn. 148; im Bereich des Bundes sind Abstimmungen nur gemäß Art. 29, 118, 118 a GG für eine Länderneugliederung vorgesehen.

${ }^{487}$ B VerfGE 83, 60 (72 f.); 93, 37 (67); 107, 59 (87).

${ }^{488}$ Sommermann, in: Starck, GG, Band 2, Rn. 63; Degenhart, Staatsrecht I, Rn. 24 f.

${ }^{489}$ Starck, in: Isensee/Kirchhof, HandbStR, Band III, § 33 Rn. 32; Sommermann, in: Starck, GG, Band 2, Art. 20 Abs. 2, Rn. 158.
} 
Druck auf die Entscheidungsfreiheit des Wählers von außen aus. Gleich ist die Wahl schließlich nur, wenn jede Stimme das gleiche Gewicht, den gleichen Zählwert und grundsätzlich den gleichen Erfolgswert hat, also in gleicher Weise bei der Zuteilung von Mandaten zu berücksichtigen ist. $^{490}$

\section{bb. Einigungs- und Mehrheitsprinzip}

Eine demokratische Ordnung muss festlegen, wie angesichts des Neben- und Gegeneinanders der unterschiedlichen Willen ein verbindlicher Wille zu bilden ist. Eine freie politische Willensbildung beruht in erster Linie auf Einigung. Dabei handelt es sich oft um einen mühevollen Prozess. Wird jedoch eine gemeinsame Lösung gefunden, lässt sich diese meist leichter umsetzen, weil sich alle in ihren Interessen berücksichtigt sehen. Da Einigung aber immer nur ein Minimum enthält, über das sich alle Beteiligten verständigen können, kann das Einigungserfordernis in der Sache zur Starre führen. Es muss deshalb eine Möglichkeit bestehen, eine Sachentscheidung auch ohne Einigung herbei zu führen. In diesem Fall müssen Entscheidungen nach dem Mehrheitsprinzip getroffen werden. Der Mehrheitswille ist nicht als solcher der sachlich richtigere. Er verwirklicht das Freiheitsprinzip aber insoweit, als wenigstens der Mehrheit keine Aktionen aufgezwungen werden, die sie missbilligt. Damit das Mehrheitsprinzip im Hinblick auf die unterliegende Minderheit sachlich gerechtfertigt ist, müssen zwei Voraussetzungen gegeben sein: Erstens müssen sich alle darüber einig sein, dass die Mehrheit den Ausschlag geben soll. Zweitens muss die Möglichkeit unterschiedlicher und sich verändernder Mehrheitsverhältnisse bestehen, so dass die zunächst unterliegende Minderheit im Falle einer späteren Entscheidung die reale Chance auf das Gewinnen der Mehrheit hat.

In den Fällen, in denen eine Entscheidung nur mit qualifizierter Mehrheit getroffen werden kann, nähert sich das Mehrheits- dem Einigungsprinzip an. ${ }^{491}$

\section{cc. Minderheitenschutz}

Wäre Demokratie im Sinne des Grundgesetzes nichts anderes als Mehrheitsherrschaft, dann würde sie die Möglichkeit einer Mehrheitsdiktatur enthalten. Diese würde sich von der Minderheitsdiktatur lediglich durch die geringere Zahl der Unterdrückten unterscheiden. Wenn aber der politische Prozess Sache des ganzen Volkes sein soll, dann kommt es nicht nur auf die Mehrheit sondern auch auf die Minderheiten an. Diese müssen die Möglichkeit haben, ihren Standpunkt in die Willensbildungsprozesse einzubringen. Der Schutz der Minderheit sichert einerseits ihre

\footnotetext{
${ }^{490}$ Starck, in: Isensee/Kirchhof, HandbStR, Band III, § 33, Rn. 34; Degenhart, Staatsrecht I, Rn. 74 ff.; Hesse, Rn. 146; ausführlich hierzu Meyer, in: Isensee/Kirchhof, HandbStR, Band III, $\S \S ~ 45,46$.

${ }^{491}$ Hesse, Rn. 140 ff.; Streinz, in: Sachs, GG, Art. 20 Rn. 21, 24.
} 
Chance, einmal zur Mehrheit zu werden. Andererseits ist es unerheblich, ob die Minderheit dies nach der Lage der Dinge tatsächlich werden kann oder ob sie die Mehrheit überhaupt anstrebt. Schutzwürdig erscheint es unter demokratischen Gesichtspunkten bereits, dass das Einbeziehen der Sicht der Minderheit einen Konflikt möglichst umfassend beleuchtet und damit wiederum möglichst allen im Volke bestehenden Ansichten eine Stimme gegeben wird. ${ }^{492}$

\section{dd. Öffentlichkeit der Beratungs- und Entscheidungsprozesse}

Demokratie verlangt Publizität des politischen Prozesses. Diese Öffentlichkeit ist Voraussetzung dafür, dass die Bürger Verständnis für die Prozesse politischer Willensbildung entwickeln und Vertrauen in einen geordneten Ablauf gewinnen. ${ }^{493}$ Auf diese Weise werden sie wiederum in die Lage versetzt, sich ein Urteil über die zu entscheidenden (Sach-)Fragen und die Qualität der Arbeit der politisch Verantwortlichen zu bilden. Das demokratische Verfahren lässt den Vorgang der politischen Willensbildung damit nicht im Dunkeln der Abmachungen oder Entschlüsse von unkontrollierten Machthabern, sondern rückt ihn prinzipiell in das Licht der Öffentlichkeit. ${ }^{494}$

\section{ee. Freiheit und Gleichheit}

Demokratie setzt Freiheit und Gleichheit der Bürger voraus. ${ }^{495}$ Sie sind unverzichtbare Bedingung dafür, dass die Bürger die ihnen zustehenden Beteiligungsformen rechtlich und tatsächlich auch wirklich ausüben können.

Das Gleichheitsprinzip verlangt in diesem Sinne, dass alle Staatsangehörigen die gleichen staatsbürgerlichen Rechte besitzen, also insbesondere bei Wahlen und Abstimmungen sowie beim Ämterzugang gleiche Mitwirkungsmöglichkeiten haben. ${ }^{496}$

Die Demokratie des Art. 20 Abs. 1 GG ist eine freiheitliche Demokratie. Das Volk soll die Grundrichtung der staatlichen Willensbildung auch tatsächlich frei und maßgeblich bestimmen. Große Bedeutung haben in diesem Zusammenhang die Grundrechte. ${ }^{497}$ In ihrer freiheitssichernden Bedeutung sind hier in besonderem Maße Art. 5, 8 und 9 GG hervorzuheben. Das Bundesverfassungsgericht hat die in Art. 5 GG verbürgten Grundrechte mehrfach als schlechthin konstituierend für die freiheitlich-demokratische Grundordnung bezeichnet, weil es die ständige geisti-

\footnotetext{
${ }^{492}$ B VerfGE 44, 125 (142); Streinz, in: Sachs, GG, Art. 20, Rn. 26; Hesse, Rn. 154.

${ }^{493}$ Streinz, in: Sachs, GG, Art. 20, Rn. 18; Hesse, Rn. 138.

${ }^{494}$ Hesse, Rn. 138, 152.

${ }^{495}$ Streinz, in: Sachs, GG, Art. 20, Rn. 16.

${ }^{496}$ Antoni, in: Hömig, GG, Art. 20, Rn. 3; Streinz, in: Sachs, GG, Art. 20, Rn. 19.

${ }^{497}$ Starck, in: HandbStR, Band III, § 33, Rn. 4, 14; Antoni, in: Hömig, GG, Art. 20, Rn. 3.
} 
ge Auseinandersetzung und den Kampf der Meinungen ermöglicht. ${ }^{498}$ Art. 8 und 9 GG gewährleisten das Recht, sich im Hinblick auf eine politische Meinung einmalig oder für längere Zeit in Gruppen zu organisieren. Auf diese Weise kann eine politische Sichtweise an Bedeutung und Aufmerksamkeit in der Öffentlichkeit gewinnen und hat bessere Chancen, im Prozess der politischen Willensbildung auch berücksichtigt zu werden.

Anders ausgedrückt gewährleisten die Grundrechte auch die unverzichtbaren Bedingungen für die Vorformung eines politischen Willens. ${ }^{499}$ Sie betrifft einen Zeitraum, in dem die Entscheidungen noch nicht fallen, eine Thematik aber aus der Sicht unterschiedlicher Bevölkerungsgruppen diskutiert wird. Die Ergebnisse dieser öffentlichen Diskussionen bereiten die zu fällenden Entscheidungen vor. Träger dieser Vorformung sind die Verbände und die nach Art. 21 GG geschützten Parteien. Während die Verbände auf die nicht verbindliche Vorformung beschränkt sind, tragen die Parteien die vorgeformten Meinungen in den Prozess der institutionalisierten Willensbildung in Regierung und Parlament. Auf diese Weise besetzen sie eine Schnittstelle zwischen Volk und Volksvertretung. Verbände und Parteien sind unter den Bedingungen der Gegenwart notwendige Faktoren demokratischer Willensbildung. Politische Antriebe gehen nur noch in geringem Maße von Einzelpersonen aus, sie bedürfen der Sammlung, Sichtung und des vermittelnden Ausgleichs; nur durch das Mittel des gruppenmäßigen Zusammenschlusses haben sie Aussicht, verwirklicht zu werden und schließlich bringen sie die Sachkenntnis der unmittelbar Betroffenen in den Prozess der politischen Willensbildung ein.

\section{b. Aufgaben des Bundestages}

Es wurde bereits festgestellt, dass ein den Willen des Volkes repräsentierendes Organ die Regierung kontrollieren können sowie über umfassende Gesetzgebungsrechte verfügen muss. ${ }^{500}$ Ausgehend hiervon soll eine Darstellung der Aufgaben und Rechte des Bundestages die Basis für die Beurteilung bilden, ob er im Zusammenhang mit dem SDÜ angemessen beteiligt wurde.

\section{aa. Grundsätzliches}

Der deutsche Bundestag ist das Parlament der Bundesrepublik Deutschland und Kernstück der repräsentativen Demokratie des Grundgesetzes. Die Struktur der vom Grundgesetz vorgegebenen Demokratie beruht darauf, dass die Staatsgewalt in allen ihren Funktionen demokratisch konstituiert und legitimiert und auf dieser Grundlage gewaltenteilig organisiert ist. Trotz seiner

\footnotetext{
${ }^{498}$ BVerfGE 7, 198 (208); 20, 56 (97); 93, 266 (292).

${ }^{499} \mathrm{Vgl}$. Hesse, Rn. 150 f., der diese Thematik unter dem Gesichtspunkt unmittelbarer politischer Willensbildung darstellt bzw. als Möglichkeit, wie das Volk zeitlich auch außerhalb der Wahlen Einfluss auf die politische Gesamtrichtung nehmen kann.

${ }^{500}$ Vgl. diesen Teil der Arbeit, A. I. 1. a. aa.
} 
unmittelbaren demokratischen Legitimation ist der Bundestag also weder allen anderen Verfassungsorganen übergeordnet noch besteht eine allgemeine Zuständigkeitsvermutung zu seinen Gunsten. ${ }^{501}$ Seine Aufgaben sind in der modernen Demokratie jedoch so vielfältig, dass man sie in Aufgabenbereiche einteilt. Wichtigste Funktionen sind die Wahl anderer Staatsorgane, die Mitwirkung in Angelegenheiten der Europäischen Union nach Art. 23 Abs. 2 und 3 GG und der NATO, die Repräsentationsfunktion, die Kontrolle der Exekutive sowie die Gesetzgebung. ${ }^{502} \mathrm{Im}$ Hinblick auf das Ziel der Untersuchung sollen die drei zuletzt genannten Funktionen im folgenden Teil näher beleuchtet werden.

\section{(1) Repräsentationsfunktion}

Die Mitglieder des Bundestages repräsentieren das Gesamtvolk. Mit diesem Begriff soll zum einen deutlich werden, dass gerade keine Identität zwischen Regierenden und Regierten gemeint ist. Zum anderen bedeutet Repräsentation auch gerade nicht Vertretung in einem ständischen Sinne oder im Rechtssinne. ${ }^{503}$ Nach Art. 38 Abs. 1 S. 2 GG sind die Abgeordneten zwar „Vertreter" des ganzen Volkes, damit soll jedoch zum Ausdruck kommen, dass sie sich nicht von vornherein und ausschließlich für die Interessen eines Landes, eines Wahlkreises, einer Partei oder sonstigen Bevölkerungsgruppe einsetzen. Obwohl es im Volk zu einer Fragestellung notwendigerweise unterschiedliche Meinungen und Interessenlagen gibt, ist es doch Aufgabe der Abgeordneten, bei der Beantwortung das „Wohl des Gesamtvolkes“ als übergeordnetes Ziel nicht aus den Augen zu verlieren. ${ }^{504}$

Der Begriff der Repräsentation trägt dem Umstand Rechnung, dass das „Volk“ als solches nirgendwo anwesend und vor allem nicht handlungsfähig ist. Das Parlament hat deshalb die Funktion, das Volk zu verkörpern, es gleichsam anwesend werden zu lassen. ${ }^{505}$

\section{(2) Kontrolle der Exekutive}

Auch, wenn der Begriff dies nahe legen mag, meint Parlamentarische Kontrolle nicht die nachträgliche Beaufsichtigung der Erledigung von Angelegenheiten eines anderen Aufgabenträgers. Sie ist weit mehr und anderes als bloße Reaktion auf das Verhalten der Regierung. Die Regierung soll durch parlamentarische Willensäußerungen in ihren Entscheidungen beeinflusst wer-

\footnotetext{
${ }^{501}$ Klein, in: Isensee/Kirchhof, HandbStR, Band III, § 50, Rn. 1; Silberkuhl, in: Hömig, GG, vor Art. 38 , Rn. 4.

${ }^{502}$ Ipsen, Staatsrecht I, Rn. 200; vgl. Degenhart, Staatsrecht I, Rn. 597.

${ }^{503}$ Klein, in: Isensee/Kirchhof, HandbStR, Band III, § 50, Rn. 4; Ipsen, Staatsrecht I, Rn. 246 f.

${ }^{504}$ Silberkuhl, in: Hömig, GG, Art. 38, Rn. 12.

${ }^{505}$ Ipsen, Staatsrecht I, Rn. 248 ff. mit Verweis auf C. Schmitt, Verfassungslehre, 8. Auflage 1993, S. 208 ff. und G. Leibholz, Die Repräsentation in der Demokratie, 3. Auflage 1966, Nachdr. 1973, S. 26.
} 
den. ${ }^{506}$ Unverzichtbare Voraussetzung hierfür ist die Information des Parlamentes. Zwar wird der Bundestag nicht in der Lage sein, den Informationsvorsprung der Regierung auszugleichen, verfügt diese doch durch ihre Zugehörigkeit zu inländischen und ausländischen Entscheidungsgremien über besondere Detailinformationen sowie eine Administration, die diese Informationen entsprechend verarbeitet. Das Parlament benötigt jedoch nicht sämtliche Informationen, um seiner kontrollierenden Aufgabe gerecht werden zu können. Dabei ist eine punktuelle Vollständigkeit nicht ausgeschlossen. ${ }^{507}$

Vorrangige Instrumente der parlamentarischen Kontrolle sind das Zitier- und Interpellationsrecht, die Einsetzung von Untersuchungsausschüssen sowie schlichte Parlamentsbeschlüsse. ${ }^{508}$

\section{(a) Zitier- und Interpellationsrecht}

Mit Hilfe des Zitierrechtes nach Art. 43 Abs. 1 GG können der Bundestag und seine Ausschüsse jederzeit die Anwesenheit jedes Mitglieds der Bundesregierung verlangen, wenn das jeweilige Organ mit einfacher Mehrheit einen entsprechenden Beschluss fasst. ${ }^{509}$ Die Mitglieder der Regierung trifft eine verfassungsrechtliche Pflicht, der Aufforderung Folge zu leisten. Aus dem Zitierrecht folgt auch ein Fragerecht von Bundestag und Ausschüssen, so dass das jeweilige Regierungsmitglied nicht nur eine Anwesenheits- sondern auch ein eine Antwortpflicht trifft. Die Antwort muss der Wahrheit entsprechen und grundsätzlich vollständig sein. ${ }^{510}$

Eng verbunden mit dem Zitierrecht ist das Interpellationsrecht, das seine Grundlage in dem durch Art. 38 Abs. 1 GG gewährleisteten Status des einzelnen Abgeordneten hat. ${ }^{511}$ Gemeint ist damit die Befugnis des Bundestages, Anfragen an die Regierung zu richten. Die Geschäftsordnung des Bundestages ${ }^{512}$ konkretisiert dieses Recht in verschiedenen Formen. Die „Große Anfrage“ nach Art. 100 ff. GOBT betrifft wichtige Gegenstände der Politik und wird, wenn eine Fraktion oder fünf Prozent der Mitglieder des Bundestages es verlangen, regelmäßig unter Einbeziehung der Antwort der Bundesregierung im Bundestag beraten. Die „Kleine Anfrage“ nach $§ 104$ GOBT unterscheidet sich von der „Großen Anfrage“ dadurch, dass sie nicht als Verhandlungsgegenstand auf die Tagesordnung gesetzt werden kann, dass also keine Debatte im Bundestag

\footnotetext{
${ }^{506}$ Klein, in: Isensee/Kirchhof, HandbStR, Band III, § 50, Rn. 33.

${ }^{507} \mathrm{Vgl}$. Ipsen, Staatrecht I, Rn. 224; Klein, in: Isensee/Kirchof, HandbStR, Band III, § 50, Rn. 36.

${ }^{508}$ Vgl. Ipsen, Staatsrecht I, Rn. 204 ff.; unter dem Aspekt der rechtlich verbindlichen Einflussnahme könnte man auch die Gesetzgebung als Kontrollinstrument aufführen, vgl. Klein, der in diesem Zusammenhang von ,vorauswirkender parlamentarischer Kontrolle“" spricht, Klein, in: Isensee/Kirchof, Handbuch des Staatsrechts, Band III, § 50, Rn. 33.

${ }^{509}$ Das Erfordernis der einfachen Mehrheit ergibt sich für den Bundestag aus Art. 42 Abs. 2 S. 1 GG, für die Ausschüsse aus den $\S \S 48$ Abs. 2 S. 1, 74 GOBT.

${ }^{510}$ Hömig, in: Hömig, GG, Art. 43, Rn. 2 f.; Ipsen, Staatsrecht I, Rn. 204.

${ }^{511}$ Hömig, in: Hömig, GG, Art. 43, Rn. 4; a.A. wohl Ipsen, der das Recht in Zusammenhang mit Art. 43 Abs. 1 GG stellt, Ipsen, Staatsrecht I, Rn. 204.

${ }^{512} \mathrm{Im}$ Folgenden: GOBT.
} 
darüber stattfindet. In der Regel ist sie innerhalb von vierzehn Tagen von der Bundesregierung schriftlich zu beantworten.

In der „Fragestunde“ nach $\S 105$ GOBT können einzelne Abgeordnete kurze Fragen zur mündlichen oder schriftlichen Beantwortung an die Bundesregierung richten. Für die Fragen zur mündlichen Beantwortung sind in jeder Sitzungswoche insgesamt drei Stunden bei regelmäßiger Anwesenheit des zuständigen Bundesministers oder seines Vertreters vorgesehen ${ }^{513}$; die Fragen zur schriftlichen Beantwortung werden von der Bundesregierung in der Regel innerhalb einer Woche bearbeitet. ${ }^{514}$

Die „Aktuelle Stunde“ nach $\S 106$ Abs. 1 GOBT ist für Kurzbeiträge zu einem aktuellen Thema von allgemeinem Interesse vorgesehen. Die „Aktuelle Stunde“ wird ihrem Wesen nach möglichst bald nach einem entsprechenden Verlangen ${ }^{515}$ durchgeführt, wobei jedem Redner maximal fünf Minuten Redezeit zur Verfügung stehen und die gesamte Aussprache höchstens eine Stunde dauert. $^{516}$

Bei der „Befragung der Bundesregierung“ nach $§ 106$ Abs. 2 GOBT schließlich geht es vorrangig um die unmittelbar vorangegangene Kabinettssitzung. Die Befragung findet in Sitzungswochen mittwochs um 13.00 Uhr statt und dauert in der Regel 30 Minuten. ${ }^{517}$

\section{(b) Einsetzung von Untersuchungsausschüssen}

Die in Art. 44 GG geregelten Untersuchungsausschüsse sind ein traditionelles Mittel parlamentarischer Kontrolle, das zur Aufklärung ungeklärter Umstände eingesetzt wird. ${ }^{518}$ Der Bundestag kann und auf Antrag eines Viertels seiner Mitglieder muss er einen Untersuchungsausschuss einsetzen, der in grundsätzlich öffentlicher Verhandlung die erforderlichen Beweise erhebt. Das Untersuchungsverfahren endet in der Regel mit der Vorlage des schriftlichen Abschlussberichtes des Ausschusses an den Bundestag, in dem der Gang des Verfahrens, die ermittelten Tatsachen und das Ergebnis der Untersuchung dargestellt werden. ${ }^{519}$ Der Bundestag berät den Abschlussbe-

\footnotetext{
${ }^{513}$ I. 1., Gegenschluss aus III. 11. Anlage 4 GOBT.

${ }^{514}$ IV. 14. Anlage 4 GOBT.

515 Nach Vereinbarung im Ältestenrat, nach Verlangen einer Fraktion oder von fünf Prozent der anwesenden Mitglieder des Bundestages zur Antwort der Bundesregierung auf eine mündliche Anfrage sowie unabhängig von einer für die Fragestunde eingereichten Frage von einer Fraktion oder von fünf Prozent der Mitglieder des Bundestages, vgl. I. 1. Anlage 5 GOBT.

${ }^{516}$ III. 6. Abs. 1 S. 1 , 7. Abs. 1 S. 1 Anlage 5 GOBT.

${ }^{517} 1 ., 4$. Anlage 7 GOBT.

${ }^{518}$ Ipsen, Staatsrecht I, Rn. 212; Bergmann, in: Hömig, GG, Art. 44, Rn. 1.

${ }^{519}$ Geis, in: Isensee/Kirchhof, HandbStR, Band III, § 55, Rn. 61 mit Verweis auf $\S 33$ Abs. 1 S. 1 und 2 Gesetz zur Regelung des Rechts der Untersuchungsausschüsse des Deutschen Bundestages - PUAG - vom 19. Juni 2001, BGB1. 2001, 1142; das PUAG hat das Recht der Untersuchungsausschüsse detailliert geregelt; die Pflicht, dem Bundestag einen Abschlussbericht vorzulegen bestand aber schon vorher, vgl. Ipsen, Staatsrecht I, 8. A., Rn. 165.
} 
richt im Plenum. Er kann ihn zurückweisen, folgt aber regelmäßig der Empfehlung, ihn zur Kenntnis zu nehmen. ${ }^{520}$

\section{(c) Schlichte Parlamentsbeschlüsse}

In sogenannten schlichten Parlmamentsbeschlüssen bekundet das Parlament seine politischen Absichten, ohne Staatsorgane oder Bürger dabei binden zu können. Diese Beschlüsse haben insofern Bedeutung, als darin die Mehrheitsauffassung des Bundestages zutage tritt.

Der Bundestag kann zu jedem Thema seine Meinung bekunden, sofern er sich im Rahmen der Bundeskompetenzen hält. Er ist dabei nicht auf Inhalte beschränkt, die Gegenstand eines Gesetzes sein könnten; er kann sich auch zu Regierungsakten und anderen exekutivischen Entscheidungen äußern. ${ }^{521}$

\section{(3) Gesetzgebung}

Schließlich hat der Bundestag im Rahmen seiner Zuständigkeit die Aufgabe der Gesetzgebung. Das Verfahren hierzu ist durch die Verfassung nur in einigen Punkten bestimmt, Art. 76 ff. GG; weitergehende Regelungen befinden sich in der GOBT.

\section{bb. Funktion des Bundestages bei der Gesetzgebung}

Da die eingangs genannte Kritik ${ }^{522}$ vor allem im Zusammenhang mit der Beteiligung des Bundestages beim Zustimmungsgesetz zum Schengener Durchführungsabkommen steht, soll das Augenmerk im Folgenden auf die Rolle des Bundestages bei Gesetzen mit innenpolitischem Bezug einerseits und im Gegensatz dazu andererseits mit außenpolitischem Bezug gelegt werden. Anschließend wird geprüft, ob der Bundestag vor diesem Hintergrund beim Zustimmungsgesetz zum Schengener Abkommen auf rechtmäßige Weise beteiligt worden ist.

\section{(1) Funktion des Bundestages bei Gesetzen mit maßgeblich innenpolitischem Bezug}

Nach Art. 76 Abs. 1 GG können Gesetzesvorlagen beim Bundestag durch die Bundesregierung, aus der Mitte des Bundestages oder durch den Bundesrat eingebracht werden. Die Entwürfe werden in der Regel in drei Lesungen behandelt, wobei in der ersten Beratung grundsätzlich keine allgemeine Aussprache stattfindet. Am Schluss der ersten Aussprache wird der Entwurf an

\footnotetext{
${ }^{520}$ Morlok, in: Dreier, GG, , Band II, Art. 44, Rn. 55; Geis, in: Isensee/Kirchhof, HandbStR, Band III, § 55, Rn. 61.

${ }^{521}$ Ipsen, Staatsrecht I, Rn. 218 f.; Bergmann, in: Hömig, GG, vor Art. 62, Rn. 4.

${ }^{522}$ Dieser Teil der Arbeit, A. I.
} 
den zuständigen, also den sachnächsten, Ausschuss überwiesen. ${ }^{523} 524$ Die Ausschüsse des Bundestages, deren Mitgliederanteile entsprechend der Stärke der Fraktionen im Bundestag zusammengesetzt sind, ${ }^{525}$ entlasten das Plenum des Bundestags durch sachliche und sachkundige Vorbereitung. Man kann sogar sagen, dass die parlamentsinterne Beratung und interfraktionelle Meinungsbildung vorwiegend in den Ausschüssen geleistet wird. ${ }^{526}$ Nach der Ausschussphase ist ein Gesetzesentwurf in der sogenannten Ausschussfassung in aller Regel reif zur Annahme oder Ablehnung durch den Bundestag. Die zweite Beratung, die nach Abschluss der Ausschusssitzungen und aufgrund der Empfehlungen der beteiligten Ausschüsse stattfindet, dient insofern in erster Linie dazu, die relevanten Gesichtspunkte eines Gesetzes öffentlich darzustellen. ${ }^{527}$ In dieser Beratung können gleichwohl Änderungsanträge gestellt werden, über die abzustimmen ist. Werden keine Änderungen beschlossen, folgt die dritte Beratung direkt im Anschluss an die zweite Beratung. ${ }^{528}$ Sind Änderungen beschlossen, werden diese in einer Drucksache zusammengestellt. Am zweiten Tag nach der Verteilung dieser Drucksachen kommt es zur dritten Lesung.

Am Ende der dritten Lesung wird über den Gesetzentwurf abgestimmt. ${ }^{529}$

Die Regeln der Geschäftsordnung lassen auf Antrag bestimmter Gruppen und Mehrheiten zahlreiche Ausnahmen vom oben skizzierten grundsätzlichen Ablauf zu. ${ }^{530}$ Gleichwohl bleiben die Bestimmungen stets darauf gerichtet, das Verfahren stringent zu einem zügigen Abschluss zu bringen..$^{531}$

\section{(2) Funktion des Bundestages bei Gesetzen mit maßgeblich außenpolitischem Bezug}

Nach Art. 59 Abs. 2 S. 1 GG bedürfen Verträge, die die politischen Beziehungen des Bundes regeln oder sich auf Gegenstände der Bundesgesetzgebung beziehen, sogenannte Staatsverträ-

\footnotetext{
${ }^{523} \S \S 78$ Abs. 1 S. 1, 1. Teil, 79 S. 1, 80 Abs. 1 S. 1 GOBT; Geis, in: Isensee/Kirchhof, HandbStR, Band III, § 54 Rn. 4.

${ }^{524}$ Vom GG vorgesehen sind der Ausschuss für die Angelegenheiten der Europäischen Union, Art. 45, der Ausschuss für auswärtige Angelegenheiten, Art. 45a Abs. 1 1. Alt, der Ausschuss für Verteidigung, Art. 45a Abs. 12. Alt und Abs. 2, der Petitionsausschuss, Art. 45c, der Vermittlungsausschuss, Art. 77 Abs. 2 GG, der Gemeinsame Ausschuss, Art. 53a, 115 e sowie allgemein der oben bereits erwähnte Untersuchungsausschuss, Art. 44. Hinzu treten durch Bundesgesetz geschaffene Ausschüsse sowie Ständige Ausschüsse, Sonderausschüsse und Unterausschüsse nach §§ 54 f. GOBT, vgl. Geis, in: Isensee/Kirchof, HandbStR, Band III, § 54 Rn. 22 ff.

${ }^{525} \S 12 \mathrm{~S} .1 \mathrm{GOBT}$.

${ }^{526}$ Geis, in: Isensee/Kirchof, HandbStR, Band III, § 54 Rn. 1.

${ }^{527}$ Zeh, in: Isensee/Kirchof, HandbStR, Band III, § 52 Rn. 39.

$528 \S 81,82$ Abs. 1 S. 1,84 S. 1 a) GOBT.

${ }^{529}$ Art. 77 Abs. 1 S. 1 GG; $\$ \S 83,84$ S. 1 b), 85, 86 S. 1 GOBT.

${ }^{530} \mathrm{Vgl}$. z.B. § 79 GOBT zu einer allgemeinen Aussprache in der ersten Beratung; § 85 Abs. 1 S. 1 GOBT zu Änderungsanträgen zu Gesetzentwürfen noch in dritter Beratung.

${ }^{531}$ So werden in einer allgemeinen Aussprache in erster Lesung keine Einzelheiten besprochen; zudem dürfen noch keine Sachanträge gestellt werden, vgl. § 79 S. 2, 3 GOBT; die Änderungsanträge, die in dritter Lesung eingebracht werden, dürfen sich nur auf diejenigen Bestimmungen beziehen, zu denen in zweiter Beratung Änderungen beschlossen wurden, vgl. § 85 Abs. 1 S. 2 GOBT.
} 
ge ${ }^{532}$ der Zustimmung oder der Mitwirkung der jeweils für die Bundesgesetzgebung zuständigen Körperschaften in Form eines Bundesgesetzes. Für Verwaltungsabkommen, d.h. alle völkerrechtlichen Verträge, die von der Regierung selbst verbindlich abgeschlossen werden können, ${ }^{533}$ gelten dagegen nach Art. 59 Abs. 2 S. 2 GG die Vorschriften über die Bundesverwaltung entsprechend. Die Regelung des Art. 59 Abs. 2 S. 1 GG, die der Legislative eindeutig nicht rein repräsentative sondern materielle Befugnis verleiht, hat zu einem Streit darüber geführt, ob die Exekutive eine grundsätzliche Alleinzuständigkeit im Bereich der Außenpolitik für sich beanspruchen kann oder ob die auswärtige Gewalt dagegen der Legislative und der Exekutive zur gemeinsamen Wahrnehmung als „kombinierte Gewalt“ überantwortet ist. ${ }^{534}$ Das Bundesverfassungsgericht hat sich sehr früh im Sinne der ersten Alternative positioniert. ${ }^{535}$ Es fasst die Beteiligungsrechte der Legislative nach Art. 59 Abs. 2 S. 2 GG als eng zu interpretierende Ausnahme auf und wählt als Ausgangspunkt für diese Überlegungen das Gewaltenteilungsprinzip. Danach ordnet dieses Prinzip die Gestaltung der Außenpolitik der Exekutive zu. Dieser Ansatz erscheint überzeugend, denn ergänzend lässt sich anführen, dass institutionell und auf Dauer typischerweise allein die Regierung in hinreichendem Maße über die personellen, sachlichen und organisatorischen Möglichkeiten verfügt, auf wechselnde äußere Lagen zügig und sachgerecht zu reagieren. ${ }^{536}$ Durch die grundsätzliche Zuweisung der Außenpolitik an die Regierung wird mit anderen Worten die außenpolitische Handlungsfähigkeit bestmöglich gesichert. Gestützt wird dieses Ergebnis auch durch den Wortlaut des Art. 59 Abs. 2 S. 1 GG, der eine Mitwirkung der Gesetzgebungsorgane eindeutig nicht für alle völkerrechtlichen Rechtsakte, sondern nur bei Verträgen und hier wiederum lediglich bei politischen und gesetzgebungsbezogenen Verträgen vorsieht. Auch gingen die Mütter und Väter des Grundgesetzes offenbar davon aus, dass die Wiedereingliederung der Bundesrepublik in die internationale Staatengemeinschaft am ehesten zu verwirklichen sei, wenn nach weit verbreiteter und historisch überlieferter Übung dem Parlament nur bei bestimmten Vorgängen ein Mitwirkungsrecht eingeräumt wird. ${ }^{537}$

Neben den protokollarisch-repräsentativen Befugnissen des Bundespräsidenten nach Art. 59 Abs. 1 GG liegt demnach der Schwerpunkt der Kompetenzen bei der Bundesregierung und hier insbesondere beim Bundeskanzler und beim Bundesaußenminister. Der Bundeskanzler bestimmt

\footnotetext{
${ }^{532}$ Ipsen, Staatsrecht I, Rn. 1100.

${ }^{533}$ Streinz, in: Sachs, GG, § 59, Rn. 76; Kempen, in: Starck, GG, § 59 Abs. 2, Rn. $101 \mathrm{f}$.

${ }^{534}$ Eine Übersicht zum Streit findet sich bei Kempen, in: Starck, GG, Band 2, Art. 59 Abs. 2, Rn. 31 ff. und bei Müller, Die innerstaatliche Umsetzung, S. 25 ff.

${ }^{535}$ BVerfGE 1, 351 (369); 1, 372 (394).

${ }^{536}$ BVerfGE 68, 1 (87 f.); 90, 286 (357).

${ }^{537}$ Vgl. Kempen, in: Starck, GG, Band 2, Art. 59 Abs. 2 GG, Rn. 36; im Ergebnis wie hier: Streinz, in: Sachs, GG, Art. 59, Rn. 27; Fastenrath, Kompetenzverteilung, S. 215; Ipsen, Staatsrecht I, Rn. 1097; Silberkuhl, in: Hömig, GG, vor Art. 38, Rn. 2; Müller, Die innerstaatliche Umsetzung, S. 25.
} 
nach Art. 65 Abs. 1 GG auch die Richtlinien der Außenpolitik, während der Bundesaußenminister das Auswärtige Amt nach Art. 65 S. 2 GG innerhalb der vom Kanzler festgelegten Richtlinien selbständig und in eigener Verantwortung leitet. ${ }^{538}$ Die Legislative hat dagegen nach Art. 59 Abs. 2 S. 1 GG nur dann ein Mitwirkungsrecht, wenn die Regierung außenpolitisch kraft ihrer völkerrechtlichen Vertretungsbefugnis mehr kann als sie allein innenpolitisch umzusetzen vermag. ${ }^{539}$

Für das Gesetzgebungsverfahren gelten grundsätzlich die Art. 76 ff. GG. ${ }^{540}$

Unterschiede ergeben sich jedoch aufgrund der Tatsache, dass die Pflege der auswärtigen Beziehungen hauptsächlich der Exekutive als Aufgabe zugeordnet wird.

Hieraus ergibt sich zunächst, dass das Gesetzesinitiativrecht allein bei der Exekutive liegt, da diese die Verträge mit anderen Staaten aushandelt und der Inhalt der Gesetze damit weitgehend vorgegeben ist. ${ }^{541}$ Zudem werden die Vertragsgesetze statt in drei Lesungen in zwei Lesungen behandelt. $^{542}$ Am Ende der ersten Lesung wird der Vertragsgesetzentwurf an die zuständigen Ausschüsse überwiesen. Die eigentliche zweite Beratung, die grundsätzlich zur Einbringung von Änderungsanträgen dient, entfällt, da der Inhalt der völkerrechtlichen Verträge feststeht und daher Änderungsanträge zu Vertragsgesetzen nach Art. 59 Abs. 2 GG gemäß $§ 82$ Abs. 2 GOBT unzulässig sind. Am Ende der zweiten Lesung wird über das Vertragsgesetz abgestimmt.

\section{Konkrete Beteiligung des Bundestages beim SDÜ}

$\mathrm{Zu}$ prüfen ist, ob der Bundestag bei der Zustimmung zum SDÜ in rechtmäßiger Weise beteiligt wurde.

Der Vertrag bezieht sich auf Gegenstände der Bundesgesetzgebung wie das Ausländer-, Waffenund Melderecht ${ }^{543}$ und bedurfte nach Art. 59 Abs. 2 GG insofern der Zustimmung des Bundestages. Das Vertragsgesetz wurde von der Bundesregierung in das parlamentarische Verfahren eingebracht. ${ }^{544}$ Die erste Beratung, in deren Rahmen es eine mehrstündige Aussprache gab, fand am 30. April 1992 statt. Der eindeutige inhaltliche Schwerpunkt der Debatte knüpfte an die asylrechtlichen Zuständigkeitsbestimmungen des SDÜ an. Streitgegenstand war, ob die Zustimmung zum Vertragsgesetz zum SDÜ notwendigerweise mit einer Änderung des deutschen Grundrech-

\footnotetext{
${ }^{538}$ Bergmann, in: Hömig, GG, Art. 65, Rn. 4.

${ }^{539}$ Ipsen, Staatsrecht I, Rn. 1097, 1102 f.

${ }^{540}$ Ipsen, Staatsrecht I, Rn. 1114.

${ }^{541}$ Ipsen, Staatsrecht I, Rn. 1114.

${ }^{542} § 78$ Abs. 1 GOBT.

543 Änderungen erfuhren das Melderechtsrahmen-, das Ausländer- und das Waffengesetz, vgl. Art. 2 bis 4 Zustimmungsgesetz zum SDÜ, BGB1. II 1993, 1010.

${ }^{544}$ Plenarprotokoll 12/89, S. 7296 mit Verweis auf die BT-Drs. 12/2453.
} 
tes auf Asyl verbunden sein muss ${ }^{545}$ Am Ende der ersten Beratung wurde der Beschluss gefasst, den Entwurf an die zuständigen Ausschüsse zu überweisen. ${ }^{546}$ Zur zweiten Beratung, in der 11 Redner das Wort ergriffen, kam es am 17. Juni 1993. Am Ende der Lesung wurde das Vertragsgesetz mit der notwendigen Mehrheit angenommen. ${ }^{547}$

Damit entsprach die verfahrensmäßige Beteiligung des Bundestages den oben dargestellten Vorschriften und ist in dieser Hinsicht grundsätzlich ohne formelle Mängel zustande gekommen. Zudem fand in beiden Beratungen eine umfangreiche Debatte statt. Eine Verletzung des Demokratieprinzips aufgrund der mangelhaften Beteiligung des Bundestages scheint somit ausgeschlossen.

Gleichwohl bleibt zu untersuchen, ob eine nähere Prüfung der eingangs dargestellten Kritik zu einem abweichenden Ergebnis führt. Das könnte der Fall sein, wenn beim Zustimmungsgesetz zum SDÜ Besonderheiten vorliegen, die eine andere Einbindung des Bundestages, etwa wie in innenpolitischen Angelegenheiten, erforderlich gemacht hätten.

\section{Besonderheiten}

Die Besonderheiten könnten sich ergeben aus einer ungewöhnlich unzureichenden Information und Einbindung des Parlamentes vor dem völkerrechtlichen Abschluss des SDÜ, aus der außergewöhnlichen Sensibilität der Materie oder aus der speziellen Stellung, die Justiz- und Innenpolitik zum fraglichen Zeitpunkt im europäischen Rahmen hatten.

\section{a. Unzureichende Information und Einbindung des Parlamentes im Vorfeld}

Bei näherer Betrachtung wird deutlich, dass die Kritik auf den Zeitraum vor Abschluss des völkerrechtlichen Vertrages zielt. Da mit der Unterzeichnung der Inhalt zwischen den Staaten verbindlich festgelegt wird, hätte der Bundestag auf den Inhalt des Übereinkommens nur dann differenzierten Einfluss nehmen können, wenn er zum Zeitpunkt der Vertragsverhandlungen, also zeitlich zwischen dem Abschluss des Schengener Abkommens am 14. Juni 1985 und der Unterzeichnung des Schengener Durchführungsabkommens am 19. Juni 1990, eingebunden worden wäre.

\footnotetext{
${ }^{545}$ Vgl. den entsprechenden Entwurf eines Gesetzes zur Änderung des Grundgesetzes (Art. 16 und 24), BT-Drs. $12 / 2112$

${ }^{546}$ Innenausschuss als federführend, zudem Auswärtiger Ausschuss, Rechtsausschuss, Ausschuss für Arbeit und Sozialordnung, Ausschuss für Umwelt, Naturschutz und Reaktorsicherheit, Ausschuss für Fremdenverkehr und Tourismus, EG-Ausschuss sowie Haushaltsausschuss, vgl. Plenarprotokoll 12/89, S. 7296 und S. 7346.

${ }^{547}$ Plenarprotokoll 12/163, S. 14013 ff., S. 14029.
} 
Zunächst ist zu prüfen, ob es zu einer solchen Einbindung, die dem Maß einer für außenpolitische Angelegenheiten typischen Beteiligung entsprach, nicht doch gekommen ist oder ob die Regierung dem Parlament dagegen in untypischer Weise Informationen versagt hat. Bei der Auswertung ergibt sich ein uneinheitliches Bild. Einerseits wird darauf hingewiesen, dass die Bundesregierung die entscheidenden Legislativorgane insbesondere durch Information des Innenausschusses am Meinungs- und Willensbildungsprozess von Anfang an beteiligt habe. ${ }^{548}$ Andererseits bleibt die Feststellung zahlreicher Autoren bestehen, dass sich die Arbeiten im Rahmen von Schengen im Schatten von intergouvernementalen Expertengremien vollzogen und so eine öffentliche Diskussion der Regelungsinhalte verhindert hätten. ${ }^{549}$

Die Diskussion könnte allerdings letztlich dahinstehen, wenn man zu dem Ergebnis käme, dass der Bundestag jedenfalls im Vorfeld zahlreiche Gelegenheiten der inhaltlichen Einflussnahme gehabt, diese jedoch nicht genutzt hat. Ausgangspunkt für diese Überlegung ist das Schengener Abkommen vom 14. Juni 1985, dessen Inhalt allen Bundestagsabgeordneten bekannt war. ${ }^{550} \mathrm{Ti}^{5}$ tel II dieses Abkommens ist den bis zum 1. Januar 1990 durchzuführenden Maßnahmen gewidmet. ${ }^{551}$ Ihr Gegenstand sind der Abbau der Kontrollen an den gemeinsamen Grenzen und deren Verlegung an die Außengrenzen sowie die damit verbundenen rechtlichen Harmonisierungen, die ergänzenden Maßnahmen zum Schutz der inneren Sicherheit und zur Verhinderung der unerlaubten Einreise. ${ }^{552}$ Die Artikel 18 bis 20 Schengener Abkommen konkretisieren, welche Rechtsgebiete betroffen sein sollen, nämlich die polizeiliche Zusammenarbeit im Bereich der präventiven Verbrechensbekämpfung und der Fahndung, internationale Rechtshilfe und Auslieferung, gemeinsame Verbrechensbekämpfung unter Einbeziehung eines Nacheilerechts, das Betäubungsmittel- und Hotelmelderecht, das Recht des Waffen und Sprengstoffverkehrs sowie das Visa- und Ausländerrecht. U.a. mit Blick auf dieses Abkommen hat der Bundestag am 13. März 1986 mehrheitlich den Abbau der Grenzkontrollen unterstützt und die Bundesregierung gebeten, mit ihren Partnerstaaten zum Ausgleich der verringerten Grenzkontrollen geeignete Maßnahmen zu vereinbaren, damit der erleichterte Grenzübertritt nicht zu Sicherheitsdefiziten und illegaler Einreise führt. ${ }^{553}$ Dass die Bundesregierung auf den genannten Rechtsfeldern Verhandlungen mit dem Zeithorizont 1. Januar 1990 führte, wussten die Parlamentarier demnach. Ebenso war ihnen bewusst, dass sie über die ausgehandelten Inhalte würden abstimmen müssen, da in Art. 19 und

\footnotetext{
${ }^{548}$ Ingenerf, KR 1989, 341 (342); Schreiber, Wolfgang, KR 1991, 369 (370).

${ }^{549}$ Neben den oben in Fn. 473 genannten Autoren kritisiert dies auch Hailbronner, AnwB1. 1989, 485 (494). Diese Kritik ist insofern besonders hervorzuheben, als er Interessenvertreter der damaligen Bundesregierung im Prozess vor dem Bundesverfassungsgericht zum sogenannten Asylkompromiss war, BVerfGE 94, 49 (51).

${ }^{550}$ Bekanntmachung des Bundesinnenministeriums vom 29. Januar 1986, GMB1. 1986, 79.

${ }^{551}$ Siehe 2. Teil A. IV. dieser Arbeit.

${ }^{552}$ Art. 17 SÜ.

553 Zustimmung des Bundestages zur Beschlussempfehlung des Innenausschusses, vgl. BT-Drs. 10/4555 und Plenarprotokoll 10/204, S. 15715 C-D.
} 
20 SDÜ ausdrücklich von Gesetzesharmonisierung in Bereichen, die auch die Bundesgesetzgebung betreffen, die Rede ist und Art. 59 Abs. 2 GG für diese Fälle die Zustimmung des Bundestages vorsieht. ${ }^{554}$ Gleichwohl forderte das Parlament in seiner Mehrheit keine Einbeziehung. Ein Antrag, der auf regelmäßige Unterrichtung des Bundesministeriums des Innern vor und nach Konferenzen der Staaten des Schengener Abkommens zielte, fand keine ausreichende Unterstützung. ${ }^{555}$ So blieb es bis zur unterschriftsreifen Version des Abkommens im Spätherbst 1989 bei einer „Kleinen“ und einer „Großen Anfrage“, die jeweils schriftlich beantwortet wurde. ${ }^{556}$ Eine umfassende Plenardebatte zur Umsetzung des Schengener Abkommens hat das Parlament nicht durchgesetzt, obwohl ihm die Geschäftsordnung dazu die Mittel an die Hand gibt. Der Inhalt einer „Großen Anfrage“ beispielsweise muss im Bundestag beraten werden, wenn eine Fraktion oder fünf Prozent der Abgeordneten dies verlangen. Dabei regelt $§ 101$ S. 3 GOBT den Fall, dass die Antwort der Bundesregierung zur Anfrage vorliegt, während § 102 S. 2 GOBT die Konstellation meint, dass die Beratung ohne eine solche Antwort erfolgt. In diesem Fall hätten die Abgeordneten jedoch die Möglichkeit, einen zuständigen Minister nach Art. 43 Abs. 1 GG ins Plenum zu zitieren und die Diskussion unter Einbeziehung seiner Antwort zu führen.

Zudem wäre das Parlament wegen des letztlich notwendigen Zustimmungsgesetzes zum Schengener Durchführungsabkommen grundsätzlich in der Lage gewesen, seine frühzeitige Einbindung wirksam einzufordern. Als praktisches Beispiel hierfür kann die Rolle des EU-Parlamentes im Zusammenhang mit der von Kommissionspräsident José Manuel Barroso im Herbst 2004 vorgestellten EU-Kommission dienen. Nach Art. 214 Abs. 2 Unterabsatz 3 EGV $^{557}$ stellt sich die Kommission dem Parlament als Kollegium zur Wahl. Im Vorfeld der Wahl wurde deutlich, dass das Parlament der Kommission im Ganzen nicht zustimmen würde, weil es in seiner Mehrheit die geplante Besetzung des Kommissionspostens für Inneres und Justiz für untragbar hielt. Aus diesem Grund stellte der Kommissionspräsident nach drei Wochen eine auf drei Positionen, unter anderem auf der Position des Kommissars für Inneres und Justiz, umgebildete Kommission vor, die daraufhin eine große Mehrheit im Europäischen Parlament erhielt. ${ }^{558}$ Sicher lässt sich dieser Vorgang nicht in allen Punkten mit der Situation des deutschen Parlamentes in den Jahren 1986 bis 1989 vergleichen. Dennoch wird deutlich, dass in der Zustimmungsbedürftigkeit, sei es auch bezogen auf das ganze Paket, eine große Einflussmöglichkeit bereits im Vorfeld liegt.

\footnotetext{
${ }^{554}$ Auch in ihrer Antwort auf eine „Kleine Anfrage“ spricht die Bundesregierung von einem jeweils in innerstaatliches Recht umzusetzenden Staatsvertrag, vgl. BT-Drs. 11/3594 vom 30. November 1988, S. 2.

${ }^{555}$ Der Antrag der Fraktion die GRÜNEN vom 26. September 1989, BT-Drs. 11/5245, wurde an den Innenausschuss überwiesen und später im Plenum nicht wieder aufgegriffen, vgl. Plenarprotokoll vom 28. September 1989, 11/161, S. 12277 B ff. sowie Sachregister Deutscher Bundestag - Bundesrat, 11. Wahlperiode 1987-1990, S. 3109, 1, 4. Spstr.

${ }^{556}$ Sachregister Deutscher Bundestag - Bundesrat, 11. Wahlperiode 1987-1990, S. 3109.

${ }^{557}$ EGV in der Fassung des Vertrages von Nizza, AB1. C 325, 1, vom 24. Dezember 2002.

${ }^{558}$ FAZ Nr. 271 vom 19. November 2004, S. 7.
} 
Selbstverständlich sollte es zum guten Umgang zwischen Parlament und Regierung zählen, dass das Parlament regelmäßig und rechtzeitig informiert wird. Gewinnen die Parlamentarier jedoch den Eindruck, nicht ausreichend eingebunden zu werden, steht ihnen z.B. das Zitier- und Interpellationsrecht zur Verfügung. ${ }^{559}$ Zudem könnten sie eine Entschließung, also einen schlichten Parlamentsbeschluss, des Inhalts formulieren, dass eine Zustimmung fraglich ist, wenn die Regierung nicht alles tut, um eine umfassende Parlamentsdiskussion zu ermöglichen. Voraussetzung hierfür ist, dass das Parlament mehrheitlich hinter einer solchen Bedingung steht. Gibt es solche Mehrheiten nicht bereits, so ist es Aufgabe der Abgeordneten bzw. der Fraktionen, sie zu organisieren. Zwar hat eine solche Organisation entgegen der die Regierung stützenden Parteien keine guten Erfolgsaussichten, aber sie ist aufgrund der vom Grundgesetz vorgegebenen Rollen von Parlament und Regierung grundsätzlich möglich. Scheitern die Bemühungen, eine Parlamentsmehrheit zu organisieren, liegt darin nicht eine Verletzung des Demokratieprinzips, sondern es kommt in erster Linie das demokratische Mehrheitsprinzip zum Ausdruck. Offenbar ist die Mehrheit der Abgeordneten dann der Auffassung, dass die Beteiligung des Bundestages insbesondere mit Blick auf die grundsätzliche Aufgabenverteilung zwischen Bundesregierung und Bundestag im Bereich der auswärtigen Beziehungen im konkreten Fall als ausreichend anzusehen ist. Möglicherweise sieht sie es bereits als nennenswerten Fortschritt an, dass das SDÜ im Gegensatz z.B. zum Schengener Abkommen überhaupt den Gesetzgebungsprozess durchläuft und somit mehr Transparenz über Aufgaben, Ziele und Verfahren der Sicherheitskooperation entsteht. ${ }^{560}$

In diesem Zusammenhang lässt sich auch die Rolle des niederländischen Parlamentes im Schengen-Prozess anführen. Auf ihren ausdrücklichen Wunsch hin wurde die zweite Kammer des Parlamentes von der holländischen Regierung konkret bereits in den SDÜ-Verhandlungsprozess ab dem Jahr 1988 einbezogen. ${ }^{561}$ Die Regierung informierte das Parlament, dessen Mitwirkung auch in den Niederlanden grundsätzlich auf ein „Ja“ oder ein „Nein“ beschränkt war, von diesem Zeitpunkt an vor den internationalen Verhandlungen über den aktuellen Verhandlungsstand und mögliche Handlungsoptionen. ${ }^{562}$ Ermöglicht wurde der auf diesem Wege gewonnene Einfluss des Parlamentes jedoch nur, weil zwischen Sozialdemokraten und Linksliberalen Einigkeit bestand, dass die im Schengen-Prozess behandelten Themen wie Asyl und Minderheitenrechte nicht ohne das Parlament bearbeitet werden sollten. Insofern konnten die Parlamentarier - unterstützt von einflussreichen Interessengruppen wie z.B. dem Niederländischen Flüchtlingswerk -

\footnotetext{
${ }^{559}$ Siehe hierzu oben in diesem Teil der Arbeit A. I. 1. b. aa. (4) (a).

${ }^{560} \mathrm{Vgl}$. Lange, Innere Sicherheit, S. 161.

${ }^{561}$ Schütz, AöR 1995, 509 (528).

${ }^{562}$ Van Iersel, in: Schermers, Free Movement, S. 369 (370).
} 
gegenüber der Regierung zahlenmäßig mit Nachdruck auftreten und die notwendigen Informationen wirksam einfordern. ${ }^{563}$ Mit anderen Worten zeigt dieses Beispiel, dass ein Parlament seinen Einfluss frühzeitig geltend machen kann, wenn es gelingt, die notwendigen Mehrheiten zu organisieren.

Abschließend lässt sich feststellen, dass das Parlament auch unter Berücksichtigung der konkreten Art der Information und Einbindung des Parlamentes im Vorfeld zur Unterzeichnung des SDÜ verfahrensmäßig korrekt beteiligt wurde. Demnach liegt hierin keine Verletzung des Demokratieprinzips.

\section{b. Besondere Sensibilität der Materie}

Möglicherweise hätte sich aber aus der besonderen Sensibilität der Materie die Pflicht ergeben, das Parlament etwa nach dem Verfahren bei innenpolitischen Angelegenheiten einzubinden. $A k$ $m a n n^{564}$ spricht davon, dass die Inhalte des SDÜ unmittelbar die Grundrechtssphäre des Bürgers berühren und dass die nationalen Parlamente im völkerrechtlichen Ratifikationsverfahren im Hinblick darauf nur unzureichende Einflussmöglichkeiten hätten. Richtig ist, dass die Regelungsmaterie des SDÜ eine hohe Grundrechtsrelevanz besitzt. So steht die asylrechtliche Zuständigkeitsregelung im SDÜ beispielsweise im engen Zusammenhang mit der umfassenden Änderung des deutschen Asylgrundrechtes. ${ }^{565}$ Die Datenspeicherung im SIS warf damals Fragen nach ihrer Vereinbarkeit mit dem Recht auf informationelle Selbstbestimmung auf; die Vorschriften nach Art. 40 und 41 SDÜ zu Observation und Nacheile können im konkreten Fall das Freiheitsgrundrecht nach Art. 2 Abs. 2 S. 2 GG einschränken. Damit eine Abwandlung des üblichen völkerrechtlichen Ratifikationsverfahrens jedoch ernsthaft in Betracht käme, erscheint eine bloße Grundrechtsrelevanz wie eben erwähnt nicht ausreichend. Zahlreiche völkerrechtliche Vereinbarungen wie z.B. solche, die den Bereich Umweltschutz oder den Umgang mit Atomwaffen betreffen, haben Relevanz für die in Art. 2 Abs. 2 S. 1 und 2 GG verbürgten Grundrechte. Je nach Ausgestaltung der Verträge kann der angestrebte Schutz für Gesundheit und Leben stärker oder schwächer ausfallen. Wollte man in allen diesen Fällen vom Regelverfahren abweichen, könnte man nicht mehr von einem Regel-Ausnahme-Verhältnis sprechen. Erforderlich wäre aus diesem Grund jedenfalls ein offensichtlicher Grundrechtsverstoß oder eine Bestimmung, die ein Grundrecht so sehr einschränkt, dass ihm kein praktischer Anwendungsbereich verbliebe. Nur dann wäre zu prüfen, ob ein so außergewöhnlicher Fall vorliegt, dass ihm das regelmäßige Ver-

\footnotetext{
${ }^{563}$ Van Iersel, in: Schermers, Free Movement, S. 369 (375).

${ }^{564}$ JA 1994, 49 (55).

${ }^{565}$ Obwohl dies rechtlich nicht zwingend war, vgl. Schoch, DVB1. 1992, 525 (533), stimmten die Abgeordneten einem entsprechenden Gesetzesentwurf mit der nötigen Zwei-Drittel-Mehrheit zu, Plenarprotokoll 12/160, S. 13628 vom 26. Mai 1993 unter Bezugnahme auf BT-Drs. 12/4152.
} 
fahren für außenpolitischen Angelegenheiten unter demokratischen Gesichtspunkten nicht gerecht wird und welche konkreten Folgen das für ein unter derartigen Umständen zustande gekommenes Gesetz haben könnte.

\section{c. Strukturelles Defizit in Bezug auf Justiz- und Innenpolitik}

Möglicherweise hätte ein strukturelles Defizit, das sich zum damaligen Zeitpunkt mit Blick auf die Innen- und Justizpolitik feststellen ließ, zu einer umfassenderen, dem Verfahren bei innenpolitischen Angelegenheiten gleichen, Einbindung des Bundestages führen müssen.

Wie im 2. Teil ${ }^{566}$ dieser Arbeit erwähnt, waren sich die Mitgliedstaaten der Europäischen Gemeinschaft lange Zeit nicht darüber einig, welche Kompetenzen der Europäischen Gemeinschaft im Hinblick auf Justiz und Inneres zustanden bzw. zustehen sollten. Neben diesen rechtlichen Bedenken gab es auch politische Bedenken, eine Regelung auf EG-Ebene zu vereinbaren. Gleichzeitig war der Wunsch nach einer für die Bürger im täglichen Leben spürbaren Europäisierung vorhanden und nach dem damaligen Art. 8 a EGV ${ }^{567}$ auch erklärtes Ziel der EG-Staaten. Mit der Öffnung der Binnengrenzen ging nach vorherrschender Überzeugung die Notwendigkeit einher, auf den Gebieten von Innen- und Justizpolitik gemeinsame Wege zu beschreiten. Diese Kluft zwischen dem umfänglichen Harmonisierungsbedürfnis in der Sachmaterie und der dahinter zurückbleibenden Rechtssetzungskompetenz der EG führte zu der bekannten zwischenstaatlichen Lösung. ${ }^{568}$ Damit hatte das Europäische Parlament als die einzige direkt durch Wahlen legitimierte europäische Institution keine wirklichen Mitentscheidungsrechte. ${ }^{569}$ Gleichzeitig waren die nationalen Parlamente auf die Beteiligung in außenpolitischen Angelegenheiten beschränkt, obwohl die zu regelnden Gegenstände der Sache nach zu einem großen Teil innenpolitischer Natur waren. ${ }^{570}$ Während also die nationalen Parlamente nicht mehr nach dem üblichen Verfahren eingebunden waren, gab es auf europäischer Ebene noch kein parlamentarisches Gremium, dem die ehemaligen Einflussmöglichkeiten der nationalen Parlamente zustanden. Von zahlreichen Autoren wurde diese Konstellation als ein strukturelles Defizit gewertet und die Exekutivlastigkeit der europäischen Innen- und Justizpolitik beklagt. ${ }^{571} 572$

\footnotetext{
${ }^{566}$ Dort Abschnitt A.

${ }^{567}$ In der Fassung der Einheitlichen Europäischen Akte vom 28. Februar 1986, AB1. L 169, 1, vom 29. Juni 1987.

${ }^{568}$ Schoch, DVB1. 1992, 525 (530).

${ }^{569}$ Kritisch zur demokratischen Legitimation des Europäischen Parlamentes: BVerfGE 89, 155 (186); Huber, in: Streinz, EUV/AEUV, Art. 14 EUV, Rn. 39.

${ }^{570}$ Akmann, JA 1994, 49 (55).

${ }^{571}$ Classen, ZRP 1993, 57 (59) mit weiteren Nachweisen in Fußnote 35; Akmann, JA 1994, 49 (55); Busch, Vorgänge 1992, 53 (62); Schoch, DVB1. 1992, 525 (530).

${ }^{572}$ Eine gewisse Machtverschiebung zugunsten des Europäischen Parlamentes war mit dem Vertrag von Maastricht verbunden, der die drei-Säulen-Struktur der EU begründete und die Innen- und Justizpolitik im Wesentlichen der sogenannte dritten Säule zuordnete. Zwar war diese Politik noch immer eine intergouvernementale, aber zumindest erhielt das Europäische Parlament nach Art. K. 6 EUV moderate Einflussmöglichkeiten. Mit dem Vertrag von Am-
} 
Festzustellen ist, welche Auswirkung der Befund eines strukturellen Defizits im hier zu überprüfenden Zusammenhang hat. Möglicherweise wiegt das Defizit so schwer, dass man von einer Verletzung des innerstaatlichen Demokratieprinzips sprechen kann, die mangels europäischer Instrumente bei gleichzeitig drängendem Regelungsbedarf nur durch Beteiligung des Parlamentes wie bei einer innenpolitischen Angelegenheit hätte vermieden werden können. Der Befund eines demokratischen Defizits ist ohne weiteres nachvollziehbar und eine inhaltlich stärkere Beteiligung des Parlamentes mit Hilfe eines parlamentsfreundlicheren Verfahrens wäre wünschenswert gewesen. Gleichwohl gilt auch hier, was bereits unter Buchstabe a. festgestellt wurde: Die Einflussmöglichkeit der Parlamente ist gegenüber dem Verfahren bei innenpolitischen Angelegenheiten zwar eingeschränkt. Wenn sich jedoch entsprechende Mehrheiten finden, hat das Parlament die Macht, inhaltlich bereits im Vorfeld mitzugestalten. Zu berücksichtigen ist, dass sich die europäische Innen- und Justizpolitik bezüglich zahlreicher Sachmaterien seit den 80er Jahren in einer Zeit des schrittweisen Übergangs von der nationalen auf die europäische Ebene befindet. In einer solchen Zeit des Übergangs wird häufig festzustellen sein, dass das alte System nicht mehr und das neue noch nicht umfassend funktioniert. Da Veränderungen eines komplexen Systems aber insbesondere mit Blick auf nationale Befindlichkeiten, Souveränitätsverlustängste und divergierende Interessenlagen der Beteiligten nicht in einem Akt durchzusetzen sind, erscheint ein Zeitraum des Übergangs unumgänglich. Wollte man ihn vermeiden, hieße das, auf Veränderungen ganz zu verzichten. Ein strukturelles Defizit erscheint deshalb unter Berücksichtigung des Demokratieprinzips so lange hinnehmbar, wie dem nationalen Parlament dennoch maßgebliche Einflussmöglichkeiten oder anders ausdrückt Aufgaben und Befugnisse von substanziellem Gewicht verbleiben. Das ist hier über die Beteiligung nach Art. 59 Abs. 2 GG sichergestellt.

\section{Zwischenergebnis}

Zusammenfassend lässt sich festhalten, dass die Art der Beteiligung des deutschen Parlamentes am Zustimmungsgesetz zum SDÜ sowohl unter Berücksichtung des regelhaften Verfahrens als auch unter Bewertung der Besonderheiten nicht zu einer Verletzung des verfassungsrechtlichen Demokratieprinzips führt.

sterdam wurden Kompetenzen bezüglich der Kontrolle der Außengrenzen, Einwanderungs- und Asylpolitik sowie zur justiziellen Zusammenarbeit in Zivilsachen in die erste Säule, den EGV, überführt, so dass unter bestimmten Voraussetzungen das Verfahren der Mitentscheidung zur Anwendung kam. Eine signifikante Veränderung zugunsten der Einflussmöglichkeiten des Parlamentes brachte erst der Vertrag von Lissabon, vgl. Art. 67 ff., 294 AEUV. 


\section{Notwendigkeit eines Gesetzes nach Art. 24 Abs. 1 GG}

Neben der Beteiligung des deutschen Gesetzgebers nach Art. 59 Abs. 2 GG wird von einigen Autoren $^{573}$ thematisiert, ob damals auch ein Anwendungsfall von Art. 24 Abs. 1 GG vorgelegen hat. Danach kann der Bund durch Gesetz Hoheitsrechte auf zwischenstaatliche Einrichtungen übertragen. Rein technisch hätte es keines zusätzlichen Gesetzes bedurft, ${ }^{574}$ allerdings hätte das Vertragsgesetz auf Art. 24 Abs. 1 GG Bezug nehmen müssen mit der Folge, dass die Zustimmung des Parlamentes im Bewusstsein erfolgt wäre, Hoheitsrechte auf eine zwischenstaatliche Einrichtung zu übertragen. Vor der Prüfung der Voraussetzungen von Art. 24 Abs. 1 GG stellt sich jedoch die Frage, welche rechtliche Relevanz eine möglicherweise fehlende Zustimmung heute noch hätte. Diese Frage lässt sich konkret nur beantworten, wenn man die in Betracht kommenden Hoheitsrechte bestimmt. Allerdings kann man allgemein feststellen, dass die zwischenstaatliche Einrichtung bei fehlender aber notwendiger Zustimmung für die Ausübung der Hoheitsrechte formell nicht zuständig wäre und ihr auch materiell die entsprechende Befugnis fehlen würde. Die aufgrund der ihr vermeintlich zustehenden Rechte erlassenen Rechtsakte wären ohne Grundlage und damit unter Umständen rechtlich angreifbar. ${ }^{575}$ Insofern ist es weiterhin von rechtlicher Relevanz, ob ein Gesetz nach Art. 24 Abs. 1 GG erforderlich gewesen wäre.

\section{1. Übertragung von Hoheitsrechten}

Fraglich ist, worin hier eine Übertragung in diesem Sinne liegen kann. Die Autoren, die diese Frage behandeln, diskutieren zwei unterschiedliche Regelungsbereiche.

\section{a. Prüfung der Ausschreibungsvoraussetzungen durch einen anderen Staat}

Einerseits problematisiert Scheller, ob die Übertragung von Hoheitsrechten darin besteht, dass der ausschreibende Staat die Rechtmäßigkeit einer Ausschreibung nach Art. 95 SDÜ nach dem Recht des ersuchten Staates und bei Art. 99 SDÜ nur nach eigenem Recht prüft und die Fahndung mit dem Ergebnis dieser Prüfung in das System eingegeben wird. Im Gegensatz zur vorherigen Rechtslage, bei der der ersuchte Staat ausländische Fahndungsersuchen vor dem Vollzug nach seinem Recht selbst prüfen könne, müsse man hier von einem Rechtshilfeersuchen ,per

\footnotetext{
${ }^{573}$ Scheller, JZ 1992, 904; Dörr, DÖV 1993, 696; Schütz, AöR 1995, 509; Randelzhofer, in: Herzog u.a., GG, Band III, Art. 24 (Stand: Dezember 1992), Rn. 192; Deiseroth, in: Umbach/Clemens, GG, Band I, Art. 24, Rn. 130; Rojahn, in: Kunig, GG, Band 1, Art. 24, Rn. 54; Pitschas, ZRP 1993, 174 (175), der allerdings ohne weitere inhaltliche Auseinandersetzung nur feststellt, dass das Übereinkommen lediglich der Mitwirkung der deutschen gesetzgebenden Körperschaften nach Art. 59 Abs. II S. 1 GG in Form eines Bundesgesetzes bedurfte.

${ }^{574}$ Risse, in: Hömig, GG, Art. 24, Rn. 2; Randelzhofer, in: Herzog u.a., GG, Band III, Art. 24 (Stand: Dezember 1992), Rn. 12.

${ }^{575}$ Anschließen müsste sich die Frage, wie sich in dieser Hinsicht die Übernahme des Schengen-Besitzstandes in den Rahmen der Europäischen Union durch den Vertrag von Amsterdam auswirkt.
} 
Computer“" sprechen, das eine Vollzugsanordnung enthalte. Darin liege eine Übertragung von Hoheitsrechten durch den ersuchten Staat. ${ }^{576}$

Gegen die Ansicht von Scheller spricht, dass der ersuchte Staat nach Art. 94 Abs. 4, 95 Abs. 3 und 99 Abs. 6 SDÜ grundsätzlich die Möglichkeit hat, die Ausschreibungen kennzeichnen zu lassen, wenn er sie für nicht vereinbar hält mit seinem nationalen Recht, internationalen Verpflichtungen oder wesentlichen nationalen Interessen bzw. besonderen Opportunitätsgründen. Er kann die Ausschreibung auf seinem Hoheitsgebiet also vorübergehend oder ganz stoppen. Er hat sogar das Recht, Ausschreibungen, die nach Art. 95 SDÜ seine eigenen Staatsbürger betreffen, systematisch kennzeichnen zu lassen. ${ }^{577}$ Scheller misst den Kennzeichnungsmöglichkeiten allerdings wenig Bedeutung zu und begründet dies damit, dass Art. 24 GG ihrer Ansicht nach keine irreversible Übertragung verlange. Dafür spreche auch die Praxis völkerrechtlicher Vertragsabschlüsse, bei der Widerrufsmöglichkeiten und Ausnahmeklauseln die Regeln sind. ${ }^{578}$ Selbst wenn man der Ansicht der Autorin, dass eine irreversible Übertragung nicht erforderlich sei, folgt, so verkennt sie doch die Bedeutung der Kennzeichnungsmöglichkeiten. Eine Kennzeichnung bedarf anders als in aller Regel die erwähnten Widerrufmöglichkeiten und Ausnahmeklauseln bei völkerrechtlichen Verträgen keiner Entscheidung auf einer gewissen staatlichen Ebene, etwa auf Regierungs- bzw. Ministerebene. Ihr fehlt der notwendige Ausnahmecharakter. Für diese Sichtweise spricht auch der Standort der Kennzeichnungsbestimmungen innerhalb des SDÜ. Ausnahmeklauseln in dem von Scheller erwähnten Sinn würde man eher etwa in den abschließenden Vorschriften zum SIS oder in einem gesonderten Protokoll vermuten. Die Kennzeichnungsregeln haben jedoch einen anderen Standort. Sie sind unmittelbar eingebettet in die Vorschriften zum SIS. Ergänzend kann auch die Tatsache herangezogen werden, dass sich das Sirene-Handbuch ausführlich mit den Kennzeichnungsmöglichkeiten befasst. ${ }^{579}$ Sinn und Zweck eines Handbuches ist es, Antworten auf typischerweise und im Alltagsgeschäft auftretende Fragestellungen zu geben. Insofern wird deutlich, dass eine Kennzeichnung in den Sirenen ein normaler Vorgang und ständig zu bearbeiten ist. Soweit Scheller darauf verweist, dass Deutschland die ihm zustehenden Rechte in der Praxis möglicherweise nicht voll ausüben wird, ${ }^{580}$ kann das für die rechtliche Beurteilung keine so entscheidende Rolle spielen, dass von einer Übertragung im Sinne von Art. 24 Abs. 1 GG gesprochen werden kann. Es liegt also in der Prüfung der Ausschreibungsvoraussetzungen nach Art. 95 und 99 SDÜ durch einen anderen Mitgliedstaat keine Übertragung von Hoheitsrechten.

\footnotetext{
${ }^{576}$ Scheller, JZ 1992, 904 (906 ff.).

${ }^{577}$ Siehe 2. Teil, B. VI. 4. b. dieser Arbeit.

${ }^{578}$ Scheller, JZ 1992, 904, (909).

${ }^{579}$ Sirene-Handbuch, 2.15., 3.5., 5.1. und 7.3., AB1. L 186, 1, vom 15. Juli 2011.

${ }^{580}$ Scheller, JZ 1992, 904 (906).
} 


\section{b. Befugnisse des Exekutivausschusses}

Andere Autoren ${ }^{581}$ wählen dagegen als Ansatzpunkt die Befugnisse des Exekutivausschusses und fragen, ob diese einer Übertragung nach Art. 24 Abs. 1 GG bedurft hätten. Die Art. 131 bis 133 SDÜ enthalten grundsätzliche Bestimmungen zum Exekutivausschuss. ${ }^{582}$ Allgemein ist ihm die Aufgabe übertragen, auf die richtige Anwendung des SDÜ zu achten. Jede Vertragspartei hat einen Sitz und er fasst seine Beschlüsse einstimmig.

Wann eine Übertragung des Art. 24 GG vorliegt, ist umstritten. Nach weit verbreiteter Auffassung im Schrifttum und nach älterer Rechtsprechung des Bundesverfassungsgerichtes ist damit die Kompetenz zum verbindlichen Handeln im Durchgriff gemeint, also die Möglichkeit, unmittelbare hoheitliche Rechtsbeziehungen zu den einzelnen Rechtsunterworfenen in den beteiligten Staaten zu begründen oder den einzelstaatlichen Behörden unmittelbar wirksame Rechtsbefehle zu erteilen. ${ }^{583}$ Bei einer Übertragung von Hoheitsrechten nimmt die Bundesrepublik Deutschland ihren ausschließlichen Herrschaftsanspruch im Geltungsbereich des Grundgesetzes zurück und liefert den Bürger einer außerstaatlichen Hoheitsgewalt aus. ${ }^{584}$

Die Gegenauffassung, insbesondere von der Nachrüstungs-Entscheidung des BVerfG aus dem Jahr 1984 getragen, hält die Befugnis zum Durchgriff nicht für zwingend und lässt schlichthoheitliches Handeln genügen. Unter Art. 24 Abs. 1 GG könne auch der Vorgang fallen, dass ein zuvor tatsächlich zustehendes oder rechtlich mögliches ausschließliches Herrschaftsrecht zugunsten fremder Hoheitsgewalt zurückgenommen wird. ${ }^{585}$

Gegen die zuletzt genannte Auffassung spricht, dass nur mit dem Festhalten am Kriterium des Durchgriffs ein klarer eigener Anwendungsbereich für Art. 24 Abs. 1 GG verbleibt. Während die traditionelle völkerrechtliche Zusammenarbeit, die die Verpflichtung zwischen den Staaten ermöglicht, von Art. 59 Abs. 2 GG abgedeckt wird, erlaubt Art. 24 Abs. 1 GG mit der Übertragung von Hoheitsrechten eine Kooperation von gesteigerter Intensität. Unausweichlich wäre eine ex-

\footnotetext{
${ }^{581}$ Dörr, DÖV 1993, 696 (696 ff.); Schütz, AöR 1995, 509 (513 ff.); Randelzhofer, in: Herzog u.a., GG, Band III, Art. 24 (Stand: Dezember 1992) Rn. 192 f.; Deiseroth, in: Umbach/Clemens, GG, Band I, Art. 24, Rn. 130; Rojahn, in: Kunig, GG, Band 1, Art. 24, Rn. 54.

${ }^{582}$ Der Exekutivausschuss besteht nicht mehr seit der Überführung des Schengen-Besitzstandes in den Rahmen der Europäischen Union; an seine Stelle ist der Rat der Europäischen Union getreten, vgl. Art. 2 Abs. 1 UA 1 S. 2 des Protokolls zur Einbeziehung des Schengen-Besitzstandes in den Rahmen der Europäischen Union. Da es jedoch um die Notwendigkeit eines Gesetzes nach Art. 24 Abs. 1 GG zum damaligen Zeitpunkt geht, wird in diesem Abschnitt der Arbeit auf das SDÜ in seiner Fassung von 1993, BGB1. II 1993, 1013, Bezug genommen.

${ }^{583}$ Dörr, DÖV 1993, 696 (699); Schütz, AöR 1995, 509 (517); Tomuschat, in: Dolzer u.a., BK, Band 6, Art. 24 (Zweitbearbeitung, Stand: April 1981), Rn. 8; Pernice, in: Dreier, GG, Band II, Art. 24, Rn. 20; Rojahn, in: Kunig, GG, Band 1, Art. 24, Rn. 25; Randelzhofer, in: Herzog u.a., GG, Band III, Art. 24 (Stand: Dezember 1992), Rn. 12, $30,42$.

${ }^{584}$ BVerfGE 37, 271 (280); 58, 1 (28).

${ }^{585}$ BVerfGE 68, 1 (90, 94); Deiseroth, in: Umbach/Clemens, GG, Band I, Art. 24, Rn. 50 ff., 55 ; allerdings ist das BVerfG von dieser Auslegung mit BVerfGE 90, 286 (346) wieder abgewichen und verlangt für Art. 24 Abs. 1 GG die Zuweisung der Kompetenz, „Hoheitsbefugnisse mit unmittelbarer Wirkung im innerstaatlichen Bereich auszuüben“.
} 
tensive Auslegung des Art. 24 Abs. 1 GG dagegen erst, wenn sich der Rahmen, den Art. 59 GG für den Abschluss völkerrechtlicher Verträge zur Verfügung stellt, für die Betrauung internationaler Organisationen mit schlicht-hoheitlichen Befugnissen als zu eng erweist. Das ist nicht der Fall. Insoweit ist aus Gründen der klaren rechtsdogmatischen Abgrenzung am Erfordernis des Durchgriffs festzuhalten. ${ }^{586}$

Der Charakter der Rechte, die dem Exekutivausschuss übertragen wurden, bedarf somit einer genauen Prüfung.

\section{aa. Inkraftsetzen}

Zunächst oblag es dem Ausschuss, das SDÜ, obwohl es völkerrechtlich durch die Zustimmung der gesetzgebenden Organe bereits wirksam war, zusätzlich in Kraft zu setzen. ${ }^{587}$ Durch diesen Inkraftsetzungsmechanismus wurde die effektive völkerrechtliche Wirksamkeit des Abkommens von seinem Inkrafttreten abgekoppelt. Das Ratifikationsverfahren war damit notwendige, jedoch nicht hinreichende Bedingung für die Effektivität der Freizügigkeit im Schengen-Raum. ${ }^{58}$

\section{bb. Überwachung der Schengener Außengrenzen}

Nach Art. 3 Abs. 1 SDÜ dürfen die Außengrenzen grundsätzlich nur an den Grenzübergangsstellen und während der festgesetzten Verkehrsstunden überschritten werden. „Das Nähere sowie die Ausnahmen und die Modalitäten des kleinen Grenzverkehrs und die Vorschriften für bestimmte Sonderkategorien des Seeverkehrs, wie die Vergnügungsschifffahrt und die Küstenfischerei“ heisst es weiter, „legt der Exekutivausschuss fest.“

Art. 5 SDÜ benennt die Voraussetzungen, unter denen einem Drittausländer ein Aufenthalt von bis zu drei Monaten im Hoheitsgebiet der Vertragsparteien erlaubt werden kann. Der Exekutivausschuss „bestimmt“, im Besitz welcher gültiger Grenzübertrittspapiere bzw. welches Papiers der Drittausländer sein muss. ${ }^{589}$ Grundsätzlich ist die Einreise nach Art. 5 Abs. 2 S. 1 SDÜ zu verweigern, wenn der Drittausländer nicht alle aufgeführten Voraussetzungen erfüllt.

Nach Art. 6 Abs. 3 SDÜ überwachen die zuständigen, nationalen Behörden die Außengrenzen außerhalb der Grenzübergangsstellen sowie die Grenzübergangsstellen außerhalb der für sie festgesetzten Verkehrsstunden durch Streifen. Diese Überwachung muss so ausgeführt werden,

\footnotetext{
${ }^{586}$ Vgl. Tomuschat, in: Dolzer u.a., BK, Band 6, Art. 24 (Zweitbearbeitung, Stand: April 1981), Rn. 8; Randelzhofer, in: Herzog u.a., GG, Band III, Art. 24 (Stand: Dezember 1992), Rn. 30 ff., 42; Rojahn, in: Kunig, GG, Band 1, Art. 24, Rn. 25.

${ }^{587}$ Vgl. 2. Teil, A.

${ }^{588}$ Schütz, AöR 1995, 509 (513).

${ }^{589}$ Art. 5 Abs. 1 a) SDÜ.
} 
dass kein Anreiz für eine Umgehung der Kontrollen an den Grenzübergangsstellen entsteht. Die Überwachungsmodalitäten sind hierbei gegebenenfalls vom Exekutivausschuss „festzulegen“.

Schließlich bestimmt Art. 8 SDÜ in diesem Abschnitt abschließend, dass der Exekutivausschuss „die erforderlichen Entscheidungen über die praktischen Einzelheiten der Durchführung der Kontrollen und der Überwachung der Grenzen trifft.“

\section{cc. Gemeinsame Sichtvermerkspolitik}

Art. 9 bis 17 SDÜ beschäftigen sich mit der Sichtvermerkspolitik für einen kurzfristigen Aufenthalt innerhalb der Schengen-Staaten. In diesem Zusammenhang regelt Art. 10 Abs. 1 SDÜ die Einführung eines einheitlichen Sichtvermerks, für dessen Erteilung nach Art. 12 Abs. 2 S. 1 SDÜ grundsätzlich die Vertragspartei zuständig ist, in deren Hoheitsgebiet das Hauptreiseziel liegt. Nach Art. 12 Abs. 3 SDÜ ,legt“ der Exekutivausschuss hinsichtlich der Sichtvermerkserteilung die Anwendungsmodalitäten und insbesondere die Kriterien zur Bestimmung des Hauptreiseziels ,fest.“

Art. 17 SDÜ erwähnt die Aufgaben des Exekutivausschusses in jedem seiner drei Absätze. Nach Absatz 1 „legt“ der Ausschuss allgemein formuliert „gemeinsame Regelungen für die Prüfung der Sichtvermerksanträge fest, achtet auf deren richtige Anwendung und passt sie an neue Situationen und Umstände an.“ Nach Absatz 2 „legt“ er die Fälle „fest“, in denen die Erteilung eines Sichtvermerks von der Konsultation der zentralen Behörde der betroffenen Vertragspartei und unter Umständen von der Konsultation der zentralen Behörden der anderen Vertragsparteien abhängig ist. Schließlich „,trifft“ er nach Absatz 3 ,die erforderlichen Entscheidungen“ für die in sieben Punkten aufgeführten Bereiche, u.a. sichtvermerksfähige Reisedokumente, die für die Sichtvermerkserteilung zuständigen Behörden, Form, Inhalt und Gültigkeitsdauer der Sichtvermerke sowie Gebühren für die Ausstellung.

\section{dd. Kosten der Abschiebung von Drittausländern}

Art. 23 SDÜ befasst sich mit der Abschiebung von Drittausländern, bei denen die Voraussetzungen für einen rechtmäßigen Aufenthalt im Hoheitsgebiet der Vertragsparteien nicht oder nicht mehr vorliegen. Nach Art. 24 SDÜ „bestimmt“ der Exekutivausschuss die geeigneten praktischen Kriterien und Modalitäten, nach denen die Vertragsparteien die finanziellen Ungleichgewichte ausgleichen, die infolge der in Art. 23 SDÜ festgelegten Abschiebungsverpflichtung entstehen. 


\section{ee. Zuständigkeit für Asylbegehren}

Art. 28 bis 38 SDÜ regeln die Zuständigkeit für die Bearbeitung von Asylbegehren. Grundsätzlich ist nach Art. 30 Abs. 1 a) die Partei zuständig, die dem Asylbegehrenden einen Sichtvermerk oder eine Aufenthaltserlaubnis erteilt. Ist der Asylbegehrende jedoch in das Hoheitsgebiet der Vertragsparteien eingereist, ohne im Besitz der vom Exekutivausschuss bestimmten gültigen Grenzübertrittspapiere bzw. des entsprechenden Papiers zu sein, ${ }^{590}$ ist die Vertragspartei zuständig, über deren Außengrenze der Asylbegehrende einreiste.

\section{ff. Verkehr mit Betäubungsmitteln}

Art. 70 bis 76 SDÜ beschäftigen sich mit den Möglichkeiten der Vertragsparteien bei der Bekämpfung der Betäubungsmittelkriminalität. Soweit eine Person Betäubungsmittel im Rahmen einer ärztlichen Behandlung mit sich führt, soll sie nach Art. 75 Abs. 1 SDÜ bei einer Kontrolle eine Bescheinigung der zuständigen Behörde ihres Aufenthaltsstaates vorlegen. Der Exekutivausschuss „legt“ nach Abs. 2 der Vorschrift Form und Inhalt der Bescheinigung, nämlich insbesondere Angaben bezüglich der Art, der Menge und der Reisedauer „fest.“

\section{gg. Erwerb und Besitz von Feuerwaffen}

Art. 77 bis 91 SDÜ befassen sich mit dem Erwerb, dem Besitz, dem Vertrieb und dem Überlassen von Feuerwaffen und Munition durch Privatpersonen. Die Waffen werden in verbotene, erlaubnispflichtige sowie meldepflichtige Waffen aufgeteilt und nach Art 79 bis 81 SDÜ in entsprechende Listen aufgenommen. Gemäß Art. 89 S. 2 SDÜ kann der Exekutivausschuss diese Listen ändern oder ergänzen.

\section{hh. Warenverkehr}

In den Artikeln 120 bis 125 SDÜ, die sich auf Transport und Warenverkehr beziehen, legt Art. 121 Abs. 1 SDÜ fest, dass die Vertragsparteien für bestimmte Pflanzen und Pflanzenerzeugnisse auf nach Gemeinschaftsrecht eigentlich erforderliche Untersuchungen und die Vorlage von Pflanzengesundheitszeugnissen verzichten. Der Exekutivausschuss bestimmt nach Absatz 2 hier wiederum die Liste der in diesem Sinne privilegierten Pflanzen und Pflanzenerzeugnisse. Er kann sie ändern und bestimmt den Zeitpunkt, zu dem die Änderungen in Kraft treten sollen.

\footnotetext{
${ }^{590}$ Bezugnahme auf Art. 5 Abs. 1 a) SDÜ.
} 


\section{c. Diskussion}

Bei der Beurteilung des „Durchgriffscharakters“ der Kompetenz nach aa. ist zu berücksichtigen, dass bei der Einführung des SIS technische Fragestellungen eine ungewöhnlich große Rolle spielten. Die verzögerte tatsächliche Geltung war den technischen Unwägbarkeiten geschuldet. Die Entscheidung, ob das Abkommen überhaupt in Kraft treten sollte, oblag jedoch dem deutschen Gesetzgeber. Die Entscheidung des Inkraftsetzens hat demgegenüber rechtlich nicht ein solches Gewicht, dass man von einer Durchgriffswirkung sprechen könnte.

Hinsichtlich der unter bb. bis hh. angeführten Kompetenzen ist weiterhin davon auszugehen, dass den Regelungen gemäß Art. 24, 30 Abs. 1 e), 89, 131 Abs. 2 sowie 17 Abs. 1 SDÜ ein Durchgriffscharakter nicht zukommt. ${ }^{591}$

Bei Art. 24 SDÜ, der den zwischenstaatlichen Finanzausgleich wegen der Kosten von Abschiebungen regelt, ist Regelungsgegenstand die Pflicht zur finanziellen Unterstützung der Vertragsstaaten untereinander, so dass auch nur diese Adressat sein können.

Art. 30 Abs. 1 e) SDÜ nimmt zum einen lediglich mittelbar Bezug auf Befugnisse des Exekutivausschusses; zudem hat die Regelung unmittelbare Rechtsfolgen ebenfalls nur für den Vertragsstaat als ganzen.

Nach der Systematik der Regelungen zu Feuerwaffen und Munition ist ein Durchgriff auf nationale Behörden durch die Regelung des Art. 89 SDÜ gleichfalls abzulehnen. Art. 77 Abs. 1 SDÜ geht für die Regelungen des gesamten Kapitels davon aus, dass es zusätzlich einer Anpassung der innerstaatlichen Rechtsvorschriften bedarf.

Auch Art. 131 Abs. 2 und 17 Abs. 1 SDÜ, die die Wächterfunktion des Exekutivausschusses beschreiben, geben diesem keine konkreten Handlungsinstrumente.

Einer näheren Betrachtung bedürfen dagegen die übrigen oben erläuterten Kompetenzen des Ausschusses nach Art. 3 Abs. 1 S. 2, Art. 5 Abs. 1 a), Art. 6 Abs. 3 S. 3, Art. 8, Art. 12 Abs. 3 , Art. 17 Abs. 1 und 2, Art. 75 Abs. 2 sowie Art. 121 Abs. 1 und 2 SDÜ. Dörr führt an dieser Stelle eine Vertragsauslegung nach den Art. 31 bis 33 der Wiener Vertragsrechtskonvention ${ }^{592}$ durch. Seiner Ansicht nach liefert der Wortlaut der Bestimmungen zunächst nur Indizien für eine Durchgriffswirkung, während der systematische Zusammenhang sowie Sinn und Zweck ganz deutlich für diese Wirkung sprächen.

\footnotetext{
${ }^{591}$ Dörr, DÖV 1993, 696 (702).

${ }^{592}$ Im Folgenden: WVRK; zwar galt die WVRK vom 23. Mai 1969 zum Zeitpunkt der deutschen Zustimmung zum SDÜ im Juni 1993 nicht für alle Schengen-Vertragsstaaten, jedoch können die Auslegungsgrundsätze als Kodifizierung bestehenden Völkergewohnheitsrechts für die Auslegung herangezogen werden, Dörr, DÖV 1993, 696 (702) sowie Schütz, AöR 1995, 509 (Fußnote 16).
} 


\section{aa. Wortlautauslegung}

Bei der Wortlautauslegung zitiert Dörr aus den Vorschriften Begriffe wie „festlegen“, „,bestimmen“, „Entscheidungen treffen“. Zudem bezieht er sich auf Art. 131 Abs. 1 SDÜ, wonach der Exekutivausschuss „,im Hinblick auf die Anwendung“ des SDÜ eingerichtet wird. Von einer „Anwendung“ ließe sich nur sprechen, wenn davon auch die unmittelbare Bindung der Subsumtion im Einzelfall durch die einzelstaatlichen Behörden umfasst sei. ${ }^{593}$ Dabei verkennt Dörr jedoch, dass sich die mit diesen Ausdrücken einhergehende Verbindlichkeit nicht unbedingt auf das Verhältnis Exekutivausschuss - Bürger beziehen muss. Möglich ist ebenfalls, dass die Festlegung im Verhältnis zwischen den Vertragsparteien getroffen wird. Auch Fragen der Anwendung könnten lediglich in diesem Verhältnis entschieden werden. ${ }^{594}$

\section{bb. Systematische Auslegung}

In systematischer Hinsicht weist Dörr darauf hin, dass nirgendwo in Zusammenhang mit den zu untersuchenden Bestimmungen von einer Verpflichtung der Vertragsstaaten zur Umsetzung des materiell Vereinbarten in die nationalen Rechtsordnungen die Rede ist. Eine Vorschrift wie Art. 77 Abs. 1 SDÜ, der die Staaten zur Anpassung ihrer nationalen Vorschriften verpflichtet, fehle in den oben genannten Bereichen. Daraus schlussfolgert er, dass es einer Umsetzung nicht bedürfe, da die Beschlüsse des Exekutivausschusses auch ohne diese wirksam sein sollen. Eine solche Betrachtungsweise ist aber nicht zwingend. Eine Verpflichtung zur Umsetzung des Abkommens muss nicht ausdrücklich normiert werden; sie ergibt sich bereits aus der den Vertragsparteien obliegenden Pflicht, einen Vertrag nach Treu und Glauben zu erfüllen, Art. 26 WVRK. So ist es den Vertragsparteien unbenommen, etwa die gültigen Grenzübertrittspapiere nach Art. 5 Abs. 1 a) durch eine möglicherweise inhaltsgleichen Umsetzungsakt in nationales Recht zu transformieren. ${ }^{595}$ Weiter führt Dörr im systematischen Zusammenhang an, dass der Ausschuss für die Vorbereitung seiner Entscheidungen Arbeitsgruppen einsetzen kann, die aus Vertretern der nationalen Verwaltungen bestehen sollen. ${ }^{596}$ Seiner Ansicht nach ist die Bestimmung nur dann sinnvoll, wenn auf diese Weise eine optimale Anwendung unmittelbar wirksamer Regelungen in den verschiedenen Verwaltungsapparaten der Vertragsstaaten sichergestellt werden soll. Sollten diese Regelungen erst im Anschluss an eine nationale Transformation praktisch anzuwenden sein, bedürfe es der Einschaltung bürokratischen Sachverstandes vor ihrem Erlass wohl nicht. Auch diese Überlegung ist nachvollziehbar; jedoch ist der Schluss, den Dörr zieht, nicht zwingend. Diejenigen frühzeitig mit einzubeziehen, die konkret umsetzen, erscheint auch dann sinnvoll, wenn

\footnotetext{
${ }^{593}$ Dörr, DÖV 1993, 696 (703).

${ }^{594}$ Vgl. Schütz, AöR 1995, 509 (517).

${ }^{595}$ Vgl. Schütz, AöR 1995, 509 (517).

${ }^{596}$ Art. 132 Abs. 4 SDÜ.
} 
nur ein noch auszufüllender Rahmen beschlossen werden soll. In einer solchen Konstellation können die Endanwender aus ihrer praktischen Erfahrung wertvolle Hinweise zur Gestaltung dieses Rahmens geben. Auf diese dargelegte Weise lässt sich die Ermächtigung des Ausschusses nach Art. 132 Abs. 4 SDÜ ebenfalls in einen nachvollziehbaren systematischen Zusammenhang stellen.

Dörr und Randelzhofer argumentieren weiter systematisch und vergleichen die Befugnisse einer nach Art. 70 SDÜ einzusetzenden Arbeitsgruppe mit denen des Exekutivausschusses. ${ }^{597}$ Diese Arbeitsgruppe soll aus Vertretern der Polizei und des Zolls gebildet werden und dem Exekutivausschuss Vorschläge zur besseren Bekämpfung der Betäubungsmittelkriminalität machen, wobei praktische und technische Aspekte im Vordergrund stehen. Die Autoren stellen fest, dass dieser Arbeitsgruppe erkennbar keine Durchgriffsbefugnisse übertragen worden seien und schlussfolgern daraus, dass im Gegensatz dazu mit den deutlich konkreteren Bestimmungen für den Exekutivausschuss eine Durchgriffswirkung verbunden sein muss. Auch dieser Schluss erweist sich jedoch nicht als unausweichlich. Nur weil zwei Gremien, deren Befugnisse sich zweifelsohne voneinander unterscheiden, in einem völkerrechtlichen Vertragstext genannt werden, müssen die Befugnisse des einen Gremiums nicht zwingend von solcher Bedeutung sein, dass mit ihrer Hilfe innerstaatlich unmittelbar Rechtswirkungen gesetzt werden können.

Sowohl Dörr als auch Randelzhofer thematisieren weiterhin eine Gemeinsame Erklärung der Vertragsstaaten in der Schlussakte zum SDÜ, die nach Art. 31 Abs. 2 a) WVRK zur Auslegung heranzuziehen ist. ${ }^{598}$ In dieser Erklärung heisst es zu Art. 132 SDÜ, dass die Vertragsparteien ihre nationalen Parlamente über die Anwendung des Übereinkommens - lediglich - unterrichten werden. In Art. 132 SDÜ geht es um die Mitglieder des Exekutivausschusses ${ }^{599}$ sowie allgemein um Modalitäten der Beschlussfassung und deren Vorbereitung. ${ }^{600}$ Dörr und Randelzhofer ziehen den Schluss, dass bei der bloßen Unterrichtung an eine konstitutive Mitwirkung des nationalen Gesetzgebers offenbar nicht gedacht sei. Dabei übersehen sie jedoch, dass sich die Erklärung ausdrücklich nur auf Art. 132 SDÜ bezieht, nicht jedoch auf sämtliche Befugnisse des Exekutivausschusses, die ihm das SDÜ einräumt. Art. 132 SDÜ verleiht dem Exekutivausschuss unstreitig keine Durchgriffsbefugnisse. Man kann die Erklärung also auch so verstehen, dass die Parlamente über die konkreten Mitglieder des Exekutivausschusses, über seine noch festzulegende

\footnotetext{
${ }^{597}$ Dörr, DÖV 1993696 (703); Randelzhofer, in: Herzog u.a., GG, Band III, Art. 24 (Stand: Dezember 1992), Rn. 192 bezüglich der Art. 3 Abs. 1 S. 2, 6 Abs. 3 sowie 8 SDÜ.

${ }^{598}$ Dörr, DÖV 1993, 696 (703 f.); Randelzhofer, in: Herzog u.a., GG, Band III, Art. 24 (Stand: Dezember 1992), Rn. 192.

${ }^{599}$ Art. 132 Abs. 1 SDÜ.

${ }^{600}$ Art. 132 Abs. 2 - 4 SDÜ.
} 
Arbeitsmethode sowie über die zur Beschlussvorbereitung eingesetzten Arbeitsgruppen informiert werden. Auch bei diesem Verständnis hätte dieser Teil der Schlussakte einen Sinn.

Randelzhofer führt weiter die Regelungen zur Sichtvermerkspolitik nach Art. 9 bis 17 SDÜ an und sieht in den Art. 12 Abs. 3, 17 Abs. 1, 2 und 3 SDÜ Durchgriffsbefugnisse für den Exekutivausschuss, obwohl der einheitliche Sichtvermerk letztlich von den nationalen Behörden erteilt wird. Er sieht in diesem Nebeneinander von einzelbehördlicher Anwendungszuständigkeit und avisierter Sekundärrechtssetzung durch den Exekutivausschuss nur Sinn, wenn letztere für erstere unmittelbare Rechtsbindung erzeugt. Auch diesem Argument lässt sich entgegenhalten, dass man das so sehen kann, aber nicht zwingend muss. Wie bereits festgestellt, kann die Sekundärrechtssetzung auch nur zu einer Bindung zwischen den Staaten führen. Der Sinn würde dann darin bestehen, dass man sich zumindest zwischenstaatlich auf ein einheitliches Regelwerk geeinigt hätte, was ebenfalls im Ergebnis eine deutlich größere Einheitlichkeit in der Rechtsanwendung mit sich brächte.

Dieses Argument lässt sich auch der Auffassung entgegenhalten, wonach der vom Exekutivausschuss zu bestimmenden Pflanzen-Liste nach Art. 121 Abs. 1 S. 2 SDÜ unmittelbare Wirkung zukommen soll. $^{601}$

\section{cc. Teleologische Auslegung}

Im Rahmen der teleologischen Auslegung zieht Dörr den völkergewohnheitsrechtlichen Grundsatz heran, wonach ein Vertrag in dem durch Wortlaut und Systematik vorgegebenen Rahmen stets so auszulegen ist, dass sein Regelungszweck bestmöglich erreicht wird. Seiner Ansicht nach sind die Ziele des SDÜ am ehesten zu erreichen, wenn sich ihre Umsetzung im Einzelfall unmittelbar an zwischenstaatlichen Vorgaben zu orientieren hat. ${ }^{602}$ Zum einen ließe sich dieses Argument bei jedem der zahlreichen auf Vereinheitlichung und Harmonisierung angelegten völkerrechtlichen Abkommen anführen. Zum anderen spricht dagegen, dass der durch Wortlaut und Systematik vorgegebene Rahmen nicht zwingend der von Dörr skizzierte sein muss. Hiermit kann man die Argumentation von Dörr entkräften, denn auch er kommt zu seinem Gesamtauslegungsergebnis nur in Zusammenschau der Ergebnisse aller drei von ihm genannten Auslegungsmethoden.

\section{dd. Historische Auslegung}

Ergänzend ist vielmehr anzumerken, dass Dörr die vierte gängige Auslegungsmethode, die historische ${ }^{603}$ gänzlich außer acht lässt. Zwar schildert er an anderer Stelle seines Beitrages den In-

\footnotetext{
${ }^{601}$ Dörr, DÖV 1993, 696 (703); Randelzhofer, in: Herzog u.a., GG, Band III, Art. 24 (Stand: Dezember 1992), Rn. 193.

${ }^{602}$ Dörr, DÖV 1993, 696 (704).

${ }^{603}$ Art. 31 Abs. 1 WVRK.
} 
formationsaustausch von Bundesregierung und Bundesrat zum fraglichen Gesetz, greift diese Tatsachen jedoch im Rahmen der Auslegung nicht wieder auf. Auf die Frage des Bundesrates, ob die vom Exekutivausschuss zu treffenden Regelungen der Umsetzung in innerstaatliches Recht bedürfen, erklärte die Bundesregierung, dass die Umsetzung der Entscheidungen des Exekutivausschusses in der Verantwortung der Vertragsstaaten liege. ${ }^{604}$

Auch Randelzhofer greift diesen Argumentationsaustausch zwischen Bundesregierung und Bundesrat auf, misst der Antwort der Bundesregierung jedoch im Hinblick auf die oben bereits erwähnte Gemeinsame Erklärung nach Nr. 6) der Schlussakte zum SDÜ keine entscheidende Bedeutung zu. Da nach dieser Erklärung zu Art. 132 SDÜ an ein rechtlich wirksames Dazwischentreten nationaler Instanzen offenbar nicht gedacht sei, könne die Aussage der Bundesregierung daran alleine nichts ändern. ${ }^{605}$ Dem lässt sich jedoch wiederum entgegenhalten, dass sich die Erklärung in der Schlussakte nicht notwendig auf den Charakter der Befugnisse des Exekutivausschusses bezieht, sondern möglicherweise nur auf die in Art. 132 SDÜ geregelten Bereiche. Demgegenüber bezieht sich die Aussage der Bundesregierung eindeutig auf sämtliche Entscheidungen des Exekutivausschusses und ist deshalb maßgeblich $\mathrm{zu}$ beachten. Mit dieser klaren Formulierung in den deutschen Gesetzesmaterialien kommt die historische Auslegung zu dem Ergebnis, dass dem Exekutivausschuss mit dem SDÜ keine unmittelbaren Durchgriffsbefugnisse verliehen werden sollen.

Im Ergebnis lässt sich festhalten, dass die umfangreiche Auslegung zu keinem eindeutigen Ergebnis kommt, und es stellt sich die Frage, welche Auslegungsregel in einem solchen Zweifelsfall gelten soll. Für die Auffassung, die dem Exekutivausschuss im Zweifel Durchgriffsbefugnisse zugesteht, lässt sich die grundsätzliche Völkerrechtsrechtsfreundlichkeit des Grundgesetzes ${ }^{606}$ anführen. Art. 24 GG will gerade eine internationale Verflechtung der Bundesrepublik fördern und ermöglichen. Auf der anderen Seite wird von zwei Grundsätzen abgewichen, wonach völkerrechtliche Verträge erstens keine unmittelbaren Rechte und Pflichten auf der Ebene des nationalen Rechts erzeugen ${ }^{607}$ und zweitens ein Staat für seine Angehörigen selbst und ausschließlich entscheidet. Weicht ein Staat von diesen Grundsätzen ab und bricht seinen „Souveränitätspanzer ${ }^{6008}$ gleichsam auf, handelt es sich um eine bedeutende Ausnahme. Aus diesem Grund wird man verlangen können, dass ein Vertragstext ein solches Bewusstsein und einen entspre-

\footnotetext{
${ }^{604}$ BT-Drs., 12/2453, S. 97, 99.

${ }^{605}$ Randelzhofer, in: Herzog u.a., GG, Band III, Art. 24 (Stand: Dezember 1992), Rn. 192.

${ }^{606}$ Ipsen, Staatsrecht I, Rn. 1075; Rojahn, in: Kunig, GG, Band 1, Art. 24, Rn. 1 ff.; Randelzhofer, in: Herzog u.a., GG, Band III, Art. 24 (Stand: Dezember 1992), Rn. 2.

${ }^{607}$ Ipsen, Staatsrecht I, Rn. 1079.

${ }^{608}$ Vgl. Tomuschat, in: Dolzer u.a., BK, Band 6, Art. 24 (Zweitbearbeitung, Stand: April 1981), Rn. 8.
} 
chenden Willen eindeutig zum Ausdruck bringt. Nur aufgrund einer derartigen Formulierung kann man davon ausgehen, dass Hoheitsrechte übertragen worden sind.

Ebenfalls in diese Richtung argumentiert Rojahn, der für den Exekutivausschuss keine eindeutigen Befugnisnormen sieht und in einem solchen Zweifelsfall davon ausgeht, dass die Vertragsstaaten weniger einschneidende Beschränkungen ihrer Entscheidungs- und Gestaltungsfreiheit gewählt haben. ${ }^{609}$

Zusammenfassend lässt sich also feststellen, dass sich dem Schengener Durchführungsabkommen zum Zeitpunkt, zu dem die deutschen Gesetzgebungskörperschaften demselben zustimmten, keine unmittelbaren Durchgriffsbefugnisse für den Exekutivausschuss entnehmen lassen. Eine Übertragung von Hoheitsrechten ist somit nicht erfolgt. ${ }^{610}$

Die Folgefrage, ob es sich beim Exekutivausschuss um eine zwischenstaatliche Einrichtung handelt, erübrigt sich daher. ${ }^{611}$

\section{Ergebnis}

Eine Befassung des Gesetzgebers nach Art. 24 Abs. 1 GG war somit nicht erforderlich.

\footnotetext{
${ }^{609}$ Rojahn, in: Kunig, GG, Band 1, Art. 24, Rn. 54.

${ }^{610}$ So im Ergebnis auch Schütz, AöR 1995, 509 (518).

${ }^{611}$ Dörr bejaht dies, vgl. DÖV 1993, 696 (698), allerdings erscheint auch dieses Ergebnis mit Blick auf die eindeutig gegenteilige Aussage der Bundesregierung zumindest als diskussionswürdig, vgl. BT-Drs. 12/2453, S. 99; Scheller fragt in Konsequenz ihres Ansatzes, ob der fremde, die Ausschreibungsvoraussetzungen prüfende Staat als zwischenstaatliche Einrichtung anzusehen ist und bejaht dies mit der Ratio des Art. 24 Abs. 1 GG im Wege eines Erstrecht-Schlusses, vgl. Scheller, JZ 1992, 904 (909 f.). Auch dieses Ergebnis, das dem Wortlaut der Vorschrift klar widerspricht, bedürfte der näheren Diskussion, vgl. zu diesem Punkt ebenfalls ablehnend und m.w.N. Streinz, in: Sachs, GG, Art. 24, Rn. 19 f.
} 


\section{B. Vereinbarkeit der verdeckten Registrierung mit Art. 8 GR-Charta}

Im 2. Teil dieser Arbeit unter B.III.5. ist dargelegt worden, dass Art. 99 SDÜ zwei Ausschreibungsalternativen vorsieht, nämlich die der verdeckten Registrierung und die der gezielten Kontrolle. Da Rechtsgrundlagen zur gezielten Kontrolle in Deutschland nur in einigen Polizeigesetzen vorhanden sind, spielt diese Variante hierzulande nur eine untergeordnete Rolle. Die meisten Ausschreibungen zur gezielten Kontrolle aus anderen Mitgliedstaaten werden automatisch in eine verdeckte Registrierung umgewandelt, Art. 99 Abs. 5 S. 2 SDÜ. Weiterhin sind im 2. Teil unter besonderer Berücksichtigung von Art. 99 Abs. 1 und Art. 104 SDÜ drei Ausschreibungsvarianten der verdeckten Registrierung ermittelt worden, nämlich eine strafprozessuale, eine polizeirechtliche und eine geheimdienstliche. Da es den Rahmen dieser Arbeit sprengen würde, soll im Folgenden ausschließlich die strafprozessuale Variante auf ihre Vereinbarkeit mit übergeordneten Rechtsgrundsätzen geprüft werden. Dazu ist zunächst der richtige Prüfungsmaßstab zu bestimmen.

\section{Bestimmung des Prüfungsmaßstabes}

Die Zulässigkeit der verdeckten Registrierung beruht in ihren wesentlichen Merkmalen auf dem SDÜ, einem völkerrechtlichen Vertrag, dem nach Art. 59 Abs. 2 GG von den gesetzgebenden Körperschaften zugestimmt wurde und auf strafprozessualen Normen, die ebenfalls den Rang eines einfachen Bundesgesetzes haben. Bis zum Zeitpunkt der Überführung des SchengenBesitzstandes in den rechtlichen Rahmen der EU mit dem Vertrag von Amsterdam handelte es sich um eine so gesehen rein nationale Materie, deren Rechtmäßigkeit am Maßstab des Grundgesetzes und hier auf die Vereinbarkeit mit dem Recht auf informationelle Selbstbestimmung nach Art. 2 Abs. 1 i.V.m. Art. 1 Abs. $1 \mathrm{GG}^{612}$ zu prüfen war.

Doch auch mit dem Vertrag von Amsterdam blieb der einschlägige Prüfungsmaßstab das deutsche Grundgesetz. Nach Art. 2 Abs. 1 Unterabs. 2 S. 2 des Protokolls zur Einbeziehung des Schengen-Besitzstandes in den Rahmen der Europäischen Union ${ }^{613}$ legt der Rat einstimmig gemäß den einschlägigen Bestimmungen der Verträge die Rechtsgrundlage für jede Bestimmung und jeden Beschluss fest, die den Schengen-Besitzstand ${ }^{614}$ bilden. Der Rat musste die Schenge-

\footnotetext{
${ }^{612} \mathrm{Vgl}$. hierzu die wegweisende Entscheidung des BVerfG im Volkszählungsurteil, BVerfGE 65, 1.

${ }^{613}$ ABl. EG 1997 C 340, 93.

${ }^{614}$ Im Anhang vom Schengen-Protokoll findet sich eine Auflistung dieses Besitzstandes. Zu ihm zählen danach 1. das Schengener Abkommen von 1985, 2. das SDÜ von 1990, 3. die Beitrittsprotokolle und -übereinkommen zum Schengener Abkommen und zum SDÜ sowie 4. Beschlüsse und Erklärungen des aufgrund des SDÜ eingesetzten Exekutivausschusses und Rechtsakte zur Durchführung des SDÜ, die von den Organen erlassen worden sind, denen der Exekutivausschuss Entscheidungsbefugnisse übertragen hat.
} 


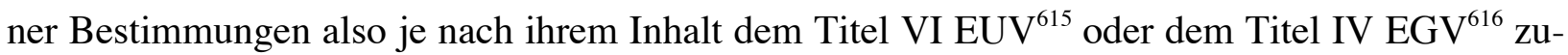
ordnen. Soweit der Rat keine Bestimmung traf, galten die Schengen-Vorschriften nach Art. 2 Abs. 1 Unterabs. 4 des Schengen-Protokolls als Bestimmungen und Beschlüsse der dritten Säule. Problematisch am einheitlichen Fahndungssystem SIS erwies sich, dass es mit Art. 96 SDÜ eine Fahndungskategorie enthält, die wegen der damit verbundenen Visa- und Asylfragen einen engen Bezug zur Erste-Säule-Materie hat. ${ }^{617}$ Die anderen Fahndungskategorien lassen sich ihrem Inhalt nach unter die polizeiliche und justizielle Zusammenarbeit in Strafsachen fassen, die bis zum Inkrafttreten des Vertrages von Lissabon eindeutig der dritten Säule zuzuordnen war. ${ }^{618}$ Vermutlich aus diesem Grund hat der Rat das SIS nie einer Säule ausdrücklich zugeordnet. In der Praxis behalf man sich damit, die Weiterentwicklungen der Bestimmungen zum SIS sowohl mit einem Rechtsinstrument der Ersten als auch der Dritten Säule zu betreiben. Dabei wurde keine ausdrückliche Differenzierung vorgenommen, welcher Teil mit dem jeweils angewandten Instrument verabschiedet wurde; die Dokumente waren, soweit sie das ganze System betrafen, im Wesentlichen wortgleich. ${ }^{619}$

Da es bis zum 1. Dezember 2009 nicht zu einer Zuordnung der Rechtsgrundlagen des SIS zur Ersten Säule gekommen ist, ${ }^{620}$ waren die Bestimmungen zum SIS trotz der teilweisen Inanspruchnahme der Instrumente der Ersten Säule überwiegend als Dritte-Säule-Materie anzusehen und daher weiterhin Gegenstand der zwischenstaatlichen Zusammenarbeit. Insofern blieb es beim Prüfungsmaßstab Grundgesetz.

Einen Wendepunkt im Hinblick auf den Prüfungsmaßstab bildet das Inkrafttreten des Vertrags von Lissabon am 1. Dezember 2009. ${ }^{621}$ Seitdem unterliegt die Rechtsmaterie eines Raums der Freiheit, der Sicherheit und des Rechts nach den Art. 67 ff. AEUV einer Art konkurrierenden Gesetzgebung zwischen der EU und den Mitgliedstaaten. Ausdrückliche Erwähnung findet der Schengen-Besitzstand in den Vorschriften über die polizeiliche Zusammenarbeit in Art. 87 Abs.

\footnotetext{
${ }^{615}$ In der Fassung des Vertrags von Amsterdam bzw. Nizza, AB1. 1997 C 340, 173 bzw. AB1. 2001 C 80, 1.

${ }^{616}$ In der Fassung des Vertrags von Amsterdam bzw. Nizza, AB1. 1997 C 340, 173 bzw. ABl. 2001 C 80, 1.

${ }^{617} \mathrm{Vgl}$. hierzu die mit dem Vertrag von Amsterdam geltenden Art. 61 ff. EGV, AB1. 1997 C 340, 173.

${ }^{618}$ Vgl. hierzu Art. 29 ff. EUV.

${ }^{619}$ Vgl. hierzu z.B. die VO (EG) Nr. 2424/2001 des Rates vom 6. Dezember 2001 über die Entwicklung des Schengener Informationssystems des zweiten Generation (SIS II), AB1. L 328, 4 und den Beschluss des Rates 2001/886/JI vom 6. Dezember 2001 über die Entwicklung des Schengener Informationssystems des zweiten Generation (SIS II), AB1. L 328, 1; teilweise differenzierend: VO (EG) Nr. 871/2004 des Rates vom 29. April 2004 über die Einführung neuer Funktionen für das Schengener Informationssystem, auch im Hinblick auf die Terrorismusbekämpfung, ABl. 2004 L 162, 29 sowie Beschluss 2005/211/JI des Rates vom 24. Februar 2005 über die Einführung neuer Funktionen für das Schengener Informationssystem, auch im Hinblick auf die Terrorismusbekämpfung, AB1. 2005 L 68, 44; die Verordnung enthält im Gegensatz zum Beschluss keine Bestimmung über die neuen Zugriffsmöglichkeiten von Europol und Eurojust, weil damit kein Zugriff auf Daten nach Art. 96 SDÜ ermöglicht wird; ansonsten handelt es sich um die gleichen Bestimmungen.

${ }^{620}$ Für den Zeitraum vom Inkrafttreten des Vertrages von Amsterdam bis zum Jahr 2004: Geiger, EUV/EGV, 4. A., Art. 29 EUV, Rn. 14.

${ }^{621}$ Text des Vertrages vom 13. Dezember 2007, AB1. C 306, 1.
} 
3 Unterabs. 4 AEUV. Wenn die Mitgliedstaaten aufgrund des SIS tätig werden, führen sie nunmehr Recht der Union aus. Prüfungsmaßstab sind damit nicht mehr die durch das Grundgesetz vermittelten Grundrechte, sondern auf europäischer Ebene gewährleistete Grundrechte. Ihre Existenz ist durch den EuGH seit langem anerkannt, ${ }^{622}$ und die EU hat sich ihnen in der Form verpflichtet gefühlt, wie sie in der EMRK niedergelegt sind und ,wie sie sich aus gemeinsamen Verfassungsüberlieferungen der Mitgliedstaaten als allgemeine Grundsätze des Gemeinschaftsrechts ergeben.“623 Die gleichzeitig mit dem Vertrag von Lissabon in Kraft getretene Charta der Grundrechte der Europäischen Union greift diese Gewährleistung auf und bildet den ersten geschriebenen Grundrechte-Katalog der Europäischen Union. Die GR-Charta steht nach Art. 6 Abs. 1 Unterabs. 1 EUV normhierarchisch auf der gleichen Ebene wie der EUV und der AEUV. Nach ihrem Art. 51 Abs. 1 gilt die GR-Charta auch für die Mitgliedstaaten bei der Durchführung des Rechts der Union. Aus alledem ergibt sich, dass der richtige materielle Prüfungsmaßstab seit dem 1. Dezember 2009 vorrangig die GR-Charta ist. Da aber das BVerfG einen europäischen Grundrechtsschutz verlangt, der ,nach Konzeption, Inhalt und Wirkungsweise dem Grundrechtsstandard des Grundgesetzes im Wesentlichen gleichzuachten“ " ist, ${ }^{624}$ dürfen die durch das BVerfG im Volkszählungsurteil festgelegten Grundsätze nicht außer Betracht bleiben. Vielmehr ist Art. 8 GR-Charta auch an den in dieser Entscheidung festgelegten Grundsätzen zu messen. ${ }^{625}$

\section{Bedeutung der Kritik an $§ 163$ e StPO}

Bei der Prüfung soll berücksichtigt werden, dass $§ 163$ e StPO, die nationale Entsprechung der verdeckten Registrierung in ihrer strafprozessualen Variante, im Schrifttum z.T. deutlicher Kritik ausgesetzt ist. ${ }^{626}$ Die durch Vergleich ermittelte Kombinationsnorm ${ }^{627}$ weist in ihrer Struktur große Ähnlichkeit mit der nationalen Vorschrift auf. Dennoch gibt es klare Unterschiede. So gestattet die strafprozessuale Kombinationsnorm im Gegensatz zu $§ 163$ e StPO beispielsweise nicht die Ausschreibung von Personen, die mit dem mutmaßlichen Täter lediglich in Verbindung stehen. Zudem benennt die strafprozessuale Kombinationsnorm anders als das nationale Recht deutlich, welche Art von Informationen aufgrund der Ausschreibung übermittelt werden dürfen. ${ }^{628}$ Aus diesem Grund scheidet die in dieser Hinsicht vorgebrachte Kritik in Bezug auf die

\footnotetext{
${ }^{622}$ Walter, in: Ehlers, Europäische Grundrechte, § 1, Rn. 27 mit Verweis auf EuGH, Slg. 1969, 419 - Stauder; ebenso Kraus, in: Grote/Marauhn, EMRK/GG, Kap. 3, Rn. 14.

${ }^{623}$ Art. 6 Abs. 2 EUV in der Fassung des Vertrags von Nizza, aber auch bereits nach Art. F Abs. 2 EUV in der Fassung des Vertrags von Maastricht.

${ }^{624}$ BVerfGE 73, 339 (378), bestätigt durch BVerfGE 102, 147.

${ }^{625}$ Johlen, in: Tettinger/Stern, Kölner Gemeinschaftskommentar, Art. 8, Rn. 25.

${ }^{626}$ Vgl. hierzu u.a. Zöller, in: Julius u.a., StPO, § 163 e, Rn. 2 f.; Erb, in: Erb u.a., Löwe-Rosenberg-StPO, Fünfter Band, § 163 e, Rn. 2, 5 f.; Meyer-Goßner, § 163 e, Rn. 2; Schoreit, in: Hannich, KK zur StPO, § 163 e, Rn. 2 ff. ${ }^{627} \mathrm{Vgl}$. oben 2. Teil, B. III. 5. a. aa. (10).

${ }^{628}$ Vgl. zum nationalen Recht: Wolter, in: Rudolphi u.a., SK StPO, Band 3, § 163 e (Stand: Mai 1997), Rn. 5 a.
} 


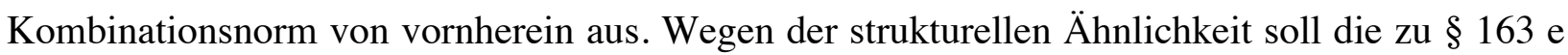
StPO vorgetragene Kritik bei der Prüfung jedoch im Übrigen berücksichtigt werden.

\section{Eingriff in Schutzbereich ${ }^{629} 630$}

\section{Schutzbereich Art. 8 GR-Charta}

Ein großer Teil der sicherheitsbehördlichen Tätigkeit besteht in der Erhebung, Verarbeitung und Nutzung personenbezogener Daten. Diese Aktivität ist weitaus weniger spektakulär als Verfolgungsjagden der Polizei oder Großeinsätze bei Geiselnahmen, die das besondere Interesse der Massenmedien und des Publikums finden. Diese Tätigkeit wurde denn auch zunächst nicht als möglicher Eingriff in Grundrechte wahrgenommen; besondere Regelungen über die Datenverarbeitung bei der Polizei betrachtete man als entbehrlich. Zudem fehlt auch in vielen Verfassungen der europäischen Mitgliedstaaten, anders als im Hinblick auf körperliche Eingriffe der Staatsgewalt, eine entsprechende explizite Grundrechtsgewährleistung. ${ }^{631}$ Die heute im Wesentlichen unumstrittene Ansicht, dass der Umgang der Strafverfolgungsbehörden ${ }^{632}$ mit personenbezogenen Informationen grundrechtliche Relevanz besitzt, setzte sich in der Dogmatik des Polizei- und Strafverfahrensrechts nur allmählich durch. ${ }^{633}$

Ausgangspunkt für die Bestimmung des Schutzbereiches auf europäischer Ebene muss nunmehr Art. 8 GR-Charta sein, der formuliert, dass jede Person das Recht auf Schutz der sie betreffenden personenbezogenen Daten hat. Zum Zeitpunkt des Abschlusses der Arbeiten an der GR-Charta hatte der Gemeinschaftsrechtsgeber durch die Schaffung von Sekundärrecht mit der RL 95/46/EG und durch die Vorschrift des Art. 286 EGV $^{634}$ bereits auf die Zunahme der Datenströme innerhalb der Gemeinschaft reagiert. In Gestalt von Art. 8 EMRK und dem Übereinkommen des Europarates vom 28. Januar 1981 zum Schutz des Menschen bei der automatischen Verarbeitung personenbezogener Daten ${ }^{635}$ hatte zudem auch der Europarat (Mindest-) Standards aufgestellt. Diese bestehenden Vorgaben führten dazu, dass die Vorschrift in erster Linie dem Gemeinschaftsrecht nachgebildet ist und in zweiter Linie dem Datenschutzrecht des Europarates. Auch die als Interpretationshilfe dienenden Erläuterungen des Präsidiums des Konvents, das die

\footnotetext{
${ }^{629}$ Das Prüfungsschema und seine Terminologie orientieren sich im Wesentlichen an: Jarass, EU-Grundrechte, $\S \S 6$ und 13.

${ }^{630}$ Für den Text der strafprozessualen Ausschreibungsvariante wird auf den 2. Teil, B. III. 5. a. aa. verwiesen.

${ }^{631} \mathrm{Im}$ deutschen Verfassungsrecht wird das Grundrecht aus Art. 2 Abs. 1 i.V.m. Art. 1 Abs. 1 hergeleitet, BVerfGE 65, 1 (41 ff.); Johlen, in: Tettinger/Stern, Kölner Gemeinschaftskommentar, Art. 8, Rn. 24.

${ }^{632}$ Und auch der Gefahrenabwehrbehörden.

${ }^{633}$ Zur Entwicklung in Deutschland mit Beginn der 70er Jahre vgl. Kutscha, in: Lange, Staat, Demokratie und Innere Sicherheit, S. 355 (357); Zöller, Informationssysteme und Vorfeldmaßnahmen, S. 29 f.

${ }^{634}$ Nunmehr ersetzt durch Art. 16 und Art. 39 AEUV.

${ }^{635}$ Siehe auch 2. Teil, B. IV. 1. a. aa.
} 
Charta der Grundrechte ausgearbeitet hat, nehmen im Hinblick auf Art. 8 GR-Charta Bezug auf die oben genannten Vorschriften und Übereinkommen. Ergänzend wird dort auf die VO (EG) Nr. 45/2001 ${ }^{636}$ verwiesen. ${ }^{637}$ Kritisch sei an dieser Stelle angemerkt, dass es durch die Bezugnahme auf die RL 95/46/EG und die VO (EG) Nr. 45/2001 letztlich zu einer Definition von Primärrecht durch Sekundärrecht kommt. ${ }^{638}$ Diese Vorgehensweise erscheint aus normsystematischer Sicht unbefriedigend, da doch gerade umgekehrt das Primärrecht Vorgaben für das Sekundärrecht machen sollte. ${ }^{639}$ Gleichwohl war es wohl der eindeutige Wille der Vertragsstaaten, die bereits vereinbarten unter-primärrechtlichen Standards auf diese Weise auf die primärrechtliche Ebene zu heben und nicht erst entsprechende Rechtsprechung des EuGH zu Art. 8 GR-Charta abzuwarten.

Nichtsdestotrotz hat sich der EuGH bereits vor dem Inkrafttreten der GR-Charta mehrfach mit der Frage des Datenschutzes befasst. Zwar gibt es auf europäischer Ebene kein Urteil wie das Volkszählungsurteil des Bundesverfassungsgerichtes aus dem Jahr 1983, das umfassend darlegt, welch hohen Stellenwert der Schutz personenbezogener Daten für den einzelnen und für die Gemeinschaft hat und welche Regeln für die Einschränkung dieses Rechts gelten. Der EuGH hat jedoch beginnend mit dem Jahr 1969 das Recht auf Achtung der Privatsphäre als allgemeinen Rechtsgrundsatz und als einen Teilaspekt dieses Rechts auch den Schutz bei der Verarbeitung personenbezogener Daten anerkannt. ${ }^{640}$ In späteren Entscheidungen greift er zur Ausfüllung dieses Rechts auf die RL 95/46/EG sowie auf Art. 8 EMRK zurück. ${ }^{641}$

Die Relevanz der Bestimmungen der EMRK für die Europäische Union ergab sich bisher aus Art. 6 Abs. 2 EUV in der Fassung des Vertrags von Nizza und findet ihre aktuelle Grundlage in Art. 6 Abs. 2 EUV in der Fassung des Vertrags von Lissabon. Auf die ausdrückliche Bezugnahme in den Erläuterungen zu Art. 8 GR-Charta wurde bereits hingewiesen. Aus diesen Gründen ist bei der Auslegung von Art. 8 GR-Charta auch die Rechtsprechung des EGMR zu berücksichtigen. Art. 8 EMRK gewährleistet das Recht jeder Person auf Achtung ihres Privat- und Familienlebens, ihrer Wohnung und ihrer Korrespondenz. Der Datenschutz ist nicht ausdrücklich be-

\footnotetext{
${ }^{636}$ Verordnung des Europäischen Parlamentes und des Rates zum Schutz natürlicher Personen bei der Verarbeitung personenbezogener Daten durch die Organe und Einrichtungen der Gemeinschaft und zum freien Datenverkehr, AB1. L 8, 1, vom 12. Januar 2001.

${ }^{637}$ Eine Aktualisierung der Erläuterungen nahm in der Folge das Präsidium des Europäischen Konvents vor; die aktualisierten Erläuterungen sind beispielsweise abgedruckt bei: Beck, Europäischer Unionsvertrag, 6. A., Stand: Mai 2008, Teil A, 5, vgl. hier Erläuterung zu Art. 8 GR-Charta.

${ }^{638}$ Vgl. hierzu Siemen, EuR 2004, 306 (316), die explizit von einem Grundrechtschutz durch die Richtlinie spricht.

${ }^{639}$ Albers, Informationelle Selbstbestimmung, S. 309 f.

${ }^{640}$ EuGH, Slg. 1969, 419 - Stauder.

${ }^{641}$ EuGH Slg. 2003, I-4989 - österreichischer Rundfunk sowie EuGH, Slg. 2003, I-12971 - Lindqvist., vgl. aus jüngerer Zeit auch das Urteil des EuGH vom 9. November 2010, EuZW 2010, 939, in dem das Gericht im Zusammenhang mit der Veröffentlichung von Agrarbeihilfen eine Abwägung zwischen dem gemeinschaftsrechtlichen Transparenzgrundsatz und dem Datenschutzgrundrecht vornimmt.
} 
nannt, wird aber vom EGMR als ein spezifisch ausgestalteter Teilbereich des Rechts auf Achtung der Privatsphäre angesehen. ${ }^{642}$

In Anlehnung an Art. 2 lit. a RL 95/46/EG und Art. 2 lit. a VO 45/2001 sind personenbezogene Daten alle Informationen über eine bestimmte oder bestimmbare natürliche Person. Die Daten, die bei einer verdeckten Registrierung in der strafprozessualen Variante erhoben und verwendet werden, sind als derartige Informationen einzustufen. Problematisch erscheint es, ob zur Interpretationshilfe überhaupt die RL 95/46/EG herangezogen werden kann, da sie wegen ihres Gesamtzwecks nur personenbezogene Daten mit Binnenmarktrelevanz erfasst und in Art. 3 Abs. 2 1. Spiegelstrich u.a. die Tätigkeiten des Staates im strafrechtlichen Bereich ausdrücklich aus dem Anwendungsbereich der Richtlinie herausnimmt. Da das Präsidium des Grundrechtekonvents in seinen Erläuterungen auch auf die Rechtstexte des Europarates verweist, die eine vergleichbare Einschränkung nicht vornehmen, erscheint es an dieser Stelle nicht notwendig, die Frage zu beantworten. Es ist davon auszugehen, dass Art. 8 GR-Charta auch Daten erfasst, die Strafverfolgungszwecken dienen. ${ }^{643}$

Das „Recht auf Schutz“ in Art. 8 Abs. 1 GR-Charta lässt an eine leistungsrechtliche Schutzpflicht denken. Gemeint ist jedoch primär ein Grundrechtsschutz im abwehrrechtlichen Sinn. ${ }^{644}$ Den von einer verdeckten Registrierung Betroffenen geht es auch gerade um die Abwehr staatlicher Informationstätigkeit, so dass festgestellt werden kann, dass der Schutzbereich von Art. 8 GR-Charta betroffen ist.

\section{Eingriff}

$\mathrm{Zu}$ prüfen ist weiterhin, ob durch die ermittelte Norm in das Grundrecht eingegriffen wird. Generell liegt ein Eingriff vor, wenn der von einer Regelung Betroffene in seinem grundrechtlich geschützten Verhalten beeinträchtigt ist. ${ }^{645}$ Im konkreten Fall von Art. 8 GR-Charta liegt diese Beeinträchtigung im Verarbeiten persönlicher Daten des Grundrechtsträgers durch den Grundrechtsadressaten, hier also eine staatliche Stelle, die aufgrund der Vorschriften des SDÜ tätig wird. Unter Verarbeiten ist in Anlehnung an Art. 2 lit. b RL 95/46/EG und Art. 2 lit. b VO 45/2001 jede Erhebung, Speicherung oder Verwendung von Daten unabhängig davon zu verste-

\footnotetext{
${ }^{642}$ EGMR, Urt. vom 6. September 1978, - Klass ./. Deutschland -, EGMR-E 1, 320; Urt. vom 26. März 1987 - Leander./. Schweden -, EGMR-E 3, 430; Johlen, in: Tettinger/Stern, Kölner Gemeinschaftskommentar, Art. 8, Rn. 17 sowie Fn. 35 mit Verweis auf Urt. vom 16. Februar 2000, - Amann ./. Schweiz - und Urt. vom 4. Mai 2000, - Rotaru ./. Rumänien; Frowein, in: Frowein/Peukert, EMRK, Art. 8, Rn. 5 ff. sowie Fn. 12 mit Verweis auf Urt. vom 6. Juni 2006, - E. Segerstedt-Wiberg ./.Schweden; Meyer-Ladewig, EMRK, Art. 8, Rn. 40.

${ }^{643}$ Bernsdorff, in: Meyer, GR-Charta, Art. 8, Rn. 15; Johlen, in: Tettinger/Stern, Kölner Gemeinschaftskommentar, Art. 8, Rn. 32.

${ }^{644}$ Albers, Informationelle Selbstbestimmung, S. 305; Knecht, in: Schwarze, EU-Kommentar, Art. 8 GRC, Rn. 4.

${ }^{645}$ Jarass, EU-Grundrechte, § 6, Rn. 20.
} 
hen, ob die Verarbeitung mit oder ohne Hilfe automatisierter Verfahren erfolgt. ${ }^{646}$ Da die VO 45/2001 eine weitgehend wortgleiche Definition wie die RL 95/46/EG enthält, spielt die Frage, ob die Bestimmungen der RL 96/46/EG wegen ihres eigentlich eingeschränkten Anwendungsbereiches überhaupt zur Anwendung kommen sollen, hier ebenfalls keine Rolle.

Bei der weiteren Untersuchung ist zwischen verschiedenen Eingriffsbefugnissen zu differenzieren. Insgesamt kommt man dabei auf die beachtliche Summe von acht verschiedenen möglichen Eingriffen. Dieses Ergebnis mag als künstliche Aufspaltung eines einheitlichen oder doch zumindest nur zweiaktigen Lebenssachverhaltes ${ }^{647}$ erscheinen. Bei genauerer Betrachtung wird jedoch deutlich, dass jede einzelne Maßnahme den Betroffenen auf ihre Weise in der Ausübung seines Rechtes beschränkt. Es handelt sich dabei um:

1. die Speicherung der Daten im SIS zum Zwecke der Ausschreibung,

2. die Feststellung der Identität des Kontrollierten,

3. den Abruf der im SIS gespeicherten Daten durch den kontrollierenden Beamten,

4. den Abgleich mit der Identität des Betroffenen,

5. die Erhebung der Daten, die an die ausschreibende Stelle übermittelt werden sollen,

6. die Übermittlung der Daten an die Sirene, ${ }^{648}$

7. Übermittlung der Daten von der Sirene an die ausschreibende Stelle,

8. die Verwendung der Daten bei der ausschreibenden Stelle.

Gegenstand sämtlicher Maßnahmen ist der Umgang mit personenbezogenen Daten. In den Fällen, in denen der Betroffene namentlich ausgeschrieben wird, liegt das auf der Hand. Jedoch hat auch das Ausschreiben eines Kfz-Kennzeichens Personenbezug in dem Sinne, dass darüber eine natürliche Person bestimmbar ist, was nach Art. 2 lit. a) VO 45/2001 für die Annahme von personenbezogenen Daten ausreicht.

Bei allen Maßnahmen bis auf Punkt 4 geht es um die Verarbeitung von Daten im Sinne der eingangs genannten Definition. Im deutschen Recht wird zudem Handlungen wie dem Datenabgleich Eingriffscharakter beigemessen, weil es sich um einen Akt der Auswahl für die weitere Auswertung handelt. ${ }^{649}$ Da bei Art. 8 GR-Charta von einer weiten Definition des Begriffs der

\footnotetext{
${ }^{646}$ Kingreen, in: Callies/Ruffert, EUV/AEUV, Art. 8 GRCh, Rn. 12; vgl. Jarass, EU-Grundrechte, § 13, Rn. 7; Bernsdorff, in: Meyer, GR-Charta, Art. 8, Rn. 16.

${ }^{647}$ Ausschreibung und Verfahren im Trefferfall.

${ }^{648}$ In einem Fall einer Ausschreibung im Inland und eines Treffers im Ausland zunächst an die Sirene des ersuchten Staates, die dann Kontakt mit der Sirene des ersuchenden Staates aufnimmt, vgl. Mokros, in: Lisken/Denninger, HandbPolR, O, Rn. 202.

${ }^{649}$ Vgl. hierzu Schoch, JURA 2008, 352 (357) mit Verweis auf BVerfGE 115, 320 (343 f.).
} 
Verarbeitung ausgegangen wird, ${ }^{650}$ ist kein Grund ersichtlich, diese für das deutsche Recht entwickelte Begründung im Rahmen der Prüfung der GR-Charta nicht anzuwenden.

Näherer Erläuterung bedarf schließlich noch der achte Eingriff. Er wird in der Norm nicht erwähnt, und es handelt es sich nicht um Daten, die im SIS gespeichert werden. Zudem führen die Mitgliedstaaten durch die Verwendung der Daten im Rahmen eines nationalen Ermittlungsverfahrens nicht Recht der Union i.S.v. Art. 51 Abs. 1 S. 1 GR-Charta aus. Der achte Eingriff würde danach nicht in den Schutzbereich von Art. 8 GR-Charta sondern von Art. 1 Abs. 1 i.V.m. Art. 2 Abs. 1 GG erfolgen. Dennoch muss man diese Maßnahme hinzudenken, weil sie unverzichtbarer Teil der Fahndungsmethode ist. Diese ist als Langzeitmaßnahme ${ }^{651}$ darauf gerichtet, über einen gewissen Zeitraum hinweg Informationen zu sammeln und aus dem Ergebnis - aus Strafverfolgungssicht im besten Fall - verschiedener Kontrollen, Schlüsse ziehen zu können. Das ist aber nur möglich, wenn alle Ergebnisse bei der ausschreibenden Stelle automatisiert verarbeitet und genutzt werden dürfen. ${ }^{652}$ Dieser einheitliche Sachverhalt muss auch an einem einheitlichen Grundrecht geprüft werden. Da die ganz überwiegende Zahl der Eingriffe, nämlich sieben von acht, Art. 8 GR-Charta zuzuordnen sind, soll diese Norm den einheitlichen Prüfungsmaßstab bilden.

An einem Eingriff fehlt es nach Art. 8 Abs. 2 S. 1 GR-Charta, wenn der Betroffene in Kenntnis der Sachlage in die Verarbeitung seiner Daten einwilligt. ${ }^{653}$ Da die hier in Frage stehenden Daten aber gerade heimlich erhoben werden, besteht beim Grundrechtsträger keine Kenntnis der Sachlage, so dass eine Einwilligung ausscheidet.

\section{Rechtfertigung von Eingriffen}

\section{Schranken}

Der in Art. 8 Abs. 1 GR-Charta erwähnte Schutz ist nicht im Sinne einer Alleinherrschaft der betroffenen Person zu verstehen. Das Grundrecht wird also nicht uneingeschränkt gewährleistet. Vielmehr formuliert Art. 8 Abs. 2 GR-Charta, dass die Daten grundsätzlich nur auf einer gesetzlichen Grundlage verarbeitet werden dürfen. Die Bestimmung des Gesetzesvorbehaltes greift auch der hier anzuwendende Art. 52 Abs. 1 S. 1 GR-Charta auf. ${ }^{654}$

\footnotetext{
${ }^{650}$ Bernsdorff, in: Meyer, GR-Charta, Art. 8, Rn. 16; Johlen, in: Tettinger/Stern, Kölner Gemeinschaftskommentar, Art. 8, Rn. 36.

${ }^{651}$ Vgl. Erb, in: Erb u.a., Löwe-Rosenberg-StPO, Fünfter Band, § 163e, Rn. 39.

${ }^{652}$ Vgl. Schoreit, in: Hannich, KK zur StPO, § 163 e, Rn. 8; Krahl, NStZ 1998, 339 (341).

${ }^{653} \mathrm{Vgl}$. Jarass, EU-Grundrechte, $\S 13$, Rn. 8.

${ }^{654}$ Jarass, EU-Grundrechte, $§ 13$, Rn. 9; vgl. Kingreen, in: Callies/Ruffert, EUV/AEUV, Art- 8 GRCh, Rn. 14 sowie Johlen, in: Tettinger/Stern, Kölner Gemeinschaftskommentar, Art. 8, Rn. 40 ff. mit weiteren Nachweisen.
} 
Die strafrechtliche Kombinationsnorm besteht aus Regelungen des Zustimmungsgesetzes zum SDÜ in Verbindung mit den Regelungen des SDÜ sowie den einschlägigen Regelungen der StPO. Ein Gesetz ist für diesen Bereich damit grundsätzlich vorhanden. Da die Kombinationsnorm aber, wie oben dargelegt, darauf gerichtet ist, insgesamt acht verschiedene Eingriffe zu ermöglichen, muss an dieser Stelle überprüft werden, ob es für jeden dieser Eingriffe in den genannten Gesetzen eine Grundlage gibt:

1. Speicherung der Daten im SIS zum Zwecke der Ausschreibung, die gesetzliche Grundlage für die Speicherung der Daten im Rahmen der Ausschreibung zur verdeckten Registrierung nach Strafprozessrecht findet sich in Art. 99 Abs. 1 und 2 i.V.m. Art. 94 Abs. 3 SDÜ i.V.m. Art. 1 des deutschen Zustimmungsgesetz i.V.m. § 163 e Abs. 1 und 2 StPO; 2. Feststellung der Identität des Kontrollierten, die Befugnis zur Feststellung der Identität des Kontrollierten ergibt sich nicht aus dem SDÜ, weil ja gerade Daten genutzt werden sollen, die aus einem anderen Anlass erhoben werden. Diese Anlässe können ganz unterschiedliche sein; sie können ihre Grundlage u.a. in strafprozessualen, ${ }^{655}$ polizeirechtlichen, ${ }^{656}$ zollrechtlichen oder straßenverkehrsrechtlichen ${ }^{657}$ Normen haben, die Identitätskontrollen erlauben;

3. Abruf der im SIS gespeicherten Daten durch den kontrollierenden Beamten, die Befugnis hierzu ergibt sich aus Art. 1 des deutschen Zustimmungsgesetzes i.V.m. Art. 101 Abs. 1 S. 1 SDÜ, der den unmittelbaren Zugriff auf die im SIS gespeicherten Daten den Stellen erlaubt, die für Grenzkontrollen und sonstige polizeiliche und zollrechtliche Überprüfungen im Inland zuständig sind;

4. den Abgleich mit der Identität des Betroffenen, die Abgleichbefugnis hat ihre Grundlage bereichsspezifisch, also abhängig davon, auf welcher Rechtsgrundlage die Identitätskontrolle durchgeführt wurde. Abgleichsvorschriften finden sich insbesondere in $\S 34$ BPolG, $\S 45$ Nds. SOG und $§ 98$ c StPO;

5. die Erhebung der Daten nach Art. 99 Abs. 4 bzw. Abs. 8 strafprozessuale Kombinationsnorm, Rechtsgrundlage hierfür ist Art. 99 Abs. 4 SDÜ i.V.m. Art. 1 des Zustimmungsgesetzes; 6. die Übermittlung der Daten an die Sirene,

\footnotetext{
${ }^{655}$ Z.B. $\S 111$ StPO.

${ }^{656}$ Z.B. $§ 13$ Nds. SOG.

${ }^{657}$ Z.B. $§ 36$ Abs. 5 StVO.
} 
die Ermächtigung findet sich in Art. 99 Abs. 4 SDÜ i.V.m. Art. 1 des Zustimmungsgesetzes sowie in Art. 92 Abs. 4 S. 1 SDÜ̈ ${ }^{658}$ und $\S 3$ Abs. 1 a BKAG; ${ }^{659} 660$ erst im Jahr 2005 wurde Art. 92 Abs. 4 SDÜ eingefügt. Nach seiner umständlichen Formulierung meint er vorrangig die zusätzlichen Informationen, die der Beamte vor Ort im Trefferfall von der Sirene erhalten kann, um die geeigneten Maßnahmen ergreifen zu können. Hier geht es jedoch um die Informationen, die der Beamte vor Ort bei Antreffen an die Sirene übermittelt. Im Hinblick auf die Zentralstellenfunktion der Sirenen nach Art. 108 SDÜ sollte die Vorschrift so ausgelegt werden, dass damit der Austausch von Informationen über die Sirenen in Zusammenhang mit dem SIS insgesamt gemeint ist. Dafür sprechen auch die Erwägungen zur Einführung der Vorschrift, in denen es als nützlich erachtet wurde, Bestimmungen über den Austausch sämtlicher Zusatzinformationen über die von den Mitgliedstaaten zu diesem Zweck bezeichneten Stellen zu erlassen, wodurch eine gemeinsame Rechtsgrundlage für diese Stellen geschaffen wür$\mathrm{de},{ }^{661}$

7. die Übermittlung der Daten von der Sirene an die ausschreibende Stelle, die Ermächtigung findet sich in Art. 92 Abs. 4 S. 1 SDÜ i.V.m. Art. 1 des deutschen Zustimmungsgesetzes i.V.m. § 3 Abs. 1 a BKAG; ${ }^{662}$

8. die Speicherung und Verwendung der Daten bei der ausschreibenden Stelle, für diesen Eingriff enthält das SDÜ keine Regelung; es gilt damit das nationale Recht. Bis zum Jahr 1999 gab es kein deutsches Gesetz, das sich mit der Thematik befasste. Wollte man sich zehn Jahre und mehr nach dem Volkszählungsurteil nicht darauf berufen, dass es sich noch um eine Übergangsphase handele, blieb nur der manuelle Datenabgleich. Da dieser für die Praxis

\footnotetext{
${ }^{658}$ Siehe Art. 1 Nr. 1 des Beschlusses 2005/211/JI des Rates vom 24. Februar 2005, ABl. 2005 L 68, 44, sowie Art. 1 Nr. 1 der VO (EG) Nr. 871/2004 des Rates vom 29. April 2004, ABl. 2004 L 162, 29; die Bestimmung tritt in Kraft bzw. gilt ab dem 13. Juni 2005, vgl. Art. 2 Abs. 1 des Beschlusses 2005/211/JI des Rates vom 24. Februar 2005 sowie Art. 2 der VO (EG) Nr. 871/2004 des Rates vom 29. April 2004 und Art. 1 Abs. 1 des Beschlusses 2005/451/JI des Rates vom 13. Juni 2005, AB1. L 158, 26.

${ }^{659}$ Wolter, in: Rudolphi u.a., SK StPO, Band 3, § 163 e (Stand: Mai 1997), Rn. 5 b, stellt fest, dass $\S 163$ e Abs. 3 StPO keine ausreichende Grundlage dafür bietet, Informationen über Reisewege, Reiseziele, mitgeführte Sachen etc. zu erheben und zu melden. Die Informationserhebung sei strikt auf die Daten begrenzt, die im Rahmen der ohnehin stattfindenden Personenkontrollen festgestellt werden dürfen. Nach Ansicht anderer Autoren enthält, Art. $163 \mathrm{e}$ StPO die entsprechende Grundlage, vgl. Plöd, in: von Heintschel-Heinegg, KMR-StPO, Band 3, § 163 e (Stand: November 2009), Rn. 3; Meyer-Goßner, § 163 e, Rn. 4. Bei der hier zu prüfenden strafprozessualen Norm spielt dieser Streit nach Ansicht der Verfasserin keine Rolle, weil Art. 99 Abs. 4 SDÜ im Gegensatz zu § 163 e StPO ausreichend detailliert benennt, dass und welche zusätzlichen Informationen erhoben werden dürfen.

${ }^{660}$ Vgl. zur Gültigkeit auch Art. 2 Nr. 2, Art. 5 sowie Art. 7 Abs. 1 S. 1 SIS II-Gesetz vom 6. Juni 2009, BGBl. $2009,1226$.

${ }^{661}$ Erwägungsgrund Nr. 5 Beschluss 2005/211/JI des Rates vom 24. Februar 2005, AB1. 2005 L 68, 44.

${ }^{662}$ Mokros, in: Lisken/Denninger, HandbPolR, O, Rn. 205, der drei Fälle erwähnt, nämlich die verdeckte Registrierung eines Deutschen in Deutschland aufgrund einer deutschen Ausschreibung, die verdeckte Registrierung eines Ausländers in Deutschland aufgrund einer ausländischen Ausschreibung sowie die verdeckte Registrierung eines Deutschen in Deutschland aufgrund einer ausländischen Ausschreibung; im dritten Fall hält er es für erforderlich, für die Übermittlung der Daten nach dem Schutzzweck des durch die Staatsangehörigkeit maßgeblichen Grundgesetzes auf nationale Normen zurückzugreifen.
} 
mittlerweile bedeutungslos geworden war, gab es keinen Anwendungsbereich für die Auswertung von im Wege der polizeilichen Beobachtung erlangten Daten und damit für die polizeiliche Beobachtung insgesamt. Ging man davon aus, dass eine automatische Auswertung gleichwohl vorgenommen wurde, führte das zu einer Verletzung des Gesetzesvorbehaltes. ${ }^{663}$ Das Strafverfahrensänderungsgesetz $1999^{664}$ brachte zwar keine spezialgesetzliche Grundlage, aber allgemeine Regelungen in den $\S \S 483 \mathrm{ff}$. StPO, die für den fraglichen Eingriff die erforderliche gesetzliche Grundlage bieten. ${ }^{665}$

\section{Anforderungen an das einschränkende Gesetz}

Weiterhin muss das einschränkende Gesetz selbst formell und materiell verfassungsgemäß sein.

\section{a. Formelle Anforderungen}

Wie eben dargelegt wurde, hat die verdeckte Registrierung in ihrer strafrechtlichen Variante nicht nur ein Gesetz zur Grundlage; insbesondere durch die unterschiedlichen Anlässe der Kontrollen ergeben sich die Ermächtigungsgrundlagen aus verschiedenen Regelungsbereichen. Es ist an dieser Stelle davon auszugehen, dass die entsprechenden Gesetze wie das StVG, die StPO oder das BPolG formell auf rechtmäßige Weise zustande gekommen sind, dass also das zuständige Organ mit dem richtigen Verfahren und in der vorgesehenen Form tätig wurde.

Davon ist im übrigen auch in Bezug auf das SDÜ auszugehen. Allerdings muss hier zwischen dem Zustimmungsgesetz zum SDÜ aus dem Jahr 1993 und dem späteren Übergang in den europarechtlichen Rahmen differenziert werden.

Das Zustimmungsgesetz zum SDÜ aus dem Jahr 1993 ist vom richtigen Gesetzgeber, nämlich Bundestag und Bundesrat, verabschiedet worden. Soweit die Ansicht vertreten wird, der Bundestag sei im Vorfeld der Abstimmung über das Zustimmungsgesetz nicht ausreichend beteiligt worden, könnte das Zweifel an der Rechtmäßigkeit des Verfahrens begründen. In diesem Teil der Arbeit ${ }^{666}$ ist jedoch bereits umfassend dargelegt worden, dass die Art der Beteiligung als ausreichend anzusehen ist.

Art. 92 Abs. 4 SDÜ, der erst im Jahr 2004/2005 nach Überführung des Schengen-Besitzstandes in den europarechtlichen Rahmen eingefügt wurde ${ }^{667}$ konnte vom Zustimmungsgesetz aus dem Jahr 1993 denklogisch nicht umfasst sein. Im Rahmen dieser Arbeit soll jedoch davon ausgegangen werden, dass die formellen Anforderungen sowohl hinsichtlich der Beteiligung der deut-

\footnotetext{
${ }^{663}$ Vgl. in diesem Sinne Krahl, NStZ 1998, 339 (341) und Schoreit, in: Pfeiffer, KK zur StPO, 3. A., § 163 e, Rn. 7.

${ }^{664}$ BGB1. 2000, 1253.

${ }^{665}$ Schoreit, in: Hannich, KK zur StPO, § 163 e, Rn. 8; Erb, in: Erb u.a., Löwe-Rosenberg-StPO, Fünfter Band, § 163 e, Rn. 6, allerdings hält der Autor die Regelung weiterer Einzelfragen der Verwendung für wünschenswert.

${ }^{666}$ Unter A. I.

${ }^{667}$ Art. 1 Nr. 1 Beschluss 2005/211/JI des Rates vom 24. Februar 2005, AB1. L 68, 44.
} 
schen Gesetzgebungskörperschaften bei der Zustimmung zum Vertrag von Amsterdam ${ }^{668}$ als auch beim Zustandekommen des für den Bereich des Art. 99 SDÜ relevanten Beschluss 2005/211/JI des Rates vom 24. Februar 2005 eingehalten wurden. ${ }^{669}$

\section{b. Materielle Anforderungen}

Die materiellen Anforderungen an die einschränkenden Regelungen ergeben sich aus Art. 8 Abs. 2 S. 1 sowie Art. 52 Abs. 1 GR-Charta. ${ }^{670}$ Danach dürfen die Daten nur nach Treu und Glauben für festgelegte Zwecke unter Achtung des Wesensgehaltes und des Grundsatzes der Verhältnismäßigkeit verarbeitet werden, wenn sie den von der Union anerkannten dem

Gemeinschaftswohl dienenden Zielsetzungen oder den Erfordernissen des Schutzes der Rechte und Freiheiten anderer tatsächlich entsprechen.

\section{aa. Festlegung des Zwecks}

Nach dem Wortlaut der strafprozessualen Norm ist Zweck der Ausschreibung, für die Aufgaben der ausschreibenden Stelle verdeckt Informationen nach Absatz 8 zu erlangen und damit zur Erforschung des Sachverhaltes oder zur Ermittlung des Aufenthaltsortes des Täters beizutragen. ${ }^{671}$ Der dahinter stehende Zweck ist es, vom Täter ein Bewegungsbild zeichnen zu können. Darüber hinaus geht es darum, Zusammenhänge und Querverbindungen zwischen dieser und anderen Personen zu erfassen, um so kriminelle Strukturen zu erkennen und Delikte der Organisierten Kriminalität ${ }^{672} \mathrm{zu}$ verfolgen. ${ }^{673}$

Da sich die zuletzt genannten Zwecke, nämlich Erstellung eines Bewegungsbildes und Erkennen krimineller Strukturen, dem Wortlaut so nicht entnehmen lassen, handelt es sich nicht um aus-

\footnotetext{
${ }^{668}$ AB1. Nr. C 340, 173, vom 10. November 1997.

${ }^{669}$ Der Vertrag von Amsterdam schuf in doppelter Hinsicht eine Grundlage für den Beschluss 2005/211/JI des Rates: Mit dem dem Vertrag beigefügten Schengen-Protokoll wurde die Schengen-Materie zur EU-Materie und mit den teilweise neu aufgenommenen bzw. präzisierten Art. 30 Abs. 1 lit. a und b, Art. 31 lit. a und b sowie Art. 34 Abs. 2 lit. c EUV, auf die sich der Beschluss stützt, konnte der Schengen-Besitzstand im Rahmen der EU weiterentwickelt werden; der deutsche Gesetzgeber hat dem Vertrag von Amsterdam mit seinen Protokollen am 8. April 1998 zugestimmt, vgl. BGB1. II vom 16. April 1998, 386.

${ }^{670}$ Vgl. auch Kingreen, in: Callies/Ruffert, EUV/AEUV, Art. 8 GRCh, Rn. 14; Jarass, EU-Grundrechte, § 13, Rn. 9; Johlen, in: Tettinger/Stern, Kölner Gemeinschaftskommentar, Art. 8, Rn. 40 ff.

${ }^{671}$ Absatz 2 der strafprozessualen Norm.

${ }^{672}$ Nach der Festlegung der Innen- und Justizminister der Bundesländer ist Organisierte Kriminalität die von Gewinn- oder Machtstreben bestimmte, planmäßige Begehung von Straftaten, die einzeln oder in ihrer Gesamtheit von erheblicher Bedeutung sind, wenn mehr als zwei Beteiligte auf längere oder unbestimmte Dauer arbeitsteilig

- unter Verwendung gewerblicher oder geschäftsähnlicher Strukturen,

- unter Anwendung von Gewalt oder anderer zur Einschüchterung geeigneter Mittel oder

- unter Einflussnahme auf Politik, Medien, öffentliche Verwaltung, Justiz oder Wirtschaft zusammenwirken, Richtlinie für die Zusammenarbeit von Staatsanwaltschaft und Polizei bei der Verfolgung der OK; Gem. Runderlass der MJ und der MI vom 16. Juli 2008, Nds. Ministerialblatt Nr. 30/2008.

${ }^{673}$ Mokros, in: Lisken/Denninger, HandbPolR, O, Rn. 200; vgl. Krahl, NStZ 1998, 339 (339) zu 163 e StPO; vgl. Meyer-Goßner, StPO, § 163 e, Rn. 2; BT-Drs. 12/989, 43 f.
} 
drücklich festgelegte Zwecke. Allerdings ergibt sich ein Bewegungsbild automatisch, wenn ein möglicher Täter mehrfach kontrolliert wird; ebenso können Informationen über Reiseweg und ziel sowie die Begleitpersonen aus verschiedenen Kontrollen Verbindungen und Strukturen aufdecken. Dass die erwähnten übergeordneten bzw. dahinter stehenden Zwecke mit der verdeckten Registrierung angestrebt werden, liegt also zum einen gedanklich sehr nahe. Zum anderen sind sie vom Wortlaut der Norm umfasst, da ein Bewegungsbild aus verschiedenen festgestellten Aufenthaltsorten des Betroffenen entsteht und sich das Erkennen von Strukturen unter die Erforschung des Sachverhaltes fassen lässt.

$\mathrm{Zu}$ berücksichtigen ist hier allerdings, dass eine Ausschreibung immer an einen konkreten Straftatverdacht anknüpft. Erscheint der Sachverhalt zu dieser Straftat bzw. zu diesem Straftatenkomplex $^{674}$ genügend aufgeklärt, liegen also die dem Erforschungsauftrag des $§ 160$ StPO entsprechenden Erkenntnisse zu Tatbestandserfüllung, Rechtswidrigkeit, Schuld sowie gegebenenfalls zu Indizien und zu Umständen für die Rechtsfolgenzumessung vor, reicht es nicht aus, dass weitere Aufschlüsse zu erwarten sind, die außerhalb der aufzuklärenden Straftaten allein Erkenntnisse über kriminelle Strukturen und Querverbindungen vermitteln können. Das Eindringen in den Kernbereich einer Grundstruktur von kriminellen Organisationen ist als solches kein legitimes Ziel des Strafprozesses. ${ }^{675}$

Eine präzise Zweckfestlegung ist bei diesem Verständnis gegeben. ${ }^{676}$

Das SDÜ sieht jedoch auch die Möglichkeit der Änderung von Zwecken vor. Art. 5 lit. b des Datenschutzübereinkommens des Europarates und Art. 6 RL 95/46/EG, denen Art. 8 GR-Charta nachgebildet ist, formulieren hierzu weitgehend übereinstimmend, dass die (Weiter-) verarbeitung mit den festgelegten Zwecken vereinbar sein muss. Relevant für eine Zweckänderung der nach Art. 99 SDÜ gespeicherten Daten im Rahmen des SIS ist Art. 102 Abs. 3 SDÜ. Diese Vorschrift formuliert die Ausnahmen eng. Der Ersatz einer Ausschreibungskategorie durch eine andere ist nur zulässig, wenn die ausschreibende Vertragspartei zustimmt. Zudem muss der Wechsel zur Abwehr einer schwerwiegenden und unmittelbar bevorstehenden Gefahr für die öffentli-

\footnotetext{
${ }^{674}$ Voraussetzung für die Ausschreibung im SIS ist ja, dass der Betroffene außergewöhnlich schwere Straftaten in erheblichem Umfang begeht.

${ }^{675}$ Vgl. Erb, in: Erb u.a., Löwe-Rosenberg-StPO, Fünfter Band, § 163 e, Rn. 15; Wolter, in: Rudolphi u.a., SK StPO, Band 3, § 163 e (Stand: Mai 1997), Rn. 11.

${ }^{676}$ Die umfassende Zweckbestimmung hat einige Autoren dazu veranlasst, den Zweck der polizeilichen Beobachtung nach $\S 163$ e StPO weniger in einer gezielten Ermittlung zu sehen, als in einer zufallsbedingten „Abrundung des Persönlichkeitsbildes“, vgl. Schoreit, in: Hannich, KK zur StPO, § 163 e, Rn. 3; Wolter, in: Rudolphi u.a., SK StPO, Band 3, § 163 e (Stand: Mai 1997), Rn. 7; Krahl, NStZ 1998, 339 (341); allerdings führt eine solche Einschätzung nach Ansicht der Verfasserin auch zu keinem anderen Ergebnis: Zum einen können die zu übermittelnden Informationen nahe liegender weise teilweise Aufschluss über die Persönlichkeit des Täters geben; zum anderen dient diese Teilinformation zur Persönlichkeit des Täters, die aber nicht im Sinne eines Totalabbildes zu verstehen ist, ebenfalls der Erforschung des Sachverhaltes.
} 
che Sicherheit und Ordnung oder aus schwerwiegenden Gründen der Sicherheit des Staates oder zur Verhütung einer Straftat mit erheblicher Bedeutung erforderlich sein. Diese hohen Anforderungen sowie die Tatsache, dass die Daten lediglich in eine andere, jeweils klar bezeichnete, Fahndungskategorie des SIS übernommen werden dürfen, lassen an der geforderten Vereinbarkeit keinen Zweifel.

Während Art. 102 Abs. 3 SDÜ die Nutzung der Daten im Rahmen einer anderen Ausschreibungskategorie regelt, beschäftigt sich Art. 92 Abs. 4 S. 2 SDÜ mit den (zusätzlichen) Informationen, die im Trefferfall ausgetauscht werden. Die Norm legt fest, dass die Informationen nur für die Zwecke verwendet werden dürfen, zu denen sie übermittelt wurden. Im Falle der im Rahmen der Ausschreibung zur verdeckten Registrierung erbetenen Informationen bedeutet das, dass sie grundsätzlich nur zur Erforschung des Sachverhaltes der konkreten Tat, die zur Ausschreibung geführt hat, bzw. zur Aufenthaltsermittlung des Täters eingesetzt werden dürfen.

Eine ausreichende Zweckfestlegung ist gegeben.

\section{bb. Organisatorische und verfahrensrechtliche Vorkehrungen}

Als eine spezielle Ausprägung des Grundsatzes der Verhältnismäßigkeit bestimmen Art. 8 Abs. 2 S. 2 sowie Abs. 3 GR-Charta, dass jede Person das Recht hat, Auskunft über die sie betreffenden erhobenen Daten zu erhalten, die Berichtigung der Daten zu erwirken und dass die Einhaltung der Vorschriften von einer unabhängigen Stelle überwacht wird.

Bei der Überprüfung wird ein nicht auflösbarer Widerspruch deutlich: Einerseits soll der Bürger jederzeit wissen können, was wo über ihn bekannt ist. Andererseits will der Staat, jedenfalls zunächst, heimlich Erkenntnisse sammeln. Das Verwirklichen beider Ziele zur gleichen Zeit schließt sich aus. Der Gesetzgeber hat durch verschiedene Regelungen versucht, die Widersprüchlichkeit zu entschärfen. Soweit man heimliche Ermittlungsmethoden nicht grundsätzlich ablehnt, kann man von einer weitgehend zufrieden stellenden Lösung sprechen. Wenn eine Auskunft während der Maßnahme nach Art. 109 Abs. 2 S. 2 SDÜ unterbleibt sowie immer nach Beendigung der Maßnahme, besteht nach Absatz 6 der Norm die Pflicht zur nachträglichen Benachrichtigung. Sie ist unter den geschilderten Umständen der akzeptable Ersatz für die eigentlich zu erteilende, aber unterbliebene Auskunft.

Die Maßnahme darf grundsätzlich nur durch das Gericht angeordnet und kann nach Beendigung gerichtlich überprüft werden. ${ }^{677}$ Soweit Art. 110 und 111 SDÜ Berichtigungs-, Löschungs- und

\footnotetext{
${ }^{677}$ Kritisiert wird hier z.T., dass Einzelfragen der Anordnung nicht geregelt sind, vgl. Erb, in: Erb u.a., LöweRosenberg-StPO, Fünfter Band, § 163 e, Rn. 6; es ist jedoch mit Wolter davon auszugehen, dass die Anordnung
} 
Schadensersatzansprüche nennen, dürfte im Bereich der verdeckten Registrierung wegen der erst nachträglichen Auskunft allein der einklagbare Schadensersatzanspruch eine Rolle spielen.

Zur Kontrolle sind nach Art. 114 SDÜ die unabhängigen nationalen Instanzen berufen; ${ }^{678}$ das C.SIS unterliegt der Überprüfung durch die ebenfalls unabhängige Gemeinsame Kontrollinstanz ${ }^{679}$ Ergänzend kontrolliert der unabhängige Europäische Datenschutzbeauftragte Organe und Einrichtungen der EU, wenn sie in Bezug auf das SIS handeln. ${ }^{680} 681$

Schließlich wird man aufgrund der Grundrechte-Charta auch fordern können, dass die Betroffenen die Möglichkeit haben müssen, ihre Rechte nötigenfalls gerichtlich durchzusetzen. Es mag hier dahinstehen, ob man dieses Recht aus Art. 8 GR-Charta selbst ableitet oder auf die allgemeine Regel des Art. 47 GR-Charta zugreift. Jedenfalls wird dem Bürger in Art. 111 SDÜ ein entsprechendes Klagerecht eingeräumt.

Die organisatorischen und verfahrensrechtlichen Vorkehrungen erscheinen somit als zufriedenstellend.

\section{cc. Wesensgehalt}

Art. 52 Abs. 1 S. 1 GR-Charta bestimmt, dass jede Einschränkung den Wesensgehalt des eingeschränkten Rechtes achten muss. Die Erläuterungen zu Art. 52 GR-Charta geben keine nähere Auskunft darüber, wie der Wesensgehalt zu bestimmen ist. Allerdings formuliert das Präsidium in den Erläuterungen zu Art. 1 GR-Charta, dass die Würde des Menschen zum Wesensgehalt der in dieser Charta festgelegten Rechte gehört. Wer sie antastet, tastet auch den Wesensgehalt an. ${ }^{62}$ Mangels weiterer Vorgaben aus der Rechtsprechung des zu dem auch von ihm grundsätzlich

schriftlich und inhaltlich so präzise wie möglich zu fassen ist, vgl. Wolter, in: Rudolphi u.a, SK StPO, Band 3, § 163 e (Stand: Mai 1997), Rn. 24.

${ }^{678}$ Keine Relevanz hat an dieser Stelle das Urteil des EuGH vom 9. März 2010, das sich mit der Unabhängigkeit deutscher Datenschutzstellen befasst. Der Gerichtshof differenziert zwischen der Datenschutzaufsicht über die Privatwirtschaft und derjenigen über öffentliche Stellen. Letztere, um die es auch im hiesigen Zusammenhang geht, seien nur ihren Parlamenten rechenschaftspflichtig und unterlägen keinerlei Aufsicht, Weisungen oder sonstigem Einfluss der von ihnen zu kontrollierenden Stellen. Ihre Unabhängigkeit stellt der EuGH demnach nicht in Frage, NJW 2010, 1265 (1265, 1267).

${ }^{679}$ Siehe 2. Teil B. IV. 1. b. ee.

${ }^{680}$ Art. 3, Abs. 1; 46 c, f ii VO (EG) Nr. 45/2001, AB1. L 8, 1, vom 12. Januar 2001.

${ }^{681}$ An dieser Stelle wird Albers zugestimmt, die die in Art. 8 GR-Charta explizit verankerten Elemente wie den Auskunfts- und Berichtigungsanspruch als „eklektizistisch“ bezeichnet; die Formulierung des Bundesverfassungsgerichts, wonach organisatorische und verfahrensrechtliche Regelungen zum Schutz des Rechts auf informationelle Selbstbestimmung geschaffen werden müssen, ermöglicht dagegen eine umfassendere Prüfung, weil auf diese Weise ein in seinen Elementen aufeinander abgestimmtes Schutzsystem gefordert wird. Die Nennung lediglich einzelner Punkte hat dagegen schutzverkürzende Folgen; so fehlen an dieser Stelle z.B. Erwägungen zum technischen Datenschutz, zu Protokollierungspflichten, zu Löschungs- und Befristungsregeln, vgl. Albers, Informationelle Selbstbestimmung, S. 305 f. sowie BVerfGE 65, $1(44,46)$.

${ }^{682}$ Erläuterungen abgedruckt bei: Beck, Europäischer Unionsvertrag, 6. A., Stand: Mai 2008, Teil A, 5, vgl. hier Erläuterung zu Art. 1 GR-Charta. 
anerkannten Wesensgehaltsschutz ${ }^{683}$ soll dieser Bezug zur Menschenwürde als Ausgangspunkt für die weitere Prüfung genommen werden. Das deutsche Bundesverfassungsgericht, dass das Recht auf informationelle Selbstbestimmung teilweise auch in Art. 1 Abs. 1 GG verankert, sieht den Menschenwürdegehalt des Rechtes dann als verletzt an, wenn eine Maßnahme den Kernbereich privater Lebensgestaltung betrifft. ${ }^{684}$ Das wäre z.B. der Fall, wenn sich durch die Zusammenführung einzelner Lebens- und Sozialdaten zur Erstellung von Persönlichkeitsprofilen ein Totalabbild der jeweiligen Person ergäbe ${ }^{685}$ Wendet man diese Überlegung auf die verdeckte Registrierung nach der strafprozessualen Variante an, kommt man zu folgendem Ergebnis: Zwar haben die Daten persönlichen Bezug von einigem Gewicht, geben sie doch Auskunft über Reisewege, - mittel, -ziele, -umstände und Begleitpersonen. Dennoch kann man diesen Daten keinen höchstpersönlichen Charakter ${ }^{686}$ beimessen, so dass sie zum Kernbereich privater Lebensgestaltung zu zählen wären. Wer mit wem in welchem Auto fährt, ist beispielsweise für die Nachbarn offensichtlich; Reiseziele bespricht man grundsätzlich auch mit entfernt Bekannten. Zudem kann mit Hilfe der Daten kein vollständiges Persönlichkeitsbild erstellt werden. Obwohl die Maßnahme langfristig angelegt und regelmäßig gerade darauf gerichtet ist, Informationen aus verschiedenen Kontrollen zu erlangen, erfolgen diese Kontrollen gerade nicht systematisch. Insofern hängt es ganz stark vom Zufall ab, ob eine ausgeschriebene Person überhaupt oder häufiger kontrolliert wird. Wegen dieses Zufallscharakters und weil die Kontrolle typischerweise nur dann stattfindet, wenn sich der Betroffene im öffentlichen und damit offen zugänglichen Raum bewegt, ist die Erstellung eines umfassenden Persönlichkeitsbildes nicht möglich. Insofern ist der Menschenwürdegehalt des Rechtes nicht angetastet. Damit wird der Wesensgehalt i.S.v. Art. 52 Abs. 1 S. 1 GR-Charta geachtet.

\section{dd. Verhältnismäßigkeit}

Nach dem Grundsatz der Verhältnismäßigkeit muss eine Maßnahme zur Erreichung des angestrebten und legitimen Zweckes geeignet und erforderlich sein; zudem darf der mit ihr verbundene Eingriff seiner Intensität nach nicht außer Verhältnis zur Bedeutung der Sache und den vom Bürger hinzunehmenden Einbußen stehen. ${ }^{687}$

\footnotetext{
${ }^{683}$ EuGH, Slg. 1989, 2609, Rn. 18 - Wachauf; Slg. 1989, 2237, Rn. 15 - Schräder, Slg. 2000, I-2737, Rn. 58 Karlsson.

${ }^{684}$ B VerfGE 109, 279 (Leitsatz 2).

${ }^{685}$ BVerfGE 65, 1 (53, 57); Schoch, JURA 2008, 352 (357).

${ }^{686} \mathrm{Vgl}$. zu diesem Kriterium Petri, in: Lisken/Denninger, HandbPolR, H, Rn. 22.

${ }^{687}$ Jarass, EU-Grundrechte, $\S 13$, Rn. 12.
} 


\section{(1) Zweck und Geeignetheit}

Der Zweck der verdeckten Registrierung zu strafprozessualen Zwecken ist es, den Sachverhalt zu erforschen, den Aufenthaltsort des Täters zu ermitteln sowie ein Bewegungsbild zu erstellen und kriminelle Strukturen und Verbindungen zu erkennen. ${ }^{688}$ Legtimer Zweck können nach Art. 52 Abs. 1 S. 2 GR-Charta grundsätzlich nur Zielsetzungen sein, die von der Union anerkannterweise dem Gemeinwohl oder dem Schutz der Rechte und Freiheiten anderer dienen. Übergeordneter Zweck der verdeckten Registrierung ist die Gewährleistung der Sicherheit innerhalb der Europäischen Union. Mit Hilfe dieser Zielsetzung sollen die Rechte der Bürger auf Leben, Gesundheit, Eigentum und Freiheit geschützt werden. Zudem ist mit Blick auf Art. 3 Abs. 2 EUV 689 davon auszugehen, dass dieses Ziel nach der Auffassung der Union auch dem Gemeinwohl dient. Ein legitimer Zweck ist gegeben.

Das eingesetzte Mittel muss geeignet sein. Dieses Element des Verhältnismäßigkeitsgrundsatzes lässt sich auch der Formulierung des Art. 52 Abs. 1 S. 2 GR-Charta entnehmen, dass die Einschränkung dem Einschränkungsgrund „tatsächlich entsprechen“ muss. Geeignet ist ein Mittel immer dann, wenn das angestrebte Ziel mit seiner Hilfe jedenfalls gefördert wird. ${ }^{690}$

Bei der polizeilichen Beobachtung nach nationalem Recht wird insbesondere wegen des Zufallselements der Maßnahme vielfach die Geeignetheit in Frage gestellt bzw. ein praktischer Anwendungsbereich verneint. ${ }^{691}$ Die hierzu vorgebrachten Bedenken lassen sich auch auf die verdeckte Registrierung im SIS übertragen. Entscheidender Ansatzpunkt ist, dass eine verdeckte Registrierung keine gezielte Beobachtung meint. Vielmehr will man Informationen nutzen, die bei Gelegenheit einer aus anderen Gründen stattfindenden Kontrolle ohnehin anfallen. Der Erkenntnisgewinn bei der Strafverfolgung hängt bei dieser Methode vollständig vom Zufall ab. ${ }^{692}$ Die strafprozessuale Norm der verdeckten Registrierung setzt zureichende tatsächliche Anhaltspunkte dafür voraus, dass außergewöhnlich schwere Straftaten in erheblichem Umfang begangen wurden. In diesen Fällen wird gleichzeitig ein Ermittlungsverfahren anhängig sein, das auf Aufklärung der Straftat gerichtet ist. ${ }^{693}$ Es gilt nun festzustellen, wie die Fahndungsmethode zur Strafverfolgung beitragen kann. Der Verdächtige darf allein aufgrund der Ausschreibung weder fest-

\footnotetext{
${ }^{688}$ Mokros, in: Lisken/Denninger, HandbPolR, O, Rn. 200; vgl. Krahl, NStZ 1998, 339 (339) zu 163 e StPO; vgl. Meyer-Goßner, StPO, § 163 e, Rn. 2.

${ }^{689}$ Vgl. hierzu die Erläuterungen der GR-Charta zu Art. 52, 1. Abs., abgedruckt bei: Beck, Europäischer Unionsvertrag, 6. A., Stand: Mai 2008, Teil A, 5.

${ }^{690}$ Jarass, EU-Grundrechte, $\S 6$, Rn. 46.

${ }^{691}$ Zöller, in: Julius u.a., StPO, § 163 e, Rn. 2; Wolter, in: Rudolphi u.a., SK StPO, Band 3, § 163 e (Stand: Mai 1997), Rn. 8; Erb, in: Erb u.a., Löwe-Rosenberg-StPO, Fünfter Band, § 163 e, Rn. 4; Meyer-Goßner, § 163 e, Rn. 2 ; Schoreit, in: Hannich, KK zur StPO, § 163 e, Rn. 3.

${ }^{692} \mathrm{Vgl}$. Zöller, in: Julius u.a., StPO, $\$ 163$ e, Rn. 2.

${ }^{693} \S 160$ Abs. 1 i.V.m. § 152 Abs. 2 StPO.
} 
genommen, noch verhört, noch dürfen sonstige Ermittlungshandlungen vorgenommen werden. Dazu gibt die Norm keine Rechtsgrundlage, und außerdem würde das ihrer Konzeption zuwider laufen, denn die Informationen sind ja gerade verdeckt zu erheben.

Übermittelt werden dürfen Informationen über das Antreffen der ausgeschriebenen Person oder des ausgeschriebenen Fahrzeugs, über Ort, Zeit oder Anlass der Überprüfung, Reiseweg und Reiseziel, Begleitpersonen oder Insassen, das benutzte Fahrzeug, mitgeführte Sachen sowie über die Umstände des Antreffens der Person oder des Fahrzeugs. Diese Informationen können zu wichtigen Erkenntnissen bei der Aufklärung der Straftat führen. Eine veröffentlichte systematische Untersuchung über die Effektivität des Instrumentes auf nationaler Ebene gibt es bislang nicht. ${ }^{694}$ Bei der Frage der Geeignetheit kommt es jedoch auch im Rahmen der SIS-Fahndung allein darauf an, dass die Förderung des Zwecks denklogisch möglich erscheint. Obwohl das Zufallselement in aller Regel zu einem nur schmalen praktischen Anwendungsbereich führen wird, ist das der Fall.

Möglicherweise lässt sich der Anwendungsbereich für die verdeckte Registrierung jedoch auch noch erweitern, so dass von einem höheren Maß an Geeignetheit ausgegangen werden könnte. Im deutschen Strafprozessrecht wird die Ausschreibung zur polizeilichen Beobachtung auch in späteren Strafverfahrensstadien als dem Ermittlungsverfahren als zulässig angesehen ${ }^{695}$ So kann man sie etwa einsetzen zur Ermittlung des Aufenthaltes eines Angeschuldigten, wenn das Verfahren wegen seiner Abwesenheit nach § 205 StPO vorläufig eingestellt ist. Zur Aufenthaltsermittlung oder -überprüfung soll die polizeiliche Beobachtung nach $\S 457$ Abs. 3 S. 1 StPO auch im Vollstreckungsverfahren und nach $\S 463$ a Abs. 2 StPO im Rahmen der Führungsaufsicht dienen. Mangels einer ausdrücklichen Verweisung - wie sie das deutsche Recht enthält - in den Vorschriften des SDÜ ist eine Ausschreibung zur verdeckten Registrierung im SIS für Zwecke des Vollstreckungsverfahrens und der Führungsaufsicht abzulehnen. Fraglich ist dagegen, ob der Anwendungsbereich wie im nationalen Recht vielfach befürwortet auf das gerichtliche Verfahren ausgedehnt werden kann. Dagegen spricht der klare Wortlaut der Vorschrift, der an ein Verfahrensstadium anknüpft, in dem lediglich konkrete Anhaltspunkte für bestimmte Straftaten gefordert werden. Im gerichtlichen Verfahren halten Staatsanwaltschaft und Gericht eine Verurteilung aber bereits für hinreichend wahrscheinlich. ${ }^{696}$ Zudem steht zur Aufenthaltsermittlung in diesem Verfahrensabschnitt das Instrument einer Ausschreibung nach Art. 98 Abs. 1 2. Alt. SDÜ

\footnotetext{
${ }^{694}$ Petri, in: Lisken/Denninger, HandbPolR, H, Rn. 277.

${ }^{695}$ Zöller, in: Julius u.a., StPO, § 163 e, Rn. 1; Erb, in: Erb u.a., Löwe-Rosenberg-StPO, Fünfter Band, § 163 e, Rn. 7. ${ }^{696} \S \S 170$ Abs. 1, 203 StPO.
} 
zur Verfügung. Insofern bleibt es bei dem relativ schmalen Anwendungsbereich der Ausschreibung zur verdeckten Registrierung in der strafprozessualen Variante.

\section{(2) Erforderlichkeit}

Erforderlich ist das gewählte Mittel nur dann, wenn es kein anderes milderes, aber zur Zweckerreichung ebenso geeignetes Mittel gibt. ${ }^{697}$

Diesen Gedanken der Erforderlichkeit nimmt auch die strafprozessuale Norm auf, wonach die Anordnung nur dann getroffen werden darf, wenn die Erforschung des Sachverhaltes oder die Ermittlung des Aufenthaltsortes des Täters auf andere Weise erheblich weniger erfolgversprechend oder wesentlich erschwert wäre. Es geht also um die Suche nach alternativen Mitteln, die im Hinblick auf die Zweckerreichung nicht erheblich weniger erfolgversprechend und damit im Wesentlichen gleich geeignet sind. Diese Subsidiaritätsklausel erscheint in doppelter Hinsicht kritikwürdig: Zum einen enthält sie keine entscheidende Aussage, die über diejenige des allgemeinen Erforderlichkeitsgrundsatzes als Bestandteil des Verhältnismäßigkeitsgrundsatzes hinausgeht. An den Verhältnismäßigkeitsgrundsatz sind die Strafverfolgungsorgane über Art. 51 und Art. 52 Abs. 1 GR-Charta ohnehin gebunden. ${ }^{698}$ Die Klausel schadet zwar nicht, ${ }^{699}$ hat aber bei genauerer Betrachtung lediglich einen floskelhaften Charakter. Zudem vermittelt sie den Eindruck, dass sie wegen ihrer Eingriffsschwere möglichst nur hilfsweise und nach weniger grundrechtsrelevanten Ermittlungsmethoden eingesetzt werden soll. Das erweist sich in der Praxis aber als schwierig. Es ist unklar, wie die Erfolgsaussicht einer verdeckten Registrierung eingeschätzt werden kann, wenn die Tatsache der Kontrolle vollständig vom Zufall abhängt. Wenn man eine solche Erfolgsaussicht aber nicht bestimmen kann, fehlt der Bezugspunkt für den Vergleich mit den Erfolgsaussichten anderer Ermittlungsmethoden. Allgemein wird die Vorschrift deshalb so interpretiert, dass sie keine sichere Vorhersage zu Erfolg oder Misserfolg der anderen Maßnahmen oder einer verdeckten Registrierung fordert. Ausreichend soll eine Prognose sein, wonach ein deutliches Aufklärungsdefizit zu erwarten ist, wenn die Durchführung der verdeckten Registrierung unterbleibt. Eine wesentliche Erschwerung liegt nach dieser Interpretation dann vor, wenn durch den Einsatz anderer Aufklärungsmittel eine nicht vertretbare Verfahrens-

\footnotetext{
${ }^{697}$ Jarass, EU-Grundrechte, $§ 6$, Rn. 47.

${ }^{698}$ Bei Sachverhalten mit rein innerstaatlichem Bezug ergibt sich die Bindung aus dem dem Rechtsstaatsprinzip entspringenden Verhältnismäßigkeitsgrundsatz; das Rechtsstaatsprinzip haben die Strafverfolgungsorgane aber als Teil der staatlichen Gewalt über Art. 20 Abs. 3 GG bereits von Verfassungs wegen zu achten, vgl. Zöller, StraFo 2008, 15 (20).

${ }^{699}$ Manche Autoren begrüßen den darin enthaltenen Appell, den allgemeinen Verhältnismäßigkeitsgrundsatz zu beherzigen, vgl. Schoreit, in: Hannich, KK zur StPO, § 163 e, Rn. 15 mit weiterem Nachweis.
} 
verzögerung zu besorgen wäre. ${ }^{700}$ Zudem kann die Ausschreibung vorgenommen werden, wenn dadurch ein zusätzlicher, auf andere Weise nicht ebenso erfolgversprechend oder einfach zu erreichender Ermittlungserfolg zu erwarten ist. Gerade diese Ermittlungsmaßnahme wird selten für sich allein aussichtsreich sein. ${ }^{701}$

Überraschen mag unter Erforderlichkeitsgesichtspunkten auch die Eilzuständigkeit der Staatsanwaltschaft. ${ }^{702}$ Da die ermittelnden Personen nicht wissen, wann eine zufällige Kontrolle stattfindet, kann die Sache grundsätzlich auch nicht als eilig oder nicht eilig eingeschätzt werden. Die Zuständigkeit der Staatsanwaltschaft wäre dann nicht erforderlich. Dennoch kann es Konstellationen geben, in denen es gewisse Anhaltspunkte dafür gibt, dass der Betroffene in Kürze bestimmte Kontrollstellen passieren wird. Für solche Fälle mag die Eilzuständigkeit der Staatsanwaltschaft gedacht sein. In diesem Zusammenhang ist zu berücksichtigen, dass dem Gesetzgeber wie im Rahmen der Geeignetheitsprüfung bei der Wahl der erforderlichen Mittel ein Einschätzungs- und Gestaltungsspielraum zusteht, den die Judikative nicht im Detail überprüfen kann. ${ }^{703}$

Problematisch erscheint unter Erforderlichkeitsgesichtspunkten auch der Begriff der außergewöhnlich schweren Straftaten, die in erheblichem Umfang begangen werden müssen. ${ }^{704}$ Sowohl beim Begriff der außergewöhnlich schweren Straftat wie beim Begriff des erheblichen Umfangs handelt es sich um unbestimmte Rechtsbegriffe, da das SDÜ hierzu keine weiteren Erläuterungen enthält. Der Grad der Bestimmtheit einer Norm hat im Hinblick auf die Erforderlichkeit Bedeutung, weil unklare Gesetze mehr Eingriffe ermöglichen als notwendig sind. ${ }^{705} \operatorname{Im} 2$. Teil der Arbeit $^{706}$ war festgestellt worden, dass dieses Tatbestandsmerkmal höhere Anforderungen an den Sachverhalt stellt als die „Straftat von erheblicher Bedeutung“ in $§ 163$ e StPO. Allerdings ist mit dieser Erkenntnis keine große begriffliche Schärfe gewonnen, da es auch für die Straftat von erheblicher Bedeutung keine genaue Definition gibt. ${ }^{707}$ Bei der Vereinbarung des SDÜ im Jahr 1990 hat man sich vermutlich nicht auf einen Straftatenkatalog einigen können oder wegen der unterschiedlichen innerstaatlichen strafrechtlichen Vorschriften auch nicht einigen wollen. Insofern wurde im Rahmen des Art. 99 SDÜ ein auslegungsbedürftiger Rechtsbegriff gewählt. Diese

\footnotetext{
${ }^{700}$ Vgl. Zöller, in: Julius u.a., StPO, § 163 e, Rn. 6; vgl. Erb, in: Erb u.a., Löwe-Rosenberg-StPO, Fünfter Band, § 163 e, Rn. 18.

${ }^{701}$ Vgl. Erb, in: Erb u.a., Löwe-Rosenberg-StPO, Fünfter Band, § 163 e, Rn. 19.

${ }^{702}$ Strafprozessuale Norm Abs. 4; vgl. Schoreit, in: Hannich, KK zur StPO, § 163 e, Rn. 21.

${ }^{703}$ EuGH, NVwZ 2010, 629, Ls. 3; Ehlers, in: Ehlers, Europäische Grundrechte, § 14, Rn. 71; vgl. Jarass, EUGrundrechte, $\S 6$, Rn. 52 f.

${ }^{704}$ Abs. 1 strafprozessuale Norm.

${ }^{705}$ Vgl. Pieroth/Schlink, Staatsrecht II, Rn. 325.

${ }^{706}$ Dort A. III. 5. a. aa. (1) (c).

${ }^{707}$ Zöller, in: Julius u.a., StPO, $§ 163$ e, Rn. 4; Erb, in: Erb u.a., Löwe-Rosenberg-StPO, Fünfter Band, § 163 e, Rn. 14.
} 
Lösung ist jedenfalls aus heutiger Sicht unbefriedigend und entspricht nicht dem Grundsatz der Erforderlichkeit.

Weiterführend sei an dieser Stelle darauf hingewiesen, dass die rechtlichen Bedenken beispielsweise durch Rückgriff auf die Katalogstraftaten des Art. 2 Abs. 2 des Rahmenbeschlusses zum Europäischen Haftbefehl, ${ }^{708}$ der für Art. 95 SDÜ ja ohnehin zwischen dem größten Teil der Teilnehmerstaaten Anwendung findet, ausgeräumt werden könnten. ${ }^{709}$ Liegt eine dieser Taten vor, müssten gleichwohl die außergewöhnliche Schwere und der erhebliche Umfang besonders geprüft und begründet werden. Zwar indizieren viele der aufgeführten Taten eine außergewöhnliche Schwere, wie etwa Menschenhandel oder der illegale Handel mit nuklearen oder radioaktiven Substanzen. Da jedoch auch Betrugsdelikte und Erpressung nur mit der Einschränkung erfasst sind, dass sie im innerstaatlichen Recht mit einer Freiheitsstrafe im Höchstmaß von mindestens drei Jahren bedroht sind, können darunter auch Delikte fallen, die zu einem nur geringen Vermögensschaden führen oder bei deren Ausführung die kriminelle Energie die Grenze zur Strafbarkeit gerade überschritten hat. Hilfreiche Kriterien wären hier z.B. das Vorliegen eines besonders großen Vermögensschadens oder dass im Rahmen einer Erpressung glaubhaft mit einem äußerst empfindlichen Übel gedroht wird.

Während die „,außergewöhnliche Schwere“ auf die Qualität der Taten Bezug nimmt, knüpft „,der erhebliche Umfang“" an die Quantität an. Mangels einer Definition im SDÜ und anderen europäischen Vorschriften kann unter Umständen ein Blick in das deutsche materielle Strafrecht Anhaltspunkte geben. Der Begriff weckt Assoziationen zum Bandendiebstahl nach $\S 244$ Abs. $1 \mathrm{Nr}$. 2 StGB, der eine „fortgesetzte Begehung“ als Tatbestandsmerkmal nennt. Gemeint ist damit die geplante Begehung einer Vielzahl von selbständigen, im einzelnen noch ungewissen Taten, wobei bereits die erste Tat als fortgesetzt in diesem Sinne angesehen werden kann. Die Tat muss Bestandteil der Kette der fortlaufenden Begehung der von der Bande geplanten Taten sein. ${ }^{710}$ Die Definition erweist sich für die verdeckte Registrierung als teilweise unbrauchbar, weil sie die Verabredung durch mehrere Personen betrifft. Täter der Straftaten, die Art. 99 SDÜ voraussetzt, kann jedoch auch ein Einzeltäter sein. Einzig hilfreich erscheinen die Begriffe der „Vielzahl von Taten“ bzw. einer „Kette von Taten.“ Mit diesen Assoziationen und dem einfachen Wortverständnis von ,erheblichem Umfang“ lässt sich fordern, dass der Verdacht besteht, dass Straftaten von außergewöhnlicher Schwere jedenfalls drei Mal begangen wurden. Unter Erforderlichkeits-

\footnotetext{
${ }^{708}$ Rahmenbeschluss 2002/584/JI des Rates vom 13. Juni 2002, AB1. L 190, 1.

${ }^{709}$ Diese Empfehlung gibt auch der Hessische Datenschutzbeauftragte in seinem 36. Tätigkeitsbericht, 2007, S. 37; vgl. auch Beschluss des Rates zum SIS II, der diesen Vorschlag aufnimmt, Art. 36 Abs. 2 Beschluss des Rates 2001/886/JI vom 6. Dezember 2001 über die Entwicklung des Schengener Informationssystems des zweiten Generation (SIS II), ABl. L 328, 1.

${ }^{710}$ Haft, BT 1, S. 20 f.; Schmitz, in: Joecks/Miebach, MüKo, Band 3, § 244, Rn. 41.
} 
gesichtspunkten erscheint dieser unbestimmte Rechtsbegriff hinnehmbar, da bereits das einfache Wortverständnis eine nahe liegende Konkretisierung bringt.

Maßgebend für die Beurteilung ist der Erkenntnisstand zum Zeitpunkt der Anordnung der Maßnahme. ${ }^{711}$

Zusammenfassend bleibt festzustellen, dass der unbestimmte Rechtsbegriff der außergewöhnlich schweren Straftat gegen den Grundsatz der Erforderlichkeit verstößt.

In Anlehnung an die an dieser Stelle im innerstaatlichen Bezug zu berücksichtigende Figur der verfassungskonformen Auslegung ${ }^{712}$ muss daran gedacht werden, ob eine grundrechtschartakonforme Auslegung dieses Ergebnis verhindern könnte. Eine solche Auslegung kommt jedoch bereits deshalb nicht in Betracht, weil der Gesetzgeber selbst Festlegungen treffen muss, welche Kriterien in Betrugs- oder Erpressungsfällen für die Bestimmung der außergewöhnlichen Schwere herangezogen werden sollen.

\section{(3) Angemessenheit}

Art. 52 Abs. 1 S. 2 GR-Charta verlangt im Rahmen der Verhältnismäßigkeitkontrolle nach der Prüfung von Geeignetheit und Erforderlichkeit auch die Prüfung der Angemessenheit: Die Maßnahme darf im Hinblick auf den verfolgten Zweck keinen unverhältnismäßigen, nicht tragbaren Eingriff darstellen. ${ }^{713}$

\section{(a) Kontrolldichte}

Der EGMR, dessen Rechtsprechung wegen der Grundlagen von Art. 8 GR-Charta grundsätzlich berücksichtigt werden muss, gesteht den Mitgliedstaaten bei der Verhältnismäßigkeitsprüfung im Allgemeinen einen relativ weiten Beurteilungsspielraum zu. Dieses Zugeständnis hängt ganz wesentlich damit zusammen, dass der Gerichtshof die unterschiedlichen Wertvorstellungen in den Konventionsstaaten nicht durchweg harmonisieren will. ${ }^{714}$ Auch bei der Prüfung der Verhältnismäßigkeit nach Art. 8 EMRK und hier bezüglich der Verarbeitung von Daten, die dem Schutz der nationalen Sicherheit dienen sollen, ist die Kontrolldichte häufig reduziert. ${ }^{715}$

\footnotetext{
${ }^{711}$ Vgl. Erb, in: Erb u.a., Löwe-Rosenberg-StPO, Fünfter Band, § 163 e, Rn. 14 sowie Zöller, in: Julius u.a., StPO, § 163 e, Rn. 4.

${ }^{712}$ BVerfGE 59, 360 (386 f.); BVerfGE 70, 134 (136 f.).

${ }^{713}$ EuGH, Slg. 1992, I-35, Rn. 16; Slg. 1995, I-3115, Rn. 55; Slg. 2003, I-5659, Rn. 80 sowie Jarass, EUGrundrechte mit weiteren Nachweisen.

${ }^{714}$ Jarass, EU-Grundrechte, § 6, Rn. 52; Marauhn/Meljnik, in: Grote/Marauhn, EMRK/GG, Kap. 16, Rn. 25.

${ }^{715}$ Marauhn/Meljnik, in: Grote/Marauhn, EMRK/GG, Kap. 16, Rn. 92 mit Verweis auf EGMR A 116, § 59 - Leander; vgl. auch Meyer-Ladewig, EMRK, Art. 8 Rn. 43.
} 
Dem EuGH ist diese Überlegung ebenfalls nicht fremd. ${ }^{716}$ Im Verfahren zwischen Europäischem Parlament und Rat sowie Kommission der Europäischen Union zur Frage der Rechtmäßigkeit der Verarbeitung von Fluggastdatensätzen und deren Übermittlung durch die Fluggesellschaften an die Vereinigten Staaten von Amerika zum Zweck der Terrorismusbekämpfung spielten Fragen der Kontrolldichte auch eine Rolle. Zwar hatte der Gerichtshof letztlich nicht darüber zu entscheiden, weil die angegriffenen Maßnahmen bereits einer richtigen Rechtsgrundlage entbehrten. ${ }^{717}$ Gleichwohl befasst sich der Generalanwalt mit der Thematik in seinen Schlussanträgen. Er plädiert auch mit Blick auf die Rechtsprechung des EGMR dafür, Rat und Kommission einen weiten Beurteilungsspielraum zuzugestehen. Dafür würden Wesen und Bedeutung des Ziels der Terrorismusbekämpfung und der politisch sensible Kontext sprechen, in dem die Verhandlungen zwischen den Vereinigten Staaten und der Gemeinschaft stattgefunden hätten. Auf diese Weise würde der Gerichtshof es verhindern, dass er die Beurteilung der politischen Stellen zur Frage, welche Maßnahmen in Kampf gegen den Terrorismus und andere schwere Straftaten nach ihrem Wesen angemessen sind, durch seine eigene Beurteilung ersetzt. ${ }^{718}$ An dieser grundsätzlichen Haltung wird vielfach Kritik geübt. So könne die Reduktion der Kontrolldichte dazu führen, dass die Verhältnismäßigkeitsprüfung ins Leere geht, ${ }^{719}$ also im Grunde genommen keine Kontrollwirkung mehr habe. Diese Kritik erscheint berechtigt. Nach der oben dargelegten Auffassung wird die Verhältnismäßigkeitsprüfung deshalb nur kursorisch durchgeführt, weil die Judikative ansonsten in den Machtbereich der Exekutive bzw. Legislative eingreifen und eigentlich politische Entscheidungen an sich ziehen würde. Im Fall von Art. 8 GR-Charta wird bei dieser Auffassung aber übersehen, dass eine Überbetonung des Zieles der Kriminalitätsbekämpfung nicht nur politische Folgen hätte. In seinem Volkszählungsurteil hat das Bundesverfassungsgericht sehr deutlich aufgezeigt, dass das Art. 8 GR-Charta entsprechende innerstaatliche Recht auf informationelle Selbstbestimmung in engem Zusammenhang mit anderen Grundrechten steht, deren tatsächliche Ausübbarkeit für eine freiheitlich-demokratische Grundordnung unerlässlich ist. Dort heisst es: „Wer nicht mit hinreichender Sicherheit überschauen kann, welche ihn betreffende Informationen in bestimmten Bereichen seiner sozialen Umwelt bekannt sind, und wer das Wissen möglicher Kommunikationspartner nicht einigermaßen abzuschätzen vermag, kann in seiner Freiheit wesentlich gehemmt werden, aus eigener Selbstbestimmung zu planen oder zu entscheiden. Wer unsicher ist, ob abweichende Verhaltensweisen jederzeit notiert und als Infor-

\footnotetext{
${ }^{716}$ Ruffert, in: Ehlers, Europäische Grundrechte, § 16.3, Rn. 38 mit Verweis auf EuGH, Slg. 1989, 1991, Rn. 19 Leukhardt; Slg. 1994, I-4973, Rn. 89 ff - Deutschland/Rat (Bananen); Slg. 1994, I-5555, Rn. 21 - SMW Winzersekt.

${ }^{717}$ EuGH, Slg. 2006, I-4795 (4827 f., 4831 f.).

${ }^{718}$ EuGH, Slg. 2006, I-4724 ((4781 ff.), Schlussanträge des Generalanwaltes vom 22. November 2005.

${ }^{719}$ Ruffert, $\S 16.3$, Rn. 38 m.w.N. sowie Callies, $\S 16.4$, Rn. 50, beide in: Ehlers, Europäische Grundrechte.
} 
mation dauerhaft gespeichert, verwendet oder weiter gegeben werden, wird versuchen, nicht durch solche Verhaltensweisen aufzufallen. Wer damit rechnet, dass etwa die Teilnahme an einer Versammlung oder einer Bürgerinitiative behördlich registriert wird und dass ihm dadurch Risiken entstehen können, wird möglicherweise auf die Ausübung seiner entsprechenden Grundrechte (Art. 8,9 GG) verzichten. Dies würde aber nicht nur die individuellen Entfaltungschancen des Einzelnen beeinträchtigen, sondern auch das Gemeinwohl, weil Selbstbestimmung eine elementare Funktionsbedingung eines auf Handlungs- und Mitwirkungsfähigkeit seiner Bürger begründeten freiheitlichen demokratischen Gemeinwesens ist.“720 Das Bundesverfassungsgericht beschreibt hier mit anderen Worten die objektiv-rechtliche Seite des Grundrechtes. Diese Dimension ist auch für die europäischen Grundrechte anerkannt. ${ }^{721}$ Wird das Recht nach Art. 8 GRCharta zu sehr eingeschränkt, werden viele Menschen aus Unsicherheit und Misstrauen auch ihre Rechte nach Art. 11 GR-Charta auf freie Meinungsäußerung sowie nach Art. 12 GR-Charta auf Versammlungs- und Vereinigungsfreiheit nicht mehr ausüben. Ein solches Verhalten hätte erhebliche negative Auswirkungen auf die gesamte Gesellschaftsordnung. Insofern handelt es sich bei der Frage, ob die oben festgestellten Eingriffe in Art. 8 GR-Charta verhältnismäßig sind, nicht in erster Linie um eine politische, sondern vor allen Dingen um eine durch das Gericht zu beantwortende Frage.

Wie bereits festgestellt wurde, verlangt das BVerfG zudem einen europäischen Grundrechtsschutz, der „nach Konzeption, Inhalt und Wirkungsweise dem Grundrechtsstandard des Grundgesetzes im Wesentlichen gleichzuachten“ ist. Insofern darf sich die hier durchzuführende Angemessenheitsprüfung nicht darauf beschränken, grobe Fehler zu korrigieren. Vielmehr ist sie auf „klassische“ Weise, das heißt grundsätzlich ohne das Zugestehen weiter Beurteilungsspielräume für die Exekutive bzw. Legislative durchzuführen.

In die Waagschale geworfen wird demnach auf der einen Seite das Interesse an der Freiheit vor staatlichen Maßnahmen und auf der anderen Seite das Interesse an der Gewährleistung von Sicherheit durch den Staat. Um der Prüfung Struktur zu verleihen, soll sie in drei Abschnitte gegliedert werden. ${ }^{722}$ Im ersten Abschnitt wird danach zu fragen sein, ob die beiden gegeneinander abzuwägenden Rechtsgüter Freiheit und Sicherheit abstrakt rechtlich gleichrangig sind oder ob eines im Rang höher steht. Anschließend wird konkret zu prüfen sein, welche Individual- und Gemeinschaftsrechtsgüter betroffen sind und welche Gefahren ihnen drohen. Schließlich sind auf

\footnotetext{
${ }^{720}$ BVerfGE 65, 1 (43).

${ }^{721}$ Ehlers, in: Ehlers, Europäische Grundrechte, § 14, Rn. 39; Albers, Informationelle Selbstbestimmung, S. 304.

${ }^{722}$ Diese Struktur orientiert sich an den Ausführungen von Stubenrauch, Gemeinsame Verbunddateien, S. 170 ff., 202.
} 
einer weiteren Ebene die objektiv-rechtlichen Belange gegeneinander abzuwägen. Hier ist den kollektiven Sicherheitsinteressen der objektiv-rechtliche Gehalt des betroffenen Grundrechts gegenüber zu stellen und nach den Auswirkungen der Eingriffsmaßnahme auf die Allgemeinheit zu fragen.

\section{(b) Sicherheit und Freiheit}

\section{(aa) Staatstheoretische Erwägungen}

Wenn man im Wege einer Vorüberlegung versucht, die beiden Begriffe zueinander ins Verhältnis zu setzen, kommt man zu der Erkenntnis, dass Freiheit Sicherheit voraussetzt. Denn wer um sein Leben, seine Gesundheit, sein Eigentum fürchten muss, hat weder den Mut noch die Zeit noch die Kraft, Freiheit zu leben. ${ }^{723}$ Diesen Gedanken griff der englische Philosoph Thomas Hobbes Mitte des 17. Jahrhunderts auf. Nach seiner Idee befinden sich die Menschen in einem Naturzustand, in dem es weder rechtliche Ordnung noch Grenzen der Freiheit des einzelnen gibt, in der also jeder tun und lassen kann, was er will, in einem Krieg aller gegen alle. Diesen $\mathrm{Zu}-$ stand kann nur der souveräne Staat beenden, dem die Bürger das Gewaltmonopol übertragen. Sie schulden ihm Gewaltverzicht und Gehorsam und werden als Gegenleistung durch den Staat vor Übergriffen Dritter geschützt. ${ }^{724}$ Auf diese Weise werden bei den einzelnen Bürgern die Kräfte und das Vertrauen frei, um sich gesellschaftlich und ökonomisch nach ihren Wünschen und Fähigkeiten zu betätigen. Insofern ist erster Entstehungs- und Legitimationsgrund des Staates die Gewährleistung der Sicherheit seiner Bürger. ${ }^{725}$ Aus diesem Zusammenhang könnte man schlussfolgern, dass ein Mehr an Sicherheit immer auch ein Mehr an Freiheit bedeutet. ${ }^{726}$ Dabei ließe man jedoch außer Betracht, dass die Machtbündelung bei der Institution Staat auch zur Bedrohung für die Menschen werden kann. ${ }^{727}$ Insofern bedeutet ein Mehr an Sicherheit zugleich eine Einbuße an Freiheit, wenn mit dem Ziel der Gewährleistung der Sicherheit Freiheitsrechte beschnitten werden. Führt dieses Beschneiden von Freiheitsrechten dazu, dass sie gar nicht mehr ausgeübt werden können, hat der Staat, da Sicherheit wie oben erläutert kein Selbstzweck ist, seine Legitimation verloren. Zudem haben auch nur freie Bürger die Freiheit, für ihren Staat aus Überzeugung einzutreten. Eingeschüchterte, ängstliche Menschen werden ihn vor neuen Gefahren von innen oder außen über längere Sicht nicht verteidigen wollen oder können, wie bei-

\footnotetext{
${ }^{723}$ Rupprecht/Hellenthal, in: Rupprecht/Hellenthal, Innere Sicherheit, S. $23(33,51)$.

${ }^{724}$ Hobbes, Leviathan, 13., 17. und 18 Kapitel; ders., Vom Bürger, Kapitel 6, 3.

${ }^{725}$ Isensee, in: Isensee/Kirchhof, HandbStR, Band I, § 13, Rn 102; Rupprecht/Hellenthal, in: Rupprecht/Hellenthal, Innere Sicherheit, S. 23 (53).

${ }^{726}$ So die Verfassungsrichterin Haas in einer abweichenden Meinung, BVerfGE 115, 320 (374).

${ }^{727}$ Stubenrauch, Gemeinsame Verbunddateien, S. 177.
} 
spielsweise der Zusammenbruch der DDR eindrücklich gezeigt hat. Insofern schützen freie Bürger den Fortbestand des Staates und damit wiederum die Sicherheit, die er gewährleistet.

Man kann also sagen, dass es ohne Sicherheit keine Freiheit gibt, aber ohne Freiheit auf längere Sicht auch keine Sicherheit. ${ }^{728}$ Diese grundsätzlichen staatstheoretischen Überlegungen ${ }^{729}$ legen nahe, dass die beiden Rechtsgüter nicht in einem Rangverhältnis der Über- oder Unterordnung zueinander stehen. ${ }^{730}$

\section{(bb) Festlegungen im europäischen Primärrecht}

Diese Annahme soll anhand der europäischen primärrechtlichen Bestimmungen geprüft werden. Die Begriffe Freiheit und Sicherheit finden im EUV, AEUV und in der GR-Charta Erwähnung.

Art. 3 Abs. 2 EUV sowie Art. 67 Abs. 1 AEUV sprechen von einem Raum u.a. der Freiheit und der Sicherheit. Über das Verhältnis der beiden zueinander treffen die Vertragstexte keine Aussage. Die Tatsache, dass sie in den Verträgen textlich gleichrangig verankert sind, führt jedoch zu der Annahme, dass keinem der beiden Werte ein grundsätzlicher Vorrang zukommt.

Nach Art. 6 GR-Charta hat jeder Mensch das Recht auf Freiheit und Sicherheit. Der weite Wortlaut lässt an eine Gewährleistung in einem generellen Sinn denken. Im Hinblick auf die Sicherheit vertritt Tettinger die Auffassung, dass die Mitgliedstaaten im Sinne eines status positivus allgemein dafür Sorge tragen müssen, dass die Bürger einander nicht schädigen. Diese Verpflichtung ergäbe sich aus den Vertragszielen nach dem EUV und dem AEUV in Verbindung mit dem Grundrecht aus Art. 6 GR-Charta gerade auch im Hinblick auf die im letzten Jahrzehnt gestiegene terroristische Anschlagsgefahr. ${ }^{731}$ Nach Auffassung anderer Kommentatoren lässt Art. 6 GR-Charta sowohl im Hinblick auf die Freiheit wie auf die Sicherheit nur eine enge Auslegung zu. Wie auch Tettinger ${ }^{732}$ gehen sie bezüglich des Begriffs der „Freiheit“ davon aus, dass Art. 6 GR-Charta in Anlehnung an die Rechtsprechung des EGMR lediglich die körperliche Bewegungsfreiheit meint. Über den Begriff der Sicherheit würde aber nur die Integrität des Betroffenen in hoheitlichem Gewahrsam geschützt. ${ }^{733}$ Folgte man der zuerst genannten Ansicht, ließen sich aus Art. 6 GR-Charta möglicherweise Anhaltspunkte für ein größeres Gewicht der Sicherheit gegenüber der Freiheit ableiten. Für die andere Auffassung spricht jedoch zum einen der

\footnotetext{
${ }^{728}$ Im Ergebnis so auch Denninger, Prävention und Freiheit, S. 16.

${ }^{729}$ Sicher ließe sich an dieser Stelle sehr viel mehr ausführen, im Rahmen dieser Arbeit soll es jedoch mit Blick auf den konkreten Untersuchungsgegenstand bei den erwähnten grundsätzlichen Erwägungen bleiben.

${ }^{730}$ So im Ergebnis Schwetzel, Freiheit, Sicherheit, Terror, S. 7.

${ }^{731}$ Tettinger, in: Tettinger/Stern, Kölner Gemeinschaftskommentar, Art. 6, Rn. 21 ff.

${ }^{732}$ Tettinger, in: Tettinger/Stern, Kölner Gemeinschaftskommentar, Art. 6, Rn. 12.

${ }^{733}$ Schorkopf, in: Ehlers, Europäische Grundrechte, § 16.1, Rn. 5 f.; Bernsdorff, in: Meyer, GR-Charta, Art. 6, Rn. 12; Jarass, EU-Grundrechte, $\S 11$, Rn. 6.
} 
enge Bezug zur EMRK, den das Präsidium in den Erläuterungen zu Art. 6 GR-Charta ausdrücklich erwähnt. ${ }^{734}$ Weder EMRK noch EGMR haben bisher mit der notwendigen Klarheit festgestellt, dass der Art. 6 GR-Charta entsprechende Art. 5 Abs. 1 S. 1 EMRK über ein bloßes Eingriffsverbot hinausgeht und die Staaten zusätzlich positiv verpflichtet, die Sicherheit des Einzelnen durch konkrete Maßnahmen zu gewährleisten. ${ }^{735}$ Hinzu tritt eine systematische Überlegung: Es wäre schwer nachvollziehbar, warum innerhalb einer einheitlichen Grundrechtsverbürgung, die unstreitig zwei Seiten der gleichen Medaille beschreibt, ${ }^{736}$ in Bezug auf die Freiheit von allen Kommentatoren lediglich eine sehr enges Verständnis zugrunde gelegt wird, in Bezug auf die Sicherheit aber ein genereller Ansatzpunkt gelten soll. Bei systematischer Stringenz müsste man bei der Verankerung innerhalb eines Grundrechtes auch der Freiheitsgewährleistung eine umfassende Bedeutung zusprechen. Diese Auffassung vertritt Tettinger aber, wie bereits erwähnt, nicht. Insofern ist der zweiten Auffassung, die eine enge Auslegung vertritt, beizupflichten.

Art. 6 GR-Charta liefert damit keine weitergehende Erkenntnisse über das Verhältnis von Freiheit und Sicherheit im hier untersuchten Sinn.

\section{(cc) Zwischenergebnis}

Zusammenfassend wird also festgestellt, dass beide Werte als gleichberechtigt einzustufen sind und ein abstrakter Vorrang unter staatstheoretischen oder europäischen primärrechtlichen Gesichtspunkten nicht besteht. ${ }^{737}$

\section{(c) Individual- und Gemeinschaftsrechtsgüter und konkrete Gefahren}

Zur Lösung hinführen kann nur eine differenzierte Verhältnismäßigkeitsprüfung. Die Beurteilung der Angemessenheit im engeren Sinn soll deshalb unter Rückgriff auf die von Stubenrauch in ihrer Arbeit verwendeten detaillierten Kriterien erfolgen. ${ }^{738}$

\section{(aa) Gewicht und Rang der kollidierenden Rechtsgüter}

Zweck der Ausschreibung ist - zusammengefasst - die Aufklärung außergewöhnlich schwerer Straftaten, ${ }^{739}$ die wiederum zum Funktionieren der Strafrechtspflege beiträgt. Eine funktionieren-

\footnotetext{
${ }^{734}$ Abgedruckt bei Beck, Europäischer Unionsvertrag, 6. A., Stand: Mai 2008, Teil A, 5, vgl. hier Erläuterung zu Art. 6 GR-Charta.

${ }^{735}$ Peukert, in: Frowein/Peukert, EMRK, Art. 5, Rn. 3 mit Verweis auf die einschlägige Rechtsprechung; Bernsdorff, in: Meyer, GR-Charta, Art. 6, Rn. 12.

${ }^{736}$ Tettinger, in: Tettinger/Stern, Kölner Gemeinschaftskommentar, Art. 6, Rn. 25.

${ }^{737} \mathrm{Vgl}$. mit gleichem Ergebnis zur deutschen Rechtslage: Stubenrauch, Gemeinsame Verbunddateien, S. 196.

${ }^{738}$ Stubenrauch, Gemeinsame Verbunddateien, S. 205 ff.; vgl. zu einigen der Kriterien im Rahmen der Verhältnismäßigkeit auch Kingreen, in: Callies/Ruffert, EUV/AEUV, Art. 8 GRCh, Rn 15, 16.
} 
de Strafrechtspflege kommt den anerkannten Strafrechtszwecken der Strafe zur Vergeltung und

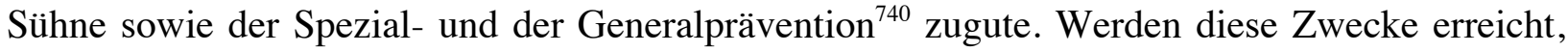
dient das dem Schutz der durch die Straftaten bedrohten Rechtsgüter wie Leben, Gesundheit und Eigentum der Bürger. Diese Rechte haben einen hohen Rang und sind nach Art. 2, 3 und 17 GRCharta verbürgt.

Auf der anderen Seite steht das Recht des Ausgeschriebenen und der Begleitpersonen auf den Schutz ihrer personenbezogenen Daten. Auch dieses Recht ist auf europäischer Ebene grundrechtlich verbürgt. Möchte man festlegen, welchem Rechtsgut mehr Bedeutung beizumessen ist, steht dahinter wieder die Frage, ob letztlich der Sicherheit oder der Freiheit der Vorrang gebührt. Der untrennbare Zusammenhang zwischen Freiheit und Sicherheit wurde jedoch bereits dargelegt, so dass dieses Kriterium der Güterabwägung nicht zum Absinken der Waage in die eine oder die andere Richtung führt.

\section{(bb) Eingriffsintensität}

Weiterhin ist die Eingriffsintensität zu bestimmen. Zu berücksichtigen sind hier die

- Zahl der einzelnen Informationsakte,

- die Art der verarbeiteten Daten,

- die Art und Weise des Informationseingriffs,

- die Anzahl und Art der mit den Daten befassten staatlichen Stellen sowie

- die Wirkungen und Folgen des Eingriffs.

Zur Zahl der Eingriffe ist festzustellen, dass eine Kumulation die Eingriffsintensität noch einmal erhöht. Zu differenzieren ist hier zwischen den ausgeschriebenen Personen und den Begleitpersonen. Die ausgeschriebenen Personen sind von insgesamt acht Eingriffen betroffen, während die Begleitpersonen Eingriffe nicht schon durch die Ausschreibung hinnehmen müssen; bei ihnen lassen sich vier Eingriffe feststellen, nämlich die Erhebung ihrer Daten, die Übermittlung an die Sirene, die Übermittlung der Daten von der Sirene an die anfragende Stelle sowie die Speicherung bei dieser Stelle. ${ }^{741}$

\footnotetext{
${ }^{739}$ Ausführlicher zum Zweck siehe oben in diesem Teil der Arbeit, B. IV. 2. b. aa.

${ }^{740}$ Roxin, Strafrecht AT, Band I, § 3, Rn. 1 ff., 35 ff.; Wessels/Beulke, Strafrecht AT, Rn. 12 a.

${ }^{741}$ Bei Sachverhalten mit Auslandsbezug ist regelmäßig eine weitere Sirene eingebunden, was zu einem weiteren Eingriff führt.
} 
Die Art der verarbeiteten Daten kann die Eingriffsintensität erhöhen, wenn sie für die Persönlichkeit des Betroffenen eine hohe Relevanz haben, etwa wenn er ein besonderes Interesse an der Vertraulichkeit der Information besitzt. Wie bei der Bestimmung des Wesensgehaltes bereits festgestellt wurde, ${ }^{742}$ haben die Daten sowohl in Bezug auf den Betroffenen als auch in Bezug auf Begleitpersonen keine besonders hohe Sensibilität im dargelegten Sinn.

Zur Art und Weise des Informationseingriffs ist festzustellen, dass die Eingriffsintensität z.B. durch die Heimlichkeit der Maßnahme erhöht wird. ${ }^{743}$ Diese Wertung lässt sich auch Art. 8 Abs. 2 S. 1 GR-Charta entnehmen, der die Verarbeitung personenbezogener Daten nur nach Treu und Glauben erlaubt. Hinter dieser Formulierung steht die Annahme, dass jeder Bürger vom Staat ein transparentes und offenes Verhalten erwarten kann. Handelt der Staat dagegen geheim, entspricht dies grundsätzlich nicht den Grundsätzen von Treu und Glauben. ${ }^{744}$ Wenn man heimliches Tun des Staates nicht ganz verbieten möchte, liegt hierin aber jedenfalls ein Eingriff von besonderer Schwere. Das Kriterium der Heimlichkeit ist hier erfüllt, da sowohl die Ausschreibung als auch die Erhebung der Daten ohne Kenntnis der Betroffenen erfolgt. Zudem wirkt erschwerend, dass es sich nicht um eine einmalige, sondern um eine auf Dauer angelegte Maßnahme handelt. ${ }^{745}$

Je mehr staatliche Stellen Kenntnis von den personenbezogenen Daten des Betroffenen erhalten, desto höher ist die Eingriffsintensität. Erhöht wird sie auch, wenn Behörden aus ganz unterschiedlichen Bereichen auf die Daten zugreifen können, etwa Behörden aus dem Bereich der Leistungs- und der Eingriffsverwaltung. Mit den Daten typischerweise befasst sind die ermittelnden Stellen bei Polizei oder Staatsanwaltschaft, die Gerichte, die im nachfolgenden Verfahren zu urteilen haben, die Sirene(n) des betroffenen Staates bzw. der betroffenen Staaten sowie die Beamten, die vor Ort die Kontrolle durchführen. Dabei handelt es sich ausschließlich um Behörden der Eingriffsverwaltung, jedoch ist eine relativ hohe Zahl von Behörden involviert. Eingriffsmildernd wirkt aber, dass eine langfristige Speicherung der Daten, die vom kontrollierenden Beamten übermittelt werden, nur bei der ermittelnden Stelle und ggf. später durch das Gericht erfolgt.

\footnotetext{
${ }^{742}$ Dieser Teil der Arbeit, B. IV . 2. b. cc.

${ }^{743}$ Vgl. BVerfG, NJW 2006, S. 1939 (1944); vgl. auch Kingreen, in: Callies/Ruffert, EUV/AEUV, Art. 8 GRCh, Rn. 15 .

${ }^{744}$ Johlen, in: Tettinger/Stern, Kölner Gemeinschaftskommentar, Art. 8, Rn. 49.

${ }^{745}$ Gegenüber vergleichbaren Maßnahmen ist dies eine lange Dauer, vgl. Erb, in: Erb u.a., Löwe-Rosenberg-StPO, Fünfter Band, § 163 e, Rn. 39.
} 
Die Schwere des Eingriffs bemisst sich in besonderem Maße auch durch die Nachteile, die den Betroffenen aufgrund der Eingriffe drohen oder von ihnen nicht ohne Grund befürchtet werden. So kann die Übermittlung und Verwendung von Daten das Risiko begründen, Gegenstand staatlicher Ermittlungsmaßnahmen zu werden, das über das allgemeine Risiko hinausgeht, einem unberechtigten Verdacht ausgesetzt zu werden und unter Erklärungsdruck zu geraten. ${ }^{746} \mathrm{Zu}$ differenzieren ist hier zwischen den Daten der Ausschreibung und den Daten, die aufgrund der Kontrolle übermittelt werden. Für die Daten der Ausschreibung gibt es klare Befristungs- und Löschungsregeln. Für die Daten, die der ermittelnden Stelle zu Betroffenen und Begleitpersonen übermittelt werden, gilt das nicht. Sie können nach $§ 483$ Abs. 1 StPO im Rahmen des fraglichen Strafverfahrens gespeichert werden. Darüber hinaus können sie jedoch nach $\S 483$ Abs. 2 StPO auch für andere Strafverfahren genutzt werden. Akteneinsicht bzw. Abschriften aus den Akten erhalten nach den $\S \S 474$ Abs. 1, 477 Abs. 1 StPO zudem Gerichte, Staatsanwaltschaften und andere Justizbehörden, wenn das für Zwecke der Rechtspflege erforderlich ist. Trotz einer gewissen Verwendungseinschränkung in $\S 477$ Abs. 2 S. 2 StPO, die wegen des Erfordernisses einer außergewöhnlich schweren Straftat auch für die Daten gelten sollte, die aus einer verdeckten Registrierung stammen, bleibt die Möglichkeit, dass die fraglichen personenbezogenen Daten jedenfalls als Spurenansatz auch in Zukunft für die Aufklärung aller anderen Straftaten genutzt werden können. ${ }^{747}$ Hinzu kommt, dass Polizeibehörden, nach $\S 481$ Abs. 1 StPO nach Maßgabe der Polizeigesetze personenbezogene Daten aus Strafverfahren verwenden dürfen.

Selbst, wenn sich ein Verdacht nach einiger Zeit nicht als stichhaltig erweist, hatten auf die personenbezogenen Daten aus der verdeckten Registrierung zwischenzeitlich unterschiedliche Stellen Zugriff. Es kann also sein, dass die personenbezogenen Daten eines Betroffenen jahrelang als Spurenansatz in dem einen oder anderen Verfahren gespeichert werden, ohne dass es letztlich zu einer Verurteilung kommt. Wer also einmal von einer Strafverfolgungsbehörde in Zusammenhang mit einer außergewöhnlich schweren Straftat gebracht wurde, muss wegen der erläuterten Zugriffsmöglichkeiten damit rechnen, dass seine Daten jahrelang im Zusammenhang auch mit anderen Strafverfahren gespeichert werden. Insofern ist er einem höheren Risiko als die Allgemeinheit ausgesetzt, unberechtigt verdächtigt zu werden.

Zusammenfassend kann festgestellt werden, dass die Eingriffsintensität verstärkend die Heimlichkeit und die Dauer der Maßnahme sowie die langfristigen späteren Verwendungsmöglichkeiten bei den Strafverfolgungs- und Polizeibehörden wirken. Diese Einschätzung gilt auch für Begleitpersonen, da ja eben nicht nur die Ausschreibung an sich sondern ebenfalls die Erhebung

\footnotetext{
${ }^{746}$ Vgl. BVerfG NJW 2006, 1939 (1942) und BVerfG, NJW 2010, 833 (838); Stubenrauch, Gemeinsame Verbunddateien, S. 209.

${ }^{747}$ Zöller, StraFo 2008, 15 (24).
} 
geheim erfolgt. Zudem macht es die lange Dauer der Maßnahme wahrscheinlicher, als Begleitperson registriert zu werden und schließlich gelten für die Verwendungsmöglichkeiten der gemeldeten Daten hinsichtlich Ausgeschriebenen und Begleitpersonen die gleichen, oben dargelegten, Regeln. Insgesamt ist die Eingriffsintensität aus diesen Gründen als im mittleren bis hohen Bereich liegend zu bezeichnen.

\section{(cc) Gestaltung der Eingriffsschwellen}

In materieller Hinsicht sind hier die Voraussetzungen der Datenspeicherung und -verwendung relevant; zudem kommt es darauf an, welches Gewicht die verletzten Rechtsgüter haben und ob der einzelne Anlass für den Eingriff in seine Grundrechte gegeben hat.

Zunächst soll die Rechtslage bezüglich des zur Fahndung Ausgeschriebenen betrachtet werden:

Dem zur Fahndung Ausgeschriebenen kommt in materieller Hinsicht „zugute“, dass er unter Verdacht stehen muss, Straftaten von besonderer Qualität begangen zu haben. Straftaten von besonderer Qualität richten sich regelmäßig gegen Rechtsgüter von besonderer Bedeutung, also etwa das Leben, die Gesundheit und das Eigentum. Durch diese Bestimmung wird die Eingriffsschwelle maßgeblich erhöht. Gleiches gilt dafür, dass die Straftaten in erheblichem Umfang begangen werden müssen. Denn wenn jemand in diesem Sinne nicht nur einmal tätig geworden ist, sind die jeweiligen Rechtsgüter in einem sehr viel größeren Maße betroffen. Keine besonderen Anforderungen bestehen hinsichtlich des Verdachtsgrades; zureichende tatsächliche Anhaltspunkte reichen aus. Dennoch bedarf es einer gewissen Tatsachenbasis dafür, dass der Ausgeschriebene der Täter ist. Insofern besteht zum Zeitpunkt der Ausschreibung die Möglichkeit, dass er den Anlass für die Fahndung selbst gesetzt hat.

In formeller Hinsicht sind vor allem die bereits erwähnten organisatorischen und verfahrensrechtlichen Vorkehrungen bedeutsam. ${ }^{748}$ Hervorgehoben werden soll an dieser Stelle die Heimlichkeit der Maßnahme, die einem transparenten und fairen Verfahren grundsätzlich widerspricht. Zur Entschärfung tragen hier jedoch in einem gewissen Maße der Richtervorbehalt und die Benachrichtigungspflicht bei. Der Richtervorbehalt gewährleistet während des Zeitraums der Ausschreibung einen gewissen Ausgleich der Heimlichkeit der Maßnahme, ${ }^{749}$ während die Benachrichtigungspflicht dies nach Beendigung tut.

Zusammenfassend lässt sich die Eingriffschwelle in Bezug auf den Ausgeschriebenen also als hoch bezeichnen.

\footnotetext{
${ }^{748}$ Dieser Teil der Arbeit, B. IV. 2. b. bb.

749 Zöller, StraFo 2008, 15 (20); vgl. jedoch auch die Ausführungen von Zöller zur mangelhaften praktischen Umsetzung. Danach erfüllen die Ermittlungsrichter ihre Kontroll- und Dokumentationspflichten nur unzureichend, vgl. Zöller, StraFo 2008, 15 (20 f.).
} 
Hinsichtlich der Begleitpersonen kann ein solches Ergebnis nicht festgehalten werden. Da sie selbst nicht ausgeschrieben sind, kommen ihnen die relativ hohen Hürden, die die verdeckte Registrierung aufstellt, auch nicht zugute. Die einzige Tatsache, die sie in die Nähe der verfolgten Straftat rückt, ist ihre räumliche Nähe zum mutmaßlichen Täter im Zeitpunkt einer zufällig stattfindenden Kontrolle. Möglicherweise handelt es sich bei ihnen lediglich um zufällige Sitznachbarn im Zug oder um Nutzer einer Mitfahrgelegenheit. Selbst, wenn sich die Begleitperson nicht nur dieses eine Mal in der Nähe des Verdächtigen befindet, sondern es sich beispielsweise um die Ehefrau oder den Ehemann handelt, rückt sie damit nicht automatisch näher an die Rechtsgutsverletzung heran. Begleitpersonen haben anders ausgedrückt in materieller Hinsicht außer einem räumlichen keinen Anlass dafür gesetzt, mit der Gefährdung der o.g. Rechtsgüter in Verbindung gebracht zu werden. Eine inhaltliche Verbindung wird nicht gefordert.

Die Eingriffschwelle in Bezug auf Begleitpersonen ist folglich als niedrig zu bezeichnen.

\section{(dd) Grad der Geeignetheit bzw. Nutzen der Maßnahme}

Nachdem nun Eingriffsintensität und Eingriffsschwelle bestimmt sind, stellt sich im Rahmen der Abwägung auch die Frage, was eine solche Maßnahme - auch gerade im Rahmen der SchengenZusammenarbeit - für die angestrebten Zwecke bringt. Misslich wirkt es sich hier aus, dass über eine verdeckte Maßnahme regelmäßig nur wenige Daten und Zahlen bekannt sind. In den Schengen-Erfahrungsberichten werden die Zahlen zur verdeckten Registrierung nicht gesondert ausgewiesen. ${ }^{750}$ Eine ungefähre Größenordnung lässt sich jedoch der Arbeit von Piosek ${ }^{751}$ entnehmen, wonach in Deutschland aufgrund einer ausländischen Ausschreibung im Jahr 2003 in 446 Fällen verdeckt registriert wurde, während es im Ausland in der gleichen Zeit aufgrund einer deutschen Ausschreibung $236 \mathrm{Mal}$ dazu kam. ${ }^{752}$ Aus diesen Zahlen kann man zumindest schließen, dass die verdeckte Erhebung und Übermittlung von Daten aufgrund einer Ausschreibung nach Art. 99 SDÜ keine Seltenheit ist. Man weiss allerdings nicht, wie viele deutsche Ausschreibungen insgesamt vorlagen und wie häufig es bezogen auf diese Ausschreibungen zu einer zufälligen Kontrolle gekommen ist. Selbst wenn man diese Zahlen kennen würde und beispielsweise feststellen könnte, dass eine Ausschreibung nach Art. 99 SDÜ etwa in jedem zweiten Fall auch zur Übermittlung von Daten wegen eines Antreffens führt, ließe sich noch nicht bewerten, wie effektiv diese Maßnahme im Hinblick auf die Zwecke, nämlich Ermittlung des Sachverhaltes

\footnotetext{
750 Bundesministerium des Innern, vgl. Schengen-Erfahrungsbericht 2000, S. 43 ff.; dass., SchengenErfahrungsbericht 2003, S. 27 f.; dass., Schengen-Erfahrungsbericht 2004, S. 27 f.; dass., SchengenErfahrungsbericht $2005-2007$, S. 35 f.

${ }^{751}$ Piosek, S. 81.

${ }^{752}$ Im Jahr 2000 gab es 264 Treffer in Deutschland aufgrund einer ausländischen Ausschreibung und 192 Treffer im Ausland aufgrund einer deutschen Ausschreibung, Piosek, S. 81.
} 
und des Aufenthaltsort des Täters, Erstellung eines Bewegungsbildes und Erkennen krimineller Verbindungen und Strukturen, einzustufen ist. Da es bereits auf deutscher nationaler Ebene keine veröffentlichte systematische Untersuchung zu diesem Punkt gibt, ${ }^{753}$ kann auch eine Einschätzung bezüglich der Effektivität des Fahndungsinstrumentes auf der Schengen-Ebene nur abstrakt erfolgen.

Das große Manko der verdeckten Registrierung ist, wie bereits erwähnt, dass die Übermittlung von Daten vom Zufall abhängt. Die Möglichkeit der Erstellung eines Bewegungsbildes aufgrund der Daten aus der verdeckten Registrierung ist damit äußerst fraglich. Hinzu kommt, dass die Übermittlung der erbetenen Daten in vielen Fällen nicht unbedingt zur Zweckerfüllung beiträgt. Zwar ist es angesichts des Charakteristikums der Organisierten Kriminalität, in großen Netzwerken und damit häufig auch grenzüberschreitend tätig zu sein, sinnvoll, ein internationales, zumindest schengenweites Fahndungsinstrument einzusetzen. Diese abstrakte Eignung sagt aber eben noch nichts über den Grad der Eignung im Hinblick auf die Erreichung des angestrebten Zwecks aus. So kann die Meldung eines Grenzübertritts mit einem bestimmten PKW bei der Sachverhaltsermittlung im konkret laufenden Verfahren helfen. Sie kann aber auch gar nichts damit zu tun haben. Die Meldung von bestimmten Begleitpersonen kann einen entscheidenden Hinweis auf kriminelle Verbindungen liefern, deren Kenntnis die in engem Zusammenhang mit der zu ermittelnden Tat sogenannten Hintermänner überführt. Genauso gut kann es sich aber ausschließlich um unbeteiligte Dritte handeln. Etwas anderes ergibt sich auch nicht daraus, dass die übermittelten Daten bei der Ermittlung in künftigen Strafverfahren von Vorteil sein könnten. Das Instrument der verdeckten Registrierung ist auf eine Vorsorge für die künftige Strafverfolgung $^{754}$ nicht gerichtet. Vielmehr soll sie primär der Ermittlung eines konkreten bereits bestehenden Tatverdachtes und seiner Hintergründe dienen. Auch wenn die verdeckte Registrierung im Einzelfall dafür wertvolle Hinweise und Ermittlungsansätze liefern mag, bleibt eine Bewertung ihrer Effektivität im Ungefähren und ist aufgrund der oben angestellten Überlegungen insgesamt im unteren Bereich anzusiedeln.

\section{(ee) Gegenüberstellung und Abwägung}

Stellt man diese Einschätzung nun der oben ermittelten Eingriffsintensität und Eingriffsschwelle gegenüber, so ist bezüglich der ausgeschriebenen Person eine mittlere bis hohe Eingriffintensität anzunehmen, während die Eingriffschwelle als hoch anzusehen ist. Da also vor allem über die geforderte besondere Qualität der Straftaten sowie den Richtervorbehalt hohe Anforderungen für

\footnotetext{
${ }^{753}$ Petri, in: Lisken/Denninger, HandbPolR, H, Rn. 277.

${ }^{754}$ Zum Begriff: Zöller, Informationssysteme und Vorfeldmaßnahmen, S. 86 ff.
} 
eine Ausschreibung bestehen, fällt demgegenüber die bedingte Geeignetheit der Maßnahme nicht so sehr ins Gewicht. Insofern kann der Eingriff bezüglich der ausgeschriebenen Person noch als verhältnismäßig angesehen werden.

Für Begleitpersonen lässt sich feststellen, dass die verdeckte Registrierung eine mittlere bis hohe Eingriffsintensität und eine niedrige Eingriffsschwelle aufweist, während der Nutzen der Maßnahme als relativ gering anzusehen ist. Aus dieser Gegenüberstellung ergibt sich die Unangemessenheit in Bezug auf die Übermittlung der Daten von Begleitpersonen.

Möglicherweise kann eine grundrechtschartakonforme Auslegung dieses Ergebnis verhindern. Beispielsweise könnte man die strafprozessuale Variante der verdeckten Registrierung dahingehend interpretieren, dass der kontrollierende Beamte nur die Daten von Begleitpersonen übermitteln darf, die offenbar mit den Straftaten in Verbindung stehen, die Gegenstand der Ausschreibung sind. Dem kontrollierenden Beamten fehlen dafür jedoch die notwendigen Informationen, da er das konkrete Ermittlungsverfahren nicht kennt. Zudem muss er seine Fragen relativ allgemein halten, will er die Kontrollierten nicht stutzig machen und damit den verdeckten Charakter der Maßnahme gefährden. ${ }^{755}$ Insofern bleibt es bei der festgestellten Unverhältnismäßigkeit der Maßnahme in Bezug auf Begleitpersonen.

\section{(d) Kollektive Sicherheitsinteressen und objektiv-rechtlicher Gehalt des Grundrechts}

Nachdem eine konkrete Gegenüberstellung der betroffenen Rechtsgüter eine UnverhältnismäBigkeit im Hinblick auf die Übermittlung der Daten von Begleitpersonen ergeben hat, soll die Abwägung nun auf einer abstrakteren Ebene erfolgen. Nur bei Berücksichtigung ausdrücklich auch der objektiv-rechtlichen Dimension erscheint die Bedeutung des Grundrechtes zutreffend erfasst. Ziel ist deshalb die Feststellung, ob der beabsichtigte Schutz kollektiver Sicherheitsinteressen durch die verdeckte Registrierung im Hinblick auf den objektiv-rechtlichen Gehalt des Grundrechtes verhältnismäßig erscheint.

Offenbart sich dabei die Tendenz einer Verrechtlichung im Bereich der inneren Sicherheit, die den Einzelnen zwar im Hinblick auf die einzelnen Maßnahmen allein noch nicht übermäßig einschränkt, in ihrer Gesamtheit aber ein Klima der Überwachung erzeugt, kann sich gemäß dem objektiv-rechtlichen Gehalt der Freiheitsrechte die zu beurteilende Maßnahme als unverhältnismäßig erweisen. ${ }^{756}$

\footnotetext{
${ }^{755}$ Zöller weist im übrigen darauf hin, dass Versuche der verfassungskonformen restriktiven Auslegung zur faktischen Unanwendbarkeit des $\S 163$ e StPO führen, Zöller, in: Julius u.a., StPO, § 163 e, Rn. 9.

${ }^{756} \mathrm{Vgl}$. Stubenrauch, Gemeinsame Verbunddateien, S. 202.
} 


\section{(aa) Kollektive Sicherheitsinteressen}

Daran, dass der Staat bzw. die europäische Staatengemeinschaft die kollektiven Sicherheitsinteressen schützen soll, besteht kein Zweifel. Ebenso selbstverständlich erscheint es, dass man ihm bzw. ihr zur Erfüllung dieser Aufgabe die geeigneten und notwendigen Mittel an die Hand geben sollte. ${ }^{757}$ Welche Mittel das sind, hängt von der konkreten Art der Bedrohung ab. Die Art der Bedrohung kann nicht einmal und damit dauerhaft festgestellt werden. Vielmehr befinden sich auch die Erscheinungsformen von Kriminalität in einem dauernden Prozess der Veränderung. ${ }^{758}$ So wirkt es sich u.a. aus, dass neue Errungenschaften wie Computer, Internet, Handys, moderne Waffen sowie internationale Beweglichkeit mit Hilfe schnellster Transportmittel nicht nur die legal agierenden Teile der Gesellschaft nutzen, sondern auch die illegal agierenden. ${ }^{759}$ Nach einer relativ aktuellen Darstellung ${ }^{760}$ der internationalen Erscheinungsformen von Kriminalität und Gewalt bestehen alte und neue Gefahren durch den internationalen Terrorismus, die Organisierte Kriminalität sowie unterschiedliche Formen der Informations- und Kommunikationskrimininalität, sogenannte IuK-Kriminalität. Der internationale Terrorismus gewinnt durch das Handeln religiös motivierter Täter eine neue Dimension der Gefährlichkeit, die sich u.a. daraus ergibt, dass die Attentäter bereit sind oder sogar danach streben, ihr Leben für die Ausführung eines Anschlages zu opfern. ${ }^{761}$ Zudem gibt es in einigen Ländern strukturelle Verbindungen zwischen Terrorismus und Organisierter Kriminalität. Beispielsweise finanzieren sich in Afghanistan Kämpfer der Taliban hauptsächlich durch Drogenhandel. Deutschland und Europa spielen bei dieser Frage insofern keine unerhebliche Rolle, als sie Transit- und Zielland für Heroin und Kokain sind. ${ }^{762}$ Die IuK-Kriminalität umfasst die Bedrohung von IT-Systemen durch Computerviren und Würmer. Zudem bietet das Internet die Möglichkeit, es in großem Umfang illegal zu nutzen, z.B. als Propaganda-Instrument für politisch motivierte Straftaten aus dem rechtsextremistischen und terroristischen Bereich, zur Verbreitung von kinderpornographischem Material, zum Handel mit gefälschten Medikamenten, für Wirtschafts- und Konkurrenzspionage sowie zum Angriff auf kritische Infrastrukturen, die die Versorgung mit Energie, Wasser, Kommunikation, Mobilität sowie das Finanz-, Geld- und Versicherungswesen betreffen. ${ }^{763}$

Die erwähnten unterschiedlichen Kriminalitätsphänomene weisen Gemeinsamkeiten auf: So besteht regelmäßig eine internationale netzwerkartige Verflechtung der Tatbegehung, wobei diese in Teilbereichen stark durch technisches und sonstiges Spezialwissen charakterisiert ist. Zudem

\footnotetext{
${ }^{757}$ Middel, Innere Sicherheit, S. 370.

${ }^{758}$ Ziercke, KR 2005, 700 (700).

${ }^{759}$ Kühne, Bürgerfreiheit, S. 10.

${ }^{760}$ Ziercke, KR 2005, $700 \mathrm{ff}$.

${ }^{761}$ Middel, Innere Sicherheit, S. 360; Limbach, AnwB1. 2002, 454 (454).

${ }^{762}$ Ziercke, KR 2005, 700 (701).

${ }^{763}$ Ziercke, KR 2005, 700 (701 f.).
} 
haben die Phänomene ein enormes Schadens- und Bedrohungspotenzial, was allein ein Blick auf die Anzahl der Personen- und Sachopfer durch terroristische Akte zeigt. ${ }^{764}$

Um diesen Bedrohungen auch mit strafrechtlichen Mitteln zu begegnen, haben die Sicherheitsbehörden auf deutscher, europäischer und internationaler Ebene nach und nach neue Befugnisse erhalten. Zu nennen sind an dieser Stelle für den nationalen Bereich insbesondere das Gesetz zur Bekämpfung der Organisierten Kriminalität von 1992, mit dem in den $\S \S 98$ a und b StPO die strafprozessuale Rasterfahndung und mit $§ 163$ e StPO die Polizeiliche Beobachtung kodifiziert wird, ${ }^{765}$ das Verbrechensbekämpfungsgesetz von 1994, das die Zulässigkeit der Übermittlung nachrichtendienstlicher Abhörerkenntnisse an die Strafverfolgungsbehörden erlaubt; ${ }^{766}$ das Gesetz zur Verbesserung der Bekämpfung der organisierten Kriminalität von $1998,{ }^{767}$ das die akustische Wohnraumüberwachung einführt; ${ }^{768}$ das Terrorismusbekämpfungsgesetz von 2001, das die Befugnisse des BKA im Bereich der Strafverfolgung erweitert; ${ }^{769}$ das Gesetz zur Änderung der Strafprozessordnung aus 2002, das mit dem neuen $§ 100$ i StPO den Einsatz eines Peilgerätes zur Ermittlung eines Handy-Standortes erlaubt; ${ }^{770}$ das Vierundreißigste Strafrechtsänderungsgesetz aus 2002, mit dem $\S 129$ b StGB eingeführt wird; ${ }^{771}$ das Gemeinsame Dateien-Gesetz aus 2006, das die Einrichtung der sogenannten Antiterrordatei ermöglicht: ${ }^{772}$ das Terrorismusbekämpfungsergänzungsgesetz von 2007, das u.a. die Geltung des durch das Terrorismusbekämpfungsgesetz aus 2002 eingeführten $\S 7$ Abs. 2 BKAG fortschreibt ${ }^{773}$ und das Gesetz zur Verfolgung der Vorbereitung von schweren staatsgefährdenden Gewalttaten von 2009, mit dem die $\S \S$ 89 a, 89 b, 91 und 91 a StGB sowie entsprechende Änderungen in der Strafprozessordnung eingefügt werden. ${ }^{774}$

Für die europäische Ebene seien hier beispielhaft die EG-Passverordnung aus 2004, die Richtlinie zu Vorratsdatenspeicherung von 2006 und der Europol-Beschluss aus 2009 genannt. Erstere bestimmt u.a die obligatorische Aufnahme biometrischer Daten in Pässe und Reisedokumente, ${ }^{775}$ die genannte Richtlinie verpflichtet die Mitgliedstaaten zu Maßnahmen, die die Vorratsdaten-

\footnotetext{
${ }^{764}$ Ziercke, KR 2005, 700 (702).

${ }^{765}$ Art. 3 Gesetz vom 15. Juli 1992, BGB1. 1992, 1302.

${ }^{766}$ Art. 13 Gesetz vom 28. Oktober 1994, BGB1. 1994, 3186; vgl. hierzu jedoch auch das Urteil des BVerfG vom 14. Juli 1999, BVerGE 100, 313; eine das Urteil berücksichtigende Übermittlungsregelung findet sich nunmehr in $\S 7$ Abs. 4 S. 2 Gesetz zur Beschränkung des Brief-, Post- und Fernmeldegeheimnisses.

${ }^{767}$ BGB1. 1998, 845 .

${ }^{768} \S 100$ c Abs. 1 Nr. 3 StPO, Art. 2 Gesetz vom 4. Mai 1998, BGB1. 1998, 845.

${ }^{769}$ Art. 10 Gesetz vom 9. Januar 2002, BGB1. 2002, 361.

${ }^{770}$ Art. 1 Gesetz vom 6. August 2002, BGB1. 2002, 3018.

${ }^{771}$ Art. 1 Gesetz vom 22. August 2002, BGB1. 2002, 3390.

${ }^{772}$ Art. 1 Gesetz vom 22. Dezember 2006, BGB1. 2006, 3409.

${ }^{773}$ vgl. Art. 11 Gesetz vom 5. Januar 2007, BGB1. 2007, 2.

${ }^{774}$ Art. 1 und 3 Gesetz vom 30. Juli 2009, BGB1. 2009, 2437.

${ }^{775}$ Art. 1 VO (EG) Nr. 2252/2004 des Rates vom 13. Dezember 2004; AB1. L 385, 1.
} 
speicherung von Telefon- und Internetverbindungsdaten vorsehen, ${ }^{776}$ und schließlich erweitert die zuletzt genannte Maßnahme das grundsätzliche Aufgabenfeld von Europol und ermöglicht u.a. die Einrichtung gemeinsamer Ermittlungsgruppen. ${ }^{777}$

Für die Vereinigten Staaten von Amerika und den Geist der in diesem Teil der Welt angenommenen Haltung zum Schutz kollektiver Sicherheitsinteressen sei an dieser Stelle nur Bezug genommen auf den sogenannten USA PATRIOT Act vom 26. Oktober 2001, der umfangreiche neue bzw. erweiterte Befugnisse von Polizei und Geheimdiensten als Reaktion auf den 11. September 2001 vorsah. ${ }^{778}$

Zusammenfassend wurden mit den erwähnten Maßnahmen zusätzliche heimliche Ermittlungsbefugnisse und erweiterte Möglichkeiten zum Datenaustausch geschaffen. In diese Richtung zielt auch eine Forderung von BKA-Präsident Ziercke im Rahmen der oben erwähnten Darstellung, wenn er neue Behörden im Sicherheitsbereich ablehnt und stattdessen eine überzeugende Konzeption für systematisierte Kommunikation und Kooperation fordert. ${ }^{779}$

\section{(bb) Objektiv-rechtlicher Gehalt des Grundrechts}

Den kollektiven Sicherheitsinteressen steht der objektiv-rechtliche Gehalt des Grundrechts auf den Schutz personenbezogener Daten gegenüber. Bisher wurde seine Bedeutung in der Kommentarliteratur zu Art. 8 GR-Charta nicht näher beleuchtet. In den entsprechenden Entscheidungen des EGMR und des EuGH bestand zu umfangreicheren Ausführungen schon deshalb kein Anlass, weil die Prüfung der Verhältnismäßigkeit dem Grundrechtsadressaten regelmäßig einen großen Beurteilungsspielraum zugesteht. Angesichts der grundsätzlich anerkannten Funktion der Unionsgrundrechte als Elemente objektiver Ordnung kann für Art. 8 GR-Charta jedoch an dieser Stelle im Wesentlichen auf die vom BVerfG herausgearbeiteten Grundsätze zurückgegriffen werden. Danach ist zu berücksichtigen, dass das Grundrecht nicht nur der individuellen Freiheitssicherung dient, sondern über seine objektive Komponente auch der Stabilisierung einer Gesellschaftsordnung. Eine demokratische politische Kultur lebt von der Meinungsfreude und dem Engagement der furchtlosen Bürger. Diese Furchtlosigkeit droht verloren zu gehen, wenn

\footnotetext{
${ }^{776}$ Art. 3 und Art. 5 RL 2006/24/EG vom 15. März 2006, ABl. L 105, 54.

${ }^{777}$ Nach Art. 4 Abs. 1 Beschluss 2009/371/JI des Rates vom 6. April 2009, AB1. L 121, 37, verlangt ein Tätigwerden von Europol nicht mehr, dass tatsächliche Anhaltspunkte für eine kriminelle Organisationsstruktur vorliegen; zu den gemeinsamen Ermittlungsgruppen vgl. Art. 6 des Beschlusses.

${ }^{778}$ USA PATRIOT Act steht für „Uniting and Strengthening America by Providing Appropriate Tools Required to Intercept and Obtruct Terrorism“, Karg, Mehr Sicherheit, S. 21 f.

${ }^{779}$ Ziercke, KR 2005, 700 (707).
} 
die Bürger in dem Gefühl leben, dass staatliche Stellen jede ihrer Handlungen erfassen und auswerten können. ${ }^{780}$

\section{(cc) Abwägung}

Bei der folgenden Abwägung sollen auch Überlegungen einbezogen werden, die einen „Blick über den Tellerrand“" werfen, die also das Umfeld der Sicherheitsdebatte beleuchten und andere systematische Ansätze für den Schutz kollektiver Sicherheit wählen. Nur eine solche umfassende Betrachtung wird der komplexen Thematik gerecht. Berücksichtigt werden sollen insbesondere folgende Aspekte:

Welche Rolle spielen das aktuelle politische Klima und das Gefühl von Angst bei der Frage, welche Maßnahmen zur Gewährleistung von Sicherheit als angemessen angesehen werden? Wenn sie eine Rolle spielen, wie wirkt sich das rechtlich aus?

Wie hoch ist der Nutzen der fraglichen Maßnahme? Gibt es auch andere Ansätze im Bereich der Strafverfolgung und wie überzeugend erscheinen sie? Was sind die wahrscheinlichen Ursachen für Terrorismus und was lässt sich daraus schlussfolgern?

Welche Blickrichtung wird bei der Prüfung der Angemessenheit von Eingriffsbefugnissen typischerweise eingenommen und inwiefern antizipiert diese Blickrichtung ein bestimmtes Ergebnis?

\section{(aaa) Politisches Klima und Angstgefühl}

Verfolgt man die politische Diskussion zu Sicherheitsfragen, so entsteht zunächst der Eindruck, dass die zuständigen Politiker ihre Forderungen ausschließlich von objektiv nachvollziehbaren Notwendigkeiten abhängig machen. Ein Blick in die vergangenen Jahrzehnte - deutscher - Sicherheitspolitik legt jedoch die Annahme nahe, dass ein weicher Faktor wie das jeweilige politische Klima durchaus eine wichtige Rolle spielt. So verkraftete die (rechts-)politische Diskussion in der frühen Nachkriegsgeschichte die Einführung der expliziten Belehrungspflicht des Beschuldigten über sein Schweigerecht im Jahr 1964, obwohl es die Polizei als „Verbrecherschutzgesetz“ bezeichnete. Der Terrorismus der RAF dagegen führte zu einer ersten Welle der Verschärfung strafprozessualer Zwangsmaßnahmen ${ }^{781}$ und ab der zweiten Hälfte der 80er Jahre war die Bekämpfung der Organisierten Kriminalität die Legitimation für weitere Grundrechtsein-

\footnotetext{
${ }^{780}$ Vgl. BVerfGE 65, 1 (43); vgl. Limbach, AnwB1. 2002, 454 (457); vgl. Schoch, JURA 2008, 352 (356); Bölsche, Überwachungsstaat, S. $13 \mathrm{ff}$.

${ }^{781}$ U.a. Beschränkung der Anzahl der Verteidiger auf drei, Art. 1 Nr. 5 a) Gesetz vom 20. Dezember 1974, BGB1. 1974, 3686; Kontaktsperreregelung, Art. 1 Gesetz vom 30. September 1977, BGB1. 1977, 1877; Trennscheibenregelung, Art. 1 Nr. 9 Gesetz vom 14. April 1978, BGB1. 1978, 497; vgl. zur Änderung des materiellen Strafrechts: $\S$ 129 a StGB, eingeführt durch Art. 1 Nr. 1 Gesetz vom 18. August 1976, BGB1. 1976, 2181.
} 
schränkungen. Schließlich führte der Anschlag vom 11. September $2001^{782}$ zu einer Erweiterung polizeilicher und strafprozessualer Eingriffsbefugnisse.

Bezüglich der Maßnahmen gegen den RAF-Terrorismus und die Organisierte Kriminalität fand eine nennenswerte politische Diskussion im Hinblick auf Sinn und Effizienz statt. Mit den Anschlägen vom 11. September $2001 \mathrm{kam}$ es jedoch zu einer Veränderung im politischen Klima. Wie bereits oben dargelegt, wurden in der Folge auf verschiedenen Ebenen zahlreiche Sicherheitsgesetze verabschiedet. Dabei war es in der politischen Diskussion oft ausreichend, die Notwendigkeit der neuen Maßnahmen schlicht zu behaupten. ${ }^{783} 784$

Das gesellschaftliche und politische Klima wird in nicht unerheblichem Maße davon bestimmt, wie groß die Angst der Bürger davor ist, Opfer der fraglichen Gefahr zu werden. Angst ist die natürliche Reaktion des Menschen auf Gefahren und schützt ihn davor, sich entsprechenden Risiken auszusetzen. Je weniger sich die Gefahr jedoch einschätzen lässt, desto diffuser erscheint die Angst und desto intensiver wird sie erlebt. ${ }^{785}$ Die Angst, einem Terroranschlag zum Opfer zu fallen, kann durchaus als diffus bezeichnet werden. Selbstmordattentäter können sich überall, im Kaufhaus, in der Bahn, im Restaurant, in die Luft sprengen. Ähnlich beklemmende Gefühle der Unsicherheit und Hilflosigkeit löst die Vorstellung aus, dass es einem Terroristen gelingt, weite Teile der Bevölkerung mit biologischen oder chemischen Kampfstoffe zu infizieren bzw. zu vergiften. Solche Ängste sind eine Ressource für die Politik und werden von ihr für entsprechende Gesetzesvorhaben auch und gerade im Sicherheitsbereich genutzt. ${ }^{786}$ Der Schweizer Sozialhistoriker Jakob Tanner bemerkt dazu: „Es gibt keine unschuldige Besorgnis über die Zustände in der Gesellschaft. Es sind immer Kräfte da, die Ängste bündeln, verstärken und in politische Anliegen transformieren. “787 Zunächst lässt sich also feststellen, dass bei der Entstehung eines Gesetzes nicht allein objektive sondern auch ,weiche“ Faktoren wie Gefühle und politisches Klima eine Rolle spielen. Für die rechtliche Beurteilung ist von Interesse, ob diese Faktoren zur Rechtfertigung einer Maßnahme beitragen können. Das politische Klima hat in diesem Zusammenhang für sich allein betrachtet keine Bedeutung; es spricht weder für noch gegen die RechtmäBigkeit, vielmehr ist es als ein Faktor, der die Gesetzgebungstätigkeit beeinflusst, hinzunehmen. Ist das politische Klima jedoch wie seit dem 11. September 2001 in einem bislang ungekannten Ausmaß von Angst geprägt, wird es zur Aufgabe der Rechtsprechung, genauer hinzusehen. Sie

\footnotetext{
${ }^{782}$ Und in seiner Folge die Anschläge von Madrid 2004 und London 2005.

${ }^{783}$ Kühne, Bürgerfreiheit, S. 8 f.; Stubenrauch, Gemeinsame Verbunddateien, S. 195 f.

${ }^{784}$ Ein weiteres Beispiel für die Relevanz des politischen Klimas ist die 1998 mit $§ 100$ c Abs. 1 Nr. StPO eingeführte Möglichkeit der akustischen Wohnraumüberwachung. Dabei handelt es sich um eine Maßnahme, die zu einem früheren Zeitpunkt undenkbar gewesen wäre, weil bis dahin derartige Maßnahmen als typisch für den Unrechtsstaat der damaligen DDR galten und damit in Westdeutschland tabu waren, vgl. Kühne, Bürgerfreiheit, S. 12.

${ }^{785}$ Schaaf, Frankfurter Allgemeine Sonntagszeitung Nr. 49 vom 6. Dezember 2009, S. 57.

${ }^{786}$ Schaaf, Frankfurter Allgemeine Sonntagszeitung Nr. 49 vom 6. Dezember 2009, S. 57.

${ }^{787}$ Nachweis bei Schaaf, Frankfurter Allgemeine Sonntagszeitung Nr. 49 vom 6. Dezember 2009, S. 57.
} 
hat festzustellen, ob das Maß der Angst nach dem aktuellen Kenntnisstand dem Grad der objektiven Gefahr entspricht. Ist das der Fall, wäre der Verweis auf den zu bekämpfenden Terrorismus ein sehr ernst zu nehmender Belang. Entspricht das Maß der Angst aller Wahrscheinlichkeit nach nicht der objektiven Gefahr, verliert auch der Belang „Terrorismusbekämpfung“ an Gewicht und kann jedenfalls nicht alle anderen Belange automatisch überwiegen. Wie in vielen anderen Bereichen spricht vieles dafür, dass der Grad der subjektiv empfundenen Angst deutlich höher ist als die wahrscheinliche objektive Gefahr. ${ }^{788}$ Typischerweise haben Menschen Angst vor den Risiken, die sie am wenigsten wahrscheinlich das Leben kosten. Man befürchtet, einem Terroranschlag zum Opfer zu fallen, obwohl es sehr viel wahrscheinlicher ist, als eines von 3000 Opfern jährlich am Passivrauchen zu sterben oder bei einem Autounfall ums Leben zu kommen. ${ }^{789}$ Bei dieser Sichtweise kann die Gefahr eines Anschlags bzw. unter strafprozessualen Gesichtspunkten die Gefahr, die Täter eines (versuchten) Anschlags nicht dingfest machen zu können, demnach nicht pauschal als Grund für die Angemessenheit entsprechender Befugnisse der Sicherheitsbehörden angeführt werden..$^{790}$

\section{(bbb) Nutzen der Maßnahme}

Bei der Abwägung muss auch der Grad der Geeignetheit von Maßnahmen geprüft werden, da das bloße Erzeugen von Scheinsicherheit nicht zur Rechtfertigung von Eingriffen im Rahmen einer Rechtsprüfung dienen kann. ${ }^{791}$ Neben dem zu erörternden Nutzen der unter (aa) aufgeführten Instrumente gilt es auch, den - möglicherweise größeren - Nutzen anderer Instrumente zu erwägen.

\section{(i) Wünschenswerter bzw. realistischer Grad von Geeignetheit}

Beschäftigt man sich mit der Frage der Geeignetheit sollte man sich zur Bestimmung des anzustrebenden Ziels zunächst darüber im Klaren werden, welcher Grad von Geeignetheit wünschenswert bzw. realistisch ist.

Erlaubte man maximale Sicherheitsmaßnahmen und unterstellte, dass damit absolute Sicherheit gewährleistet ist, würde das zumindest zu einem Überleben im physischen Sinne führen.

In einer auf Würde und Freiheit ausgerichteten liberalen und demokratischen Staatengemeinschaft wie der EU ist Leben aber nicht nur im Sinne eines biologisch-physischen Zustandes zu

\footnotetext{
${ }^{788} \mathrm{Vgl}$. hierzu auch die Untersuchung von Schewe, der in seiner Arbeit zum Sicherheitsgefühl feststellt, dass sich ältere Frauen am meisten vor Gewaltkriminalität fürchten, obwohl die objektive Wahrscheinlichkeit, dass sie betroffen werden, gering ist. Gleichzeitig sind Opfer von Gewaltkriminalität regelmäßig junge Männer, die aber die niedrigsten Furchtraten aufweisen, vgl. Schewe, Sicherheitsgefühl, S. 108, 111.

${ }^{789}$ Schaaf, Frankfurter Allgemeine Sonntagszeitung Nr. 49 vom 6. Dezember 2009, S. 57, mit Verweis auf den Risikoforscher Gerd Gigerenzer; Minkmar, Frankfurter Allgemeine Sonntagszeitung Nr. 25 vom 24. Juni 2007, S. 28, unter Verweis auf Erkenntnisse der Harvard-Professorin Louise Richardson.

${ }^{790}$ So im Ergebnis auch Stubenrauch, Gemeinsame Verbunddateien, S. 195 f. und Kühne, Bürgerfreiheit, S. 13 f.

${ }^{791}$ Limbach, AnwB1. 2002, 454 (456); vgl. Ziercke, KR 2002, 346 (348).
} 
verstehen, sondern im Sinne einer biologisch-seelisch-geistigen Ganzheit, die insbesondere auf soziale Kommunikation und freie Selbst- und Mitbestimmung angewiesen ist. Sicherheit als Schutz des Lebens und der Lebensgrundlagen ist in diesem Sinne also nicht verkürzt als Sicherung des Überlebens, sondern als Gewährleistung eines Zustandes zu begreifen, in dem sich der Mensch als Träger von Würde und Freiheit und in seiner Rolle als soziales Wesen entfalten kann. $^{792}$

Einerseits ist absolute Sicherheit demnach nicht mit den Vorstellungen der europäischen Staaten von Freiheit und Demokratie vereinbar. Andererseits gilt es zu akzeptieren, dass sie auch tatsächlich nicht zu gewährleisten ist. ${ }^{793}$ Wie die Situation in Israel seit vielen Jahren zeigt, können selbst schärfste Sicherheitsmaßnahmen nichts gegen die zahlreichen zum Selbstmord entschlossenen Attentäter ausrichten. ${ }^{794}$

Somit wird festgestellt, dass die fraglichen Maßnahmen keine absolute Sicherheit erzeugen sollen und können.

\section{(ii) Wirkung staatlicher Eingriffsbefugnisse und Ursachen von Terrorismus}

Für die Frage der Geeignetheit sollte weiterhin Berücksichtigung finden, wie staatliche Eingriffsbefugnisse wirken bzw. was ihr Anteil bei der Bekämpfung der Kriminalität ist. Einzubeziehen sind auch die wahrscheinlichsten Ursachen für Terrorismus und was sich daraus für die zu wählenden Mittel bei Gegenmaßnahmen ergibt.

Zur Beantwortung des ersten Aspekts ist festzuhalten, dass Strafrecht und mit ihm zusammenhängend Strafprozessrecht weniger vermag als viele Menschen gemeinhin annehmen. Ohne einen grundsätzlichen Wertekonsens, der von angemessenen sozialen Strukturen getragen wird, bleibt alles Strafrecht wirkungslos. Als Beispiele seien hier Abtreibungs-, Alkohol- und Prostitutionsverbote genannt. ${ }^{795}$ Zudem gibt es die vermutete Proportionalität zwischen Kontrollbefugnissen und Kontrollerfolgen nicht. Erfolgversprechend sind stattdessen Hinweise aus der Bevölkerung. 95 bis $98 \%$ aller relevanten Informationen über die Begehung von Straftaten werden der Polizei durch Bürger zugetragen. ${ }^{796}$ Das setzt voraus, dass sich die Bürger auch untereinander kennen und in Kontakt stehen. Wegen der in solchen sozialen Strukturen ausgeübten informellen Verhaltenskontrolle ist es besonders schwer, auch nur Vorbereitungen für Straftaten unentdeckt zu bewerkstelligen. ${ }^{797} 798$

\footnotetext{
${ }^{792}$ Vgl. Stubenrauch, Gemeinsame Verbunddateien, S. 192 f. mit Verweis auf Denninger, KJ 35 (2002), 467 (469).

${ }^{793}$ Schaaf, Frankfurter Allgemeine Sonntagszeitung Nr. 49 vom 6. Dezember 2009, S. 57.

${ }^{794}$ Middel, Innere Sicherheit, S. 364 f., mit weiteren Nachweisen.

${ }^{795}$ Kühne, Das Paradigma, S. 14 f.

${ }^{796}$ Kühne, Das Paradigma, S. 16.

${ }^{797}$ Schewe, Sicherheitsgefühl, S. 125 f.; Kühne, Das Paradigma, S. 16 f.; ders., Bürgerfreiheit, S. 22 f.

${ }^{798}$ In diesen Zusammenhang passt es auch, dass einem Attentäter am 25. Dezember 2009 in einem Flugzeug einer amerikanischen Fluggesellschaft beim Landeanflug auf Detroit ein Anschlagsversuch gelang, obwohl der Vater des
} 
Da, wie bereits mehrfach erwähnt, die Zahl der Eingriffsbefugnisse mit dem Aufkommen des internationalen islamistischen Terrorismus sprunghaft gestiegen ist, sollen an dieser Stelle auch die wahrscheinlichen Gründe für diese Art von Kriminalität Erwähnung finden. Erkenntnisse von Wissenschaftlern der Universität Harvard zeigen, dass entscheidender Ansatzpunkt das Ehrgefühl der zumeist jungen Männer ist. Haben sie die Erfahrung von Demütigung gemacht, steigt folglich ihre Bereitschaft, sich radikal-islamischen Gruppen zuzuwenden, signifikant. ${ }^{799}$

\section{(iii) Schlussfolgerungen}

Nachfolgend soll darlegt werden, welche Schlüsse sich nun aus den eben genannten Erkenntnissen ziehen lassen, d.h. welche Mittel zur Kriminalitätsbekämpfung besonders geeignet erscheinen.

Wegen der Bedeutung der Kooperationsbereitschaft der Bürger mit der Polizei ist es von allergrößter Wichtigkeit, dass sich der Staat das Vertrauen seiner Bürger erhält. Vermehrte Eingriffsbefugnisse bergen in diesem Zusammenhang eine grundsätzliche Gefahr: Da es um die Abklärung eines bloßen Verdachtes geht, kann Adressat eines Eingriffs immer auch der letztlich unbescholtene Bürger werden. ${ }^{800}$ Hätten aber alle Bürger wachsende Bedenken, grundsätzlich unter Generalverdacht zu stehen, würden sie die Polizei eher als bedrohliche denn als helfende Instanz empfinden und sich zurückziehen. ${ }^{801}$

Man könnte diesem Argument entgegenhalten, dass im Hinblick auf den Datenschutz weniger die beim Staat gespeicherten Daten als vielmehr die von Privaten gesammelten Daten eine Rolle spielen. So kann man davon ausgehen, dass das Ausmaß an personenbezogenen Daten, die durch die Nutzung des Internets preisgegeben werden, die Datensammlungen des Staates um ein Vielfaches übersteigt. ${ }^{802}$ Hierbei ist jedoch zu berücksichtigen, dass unter den privaten Datensammlern keine organisierte Vernetzung wie bei den öffentlichen Stellen, insbesondere denen zur Kriminalitätsbekämpfung berufenen, besteht. Die Daten aus den unterschiedlichsten Bereichen können nicht zusammengeführt werden und bergen insofern eine geringere Gefahr der Überwachung. ${ }^{803}$ Doch selbst, wenn es so wäre, bestünde kein Grund, auch dem Staat schrankenlos

\footnotetext{
Attentäters den Behörden bereits entsprechende Warnungen hatte zukommen lassen; http://www.sueddeutsche.de/polititk/679/498965/text/, Abruf vom 29. Juli 2010; wichtige Informationen erhielt die Behörde also, weil der Vater Vertrauen in sie setzte und nicht, weil sie umfangreich heimlich ermittelte.

${ }^{799}$ Limbach, AnwB1. 2002, 454 (458); Minkmar, Frankfurter Allgemeine Sonntagszeitung Nr. 25 vom 24. Juni 2007, S. 28, mit Verweis auf das Buch der Harvard-Professorin Louise Richardson aus dem Jahr 2007 mit dem Titel: „Was Terroristen wollen. Die Ursachen der Gewalt und wie wir sie bekämpfen können“.

${ }^{800}$ Zöller, Informationssysteme und Vorfeldmaßnahmen, S. 23 f.; Limbach, AnwB1. 2002, 454 (455).

${ }^{801}$ Kühne, Das Paradigma, S. 16; ders., Bürgerfreiheit, S. 22 f.

${ }^{802}$ Middel, Innere Sicherheit, S. 369.

${ }^{803}$ Diesen Gedanken aufgreifend auch BVerfG vom 2. März 2010 zur Vorratsdatenspeicherung, BVerfG, NJW 2010,833 (839).
} 
sämtliche Angaben zur Verfügung zu stellen. Es gibt keine Veranlassung, aufgrund derer sich der Staat ein schlechtes Beispiel zum Vorbild nehmen sollte.

Voraussetzung dafür, dass die Bürger die letztlich für die Sicherheit relevanten Kenntnisse überhaupt erhalten, ist der Kontakt untereinander. Das gilt vor allem bezogen auf das nahe räumliche Umfeld. Der Staat bzw. die europäische Staatengemeinschaft sollte diesen Kontakt deshalb mit den unterschiedlichsten Mitteln fördern, z.B. durch entsprechende soziale Projekte und Begegnungsstätten sowie geeignete städtebauliche Maßnahmen in den Wohngebieten, also insgesamt durch eine auf Integration aller Gesellschaftsteile gerichteten Politik. ${ }^{804}$

Ergänzend zu diesen Maßnahmen und gerade auch im Hinblick auf die internationale Dimension von Kriminalität sollte die Kontrolle des nationalen wie internationalen Umgangs mit gefährlichen Stoffen und Waffen verbessert werden. Atomrecht und Umweltrecht geben beispielhaft Regelungen vor, indem sie Risiken bei der Schaffung sozial erwünschter Produkte durch ein Netz von vorwiegend präventiven Maßnahmen zu steuern suchen. Diese Offenlegungs- und sonstigen Pflichtigkeiten knüpfen an ein legales Gefährdungsverhalten an und rechtfertigen sich damit, ohne die Betroffenen dadurch unter einen Generalverdacht zu stellen. ${ }^{805}$ Sobald solche Regelungen in den Bereich des Strafrechts wandern, ist mit ihnen ein moralisches Unwerturteil verbunden. Es ist also sinnvoll, auf die zivil- und öffentlichrechtliche Kontrolle beim legalen Risikoproduzenten zu setzen. ${ }^{806}$

Zusätzlich sollte aus den Erkenntnissen über die Wurzeln des Terrorismus der Schluss gezogen werden, dass es in allererster Linie gilt, demütigende Handlungen auch und gerade im Umgang mit mutmaßlichen oder potentiellen Terroristen zu vermeiden. ${ }^{807}$ Zustände wie beispielsweise in den Gefängnissen von Guantanamo und Abu Ghraib erscheinen unter diesem Gesichtspunkt absolut „kontraproduktiv“, weil sie darauf gerichtet sind, die Insassen zu erniedrigen und sie ihrer Ehre zu berauben. Angezeigt wäre stattdessen ein Umgang, der diese Menschen nach rechtsstaatlichen Grundsätzen behandelt, sie in ihrem kulturellen Anderssein grundsätzlich respektiert und ernst nimmt und damit künftige Demütigungen vermeidet.

\footnotetext{
${ }^{804} \mathrm{Vgl}$. hierzu ausführlich Schewe, Sicherheitsgefühl, S. 285 f., der zu den städtebaulichen Maßnahmen u.a. Vorgaben durch die Kommune dahingehend vorschlägt, dass größere Wohnanlagen intern unterteilt werden müssen, was ein engeres Nachbarschaftsgefühl fördert; Stubenrauch, Gemeinsame Verbunddateien, S. 185.

${ }^{805}$ Durchaus kritisch hierzu: Di Fabio, der die Übertragung der Aufgabe der Risikoermittlung durch Unterlagenprüf- oder Anmeldeverfahren wie z.B. im Arzneimittelrecht auf den Antragsteller/Anmelder u.a. im Hinblick auf $\S 24$ Verwaltungsverfahrensgesetz sowie das Grundprinzip des Eingriffsdenkens als problematisch ansieht; nicht mehr der Staat habe die Erfüllung der gesetzlichen Voraussetzungen seines Eingreifens darzulegen und zu beweisen, vielmehr obliege es dem Privaten im jeweiligen Risikobereich, Belege für die Unschädlichkeit seines Tuns vorzulegen, Di Fabio, Risikoentscheidungen, S. 457 f.

${ }^{806}$ Kühne, Bürgerfreiheit, S. 18 f.; möglicherweise entfällt dann auch die Beschwerde einiger Staaten, die an im besten Falle unzuverlässige Gruppen Sprengstoff und Waffen liefern und sich anschließend darüber beklagen, wenn diese Vernichtungsmittel anders als vom Verkäufer geplant eingesetzt werden, vgl. ebenfalls Kühne, Bürgerfreiheit, S. 22 .

${ }^{807}$ Limbach, AnwB1. 2002, 454 (458).
} 
Es lässt sich also festhalten, dass die „traditionellen“ Mittel der Prävention und Repression bei konsequenter Nutzung ein hohes Potential zur Kontrolle auch der gefährlichsten und modernsten Formen von Kriminalität haben. ${ }^{808}$

\section{(iv) Übliche Blickrichtung und Konsequenzen}

Nach diesen Überlegungen gilt es sich für die Abwägung noch bewusst zu machen, welche Blickrichtung in der Diskussion regelmäßig eingenommen wird und wie sich diese auf die grundsätzlichen Diskussionsgegenstände auswirkt. Die Fragestellung lautet in aller Regel: „Brauchen wir mehr Befugnisse?“ Die verdeckte Registrierung ist keine neue Maßnahme. Sie wurde in ihrer deutschen Entsprechung im Jahr 1992 in die StPO eingefügt ${ }^{809}$ und ist im Rahmen der Schengen-Zusammenarbeit seit 1995 möglich. Die oben aufgeführten Überlegungen werfen jedoch nicht nur eine in die Zukunft gerichtete Frage auf, sondern sie geben genauso viel Anlass zu der - selten gestellten - Frage: „Können wir nicht alte Befugnisse abschaffen, wenn sie sich nicht bewährt haben?“ Zwar sah das deutsche Terrorismusbekämpfungsgesetz aus dem Jahr 2002 eine Evaluierung bestimmter Vorschriften nach fünf Jahren vor. ${ }^{810}$ Der entsprechende Bericht aus dem Jahr 2007 kam zu dem Ergebnis, dass alle untersuchten Regelungen beibehalten werden sollten. ${ }^{811}$ Zum einen erfasst er jedoch nur einen Bruchteil der bestehenden Eingriffsbefugnisse. Zum anderen wurde er unter Federführung des Bundesministeriums des Innern ohne externen Sachverstand im Sinne unabhängiger Wissenschaftler erstellt. ${ }^{812}$ Wünschenswert wäre dagegen die regelmäßige Evaluierung sämtlicher sicherheitssichernder Eingriffsbefugnisse durch unabhängige Fachleute - im Hinblick auf die vorliegende Fragestellung auf europäischer Ebene. Selbstverständlich ist auch immer wieder der Gesetzgeber und sind die Gerichte berufen, die Angemessenheit von Eingriffsbefugnissen zu überprüfen. Die Gerichte werden jedoch nicht in Bezug auf jede Maßnahme um Prüfung gebeten. Gerade, wenn es sich, wie im Fall der verdeckten Registrierung um eine Ermittlungsmaßnahme handelt, die auf nationaler Ebene schon lange zum Instrumentarium gehört, wird ihre Rechtmäßigkeit regelmäßig von keiner möglichen Verfahrenspartei in Frage gestellt. Es geht bei der durch die europäischen Grundrechte aufgestellten objektiven Wertordnung aber gerade um ein komplexes System. Um beurteilen zu können, welche Rolle einzelne Befugnisse in diesem System spielen, müsste man sie in einen Gesamtzusammenhang stellen.

\footnotetext{
${ }^{808}$ Kühne, Bürgerfreiheit, S. 23.

${ }^{809}$ Art. 3 Gesetz vom 15. Juli 1992, BGB1. 1992, 1302.

${ }^{810}$ Art. 22 Abs. 2 und 3 Gesetz vom 9. Januar 2002, BGB1. 2002, 361.

${ }^{811}$ S. 6 des Evaluierungsberichtes, http://www.bmi.bund.de/cae/servlet/contentblob/132848/publicationFile/9102/ Fakten_Evaluierung_Terrorismusbekämpfungsgesetz.pdf, Abruf vom 29. Juli 2010.

${ }^{812} \mathrm{Vgl}$. Antwort der Bundesregierung vom 21. Juli 2006 auf eine Kleine Anfrage der Abgeordneten Ulla Jelpke u.a., BT-Drs. 16/2285, S. 2, Nr. 1 und 2.
} 
Eigentlich sollte auch der Gesetzgeber diesen Zusammenhang berücksichtigen; allerdings handelt es sich dabei jedenfalls in Zeiten terroristischer Bedrohung um einen unrealistischen Wunsch. Käme es zu einem weiteren Anschlag in Europa und schreit ein in Panik geratenes Volk mit Hilfe der Medien nach einer Reaktion der Staatengemeinschaft, werden die für die Sicherheit verantwortlichen Politiker mit sachlichen Überlegungen zur Geeignetheit von Maßnahmen und ihren Auswirkungen auf das Gesamtsystem wenig Gehör finden. ${ }^{813}$ Es ist zu hoffen, dass ein Gremium von anerkannten Fachleuten dieses Augenmaß eher behalten würde. Da sich die für die Sicherheit des Staates zuständigen Stellen regelmäßig schwer tun, wenn es um die Offenlegung ihrer Instrumente, Erfolge, Misserfolge und Strategien geht, sollte das Gremium zunächst unter Ausschluss der Öffentlichkeit arbeiten. Kommt es jedoch zu dem Ergebnis, dass diese oder jene Eingriffsbefugnis das Fass in Richtung eines Überwachungsstaates zum Überlaufen bringt, oder dass die Ergebnisse einer Eingriffsbefugnis über Jahre wenig ergiebig sind und auch keine Besserung zu erwarten ist, sollte es dem Gesetzgeber offen die Abschaffung dieser Befugnis vorschlagen. Damit wäre die Legislative zumindest in der Pflicht, sich mit bereits bestehenden Regelungen argumentativ detailliert auseinanderzusetzen. Sie müsste öffentlich und genau begründen, warum sie an dem fraglichen Instrument festhalten will. Der Einsatz des Gremiums würde dazu beitragen, den größeren Zusammenhang ${ }^{814}$ nicht aus den Augen zu verlieren, und er könnte zu einer Versachlichung abseits mancher oberflächlicher politischer Diskussion führen.

Festzuhalten bleibt also, dass die Angemessenheit der zu prüfenden Maßnahme bei der hier gewählten Blickrichtung nicht bereits dadurch weitgehend antizipiert ist, dass es sie schon seit langer Zeit gibt.

\section{(v) Abwägung}

Abschließend gilt es nun abzuwägen, ob die dem kollektiven Sicherheitsinteresse dienende Maßnahme der verdeckten Registrierung in der strafprozessualen Variante gegenüber den aufgezeigten Gefahren, die sie für die im Grundrecht auf den Schutz personenbezogener Daten verbürgte objektive Wertordnung mit sich bringt, angemessen erscheint. Auf der einen Seite ist davon auszugehen, dass die verdeckte Registrierung zum Schutz kollektiver Sicherheitsinteressen beitragen kann und in Einzelfällen wichtige Erkenntnisse über bestehende kriminelle, möglicherweise auch terroristische, Netzwerke liefert. Zudem mag es die Angst der Bevölkerung, Opfer von Kriminalität zu werden, in gewisser Weise besänftigen, wenn bekannt ist, dass es eine

\footnotetext{
${ }^{813}$ Vgl. hierzu Stubenrauch, Gemeinsame Verbunddateien, S. $173 \mathrm{f}$.

${ }^{814}$ Vgl. auch Zöller, der dem Gesetzgeber strukturelle und handwerkliche Fehler beim Gesetz zur Neuregelung der Telekommunikationsüberwachung und anderer verdeckter Ermittlungsmaßnahmen sowie zur Umsetzung der Richtlinie 2006/24/EG vom 21. Dezember 2007, BGB1. 2007, 3198, attestiert, Zöller, StraFo 2008, 15 (25).
} 
heimliche Ermittlungsmethode wie die hier zu prüfende gibt. Auf der anderen Seite steht die Klärung des tatsächlichen Nutzens der Einzelmaßnahme „verdeckte Registrierung“ und damit ihres Nutzens für die kollektive Sicherheit noch aus. Aufgrund abstrakter Überlegungen ist ihr Nutzen jedoch im Einzelfall ${ }^{815}$ und folglich auch in der Vielzahl von Einzelfällen eher als gering anzusehen. Zudem wiegt schwer, dass die mit der Eingriffsbefugnis verbundene Heimlichkeit in hohem Maße geeignet ist, zwischen den Bürgern und im Verhältnis zwischen den Bürgern und dem Staat Misstrauen wachsen zu lassen. Wird Misstrauen im Verhältnis zu anderen Menschen und zu Institutionen eines Staates wie beispielsweise in der damaligen DDR zur vorherrschenden Geisteshaltung, zerstört dies das Fundament einer Gesellschaft. ${ }^{816}$ Maßgebliche Berücksichtigung verdient die Erkenntnis, dass die oben aufgezeigten traditionellen Mittel, nämlich die Förderung des vertrauensvollen Bürger-Bürger- und des Bürger-Polizeikontaktes sowie die Übertragung der Grundsätze der Kontrolle des Umgangs mit gefährlichen Stoffen und Waffen auf den Sicherheitsbereich die Gesellschaft gut vor Verbrechen schützen können ${ }^{817}$ und weiterhin dass das wirksamste Mittel im Kampf gegen den Terrorismus, nicht unbedingte Härte, sondern, so schwer das im konkreten Fall auch sein mag, unbedingte Achtung der Würde potentieller bzw. mutmaßlicher Terroristen ist. Wird die Waagschale mit diesen Argumenten bestückt, so wiegen die mit der Maßnahme verbunden Nachteile schwerer als die mit ihr verbunden Vorteile. Damit ist die verdeckte Registrierung in ihrer strafprozessualen Variante als nicht angemessen anzusehen.

Auch an dieser Stelle ist keine Auslegung denkbar, die zu einer Konformität mit der Grundrechte-Charta führen würde. ${ }^{818}$

\section{(vi) Zwischenergebnis}

Die verdeckte Registrierung in ihrer strafprozessualen Variante verletzt damit das Recht aus Art. 8 GR-Charta und ist daher grundrechtscharta-widrig.

\section{ee. Bestimmtheit der gesetzlichen Grundlage}

Eine weitere Anforderung an das einschränkende Gesetz ergibt sich daraus, dass Art. 8 GRCharta nur auf einer gesetzlichen Grundlage eingeschränkt werden darf. Diese gesetzliche Grundlage muss ausreichend bestimmt sein. Ein nicht ausreichend bestimmtes Gesetz ist bereits nicht erforderlich, weil es mehr Eingriffe erlaubt, als zur Zweckerreichung notwendig sind. Gleichwohl enthält das Gebot der Bestimmtheit einen eigenen Fokus und damit eine eigenständige Schranke: Es nimmt die Perspektive des einzelnen an und verlangt, dass die Betroffenen die

\footnotetext{
${ }^{815}$ Siehe diesen Teil der Arbeit, B. IV. 2. b. dd. (3) (c) (dd).

${ }^{816} \mathrm{Vgl}$. Gauck, in: Bundeskriminalamt, Arbeitstagung „Neue Freiheiten, neue Risiken, neue Chancen“, S. 23 (26 f.).

${ }^{817}$ Kühne, Bürgerfreiheit, S. 23.

${ }^{818}$ Vgl. diesen Teil der Arbeit, B. IV. 2. b. dd. (2).
} 
Folgen voraussehen können. ${ }^{819}$ Anders formuliert: Das Bestimmtheitsgebot fordert, dass sich die Voraussetzungen und der Umfang der Beschränkungen klar und für den Bürger erkennbar ergeben. Dabei sind Offenheiten und Unklarheiten hinzunehmen, wenn die Eigenheit der Materie eine genauere Regelung nicht zulässt. ${ }^{820}$

Zunächst ist es für den Bürger schwer nachvollziehbar, wie die strafprozessuale Variante der verdeckten Registrierung durch Einbeziehung der Vorschriften aus dem SDÜ, der StPO und des deutschen Zustimmungsgesetzes ermittelt wird. Als „Normalbürger“ würde man allenfalls das SDÜ zu Rate ziehen und beispielsweise nicht erfahren, dass es nach deutschem Recht einen Richtervorbehalt und eine Benachrichtigungspflicht gibt. Diese Situation ist misslich, aber der Vielfalt der Rechtssysteme der unterschiedlichen Teilnehmerstaaten geschuldet. Möchte man deren jeweilige Besonderheiten im Sinne der Kollisionsregel des Art. 104 SDÜ berücksichtigen, hat diese Unklarkeit ihren Grund in der Eigenheit der Materie und ist damit hinzunehmen.

Problematisch erscheint weiterhin der Begriff der ,außergewöhnlich schweren Straftat“. Dieser Ausdruck ist nicht legal definiert, so dass der Bürger keinerlei Anhaltspunkte dafür hat, ob darunter lediglich eine Straftat von der Schwere eines besonders grausamen Mordes oder beispielsweise bereits ein Raubüberfall zu verstehen ist. Wie schon im Rahmen der Erforderlichkeit festgestellt wurde, ließe auch die Eigenheit der Materie mittlerweile eine präzisere Regelung zu, indem der Straftatenkatalog aus dem Rahmenbeschluss zum Europäischen Haftbefehl zugrunde gelegt würde. ${ }^{821}$ Insofern entspricht der Begriff der außergewöhnlich schweren Straftat nicht den Anforderungen an die Bestimmtheit des Gesetzes.

Anders verhält es sich mit dem Ausdruck ,in erheblichem Umfang“". Wie bereits bei der Erforderlichkeit festgestellt, ${ }^{822}$ wird man hier fordern können, dass Straftaten von außergewöhnlicher Schwere mit dem notwendigen Verdachtsgrad jedenfalls drei Mal begangen wurden. Da sich diese Präzisierung bereits durch Heranziehung des einfachen Wortverständnisses gewinnen lässt, kann der Bürger die Voraussetzungen des Gesetzes abschätzen.

Abschließend soll auf eine Kritik eingegangen werden, die auch in Bezug auf die nationale Norm des $\S 163$ e StPO geäußert wird. ${ }^{823}$ Die Verarbeitungsbefugnis der ausschreibenden Behörde richtet sich nach den allgemeinen strafprozessualen Dateiregelungen der $\S \S 483$ ff. StPO. Sie

\footnotetext{
${ }^{819}$ Jarass, EU-Grundrechte, $\S$ 6, Rn. 39, § 13, Rn. 10; Uerpmann-Wittzack, in: Ehlers, Europäische Grundrechte, § 3 , Rn. 22, zum Bestimmtheitsgebot nach der hier zu berücksichtigenden EMRK.

${ }^{820}$ Jarass, EU-Grundrechte, § 6, Rn. 39 mit Verweis auf EuGH, Slg. 1987, 2289, Rn. 31 sowie EGMR, NJW 2003, 3041.

${ }^{821}$ Siehe oben in diesem Teil der Arbeit, B. IV. 2. b. dd. (2) sowie Art. 2 Abs. 2 Rahmenbeschluss 2002/584/JI des Rates vom 13. Juni 2002, AB1. L 190, 1.

${ }^{822}$ Siehe oben in diesem Teil der Arbeit, B. IV. 2. b. dd. (2).

${ }^{823}$ Zöller, in: Julius u.a., StPO, $\$ 163$ e, Rn. 3; zu den insgesamt sehr verstreut geregelten Eingriffsbefugnissen ausführlich Wolter, in: Rudolphi u.a., SK StPO, Band 3, § 163 e (Stand: Mai 1997), Rn. 4 ff.
} 
kann die gemeldeten Daten auswerten, speichern und an zentrale Einrichtungen, die zum Zweck der Erfassung solcher Daten errichtet wurden, übermitteln. ${ }^{824} \mathrm{Im}$ Text der strafprozessualen Norm wird dieser Teil der verdeckten Registrierung nicht erwähnt. Der rechtsunkundige Bürger kann diese weiten und allgemeinen Weiterverwendungsmöglichkeiten nicht vorhersehen. Angebracht wäre im Text des $§ 163$ e StPO zumindest ein Verweis auf die $\S \S 483$ ff. StPO. Da dieser oder eine ähnliche Bezugnahme fehlt, mangelt es der Norm auch an dieser Stelle an der notwendigen Bestimmtheit.

Eine grundrechtschartakonforme Auslegung kommt nicht in Betracht, da hierdurch kein nicht vorhandener Gesetzestext einfügt werden kann.

\section{Zulässigkeit der Koppelung von Zwecken ${ }^{825}$}

Art. 101 a SDÜ ${ }^{826}$ lässt den unmittelbaren Abruf der Daten nach Art. 99 SDÜ durch eine andere Behörde, Europol, im Rahmen ihrer Aufgaben zu. Soweit der ausschreibende Mitgliedstaat zustimmt, darf Europol die Daten nach Maßgabe des Europol-Übereinkommens nutzen. ${ }^{827}$ Bisheriger Gegenstand der Prüfung war die Nutzung der Daten nach Art. 99 SDÜ für mit dem Betrieb des SIS verfolgte Zwecke. Mit dem Abruf und der Nutzung der Daten der Ausschreibung durch Europol wird ein neues Aufgabenfeld eröffnet. Problematisch erscheint diese Vorschrift unter dem Gesichtspunkt der Zweckfestlegung, die Art. 8 Abs. 2 S. 1 GR-Charta vorschreibt. Dieses Erfordernis der Zweckbindung gibt die wesentlichen Grundsätze aus Art. 5 der Datenschutzkonvention des Europarates wieder und ist dem Wortlaut von Art. 6 Abs. 1 b) RL 95/46/EG nachgebildet. Unabhängig von der Frage, ob die RL 95/46/EG für den Polizeibereich anwendbar ist, wird zunächst festgestellt, welche Regeln diese Vorschriften im Umgang der Verbindung verschiedener Zwecke aufstellen. Bezüglich der Weiterverarbeitung bzw. der Verwendung heisst es, dass diese mit den Ursprungszwecken nicht unvereinbar sein darf. ${ }^{828}$ Weitere Festlegungen gibt es zur Weiterverarbeitung nicht. Auch die Rechtsprechung von EuGH und EGMR bringt zu diesem Punkt keine weiteren Erkenntnisse. Würde jedoch für die Weiterverarbeitung lediglich das Vereinbarkeitserfordernis gelten, könnte von einer Zweckfestlegung i.S.v. Art. 8 Abs. 2 S. 1 GR-

\footnotetext{
${ }^{824} \mathrm{Vgl}$. Meyer-Goßner, StPO, § 163 e, Rn. 4 sowie Zöller, in: Julius u.a., StPO, § 163 e, Rn. 3.

${ }^{825}$ Bei der Erörterung bleibt der Rahmenbeschluss 2008/977/JI des Rates vom 27. November 2008, AB1. L 350, 60, über den Schutz personenbezogener Daten, die im Rahmen der polizeilichen und justiziellen Zusammenarbeit in Strafsachen verarbeitet werden, außer Betracht. Der Beschluss soll durch die Mitgliedstaaten bis zum 27. November 2010 umgesetzt werden, vgl. Art. 29 Abs. 1; der Rat geht im Erwägungsgrund Nr. 39 davon aus, dass Datenschutzregeln für die Arbeitsweise von Europol spezieller sind und ein in sich geschlossenes Regelwerk bilden, so dass sie dem Rahmenbeschluss vorgehen; die gleiche Überlegung findet sich in den Erwägungsgründen zum EuropolBeschluss, vgl. Erwägungsgrund $\mathrm{Nr} .12$.

${ }^{826}$ Eingefügt durch Beschluss 2005/211/JI des Rates vom 24. Februar 2005, AB1. 2005 L 68, 44; nach dem Beschluss 2006/631/JI des Rates vom 24. Juli 2006, ABl. 2006 L 256, 18, gilt Art. 101 a SDÜ ab dem 1. Oktober 2006. ${ }^{827}$ Art. 101 a Abs. 4 S. 1 und 2 SDÜ.

${ }^{828}$ Art. 5 b) Datenschutzkonvention des Europarates; Art. 6 Abs. 1 b) S. 1 RL 95/46/EG.
} 
Charta keine Rede mehr sein. Zwar wären dann die Regeln für die Datenverarbeitung rund um den Ursprungszweck relativ streng, nutzt man die Daten jedoch für weitere Zwecke, würden die von Art. 8 Abs. 2 und 3 GR-Charta aufgestellten Schranken nicht mehr gelten. Eine derartige Lockerung der Vorschriften und damit eine Aushöhlung des grundrechtlichen Gehaltes „durch die Hintertür" kann angesichts der ausdrücklichen Aufnahme von Art. 8 in die GR-Charta nicht beabsichtigt sein. Um das zu vermeiden, erscheint es mangels weiterer europäischer Vorgaben angezeigt, ergänzend die Grundsätze heranzuziehen, die das BVerfG im Volkszählungsurteil zur Koppelung von Zwecken erarbeitet hat. ${ }^{829}$ Neben dem Verbot der Unvereinbarkeit, das das BVerfG ebenfalls aufstellt, ${ }^{830}$ müssen auch die weiteren Zwecke bestimmt und begrenzt sein. ${ }^{831}$ Zudem muss persönlichen Daten auch bei ihrer Weiterverarbeitung Schutz durch Organisation und Verfahren zuteil werden. ${ }^{832} \mathrm{Zu}$ fordern sind hier mit Blick auf Art. 8 Abs. 2 und 3 GRCharta insbesondere ein Auskunfts- und Berichtigungsrecht und die Überwachung der Vorschriften durch eine unabhängige Stelle. Da sich Auskunfts- und Berichtigungsrechte gegenüber einer Behörde regelmäßig nur dann als scharfes Schwert erweisen, wenn sie auch gerichtlich durchsetzbar sind, wird man zudem wie für die Daten, die im Rahmen des SIS verarbeitet werden, einen gerichtlichen Rechtsbehelf fordern müssen.

Zunächst ist festzustellen, welche Europol-Vorschriften Gegenstand der Prüfung sein sollen. Die Europol-Tätigkeit hat Anfang des Jahres 2010 eine neue Rechtsgrundlage erhalten. Das EuropolÜbereinkommen von $1995^{833}$ ist mit Wirkung vom 1. Januar 2010 durch den Beschluss des Rates vom 6. April 2009 ersetzt worden. ${ }^{834} \mathrm{Zu}$ klären ist, ob die Verweisung in Art. 101 a SDÜ auf das „Europol-Übereinkommen“ statischer oder dynamischer Natur ist. Wäre sie statischer Natur, würden für die weitere Prüfung weiterhin die Vorschriften des Europol-Übereinkommens gelten. Wäre sie dynamischer Natur, wäre mit der Bezugnahme auf das Europol-Übereinkommen nicht zwingend die bei Geltungsbeginn von Art. 101 a SDÜ aktuelle Fassung gemeint. Vielmehr würde Bezug genommen auf die für die Tätigkeit von Europol jeweils aktuelle Rechtsgrundlage. Für ein Verständnis im Sinne einer statischen Erwägung ließe sich anführen, dass die Vorschrift andernfalls zur Klarstellung beispielsweise ,nach Maßgabe des Europol-Übereinkommens in seiner jeweils aktuellen Fassung“ hätte lauten können. Andererseits spricht für die Annahme einer dy-

\footnotetext{
${ }^{829} \mathrm{Vgl}$. auch Johlen, in: Tettinger/Stern, Kölner Gemeinschaftskommentar, Art. 8, Rn. 25.

${ }^{830}$ BVerfGE 65, 1 (62).

${ }^{831}$ BVerfGE 65, 1 (62 ff.).

${ }^{832} \mathrm{Vgl}$. BVerfGE 65, 1 (68).

${ }^{833}$ AB1. C 316, 1, vom 27. November 1995.

${ }^{834}$ Beschluss 2009/371/JI des Rates, ABl. L 121, 37, im Folgenden EuropolB; vgl. Art. 1 Abs. 1 S. 1 sowie Art. 64 Abs. 2 S. 1 1. Alt. EuropolB zum Geltungsbeginn; das deutsche Umsetzungsgesetz, Europolgesetz, hierzu findet sich in Art. 1 Gesetz vom 31. Juli 2009, BGB1. 2009, 2504.
} 
namischen Verweisung, dass sich die Europäische Union die ständige Weiterentwicklung der Union als einen Raum der Freiheit, der Sicherheit und des Rechts zum Ziel gesetzt hat. ${ }^{835}$ Eine solche Weiterentwicklung wäre maßgeblich behindert, wollte man an Verweisungen in einer statischen Weise festhalten. Vorrang ist damit der Auslegung zu geben, die die Verweisung als dynamisch ansieht.

Mit Blick auf den Europol-Beschluss gilt es nun festzustellen, ob durch die Zugriffs- und Verwendungsmöglichkeiten durch Europol eine Koppelung von unterschiedlichen Zwecken ermöglicht wird und wenn ja, ob diese zulässig ist. Für das Verhältnis der Regelungen zu Datenzugang und Verwendung in beiden Übereinkommen legt Art. 21 EuropolB sinngemäß fest, dass die Vorschriften des Europol-Übereinkommens gelten, wenn nicht dass SDÜ strengere Vorschriften enthält.

Bei der Prüfung sollen zwei Bereiche unterschieden werden: zum einen die Verwendung der Daten durch Europol selbst und zum anderen die Verwendung von Daten durch Drittstaaten und Drittstellen, an die Europol die Informationen nach Art. 101 a Abs. 4 S. 3 SDÜ weitergeben darf. $^{836}$

\section{a. Verwendung der Daten durch Europol}

$\mathrm{Zu}$ prüfen ist, ob es sich bei der Verwendung der Daten im SIS und der Verwendung der Daten nach dem Europol-Beschluss überhaupt um grundsätzlich unterschiedliche Zwecke handelt.

\section{aa. Unterschiedliche Zwecke}

Beide Instrumente dienen in einem weiteren Sinne der Aufklärung schwerer Straftaten mit grenzüberschreitendem Bezug. Die SIS-Fahndung zielt jedoch auf die Aufklärung einer konkreten Straftat, während Europol den Zweck verfolgt, die Tätigkeit der zuständigen Behörden der Mitgliedstaaten sowie deren Zusammenarbeit bei der Prävention und Bekämpfung von organisierter Kriminalität, Terrorismus und anderen Formen schwerer Kriminalität zu unterstützen und zu verstärken, wenn zwei oder mehr Europol-Mitgliedstaaten betroffen sind. ${ }^{837}$ Der Zweck, zu dem Europol die Daten nutzen darf, ist also viel abstrakter und damit weiter formuliert. Die Behörde kann auf ihre Weise zur Aufklärung der Straftat beitragen, deren Gegenstand die SISAusschreibung ist. Sie kann die Daten aber auch im Zusammenhang mit ganz anderen Straftaten

\footnotetext{
${ }^{835}$ Art. 2, 4. Spiegelstrich EUV in der Fassung des Vertrags von Nizza, vgl. ABl. C 325, 5, vom 24. Dezember 2002.

${ }^{836}$ Gegenstand der Prüfung sind nicht die Notfallbefugnisse des Direktors von Europol, vgl. Art. 23 Abs. 8 und 9 EuropolB sowie Art. 14 Beschluss 2009/934/JI des Rates vom 30. November 2009; AB1. L 325, 6.

${ }^{837}$ Art. 3 S. 1 EuropolB.
} 
verwenden, wenn es dem oben beschriebenen Zweck dient. Insofern hat Europol die Möglichkeit, mit den fraglichen Daten im Rahmen seiner Ziele andere Zwecke zu verfolgen.

\section{bb. Vereinbarkeit, Zweckbestimmung und -begrenzung}

Die Zwecke dürften nicht Unvereinbares miteinander vereinbaren. Das ist hier nicht der Fall. Die unterschiedlichen Zwecke schließen sich nicht aus. Vielmehr dienen beide, wie bereits erwähnt, der Aufklärung schwerer Straftaten mit grenzüberschreitendem Bezug.

Der Zweck muss bestimmt und begrenzt sein. In Art. 3, 4 und 5 EuropolB werden die Ziele, Zuständigkeiten und Aufgaben der Behörde benannt. Da es um den Tätigkeitsbereich einer ganzen Behörde und nicht um eine einzelne Ermittlungsmaßnahme in einem konkreten Verfahren geht, sind diese Normen naturgemäß weit formuliert. Begrenzt werden die Befugnisse des EuropolPersonals dadurch, dass es zwar in gemeinsamen Ermittlungsgruppen mitwirken, jedoch nicht an Zwangsmaßnahmen teilnehmen darf und die Mitgliedstaaten um die Einleitung strafrechtlicher Ermittlungen nur ersuchen, Ermittlungen aber nicht erzwingen kann. ${ }^{838}$ Angesichts der Weite der inhaltlichen Zuständigkeit von Europol lässt sich hier bei äußerst wohlwollender Prüfung noch von einer Zweckbegrenzung sprechen.

\section{cc. Organisations- und verfahrensrechtliche Vorschriften}

Im EuropolB und in Art. 101 a Abs. 6 SDÜ finden sich Vorschriften zu Auskunfts- ${ }^{839}$ Berichtigungs-, Löschungs- ${ }^{840}$ und Schadensersatzrechten, ${ }^{841}$ Speicherfristen, Löschungsregeln ${ }^{842}$, zu einer jeweils unabhängigen nationalen und gemeinsamen Kontrollinstanz, ${ }^{843} \mathrm{zu}$ einem unabhängigen Datenschutzbeauftragten, ${ }^{844}$ zu Protokollierungspflichten, Zugriffsbeschränkungen ${ }^{845}$ und zum technischen Datenschutz. ${ }^{846}$ Diese Bestimmungen scheinen die Ansprüche an wirksame organisatorische und verfahrensrechtliche Regelungen auf den ersten Blick umfassend zu erfüllen. ${ }^{847}$ Dennoch ist es erforderlich, die Vorschriften zum Auskunftsrecht genauer zu betrachten. Nach Art. 30 Abs. 5 EuropolB kann die Auskunft über die erfragten Daten u.a. verweigert wer-

\footnotetext{
${ }^{838}$ Art. 6 Abs. 1, Art. 7 EuropolB.

${ }^{839}$ Art. 30 EuropolB.

${ }^{840}$ Art. 31 EuropolB.

${ }^{841}$ Art. 52 EuropolB.

${ }^{842}$ Art. 20 EuropolB.

${ }^{843}$ Art. 33 und 34 EuropolB.

${ }^{844}$ Art. 28 EuropolB.

${ }^{845}$ Art. 101 a Abs. 6 lit. a und c SDÜ.

${ }^{846}$ Art. 101 a Abs. 6 lit. d SDÜ; die Regelung in Art. 118 Abs. 3 SDÜ ist i.S.v. Art. 21 EuropolB strenger, weil sie eine SDÜ-spezifische Schulung fordert.

${ }^{847} \mathrm{Vgl}$. zu den Dateiregelungen des außer Kraft getretenen Europol-Übereinkommens: Weßlau, in: Wolter u.a., Alternativentwurf Europol, S. 318.
} 
den, wenn es erforderlich ist für die ordnungsgemäße Erfüllung der Aufgaben von Europol oder zum Schutz der Sicherheit und der öffentlichen Ordnung der Mitgliedstaaten oder zur Bekämpfung von Straftaten oder aber um zu gewährleisten, dass keine nationalen Ermittlungen gefährdet werden. Im Falle einer verdeckten Registrierung nach der strafprozessualen Variante wird eine Mitteilung an den Betroffenen schon allein deshalb unterbleiben, weil der die Daten liefernde Mitgliedstaat Bezug auf Art. 109 Abs. 2 S. 2 SDÜ nehmen muss und die nationalen Ermittlungen als gefährdet ansehen wird. Anders als im Rahmen der Schengen-Zusammenarbeit ${ }^{848}$ ist auf Europol-Ebene jedoch keine nachträgliche Benachrichtigung vorgesehen. Auf diese Weise läuft das in Art. 8 Abs. 2 S. 2 GR-Charta vorgesehene Auskunftsrecht gegenüber Europol im Falle einer heimlichen Ermittlungsmaßnahme wie der verdeckten Registrierung regelmäßig ins Leere. Diese Rechtslage widerspricht der Rechtsprechung sowohl des BVerfG ${ }^{849}$ als auch des EGMR ${ }^{850}$ die eine grundsätzliche Pflicht zur nachträglichen Unterrichtung im Fall heimlicher Maßnahmen feststellen. ${ }^{851}$ Art. 101 a SDÜ, der die Verwendung der Daten durch Europol nach den Vorschriften des EuropolB zulässt und ansonsten nur von der Zustimmung der Mitgliedstaaten sowie den Bestimmungen nach seinem Absatz 6 abhängig macht, enthält im Hinblick auf eine Benachrichtigungspflicht damit keine ausreichenden verfahrensrechtlichen Regeln.

Unklar ist auch, auf welche Weise ein Betroffener derzeit die ihm zustehenden Rechte durchsetzen kann. Zwar formuliert Art. 32 EuropolB ein Beschwerderecht, über das die Gemeinsame Kontrollinstanz entscheidet. Es fehlt aber an einem klar formulierten Recht auf gerichtliche Durchsetzbarkeit. Art. 111 SDÜ kann über Art. 21 EuroplB nicht herangezogen werden, weil dieses Recht auf gerichtlichen Zugang von einem auf Nationalstaaten bezogenen System ausgeht. In den Fällen, in denen Europol als mit eigener Rechtspersönlichkeit ausgestattete Behör$\mathrm{de}^{852}$ ein Interesse an der Verwendung der Daten hat, ist ohne entsprechende Bestimmung nicht davon auszugehen, dass nationale Gerichte mit Bindung für Europol entscheiden können. ${ }^{853}$

Von einer Zuständigkeit des EuGH für Individualklagen kann im Moment nicht ausgegangen werden, weil Art. 10 Abs. 1 des Protokolls über die Übergangsbestimmungen zum Vertrag von Lissabon auf die bisherige Rechtslage verweist, nach der Art. 35 EUV $^{854}$ ebenfalls keine Klage

\footnotetext{
${ }^{848}$ Benachrichtigungspflicht nach Art. 5 deutsches Zustimmungsgesetz, BGBl. II 1993, 1010.

${ }^{849}$ B VerfGE 30, 1 (Ls. 2); vgl. BVerfGE 100, 313 (397 ff.).

${ }^{850}$ Unter ausdrücklicher Bezugnahme auf das o.g. Urteil des BVerfG, BVerfGE 30, 1, siehe EGMR, Urt. vom 6. September 1978, - Klass ./. Deutschland -, EGMR-E 1, 320 (338).

${ }^{851}$ Siehe auch Schenke, in: Wolter u.a., Alternativentwurf Europol, S. 367 (392 f.), zur Bedeutung der Benachrichtigungspflicht mit Blick auf das Europol-Übereinkommen von 1995, das eine solche Pflicht ebenfalls nicht vorsah.

${ }_{852}$ Art. 2 Abs. 1 EuropolB.

${ }^{853}$ Abhilfe könnte hier der eigentlich nicht einschlägige Art. 20 Rahmenbeschluss 2008/977/JI des Rates vom 27. November 2008 über den Schutz personenbezogener Daten, die im Rahmen der polizeilichen und justiziellen Zusammenarbeit in Strafsachen verarbeitet werden, vgl. Fn. 818, schaffen. Diese Vorschrift sieht einen Zugang zu gerichtlicher Hilfe für Betroffene vor.

${ }_{854}$ In der Fassung des Vertrags von Nizza vom 7. Februar 1992, AB1. C 191, 1.
} 
natürlicher oder juristischer Personen vor dem EuGH ermöglichte. ${ }^{855}$ Allerdings ist davon auszugehen, dass nach Ablauf der Übergangsfrist von fünf Jahren nach Inkrafttreten des Vertrags von Lissabon, also ab dem 1. Dezember 2014, der Zugang zum EuGH für Individuen grundsätzlich eröffnet ist. ${ }^{856}$ Art. 263 Abs. 1 S. 2 i.V.m. Abs. 4 AEUV wird dann die einschlägige Rechtsgrundlage für Klagen zum Schutz der Rechte aus Art. 8 GR-Charta gegen unzulässige Informationseingriffe durch Europol-Bedienste sein..$^{857}$

Abschließend lässt sich feststellen, dass die Anforderungen an Organisation und Verfahren wegen der fehlenden Benachrichtigungspflicht und der derzeit nicht bestehenden Rechtsschutzmöglichkeit für den Bürger im Einzelfall nicht erfüllt sind.

\section{b. Weitergabe der Daten an Dritte und Einrichtungen der EU}

Art. 101a Abs. 4 S. 3 SDÜ erlaubt mit Zustimmung des Mitgliedstaates die Weitergabe der Daten durch Europol auch an Dritte und Einrichtungen der EU. Diese im SDÜ offen formulierte Erlaubnis wird konkretisiert durch die entsprechenden Regelungen des EuropolB ${ }^{858}$ sowie eines Beschlusses des Rates vom 30. November $2009 .{ }^{859}$ Festzustellen ist hier wiederum, ob durch diese Weitergabemöglichkeiten unterschiedliche Zwecke gekoppelt werden und ob diese Koppelung zulässig ist.

\section{aa. Unterschiedliche Zwecke}

Zur Beantwortung der Frage der unterschiedlichen Zwecke soll zunächst ermittelt werden, welche Stellen potentielle Datenempfänger sind und ob es bei der Weitergabe Festlegungen hinsichtlich des Zwecks gibt.

Personenbezogene Daten dürfen nach den entsprechenden Vorschriften ${ }^{860}$ grundsätzlich weitergegeben werden

\footnotetext{
${ }^{855}$ Vgl. zur damaligen Rechtslage Zöller, Informationssysteme und Vorfeldmaßnahmen, S. 451 sowie Schenke, in: Wolter u.a., Alternativentwurf Europol, S. 367 (370).

${ }^{856}$ Art. 10 Abs. 3 Protokoll über die Übergangsbestimmungen.

${ }^{857} \mathrm{Vgl}$. Schenke, in: Wolter u.a., Alternativentwurf Europol, S. 367 (376 f.); Schenke bezieht sich in seinen Ausführungen im übrigen noch auf das Europol-Übereinkommen, was aber an dieser Stelle irrelevant ist.

${ }^{858}$ Die Formulierung im SDÜ nimmt Bezug auf den veralteten Art. 18 EÜ („,Datenübermittlung an Drittstaaten und Drittstellen“); die entsprechenden Vorschriften finden sich jetzt in Art. 22 und 23 EuropolB.

${ }^{859}$ Beschluss 2009/934/JI des Rates, zur Festlegung der Durchführungsbestimmungen zur Regelung der Beziehung von Europol zu anderen Stellen einschließlich des Austauschs von personenbezogenen Daten und Verschlusssachen, vgl. AB1. 2009 L 325, 6, im Folgenden als „Beschluss vom 30. November 2009“ bezeichnet; der Rechtsakt vom 12. März 1999, AB1. C 88, 1, vom 30. März 1999, der auch diese Fragestellung betraf, ist nach Art. 63 EuropolBeschluss aufgehoben.

${ }^{860}$ Vgl. Art. 22 Abs. 1 und 23 Abs. 1 EuropolB und Art. 18 Abs. 2 lit. a Beschluss vom 30. November 2009.
} 
- an Einrichtungen der EU ${ }^{861}$ wie Eurojust, die europäische Agentur für die operative Zusammenarbeit an den Außengrenzen der Mitgliedstaaten der Europäischen Union (Frontex) und die Europäische Zentralbank,

- an Dritte ${ }^{862}$ wie Interpol, internationale Organisationen und Drittstaaten ${ }^{863}$ sowie $^{2}$

- von Einrichtungen der EU und Dritten, die ein operatives Abkommen mit Europol geschlossen haben, an andere Einrichtungen der EU und Dritte, wenn Europol zustimmt und mit diesen Einrichtungen der EU oder den Dritten ebenfalls ein operatives Abkommen geschlossen hat.

An Einrichtungen der EU übermittelt Europol Daten auch schon vor Inkrafttreten einer Arbeitsvereinbarung oder eines Abkommens, wenn dies für die rechtmäßige Erfüllung von Aufgaben des Empfängers erforderlich ist. ${ }^{864}$

An Dritte übermittelt Europol personenbezogene Daten, wenn dies in Einzelfällen zur Verhütung oder Bekämpfung von Straftaten, für die Europol zuständig ist, erforderlich ist und wenn Europol mit dem betreffenden Dritten ein Abkommen geschlossen hat, das die Übermittlung der Daten auf der Grundlage einer Feststellung zulässt, dass die Stelle, an die die Daten übermittelt werden, ein angemessenes Datenschutzniveau gewährleistet. ${ }^{865}$

Eine inhaltliche Zweckbegrenzung gibt es bei der Weitergabe der Daten durch Einrichtungen der EU und Dritte an ebensolche Stellen nicht.

Es wird festgestellt, dass die Datenweitergabe an eine große Zahl von Einrichtungen der EU und an Dritte sowie von diesen an weitere Dritte und Einrichtungen der EU erfolgt. Die von den unterschiedlichen Stellen verfolgten Zwecke sind schon allein aufgrund der hohen Anzahl der Akteure derart vielgestaltig, dass von einer Koppelung unterschiedlicher Zwecke ausgegangen werden muss.

\footnotetext{
${ }^{861}$ Vgl. zum Begriff: Art. 1 lit. c Beschluss vom 30. November 2009.

${ }^{862}$ Vgl. zum Begriff: Art. 1 lit. d Beschluss vom 30. November 2009.

${ }^{863}$ Europol strebt den Abschluss eines Abkommens, das auch den Austausch personenbezogener Daten ermöglicht, zur Zeit mit 25 verschiedenen Staaten an, darunter China, Kolumbien, Russland, die U.S.A. und Indien, vgl. Art. 1 Abs. 1 sowie den Anhang des Beschlusses 2009/935/JI des Rates vom 30. November 2009 zur Festlegung der Liste von Drittstaaten und dritten Organisationen, mit denen Europol Abkommen schließt, AB1. L 325, 13, vom 11. Dezember 2009.

${ }^{864}$ Art. 22 Abs. 3 EuropolB; Art. 11 Abs. 1 Beschluss vom 30. November 2009.

${ }^{865}$ Art. 23 Abs. 6 EuropolB; Art. 9 Nr. 4 Beschluss vom 30. November 2009, Art. 5 Abs. 4 Beschluss vom 30. November 2009 zum Verfahren für die Feststellung eines solchen Datenschutzniveaus.
} 


\section{bb. Vereinbarkeit, Zweckbestimmung und -begrenzung}

Diese Zwecke müssten mit dem Ausgangszweck vereinbar sowie bestimmt und begrenzt sein. $\mathrm{Zu}$ differenzieren ist hier zwischen

- Einrichtungen der EU,

- Dritten und Einrichtungen der EU, an die Dritte und Einrichtungen der EU Daten weitergeben und

- Dritten.

Für die Einrichtungen der EU gilt: In Art. 22 Abs. 1 EuropolB werden konkret sechs verschiedene Einrichtungen der EU aufgeführt. Diese Aufzählung ist jedoch nicht abschließend; Europol kann Daten an sämtliche durch den Vertrag über die Europäische Union und die Verträge zur Gründung der Europäischen Gemeinschaften oder auf dessen/deren Grundlage errichteten Organe, Einrichtungen, Ämter und Agenturen übermitteln. Für den normalen Bürger und auch einen Rechtskundigen ist es mit erheblichem Aufwand verbunden, erst einmal herauszufinden, welche Stellen damit aktuell gemeint sind. Problematisch ist es auch, dass diese sämtlichen Stellen die Daten für ihre Zwecke nutzen dürfen; eine Bezugnahme etwa auf Zwecke der Strafverfolgung oder Verhinderung von Straftaten fehlt. Von einer ausreichenden inhaltlichen Zweckbegrenzung ist damit nicht auszugehen. Problematisch erscheint es vor diesem Hintergrund auch, eine Vereinbarkeit mit dem Ausgangszweck positiv festzustellen. Weiss man nicht, für welche konkreten Zwecke beispielsweise die Europäische Zentralbank, ein europäisches Gremium mit einem grundsätzlich anderen Tätigkeitsfeld als Europol, ${ }^{866}$ die Daten verwendet, kann man auch keine Aussage dazu treffen, ob die Zwecke vereinbar sind. Damit fehlt es an der Vereinbarkeit.

Mangels entsprechender Bestimmungen fehlt es auch an einer Zweckbegrenzung bei der Weitergabe der Daten durch Einrichtungen der EU und Dritte an ebensolche Stellen. Für die Vereinbarkeit gilt das oben Festgestellte.

Bezüglich der Datenübermittlung an Dritte lässt sich demgegenüber eine Zweckbegrenzung gerade noch annehmen, da diese ausdrücklich Bezug nimmt auf die Aufgaben von Europol. ${ }^{867}$ Auch von einer Vereinbarkeit soll wegen der inhaltlichen Bezugnahme ausgegangen werden.

\footnotetext{
${ }^{866}$ Art. 22 Abs. 1 e) EuropolB; vorrangige Aufgabe der EZB ist es, gemeinsam mit den nationalen Zentralbanken die Preisstabilität innerhalb des Euro-Raumes zu gewährleisten, Art. 282 Abs. 1 S. 1, Abs. 2 S. 2 AEUV.

${ }^{867}$ Art. 23 Abs. 6 EuropolB; Art. 9 Nr. 4 Beschluss vom 30. November 2009.
} 


\section{cc. Organisations- und verfahrensrechtliche Vorschriften}

Das Europol-Übereinkommen sowie der Beschluss vom 30. November 2009 enthalten einige Regelungen im Hinblick auf Verfahren und Organisation zum Schutz personenbezogener Daten. Für Einrichtungen der EU und Dritte gilt, dass Zweck und Gründe für ein auf die Übermittlung personenbezogener Daten gerichtetes Ersuchen angegeben werden müssen ${ }^{868}$ und dass die Daten nur übermittelt werden, wenn der Empfänger zusagt, sie lediglich zu dem angegebenen Zweck zu nutzen. ${ }^{869}$ Europol stellt sicher, dass die Einrichtung der EU oder der Dritte die Daten u.a. wegen Unrichtigkeit oder Zweckerreichung berichtigt oder löscht. ${ }^{870} 871$

Bei diesen Regelungen handelt es sich um die Beziehung zwischen den die jeweiligen Daten speichernden beteiligten öffentlich-rechtlichen Stellen. Ein Auskunfts- und Berichtungsrecht des Bürgers, das an dieser Schnittstelle ansetzt, gibt es aber nicht. Zwar zeichnet Europol jede Übermittlung und ihren Anlass auf ${ }^{872}$ jedoch ist nicht davon auszugehen, dass sich das Auskunftsrecht nach Art. 30 EuropolB auch darauf bezieht zu erfahren, an welche anderen Stellen Daten weitergeleitet wurden. Dafür spricht zum einen der Wortlaut von Absatz 1, der als Auskunftsgegenstand eine Datenverarbeitung „von Europol“ bezeichnet. Im Verfahren für die Auskunftserteilung werden zudem nur die Mitgliedstaaten konsultiert und die Liste der Versagensgründe nennt auch keine Interessen von Einrichtungen der EU oder Dritter. ${ }^{873}$

Wenn man also mit Hilfe des Auskunftsrechts gegenüber Europol nicht erfahren kann, an wen die Daten weitergeleitet wurden, ist unklar, an welche weitere Stelle man sich zur Auskunft wenden soll. Doch selbst, wenn man es wüsste, blieben zwei Fragen ungelöst: Das von Europol bei Dritten festgestellte angemessene Datenschutzniveau sagt nicht unbedingt etwas über das Bestehen von Auskunfts- und Berichtigungsrechten für den Betroffenen und deren gerichtliche Durchsetzbarkeit sowie eine unabhängige Aufsichtsbehörde aus. ${ }^{874} 875$ Zum anderen würde auch

\footnotetext{
${ }^{868}$ Art. 15 Absatz 1 Beschluss vom 30. November 2009.

${ }^{869}$ Art. 24 Abs. 2 S. 3 EuropolB; Art. 10 S. 3 Beschluss vom 30. November 2009.

${ }^{870}$ Art. 16 Beschluss vom 30. November 2009.

${ }^{871}$ Hierin liegt kein Widerspruch zur oben festgestellten fehlenden Zweckbegrenzung, da die anfordernden Stellen jeglichen Zweck benennen können, den sie innerhalb ihres Aufgabengebietes verfolgen.

${ }^{872}$ Art. 24 Abs. 2 S. 2 EuropolB und Art. 10 S. 2 Beschluss vom 30. November 2009.

${ }^{873}$ Art. 30 Abs. 4 und 5 EuropolB; Abhilfe könnte hier der eigentlich nicht einschlägige Art. 17 Abs. 1 Rahmenbeschluss 2008/977/JI des Rates vom 27. November 2008 über den Schutz personenbezogener Daten, die im Rahmen der polizeilichen und justiziellen Zusammenarbeit in Strafsachen verarbeitet werden, vgl. Fn. 818, schaffen. Diese Vorschrift gibt grundsätzlich ein Auskunftsrecht, das den Empfänger personenbezogener Daten nennt.

${ }^{874}$ Diese Schwachstelle machen auch Gleß/Zerbes, allerdings mit Blick auf die alte Rechtslage vor Geltung des EuropolB und des Beschlusses vom 30. November 2009, aus, indem sie parallel zur amtswegigen Kontrolle die Gewährleistung von Verfahrensrechten mutmaßlich Betroffener zur effektiven Überwachung individuellen Datenschutzes auch in Drittstaaten bzw. bei Drittstellen fordern, vgl. Gleß/Zerbes in: Wolter u.a., Alternativentwurf Europol, S. 346 (363).

${ }^{875}$ Zwar wird eine unabhängige Aufsichtsbehörde ausdrücklich als Kriterium für die Feststellung eines angemessenen Datenschutzniveaus erwähnt, jedoch handelt es sich nicht um eine unverzichtbare Voraussetzung; die Existenz
} 
hier wieder durchschlagen, was das Auskunftsrecht in Bezug auf Daten, die nur von Europol verwendet werden, unzureichend erscheinend lässt: Es ist nicht davon auszugehen, dass eine Benachrichtigungspflicht nach der Beendigung von verdeckten Maßnahmen besteht.

Soweit Einrichtungen der EU und Dritte Daten an ebensolche Stellen weitergeben, ist formelle Voraussetzung, dass die weitergebenden Stellen ein operatives Abkommen mit Europol geschlossen haben, dass Europol der Weitergabe zustimmt und dass die empfangenden Stellen mit Europol ebenfalls ein operatives Abkommen geschlossen haben. ${ }^{876}$ Andere Bestimmungen gibt es nicht. Aus Sicht des Bürgers bestehen deshalb in dieser Konstellation die gleichen Kritikpunkte wie bei der Weitergabe unmittelbar durch Europol an Einrichtungen der EU und Dritte.

Zusammenfassend lässt sich feststellen, dass die Datenschutzbestimmungen, die der EuropolB und der Beschluss vom 30. November 2009 treffen, den Anforderungen, die sich für die Koppelung von Zwecken aus Art. 8 GR-Charta ergeben, nicht genügen. Hinsichtlich der Daten, die durch Europol verwaltet werden, fehlt es an einer Benachrichtigungspflicht und es bleibt derzeit unklar, auf welche Weise die dem Individuum zustehenden Rechte gerichtlich durchsetzbar sind. Bezüglich der Weitergabe der Daten fehlt es teilweise an einer Zweckbegrenzung und Vereinbarkeit der Zwecke sowie an einem dem Individuum zustehenden einklagbaren Recht auf Auskunft und Berichtigung, einer Benachrichtigungspflicht nach dem Ende einer verdeckten Maßnahme sowie an der gesicherten Existenz einer unabhängigen Aufsichtsstelle. Durch den Zugriff für Europol auf die Daten nach Art. 99 SDÜ öffnet sich bildlich gesprochen eine Schleuse und die Daten schwimmen in einem großen Datenfluss auf nicht mehr nachvollziehbare Weise davon. Trotz verschiedener individueller Rechte hat der einzelne keine effektive Kontrolle mehr über seine Daten.

Eine grundrechtschartakonforme Auslegung kommt bereits deshalb nicht in Betracht, weil die EU und die Mitgliedstaaten beispielsweise die Modalitäten und das Verfahren für eine Benachrichtigungspflicht selbst festlegen müssten.

Art. 101 a SDÜ, der für die Verwendung der Daten durch Europol keine weiteren Einschränkungen im o.g. Sinne macht, ist aus diesen Gründen nicht mit der GR-Charta vereinbar.

\footnotetext{
einer solchen Behörde findet bei der Beurteilung lediglich „Berücksichtigung“, vgl. Art. 5 Abs. 4 S. 3 Beschluss vom 30. November 2009.

${ }^{876}$ Art. 18 Abs. 2 lit. a Beschluss vom 30. November 2009.
} 


\section{Ergebnis zur strafprozessualen Kombinationsnorm}

Abschließend wird festgestellt, dass die strafprozessuale Kombinationsnorm unter verschiedenen Gesichtspunkten gegen Art. 8 GR-Charta verstößt. Durchgreifende Bedenken bestehen hinsichtlich der Erforderlichkeit, der Angemessenheit, der Bestimmtheit sowie der Zulässigkeit der Koppelung von Zwecken. Als problematisch erweist sich unter diesen Gesichtspunkten insbesondere der unbestimmte Rechtsbegriff der „außergewöhnlich schweren Straftaten“, die Inanspruchnahme potentiell unbeteiligter Personen, der geringe Nutzen und die Heimlichkeit der Maßnahme sowie das teilweise Fehlen einer Zweckbegrenzung und organisatorischer und verfahrensrechtlicher Sicherungen bei der Nutzung der Daten durch Europol. 


\section{Teil: SIS II}

Im Jahr 2001 haben die Arbeiten an einem Schengener Informationssystem zweiter Generation, sogenanntes SIS II, auf EU-Ebene begonnen. Der ursprünglich für März 2007 geplante Start musste aufgrund technischer Probleme immer wieder verschoben werden, so dass man schließlich durch eine technische Abwandlung des bestehenden SIS, sogenanntes SISone4ALL, die Teilnahme von neun der am 1. Mai 2004 der EU beigetretenen Staaten zum 21. Dezember 2007 ermöglichte. ${ }^{877}$ Nach Angaben der Europäischen Kommission kann mit einem Start des SIS II Anfang Jahres 2013 gerechnet werden. ${ }^{878}$

Dessen ungeachtet sind die erforderlichen Rechtsgrundlagen seit dem Jahr 2009 vorhanden. Es handelt sich dabei um zwei Ratsverordnungen, einen Ratsbeschluss sowie um das deutsche SISII-Gesetz zur Umsetzung des Ratsbeschlusses ${ }^{879}$ Bei den Neuerungen des geplanten SIS II lassen sich im wesentlichen drei Bereiche unterscheiden, nämlich die Integrationsmöglichkeit für neue Teilnehmer-Staaten, die Einführung fahndungsunterstützender Funktionen sowie die Erweiterung bestehender Fahndungskategorien.

Bei der Integrationsmöglichkeit für neue Teilnehmer-Staaten ist vorgesehen, deutlich mehr als 30 Schnittstellen zu schaffen, da mittel- bis langfristig weitere Staaten wie Kroatien, Serbien, Montenegro, Albanien und ggf. die Türkei der EU beitreten werden und damit auch am grenzkontrollfreien Binnenraum teilhaben werden. ${ }^{880}$

Fahndungsunterstützend sieht das SIS II u.a. folgende Neuerungen vor:

Möglich sein soll die Speicherung von und Abfrage mit Fingerabdrücken und Lichtbildern. ${ }^{881}$ Die Aufnahme dieser Daten führt zu einer schnellen und zweifelfreien Feststellung der Identität zwischen ausgeschriebener Person und kontrollierter Person.

\footnotetext{
${ }^{877}$ Tuffner, Polizei-heute 2007, 114 (116 f.); Schriever-Steinberg, in: Breitenmoser u.a., Schengen in der Praxis, S. $159(169)$.

${ }^{878} \mathrm{http}: / / \mathrm{www}$.heise.de/newsticker/meldung/EU-Kommission-sieht-SIS-II-wieder-auf-dem-richtigen-Weg1279495.html, Abruf vom 28. April 2012.

${ }^{879}$ Verordnung (EG) Nr. 1987/2006 des Europäisches Parlamentes und des Rates vom 20. Dezember 2006 über die Einrichtung, den Betrieb und die Nutzung des Schengener Informationssystems der zweiten Generation (SIS II), ABl. L 381, 4, im Folgenden VO SIS II; Verordnung (EG) Nr. 1986/2006 des Europäischen Parlamentes und des Rates vom 20. Dezember 2006 über den Zugang von für die Ausstellung von Kfz-Zulassungsbescheinigungen zuständigen Dienststellen der Mitgliedstaaten zum Schengener Informationssystem der zweiten Generation (SIS), AB1. L 381, 1; Beschluss 2007/533/JI des Rates vom 12. Juni 2007 über die Einrichtung, den Betrieb und die Nutzung des Schengener Informationssystems der zweiten Generation (SIS II), AB1. L 205, 63, im folgenden Ratsbeschluss SIS II; Gesetz zum Schengener Informationssystem des zweiten Generation (SIS-II-Gesetz) vom 6. Juni 2009, BGB1. $2009,1226$.

${ }^{880}$ Tuffner, Polizei-heute 2007, 114 (117).

${ }^{881}$ Art. 20 Abs. 3 e, f, Art. 22 Ratsbeschluss SIS II; Art. 20 Nr. 2 e, f, Art. 22 VO SIS II.
} 
In diesen Zusammenhang gehört auch die Speicherung der biometrischen Daten von Unbeteiligten im Falle einer missbräuchlich verwendeten Identität. ${ }^{882}$ Die mit Zustimmung der nicht gesuchten Person hinterlegten Fingerabdrücke und Fotos im SIS II ermöglichen eine schnelle Erkenntnis über die wahre Identität der aktuell kontrollierten Person.

Vorgesehen ist zur Fahndungsunterstützung weiterhin die Verknüpfbarkeit von Fahndungen, also etwa die Verbindung der Fahndung nach dem Mörder mit der Fahndung nach dessen Fluchtfahrzeug. ${ }^{883}$

Schließlich soll auch der Europäische Haftbefehl als Bilddatei im SIS II abgebildet werden können. ${ }^{884}$

Bei der Erweiterung von Fahndungkategorien werden in die Sachfahndung als mögliche Ausschreibungsobjekte u.a. zusätzlich Luftfahrzeuge, Wasserfahrzeuge sowie Container aufgenommen. ${ }^{885}$ Bei der Ausschreibung zur verdeckten Registrierung, die dann verdeckte Kontrolle heißen wird, können ebenfalls Flugzeuge aller Art, Schiffe, Boote und Container in die Ausschreibung einbezogen werden. ${ }^{886}$

Im Hinblick auf die in dieser Arbeit festgestellten rechtlichen Mängel ${ }^{887}$ ist festzuhalten, dass die neuen Rechtsgrundlagen teilweise Abhilfe schaffen. So nimmt Art. 36 Abs. 2 Ratsbeschluss SIS II zur Bestimmung der außergewöhnlich schweren Straftat Bezug auf den $\mathrm{RbEuHb},{ }^{888}$ so dass die im Hinblick auf die Erforderlichkeit und Bestimmtheit vorgebrachten rechtlichen Bedenken entkräftet sind. Zudem sieht jedenfalls das deutsche SIS-II-Gesetz im Falle einer verdeckten Kontrolle und der Ausschreibung durch deutsche Stellen eine differenzierte Benachrichtigungsregelung unter gerichtlicher Beteiligung vor. ${ }^{889}$ Diesbezüglich geht das Zustimmungsgesetz sogar über das hinaus, was in der Arbeit als rechtlich unabdingbar erachtet wurde.

Gleichwohl räumen die neuen Rechtsgrundlagen die bestehenden Bedenken in wesentlichen Punkten nicht aus. Nach wie vor gibt es eine Fahndungskategorie - verdeckte Kontrolle - die grundsätzlich eine heimliche Erhebung und die Erhebung von Daten Unbeteiligter erlaubt. Zudem hat Europol die auch schon im Rahmen des SDÜ bestehenden Zugriffs- und Verarbei-

\footnotetext{
${ }^{882}$ Art. 51 Ratsbeschluss SIS II; Art. 36 VO SIS II.

${ }^{883}$ Art. 20 Abs. 3 m, Art. 52 Ratsbeschluss SIS II; Art. 20 Nr. 2 m, Art. 37 VO SIS II; Tuffner, Polizei-heute 2007, 114 (117)

${ }^{884}$ Art. 27 Ratsbeschluss SIS II.

${ }^{885}$ Art. 38 Abs. 2 a, b Ratsbeschluss SIS II.

${ }^{886}$ Art. 36 f. Ratsbeschluss SIS II.

${ }^{887}$ Siehe oben 3 . Teil B. V.

${ }^{888}$ Rahmenbeschluss 2002/584/JI des Rates vom 13. Juni 2002 über den Europäischen Haftbefehl und die Übergabeverfahren zwischen den Mitgliedstaaten, AB1. L 190, 1.

${ }^{889}$ Art. 2 Nr. 5 Gesetz zum Schengener Informationssystem des zweiten Generation (SIS-II-Gesetz) vom 6. Juni 2009, BGBl. 2009, 1226.
} 
tungsmöglichkeiten. ${ }^{890}$ Eine Unvereinbarkeit mit Art. 8 GR-Charta besteht demnach weiterhin unter den Gesichtspunkten der Angemessenheit sowie der Zulässigkeit der Koppelung von Zwecken. Diese Bedenken wiegen umso schwerer, als das SIS II über die größere Zahl zukünftiger Teilnehmer-Staaten sowie die geplanten Verknüpfungsmöglichkeiten weiter an Bedeutung gewinnen wird.

${ }^{890}$ Art. 36 f., Art. 41 Ratsbeschluss SIS II. 


\section{Teil: Zusammenfassung und Bewertung}

\section{A. Zusammenfassung}

Ab Mitte der 1970er Jahre gewann in Europa die Idee eines Raumes, in dem sich die Bürger frei bewegen können, zunehmend an Bedeutung. Nach dem Scheitern entsprechender Einigungsbemühungen auf europäischer Ebene kam es im Jahr 1985 zum Abschluss des Schengener Abkommens zwischen Deutschland, Frankreich und den Beneluxstaaten. Der Durchführung dieses Abkommens diente das ebenfalls zwischen einzelnen Staaten abgeschlossene SDÜ aus dem Jahr 1990. Kern der Schengen-Zusammenarbeit war die Schaffung eines Binnenraumes ohne Grenzkontrollen bei gleichzeitiger Anwendung von Ausgleichsmaßnahmen. Herzstück dieser Ausgleichsmaßnahmen ist das elektronische SIS, das der europaweiten Fahndung nach Personen und Sachen dient und im Jahr 1995 in Betrieb ging. Dem SDÜ traten nach und nach immer mehr Mitgliedstaaten der Europäischen Union bei, so dass der sogenannte Schengen-Besitzstand mit dem Vertrag von Amsterdam aus dem Jahr 1997 in den institutionellen Rahmen der Union überführt wurde. Neue Mitgliedstaaten sind seitdem verpflichtet, diesen Besitzstand vollständig zu übernehmen (2. Teil der Arbeit, A. I. bis X.).

Das SIS vollzieht auf europäischer Ebene die datentechnische Entwicklung nach, die innerhalb Deutschlands mit dem Namen INPOL verbunden ist und löst im Schengen-Raum die Fahndung über Interpol ab (2. Teil der Arbeit, B. I.) Das SIS ist als Rechner-Verbundsystem konzipiert; es besteht aus einen nationalen Teil bei jeder Vertragspartei und einer zentralen technischen Unterstützungseinheit. Die nationalen Teile kommunizieren auf der einen Seite mit dem jeweiligen nationalen polizeilichen Informationssystem und auf der anderen Seite mit der zentralen Einheit. Ziel ist es, dass der Datenbestand in allen nationalen Teilen zu jedem Zeitpunkt identisch ist. $\mathrm{Zu}$ diesem Zweck werden die in einem Vertragsstaat eingegebenen Daten an die zentrale Einheit übermittelt und dort einer großen Kopiermaschine gleich innerhalb von Minuten an alle nationalen Teile verschickt. Die sogenannten Sirenen wachen in ihrem jeweiligen Land über die Einhaltung der Bestimmungen des SDÜ und sorgen für das reibungslose Funktionieren ihres nationalen SIS-Teils (2. Teil der Arbeit, B. II. und VI.).

Das SIS umfasst sechs Fahndungskategorien. Diese Kategorien unterscheiden danach, ob nach Personen oder Sachen gesucht und welche Art von Maßnahme bei Antreffen der Person bzw. Auffinden der Sache erbeten wird (2. Teil der Arbeit, B. III.).

Das SDÜ enthält Regeln zum Datenschutz und zum hierauf gerichteten Rechtsschutz. Zu erwähnen sind hier ein Auskunfts-, Berichtigungs-, Löschungs- und Schadensersatzrecht der betroffe- 
nen Person. Zudem gilt in Deutschland eine grundsätzliche Pflicht zur Benachrichtigung nach Ende einer verdeckten Registrierung. Über die Einhaltung der Vorschriften wachen unabhängige Kontrollinstanzen (2. Teil der Arbeit, B. IV.).

Auf europäischer Ebene gibt es mittlerweile zahlreiche Sammlungen personenbezogener Daten. Sie enthalten teilweise Daten, die mit denen des SIS identisch sind. Ihre Verwendung dient jedoch primär anderen Zwecken als der Fahndung, die Aufgabe des SIS ist (2. Teil der Arbeit, C.).

Von einigen Autoren wird die demokratische Legitimation des SDÜ, also der Rechtsgrundlage für das SIS, in Frage gestellt.

Zum einen wird bemängelt, dass der Bundestag bei der Ausarbeitung des SDÜ nicht ausreichend eingebunden und auf eine bloße Zustimmung oder Ablehnung bei der Abstimmung nach Art. 59 Abs. 2 GG beschränkt gewesen sei. Eine Überprüfung anhand des Demokratieprinzips, wie es seine Ausprägung in den Aufgaben des Bundestages gefunden hat, kommt zu dem Ergebnis, dass die Art und Weise der Beteiligung des Bundestages unter besonderer Berücksichtigung des Demokratieprinzips als ausreichend anzusehen ist (3. Teil der Arbeit, A. I.).

Der andere Kritikpunkt betrifft die Frage, ob es auch eines Gesetzes nach Art. 24 Abs. 1 GG bedurft hätte. Dies setzt voraus, dass der Bund durch Gesetz Hoheitsrechte auf eine zwischenstaatliche Einrichtung überträgt. Im Ergebnis liegt in den Befugnissen des Exekutivausschusses, auf die hier richtigerweise abzustellen ist, keine solche Übertragung, da es ihnen am notwendigen Durchgriffscharakter fehlt (3. Teil der Arbeit, A. III.).

Zur Überprüfung kommt auch die strafprozessuale Variante der verdeckten Registrierung. Prüfungsmaßstab ist nach Inkrafttreten des Vertrags von Lissabon und der Charta der Grundrechte der Europäischen Union nicht mehr das Grundgesetz sondern Art. 8 der GR-Charta. Durch die verdeckte Registrierung wird in den Schutzbereich des Grundrechts eingegriffen. Die Eingriffe sind nur zum Teil gerechtfertigt. Die Anforderungen an eine präzise Zweckfestlegung, die Achtung des Wesensgehaltes sowie organisatorische und verfahrensrechtliche Vorkehrungen erscheinen erfüllt. Durchgreifende Bedenken bestehen jedoch hinsichtlich der Erforderlichkeit, der Angemessenheit, der Bestimmtheit sowie der Zulässigkeit der Koppelung von Zwecken (3. Teil der Arbeit, B.)

Seit dem Jahr 2001 wird auf europäischer Ebene an einem SIS der zweiten Generation gearbeitet. Während sämtliche Rechtsgrundlagen vorhanden sind, scheitert die Verwirklichung bisher an 
technischen Problemen. Die in Bezug auf das SDÜ festgestellten rechtlichen Bedenken haben zum Teil auch im Hinblick auf die Rechtsgrundlagen zum SIS II Bestand (4. Teil der Arbeit).

\section{B. Bewertung}

Eine abschließende Bewertung bezieht sich auf einen Zusammenhang, in den das SIS bei seiner Einrichtung immer wieder gestellt wurde: Wie steht es um die Kriminalitätsbekämpfung innerhalb Europas und welche Bedeutung kommt dabei dem SIS zu?

Liest man die Veröffentlichungen der mit der Materie praktisch Befassten aus den 1990er Jahren, dann wird dort oft ein ernüchterndes Bild der Möglichkeiten von Polizei und Justiz insbesondere bei der transnationalen Strafverfolgung gezeichnet. Das vorhandene Gesetzinstrumentarium wird fast archaisch genannt. Bildlich gesprochen reisten die Verbrecher mit Überschallgeschwindigkeit in der Concorde, während ihnen Polizei im Porsche folge und die Justiz die Postkutsche besteige. Den (Polizei-) praktiker würde das „geregelte Chaos“, das eine schnelle Bearbeitung verhindere, zur Verzweiflung treiben. Beklagt wird die unüberschaubare Vielzahl von völkerrechtlichen Übereinkünften, Zusatzabsprachen, Vorbehalten, nationalen Regelungen, Ausführungsbestimmungen, Zuständigkeitsvereinbarungen und Erlassen. ${ }^{891}$

Insbesondere mit dem Inkrafttreten des Vertrags von Amsterdam gewinnt die Europäisierung auch im Bereich der polizeilichen und justiziellen Zusammenarbeit an Dynamik. ${ }^{892}$ Die Europäische Union nutzte insbesondere das Mittel des Rahmenbeschlusses nach Art. 34 Abs. 2 b) EUV, um bessere Grundlagen für eine effektive Zusammenarbeit zwischen den Mitgliedstaaten zu schaffen. ${ }^{893}$ Kritisiert wird angesichts der Fortschritte jedoch vielfach, dass es dabei an demokratischer Legitimation sowie justizieller Kontrolle fehle und beispielsweise eine Harmonisierung im Bereich von Beschuldigtenrechten zu kurz komme. ${ }^{894}$ Mit dem Vertrag von Lissabon wird jedenfalls über das häufig einschlägige Verfahren der Mitentscheidung die Rolle des Europäischen Parlamentes bei der Schaffung eines Raumes des Freiheit, der Sicherheit und des Rechtes

\footnotetext{
${ }^{891}$ Fätkinhäuer, KR 1994, 307 (307); Wolters, KR 1997, 86 (86); ders., in: Bundeskriminalamt, Festschrift für Herold, 225 (227 ff.); Schübel, NStZ 1997, 105 (110).

${ }^{892}$ Zieschang, ZStW 113 (2001), 255 (259, 262).

${ }^{893}$ Radtke, GA 2004, 1 (14); siehe u.a. Rahmenbeschluss 2002/584/JI des Rates vom 13. Juni 2002 über den Europäischen Haftbefehl, AB1. L 190, 1; Rahmenbeschluss 2003/577/JI des Rates vom 22. Juli 2003 über die Vollstreckung von Entscheidungen über die Sicherstellung von Vermögensgegenständen oder Beweismitteln innerhalb der europäischen Union, ABl. L 196, 45; Rahmenbeschluss 2008/978/JI des Rates vom 18. Dezember 2008 über die Europäische Beweisanordnung zur Erlangung von Sachen, Schriftstücken und Daten zur Verwendung in Strafsachen, AB1. L 350, 72; Rahmenbeschluss 2009/829/JI des Rates vom 23. Oktober 2009 über die Anwendung - zwischen den Mitgliedstaaten der Europäischen Union - des Grundsatzes der gegenseitigen Anerkennung auf Entscheidungen über Überwachungsmaßnahmen als Alternative zur Untersuchungshaft, AB1. L 294, 20.

${ }^{894}$ Sieber, ZStW 121 (2009), 1 (12 f.); Radtke, GA 2004, 1 (14); Maurer/Monar, in: Lange, Staat, Demokratie und Innere Sicherheit, S. 311 (327 f.); Gleß, mit Bezug auf die Rolle von Europol, DRiZ 2000, 365 (372 f.); vgl. hierzu auch den 3. Teil dieser Arbeit.
} 
entscheidend gestärkt. Zudem hält eine Analyse der Modelle des Europäischen Strafrechts ${ }^{895}$ eine interessante Erkenntnis bereit: Vor zehn bis fünfzehn Jahren konnte man den Eindruck gewinnen, dass eine effektive und zugleich rechtsstaatliche transnationale Kriminalitätsbekämpfung nur durch weitgehende Schaffung supranationaler Normen und Institutionen möglich wäre; dass also ein Kooperationsmodell langfristig keine Zukunft hätte. ${ }^{896}$ Man ging davon aus, dass nur ein einheitliches System die notwendige Kohärenz und Widerspruchslosigkeit gewährleistet. Diese Sichtweise ist neben der Angst um Souveränitätsverluste wohl auch der Grund dafür gewesen, dass sich die Nationalstaaten bei der Zusammenarbeit in diesem Bereich so schwer taten ${ }^{897}$ Bei einer einseitigen Bevorzugung eines einzigen Modells ließe man jedoch außer Acht, dass beide Reinformen ihre Vor- und Nachteile haben. Das kooperative Modell lässt den Nationalstaaten mehr Souveränität und trägt dem Subsidiaritätsprinzip Rechnung. Je größer jedoch die Unterschiede zwischen den kooperierenden Rechtsordnungen sind, desto größer sind - je nach Ausgestaltung - die Einbußen im Hinblick auf die Effektivität der Zusammenarbeit oder aber den rechtsstaatlichen Schutz der Beschuldigten und anderen Verfahrensbeteiligten. Das supranationale Modell bewirkt demgegenüber eine effektive Rechtsdurchsetzung und garantiert einheitliche effektive rechtsstaatliche Sicherungen. Dies geht aber zulasten nationaler Souveränität und widerspricht häufig dem Subsidiaritätsgrundsatz. Zudem fehlt es teilweise an demokratischer Legitimation und Kontrolle. Aus dieser Analyse ergibt sich die Schlussfolgerung, dass trotz der damit verbundenen Komplexität und Uneinheitlichkeit nicht die eine oder die andere, sondern einzig eine Mischform das Modell der Zukunft sein kann. Nur auf diese Weise lassen sich die Vorteile addieren und die Nachteile reduzieren, die beim Idealtyp des jeweiligen Modells bestehen. ${ }^{898}$

Das SIS hat engen Bezug zu supranationalen Regelungen, so z.B. in dem Bereich, in dem die Grundsätze des Europäischen Haftbefehls ${ }^{899}$ einheitlich angewendet werden oder die Grenzkontrollen an den Außengrenzen gemäß dem Schengener Grenzkodex ${ }^{900}$ stattfinden. Insgesamt bleibt es jedoch dezentral organisiert, da jeder Teilnehmerstaat sein eigenes N.SIS betreibt, die Möglichkeit der Kennzeichnung besteht und u.a. nach Art. 104 SDÜ nationale Regeln große Bedeutung behalten. Auch das geplante SIS II behält die dezentrale Struktur grundsätzlich bei.$^{901}$

\footnotetext{
${ }^{895}$ Sieber, ZStW 121 (2009), 1 (16 ff.).

${ }^{896}$ Radtke, GA 2004, 1 (21); Brüner/Hetzer, NStZ 2003, 113 (118); Zieschang, ZStW 113 (2001), 255 (270).

${ }^{897}$ Zöberlein, Eurojust, S. 45; Zieschang, ZStW 113 (2001), 255 (270).

${ }^{898}$ Sieber, ZStW 121 (2009), 1 (63 ff.).

${ }^{899}$ Relevant im Bereich von Art. 95 SDÜ.

${ }^{900}$ VO (EG) Nr. 562/2006 des Europäischen Parlaments und des Rates vom 15. März 2006, AB1. L 105, 1, relevant für Art. 96 SDÜ.

${ }^{901}$ Art. 4 SIS II-Ratsverordnung, VO (EG) Nr. 1987/2006 des Europäischen Parlaments und des Rates vom 20. Dezember 2006, AB1. L 381, 4; Art. 4 SIS II-Ratsbeschluss, Beschluss 2007/533/JI des Rates vom 12. Juni 2007 , AB1. L 205, 63 .
} 
Bei seiner Einführung 1995 wurde das SIS als Quantensprung in der Fahndung bezeichnet. ${ }^{902}$ Konnte man zwischenzeitlich den Eindruck gewinnen, dass die kooperativen Systeme langfristig keine Zukunft haben, ist das nun nicht mehr der Fall. Wie im 3. Teil dieser Arbeit dargelegt, bietet das SIS aus rechtlicher Sicht aber durchaus Anlass zu Kritik. Bei der festgestellten Verletzung von Art. 8 GR-Charta spielt die Heimlichkeit der Fahndungmethode der verdeckten Registrierung und das damit bei den Bürgern gesäte Misstrauen eine entscheidende Rolle. Dieses Misstrauen ist nicht hinnehmbar, wenn der Nutzen der Maßnahme gleichzeitig gering erscheint. Im Hinblick auf die anderen Fahndungskategorien, die keine Heimlichkeit voraussetzen, besteht jedoch kein Zweifel daran, dass das SIS einen wichtigen Beitrag zur Kriminalitätsbekämpfung innerhalb Europas leistet. Und: Legt man die Erkenntnisse der oben genannten Analyse zum Europäischen Strafrecht zugrunde, hat das SIS in seiner jetzigen Konzeption nichts an Aktualität verloren.

${ }^{902}$ Tuffner, KR 2000, 39 (39); Schuster, in: Bundeskriminalamt, Arbeitstagung „Neue Freiheiten, neue Risiken, neue Chancen“, 147 (158). 


\section{Anhang}

\section{Das Schengener Durchführungsübereinkommen - Konsolidierte Fassung}

Quelle: Bundesministerium des Innern

Stand: 4. Mai 2010

(letzte Änderung des Übereinkommens am 4. Mai 2010, vgl. http://eur-lex.europa.eu/LexUriServ/LexUriServ.do?uri=Celex:42000A0922(02):DE:NOT, Abruf vom 30. April 2012) 


\title{
Schengener Durchführungsübereinkommen
}

\author{
Übereinkommen vom 19. Juni 1990 \\ zur Durchführung des Übereinkommens von Schengen vom 14. Juni \\ 1985 \\ zwischen den Regierungen der Staaten der Benelux-Wirtschaftsunion, \\ der Bundesrepublik Deutschland und der Französischen Republik \\ betreffend den schrittweisen Abbau der Kontrollen an den \\ gemeinsamen Grenzen
}

ABl. Nr. L 239 vom 22. September 2000 S. 1

Inhalt

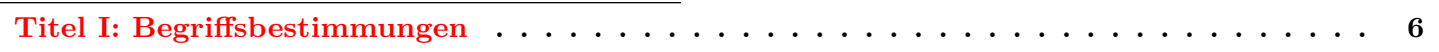

Titel II: Abschaffung der Kontrollen an den Binnengrenzen und Personenverkehr . . . . 7

Kapitel 1 Überschreiten der Binnengrenzen . . . . . . . . . . . . . . . . . . . . . . . . . . . . . . . 7

Kapitel 2 Überschreiten der Aussengrenzen . . . . . . . . . . . . . . . . . . . . . . . . . 7

Kapitel 3 Sichtvermerke . . . . . . . . . . . . . . . . . . . . . . 7

Abschnitt 1 Sichtvermerke für einen kurzfristigen Aufenthalt . . . . . . . . . . . . . . . . 7

Abschnitt 2 Sichtvermerke für einen längerfristigen Aufenthalt . . . . . . . . . . . . . . 7

Kapitel 4 Voraussetzungen für den Reiseverkehr von Drittausländern . . . . . . . . . . . . . . 7

Kapitel 5 Aufenthaltstitel und Ausschreibung zur Einreiseverweigerung . . . . . . . . . . . . . 8

Kapitel 6 Weitere Maßnahmen . . . . . . . . . . . . . . . . . . . . . . . . . . . . . . . .

Kapitel 7 Zuständigkeit für die Behandlung von Asylbegehren . . . . . . . . . . . . . . . . . . . . . . . . . . . . . . . . . . . . . . . .

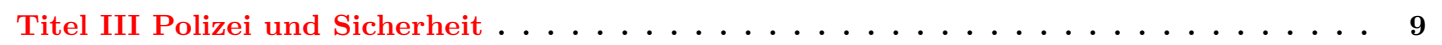

Kapitel 1 Polizeiliche Zusammenarbeit . . . . . . . . . . . . . . . . . . . . . . . . . . . . . . .

Kapitel 2 Rechtshilfe in Strafsachen . . . . . . . . . . . . . . . . . . . . . . . . . . . . . . . . . . . . . . . . . .

Kapitel 3 Verbot der Doppelbestrafung . . . . . . . . . . . . . . . . . . . . . . . . 17

Kapitel 4 Auslieferung . . . . . . . . . . . . . . . . . . . . . . . . . . 18

Kapitel 5 Übertragung der Vollstreckung von Strafurteilen . . . . . . . . . . . . . . . . . . . . . 18

Kapitel 6 Betäubungsmittel . . . . . . . . . . . . . . . . . . . . . . 18

Kapitel 7 Feuerwaffen Und Munition . . . . . . . . . . . . . . . . . . . . . . . . . . 19

Titel IV Schengener Informationssystem . . . . . . . . . . . . . . . . 22

Kapitel 1 Einrichtung des Schengener Informationssystems . . . . . . . . . . . . . . . . . 22

Kapitel 2 Betrieb und Nutzung des Schengener Informationssystems . . . . . . . . . . . . . . . 23

Kapitel 3 Datenschutz und Datensicherung im Schengener Informationssystem . . . . . . . . . . . 27

Kapitel 4 Verteilung der Kosten des Schengener Informationssystems . . . . . . . . . . . . . . 31

Titel V Transport und Warenverkehr . . . . . . . . . . . . . . . . 32

Titel VI Datenschutz . . . . . . . . . . . . . . . . . . . 33

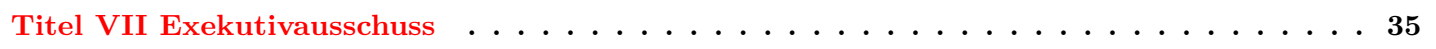

Titel VIII Schlussbestimmungen . . . . . . . . . . . . . . . . 35

Inkl. Änderungen:

1. Protokoll zur Einbeziehung des Schengen- Besitz- stands in den Rahmen der Europäischen Union (Schengen - Protokoll (abgedruckt Seite 37))

2. Übereinkommen über die Bestimmung des zuständigen Staates für die Prüfung eines in einem Mit- 
gliedstaat der Europäischen Gemeinschaften gestellten Asylantrags - Dubliner Abkommen (ersetzt durch Verordnung (EG) Nr. 343/2003, abgedruckt Seite 173)

3. Protokoll zu den Konsequenzen des Inkrafttretens des Dubliner Übereinkommens für einige Bestimmungen des „Durchführungsübereinkommens zum Schengener Übereinkommen" vom 26.4.1994 (Bonner Protokoll [BGBl. 1995 Teil II, S. 739])

4. Beschluss 1999/435/EG des Rates vom 20. Mai 1999 zur Bestimmung des Schengen-Besitzstands zwecks Festlegung der Rechtsgrundlagen für jede Bestimmung und jeden Beschluß, die diesen Besitzstand bilden, nach Maßgabe der einschlägigen Bestimmungen des Vertrags zur Gründung der Europäischen Gemeinschaft und des Vertrags über die Europäische Union (ABl. L 176 vom 10.7.1999, S. 1.)

5. Schengen-Besitzstand gemäß Artikel 1 Absatz 2 des Beschlusses 1999/435/EG des Rates vom 20. Mai 1999 (Abl. L 239 vom 22.9.2000).

6. Übereinkommen gemäß Artikel 34 des Vertrags über die Europäische Union - vom Rat erstellt über die Rechtshilfe in Strafsachen zwischen den Mitgliedstaaten der Europäischen Union (Übereinkommen über die Rechtshilfe in Strafsachen (abgedruckt Seite 156))

7. Verordnung (EG) Nr. 1091/2001 des Rates vom 28. Mai 2001 über den freien Personenverkehr mit einem Visum für den längerfristigen Aufenthalt (Abl. 2001 L 150 S. 4)

8. Richtlinie 2001/51/EG des Rates vom 28. Juni 2001 zur Ergänzung der Regelungen nach Artikel 26 des Übereinkommens zur Durchführung des Übereinkommens von Schengen vom 14. Juni 1985 (Abl. 2001 L 187 S. 0045)

9. Protokoll vom Rat gemäß Artikel 34 des Vertrags über die Europäische Union erstellt zu dem Übereinkommen über die Rechtshilfe in Strafsachen zwischen den Mitgliedstaaten der Europäischen Union (Protokoll zum Übereinkommen über die Rechtshilfe (abgedruckt Seite 169))

10. Rahmenbeschluss 2002/584/JI des Rates vom 13. Juni 2002 über den Europäischen Haftbefehl und die Übergabeverfahren zwischen den Mitgliedstaaten (Rahmenbeschluss Europäischer Haftbefehl (abgedruckt Seite 109))

11. Rahmenbeschluss 2002/946/JI des Rates vom 28 . November 2002 betreffend die Verstärkung des strafrechtlichen Rahmens für die Bekämpfung der Beihilfe zur unerlaubten Ein- und Durchreise und zum unerlaubten Aufenthalt (Abl. 2002 L 328 S. 0001)

12. Richtlinie 2002/90/EG des Rates vom 28. November 2002 zur Definition der Beihilfe zur unerlaubten Ein- und Durchreise und zum unerlaubten Aufenthalt (ABl. 2002 L 328 S. 17)
13. Beschluss 2003/169/JI des Rates vom 27. Februar 2003 zur Festlegung der Bestimmungen im Übereinkommen von 1995 über das vereinfachte Auslieferungsverfahren zwischen den Mitgliedstaaten der Europäischen Union und der Bestimmungen im Übereinkommen von 1996 über die Auslieferung zwischen den Mitgliedstaaten der Europäischen Union, die eine Weiterentwicklung des SchengenBesitzstands im Sinne des Übereinkommens über die Assoziierung der Republik Island und des Königreichs Norwegen bei der Umsetzung, Anwendung und Entwicklung des Schengen-Besitzstands darstellen (ABl. 2003 L 067 S. 25)

14. Beschluss 2003/170/JI des Rates vom 27. Februar 2003 über die gemeinsame Inanspruchnahme von Verbindungsbeamten, die von den Strafverfolgungsbehörden der Mitgliedstaaten entsandt sind (ABl. 2003 L 067 S. 27)

15. Beschluss 2003/725/JI des Rates vom 2. Oktober 2003 zur Änderung von Artikel 40 Absätze 1 und 7 des Übereinkommens zur Durchführung des Schengener Übereinkommens vom 14. Juni 1985 betreffend den schrittweisen Abbau der Kontrollen an den gemeinsamen Grenzen (ABl. 2003 L 260 S. 37)

16. Verordnung (EG) Nr. 871/2004 des Rates vom 29. April 2004 über die Einführung neuer Funktionen für das Schengener Informationssystem, auch im Hinblick auf die Terrorismusbekämpfung (ABl. 2004 L 162 S. 29)

17. Verordnung (EG) Nr. 2133/2004 des Rates vom 13. Dezember 2004 zur Verpflichtung der zuständigen Behörden der Mitgliedstaaten zum systematischen Abstempeln der Reisedokumente von Drittausländern beim Überschreiten der Außengrenzen der Mitgliedstaaten und zur diesbezüglichen Änderung der Bestimmungen des Schengener Durchführungsübereinkommens und des Gemeinsamen Handbuchs (ABl. 2004 L 369 S. 0005)

18. Beschluss 2005/211/JI des Rates vom 24. Februar 2005 über die Einführung neuer Funktionen für das Schengener Informationssystem, auch im Hinblick auf die Terrorismusbekämpfung (ABl. 2005 L 68 S. 44)

19. Verordnung (EG) Nr. 1160/2005 des Europäischen Parlaments und des Rates vom 6. Juli 2005 zur Änderung des Übereinkommens zur Durchführung des Übereinkommens von Schengen vom 14. Juni 1985 betreffend den schrittweisen Abbau der Kontrollen an den gemeinsamen Grenzen hinsichtlich des Zugangs der in den Mitgliedstaaten für die Ausstellung von Zulassungsbescheinigungen für Fahrzeuge zuständigen Stellen zum Schengener Informationssystem (ABl. 2005 L 191 S. 18)

20. Verordnung (EG) Nr. 562/2006 des Europäischen Parlaments und des Rates vom 15. März 2006 über einen Gemeinschaftskodex für das Überschreiten der Grenzen durch Personen (Schengener Grenzkodex (abgedruckt Seite 39)) 
21. Verordnung (EG) Nr. 1931/2006 des Europäischen Parlamentes und des Rates vom 20. Dezember 2006 zur Festlegung von Vorschriften über den kleinen Grenzverkehr an den Landaußengrenzen der Mitgliedstaaten sowie zur Änderung der Bestimmungen des Übereinkommens von Schengen (ABl. 2006 L 405 S. 1)

22. Verordnung (EG) Nr. 1104/2008 und Beschluss 2008/839/JI des Rates vom 24. Oktober 2008 über die Migration vom Schengener Informationssystem (SIS 1+) zum Schengener Informationssystem der zweiten Generation (SIS II) (Abl. L 299 vom 08/11/2008 S. 1. und S. 43)

23. Verordnung (EG) Nr. 810/2009 des Europäischen Parlaments und des Rates vom 13. Juli 2009 über einen Visakodex der Gemeinschaft (Visakodex) (Abl. L 243 vom 15/09/2009 S. 1)

24. Verordnung (EU) Nr. 265/2010 des Europäischen Parlaments und des Rates vom 25. März 2010 zur Änderung des Übereinkommens zur Durchführung des Übereinkommens von Schengen und der Verordnung (EG) Nr. 562/2006 in Bezug auf den Verkehr von Personen mit einem Visum für den längerfristigen Aufenthalt (Abl. L 085 vom 31/03/2010 S. 1)

Das KÖNIGREICH BELGIEN, die BUNDESREPUBLIK DEUTSCHLAND, die FRANZÖSISCHE REPUBLIK, das GROSS- HERZOGTUM LUXEMBURG und das KÖNIGREICH DER NIEDERLANDE, nachfolgend Vertragsparteien genannt -

AUFBAUEND auf dem am 14. Juni 1985 in Schengen geschlossenen Übereinkommen über den schrittweisen Abbau der Kontrollen an den gemeinsamen Grenzen,

ENTSCHLOSSEN, das in diesem Übereinkommen zum Ausdruck gebrachte Bestreben der Abschaffung der Kontrollen des Personenverkehrs an den gemeinsamen Grenzen und der Erleichterung des Transports und des Warenverkehrs zu verwirklichen,

IN DER ERWÄGUNG, dass der Vertrag zur Gründung der Europäischen Gemeinschaften, ergänzt durch die Einheitliche Europäische Akte, vorsieht, dass der Binnenmarkt einen Raum ohne Binnengrenzen umfasst,

IN DER ERWÄGUNG, dass der durch die Vertragsparteien angestrebte Zweck mit diesem Ziel übereinstimmt, unbescha- det der Maßnahmen, die zur Anwendung der Bestimmungen dieses Vertrages getroffen werden,

IN DER ERWÄGUNG, dass die Verwirklichung dieses Zieles eine Reihe von geeigneten Maßnahmen und eine enge Zusammenarbeit der Vertragsparteien erfordert

\section{HABEN FOLGENDES VEREINBART:}

\section{Titel I: Begriffsbestimmungen}

\section{Artikel 1}

Im Sinne dieses Übereinkommens bedeutet:

Binnengrenzen: die gemeinsamen Landgrenzen der Vertragsparteien sowie ihre Flughäfen für die Binnenfluege und ihre Seehäfen für die regelmäßigen Fährverbindungen ausschließlich von und nach dem Gebiet der Vertragsparteien ohne Fahrtunterbrechung in außerhalb des Gebiets gelegenen Häfen;

Außengrenzen: die Land- und Seegrenzen sowie die Flugund Seehäfen der Vertragsparteien, soweit sie nicht Binnengrenzen sind;

Binnenflug: ein Flug ausschließlich von und nach dem Gebiet der Vertragsparteien, ohne Landung auf dem Gebiet eines Drittstaates;

Drittstaat: ein Staat, der nicht Vertragspartei ist;

Drittausländer: eine Person, die nicht Staatsangehöriger eines der Mitgliedstaaten der Europäischen Gemeinschaften ist;

zur Einreiseverweigerung ausgeschriebener Drittausländer: ein Drittausländer, der gemäß Artikel 96 zur Einreiseverweigerung in dem Schengener Informationssystem ausgeschrieben ist;

Grenzübergangsstelle: ein von den zuständigen Behörden für das Überschreiten der Außengrenzen zugelassener Übergang;

Grenzkontrolle: an den Grenzen vorgenommene Kontrolle, die unabhängig von jedem anderen Anlass ausschließlich aufgrund des beabsichtigten Grenzübertritts durchgeführt wird;

Beförderungsunternehmer: natürliche oder juristische Person, die gewerblich die Beförderung von Personen auf dem Luft-, See- oder Landweg durchführt;

Aufenthaltstitel: jede von einer Vertragspartei ausgestellte Erlaubnis gleich welcher Art, die zum Aufenthalt in deren Hoheitsgebiet berechtigt. Hierzu zählen nicht die befristete Zulassung zum Aufenthalt im Hoheitsgebiet einer der Vertragsparteien im Hinblick auf die Behandlung eines Asylbegehrens oder eines Antrags auf eine Aufenthaltserlaubnis;

Asylbegehren, Asylbegehrender, Behandlung eines Asylbegehrens: 1

${ }^{1}$ Gemäß Bonner Protokoll[3] ersetzt durch Dubliner Abkommen (ersetzt durch Verordnung (EG) Nr. 343/2003, abgedruckt Seite 173) 


\section{Titel II: Abschaffung der Kontrollen an den Binnengrenzen und Personenverkehr}

\author{
Kapitel 1 Überschreiten der \\ Binnengrenzen
}

\author{
Kapitel 2 Überschreiten der \\ Aussengrenzen ${ }^{1}$
}

Kapitel 3 Sichtvermerke

\section{Abschnitt 1 Sichtvermerke für einen kurzfristigen Aufenthalt ${ }^{2}$}

\section{Abschnitt 2 Sichtvermerke für einen längerfristigen Aufenthalt}

Artikel $18^{3}$

(1) Visa für einen Aufenthalt von mehr als drei Monaten Dauer ("Visa für den längerfristigen Aufenthalt") sind nationale Visa, die von einem der Mitgliedstaaten gemäß seinen innerstaatlichen Rechtsvorschriften oder dem Unionsrecht erteilt werden. Ein solches Visum wird in Form einer einheitlichen Visummarke nach Maßgabe der Verordnung (EG) Nr. 1683/95 des Rates ${ }^{4}$ mit dem Buchstaben "Dïm Eintragungsfeld für die Art des Visums ausgestellt. Sie werden im Einklang mit den einschlägigen Vorschriften des Anhangs VII der Verordnung (EG) Nr. 810/2009 des Europäischen Parlaments und des Rates vom 13. Juli 2009 über einen Visakodex ${ }^{5}$ der Gemeinschaft (Visakodex) ausgefüllt.

(2) Visa für den längerfristigen Aufenthalt haben eine Gültigkeitsdauer von höchstens einem Jahr. Gestattet ein Mitgliedstaat einem Drittausländer einen Aufenthalt von mehr als einem Jahr, wird das Visum für einen längerfristigen Aufenthalt vor Ablauf seiner Gültigkeitsdauer durch einen Aufenthaltstitel ersetzt.

\section{Kapitel 4 Voraussetzungen für den Reiseverkehr von Drittausländern}

\section{Artikel 19}

(1) Drittausländer, die Inhaber eines einheitlichen Sichtvermerks sind und rechtmäßig in das Hoheitsgebiet einer

${ }^{1}$ Artikel 2-8 ab 13.10.2006 aufgehoben durch Schengener Grenzkodex (abgedruckt Seite 39)

2 Artikel 9-17 ab dem 04.04.2010 aufgehoben durch Visakodex [23]

${ }^{3}$ Geändert durch Verordnung 265/2010 zur Änderung des Übereinkommens zur Durchführung des Übereinkommens von Schengen [24] ab dem 05.04.2010

${ }^{4}$ ABl. L 164 vom 14.7.1995, S. 1.

${ }^{5} \mathrm{ABl}$. L 243 vom 15.9.2009, S. 1 . der Vertragsparteien eingereist sind, können sich während der Gültigkeitsdauer des Sichtvermerks und soweit sie die in Artikel 5 Absatz 1 Buchstaben a), c), d) und e) aufgeführten Einreisevoraussetzungen erfüllen, frei in dem Hoheitsgebiet aller Vertragsparteien bewegen.

(2) Bis zur Schaffung des einheitlichen Sichtvermerks können sich Drittausländer, die Inhaber eines von einer dieser Vertragsparteien ausgestellten Sichtvermerks sind und rechtmäßig in das Hoheitsgebiet einer dieser Vertragsparteien eingereist sind, während der Gültigkeitsdauer des Sichtvermerks, jedoch höchstens bis zu drei Monaten vom Datum der ersten Einreise an und soweit sie die in Artikel 5 Absatz 1 Buchstaben a), c), d) und e) aufgeführten Einreisevoraussetzungen erfüllen, frei in dem Hoheitsgebiet aller Vertragsparteien bewegen.

(3) Absätze 1 und 2 finden keine Anwendung auf Sichtvermerke, deren Gültigkeit nach Maßgabe der Bestimmungen des Kapitels 3 dieses Titels räumlich beschränkt ist.

(4) Die Bestimmungen dieses Artikels gelten unbeschadet des Artikels 22.

\section{Artikel 20}

(1) Sichtvermerksfreie Drittausländer können sich in dem Hoheitsgebiet der Vertragsparteien frei bewegen, höchstens jedoch drei Monate innerhalb einer Frist von sechs Monaten von dem Datum der ersten Einreise an und soweit sie die in Artikel 5 Absatz 1 Buchstaben a), c), d) und e) aufgeführten Einreisevoraussetzungen erfüllen.

(2) Absatz 1 berührt nicht das Recht jeder Vertragspartei, den Aufenthalt eines Drittausländers in ihrem Hoheitsgebiet in Ausnahmefällen oder in Anwendung der Bestimmungen eines bilateralen Abkommens, das bereits vor dem Inkrafttreten dieses Übereinkommens zustande gekommen ist, über drei Monate hinaus zu verlängern.

(3) Die Bestimmungen dieses Artikels gelten unbeschadet des Artikels 22 .

\section{Artikel 216}

(1) Drittausländer, die Inhaber eines gültigen, von einem der Mitgliedstaaten ausgestellten Aufenthaltstitels sind, können sich aufgrund dieses Dokuments und eines gültigen Reisedokuments bis zu drei Monate in einem Zeitraum von sechs Monaten frei im Hoheitsgebiet der anderen Mitgliedstaaten bewegen, sofern sie die in Artikel 5 Absatz 1 Buchstaben a, c und e der Verordnung (EG) Nr. 562/2006 des Europäischen Parlaments und des Rates vom 15. März 2006 über einen Gemeinschaftskodex für das Überschreiten der Grenzen durch

${ }^{6}$ Geändert durch Verordnung 265/2010 zur Änderung des Übereinkommens zur Durchführung des Übereinkommens von Schengen [24] ab dem 05.04.2010 
Personen (Schengener Grenzkodex) ${ }^{1}$ aufgeführten Einreisevoraussetzungen erfüllen und nicht auf der nationalen Ausschreibungsliste des betroffenen Mitgliedstaats stehen.

(2) Das gleiche gilt für Drittausländer, die Inhaber eines von einer der Vertragsparteien ausgestellten vorläufigen Aufenthaltstitels und eines von dieser Vertragspartei ausgestellten Reisedokuments sind.

(2a) Das in Absatz 1 festgelegte Recht auf freien Personenverkehr gilt auch für Drittausländer, die Inhaber eines von einem der Mitgliedstaaten gemäß Artikel 18 erteilten gültigen Visums für den längerfristigen Aufenthalt sind.

(3) Die Vertragsparteien übermitteln dem Rat die Liste der Dokumente, die sie als Aufenthaltserlaubnis oder vorläufigen Aufenthaltstitel und als Reisedokument im Sinne dieses Artikels ausstellen.

(4) Die Bestimmungen dieses Artikels gelten unbeschadet des Artikels 22.

\section{Artikel 22}

(1) Drittausländer, die rechtmäßig in das Hoheitsgebiet einer der Vertragsparteien eingereist sind, sind verpflichtet, unter den Voraussetzungen, die von jeder Vertragspartei festgelegt werden, sich bei den zuständigen Behörden der Vertragspartei zu melden, in deren Hoheitsgebiet sie einreisen. Die Anzeige kann nach Wahl jeder Vertragspartei entweder bei der Einreise oder, innerhalb einer Frist von drei Arbeitstagen von dem Einreisedatum an, im Landesinnern erfolgen.

(2) Drittausländer, die im Hoheitsgebiet einer Vertragspartei ansässig sind und sich in das Hoheitsgebiet einer anderen Vertragspartei begeben, unterliegen der Meldepflicht nach Absatz 1.

(3) Die Ausnahmen von Absatz 1 und 2 werden von jeder Vertragspartei festgelegt und dem Rat mitgeteilt.

\section{Artikel 23}

(1) Der Drittausländer, der die im Hoheitsgebiet einer der Vertragsparteien geltenden Voraussetzungen für einen kurzen Aufenthalt nicht oder nicht mehr erfüllt, hat grundsätzlich unverzüglich das Hoheitsgebiet der Vertragsparteien zu verlassen.

(2) Verfügt der Drittausländer über eine von einer anderen Vertragspartei ausgestellte gültige Aufenthaltserlaubnis oder über einen von einer anderen Vertragspartei ausgestellten vorläufigen Aufenthaltstitel, so hat er sich unverzüglich in das Hoheitsgebiet dieser Vertragspartei zu begeben.

(3) Soweit die freiwillige Ausreise eines solchen Drittausländers nicht erfolgt oder angenommen werden kann, dass diese Ausreise nicht erfolgen wird, oder soweit die

\footnotetext{
${ }^{1}$ Schengener Grenzkodex (abgedruckt Seite 39)
}

sofortige Ausreise des Drittausländers aus Gründen der nationalen Sicherheit oder der öffentlichen Ordnung geboten ist, muss der Drittausländer nach Maßgabe des nationalen Rechts aus dem Hoheitsgebiet der Vertragspartei abgeschoben werden, in dem er aufgegriffen wurde. Ist die Abschiebung nach nationalem Recht nicht zulässig, so kann die betroffene Vertragspartei dem Drittausländer den Aufenthalt in ihrem Hoheitsgebiet gestatten.

(4) Der betroffene Drittausländer kann in seinen Herkunftsstaat oder in einen anderen Staat, in dem seine Zulassung insbesondere nach Maßgabe der einschlägigen Bestimmungen der zwischen den Vertragsparteien geschlossenen Rückübernahmeabkommen möglich ist, abgeschoben werden.

(5) Die nationalen asylrechtlichen Bestimmungen, die Bestimmungen der Genfer Konvention vom 28. Juli 1951 über den Flüchtlingsstatus in der Fassung des Protokolls von New York vom 31. Januar 1967, sowie Absatz 2 dieses Artikels und Artikel 33 Absatz 1 dieses Übereinkommens bleiben von den Bestimmungen des Absatzes 4 unberührt.

\section{Artikel 24}

Vorbehaltlich der durch den Rat zu bestimmenden geeigneten praktischen Kriterien und Modalitäten gleichen die Vertragsparteien die finanziellen Ungleichgewichte, die infolge der in Artikel 23 vorgesehenen Abschiebungsverpflichtung entstehen, untereinander aus, wenn diese Abschiebung nicht auf Kosten des Drittausländers vorgenommen werden kann.

\section{Kapitel 5 Aufenthaltstitel und Ausschreibung zur Einreiseverweigerung}

\section{Artikel $25^{2}$}

(1) Beabsichtigt ein Mitgliedstaat, einen Aufenthaltstitel zu erteilen, so ruft er systematisch die Daten im Schengener Informationssystem ab. Beabsichtigt ein Mitgliedstaat, einem zur Einreiseverweigerung ausgeschriebenen Drittausländer einen Aufenthaltstitel zu erteilen, so konsultiert er vorab den ausschreibenden Mitgliedstaat und berücksichtigt dessen Interessen; der Aufenthaltstitel wird nur bei Vorliegen gewichtiger Gründe erteilt, insbesondere aus humanitären Gründen oder aufgrund internationaler Verpflichtungen.

Wird der Aufenthaltstitel erteilt, so zieht der ausschreibende Mitgliedstaat die Ausschreibung zurück, wobei es ihm unbenommen bleibt, den betroffenen Drittausländer in die nationale Ausschreibungsliste aufzunehmen.

Geändert durch Verordnung 265/2010 zur Änderung des Übereinkommens zur Durchführung des Übereinkommens von Schengen [24] ab dem 05.04.2010 
(1a) Vor einer Ausschreibung zum Zwecke der Einreiseverweigerung im Sinne von Artikel 96 prüfen die Mitgliedstaaten ihre nationalen Register von erteilten Visa für den längerfristigen Aufenthalt oder Aufenthaltstiteln.

(2) Stellt sich heraus, dass der Drittausländer, der über einen von einer der Vertragsparteien erteilten gültigen Aufenthaltstitel verfügt, zum Zwecke der Einreiseverweigerung ausgeschrieben ist, konsultiert die ausschreibende Vertragspartei die Vertragspartei, die den Aufenthaltstitel erteilt hat, um zu prüfen, ob ausreichende Gründe für die Einziehung des Aufenthaltstitels vorliegen.

Wird der Aufenthaltstitel nicht eingezogen, so zieht die ausschreibende Vertragspartei die Ausschreibung zurück, wobei es ihr unbenommen bleibt, den betroffenen Drittausländer in die nationale Ausschreibungsliste aufzunehmen.

(3) Die Absätze 1 und 2 finden auch auf Visa für den längerfristigen Aufenthalt Anwendung.

\section{Kapitel 6 Weitere Maßnahmen}

\section{Artikel 26}

(1) Vorbehaltlich der Verpflichtungen, die sich aus der Genfer Konvention vom 28. Juli 1951 über den Flüchtlingsstatus in der Fassung des Protokolls von New York vom 31. Januar 1967 ergeben, verpflichten sich die Vertragsparteien, die nachstehenden Regelungen in ihre nationalen Rechtsvorschriften aufzunehmen:

a) Wird einem Drittausländer die Einreise in das Hoheitsgebiet einer der Vertragsparteien verweigert, so ist der Beförderungsunternehmer, der ihn auf dem Luft-, See- oder Landweg bis an die Außengrenze gebracht hat, verpflichtet, ihn unverzüglich zurückzunehmen. Auf Verlangen der Grenzüberwachungsbehörden hat der Beförderungsunternehmer den Drittausländer in den Drittstaat, aus dem er befördert wurde, in den Drittstaat, der das Reisedokument ausgestellt hat, mit dem er gereist ist, oder in jeden anderen Drittstaat, in dem seine Zulassung gewährleistet ist, zu verbringen.

b) Der Beförderungsunternehmer ist verpflichtet, alle erforderlichen Maßnahmen zu treffen, um sich zu vergewissern, dass der auf dem Luft- oder Seeweg beförderte Drittausländer über die für die Einreise in das Hoheitsgebiet der Vertragsparteien erforderlichen Reisedokumente verfügt.

(2) Vorbehaltlich der Verpflichtungen, die sich aus der Genfer Konvention vom 28. Juli 1951 über den Flüchtlingsstatus in der Fassung des Protokolls von New York vom 31. Januar 1967 ergeben, verpflichten sich die Vertragsparteien, unter Berücksichtigung ihres Verfassungsrechts Sanktionen gegen Beförderungsunternehmer einzuführen, die Drittausländer, welche nicht über die erforderlichen Reisedokumente verfügen, auf dem Luft- oder
Seeweg aus einem Drittstaat in ihr Hoheitsgebiet verbringen.

(3) Die Absätze 1 Buchstabe b) und 2 finden auf Beförderungsunternehmer Anwendung, die im internationalen Linienverkehr Gruppen von Personen in Autobussen befördern, mit Ausnahme des Grenzverkehrs.

Artikel $27^{1}$

\section{Kapitel 7 Zuständigkeit für die Behandlung von Asylbegehren ${ }^{2}$}

\section{Titel III Polizei und Sicherheit}

\section{Kapitel 1 Polizeiliche Zusammenarbeit}

\section{Artikel 39}

(1) Die Vertragsparteien verpflichten sich, dass ihre Polizeidienste sich untereinander nach Maßgabe des nationalen Rechts und ihrer jeweiligen Zuständigkeit im Interesse der vorbeugenden Bekämpfung und der Aufklärung von strafbaren Handlungen Hilfe leisten, sofern ein Ersuchen oder dessen Erledigung nach nationalem Recht nicht den Justizbehörden vorbehalten ist und die Erledigung des Ersuchens die Ergreifung von Zwangsmaßnahmen durch die ersuchte Vertragspartei nicht erfordert. Ist die ersuchte Polizeibehörde für die Erledigung nicht zuständig, so leitet sie das Ersuchen an die zuständige Behörde weiter.

(2) Schriftliche Informationen, die von der ersuchten Vertragspartei nach Absatz 1 übermittelt werden, können nur mit Zustimmung der zuständigen Justizbehörde dieser Vertragspartei von der ersuchenden Vertragspartei als Beweismittel in einem Strafverfahren benutzt werden.

(3) Ersuchen um Hilfe nach Absatz 1 und die Antworten können zwischen den von den Vertragsparteien mit der grenzüberschreitenden polizeilichen Zusammenarbeit beauftragten zentralen Stellen übermittelt und auf demselben Weg zurückgesandt werden. In Fällen, in denen das Ersuchen nicht rechtzeitig über diesen Geschäftsweg gestellt werden kann, können Ersuchen von den Polizeibehörden der ersuchenden Vertragspartei unmittelbar den zuständigen Behörden der ersuchten Vertragspartei übermittelt und von diesen unmittelbar beantwortet werden. In diesen Fällen unterrichtet die ersuchende Polizeibehörde unverzüglich die von der ersuchten Vertragspartei mit der grenzüberschreitenden polizeilichen Zusammenarbeit beauftragte zentrale Stelle über das direkte Ersuchen.

\footnotetext{
${ }^{1}$ Abs. 1 ersetzt durch Richtlinie 2002/90/EG[12], Abs. 2 und 3 aufgehoben durch Rahmenbeschluss 2002/946/JI[11] ab 5.12.2004

Gemäß Bonner Protokoll[3] ersetzt durch Dubliner Abkommen (er-
} setzt durch Verordnung (EG) Nr. 343/2003, abgedruckt Seite 173) 
(4) Die Zusammenarbeit in den Grenzgebieten kann in Vereinbarungen zwischen den zuständigen Ministern der Vertragsparteien geregelt werden.

(5) Weitergehende bestehende und künftige bilaterale Abkommen zwischen zwei Vertragsparteien, die eine gemeinsame Grenze haben, bleiben von den Bestimmungen dieses Artikels unberührt. Die Vertragsparteien unterrichten einander über diese Abkommen.

\section{Artikel 40}

$(1)^{1}$ Beamte eines Mitgliedstaates, die im Rahmen eines Ermittlungsverfahrens in dessen Hoheitsgebiet eine Person observieren, die im Verdacht steht, an einer auslieferungsfähigen Straftat beteiligt zu sein, oder die in diesem Rahmen als notwendige Maßnahme eines Ermittlungsverfahrens eine Person observieren, bei der ernsthaft anzunehmen ist, dass sie zur Identifizierung oder Auffindung der vorgenannten Person führen kann, sind befugt, diese Observation im Hoheitsgebiet eines anderen Mitgliedstaates fortzusetzen, wenn dieser der grenzüberschreitenden Observation auf der Grundlage eines zuvor gestellten und begründeten Rechtshilfeersuchens zugestimmt hat. Die Zustimmung kann mit Auflagen verbunden werden. Auf Verlangen ist die Observation an die Beamten der Vertragspartei, auf deren Hoheitsgebiet die Observation stattfindet, zu übergeben. Das Rechtshilfeersuchen nach Satz 1 ist an die durch jede der Vertragsparteien bezeichnete Behörde zu richten, die befugt ist, die erbetene Zustimmung zu erteilen oder zu übermitteln.

(2) Kann wegen der besonderen Dringlichkeit der Angelegenheit eine vorherige Zustimmung der anderen Vertragspartei nicht beantragt werden, dürfen die Beamten die Observation einer Person, die im Verdacht steht, an einer der in Absatz 7 aufgeführten Straftaten beteiligt zu sein, unter folgenden Voraussetzungen über die Grenze hinweg fortsetzen:

a) Der Grenzübertritt ist noch während der Observation unverzüglich der in Absatz 5 bezeichneten Behörde der Vertragspartei, auf deren Hoheitsgebiet die Observation fortgesetzt werden soll, mitzuteilen.

b) Ein Rechtshilfeersuchen nach Absatz 1, in dem auch die Gründe dargelegt werden, die einen Grenzübertritt ohne vorherige Zustimmung rechtfertigen, ist unverzüglich nachzureichen.

Die Observation ist einzustellen, sobald die Vertragspartei, auf deren Hoheitsgebiet die Observation stattfindet, aufgrund der Mitteilung nach Buchstabe a) oder des Ersuchens nach Buchstabe b) dies verlangt oder wenn die Zustimmung nicht fünf Stunden nach Grenzübertritt vorliegt.

\footnotetext{
${ }^{1}$ geändert durch Beschluss 2003/725/JI zur Änderung von Artikel 40 [15]
}

(3) Die Observation nach den Absätzen 1 und 2 ist ausschließlich unter den nachstehenden allgemeinen Voraussetzungen zulässig:

a) Die observierenden Beamten sind an die Bestimmungen dieses Artikels und das Recht der Vertragspartei, auf deren Hoheitsgebiet sie auftreten, gebunden; sie haben Anordnungen der örtlich zuständigen Behörden zu befolgen.

b) Vorbehaltlich der Fälle des Absatzes 2 führen die Beamten während der Observation ein Dokument mit sich, aus dem sich ergibt, dass die Zustimmung erteilt worden ist.

c) Die observierenden Beamten müssen in der Lage sein, jederzeit ihre amtliche Funktion nachzuweisen.

d) Die observierenden Beamten dürfen während der Observation ihre Dienstwaffe mit sich führen, es sei denn, die ersuchte Vertragspartei hat dem ausdrücklich widersprochen; der Gebrauch ist mit Ausnahme des Falles der Notwehr nicht zulässig.

e) Das Betreten von Wohnungen und öffentlich nicht zugänglichen Grundstücken ist nicht zulässig.

f) Die observierenden Beamten sind nicht befugt, die zu observierende Person anzuhalten oder festzunehmen.

g) Über jede Operation wird den Behörden der Vertragspartei, auf deren Hoheitsgebiet die Operation stattgefunden hat, Bericht erstattet; dabei kann das persönliche Erscheinen der observierenden Beamten gefordert werden.

h) Die Behörden der Vertragspartei, aus deren Hoheitsgebiet die observierenden Beamten kommen, unterstützen auf Ersuchen die nachträglichen Ermittlungen einschließlich gerichtlicher Verfahren der Vertragspartei, auf deren Hoheitsgebiet eingeschritten wurde.

(4) Die in den Absätzen 1 und 2 genannten Beamten sind

für das Königreich Belgien: die Beamten der Kriminalpolizei bei den Staatsanwaltschaften, der Gendarmerie und der Gemeindepolizei sowie, unter den in geeigneten bilateralen Vereinbarungen nach Absatz 6 festgelegten Bedingungen in Bezug auf ihre Befugnisse im Bereich des unerlaubten Verkehrs mit Betäubungsmitteln und im Bereich des unerlaubten Handels mit Waffen und Sprengstoffen und des unerlaubten Verkehrs mit giftigen und schädlichen Abfällen, die Zollbeamten;

für die Bundesrepublik Deutschland: die Beamten der Polizeien des Bundes und der Länder sowie, beschränkt auf den Bereich des unerlaubten Verkehrs mit Betäubungsmitteln und des unerlaubten Handels mit Waffen, die Beamten des Zollfahndungsdienstes als Hilfsbeamte der Staatsanwaltschaft; 
für die Französische Republik: die Beamten und die Hilfsbeamten der kriminalpolizeilichen Abteilungen der Nationalen Polizei und der Nationalen Gendarmerie sowie, unter den in geeigneten bilateralen Vereinbarungen nach Absatz 6 festgelegten Bedingungen in Bezug auf ihre Befugnisse im Bereich des unerlaubten Verkehrs mit Betäubungsmitteln und im Bereich des unerlaubten Handels mit Waffen und Sprengstoffen und des unerlaubten Verkehrs mit giftigen und schädlichen Abfällen, die Zollbeamten;

für das Großherzogtum Luxemburg: die Beamten der Gendarmerie und der Polizei, sowie, unter den in geeigneten bilateralen Vereinbarungen nach $\mathrm{Ab}$ satz 6 festgelegten Bedingungen in Bezug auf ihre Befugnisse im Bereich des unerlaubten Verkehrs mit Betäubungsmitteln, im Bereich des unerlaubten Handels mit Waffen und Sprengstoffen und im Bereich des unerlaubten Verkehrs mit giftigen und schädlichen Abfällen, die Zollbeamten;

für das Königreich der Niederlande: die Beamten der Reichspolizei und der Gemeindepolizei, sowie, unter den in geeigneten bilateralen Vereinbarungen nach Absatz 6 festgelegten Bedingungen in Bezug auf ihre Befugnisse im Bereich des unerlaubten Verkehrs mit Betäubungsmitteln und im Bereich des unerlaubten Handels mit Waffen und Sprengstoffen und des unerlaubten Verkehrs mit giftigen und schädlichen Abfällen, die Beamten des fiskalischen Nachrichten- und Fahndungsdienstes, die im Bereich der Einfuhrzölle und Verbrauchsteuern zuständig sind.

für die Italienische Republik: Die Beamten und Hilfsbeamten der kriminalpolizeilichen Abteilungen der nationalen Polizei („Polizia di Stato“), der „Arma dei Carabinieri““ und, beschränkt auf die Bereiche der Falschmünzerei, des unerlaubten Verkehrs mit Betäubungsmitteln, des unerlaubten Handels mit Waffen und Sprengstoffen und des unerlaubten Verkehrs mit giftigen und schädlichen Abfällen, der „Guardia di Finanza“ , sowie, unter den in geeigneten bilateralen Vereinbarungen nach Absatz 6 festgelegten Bedingungen in Bezug auf ihre Befugnisse im Bereich des unerlaubten Verkehrs mit Betäubungsmitteln, des unerlaubten Handels mit Waffen und Sprengstoffen und des unerlaubten Verkehrs mit giftigen und schädlichen Abfällen, die Zollbeamten.

für das Königreich Spanien: Die Beamten des ,,Cuerpo Nacional de Policía“ und des „Cuerpo de la Guardia Civil" in der Ausübung ihrer kriminalpolizeilichen Aufgaben und, unter den in geeigneten bilateralen Vereinbarungen nach Absatz 6 festgelegten Bedingungen in Bezug auf ihre Befugnisse im Bereich des unerlaubten Verkehrs mit Betäubungsmitteln, des unerlaubten Handels mit Waffen und Sprengstoffen und des unerlaubten Verkehrs mit giftigen und schädlichen Abfällen, die der Zollverwaltung zugeordneten Beamten. für die Portugiesische Republik: Die Beamten der „Polícia Judiciária“, sowie, unter den in geeigneten bilateralen Vereinbarungen nach Absatz 6 festgelegten Bedingungen in Bezug auf ihre Befugnisse im Bereich des unerlaubten Verkehrs mit Betäubungsmitteln, des unerlaubten Handels mit Waffen und Sprengstoffen und des unerlaubten Verkehrs mit giftigen und schädlichen Abfällen, die Zollbeamten in ihrer Eigenschaft als Hilfsbeamte der Staatsanwaltschaft;

für die Griechische Republik: Die Polizeibeamten der Nationalen Polizei und der Nationalen Gendarmerie im Rahmen ihrer Kompetenzen, sowie unter den in geeigneten bilateralen Vereinbarungen nach Absatz 6 festgelegten Bedingungen in bezog auf ihre Befugnisse im Bereich des unerlaubten Verkehrs mit Betäubungsmitteln, des unerlaubten Handels mit Waffen und Sprengstoffen und des unerlaubten Verkehrs mit giftigen und schädlichen Abfällen, die der Zollverwaltung zugeordneten Beamten;

für die Republik Österreich: Die Organe des Öffentlichen Sicherheitsdienstes, das sind die Angehörigen der Bundesgendarmerie, die Angehörigen der Bundessicherheitswachekorps, die Angehörigen der Kriminalbeamtenkorps und die zur Ausübung unmittelbarer Befehls- und Zwangsgewalt ermächtigten Beamten des rechtskundigen Dienstes bei Sicherheitsbehörden, sowie, unter den in geeigneten bilateralen Vereinbarungen nach $\mathrm{Ab}$ satz 6 festgelegten Bedingungen in Bezug auf ihre Befugnisse im Bereich des unerlaubten Verkehrs mit Betäubungsmitteln, des unerlaubten Handels mit Waffen und Sprengstoffen und des unerlaubten Verkehrs mit giftigen und schädlichen Abfällen, die Zollbeamten;

für das Königreich Dänemark: Die den örtlichen Polizeipräsidenten und dem Reichspolizei-Chef unterstehenden Polizeibeamten (Polititjenestemaend hos lokale politimestre og hos Rigspolitichefen) sowie, unter den in geeigneten bilateralen Vereinbarungen nach Absatz 6 festgelegten Bedingungen in Bezug auf ihre Befugnisse im Bereich des unerlaubten Verkehrs mit Betäubungsmitteln, des unerlaubten Handels mit Waffen und Sprengstoffen und des unerlaubten Verkehrs mit giftigen und schädlichen Abfällen, die Zollbeamten;

für die Republik Finnland: Die Polizeibeamten (poliisin virkamiehistä poliisimiehet - av polisens tjänste-män polismän), die Beamten der Grenzüberwachungsbehörde (rajavartiolaitoksen virkamiehistä rajavartiomiehet - av gränsbevakningsväsendets tjänstemän gränsbevakningsmän) für den Menschenhandel nach Absatz 7 sowie, unter den in geeigneten bilateralen Vereinbarungen nach Absatz 6 festgelegten Bedingungen in Bezug auf ihre Befugnisse im Bereich des unerlaubten Verkehrs mit Betäubungsmitteln, des unerlaubten Handels mit Waffen und Sprengstoffen und des unerlaubten Verkehrs mit giftigen und schädlichen Abfällen, die Zollbeamten (tullimiehet - tulltjänstemän); 
für das Königreich Schweden: Die den schwedischen Polizeibehörden unterstehenden zuständigen Polizeibeamten (Polismän som är anställda av svenska polismyndigheter), die den schwedischen Zollbehörden unterstehenden zuständigen Zollbeamten, wenn sie polizeiliche Befugnisse haben, hauptsächlich hinsichtlich strafbarer Handlungen im Zusammenhang mit Schmuggel und anderen strafbaren Handlungen im Zusammenhang mit der Einreise in den und der Ausreise aus dem Staat (Tulltjänstemän, som är anställda vid svensk tullmyndig-het i de fall de har polisiära befogenheter, dvs främst i samband med smugglingsbrott och andra brott i samband med inresa och utresa till och fran riket), sowie die der schwedischen Küstenwacht unterstehenden Beamten im Zusammenhang mit der Überwachung auf See (Tjänsteman anställda vid den svenska Kustbevakningen i samband med övervakning till sjöss);

für das Vereinigte Königreich: Die Beamten der Polizeikräfte des Vereinigten Königreichs und die Beamten der Zoll- und Steuerbehörden;

für die Republik Island: Die Beamten der isländischen Polizei;

für das Königreich Norwegen: Die norwegischen Polizeibeamten.

(5) Die in den Absätzen 1 und 2 genannte Behörde ist

für das Königreich Belgien: das Generalkommissariat der Kriminalpolizei;

für die Bundesrepublik Deutschland: das Bundeskriminalamt;

- für die Französische Republik: die Zentraldirektion der Kriminalpolizei;

- für das Großherzogtum Luxemburg: der Generalstaatsanwalt;

- für das Königreich der Niederlande: der landesweit zuständige Staatsanwalt für grenzüberschreitende Observation.

- für die Italienische Republik: die Zentraldirektion der Kriminalpolizei des Ministeriums des Innern.

für das Königreich Spanien: La Dirección General de la Policía;

für die Portugiesische Republik: A DirecçâoGeneral da Polícia Judiciária;

für die Griechische Republik: Die Direktion für Internationale Polizeiliche Zusammenarbeit;

für die Republik Österreich: Die Generaldirektion für die öffentliche Sicherheit im Bundesministerium für Inneres;

für das Königreich Dänemark: Das Büro des nationalen Polizeipräfekten (Rigspolitichefen);

für die Republik Finnland: Das nationale Büro der Kriminalpolizei (Keskusrikospoliisi - Centralkriminalpolisen); für das Königreich Schweden: Die nationale Direktion der schwedischen Polizei (Rikspolisstyrelsen);

für das Vereinigte Königreich: Der National Criminal Intelligence Service;

für die Republik Island: Der nationale Polizei-Chef (Ríkislögreglustjorínn);

für das Königreich Norwegen: Die Zentrale der Kriminalpolizei (Kriminalpolitisentralen).

(6) Die Vertragsparteien können im Wege bilateraler Vereinbarungen den Anwendungsbereich dieses Artikels erweitern und zusätzliche Regelungen zu seiner Durchführung treffen.

$(7)^{1}$ Eine Observation nach Absatz 2 ist nur zulässig, wenn eine der nachstehenden Straftaten zugrunde liegt:

Mord,

Totschlag,

Schwere Straftat sexueller Natur, vorsätzliche Brandstiftung,

Fälschung und Verfälschung von Zahlungsmitteln, schwerer Diebstahl, Hehlerei und Raub,

Erpressung,

Entführung und Geiselnahme,

Menschenhandel,

unerlaubter Verkehr mit Betäubungsmitteln,

Verstoß gegen die gesetzlichen Vorschriften über Waffen und Sprengstoffe,

Vernichtung durch Sprengstoffe,

unerlaubter Verkehr mit giftigen und schädlichen Abfällen.

schwerer Betrug,

Schleuserkriminalität,

Geldwäsche,

illegaler Handel mit nuklearem und radioaktivem Material,

Beteiligung an einer kriminellen Vereinigung im Sinne der Gemeinsamen Maßnahme 98/733/JI des Rates vom 21. Dezember 1998 betreffend die Strafbarkeit der Beteiligung an einer kriminellen Vereinigung in den Mitgliedstaaten der Europäischen Union,

terroristische Straftaten im Sinne des Rahmenbeschlusses 2002/475/JI des Rates vom 13. Juni 2002 über die Bekämpfung des Terrorismus.

geändert durch Beschluss 2003/725/JI zur Änderung von Artikel $40[15]$ 


\section{Artikel 41}

(1) Beamte einer Vertragspartei, die in ihrem Land eine Person verfolgen, die auf frischer Tat bei der Begehung von oder der Teilnahme an einer Straftat nach Absatz 4 betroffen wird, sind befugt, die Verfolgung auf dem Hoheitsgebiet einer anderen Vertragspartei ohne deren vorherige Zustimmung fortzusetzen, wenn die zuständigen Behörden der anderen Vertragspartei wegen der besonderen Dringlichkeit der Angelegenheit nicht zuvor mit einem der in Artikel 44 vorgesehenen Kommunikationsmittel unterrichtet werden konnten oder nicht rechtzeitig zur Stelle sind, um die Verfolgung zu übernehmen. Gleiches gilt, wenn die verfolgte Person sich in Untersuchungshaft oder Strafhaft befand und aus der Haft geflohen ist. Spätestens beim Grenzübertritt nehmen die nacheilenden Beamten Kontakt mit der zuständigen Behörde des Gebietsstaates auf. Die Verfolgung ist einzustellen, sobald die Vertragspartei, auf deren Hoheitsgebiet die Verfolgung stattfinden soll, dies verlangt. Auf Ersuchen der nacheilenden Beamten ergreifen die örtlich zuständigen Behörden die betroffene Person, um ihre Identität festzustellen oder die Festnahme vorzunehmen.

(2) Die Nacheile wird gemäß einer der nachfolgenden Modalitäten ausgeübt, die in der Erklärung nach Absatz 9 festgelegt werden:

a) Die nacheilenden Beamten haben kein Festhalterecht.

b) Wenn kein Einstellungsverlangen vorliegt und die örtlichen Behörden nicht rechtzeitig herangezogen werden können, dürfen die nacheilenden Beamten die Person festhalten, bis die Beamten des Gebietsstaates, die unverzüglich zu unterrichten sind, die Identitätsfeststellung oder die Festnahme vornehmen.

(3) Die in den Absätzen 1 und 2 vorgesehene Nacheile wird gemäß einer der nachfolgenden Modalitäten ausgeübt, die in der Erklärung nach Absatz 9 festgelegt werden:

a) innerhalb eines in der Erklärung bestimmten Gebietes oder während einer darin bestimmten Zeit vom Überschreiten der Grenze an;

b) ohne räumliche oder zeitliche Begrenzung.

(4) In der Erklärung nach Absatz 9 legen die Vertragsparteien die in Absatz 1 vorgesehenen Straftaten gemäß einer der nachfolgenden Modalitäten fest:

a) Straftatenkatalog:

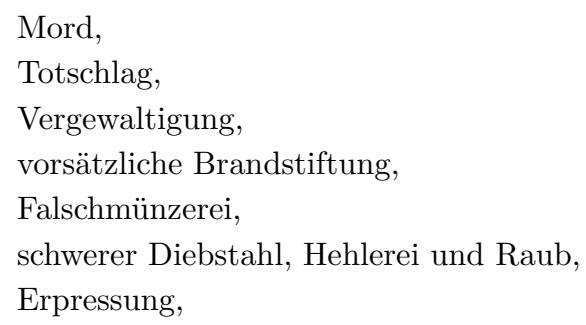

Entführung und Geiselnahme,

Menschenhandel, unerlaubter Verkehr mit Betäubungsmitteln, Verstoß gegen die gesetzlichen Vorschriften über Waffen und Sprengstoffe,

Vernichtung durch Sprengstoffe, unerlaubter Verkehr mit giftigen und schädlichen Abfällen, unerlaubtes Entfernen nach einem Unfall mit schwerer Körperverletzung oder Todesfolge;

b) die auslieferungsfähigen Straftaten.

(5) Die Nacheile darf nur unter folgenden allgemeinen Voraussetzungen ausgeübt werden:

a) Die nacheilenden Beamten sind an die Bestimmungen dieses Artikels und das Recht der Vertragspartei, auf deren Hoheitsgebiet sie auftreten, gebunden; sie haben Anordnungen der örtlich zuständigen Behörden zu befolgen.

b) Die Nacheile findet lediglich über die Landgrenzen statt.

c) Das Betreten von Wohnungen und öffentlich nicht zugänglichen Grundstücken ist nicht zulässig.

d) Die nacheilenden Beamten müssen als solche eindeutig erkennbar sein, entweder durch eine Uniform, eine Armbinde oder durch an dem Fahrzeug angebrachte Zusatzeinrichtungen; das Tragen von Zivilkleidung unter Benutzung eines getarnten Polizeifahrzeuges ohne die vorgenannte Kennzeichnung ist nicht zulässig; die nacheilenden Beamten müssen jederzeit in der Lage sein, ihre amtliche Funktion nachzuweisen.

e) Die nacheilenden Beamten dürfen ihre Dienstwaffe mit sich führen; der Gebrauch ist mit Ausnahme des Falles der Notwehr nicht zulässig.

f) Die nach Absatz 2 Buchstabe b) ergriffene Person darf im Hinblick auf ihre Vorführung vor die örtlichen Behörden lediglich einer Sicherheitsdurchsuchung unterzogen werden; es dürfen ihr während der Beförderung Handschellen angelegt werden; die von der verfolgten Person mitgeführten Gegenstände dürfen sichergestellt werden.

g) Die nacheilenden Beamten melden sich nach jedem Einschreiten gemäß den Absätzen 1, 2 und 3 bei den örtlich zuständigen Behörden der Vertragspartei, auf deren Hoheitsgebiet sie gehandelt haben und erstatten Bericht; auf Ersuchen dieser Behörden sind sie verpflichtet, sich bis zur Klärung des Sachverhalts bereitzuhalten; gleiches gilt auch, wenn die verfolgte Person nicht festgenommen werden konnte.

h) Die Behörden der Vertragspartei, aus deren Hoheitsgebiet die nacheilenden Beamten kommen, unterstützen auf Ersuchen die nachträglichen Ermittlungen einschließlich gerichtlicher Verfahren der Vertragspartei, auf deren Hoheitsgebiet eingeschritten wurde. 
(6) Die Person, die gemäß Absatz 2 durch die örtlich zuständigen Behörden festgenommen wurde, kann ungeachtet ihrer Staatsangehörigkeit zum Zwecke der Vernehmung festgehalten werden. Die einschlägigen Bestimmungen des nationalen Rechts finden sinngemäß Anwendung. Hat die Person nicht die Staatsangehörigkeit der Vertragspartei, in deren Hoheitsgebiet sie aufgegriffen wurde, wird sie spätestens sechs Stunden nach ihrer Ergreifung freigelassen, wobei die Stunden zwischen Mitternacht und neun Uhr nicht mitzählen, es sei denn, die örtlich zuständigen Behörden erhalten vor Ablauf dieser Frist ein Ersuchen gleich in welcher Form um vorläufige Festnahme zum Zwecke der Auslieferung.

(7) Die in den Absätzen 1 bis 6 genannten Beamten sind

für das Königreich Belgien: die Beamten der Kriminalpolizei bei den Staatsanwaltschaften, der Gendarmerie und der Gemeindepolizei sowie, unter den in geeigneten bilateralen Vereinbarungen nach Absatz 10 festgelegten Bedingungen in Bezug auf ihre Befugnisse im Bereich des unerlaubten Verkehrs mit Betäubungsmitteln und im Bereich des unerlaubten Handels mit Waffen und Sprengstoffen und des unerlaubten Verkehrs mit giftigen und schädlichen Abfällen, die Zollbeamten;

für die Bundesrepublik Deutschland: die Beamten der Polizeien des Bundes und der Länder sowie, beschränkt auf den Bereich des unerlaubten Verkehrs mit Betäubungsmitteln und des unerlaubten Handels mit Waffen, die Beamten des Zollfahndungsdienstes als Hilfsbeamte der Staatsanwaltschaft;

für die Französische Republik: die Beamten und die Hilfsbeamten der kriminalpolizeilichen Abteilungen der Nationalen Polizei und der Nationalen Gendarmerie sowie, unter den in geeigneten bilateralen Vereinbarungen nach Absatz 10 festgelegten Bedingungen in Bezug auf ihre Befugnisse im Bereich des unerlaubten Verkehrs mit Betäubungsmitteln und im Bereich des unerlaubten Handels mit Waffen und Sprengstoffen und des unerlaubten Verkehrs mit giftigen und schädlichen Abfällen, die Zollbeamten;

für das Großherzogtum Luxemburg: die Beamten der Gendarmerie und der Polizei, sowie, unter den in geeigneten bilateralen Vereinbarungen nach $\mathrm{Ab}-$ satz 10 festgelegten Bedingungen in Bezug auf ihre Befugnisse im Bereich des unerlaubten Verkehrs mit Betäubungsmitteln, im Bereich des unerlaubten Handels mit Waffen und Sprengstoffen und im Bereich des unerlaubten Verkehrs mit giftigen und schädlichen Abfällen, die Zollbeamten;

für das Königreich der Niederlande: die Beamten der Reichspolizei und der Gemeindepolizei sowie, unter den in geeigneten bilateralen Vereinbarungen nach Absatz 10 festgelegten Bedingungen in Bezug auf ihre Befugnisse im Bereich des unerlaubten Verkehrs mit Betäubungsmitteln und im Bereich des unerlaubten Handels mit Waffen und
Sprengstoffen und des unerlaubten Verkehrs mit giftigen und schädlichen Abfällen, die Beamten des fiskalischen Nachrichten- und Fahndungsdienstes, die im Bereich der Einfuhrzölle und Verbrauchsteuern zuständig sind.

für die Italienische Republik: die Beamten und Hilfsbeamten der kriminalpolizeilichen Abteilungen der nationalen Polizei („Polizia di Stato“), der „Arma dei Carabinieri“ und, beschränkt auf die Bereiche der Falschmünzerei, des unerlaubten Verkehrs mit Betäubungsmitteln, des unerlaubten Handels mit Waffen und Sprengstoffen und des unerlaubten Verkehrs mit giftigen und schädlichen Abfällen, der „Guardia di Finanza“, sowie, unter den in geeigneten bilateralen Vereinbarungen nach Artikel 41 Absatz 10 des Übereinkommens von 1990 festgelegten Bedingungen in Bezug auf ihre Befugnisse im Bereich des unerlaubten Verkehrs mit Betäubungsmitteln, des unerlaubten Handels mit Waffen und Sprengstoffen und des unerlaubten Verkehrs mit giftigen und schädlichen Abfällen, die Zollbeamten.

für das Königreich Spanien: Die Beamten des „,Cuerpo Nacional de Policía“ und des „Cuerpo de la Guardia Civil" in der Ausübung ihrer kriminalpolizeilichen Aufgaben und, unter den in geeigneten bilateralen Vereinbarungen nach Absatz 10 festgelegten Bedingungen in bezug auf ihre Befugnisse im Bereich des unerlaubten Verkehrs mit Betäubungsmitteln, des unerlaubten Handels mit Waffen und Sprengstoffen und des unerlaubten Verkehrs mit giftigen und schädlichen Abfällen, die der Zollverwaltung zugeordneten Beamten;

für die Portugiesische Republik: Die Beamten der „Polícia Judiciária“, sowie, unter den in geeigneten bilateralen Vereinbarungen nach Absatz 10 festgelegten Bedingungen in Bezug auf ihre Befugnisse im Bereich des unerlaubten Verkehrs mit Betäubungsmitteln, des unerlaubten Handels mit Waffen und Sprengstoffen und des unerlaubten Verkehrs mit giftigen und schädlichen Abfällen, die Zollbeamten in ihrer Eigenschaft als Hilfsbeamte der Staatsanwaltschaft;

für die Republik Österreich: Die Organe des Öffentlichen Sicherheitsdienstes, das sind die Angehörigen der Bundesgendarmerie, die Angehörigen der Bundessicherheitswachekorps, die Angehörigen der Kriminalbeamtenkorps und die zur Ausübung unmittelbarer Befehls- und Zwangsgewalt ermächtigten Beamten des rechtskundigen Dienstes bei Sicherheitsbehörden, sowie, unter den in geeigneten bilateralen Vereinbarungen nach Absatz 10 festgelegten Bedingungen in Bezug auf ihre Befugnisse im Bereich des unerlaubten Verkehrs mit Betäubungsmitteln, des unerlaubten Handels mit Waffen und Sprengstoffen und des unerlaubten Verkehrs mit giftigen und schädlichen Abfällen, die Zollbeamten;

für das Königreich Dänemark: Die den örtlichen 
Polizeipräsidenten und dem Reichspolizei-Chef unterstehenden Polizeibeamten (Polititjenestemaend hos lokale politimestre og hos Rigspolitichefen) sowie, unter den in geeigneten bilateralen Vereinbarungen nach Absatz 10 festgelegten Bedingungen in Bezug auf ihre Befugnisse im Bereich des unerlaubten Verkehrs mit Betäubungsmitteln, des unerlaubten Handels mit Waffen und Sprengstoffen und des unerlaubten Verkehrs mit giftigen und schädlichen Abfällen, die Zollbeamten;

für die Republik Finnland: Die Polizeibeamten (poliisin virkamiehistä poliisimiehet - av polisens tjänste-män polismän), die Beamten der Grenzüberwachungsbehörde (rajavartiolaitoksen virkamiehistä rajavartiomiehet - av gränsbevakningsväsendets tjänstemän gränsbevakningsmän) sowie, unter den in geeigneten bilateralen Vereinbarungen nach Absatz 10 festgelegten Bedingungen in Bezug auf ihre Befugnisse im Bereich des unerlaubten Verkehrs mit Betäubungsmitteln, des unerlaubten Handels mit Waffen und Sprengstoffen und des unerlaubten Verkehrs mit giftigen und schädlichen Abfällen, die Zollbeamten (tullimiehet - tulltjänstemän);

für das Königreich Schweden: Die den schwedischen Polizeibehörden unterstehenden zuständigen Polizeibeamten (Polismän som är anställda av svenska polismyndigheter) und die den schwedischen Zollbehörden unterstehenden zuständigen Zollbeamten, wenn sie polizeiliche Befugnisse haben, hauptsächlich hinsichtlich strafbarer Handlungen im Zusammenhang mit Schmuggel und anderen strafbaren Handlungen im Zusammenhang mit der Einreise in den und der Ausreise aus dem Staat (Tulltjänstemän, som är anställda vid svensk tull-myndighet i de fall de har polisiära befogenheter, dvs främst i samband med smugglingsbrott och andra brott i samband med inresa och utresa till och fran riket);

für das Königreich Norwegen: Die Beamten der norwegischen Polizei.

(8) Für die betreffenden Vertragsparteien bleibt Artikel 27 des Benelux-Übereinkommens über Auslieferung und Rechtshilfe in Strafsachen vom 27. Juni 1962 in der Fassung des Protokolls vom 11. Mai 1974 unberührt.

(9) Bei der Unterzeichnung dieses Übereinkommens gibt jede Vertragspartei eine Erklärung ab, in der sie bezüglich jeder Vertragspartei, mit der sie eine gemeinsame Grenze hat, die Modalitäten der Ausübung des Nacheilerechts in ihrem Hoheitsgebiet nach Maßgabe der Absätze 2, 3 und 4 festlegt. Jede Vertragspartei kann zu jedem Zeitpunkt ihre Erklärung durch eine andere Erklärung ersetzen, soweit diese nicht die Tragweite der früheren Erklärung einschränkt.

Jeder Erklärung geht eine vorherige Abstimmung mit allen betroffenen Vertragsparteien voraus, wobei die Gleichwertigkeit der auf beiden Seiten der Binnengrenzen geltenden Regelungen angestrebt wird.
(10) Die Vertragsparteien können im Wege bilateraler Vereinbarungen den Anwendungsbereich des Absatzes 1 erweitern und zusätzliche Regelungen zur Durchführung dieses Artikels treffen.

\section{Artikel 42}

Während eines Einschreitens nach Maßgabe der Artikel 40 und 41 werden die Beamten, die im Hoheitsgebiet einer anderen Vertragspartei eine Aufgabe erfüllen, den Beamten dieser Vertragspartei in Bezug auf die Straftaten, denen diese Beamten zum Opfer fallen oder die sie begehen würden, gleichgestellt.

\section{Artikel 43}

(1) Wenn Beamte einer Vertragspartei nach den Artikeln 40 und 41 dieses Übereinkommens auf dem Hoheitsgebiet einer anderen Vertragspartei einschreiten, haftet die erste Vertragspartei nach Maßgabe des nationalen Rechts dieser anderen Vertragspartei für den durch die Beamten bei diesem Einschreiten dort verursachten Schaden.

(2) Die Vertragspartei, auf deren Hoheitsgebiet der in Absatz 1 genannte Schaden verursacht wird, verpflichtet sich, diesen Schaden so zu ersetzen, wie sie ihn ersetzen müsste, wenn ihre eigenen Beamten ihn verursacht hätten.

(3) Die Vertragspartei, deren Beamte den Schaden auf dem Hoheitsgebiet einer anderen Vertragspartei verursacht haben, erstattet dieser anderen Vertragspartei den Gesamtbetrag des Schadensersatzes, den diese an die Geschädigten oder ihre Rechtsnachfolger geleistet hat.

(4) Vorbehaltlich der Ausübung ihrer Rechte gegenüber Dritten und außer der Bestimmung des Absatzes 3 verzichtet jede Vertragspartei in dem Fall des Absatzes 1 darauf, den Betrag des erlittenen Schadens anderen Vertragsparteien gegenüber geltend zu machen.

\section{Artikel 44}

(1) Die Vertragsparteien schaffen nach Maßgabe der entsprechenden internationalen Verträge und unter Berücksichtigung der örtlichen Gegebenheiten und der technischen Möglichkeiten - insbesondere in den Grenzregionen - direkte Telefon-, Funk-, Telex- und andere Verbindungen zum Zwecke der Erleichterung der polizeilichen und zollrechtlichen Zusammenarbeit, insbesondere im Hinblick auf die rechtzeitige Übermittlung von Informationen im Zusammenhang mit der grenzüberschreitenden Observation und Nacheile.

(2) Über diese Sofortmaßnahmen hinaus werden sie insbesondere die nachstehenden Möglichkeiten prüfen:

a) Austausch von Material oder Entsendung von Verbindungsbeamten, die über geeignete Funkgeräte verfügen; 
b) Erweiterung der in den Grenzregionen benutzten Frequenzbänder;

c) Einrichtung einer gemeinsamen Verbindung zwischen den in derselben Region tätigen Polizei- und Zolldienststellen;

d) Koordinierung ihrer Programme für den Erwerb von Kommunikationsgeräten mit dem Ziel der Einrichtung genormter und kompatibler Kommunikationssysteme.

\section{Artikel 45}

(1) Die Vertragsparteien verpflichten sich, die erforderlichen Maßnahmen zu ergreifen, um sicherzustellen, dass

a) der Leiter einer Beherbergungsstätte oder seine Beauftragten darauf hinwirken, dass beherbergte Ausländer, einschließlich der Angehörigen anderer Vertragsparteien sowie anderer Mitgliedstaaten der Europäischen Gemeinschaften, soweit es sich nicht um mitreisende Ehegatten und minderjährige Kinder sowie Teilnehmer von Reisegesellschaften handelt, Meldevordrucke eigenhändig ausfüllen und unterschreiben und sich dabei gegenüber dem Leiter der Beherbergungsstätte oder seinem Beauftragten durch Vorlage eines gültigen Identitätsdokuments ausweisen;

b) die nach Buchstabe a) ausgefüllten Meldevordrucke für die zuständigen Behörden bereitgehalten oder diesen übermittelt werden, wenn dies nach deren Feststellung für Zwecke der Gefahrenabwehr, der Strafverfolgung oder der Aufklärung des Schicksals von Vermissten oder Unfallopfern erforderlich ist, soweit im nationalen Recht nichts anderes geregelt ist.

(2) Absatz 1 findet sinngemäß Anwendung, wenn Personen auf Plätzen, die geschäftsmäßig überlassen werden, insbesondere in Zelten, Wohnwagen und Wasserfahrzeugen übernachten.

\section{Artikel 46}

(1) Jede Vertragspartei kann nach Maßgabe ihres nationalen Rechts ohne Ersuchen im Einzelfall der jeweils betroffenen Vertragspartei Informationen mitteilen, die für den Empfänger zur Unterstützung bei der Bekämpfung zukünftiger Straftaten, zur Verhütung einer Straftat oder zur Abwehr von Gefahren für die öffentliche Sicherheit und Ordnung von Bedeutung sein können.

(2) Der Informationsaustausch wird unbeschadet der Regelung zur Zusammenarbeit in den Grenzgebieten in Artikel 39 Absatz 4 über eine zu benennende zentrale Stelle abgewickelt. In besonders eilbedürftigen Fällen kann der Informationsaustausch im Sinne dieses Artikels unmittelbar zwischen den betroffenen Polizeibehörden erfolgen, vorbehaltlich abweichender Regelungen im nationalen Recht. Die zentrale Stelle wird hiervon so bald wie möglich in Kenntnis gesetzt.

\section{Artikel 47}

(1) Die Vertragsparteien können bilaterale Absprachen über die befristete oder unbefristete Entsendung von Verbindungsbeamten einer Vertragspartei zu Polizeidienststellen einer anderen Vertragspartei treffen.

(2) Die unbefristete oder befristete Entsendung von Verbindungsbeamten hat zum Ziel, die Zusammenarbeit zwischen den Vertragsparteien zu fördern und zu beschleunigen, insbesondere durch

a) Unterstützung des Informationsaustausches zur präventiven und repressiven Verbrechensbekämpfung;

b) Unterstützung bei polizeilicher und justitieller Rechtshilfe in Strafsachen;

c) Unterstützung der grenzüberwachenden Behörden an den Außengrenzen.

(3) Die Verbindungsbeamten werden beratend und unterstützend tätig. Sie sind nicht zur selbständigen Durchführung von polizeilichen Maßnahmen berechtigt. Sie erteilen Informationen und erledigen ihre Aufträge im Rahmen der ihnen von der entsendenden Vertragspartei und der Vertragspartei, in die sie entsandt worden sind, erteilten Weisungen. Sie berichten regelmäßig an den Leiter des Polizeidienstes, zu dem sie entsandt sind.

(4) 1

\section{Kapitel 2 Rechtshilfe in Strafsachen}

\section{Artikel 48}

(1) Die Bestimmungen dieses Kapitels sollen das Europäische Übereinkommen über Rechtshilfe in Strafsachen vom 20. April 1959 ergänzen und seine Anwendung erleichtern. In den Beziehungen zwischen den Vertragsparteien, die der Benelux-Wirtschaftsunion angehören, gilt Satz 1 sinngemäß für Kapitel II des BeneluxÜbereinkommens über Auslieferung und Rechtshilfe in Strafsachen vom 27. Juni 1962 in der Fassung des Protokolls vom 11. Mai 1974.

(2) Die zwischen den Vertragsparteien geltenden weitergehenden Bestimmungen aufgrund bilateraler Abkommen bleiben unberührt.

Beschluss 2003/170/JI über die gemeinsame Inanspruchnahme von Verbindungsbeamten [14] 


\section{Artikel 49}

Rechtshilfe wird auch geleistet

a) 1

b) in Verfahren über Ansprüche auf Entschädigung für Strafverfolgungsmaßnahmen und ungerechtfertigte Verurteilungen;

c) in Gnadensachen;

d) in Zivilsachen, die mit einer Strafklage verbunden sind, solange das Strafgericht noch nicht endgültig über die Strafklage entschieden hat;

e) bei der Zustellung von Urkunden bezüglich der Vollstreckung einer Strafe oder einer Maßregel der Sicherung und Besserung, der Einziehung einer Geldbuße oder der Zahlung der Gerichtskosten;

f) bei Maßnahmen betreffend die Aussetzung des Ausspruchs oder der Vollstreckung einer Strafe oder Maßregel der Sicherung und Besserung, die bedingte Entlassung, den Aufschub des Vollstreckungsbeginns einer Strafe oder Maßregel der Sicherung und Besserung oder die Unterbrechung der Vollstreckung.

\section{Artikel 50²}

\section{Artikel 51}

Die Vertragsparteien unterwerfen die Erledigung von Rechtshilfeersuchen um Durchsuchung und Beschlagnahme keinen weitergehenden Bedingungen als denen, dass

a) die dem Rechtshilfeersuchen zugrunde liegende Tat nach dem Recht beider Vertragsparteien mit einer Freiheitsstrafe oder die Freiheit beschränkenden Maßregel der Sicherung und Besserung im Hoechstmaß von mindestens sechs Monaten bedroht ist, oder nach dem Recht einer der beiden Vertragsparteien mit einer Sanktion des gleichen Hoechstmaßes bedroht ist und nach dem Recht der anderen Vertragspartei als Zuwiderhandlung gegen Ordnungsvorschriften durch Behörden geahndet wird, gegen deren Entscheidung ein auch in Strafsachen zuständiges Gericht angerufen werden kann;

b) die Erledigung des Rechtshilfeersuchens im Übrigen mit dem Recht der ersuchten Vertragspartei vereinbar ist.

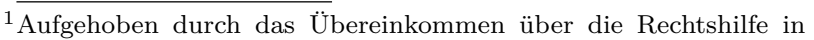
Strafsachen (abgedruckt Seite 156)

${ }^{2}$ Aufgehoben durch Protokoll zum Übereinkommen über die Rechtshilfe (abgedruckt Seite 169)
}

Artikel 52 / Artikel $53^{3}$

\section{Kapitel 3 Verbot der Doppelbestrafung}

\section{Artikel 54}

Wer durch eine Vertragspartei rechtskräftig abgeurteilt worden ist, darf durch eine andere Vertragspartei wegen derselben Tat nicht verfolgt werden, vorausgesetzt, dass im Fall einer Verurteilung die Sanktion bereits vollstreckt worden ist, gerade vollstreckt wird oder nach dem Recht des Urteilsstaats nicht mehr vollstreckt werden kann.

\section{Artikel 55}

(1) Eine Vertragspartei kann bei der Ratifikation, der Annahme oder der Genehmigung dieses Übereinkommens erklären, dass sie in einem oder mehreren der folgenden Fälle nicht durch Artikel 54 gebunden ist:

a) wenn die Tat, die dem ausländischen Urteil zugrunde lag, ganz oder teilweise in ihrem Hoheitsgebiet begangen wurde; im letzteren Fall gilt diese Ausnahme jedoch nicht, wenn diese Tat teilweise im Hoheitsgebiet der Vertragspartei begangen wurde, in dem das Urteil ergangen ist;

b) wenn die Tat, die dem ausländischen Urteil zugrunde lag, eine gegen die Sicherheit des Staates oder andere gleichermaßen wesentliche Interessen dieser Vertragspartei gerichtete Straftat darstellt;

c) wenn die Tat, die dem ausländischen Urteil zugrunde lag, von einem Bediensteten dieser Vertragspartei unter Verletzung seiner Amtspflichten begangen wurde.

(2) Eine Vertragspartei, die eine solche Erklärung betreffend eine der in Absatz 1 Buchstabe b) genannten Ausnahmen abgibt, bezeichnet die Arten von Straftaten, auf die solche Ausnahmen Anwendung finden können.

(3) Eine Vertragspartei kann eine solche Erklärung betreffend eine oder mehrere der in Absatz 1 genannten Ausnahmen jederzeit zurücknehmen.

(4) Ausnahmen, die Gegenstand einer Erklärung nach Absatz 1 waren, finden keine Anwendung, wenn die betreffende Vertragspartei die andere Vertragspartei wegen derselben Tat um Verfolgung ersucht oder die Auslieferung des Betroffenen bewilligt hat.

\section{Artikel 56}

Wird durch eine Vertragspartei eine erneute Verfolgung gegen eine Person eingeleitet, die bereits durch eine andere Vertragspartei wegen derselben Tat rechtskräftig abgeurteilt wurde, so wird jede in dem Hoheitsgebiet der

\footnotetext{
${ }^{3}$ Aufgehoben durch das Übereinkommen über die Rechtshilfe in
} Strafsachen (abgedruckt Seite 156) 
zuletzt genannten Vertragspartei wegen dieser Tat erlittene Freiheitsentziehung auf eine etwa zu verhängende Sanktion angerechnet. Soweit das nationale Recht dies erlaubt, werden andere als freiheitsentziehende Sanktionen ebenfalls berücksichtigt, sofern sie bereits vollstreckt wurden.

\section{Artikel 57}

(1) Ist eine Person im Hoheitsgebiet einer Vertragspartei wegen einer Straftat angeschuldigt und haben die zuständigen Behörden dieser Vertragspartei Grund zu der Annahme, dass die Anschuldigung dieselbe Tat betrifft, derentwegen der Betreffende im Hoheitsgebiet einer anderen Vertragspartei bereits rechtskräftig abgeurteilt wurde, so ersuchen sie, sofern sie es für erforderlich halten, die zuständigen Behörden der Vertragspartei, in deren Hoheitsgebiet die Entscheidung ergangen ist, um sachdienliche Auskünfte.

(2) Die erbetenen Auskünfte werden sobald wie möglich erteilt und sind bei der Entscheidung über eine Fortsetzung des Verfahrens zu berücksichtigen.

(3) Jede Vertragspartei gibt bei der Ratifikation, der Annahme oder der Genehmigung dieses Übereinkommens die Behörden an, die befugt sind, um Auskünfte nach diesem Artikel zu ersuchen und solche entgegenzunehmen.

\section{Artikel 58}

Die vorstehenden Bestimmungen stehen der Anwendung weitergehender Bestimmungen des nationalen Rechts über die Geltung des Verbots der Doppelbestrafung in Bezug auf ausländische Justizentscheidungen nicht entgegen.

\section{Kapitel 4 Auslieferung ${ }^{1}$}

\section{Kapitel 5 Übertragung der Vollstreckung von Strafurteilen}

\section{Artikel 67}

Für die Vertragsparteien, die dem Übereinkommen des Europarates vom 21. März 1983 über die Überstellung verurteilter Personen beigetreten sind, gilt die nachstehende Regelung als Ergänzung jenes Übereinkommens.

\footnotetext{
${ }^{1}$ ersetzt durch Rahmenbeschluss Europäischer Haftbefehl (abgedruckt Seite 109)
}

\section{Artikel 68}

(1) Eine Vertragspartei, in deren Hoheitsgebiet ein Staatsangehöriger einer anderen Vertragspartei rechtskräftig zu einer Freiheitsstrafe oder einer die Freiheit beschränkenden Maßregel der Sicherung und Besserung verurteilt wurde, kann, wenn der Betroffene sich durch Flucht in sein eigenes Land der Vollstreckung oder der weiteren Vollstreckung der Strafe oder Maßregel entzogen hat, ein Ersuchen um Übernahme der Vollstreckung an die Vertragspartei, in deren Hoheitsgebiet der Flüchtige angetroffen wird, richten.

(2) Die ersuchte Vertragspartei kann auf Ersuchen der ersuchenden Vertragspartei in Erwartung der Schriftstücke, die das Ersuchen um Übernahme der Vollstreckung der Strafe oder der Maßnahme oder des Restes der Strafe begründen, und der dazu zu treffenden Entscheidung den Verurteilten in Gewahrsam nehmen oder andere Maßnahmen zur Gewährleistung seiner Anwesenheit in dem Hoheitsgebiet der ersuchten Vertragspartei treffen.

\section{Artikel 69}

Die Übertragung der Strafvollstreckung nach Maßgabe des Artikels 68 bedarf nicht der Zustimmung der Person, gegen die eine Strafe oder eine Maßnahme verhängt wurde. Die anderen Bestimmungen des Übereinkommens des Europarates über die Überstellung verurteilter Personen vom 21. März 1983 finden sinngemäß Anwendung.

\section{Kapitel 6 Betäubungsmittel}

\section{Artikel 70}

(1) Die Vertragsparteien bilden eine ständige Arbeitsgruppe, die die Aufgabe hat, gemeinschaftliche Probleme in Bezug auf die Bekämpfung der Betäubungsmittelkriminalität zu untersuchen und gegebenenfalls Vorschläge zur notwendigen Verbesserung der praktischen und technischen Aspekte der Zusammenarbeit zwischen den Vertragsparteien zu machen. Die Arbeitsgruppe legt ihre Vorschläge dem Rat vor.

(2) Die Arbeitsgruppe nach Absatz 1, deren Mitglieder von den zuständigen nationalen Instanzen benannt werden, ist insbesondere aus Vertretern der für Aufgaben der Polizei und des Zolls zuständigen Behörden zusammengesetzt.

\section{Artikel 71}

(1) Die Vertragsparteien verpflichten sich, in Bezug auf die unmittelbare oder mittelbare Abgabe von Suchtstoffen und psychotropen Stoffen aller Art einschließlich Cannabis und den Besitz dieser Stoffe zum Zwecke 
der Abgabe oder Ausfuhr unter Berücksichtigung der bestehenden Übereinkommen der Vereinten Nationen ${ }^{1}$ alle notwendigen Maßnahmen zu treffen, die zur Unterbindung des unerlaubten Handels mit Betäubungsmitteln erforderlich sind.

(2) Unbeschadet der Artikel 74, 75 und 76 verpflichten sich die Vertragsparteien, die unerlaubte Ausfuhr von Betäubungsmitteln aller Art einschließlich CannabisProdukten sowie den Verkauf, die Verschaffung und die Abgabe dieser Mittel mit verwaltungsrechtlichen und strafrechtlichen Mitteln zu unterbinden.

(3) Zur Bekämpfung der unerlaubten Einfuhr von Suchtstoffen und psychotropen Stoffen aller Art einschließlich Cannabis verstärken die Vertragsparteien die Kontrollen des Personen- und des Warenverkehrs sowie der Transportmittel an den Außengrenzen. Einzelheiten werden durch die in Artikel 70 genannte Arbeitsgruppe festgelegt. Sie wird dabei insbesondere die Verlagerung eines Teils der an den Binnengrenzen frei werdenden Kräfte der Polizei und des Zolls sowie den Einsatz moderner Rauschgiftdetektionsmethoden und von Rauschgiftspürhunden in Betracht ziehen.

(4) Die Vertragsparteien werden zur Einhaltung der Bestimmungen dieses Artikels Örtlichkeiten, an denen erfahrungsgemäß Rauschgifthandel betrieben wird, gezielt überwachen.

(5) Hinsichtlich der Eindämmung der unerlaubten Nachfrage nach Suchtstoffen und psychotropen Stoffen aller Art einschließlich Cannabis werden die Vertragsparteien ihr Möglichstes tun, den negativen Folgen dieser unerlaubten Nachfrage vorzubeugen und entgegenzuwirken. Die Maßnahmen dazu liegen im Verantwortungsbereich der einzelnen Vertragsparteien.

\section{Artikel 72}

Die Vertragsparteien werden im Rahmen ihrer Verfassung und ihrer Rechtsordnung gewährleisten, dass nationale gesetzliche Bestimmungen geschaffen werden, die die Sicherstellung und den Verfall von Vermögensgewinnen aus dem unerlaubten Betäubungsmittelhandel ermöglichen.

\section{Artikel $73^{2}$}

\section{Artikel 74}

In Bezug auf den legalen Verkehr mit Suchtstoffen und psychotropen Stoffen vereinbaren die Vertragsparteien,

${ }^{1}$ Einheitsübereinkommen von 1961 in der durch das Protokoll von 1972 zur Änderung des Einheitsübereinkommens von 1961 geänderten Fassung; Übereinkommen von 1971 über psychotrope Stoffe; Übereinkommen der Vereinten Nationen vom 20. Dezember 1988 über den unerlaubten Verkehr mit Suchtstoffen und psychotropen Stoffen.

${ }^{2}$ Aufgehoben durch das Übereinkommen über die Rechtshilfe in Strafsachen (abgedruckt Seite 156) die Kontrollen, die vor der Abschaffung der Grenzkontrollen an den Binnengrenzen gemäß den einschlägigen Verpflichtungen nach den in Artikel 71 aufgeführten Übereinkommen der Vereinten Nationen durchgeführt wurden, soweit wie möglich in das Binnenland zu verlegen.

\section{Artikel 75}

(1) Im Reiseverkehr in das Hoheitsgebiet der Vertragsparteien oder innerhalb desselben dürfen Personen die im Rahmen einer ärztlichen Behandlung benötigten Betäubungsmittel mit sich führen, wenn sie eine von einer zuständigen Behörde ihres Aufenthaltsstaates ausgestellte oder beglaubigte Bescheinigung bei einer Kontrolle vorweisen.

(2) Die Form und der Inhalt der Bescheinigung nach Absatz 1, soweit sie von einer der Vertragsparteien ausgestellt wird, insbesondere die Angaben bezüglich der Art, der Menge und der Reisedauer, werden von dem Rat festgelegt.

(3) Die Vertragsparteien unterrichten sich darüber, welche Behörden für die Ausstellung oder Beglaubigung der Bescheinigung nach Absatz 2 zuständig sind.

\section{Artikel 76}

(1) Die Vertragsparteien treffen soweit erforderlich unter Berücksichtigung ihrer ärztlichen, ethischen und praktischen Gepflogenheiten die geeigneten Maßnahmen für die Kontrolle von Suchtstoffen und psychotropen Stoffen, die im Hoheitsgebiet einer oder mehrerer Vertragsparteien strengeren Kontrollen als in ihrem eigenen Hoheitsgebiet unterliegen, damit die Wirksamkeit dieser strengeren Kontrollen nicht beeinträchtigt wird.

(2) Absatz 1 gilt auch für Stoffe, die häufig bei der Herstellung von Suchtstoffen oder psychotropen Stoffen Verwendung finden.

(3) Die Vertragsparteien informieren sich gegenseitig über ihre Maßnahmen zur Durchführung der Überwachung des legalen Verkehrs mit den in den Absätzen 1 und 2 genannten Stoffen.

(4) Der Rat berät regelmäßig über die hierbei auftretenden Probleme.

\section{Kapitel 7 Feuerwaffen Und Munition}

\section{Artikel 77}

(1) Die Vertragsparteien verpflichten sich, die nationalen Gesetze, Verordnungen und sonstigen Vorschriften über den Erwerb, den Besitz, den Vertrieb und das Überlassen von Feuerwaffen und Munition den Bestimmungen dieses Kapitels anzupassen. 
(2) Dieses Kapitel gilt für den Erwerb, den Besitz, den Vertrieb und das Überlassen von Feuerwaffen und $\mathrm{Mu}-$ nition durch natürliche und juristische Personen; es gilt nicht für die Lieferung an sowie den Erwerb und Besitz durch staatliche Dienststellen und Gebietskörperschaften, die Streitkräfte und die Polizei, ferner nicht für die Herstellung durch staatliche Unternehmen.

\section{Artikel 78}

(1) Die Feuerwaffen werden im Rahmen dieses Kapitels wie folgt klassifiziert:

a) verbotene Waffen,

b) erlaubnispflichtige Waffen,

c) meldepflichtige Waffen.

(2) Auf Verschluss, Patronenlager und Lauf der Feuerwaffen sind die Vorschriften entsprechend anzuwenden, die für den Gegenstand gelten, dessen Bestandteil sie sind oder werden sollen.

(3) Als Kurzwaffen im Sinne dieses Übereinkommens gelten Feuerwaffen, deren Lauf nicht länger als $30 \mathrm{~cm}$ ist oder deren Gesamtlänge $60 \mathrm{~cm}$ nicht überschreitet; Langwaffen sind alle anderen Feuerwaffen.

\section{Artikel 79}

(1) In die Liste der verbotenen Feuerwaffen und Munition sind die folgenden Gegenstände aufzunehmen:

a) Feuerwaffen, die üblicherweise als Kriegsschusswaffen verwendet werden;

b) vollautomatische Feuerwaffen, auch wenn sie keine Kriegsschusswaffen sind;

c) Feuerwaffen, die einen anderen Gegenstand vortäuschen;

d) panzerbrechende Munition, Munition mit Sprengund Brandsätzen sowie Geschosse für diese Munition;

e) Pistolen- und Revolvermunition mit DumdumGeschossen oder Hohlspitzgeschossen sowie Geschosse für diese Munition.

(2) Die zuständigen Behörden können in Einzelfällen für die in Absatz 1 aufgeführten Feuerwaffen und Munition eine Erlaubnis erteilen, wenn Gründe der öffentlichen Sicherheit und Ordnung dem nicht entgegenstehen.

\section{Artikel 80}

(1) In die Liste der Feuerwaffen, für deren Erwerb und Besitz eine Erlaubnis erforderlich ist, sind mindestens folgende Feuerwaffen aufzunehmen, soweit sie nicht verboten sind:

a) halbautomatische Kurz-Feuerwaffen und kurze Repetier-Feuerwaffen; b) kurze Einzellader-Feuerwaffen mit Zentralfeuerzündung;

c) kurze Einzellader-Feuerwaffen mit Randfeuerzündung mit einer Gesamtlänge von weniger als 28 $\mathrm{cm}$;

d) halbautomatische Lang-Feuerwaffen, deren Magazin und Patronenlager mehr als drei Patronen aufnehmen kann;

e) lange Repetier-Feuerwaffen und halbautomatische Feuerwaffen mit glattem Lauf, deren Lauf nicht länger als $60 \mathrm{~cm}$ ist;

f) zivile halbautomatische Feuerwaffen, die wie vollautomatische Kriegswaffen aussehen.

(2) In die Liste der erlaubnispflichtigen Feuerwaffen sind nicht aufzunehmen:

a) Schreckschuss-, Reizstoff- und Signalwaffen, sofern bei diesen Waffen durch technische Maßnahmen sichergestellt ist, dass sie mit allgemein gebräuchlichen Werkzeugen nicht zu Waffen zum Verschießen fester Körper umgebaut werden können und das Verschießen eines Reizstoffes keine dauernden körperlichen Schädigungen zufügen kann;

b) halbautomatische Lang-Feuerwaffen, deren Magazin und Patronenlager nicht mehr als drei Patronen aufnehmen kann, ohne dass sie neu geladen werden, und unter der Bedingung, dass das Magazin unauswechselbar ist, oder soweit sichergestellt ist, dass sie mit allgemein gebräuchlichen Werkzeugen nicht umgebaut werden können zu Waffen, deren Magazin und Patronenlager mehr als drei Patronen aufnehmen kann.

\section{Artikel 81}

In die Liste der meldepflichtigen Feuerwaffen sind, sofern diese Waffen weder verboten noch erlaubnispflichtig sind, aufzunehmen:

a) lange Repetier-Feuerwaffen;

b) lange Einzellader-Feuerwaffen mit gezogenem Lauf oder gezogenen Läufen;

c) kurze Einzellader-Feuerwaffen mit Randfeuerzündung mit einer Gesamtlänge von mehr als $28 \mathrm{~cm}$;

d) die in Artikel 80 Absatz 2 Buchstabe b) aufgeführten Feuerwaffen.

\section{Artikel 82}

Die Listen der in den Artikeln 79, 80 und 81 aufgeführten Feuerwaffen umfassen folgende Gegenstände nicht:

a) Feuerwaffen, deren Modell vor dem 1. Januar 1870 entwickelt worden ist oder die vor diesem Zeitpunkt hergestellt worden sind - vorbehaltlich Ausnahmen -, wenn in ihnen keine Munition geladen werden kann, die für verbotene oder erlaubnispflichtige Feuerwaffen bestimmt ist; 
b) Reproduktionen von Waffen nach Buchstabe a), sofern daraus keine Patronen mit Metallhülsen verschossen werden können;

c) Feuerwaffen, die durch Anwendung technischer Verfahren zum Abschuss jeglicher Munition unbrauchbar gemacht worden sind, und die das Prüfzeichen einer offiziellen Dienststelle tragen oder von einer solchen Dienststelle anerkannt worden sind.

\section{Artikel 83}

Eine Erlaubnis zum Erwerb und Besitz einer Feuerwaffe nach Artikel 80 darf einer Person nur erteilt werden,

a) wenn sie das achtzehnte Lebensjahr vollendet hat, von Ausnahmen für Jagd- oder Sportzwecke abgesehen;

b) wenn sie nicht wegen einer Geisteskrankheit oder anderer geistiger oder körperlicher Mängel unfähig ist, eine Feuerwaffe zu erwerben oder zu besitzen;

c) wenn sie nicht wegen einer Straftat verurteilt wurde oder wenn nicht andere Anhaltspunkte dafür vorliegen, dass sie eine Gefahr für die öffentliche Sicherheit oder Ordnung darstellt;

d) wenn der für den Erwerb oder Besitz einer Feuerwaffe angeführte Grund als triftig anzusehen ist.

\section{Artikel 84}

(1) Die Meldung für Waffen nach Artikel 81 wird in ein von den in Artikel 85 bezeichneten Personen geführtes Register eingetragen.

(2) Wenn die Waffe durch eine Person überlassen wird, die nicht in Artikel 85 bezeichnet ist, muss dies nach den von jeder Vertragspartei festzulegenden Modalitäten gemeldet werden.

(3) Die in diesem Artikel genannte Meldung muss die für die Identifizierung der betroffenen Personen und Waffen erforderlichen Angaben enthalten.

\section{Artikel 85}

(1) Die Vertragsparteien verpflichten sich, Hersteller und Händler von erlaubnispflichtigen Feuerwaffen einer Erlaubnispflicht, Hersteller und Händler von meldepflichtigen Feuerwaffen einer Meldepflicht zu unterwerfen. Die Erlaubnis für erlaubnispflichtige Feuerwaffen umfasst auch die meldepflichtigen Feuerwaffen. Die Vertragsparteien unterziehen die Waffenhersteller und Waffenhändler einer Überwachung, die eine wirksame Kontrolle gewährleistet.

(2) Die Vertragsparteien verpflichten sich, Vorschriften zu erlassen, wonach alle Feuerwaffen mindestens mit einer dauerhaften fortlaufenden Identifizierungsnummer und der Marke des Herstellers gekennzeichnet sind.
(3) Die Vertragsparteien verpflichten Hersteller und Händler, alle erlaubnis- und meldepflichtigen Feuerwaffen zu registrieren; die Register müssen es ermöglichen, die Art der Feuerwaffen, ihre Herkunft und die Erwerber der Waffen schnell zu ermitteln.

(4) Die Vertragsparteien verpflichten sich, in Bezug auf Erlaubnisse nach Artikel 79 und 80 Vorschriften zu erlassen, wonach die Identifizierungsnummer und die Kennzeichnung der Feuerwaffen in die ihrem Besitzer ausgestellte Erlaubnisurkunde eingetragen werden.

\section{Artikel 86}

(1) Die Vertragsparteien verpflichten sich, Vorschriften zu erlassen, aufgrund deren es den rechtmäßigen Besitzern von erlaubnispflichtigen oder meldepflichtigen Feuerwaffen verboten ist, diese Personen zu überlassen, die nicht im Besitz einer Erwerbserlaubnis oder einer Anmeldebestätigung sind.

(2) Die Vertragsparteien können das vorübergehende Überlassen an Personen nach den von ihnen festzulegenden Modalitäten erlauben.

\section{Artikel 87}

(1) Die Vertragsparteien führen in ihr nationales Recht ein System ein, welches die Rücknahme der Erlaubnisse bei Personen ermöglicht, die nicht mehr die Voraussetzungen für die Erteilung der Erlaubnisse nach Artikel 83 erfuellen.

(2) Die Vertragsparteien verpflichten sich, geeignete Vorschriften, einschließlich der Beschlagnahme der Feuerwaffen und der Rücknahme der Erlaubnis zu erlassen, sowie die Verletzung der Gesetze oder sonstiger Vorschriften über Feuerwaffen mit geeigneten Sanktionen zu belegen. Dabei kann die Einziehung der Feuerwaffen vorgesehen werden.

\section{Artikel 88}

(1) Die Personen, die eine Erlaubnis zum Erwerb einer Feuerwaffe besitzen, benötigen keine Erlaubnis zum Erwerb von Munition für diese Waffen.

(2) Der Erwerb von Munition durch Personen, die nicht im Besitz einer Erlaubnis zum Waffenerwerb sind, unterliegt der entsprechenden Regelung der Waffe, für die sie bestimmt ist. Die Erlaubnis kann für eine Munitionsart oder für alle Munitionsarten ausgestellt werden.

\section{Artikel 89}

Die Listen der verbotenen, erlaubnispflichtigen und meldepflichtigen Feuerwaffen können geändert oder ergänzt werden, um die technische, wirtschaftliche und sicherheitspolitische Entwicklung zu berücksichtigen. Der Rat kann die Listen ändern oder ergänzen. 


\section{Artikel 90}

Die Vertragsparteien sind befugt, strengere Gesetze und Vorschriften in Bezug auf Feuerwaffen und Munition zu erlassen.

\section{Artikel 91}

(1) Die Vertragsparteien schaffen auf der Grundlage des Europäischen Übereinkommens vom 28. Juni 1978 über die Kontrolle des Erwerbs und des Besitzes von Schusswaffen durch Einzelpersonen nach Maßgabe ihres nationalen Rechts einen Informationsaustausch über den Erwerb von Feuerwaffen durch Personen, Privatpersonen oder Waffenhändler im Einzelhandel, die sich gewöhnlich in dem Hoheitsgebiet einer anderen Vertragspartei aufhalten oder dort ihren Sitz haben. Unter Einzelhändler ist jede Person zu verstehen, deren Erwerbstätigkeit insgesamt oder zum Teil in dem Einzelhandel von Feuerwaffen besteht.

(2) Der Informationsaustausch erstreckt sich

a) zwischen zwei Vertragsparteien, die das in Absatz 1 genannte Übereinkommen ratifiziert haben, auf die Feuerwaffen, die in Anlage 1 Teil A Nummer 1 Buchstaben a) bis h) des genannten Übereinkommens aufgeführt sind;

b) zwischen zwei Vertragsparteien, von denen mindestens eine das in Absatz 1 genannte Übereinkommen nicht ratifiziert hat, auf die Waffen, die in dem Hoheitsgebiet jeder einzelnen Vertragspartei erlaubnis- oder meldepflichtig sind.

(3) Die Informationen über den Erwerb von Feuerwaffen müssen so schnell wie möglich übermittelt werden und die folgenden Angaben enthalten:

a) das Datum des Erwerbs und die Identität des Erwerbers, nämlich,

wenn es sich um eine natürliche Person handelt: Name, Vorname, Datum und Ort der Geburt, Anschrift und Pass- oder Personalausweisnummer sowie Ausstellungsdatum und Angabe der ausstellenden Behörde, Waffenhändler oder nicht;

wenn es sich um eine juristische Person handelt: Firma und Sitz sowie Name, Vorname, Datum und Ort der Geburt, Anschrift und Pass- oder Personalausweisnummer der Person, die zur Vertretung der juristischen Person berechtigt ist;

b) Modell, Herstellungsnummer, Kaliber und die anderen Merkmale der betreffenden Feuerwaffe sowie die Identifizierungsnummer.

(4) Jede Vertragspartei benennt eine nationale Behörde, die die in den Absätzen 2 und 3 erwähnten Informationen übermittelt und empfängt und setzt die anderen Vertragsparteien unverzüglich über jede Änderung der bezeichneten Behörde in Kenntnis.
(5) Die von jeder Vertragspartei benannte Behörde kann die erhaltenen Informationen den zuständigen örtlichen Polizeidienststellen und den Grenzüberwachungsbehörden zum Zwecke der Verhütung oder Verfolgung von Straftaten und Ordnungswidrigkeiten übermitteln.

\section{Titel IV Schengener Informationssystem}

\section{Kapitel 1 Einrichtung des Schengener Informationssystems}

\section{Artikel 92}

(1) Die Vertragsparteien errichten und unterhalten ein gemeinsames Informationssystem, nachstehend das Schengener Informationssystem genannt, das aus einem nationalen Teil bei jeder Vertragspartei und einer technischen Unterstützungseinheit besteht. Durch das Schengener Informationssystem werden Ausschreibungen, die der Suche nach Personen und Sachen dienen, den durch die Vertragsparteien bezeichneten Behörden bei nach Maßgabe des nationalen Rechts durchgeführten Grenzkontrollen, sonstigen polizeilichen und zollrechtlichen Überprüfungen im Inland sowie, beschränkt auf die Ausschreibungskategorie nach Artikel 96, für Zwecke des Sichtvermerksverfahrens sowie der Erteilung der Aufenthaltstitel und der Handhabung des Ausländerrechts im Rahmen der Anwendung dieses Übereinkommens im Bereich des Personenverkehrs zum Abruf im automatisierten Verfahren bereitgehalten.

(2) Jede Vertragspartei errichtet und unterhält in eigener Verantwortung und auf eigene Kosten ihren nationalen Teil des Schengener Informationssystems, dessen Bestand durch Nutzung der technischen Unterstützungseinheit inhaltlich identisch ist mit dem Bestand des nationalen Teiles jeder anderen Vertragspartei. Im Hinblick auf die schnelle und zweckmäßige Übermittlung der Informationen nach Absatz 3 berücksichtigt jede Vertragspartei bei der Errichtung ihres nationalen Teils die durch die Vertragsparteien gemeinsam festgelegten Protokolle und Verfahren in Bezug auf die technische Unterstützungseinheit. Der Bestand jedes nationalen Teils dient innerhalb des Hoheitsgebietes der jeweiligen Vertragsparteien zum Abruf im automatisierten Verfahren. Ein Abruf aus dem Bestand des nationalen Teiles einer anderen Vertragspartei erfolgt nicht.

(3) Die Vertragsparteien errichten und unterhalten in gemeinsamer Verantwortung und auf gemeinsame Kosten die technische Unterstützungseinheit des Schengener Informationssystems. Die Französische Republik ist zuständig für diese Unterstützungseinheit; sie wird eingerichtet in Straßburg. Die technische Unterstützungseinheit umfasst einen Bestand, der der OnlineÜbermittlung der Informationen an die nationalen Bestände dient, wodurch gewährleistet wird, dass die nationalen Bestände identisch bleiben. In den Bestand der 
technischen Unterstützungseinheit werden Ausschreibungen von Personen und Sachen aufgenommen, soweit sie sich auf alle Vertragsparteien beziehen. Der Bestand der technischen Unterstützungseinheit umfasst, abgesehen von den Daten nach diesem Absatz und nach Artikel 113 Absatz 2, keine weiteren Daten.

$(4)^{1}$ Gemäß den einzelstaatlichen Rechtsvorschriften tauschen die Mitgliedstaaten über die für diesen Zweck bezeichneten Stellen (SIRENE) alle im Zusammenhang mit der Eingabe von Ausschreibungen erforderlichen zusätzlichen Informationen aus, auf deren Grundlage die geeigneten Maßnahmen ergriffen werden können, wenn zu Personen bzw. Sachen, in Bezug auf die Daten in das Schengener Informationssystem aufgenommen worden sind, als Ergebnis der Abfragen in diesem System ein Trefferfall erzielt wird. Diese Informationen dürfen nur für die Zwecke verwendet werden, für die sie mitgeteilt wurden.

\section{Artikel 92A}

${ }^{2}$ (1) Ab dem Inkrafttreten der Verordnung (EG) Nr. 1104/2008 des Rates ${ }^{3}$ und des Beschlusses 2008/839/JI des Rates ${ }^{4}$ und gestützt auf die Begriffsbestimmungen in Artikel 2 der genannten Verordnung kann die technische Architektur des Schengener Informationssystems ergänzt werden durch:

a) ein zusätzliches zentrales System, bestehend aus

einer technischen Unterstützungseinheit (Zentrales SIS II), die sich in Frankreich befindet, und einem Backup des Zentralen SIS II, das sich in Österreich befindet, mit der SIS II-Datenbank und einer einheitlichen nationalen Schnittstelle (NI-SIS);

einer technischen Verbindung zwischen dem C.SIS und dem Zentralen SIS II über den Konverter für die Konvertierung und die Synchronisation der Daten zwischen dem C.SIS und dem Zentralen SIS II;

b) einem nationalen System (N.SIS II), das aus den nationalen Datensystemen besteht und mit dem Zentralen SIS II kommuniziert;

c) einer Infrastruktur für die Kommunikation zwischen dem Zentralen SIS II und den N.SIS II, angeschlossen an die NI-SIS.

(2) Das N.SIS II kann den in Artikel 92 dieses Übereinkommens genannten nationalen Teil ersetzen; in diesem Fall brauchen die Mitgliedstaaten keinen nationalen Datenbestand unterhalten.

(3) Die Datenbank des Zentralen SIS II steht für Abfragen im automatisierten Verfahren im Hoheitsgebiet eines jeden Mitgliedstaats zur Verfügung.

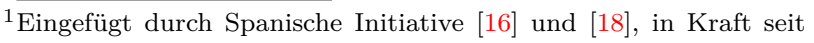
13.06.2005

${ }^{2}$ Eingefügt durch [22] ab 11.11.2008

${ }^{3}$ ABl. L 299 vom 8.11.2008, S. 1.

${ }^{4} \mathrm{ABl}$. L 299 vom 8.11.2008, S. 43
(4) Falls ein Mitgliedstaat seinen nationalen Teil durch das N.SIS II ersetzt, werden die in Artikel 92 Absätze 2 und 3 genannten obligatorischen Funktionen der technischen Unterstützungseinheit gegenüber diesem nationalen Teil - unbeschadet der in dem Beschluss 2008/839/JI des Rates und der in Artikel 5 Absatz 1 und Artikel 10 Absätze 1, 2 und 3 der Verordnung (EG) Nr. 1104/2008 des Rates genannten Pflichten - zu obligatorischen Funktionen gegenüber dem Zentralen SIS II.

(5) Das Zentrale SIS II stellt die erforderlichen Dienste für die Eingabe und die Verarbeitung von SIS-Daten, die Online-Aktualisierung der nationalen Kopien der N.SIS II, die Synchronisation und die Kohärenz zwischen den nationalen Kopien der N.SIS II und der Datenbank des Zentralen SIS II zur Verfügung und stellt die Vorgänge für die Initialisierung und die Wiederherstellung der nationalen Kopien der N.SIS II bereit.

(6) Frankreich, das für die technische Unterstützungseinheit zuständig ist, die übrigen Mitgliedstaaten und die Kommission arbeiten zusammen, um sicherzustellen, dass ein Abruf aus den Datenbeständen der N.SIS II oder aus der SIS-II-Datenbank ein Ergebnis liefert, das dem eines Abrufs aus der Datenbank der in Artikel 92 Absatz 2 genannten nationalen Teile gleichwertig ist.

\section{Kapitel 2 Betrieb und Nutzung des Schengener Informationssystems}

\section{Artikel 93}

Das Schengener Informationssystem hat nach Maßgabe der Bestimmungen dieses Übereinkommens zum Ziel, in dem Hoheitsgebiet der Vertragsparteien anhand der aus diesem System erteilten Informationen die öffentliche Sicherheit und Ordnung einschließlich der Sicherheit des Staates und die Anwendung der Bestimmungen dieses Übereinkommens im Bereich des Personenverkehrs zu gewährleisten.

\section{Artikel 94}

(1) Das Schengener Informationssystem enthält ausschließlich die durch jede der Vertragsparteien gelieferten Kategorien von Daten, die für die in den Artikeln 95 bis 100 vorgesehenen Zwecke erforderlich sind. Die ausschreibende Vertragspartei prüft, ob die Bedeutung des Falles eine Aufnahme der Ausschreibung in das Schengener Informationssystem rechtfertigt.

(2) Die Datenkategorien sind:

a) die ausgeschriebenen Personen;

b) ${ }^{5}$ die in Artikel 100 aufgeführten Sachen und die in Artikel 99 aufgeführten Fahrzeuge.

$(3)^{6}$ In Bezug auf Personen werden höchstens die folgenden Angaben mitgeteilt:

5 wird durch 18 geändert, noch nicht in Kraft

${ }^{6}$ wird durch 16 und 18 geändert, noch nicht in Kraft 
a) Name und Vorname, gegebenenfalls Aliasname in einem neuen Datensatz;

b) besondere unveränderliche und physische Merkmale;

c) erster Buchstabe des zweiten Vornamens;

d) Geburtsort und -datum;

e) Geschlecht;

f) Staatsangehörigkeit;

g) der personenbezogene Hinweis „bewaffnet“;

h) der personenbezogene Hinweis „gewalttätig“;

i) Ausschreibungsgrund;

j) zu ergreifende Maßnahme.

Andere Angaben, insbesondere die Daten, die in Artikel 6 Satz 1 des Übereinkommens des Europarates vom 28. Januar 1981 zum Schutz des Menschen bei der automatischen Verarbeitung personenbezogener Daten erwähnt sind, sind nicht zulässig.

(4) Sofern eine Vertragspartei eine Ausschreibung nach Artikel 95, 97 oder 99 für nicht vereinbar hält mit ihrem nationalen Recht, mit internationalen Verpflichtungen oder wesentlichen nationalen Interessen, kann sie nachträglich die Ausschreibung in dem Bestand ihres nationalen Teils des Schengener Informationssystems so kennzeichnen lassen, dass die Maßnahme in ihrem Hoheitsgebiet nicht aufgrund der Ausschreibung vollzogen wird. Mit den anderen Vertragsparteien müssen hierüber Konsultationen geführt werden. Wenn die ausschreibende Vertragspartei die Ausschreibung nicht zurückzieht, bleibt die Ausschreibung für die anderen Vertragsparteien nach wie vor gültig.

\section{Artikel 95}

(1) Daten in Bezug auf Personen, um deren Festnahme mit dem Ziel der Auslieferung ersucht wird, werden auf Antrag der Justizbehörde der ersuchenden Vertragspartei aufgenommen.

(2) Vor der Ausschreibung prüft die ausschreibende Vertragspartei, ob die Festnahme nach dem Recht der ersuchten Vertragsparteien zulässig ist. Sollte die ausschreibende Vertragspartei Zweifel haben, ist sie verpflichtet, die betroffenen Vertragsparteien zu konsultieren. Die ausschreibende Vertragspartei teilt den ersuchten Vertragsparteien gleichzeitig mit der Ausschreibung auf möglichst schnellem Wege folgende für den zugrunde liegenden Sachverhalt wesentliche Informationen mit:

a) die um die Festnahme ersuchende Behörde;

b) das Bestehen eines Haftbefehls oder einer Urkunde mit gleicher Rechtswirkung oder eines rechtskräftigen Urteils;

c) die Art und die rechtliche Würdigung der strafbaren Handlung; d) die Beschreibung der Umstände, unter denen die Straftat begangen wurde, einschließlich der Zeit, des Orts und der Art der Täterschaft;

e) soweit möglich die Folgen der Straftat.

(3) Eine ersuchte Vertragspartei kann die Ausschreibung in dem Bestand ihres nationalen Teils des Schengener Informationssystems so kennzeichnen lassen, dass bis zur Löschung der Kennzeichnung keine Festnahme aufgrund der Ausschreibung erfolgen darf. Die Kennzeichnung ist spätestens vierundzwanzig Stunden nach der Speicherung der Ausschreibung zu löschen, es sei denn, die betreffende Vertragspartei lehnt die erbetene Festnahme aus Rechtsgründen oder besonderen Opportunitätserwägungen ab. Sofern in besonderen Ausnahmefällen die Komplexität des Sachverhalts dies erfordert, kann die genannte Frist auf eine Woche verlängert werden. Ungeachtet einer Kennzeichnung oder einer ablehnenden Entscheidung bleiben die anderen Vertragsparteien befugt, die mit der Ausschreibung erbetene Festnahme zu vollziehen.

(4) Ersucht eine Vertragspartei wegen besonderer Eilbedürftigkeit um eine Sofortfahndung, prüft die ersuchte Vertragspartei, ob sie auf die Kennzeichnung verzichten kann. Die ersuchte Vertragspartei trifft die erforderlichen Vorkehrungen, damit die erbetene Maßnahme für den Fall, dass die Ausschreibung gebilligt wird, unverzüglich vollzogen werden kann.

(5) Ist eine Festnahme wegen einer noch nicht abgeschlossenen Prüfung oder wegen einer ablehnenden Entscheidung einer ersuchten Vertragspartei nicht möglich, so ist von dieser Vertragspartei die Ausschreibung als Ausschreibung zur Aufenthaltsermittlung zu behandeln.

(6) Die ersuchten Vertragsparteien treffen die aufgrund der Ausschreibung erbetenen Maßnahmen auf der Grundlage der geltenden Auslieferungsübereinkommen und nach Maßgabe des nationalen Rechts. Unbeschadet der Möglichkeit, den Betroffenen nach Maßgabe des nationalen Rechts festzunehmen, sind sie nicht verpflichtet, die Maßnahme zu vollziehen, wenn ein eigener Staatsangehöriger betroffen ist.

\section{Artikel 96}

(1) Die Daten bezüglich Drittausländern, die zur Einreiseverweigerung ausgeschrieben sind, werden aufgrund einer nationalen Ausschreibung gespeichert, die auf Entscheidungen der zuständigen Verwaltungsbehörden und Gerichte beruht, wobei die Verfahrensregeln des nationalen Rechts zu beachten sind.

(2) Die Entscheidungen können auf die Gefahr für die öffentliche Sicherheit und Ordnung oder die nationale Sicherheit, die die Anwesenheit eines Drittausländers auf dem Hoheitsgebiet der Vertragspartei bedeutet, gestützt werden. Dies kann insbesondere der Fall sein 
a) bei einem Drittausländer, der wegen einer Straftat verurteilt worden ist, die mit Freiheitsstrafe von mindestens einem Jahr bedroht ist;

b) bei einem Drittausländer, gegen den ein begründeter Verdacht besteht, dass er schwere Straftaten, einschließlich solcher im Sinne von Artikel 71 begangen hat, oder gegen den konkrete Hinweise bestehen, dass er solche Taten in dem Hoheitsgebiet einer Vertragspartei plant.

(3) Die Entscheidungen können ebenso darauf beruhen, dass der Drittausländer ausgewiesen, zurückgewiesen oder abgeschoben worden ist, wobei die Maßnahme nicht aufgeschoben oder aufgehoben worden sein darf, ein Verbot der Einreise oder des Aufenthalts enthalten oder davon begleitet sein muss und auf der Nichtbeachtung des nationalen Rechts über die Einreise oder den Aufenthalt von Ausländern beruhen muss.

\section{Artikel 97}

Daten in Bezug auf Vermisste oder Personen, die im Interesse ihres eigenen Schutzes oder zur Gefahrenabwehr auf Ersuchen der zuständigen Behörde oder des zuständigen Gerichts der ausschreibenden Vertragspartei vorläufig in Gewahrsam genommen werden müssen, werden aufgenommen, damit die Polizeibehörden den Aufenthalt der ausschreibenden Vertragspartei mitteilen oder die Person in Gewahrsam nehmen können, um deren Weiterreise zu verhindern, soweit es das nationale Recht erlaubt. Dies gilt insbesondere für Minderjährige und Personen, die aufgrund einer Anordnung einer zuständigen Stelle zwangsweise untergebracht werden müssen. Bei volljährigen Vermissten bedarf die Mitteilung der Einwilligung des Betroffenen.

\section{Artikel 98}

(1) Daten in Bezug auf Zeugen sowie auf Personen, die im Rahmen eines Strafverfahrens wegen Taten vor Gericht erscheinen müssen, derentwegen sie verfolgt werden oder Personen, denen ein Strafurteil oder die Ladung zum Antritt einer Freiheitsentziehung zugestellt werden muss, werden auf Ersuchen der zuständigen Justizbehörden im Hinblick auf die Mitteilung des Wohnsitzes oder des Aufenthalts aufgenommen.

(2) Die erbetenen Informationen werden der ersuchenden Vertragspartei nach Maßgabe des nationalen Rechts und der geltenden Übereinkommen über Rechtshilfe in Strafsachen mitgeteilt.

\section{Artikel 99}

$(1)^{1}$ Daten in Bezug auf Personen oder Fahrzeuge werden nach Maßgabe des nationalen Rechts der ausschreibenden Vertragspartei zur verdeckten Registrie-

\footnotetext{
${ }^{1}$ Wird geändert durch 18 , noch nicht in Kraft
}

rung oder zur gezielten Kontrolle gemäß Absatz 5 aufgenommen.

(2) Eine Ausschreibung dieser Art ist zulässig zur Strafverfolgung und zur Abwehr von Gefahren für die öffentliche Sicherheit, wenn

a) konkrete Anhaltspunkte dafür vorliegen, dass der Betroffene in erheblichem Umfang außergewöhnlich schwere Straftaten plant oder begeht, oder

b) die Gesamtbeurteilung des Betroffenen, insbesondere aufgrund der bisher von ihm begangenen Straftaten, erwarten lässt, dass er auch künftig außergewöhnlich schwere Straftaten begehen wird.

(3) Die Ausschreibung ist ferner, soweit das nationale Recht es erlaubt, auf Veranlassung der für die Sicherheit des Staates zuständigen Stellen zulässig, wenn tatsächliche Anhaltspunkte dafür vorliegen, dass die in Absatz 4 bezeichneten Informationen zur Abwehr einer von dem Betroffenen ausgehenden erheblichen Gefährdung oder anderer erheblicher Gefahren für die innere oder äußere Sicherheit des Staates erforderlich sind. Der nach diesem Absatz ausschreibende Mitgliedstaat ist verpflichtet, die anderen Mitgliedstaaten zu unterrichten. ${ }^{2}$

(4) Auf Grund der verdeckten Registrierung können anlässlich von Grenzkontrollen und sonstigen polizeilichen und zollrechtlichen Überprüfungen im Binnenland die nachstehenden Informationen ganz oder teilweise eingeholt und der ausschreibenden Stelle übermittelt werden:

a) Antreffen der ausgeschriebenen Person oder des ausgeschriebenen Fahrzeugs,

b) Ort, Zeit oder Anlass der Überprüfung,

c) Reiseweg und Reiseziel,

d) Begleitpersonen oder Insassen,

e) benutztes Fahrzeug,

f) mitgeführte Sachen,

g) Umstände des Antreffens der Person oder des Fahrzeugs.

Bei der Erhebung dieser Daten ist darauf zu achten, dass der verdeckte Charakter der Maßnahme nicht gefährdet wird.

$(5)^{3}$ Bei der in Absatz 1 genannten gezielten Kontrolle können nach Maßgabe des nationalen Rechts zur Erreichung der in den Absätzen 2 und 3 genannten Zwecke die Person, das Fahrzeug oder die mitgeführten Gegenstände durchsucht werden. Soweit nach dem Recht einer Vertragspartei die gezielte Kontrolle nicht zulässig ist, wird diese Maßnahme für diese Vertragspartei automatisch in eine verdeckte Registrierung umgesetzt.

(6) Eine ersuchte Vertragspartei kann die Ausschreibung in dem Bestand ihres nationalen Teils des Schengener Informationssystems so kennzeichnen lassen, dass bis zur Löschung der Kennzeichnung keine Maßnahme aufgrund

${ }^{2}$ Geändert durch 18 ab 03.06.2005

${ }^{3}$ Wird geändert durch 18 , noch nicht in Kraft 
der Ausschreibung zur verdeckten Registrierung oder zur gezielten Kontrolle vollzogen wird. Die Kennzeichnung ist spätestens vierundzwanzig Stunden nach der Speicherung der Ausschreibung zu löschen, es sei denn, die betreffende Vertragspartei lehnt die erbetene Maßnahme aus Rechtsgründen oder besonderen Opportunitätserwägungen $\mathrm{ab}$. Ungeachtet einer Kennzeichnung oder einer ablehnenden Entscheidung bleiben die anderen Vertragsparteien befugt, die mit der Ausschreibung erbetene Maßnahme zu vollziehen.

\section{Artikel 100}

(1) Daten in Bezug auf Sachen, die zur Sicherstellung oder Beweissicherung im Strafverfahren gesucht werden, werden in das Schengener Informationssystem aufgenommen.

(2) Ergibt eine Abfrage, dass eine Sachfahndungsnotierung besteht, so setzt sich die aufgreifende mit der ausschreibenden Stelle in Verbindung, um erforderliche Maßnahmen abzustimmen. Zu diesem Zweck können nach Maßgabe dieses Übereinkommens auch personenbezogene Daten übermittelt werden. Maßnahmen der aufgreifenden Vertragspartei werden nach Maßgabe ihres nationalen Rechts vollzogen.

(3) Es werden folgende Kategorien von Sachen einbezogen:

a) gestohlene, unterschlagene oder sonst abhanden gekommene Kraftfahrzeuge mit einem Hubraum von mehr als $50 \mathrm{ccm}$;

b) gestohlene, unterschlagene oder sonst abhanden gekommene Anhänger und Wohnwagen mit einem Leergewicht von mehr als $750 \mathrm{~kg}$;

c) gestohlene, unterschlagene oder sonst abhanden gekommene Feuerwaffen;

d) gestohlene, unterschlagene oder sonst abhanden gekommene Blankodokumente;

e) gestohlene, unterschlagene, sonst abhanden gekommene oder für ungültig erklärte ausgestellte Identitätsdokumente wie z. B. Pässe, Identitätskarten, Führerscheine, Aufenthaltstitel und Reisedokumente $^{1}$;

f) gestohlene, unterschlagene, sonst abhanden gekommene oder für ungültig erklärte Fahrzeugscheine und Kfz-Kennzeichen ${ }^{2}$;

g) Banknoten (Registriergeld).

\section{Artikel 101}

(1) Zugriff auf die im Schengener Informationssystem gespeicherten Daten mit dem Recht, diese unmittelbar

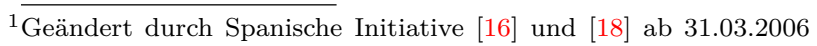
(Beschluss 2006/229)

${ }^{2}$ Geändert durch Spanische Initiative [16] und [18] ab 31.03.2006 (Beschluss 2006/228)
}

abzurufen, erhalten ausschließlich Stellen, die zuständig sind für:

a) Grenzkontrollen,

b) sonstige polizeiliche und zollrechtliche Überprüfungen im Inland sowie deren Koordinierung.

${ }^{3}$ Auch die nationalen Justizbehörden, unter anderem diejenigen, die für die Erhebung der öffentlichen Klage im Strafverfahren und justizielle Ermittlungen vor Anklageerhebung zuständig sind, können jedoch zur Erfüllung ihrer Aufgaben - wie in den einzelstaatlichen Rechtsvorschriften vorgesehen - Zugriff auf die im Schengener Informationssystem gespeicherten Daten mit dem Recht erhalten, diese unmittelbar abzurufen.

(2) ${ }^{4}$ Zugriff auf die nach Artikel 96 gespeicherten Daten und auf Daten in Bezug auf die nach Artikel 100 Absatz 3 Buchstaben d) und e) gespeicherten Personendokumente mit dem Recht, diese unmittelbar abzurufen, erhalten außerdem die für die Sichtvermerkserteilung zuständigen Stellen, die zentralen Behörden, die für die Behandlung der Sichtvermerksanträge zuständig sind, sowie die für die Erteilung von Aufenthaltstiteln und die für die Handhabung der ausländerrechtlichen Bestimmungen dieses Übereinkommens im Bereich des Personenverkehrs zuständigen Behörden. Der Zugriff auf die Daten durch diese Stellen erfolgt nach Maßgabe des nationalen Rechts der Mitgliedstaaten.

(3) Die Benutzer dürfen nur die Daten abrufen, die zur Erfüllung ihrer Aufgaben erforderlich sind.

(4) Jede Vertragspartei übermittelt dem Rat die Liste der zuständigen Behörden, die berechtigt sind, die im Schengener Informationssystem gespeicherten Daten unmittelbar abzufragen, wobei für jede Behörde angegeben wird, welche Daten für welche Aufgaben sie abrufen darf.

\section{Artikel $101 a^{5}$}

(1) Das Europäische Polizeiamt (Europol) hat im Rahmen seines Mandats und auf eigene Kosten Zugriff auf die nach den Artikeln 95, 99 und 100 im Schengener Informationssystem gespeicherten Daten mit dem Recht, diese unmittelbar abzurufen.

(2) Europol darf nur Daten abrufen, die zur Erfüllung seiner Aufgaben erforderlich sind.

(3) Stellt sich beim Abruf durch Europol heraus, dass eine Ausschreibung im Schengener Informationssystem gespeichert ist, setzt Europol den ausschreibenden Mitgliedstaat über die im Europol-Übereinkommen bestimmten Kanäle davon in Kenntnis.

(4) Die Nutzung der durch einen Abruf im Schengener Informationssystem eingeholten Informationen unterliegt der Zustimmung des betreffenden Mitgliedstaats.

\footnotetext{
${ }^{3}$ Ergänzt durch Spanische Initiative [16] und [18] ab 3.06.2005

${ }^{4}$ Neue Fassung durch [16] ab 01.11.06 (Ratsbeschluss v. 24.07.2006)

${ }^{5}$ Artikel 101a und 101b eingefügt durch [18]ab 01.10.2006 (Ratsbeschluss v. 24.07.2006)
} 
Gestattet der Mitgliedstaat die Nutzung derartiger Informationen, so erfolgt die Verarbeitung dieser Informationen nach Maßgabe des Europol-Übereinkommens. Europol darf derartige Informationen nur mit Zustimmung des betreffenden Mitgliedstaats an Drittstaaten und -stellen weitergeben.

(5) Europol kann nach Maßgabe des EuropolÜbereinkommens den betreffenden Mitgliedstaat um Zusatzinformationen ersuchen.

(6) Europol ist verpflichtet,

a) nach Maßgabe von Artikel 103 jeden seiner Abrufe zu protokollieren;

b) unbeschadet der Absätze 4 und 5 es zu unterlassen, Teile des Schengener Informationssystems, zu denen es Zugang hat, oder die hierin gespeicherten Daten, auf die es Zugriff hat, mit einem von oder bei Europol betriebenen Computersystem für die Datenerhebung und -verarbeitung zu verbinden bzw. in ein solches zu übernehmen oder bestimmte Teile des Schengener Informationssystems herunterzuladen oder in anderer Weise zu vervielfältigen;

c) den Zugriff auf die im Schengener Informationssystem gespeicherten Daten auf die eigens dazu ermächtigten Bediensteten von Europol zu beschränken;

d) Maßnahmen wie die in Artikel 118 aufgeführten anzunehmen und anzuwenden;

e) der Gemeinsamen Kontrollinstanz nach Artikel 24 des Europol-Übereinkommens zu gestatten, die Tätigkeiten Europols bei der Ausübung seines Rechts auf Zugang und Abruf der im Schengener Informationssystem gespeicherten Daten zu überprüfen.

\section{Artikel 101b}

(1) Die nationalen Mitglieder von Eurojust und die sie unterstützenden Personen haben Zugriff auf die nach den Artikeln 95 und 98 im Schengener Informationssystem gespeicherten Daten mit dem Recht, diese abzurufen.

(2) Die nationalen Mitglieder von Eurojust und die sie unterstützenden Personen dürfen nur Daten abrufen, die zur Erfüllung ihrer Aufgaben erforderlich sind.

(3) Stellt sich beim Abruf durch ein nationales Mitglied von Eurojust heraus, dass eine Ausschreibung im Schengener Informationssystem gespeichert ist, setzt das Mitglied den ausschreibenden Mitgliedstaat davon in Kenntnis. Die bei einem solchen Abruf eingeholten Informationen dürfen nur mit Zustimmung des ausschreibenden Staates an dritte Staaten und Organisationen weitergegeben werden.

(4) Dieser Artikel ist nicht so auszulegen, dass er sich auf die im Beschluss des Rates über die Errichtung von
Eurojust enthaltenen Bestimmungen betreffend den Datenschutz und die Haftung wegen unbefugter oder unrichtiger Datenverarbeitung durch die nationalen Mitglieder von Eurojust oder die sie unterstützenden Personen oder auf die Befugnisse der gemäß Artikel 23 jenes Beschlusses eingesetzten Gemeinsamen Kontrollinstanz auswirkt.

(5) Nach Maßgabe von Artikel 103 wird jeder Abruf durch ein nationales Mitglied von Eurojust oder durch eine es unterstützende Person protokolliert und jede Nutzung der von ihnen abgerufenen Daten aufgezeichnet.

(6) Die Teile des Schengener Informationssystems, zu denen die nationalen Mitglieder und die sie unterstützenden Personen Zugang haben, oder die hierin gespeicherten Daten, auf die sie Zugriff haben, werden nicht mit einem von oder bei Eurojust betriebenen Computersystem für die Datenerhebung und -verarbeitung verbunden bzw. in ein solches übernommen, noch werden bestimmte Teile des Schengener Informationssystems heruntergeladen.

(7) Der Zugriff auf die im Schengener Informationssystem gespeicherten Daten ist auf die nationalen Mitglieder und die sie unterstützenden Personen beschränkt und gilt nicht für die Eurojust-Bediensteten.

(8) Es sind Maßnahmen wie die in Artikel 118 aufgeführten anzunehmen und anzuwenden.

\section{Kapitel 3 Datenschutz und Datensicherung im Schengener Informationssystem}

\section{Artikel 102}

(1) Die Vertragsparteien dürfen die in den Artikeln 95 bis 100 genannten Daten nur für die der jeweiligen Ausschreibung entsprechenden Zwecke nutzen.

(2) Die Daten dürfen nur zu technischen Zwecken vervielfältigt werden, soweit dies zum unmittelbaren Abruf durch die in Artikel 101 genannten Stellen erforderlich ist. Ausschreibungen von anderen Vertragsparteien dürfen nicht aus dem Bestand des nationalen Teils des Schengener Informationssystems in andere nationale Datenbestände übernommen werden.

(3) Hinsichtlich der Ausschreibungen nach Artikel 95 bis 100 dieses Übereinkommens ist eine Abweichung von Absatz 1, durch die eine Ausschreibungskategorie durch eine andere ersetzt wird, nur zulässig, soweit dies zur Abwehr einer schwerwiegenden und unmittelbar bevorstehenden Gefahr für die öffentliche Sicherheit und Ordnung oder aus schwerwiegenden Gründen der Sicherheit des Staates oder zur Verhütung einer Straftat mit erheblicher Bedeutung erforderlich ist. Hierüber ist die vorherige Zustimmung der ausschreibenden Vertragspartei einzuholen. 
$(4)^{1}$ Die Daten dürfen nicht zu Verwaltungszwecken genutzt werden. Hiervon abweichend dürfen Daten, die nach Artikel 96 gespeichert wurden, und Daten in Bezug auf die nach Artikel 100 Absatz 3 Buchstaben d) und e) gespeicherten Personendokumente im Einklang mit den nationalen Rechtsvorschriften der einzelnen Mitgliedstaaten ausschließlich für die Zwecke von Artikel 101 Absatz 2 genutzt werden.

(5) Jede Nutzung der Daten, die den Absätzen 1 bis 4 nicht entspricht, wird nach dem nationalen Recht der Vertragspartei als Zweckentfremdung bewertet.

\section{Artikel 102a ${ }^{2}$}

(1) Ungeachtet des Artikels 92 Absatz 1, des Artikels 100 Absatz 1, des Artikels 101 Absätze 1 und 2 sowie des Artikels 102 Absätze 1, 4 und 5 sind die Stellen, die in den Mitgliedstaaten für die Ausstellung von Zulassungsbescheinigungen für Fahrzeuge gemäß der Richtlinie 1999/37/EG des Rates vom 29. April 1999 über Zulassungsdokumente für Fahrzeuge zuständig sind, berechtigt, Zugriff auf die nachstehenden, im Schengener Informationssystem gespeicherten Daten zu erhalten, und zwar ausschließlich um zu überprüfen, ob es sich bei den ihnen zum Zwecke der Zulassung vorgeführten Fahrzeugen um gestohlene, unterschlagene oder sonst abhanden gekommene Fahrzeuge handelt:

a) Daten betreffend gestohlene, unterschlagene oder sonst abhanden gekommene Kraftfahrzeuge mit einem Hubraum von mehr als $50 \mathrm{ccm}$,

b) Daten betreffend gestohlene, unterschlagene oder sonst abhanden gekommene Anhänger und Wohnwagen mit einem Leergewicht von mehr als $750 \mathrm{~kg}$,

c) Daten betreffend gestohlene, unterschlagene, abhanden gekommene oder für ungültig erklärte $\mathrm{Zu}-$ lassungsbescheinigungen für Fahrzeuge und KfzKennzeichenschilder.

Vorbehaltlich des Absatzes 2 erfolgt der Zugriff der betreffenden Stellen auf diese Daten nach Maßgabe des innerstaatlichen Rechts der einzelnen Mitgliedstaaten.

(2) Die Stellen nach Absatz 1, bei denen es sich um staatliche Stellen handelt, dürfen die in jenem Absatz genannten, im Schengener Informationssystem gespeicherten Daten unmittelbar abrufen.

Die Stellen nach Absatz 1, bei denen es sich um nicht staatliche Stellen handelt, erhalten nur über eine der in Artikel 101 Absatz 1 genannten Behörden Zugriff auf die in Absatz 1 genannten, im Schengener Informationssystem gespeicherten Daten. Diese Behörde ist berechtigt, die Daten unmittelbar abzurufen und sie an diese Stellen weiterzuleiten. Der betreffende Mitgliedstaat trägt dafür Sorge, dass diese Stellen und ihre Mitarbeiter verpflichtet sind, etwaigen Beschränkungen hinsichtlich der

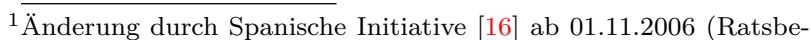
schluss vom 24.07.2006)

${ }^{2}$ Eingefügt durch [19] ab 11.01.2006
}

zulässigen Verwendung der ihnen von der Behörde übermittelten Daten Rechnung zu tragen.

(3) Artikel 100 Absatz 2 findet keine Anwendung auf eine Abfrage gemäß dem vorliegenden Artikel. Die Weiterleitung von aufgrund einer Abfrage des Schengener Informationssystems zu Tage getretenen Informationen, die auf eine strafbare Handlung schließen lassen, durch Stellen nach Absatz 1 an die Polizei- oder Justizbehörden erfolgt nach Maßgabe des innerstaatlichen Rechts.

(4) Der Rat legt jedes Jahr, nachdem er die Stellungnahme der gemäß Artikel 115 eingesetzten gemeinsamen Kontrollinstanz betreffend die Datenschutzbestimmungen eingeholt hat, dem Europäischen Parlament einen Bericht über die Anwendung dieses Artikels vor. Dieser Bericht enthält Informationen und statistische Daten über die Verwendung und die Ergebnisse der Anwendung dieses Artikels sowie Angaben darüber, auf welche Weise die Datenschutzbestimmungen angewandt wurden.

\section{Artikel 103}

3 Jede Vertragspartei gewährleistet, dass jede Übermittlung personenbezogener Daten durch die dateiführende Stelle im nationalen Teil des Schengener Informationssystems zur Kontrolle der Zulässigkeit der Abfrage protokolliert wird. Die Aufzeichnung darf nur hierfür verwendet werden und wird frühestens nach Ablauf eines Jahres und spätestens nach Ablauf von drei Jahren gelöscht.

\section{Artikel 104}

(1) Das nationale Recht der ausschreibenden Vertragspartei findet auf die Ausschreibung Anwendung, es sei denn, dieses Übereinkommen enthält engere Voraussetzungen für die Ausschreibung.

(2) Soweit dieses Übereinkommen keine besondere Regelung enthält, findet das nationale Recht der jeweiligen Vertragspartei auf die in ihrem nationalen Teil des Schengener Informationssystems gespeicherten Daten Anwendung.

(3) Soweit dieses Übereinkommen keine besondere Regelung über die Durchführung der mit der Ausschreibung erbetenen Maßnahme enthält, findet das nationale Recht der ersuchten Vertragspartei, die die Maßnahme durchführt, Anwendung. Soweit dieses Übereinkommen besondere Regelungen über die Durchführung der mit der Ausschreibung erbetenen Maßnahme enthält, werden die Befugnisse durch das nationale Recht der ersuchten Vertragspartei begrenzt. Soweit die erbetene Maßnahme nicht durchgeführt werden kann, unterrichtet die ersuchte Vertragspartei die ausschreibende Vertragspartei unverzüglich.

\footnotetext{
${ }^{3}$ neue Fassung durch [16] und [18] ab 01.01.2006 (Ratsbeschluss $2005 / 727$ und $2005 / 728)$
} 
Artikel 105

Die ausschreibende Vertragspartei ist für die Richtigkeit und Aktualität der Daten sowie die Rechtmäßigkeit der Speicherung im Schengener Informationssystem verantwortlich.

\section{Artikel 106}

(1) Die Änderung, Ergänzung, Berichtigung oder Löschung der Daten darf nur durch die ausschreibende Vertragspartei vorgenommen werden.

(2) Hat eine Vertragspartei, die selber die Ausschreibung nicht veranlasst hat, Anhaltspunkte dafür, dass Daten unrichtig sind oder unrechtmäßig gespeichert worden sind, so teilt sie dies umgehend der ausschreibenden Vertragspartei mit, die verpflichtet ist, diese Mitteilung unverzüglich zu prüfen und erforderlichenfalls die Daten unverzüglich zu berichtigen oder zu löschen.

(3) Falls die Vertragsparteien sich nicht einigen können, unterbreitet die Vertragspartei, die die Ausschreibung nicht veranlasst hat, der in Artikel 115 Absatz 1 vorgesehenen gemeinsamen Kontrollinstanz den Fall zur Stellungnahme.

\begin{abstract}
Artikel 107
Wurde in Bezug auf eine Person bereits eine Ausschreibung in das Schengener Informationssystem aufgenommen, so stimmt sich die Vertragspartei, die eine weitere Ausschreibung vornimmt, mit der Vertragspartei, die die erste Ausschreibung vorgenommen hat, über die Speicherung der Ausschreibungen ab. Hierzu können die Vertragsparteien auch generelle Regelungen treffen.
\end{abstract}

\section{Artikel 108}

(1) Jede Vertragspartei bestimmt eine Stelle, die als Zentrale für den nationalen Teil des Schengener Informationssystems zuständig ist.

(2) Jede Vertragspartei nimmt ihre Ausschreibungen über diese Stelle vor.

(3) Diese Stelle ist für das reibungslose Funktionieren des nationalen Teiles des Schengener Informationssystems verantwortlich und trifft die erforderlichen Maßnahmen für die Einhaltung der Bestimmungen dieses Übereinkommens.

(4) Die Vertragsparteien teilen einander über den Verwahrer die nach Absatz 1 bestimmte Stelle mit.

\section{Artikel 109}

(1) Das Recht jeder Person, über die zu ihrer Person im Schengener Informationssystem gespeicherten Daten Auskunft zu erhalten, richtet sich nach dem nationalen Recht der Vertragspartei, in deren Hoheitsgebiet das Auskunftsrecht beansprucht wird. Soweit das nationale Recht dies vorsieht, entscheidet die in Artikel 114 Absatz 1 vorgesehene nationale Kontrollinstanz, ob und in welcher Weise Auskunft erteilt wird. Eine Vertragspartei, die selber die Ausschreibung nicht vorgenommen hat, darf Auskunft zu diesen Daten nur erteilen, wenn sie vorher der ausschreibenden Vertragspartei Gelegenheit zur Stellungnahme gegeben hat.

(2) Die Auskunftserteilung an den Betroffenen unterbleibt, wenn dies zur Durchführung einer rechtmäßigen Aufgabe im Zusammenhang mit der Ausschreibung oder zum Schutz der Rechte und Freiheiten Dritter unerlässlich ist. Sie unterbleibt immer während der Ausschreibung zur verdeckten Registrierung.

\section{Artikel 110}

Jeder hat das Recht, auf seine Person bezogene unrichtige Daten berichtigen oder unrechtmäßig gespeicherte Daten löschen zu lassen.

\section{Artikel 111}

(1) Jeder hat das Recht, im Hoheitsgebiet jeder Vertragspartei eine Klage wegen einer seine Person betreffenden Ausschreibung insbesondere auf Berichtigung, Löschung, Auskunftserteilung oder Schadensersatz vor dem nach nationalem Recht zuständigen Gericht oder der zuständigen Behörde zu erheben.

(2) Unbeschadet des Artikels 116 verpflichten sich die Vertragsparteien, unanfechtbare Entscheidungen der Gerichte oder Behörden nach Absatz 1 zu vollziehen.

\section{Artikel 112}

(1) Die zur Personenfahndung in dem Schengener Informationssystem aufgenommenen personenbezogenen Daten werden nicht länger als für den verfolgten Zweck erforderlich gespeichert. Spätestens drei Jahre nach ihrer Einspeicherung ist die Erforderlichkeit der weiteren Speicherung von der ausschreibenden Vertragspartei zu prüfen. Für die Ausschreibung gemäß Artikel 99 beträgt diese Frist ein Jahr.

(2) Jede ausschreibende Vertragspartei bestimmt gegebenenfalls kürzere Prüffristen nach Maßgabe ihres nationalen Rechts.

(3) Die technische Unterstützungseinheit des Schengener Informationssystems weist die ausschreibende Vertragspartei mit einem Vorlauf von einem Monat automatisch auf die im System programmierte Löschung hin. 
(4) Die ausschreibende Vertragspartei kann innerhalb der Prüffrist beschließen, die Ausschreibung noch beizubehalten, wenn dies für den der Ausschreibung zugrunde liegenden Zweck erforderlich ist. Eine Verlängerung der Ausschreibung ist in die technische Unterstützungseinheit einzugeben. Absatz 1 gilt entsprechend.

\section{Artikel $112 \mathbf{a}^{1}$}

(1) Die von den Stellen nach Artikel 92 Absatz 4 auf der Grundlage des Informationsaustauschs nach jenem Absatz gespeicherten personenbezogenen Daten werden nicht länger als für den verfolgten Zweck erforderlich gespeichert. Sie werden auf jeden Fall spätestens ein Jahr nach der Löschung der Ausschreibung bzw. der Ausschreibungen zu der betroffenen Person aus dem Schengener Informationssystem gelöscht.

(2) Absatz 1 berührt nicht das Recht eines Mitgliedstaats, Daten zu einer bestimmten Ausschreibung, die dieser Mitgliedstaat vorgenommen hat, oder zu einer Ausschreibung, in deren Zusammenhang Maßnahmen in seinem Hoheitsgebiet ergriffen wurden, in einzelstaatlichen Dateien aufzubewahren. Die Frist für die Aufbewahrung der Daten in diesen Dateien wird durch einzelstaatliche Rechtsvorschriften geregelt.

\section{Artikel 113}

$(1)^{2}$ Andere als in Artikel 112 genannte Daten werden nicht länger als zehn Jahre und Daten über Gegenstände nach Artikel 99 Absatz 1 nicht länger als fünf Jahre gespeichert.

(2) Gelöschte Daten werden noch ein Jahr in der technischen Unterstützungseinheit gespeichert. Sie dürfen in dieser Zeit jedoch lediglich genutzt werden, um nachträglich ihre Richtigkeit oder die Rechtmäßigkeit der Speicherung zu prüfen. Danach sind sie zu vernichten.

\section{Artikel $113 \mathrm{~A}^{3}$}

(1) Andere als die von den Stellen nach Artikel 92 Absatz 4 auf der Grundlage des Informationsaustauschs nach jenem Absatz gespeicherten personenbezogenen Daten werden nicht länger als für den verfolgten Zweck erforderlich gespeichert. Sie werden auf jeden Fall spätestens ein Jahr nach der Löschung der Ausschreibung bzw. der Ausschreibungen zu der betroffenen Person aus dem Schengener Informationssystem gelöscht.

(2) Absatz 1 berührt nicht das Recht eines Mitgliedstaats, Daten zu einer bestimmten Ausschreibung, die dieser Mitgliedstaat vorgenommen hat, oder zu einer Ausschreibung, in deren Zusammenhang Maßnahmen in

${ }^{1} \overline{\text { Eingefügt durch [16] und }}[18]$, in Kraft seit 11.09.2005 (Ratsbeschluss 2005/451)

${ }^{2}$ geändert durch [18] ab 15.10.2005 (Ratsbeschluss 2005/719)

${ }^{3}$ Eingefügt durch [16] und [18], in Kraft seit 11.09.2005 (Ratsbeschluss 2005/451) seinem Hoheitsgebiet ergriffen wurden, in einzelstaatlichen Dateien aufzubewahren. Die Frist für die Aufbewahrung der Daten in diesen Dateien wird durch einzelstaatliche Rechtsvorschriften geregelt.

\section{Artikel 114}

(1) Jede Vertragspartei bezeichnet eine Kontrollinstanz, deren Aufgabe darin besteht, nach Maßgabe des jeweiligen nationalen Rechts den Bestand des nationalen Teils des Schengener Informationssystems unabhängig $\mathrm{zu}$ überwachen und zu prüfen, ob durch Verarbeitung und Nutzung der im Schengener Informationssystem gespeicherten Daten die Rechte des Betroffenen nicht verletzt werden. Diese Kontrollinstanz hat hierfür Zugriff auf den Bestand des nationalen Teils des Schengener Informationssystems.

(2) Jeder hat das Recht, die Kontrollinstanzen zu ersuchen, die zu seiner Person im Schengener Informationssystem gespeicherten Daten sowie deren Nutzung zu überprüfen. Dieses Recht wird nach Maßgabe des nationalen Rechts der Vertragspartei, an die das Ersuchen gerichtet wird, ausgeübt. Wurden die Daten durch eine andere Vertragspartei eingegeben, so erfolgt die Kontrolle in enger Abstimmung mit der Kontrollinstanz dieser Vertragspartei.

\section{Artikel 115}

(1) Zur Überwachung der technischen Unterstützungseinheit des Schengener Informationssystems wird eine gemeinsame Kontrollinstanz eingerichtet, die sich aus je zwei Vertretern der jeweiligen nationalen Kontrollinstanzen zusammensetzt. Jede Vertragspartei hat bei Abstimmungen eine Stimme. Die Kontrolle richtet sich nach den Bestimmungen dieses Übereinkommens, des Übereinkommens des Europarates vom 28. Januar 1981 zum Schutz des Menschen bei der automatischen Verarbeitung personenbezogener Daten, der Empfehlung R (87) 15 des Ministerausschusses des Europarates über die Nutzung personenbezogener Daten im Polizeibereich vom 17. September 1987 und nach dem nationalen Recht der für die technische Unterstützungseinheit zuständigen Vertragspartei.

(2) In Bezug auf die technische Unterstützungseinheit hat die gemeinsame Kontrollinstanz die Aufgabe, die richtige Anwendung der Bestimmungen dieses Übereinkommens zu überprüfen. Sie hat hierfür Zugriff auf den zentralen Bestand.

(3) Die gemeinsame Kontrollinstanz ist auch zuständig für die Prüfung der Anwendungs- oder Auslegungsfragen im Zusammenhang mit dem Funktionieren des Schengener Informationssystems, für die Prüfung von Fragen im Zusammenhang mit den von den nationalen Kontrollinstanzen unabhängig vorgenommenen Kontrollen oder mit der Ausübung des Auskunftsrechtes sowie für die Erarbeitung harmonisierter Vorschläge im Hinblick auf gemeinsame Lösungen für die bestehenden Fragen. 
(4) Die von der gemeinsame Kontrollinstanz erstellten Berichte werden an die Stellen übermittelt, an die die nationalen Kontrollinstanzen ihre Berichte übermitteln.

\section{Artikel 116}

(1) Wird jemand bei dem Betrieb eines nationalen Bestandes des Schengener Informationssystems geschädigt, haftet ihm hierfür jede Vertragspartei nach Maßgabe ihres nationalen Rechts. Dies gilt auch, wenn der Schaden durch die ausschreibende Vertragspartei verursacht worden ist, weil diese die Daten unrichtig eingegeben hat oder die Speicherung unrechtmäßig war.

(2) Ist die in Anspruch genommene Vertragspartei nicht die ausschreibende Vertragspartei, hat letztere den geleisteten Ersatz auf Anforderung zu erstatten, es sei denn, von der ersuchten Vertragspartei wurden die Daten vertragswidrig genutzt.

\section{Artikel 117}

(1) Jede Vertragspartei trifft spätestens bis zum Inkrafttreten dieses Übereinkommens in ihrem nationalen Recht in Bezug auf die automatische Verarbeitung personenbezogener Daten im Rahmen der Anwendung dieses Titels die erforderlichen Maßnahmen zur Gewährleistung eines Datenschutzstandards, der zumindest dem entspricht, der sich aus der Verwirklichung der Grundsätze des Übereinkommens des Europarates über den Schutz des Menschen bei der automatischen Verarbeitung personenbezogener Daten vom 28. Januar 1981 ergibt, und beachtet dabei die Empfehlung R (87) 15 des Ministerausschusses des Europarates über die Nutzung personenbezogener Daten im Polizeibereich vom 17. September 1987.

(2) Die in diesem Titel vorgesehenen Übermittlungen personenbezogener Daten dürfen erst beginnen, wenn in dem Hoheitsgebiet der an der Übermittlung beteiligten Vertragsparteien die nach Absatz 1 gebotenen datenschutzrechtlichen Regelungen in Kraft getreten sind.

\section{Artikel 118}

(1) Jede Vertragspartei verpflichtet sich, für ihren nationalen Teil des Schengener Informationssystems Maßnahmen zu treffen, die geeignet sind:

a) Unbefugten den Zugang zu Datenverarbeitungsanlagen, mit denen personenbezogene Daten verarbeitet werden, zu verwehren (Zugangskontrolle);

b) zu verhindern, dass Datenträger unbefugt gelesen, kopiert, verändert oder entfernt werden können (Datenträgerkontrolle);

c) die unbefugte Eingabe in den Speicher sowie die unbefugte Kenntnisnahme, Veränderung oder Löschung gespeicherter personenbezogener Daten zu verhindern (Speicherkontrolle); d) zu verhindern, dass automatisierte Datenverarbeitungssysteme mit Hilfe von Einrichtungen zur Datenübertragung von Unbefugten genutzt werden können (Benutzerkontrolle);

e) zu gewährleisten, dass die zur Benutzung eines automatisierten Datenverarbeitungssystems Berechtigten ausschließlich auf die ihrer Zugriffsberechtigung unterliegenden Daten zugreifen können ( $\mathrm{Zu}-$ griffskontrolle);

f) zu gewährleisten, dass überprüft und festgestellt werden kann, an welche Stellen personenbezogene Daten durch Einrichtungen zur Datenübertragung übermittelt werden können (Übermittlungskontrolle);

g) zu gewährleisten, dass nachträglich überprüft und festgestellt werden kann, welche personenbezogenen Daten zu welcher Zeit und von wem in automatisierte Datenverarbeitungssysteme eingegeben worden sind (Eingabekontrolle);

h) zu verhindern, dass bei der Übertragung personenbezogener Daten sowie beim Transport von Datenträgern die Daten unbefugt gelesen, kopiert, verändert oder gelöscht werden können (Transportkontrolle).

(2) Jede Vertragspartei hat für die Übermittlung von Daten an Stellen außerhalb des Hoheitsgebietes der Vertragsparteien besondere Vorkehrungen zur Datensicherung zu treffen. Diese sind der gemeinsamen Kontrollinstanz mitzuteilen.

(3) Jede Vertragspartei darf mit der Datenverarbeitung in ihrem nationalen Teil des Schengener Informationssystems nur Personen beauftragen, die besonders geschult und einer Sicherheitsüberprüfung unterzogen worden sind.

(4) Für die technische Unterstützungseinheit des Schengener Informationssystems trifft die hierfür zuständige Vertragspartei die in den Absätzen 1 bis 3 genannten Maßnahmen.

\section{Kapitel 4 Verteilung der Kosten des Schengener Informationssystems}

\section{Artikel 119}

$(1)^{1}$ Die Kosten für die Einrichtung und den Betrieb der technischen Unterstützungseinheit nach Artikel 92 Absatz 3 einschließlich der Leitungskosten für die Verbindung der nationalen Teile des Schengener Informationssystems mit der technischen Unterstützungseinheit sowie die Kosten der Tätigkeiten, die von Frankreich in Verbindung mit den ihm übertragenen Aufgaben in Anwendung des Beschlusses 2008/839/JI des Rates und der Verordnung (EG) Nr. 1104/2008 des Rates durchgeführt werden, werden von den Mitgliedstaaten gemeinsam getragen. Der zu leistende Kostenanteil richtet sich nach

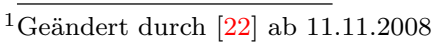


dem Anteil einer jeden Vertragspartei an der einheitlichen Mehrwertsteuer-Bemessungsgrundlage im Sinne des Artikels 2 Absatz 1 Buchstabe c) des Beschlusses des Rates der Europäischen Gemeinschaften über das System der Eigenmittel der Gemeinschaften vom 24. Juni 1988.

$(2)^{1}$ Die Kosten für die Einrichtung und den Betrieb des nationalen Teils des Schengener Informationssystems sowie für die Erfüllung der dem nationalen System gemäß dem Beschluss 2008/839/JI des Rates und der Verordnung (EG) Nr. 1104/2008 des Rates und obliegenden Aufgaben trägt jeder Mitgliedstaat selbst.

\section{Titel V Transport und Warenverkehr}

\section{Artikel 120}

(1) Die Vertragsparteien achten darauf, dass keine ihrer Rechts- oder Verwaltungsvorschriften den Warenverkehr über die Binnengrenzen in unvertretbarer Weise behindern.

(2) Die Vertragsparteien erleichtern den Warenverkehr über die Binnengrenzen dadurch, dass sie mit Verboten und Beschränkungen verbundene Förmlichkeiten bei der Abfertigung der Waren zum abgabenrechtlich freien Verkehr durchführen. Diese Abfertigung findet nach Wahl des Beteiligten entweder im Binnenland oder an der Binnengrenze statt. Die Vertragsparteien bemühen sich, die Abfertigung im Binnenland zu fördern.

(3) Soweit die nach Absatz 2 vorgesehenen Erleichterungen in bestimmten Bereichen ganz oder teilweise noch nicht verwirklicht werden können, bemühen sich die Vertragsparteien weiterhin, untereinander oder im Rahmen der Europäischen Gemeinschaften dafür die Voraussetzungen zu schaffen. Dieser Absatz findet insbesondere auf die Kontrolle der verkehrsgewerberechtlichen Genehmigung und der verkehrstechnischen Bestimmungen, des Tierschutz- und des Tierseuchenrechts sowie des Fleischhygienerechts, des Pflanzenschutzrechts sowie des Transports gefährlicher Güter und Abfälle Anwendung.

(4) Die Vertragsparteien bemühen sich weiterhin, die Förmlichkeiten für den Warenverkehr über die Außengrenze untereinander anzugleichen und deren Einhaltung nach einheitlichen Grundsätzen zu kontrollieren. Zu diesem Zweck arbeiten sie im Rat, im Rahmen der Europäischen Gemeinschaften und in anderen internationalen Gremien eng zusammen.

\section{Artikel 121}

(1) Die Vertragsparteien verzichten in Übereinstimmung mit dem Gemeinschaftsrecht für bestimmte Pflanzen

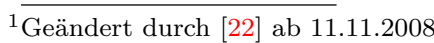

oder Pflanzenerzeugnisse auf die nach Gemeinschaftsrecht vorgesehenen phytosanitären Untersuchungen und die Vorlage von Pflanzengesundheitszeugnissen.Der Rat bestimmt die Liste der Pflanzen oder Pflanzenerzeugnisse, für die die Erleichterungen des Satzes 1 gelten. Er kann sie ändern und bestimmt den Zeitpunkt, zu dem diese Änderungen in Kraft treten sollen. Die Vertragsparteien teilen sich gegenseitig die getroffenen Maßnahmen mit.

(2) Eine Vertragspartei kann bei Gefahr der Einschleppung oder Ausbreitung von Schadorganismen die vorübergehende Wiedereinführung der gemeinschaftsrechtlich vorgeschriebenen Kontrollmaßnahmen verlangen und selbst durchführen. Sie teilt dies unverzüglich schriftlich den anderen Vertragsparteien unter Angabe der Gründe mit.

(3) Für nach Artenschutzrecht notwendige Bescheinigungen kann das Pflanzengesundheitszeugnis weiterhin verwendet werden.

(4) Auf Antrag stellt die zuständige Behörde ein Pflanzengesundheitszeugnis aus, wenn die Sendung ganz oder teilweise für die Wiederausfuhr bestimmt ist, soweit die Pflanzen oder pflanzlichen Erzeugnisse die phytosanitären Anforderungen erfuellen.

\section{Artikel 122}

(1) Die Vertragsparteien verstärken ihre Zusammenarbeit im Hinblick auf die Sicherheit des Transports gefährlicher Güter und verpflichten sich, die nationalen Bestimmungen zur Durchführung der geltenden internationalen Übereinkommen zu harmonisieren. Darüber hinaus verpflichten sie sich, insbesondere im Hinblick auf die Beibehaltung des derzeitigen Sicherheitsniveaus, zur

a) Harmonisierung der Anforderungen bezüglich der fachlichen Eignung von Fahrzeugführern;

b) Harmonisierung der Modalitäten und der Intensität der Kontrollen während des Transports und in den Unternehmen;

c) Harmonisierung der Straf- und Ordnungswidrigkeitstatbestände sowie der gesetzlichen Bestimmungen über den Straf- und Bußgeldrahmen;

d) Schaffung eines ständigen Informations- und Erfahrungsaustausches über durchgeführte Maßnahmen und Kontrollen.

(2) Die Vertragsparteien verstärken die Zusammenarbeit im Hinblick auf die Überwachung der binnengrenzüberschreitenden Verbringung von gefährlichen und nicht gefährlichen Abfällen.

Dazu bemühen sie sich, bei der Novellierung der Richtlinien der Europäischen Gemeinschaften über die Überwachung und die administrative Behandlung der Verbringung gefährlicher Abfälle und bei der Erarbeitung von Rechtsakten der Europäischen Gemeinschaften über nicht gefährliche Abfälle einen einheitlichen Standpunkt 
mit dem Ziel der Schaffung einer ausreichenden Entsorgungsinfrastruktur und der Festlegung harmonisierter Entsorgungsstandards auf hohem Niveau zu vertreten.

In Erwartung einer gemeinschaftlichen Regelung über nicht gefährliche Abfälle wird deren Verbringung durch die Anwendung eines besonderen Verfahrens überwacht, wodurch die Verbringung am Bestimmungsort bei der Abfertigung kontrolliert werden kann.

Die Bestimmungen des Absatzes 1 Satz 2 finden Anwendung.

\section{Artikel 123}

(1) Die Vertragsparteien verpflichten sich, Beratungen zu führen mit dem Ziel, die derzeit geltende Genehmigungspflicht für die Ausfuhr von strategischen Industriewaren und Technologien in ihren Beziehungen zueinander abzuschaffen und gegebenenfalls durch ein flexibles Verfahren zu ersetzen, unter der Voraussetzung, dass Bestimmungs- und Endverbleibsland Vertragsparteien sind. Vorbehaltlich dieser Beratungen bemühen sich die Vertragsparteien, im Hinblick auf die erforderlichen Kontrollen eng zusammenzuarbeiten, nach Maßgabe des nationalen Rechts Informationen auszutauschen und die dazu erforderliche Koordinierung, einschließlich Einrichtung eines Koordinierungsmechanismus, vorzunehmen.

(2) Die Vertragsparteien bemühen sich, in Bezug auf andere Waren als die strategischen Industriewaren und Technologien nach Absatz 1 einerseits die Ausfuhrformalitäten im Binnenland abwickeln zu lassen und andererseits ihre Kontrollverfahren zu harmonisieren.

(3) Im Rahmen der Ziele nach den Absätzen 1 und 2 konsultieren die Vertragsparteien die übrigen interessierten Partnerstaaten.

\section{Artikel 124}

Zahl und Intensität von Kontrollen der im Reiseverkehr über die Binnengrenzen mitgeführten Waren werden auf eine möglichst niedrige Ebene vermindert. Ihre weitere Verminderung und schließliche Abschaffung ist von der schrittweisen Anhebung der Reisefreigrenzen und von der weiteren Entwicklung bei den für den grenzüberschreitenden Reiseverkehr geltenden Vorschriften abhängig.

\section{Artikel 125}

(1) Die Vertragsparteien treffen Absprachen über die gegenseitige Entsendung von Verbindungsbeamten ihrer Zollverwaltungen.

(2) Die Entsendung von Verbindungsbeamten hat zum Ziel, die Zusammenarbeit zwischen den Vertragsparteien allgemein und insbesondere im Rahmen der bestehenden Übereinkommen und der Rechtsakte der Europäischen
Gemeinschaften über die gegenseitige Unterstützung zu fördern und $\mathrm{zu}$ beschleunigen.

(3) Die Verbindungsbeamten werden beratend und unterstützend tätig. Sie sind nicht zur selbständigen Durchführung von zollamtlichen Maßnahmen berechtigt. Sie erteilen Informationen und erledigen ihre Aufträge im Rahmen der ihnen von der entsendenden Vertragspartei erteilten Weisungen.

\section{Titel VI Datenschutz}

\section{Artikel 126}

(1) Jede Vertragspartei trifft spätestens bis zum Inkrafttreten dieses Übereinkommens in ihrem nationalen Recht in Bezug auf die automatische Verarbeitung personenbezogener Daten, die nach diesem Übereinkommen übermittelt werden, die erforderlichen Maßnahmen zur Gewährleistung eines Datenschutzstandards, der zumindest dem entspricht, der sich aus der Verwirklichung der Grundsätze des Übereinkommens des Europarates über den Schutz des Menschen bei der automatischen Verarbeitung personenbezogener Daten vom 28. Januar 1981 ergibt.

(2) Die in diesem Übereinkommen vorgesehene Übermittlung personenbezogener Daten darf erst beginnen, wenn in dem Hoheitsgebiet der an der Übermittlung beteiligten Vertragsparteien die nach Absatz 1 gebotenen datenschutzrechtlichen Regelungen in Kraft getreten sind.

(3) In Bezug auf die automatische Verarbeitung personenbezogener Daten, die nach diesem Übereinkommen übermittelt werden, gelten außerdem folgende Bestimmungen:

a) Eine Nutzung der personenbezogenen Daten durch die empfangende Vertragspartei ist ausschließlich zu den Zwecken zulässig, zu denen die Übermittlung solcher Daten in diesem Übereinkommen vorgesehen ist; eine Nutzung zu anderen Zwecken ist nur nach vorheriger Zustimmung der übermittelnden Vertragspartei und nur nach Maßgabe des Rechts der empfangenden Vertragspartei zulässig. Die Zustimmung darf erteilt werden, soweit das nationale Recht der übermittelnden Vertragspartei dies zulässt.

b) Die übermittelten personenbezogenen Daten dürfen ausschließlich durch die Behörden und Gerichte genutzt werden, die für eine Aufgabe im Rahmen der Zwecke nach Buchstabe a) zuständig sind.

c) Die übermittelnde Vertragspartei ist verpflichtet, auf die Richtigkeit der personenbezogenen Daten zu achten; erweist sich, von Amts wegen oder aufgrund eines Antrags des Betroffenen, dass unrichtige Daten oder Daten, die nicht hätten übermittelt werden dürfen, übermittelt worden sind, so ist dies der empfangenden Vertragspartei oder den 
empfangenden Vertragsparteien unverzüglich mitzuteilen. Diese ist beziehungsweise diese sind verpflichtet, die Berichtigung oder Vernichtung vorzunehmen oder zu vermerken, dass die Daten unrichtig sind oder unrechtmäßig übermittelt wurden.

d) Im Rahmen ihrer Haftung nach Maßgabe des nationalen Rechts kann eine Vertragspartei sich im Verhältnis zu dem Geschädigten zu ihrer Entlastung nicht darauf berufen, dass eine andere Vertragspartei unrichtige Daten übermittelt hat. Leistet die empfangende Vertragspartei Schadensersatz wegen eines Schadens, der durch die Nutzung von unrichtig übermittelten Daten verursacht wurde, so erstattet die übermittelnde Vertragspartei der empfangenden Vertragspartei den Gesamtbetrag des geleisteten Ersatzes.

e) Die Übermittlung und der Empfang personenbezogener Daten sind in der Datei, aus der sie übermittelt werden, und in der Datei, in der sie gespeichert werden, festzuhalten.

f) Die gemeinsame Kontrollinstanz nach Artikel 115 ist zuständig, auf Ersuchen einer Vertragspartei ein Gutachten über die Anwendungs- und Auslegungsschwierigkeiten abzugeben, die sich bei der Anwendung dieses Artikels ergeben.

(4) Dieser Artikel findet auf die Übermittlung personenbezogener Daten nach Maßgabe des Titels II Kapitel 7 und des Titels IV keine Anwendung. Absatz 3 findet keine Anwendung auf die Übermittlung personenbezogener Daten nach Maßgabe des Titels III Kapitel 2, 3, 4 und 5 .

\section{Artikel 127}

(1) Werden aufgrund dieses Übereinkommens einer anderen Vertragspartei personenbezogene Daten übermittelt, so findet auf die Übermittlung dieser Daten aus einer nichtautomatisierten Datei und ihre Aufnahme in eine solche Datei Artikel 126 sinngemäß Anwendung.

(2) Werden in anderen als den in Artikel 126 Absatz 1 oder in Absatz 1 dieses Artikels genannten Fällen einer anderen Vertragspartei personenbezogene Daten übermittelt, so gilt Artikel 126 Absatz 3 mit Ausnahme von Buchstabe e). Außerdem gelten folgende Bestimmungen:

a) Die Übermittlung und der Empfang personenbezogener Daten werden aktenkundig gemacht. Diese Verpflichtung entfällt, soweit es für die Verwendung der Daten nicht erforderlich ist, sie aktenkundig zu machen, insbesondere weil die Daten nicht oder nur kurzfristig verwendet werden.

b) Die Verwendung der übermittelten Daten genießt auf dem Hoheitsgebiet der empfangenden Vertragspartei zumindest den Schutz, der aufgrund des Rechts dieser Vertragspartei für eine Verwendung von Daten gleicher Art gilt. c) Die Entscheidung darüber, ob und unter welchen Bedingungen auf Antrag des Betroffenen über die auf seine Person bezogenen übermittelten Daten Auskunft erteilt wird, richtet sich nach dem Recht der Vertragspartei, bei der der Antrag gestellt wird.

(3) Dieser Artikel findet auf die Übermittlung personenbezogener Daten nach Maßgabe des Titel II Kapitel 7, des Titels III Kapitel 2, 3, 4 und 5 und des Titels IV keine Anwendung.

\section{Artikel 128}

(1) Die in diesem Übereinkommen vorgesehenen Übermittlungen personenbezogener Daten dürfen erst beginnen, wenn die an der Übermittlung beteiligten Vertragsparteien einer nationalen Kontrollinstanz die Aufgabe übertragen haben, auf unabhängige Weise die Einhaltung der Artikel 126 und 127 sowie der Rechtsvorschriften zur Anwendung dieser Bestimmungen in Bezug auf die Verarbeitung personenbezogener Daten in Dateien zu überwachen.

(2) Hat eine Vertragspartei nach Maßgabe ihres nationalen Rechts eine Kontrollinstanz mit der Aufgabe eingerichtet, in einem oder mehreren Sachbereichen die Einhaltung von datenschutzrechtlichen Bestimmungen in Bezug auf nicht in Dateien gespeicherte Daten auf unabhängige Weise zu überwachen, so überträgt diese Vertragspartei dieser Kontrollinstanz die Aufgabe, in diesen Sachbereichen auch die Einhaltung der Regelungen dieses Titels zu überwachen. (3) Dieser Artikel findet auf die Übermittlung personenbezogener Daten nach Maßgabe des Titels II Kapitel 7 und des Titels III Kapitel 2, 3, 4 und 5 keine Anwendung.

\section{Artikel 129}

In Bezug auf die Übermittlung personenbezogener Daten nach Titel III Kapitel 1 verpflichten sich die Vertragsparteien, unbeschadet der Artikel 126 und 127, einen Datenschutzstandard zu verwirklichen, wobei die Grundsätze der Empfehlung R (87) 15 des Ministerausschusses des Europarates über die Nutzung personenbezogener Daten im Polizeibereich vom 17. September 1987 beachtet werden. Darüber hinaus finden auf die Übermittlung nach Maßgabe des Artikels 46 die folgenden Bestimmungen Anwendung:

a) Eine Nutzung dieser Daten durch die empfangende Vertragspartei ist ausschließlich zu den durch die übermittelnde Vertragspartei angegebenen Zwecken und unter den durch diese Vertragspartei vorgeschriebenen Bedingungen zulässig.

b) Die Daten dürfen ausschließlich an Polizeidienststellen und Polizeibehörden übermittelt werden. Die weitere Übermittlung an andere Stellen darf nur mit vorheriger Zustimmung der übermittelnden Vertragspartei erfolgen. 
c) Der Empfänger unterrichtet die übermittelnde Vertragspartei auf Ersuchen über die Verwendung der übermittelten Daten und über die dadurch erzielten Ergebnisse.

\section{Artikel 130}

Erfolgt die Übermittlung personenbezogener Daten über einen in Artikel 47 oder in Artikel 125 vorgesehenen Verbindungsbeamten, so finden die Bestimmungen dieses Titels erst Anwendung, wenn der Verbindungsbeamte sie der Vertragspartei weitergegeben hat, die ihn in das Hoheitsgebiet der anderen Vertragspartei entsandt hat.

\section{Titel VII Exekutivausschuss}

Anstelle des Exekutivausschuss ist gemäß Artikel 2 Schengen-Protokoll der Rat der EU getreten

\section{Titel VIII Schlussbestimmungen}

\section{Artikel 134}

Die Bestimmungen dieses Übereinkommens sind nur anwendbar, soweit sie mit dem Gemeinschaftsrecht vereinbar sind.

\section{Artikel 135}

Die Bestimmungen dieses Übereinkommens gelten vorbehaltlich der Bestimmungen der Genfer Konvention vom 28. Juli 1951 über den Flüchtlingsstatus in der Fassung des Protokolls von New York vom 31. Januar 1967.

\section{Artikel 136}

(1) Erwägt eine Vertragspartei, mit einem Drittstaat Verhandlungen zu führen, die die Grenzkontrollen betreffen, so unterrichtet sie rechtzeitig die anderen Vertragsparteien.

(2) Vorbehaltlich des Rechts der Mitgliedstaaten der Europäischen Gemeinschaften, gemeinsam solche Übereinkommen zu schließen, werden die Vertragsparteien ohne vorherige Zustimmung der anderen Vertragsparteien keine zwei- oder mehrseitigen Vereinbarungen über die Erleichterung oder den Abbau der Grenzkontrollen mit Drittstaaten schließen.

(3) Absatz 2 findet keine Anwendung auf bilaterale Abkommen über den kleinen Grenzverkehr nach Artikel 13 der Verordnung (EG) Nr. 1931/2006 des Europäischen Parlaments und des Rates vom 20. Dezember 2006 zur
Festlegung von Vorschriften über den kleinen Grenzverkehr an den Landaußengrenzen der Mitgliedstaaten. ${ }^{1}$

\section{Artikel 137}

Vorbehalte zu diesem Übereinkommen sind mit Ausnahme der in Artikel 60 erwähnten nicht zulässig.

\section{Artikel 138}

Die Bestimmungen dieses Übereinkommens gelten für die Französische Republik nur für das europäische Hoheitsgebiet der Französischen Republik.

Die Bestimmungen dieses Übereinkommens gelten für das Königreich der Niederlande nur für das Hoheitsgebiet des Reichs in Europa.

\section{Artikel 139}

(1) Dieses Übereinkommen bedarf der Ratifikation, Annahme oder Genehmigung. Die Ratifikations-, Annahme- oder Genehmigungsurkunden werden bei der Regierung des Großherzogtums Luxemburg hinterlegt; diese notifiziert die Hinterlegung allen Vertragsparteien.

(2) Dieses Übereinkommen tritt am ersten Tag des zweiten Monats nach Hinterlegung der letzten Ratifikations-, Annahme- oder Genehmigungsurkunde in Kraft. Die Bestimmungen in Bezug auf die Einrichtung, die Tätigkeiten und die Befugnisse des Exekutivausschusses finden vom Inkrafttreten des Übereinkommens an Anwendung. Die übrigen Bestimmungen finden vom ersten Tag des dritten Monats nach Inkrafttreten des Übereinkommens an Anwendung.

(3) Die Regierung des Großherzogtums Luxemburg notifiziert allen Vertragsparteien das Datum des Inkrafttretens.

\section{Artikel 140}

(1) Jeder Mitgliedstaat der Europäischen Gemeinschaften kann diesem Übereinkommen beitreten. Der Beitritt wird in einem Übereinkommen zwischen diesem Staat und den Vertragsparteien geregelt.

(2) Dieses Übereinkommen bedarf der Ratifikation, Annahme oder Genehmigung durch den beitretenden Staat und jede Vertragspartei. Es tritt in Kraft am ersten Tag des zweiten Monats nach Hinterlegung der letzten Ratifikations-, Annahme- oder Genehmigungsurkunde.

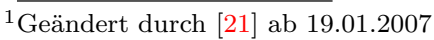




\section{Artikel 141}

(1) Jede Vertragspartei kann dem Verwahrer einen Vorschlag zur Änderung dieses Übereinkommens zuleiten. Der Verwahrer übermittelt diesen Vorschlag an die anderen Vertragsparteien. Auf Antrag einer Vertragspartei überprüfen die Vertragsparteien die Bestimmungen dieses Übereinkommens, wenn nach ihrer Auffassung eine Änderung grundlegenden Charakters in den zur Zeit des Inkrafttretens des Übereinkommens bestehenden Verhältnissen entstanden ist.

(2) Die Vertragsparteien legen die Änderungen dieses Übereinkommens einvernehmlich fest.

(3) Die Änderungen treten in Kraft am ersten Tag des zweiten Monats nach Hinterlegung der letzten Ratifikations-, Annahme- oder Genehmigungsurkunde.

\section{Artikel 142}

(1) Werden zwischen den Mitgliedstaaten der Europäischen Gemeinschaften Übereinkommen im Hinblick auf die Verwirklichung eines Raumes ohne Binnengrenzen geschlossen, so vereinbaren die Vertragsparteien, unter welchen Voraussetzungen die Bestimmungen dieses Übereinkommens unter Berücksichtigung der entsprechenden Bestimmungen der erwähnten Übereinkommen ersetzt oder geändert werden müssen. Die Vertragsparteien berücksichtigen dabei, dass die Bestimmungen dieses Übereinkommens eine weitergehende Zusammenarbeit vorsehen können als die Bestimmungen der erwähnten Übereinkommen.

Die Bestimmungen, die zu den Bestimmungen der zwischen den Mitgliedstaaten der Europäischen Gemeinschaften geschlossenen Übereinkommen in Widerspruch stehen, werden auf jeden Fall angepasst.

(2) Die Änderungen dieses Übereinkommens, die von den Vertragsparteien für erforderlich gehalten werden, bedürfen der Ratifikation, Annahme oder Genehmigung durch die Vertragsparteien. Artikel 141 Absatz 3 findet Anwendung mit der Maßgabe, dass die Änderungen nicht vor Inkrafttreten des betreffenden Übereinkommens zwischen den Mitgliedstaaten der Europäischen Gemeinschaften in Kraft treten. 